Giulio Peterlevitz Frigerio

Eng ${ }^{\circ}$ Civil-EESC-USP-1996

\title{
Retroanálise de uma escavação de vala escorada a céu aberto de uma linha do Metrô de São Paulo
}

Dissertação apresentada à Escola de Engenharia de São Carlos da Universidade de São Paulo, como parte dos requisitos para a obtenção do Título de Mestre em Geotecnia

Orientador: Prof. Dr. Tarcísio Barreto Celestino

São Carlos

2004 


\section{DEDICATÓRIA}

Dedico esta dissertação a Deus, Jesus Cristo, Gandhi, Buda, Dalai Lama, Papa João Paulo II, Alan Kardec, Francisco Xavier e Seicho Taniguchi., e a todos os discípulos das Forças do Bem que me ajudaram, me protegeram e iluminaram meu caminho.

Dedico também a todos os meus parentes da Itália, Letônia, Brasil e Hungria, que através de suas perseveranças e sofrimentos, renegaram às horas de lazer, descanso e convívio familiar, permitindo como conseqüência que eu pudesse desenvolver este trabalho.

Ao meu grande pai Franco por seu bom humor refinado, sua alegria e sua amizade e incentivos que sempre foram injeções de ânimo nos momentos mais difíceis. Meu grande companheiro nos estádios atrás dos jogos do "Palestra", inclusive nas fases ruins do time, e das caminhadas de domingo para buscar o jornal, das orquestras sinfônicas e das apreciações das óperas. Obrigado pelo grande e heróico Dodginho. Este italiano que deu o exemplo e sempre ensinou a profissão aos mais novos, que com seu trabalho, seu esforço e até sua saúde impediu que muitos funcionários ficassem sem o emprego, e contribuiu para este país como se fosse o seu, "sempre avanti".

À minha mãe Daidy, que sempre indicou o caminho do bem e nunca mediu esforços para ajudar-me, mesmo que para isso tivesse que abrir mão de seu conforto, da vaidade natural que as mulheres devem ter e das suas horas sagradas de sono e descanso. Com seu jeito alegre e acelerado, de voltagem de $380 \mathrm{~V}$ já às $5 \mathrm{~h}$ da matina, sempre com ânimo para recomeçar e com seus pratos refinados e deliciosos, sempre achou um tempinho para fazer nosso gosto chato e exigente. Foi sempre muito versátil com uma coragem diferenciada que enfrentou a tirania de governantes e foi alvo da covardia deles, mas lutou titanicamente e impediu que a corrupção e o mau uso da máquina administrativa proliferassem, se cada cidadão (inclusive eu) fizesse um décimo do que ela fez nosso país seria outro.

Dedico também ao meu irmão Mario, cientista nato, autodidata e Prof. Pardal que além de irmão também sempre foi um segundo pai, que me incentivou, ajudou e foi um grande exemplo de conduta, retidão e caridade ao próximo. Meu grande companheiro das jornadas nas estrelas, do cyborg e das incontáveis noites jogando pingpong, do surfe com prancha de isopor nas ondas de Cananéia, Itanhaém e Peruíbe, dos 
pastéis de queijo super-recheados e dos cafés e das conversas nos Shoppings. Obrigado pela HP41CV e pela HP48G.

A minha querida e amada Patrícia que com seu jeito simples, seu charme e sua bondade sempre me apoiou e me fez companhia nos momentos mais difíceis, agüentou meus maus humores e as minhas chatices. Se não fosse por sua ajuda eu não teria conseguido terminar esta dissertação. Pelas nossas idas aos cafés e a todas as padarias de São Carlos, pelas nossas viagens malucas nos extintos trens da FEPASA, pelos belos amanheceres tomando pingado e comendo pão com manteiga no vagão restaurante.Pelas chuvas frias com vento nas madrugadas que viravam os guardachuvas. Pelas heroicas idas a Santos com o Dodginho. Com as risadas com as cortinas de fumaça que o Passatão soltava. Exemplo de garra e determinação sem perder a doçura . A sua teimosia me faz rir, a sua simplicidade e seu carinho iluminam a minha vida, o brilho dos seus olhos e do seu sorriso me fazem ser feliz. "Io te voglio bene". Espero estar com você hoje e em todas as vidas que virão.Te amo muito e te admiro.

Ao meu avós Richards, Julieta e Julio e Nonno Mario que sempre trabalharam com muito afinco e garra até além do limite de suas forças como diria o meu Avô Richards agradeço imensamente por tudo o que fizeram e o exemplo que foram e por poder colher os bons frutos que vocês plantaram, que Deus os abençoe e guarde e até algum dia!

A minha querida Nonna Stefania que é um grande exemplo de coragem e simpatia com seu humor refinado, e sempre disposta a ir avanti .

Aos meus queridos Tios Dado e Marco pela amizade e pelo carinho e que sempre nos alegraram e tanto bem nos fizeram. Tio Dado com sua energia de moleque, alpinista, ciclista e sciatore que tão bem nos acolheu na Itália e que sempre que pode nos alegra com sua vinda ao Brasil. A tia Rosangela que infelizmente não conheci mas a quem sempre tive muito carinho. Enfim a todos os queridos da Itália Emanuela, Andrea e Filippo, Zia Palma e Primo Giorgio.

Ao meu tio Marco que sempre brincava muito conosco e corria feito um moleque em volta da casa e nos pagava sorvetes, com seu jeito simples e bondoso sempre cativa a todos.

A minha querida cunhada Jocelí, a irmã que eu sempre quis ter e que Deus me presenteou. Obrigado pelas boas palavras, pela paciência com minhas chatices e pelas alegrias e pelas dicas também no mestrado. 
A minha outra irmã Cristina que me acolheu em Campinas na época do estágio e sempre que precisei, com seu carinho e sua alegria me fez sentir em casa e sempre teve uma boa palavra de ânimo.

A Adriana e ao Lauro que sempre nos receberam tão bem e que agora ganharam um anjinho a Ana Laura.

A minhas queridas sobrinhas Larissa, Mariane e Ana Laura, anjinhos do Céu que Deus colocou em nossa vida que nos dão tanto brilho e alegria, muito obrigado pelo carinho, pelos bons momentos e pelas risadas.

À Dona Hortência que com seu jeito terno e sua fé sempre me acolheu e iluminou meu caminho com suas boas palavras e com sua alegria e sempre tem um tempo para cuidar dos gatinhos e da cachorrinha Radija.

A família Otsuka pela amizade e irmandade que Deus os proteja e guarde.

A todos da família Peterlevitz, Radics, Vaughan, Gazzetta e Bassora.

Aos Doutores Edson Zucolloto e Oswaldo Coimbra Jr., seres elevados e que honram a medicina com suas dignidades e acima de tudo com o respeito e a consideração com que tratam os pacientes.

Ao Cap. James T. Kirk, ao oficial de ciências Dr. Spock, ao Dr. McCoy, Eng. Scott, ao Checov, Sulu e Uhura. Vida Longa e Próspera.

Ao grande homem, aluno e exemplo de dedicação e luta e companheirismo Arquiteto Oliveiro Barbosa de Melo, que após anos construindo resolveu voltar aos estudos para graduar-se e que Deus achou por bem no $5^{\circ}$. ano levá-lo. Caro Oliveiro, tenho a certeza que o céu terá suas obras mais seguras e mais bonitas com a sua direção. Enquanto continuamos nossas obras aqui na filial, você foi chamado a arquitetar na MATRIZ. Obrigado pelos seus ensinamentos e Deus te abençoe ! 


\section{AGRADECIMENTOS}

Ao Prof. Tarcísio pela amizade e por ter me aceitado de uma forma cavalheiresca como orientando, e por ser um orientador que abre os horizontes e sabe dar asas ao orientando. Agradeço as horas que foram doadas de sua convivência familiar utilizadas para me orientar e ensinar e espero um dia fazer o mesmo para alguém.

Ao Prof. Bortolucci (grande Çula) incansável torcedor do XV de Jaú, pelo suporte dado durante o mestrado, por seu constante bom humor e pelas risadas dos intervalos de cafezinho e almoços das sextas-feiras.

Ao Prof. Benedito Bueno pela gentileza e a amizade e por toda a infra-estrutura que me proporcionou, para que eu pudesse utilizar o PLAXIS e tratando-me como se eu fosse um seu orientando, um verdadeiro Gentleman.

Ao Prof. Esquível pela amizade, pelas agradáveis conversas dos cafezinhos, pelas contribuições, pelo incentivo e por ter ajudado também os meus amigos e amigas especialmente a Darcília, poucos são os que se dispõem a estender as mãos às pessoas, mas a estes poucos muito será dado.

Ao Prof. Nimir pela gentileza e pelas sempre bem humoradas e construtivas contribuições.

Ao Prof. Faiçal Massad por sua gentileza e bondade ao receber-me na POLI, pelas ótimas referências bibliográficas, por sua tese base do meu trabalho, pela qualidade das suas aulas e grandeza de conhecimentos que não ofuscam a humildade exemplar.

Ao Prof. Gérson de Castro da POLI que na Maubertec sempre ofereceu palavras de bom ânimo e incentivo para que eu fizesse o mestrado e que detém a tranqüilidade e a sapiência dos grandes e sempre ensina, inclusive quando consultor.

Ao Prof. Aoki grande filósofo que fez com que a frustração pela falta de conversas filosóficas durante a graduação fosse suprida de longe na pós-graduação. Agradeço pelos ensinamentos e pelo seu ânimo e energia contagiantes.

Ao Prof. Cintra pelo incentivo de nossas primeiras conversas, pelas técnicas de apresentação e pela mente aberta ao trazer o Prof. Aoki para a USP - São Carlos e pelo 
exemplo de grande estrategista e por ter dedicado horas de seu convívio familiar e deixar-nos um belo livro sobre fundações diretas .

Ao grande palmeirense Prof. Lázaro, pelas aulas filosóficas que nos mostravam novos horizontes, pelas risadas dos intervalos para cafezinhos, inclusive nos feriados. Pelas opiniões, algumas polêmicas que sempre abriam debates acalorados.

Ao Prof. Orêncio pelo constante bom humor, qualidade de aula e pelo ânimo transmitido na véspera da qualificação.

Ao Prof. Parreira do Departamento de Transportes da EESC-USP, pela gentileza e grande ajuda no entendimento do modelo de endurecimento.

À Profa. Teresa Cristina Martins Dias do Departamento de Estatística da Universidade Federal de São Carlos por sua gentileza, simpatia e dedicação, sempre achando um tempo para me atender, mesmo estando em final de elaboração de sua tese de doutoramento, com seu jeito calmo e sua ótima didática esclareceu-me muitas questões sobre a estatística convencional e bayesiana.

Ao Prof. Ortigão que muito gentilmente emprestou o programa PLAXIS v.8x sem o qual não teria sido possível a realização de $50 \%$ deste trabalho.

À Capes e aos seus funcionários que nunca aparecem, mas forneceram meios para que eu tivesse infra-estrutura e a bolsa cedida durante $01^{\circ}$ ano do mestrado.

À Compania do Metropolitano de São Paulo (Metrô S.P.), que gentilmente cedeu suas instalações e seu acervo de instrumentação sem os quais este trabalho não seria possível. Em especial ao Engo . Ricardo Leite, ao Geólogo Hugo Cássio Rocha, a Eng ${ }^{\mathrm{a}}$. Cybele Azevedo de Vasconcellos, ao Eng ${ }^{\circ}$. Francisco Ribeiro Neto e a todos os funcionários que muito gentilmente me atenderam.

Ao grande amigo, irmão e coorientador Maurício Giambastiani pela amizade, companheiro das árduas batalhas do mestrado, pelas risadas e pelas conversas de alto nível, pela sua coragem e seu empenho em melhorar a pós-graduação, pela grande ajuda nas discussões deste trabalho e também a sua bela família, a sua esposa Isabel e sua filhinha Mariana.

À Daniele pela amizade e pelas grandes dicas e ajudas e pelo companheirismo das longas noites no laboratório.

Ao professor Savassi pela grande ajuda e confiança depositadas durante a graduação que tiveram importância decisiva em minha vida.

Ao grande Dito, apesar de corintiano, é sempre bem humorado, pela ajuda e pelas alegres conversas. 
Ao Paulinho (Neural), grande guru e mente brilhante que sempre teve um tempo para ajudar e dar dicas e fundamentais contribuições a este trabalho, doutor em Geotecnia e Pós-Doutor em respeito e dedicação ao próximo.

Ao grande amigo e irmão André Christóforo, pela sua ajuda e pela paciência em discutir meu trabalho, grande matemático e grande ser humano com bondade e humildade natas típicas dos elevados e pelas agradáveis conversas do pão de queijo.

A Sarinha que com seu jeito alegre e meigo sempre proporcionou momentos agradáveis e muitas risadas.

A Gilvana com seu sorriso aberto e seu carinho sempre brincando e aprontando alguma.

A Sandrinha madrugadora com seu jeito calmo e seu sorriso sempre passando muita calma e boas energias.

A Érika Sá pela alegria contagiante e pelo carinho, grande companheira das noites e madrugadas no laboratório e pelas grandes risadas e conversas no pão de queijo.

Aos grandes amigos e irmãos Dener e Elisabete Prata que sempre acharam um tempo para me ajudar e que sempre tiveram boas palavras e forneceram muito apoio nos momentos mais difíceis, devo muito de minha formação pessoal e acadêmica a voces dois, que Deus os proteja hoje e sempre.

Aos queridos compadre Rodrigo e a comadre Andrea pela grande amizade e boas palavras e dicas sempre bem vindas, que agora são papais coruja, com muita razão, pela feliz chegada do filhinho Fernando.

Ao Mauro e a Célia pela amizade e pelas boas dicas do Mauro e pela tranqüilidade transmitida nas etapas mais duras deste trabalho, que como dizíamos nasceu quase junto com a chegada da filhinha de vocês a Ana Clara.

Ao Nilson e a Rejane pela amizade, pelas dicas na qualificação e pelos almoços muito agradáveis no Shopping, freguesa preferencial que acabava com os estoques de T-Bone do restaurante que agora tem a Isabele (ASP)!

Ao Geólogo Leonardo e a Juliana pela amizade e pelas ajudas fundamentais no programa Statistica e pelas agradáveis peladas de futebol, é verdade que me custaram a unha do dedão e seis meses de banco de reservas, mas a unha nova é mais bonita que a velha!

Ao Miguel pela amizade e pela integridade que tem. 
Ao Helano, filósofo, grande amigo e irmão pelas nossas conversas, pelo exemplo e ajuda no entendimento de nossa complexa geologia e pela coragem de dizer o que pensa sem temer a ninguém, característica típica dos seres evoluídos. Deus te abençoe e proteja hoje e sempre.

Ao Yuri e a Carina pela grande ajuda, pela amizade, pelas agradáveis conversas e por terem trazido do Colorado a dissertação de validação do PLAXIS.

Ao santista Vinicius pelas risadas e pelo companheirismo nas longas horas de processamento e pelas aulas de elementos finitos.

Ao Herivelto pela grande ajuda na infra-estrutura de computação, pelas grandes risadas e pelas conversas sobre as estratégias da guerra do golfo e sobre os filmes.

A Maristela com seu jeito calmo e meigo e seu sorriso bonito, sempre achando um tempo para atender-me e ajudar nas correrias das burocracias.

Aos amigos Ivan, Jean Carlo, Henry, Rossana, Luiz Guilherme, Ricardo Gomes, Victor Hugo pela amizade e pelas boas palavras de bom ânimo.

Ao amigo Prof. Carlos Costa Branco pelo ânimo e pelos ensinamentos e pelas ótimas piadas que sempre animavam as vésperas das provas.

A Neiva pela ajuda e pelos atendimentos.

Ao corintiano Álvaro pelas gargalhadas do palmeiras e corinthians, pela amizade e por sempre estar disposto a ajudar.

A todos os amigos da Geotecnia.

A todos os amigos e amigas da bilioteca Central (minha $2^{\mathrm{a}}$. casa !) que com muita gentileza, rapidez e carinho atendiam aos meus inúmeros pedidos, sempre num clima de muita amizade mantendo o alto profissionalismo.

Aos Srs. Adão, Castilho e a todo pessoal da gráfica da EESC pela gentileza e amizade, que sempre acha um tempo para nos atender, mesmo que de última hora.

Aos grandes amigos e companheiros Flávio Marchesoni, Adriano Sales, Renê, Geraldine, Fernando, Simone, Dona Marlene, Elisângela, João Carlos, Adriano Tomitão, Roberto, Lélis, Dulce, Flávia, Valéria, Bezzon, Stelita, Ruth e a todos os queridos alunos e funcionários da Faculdade de Arquitetura e Urbanismo do Centro Universitário Barão de Mauá de Ribeirão Preto pela amizade, pelo respeito e entusiasmo pelo saber e pela forma humana e idealista que desenvolvem suas atividades. 
Ao Professor Calil pelos ensinamentos, pela oportunidade, pela qualidade das aulas e pela calma transmitida, agradeço o tempo que sempre achou para ajudar-me e por ter sido um exemplo de praticidade do engenheiro associado ao rigor do cientista.

Ao Prof. Goldenberg pela mente aberta verdadeiramente um misto de filósofo, cientista e estrategista, obrigado pelas aulas, pelas conversas edificantes e acima de tudo por todo o seu esforço e empenho para melhorar a engenharia atuando no ser humano e sempre dando um voto de confiança aos alunos.

Ao Prof. Rocco pelos ensinamentos e lições de diplomacia, ensinando-me em situações difíceis a manter o foco no fato e nunca na pessoa.

Ao Prof. Rentes que sempre nos deu injeções de ânimo e com suas aulas interessantíssimas sobre administração me mostrou novos horizontes.

Ao Prof. José Samuel Giongo que com suas ótimas aulas, que eram calmas e interessantes sempre nos tratou e respeitou na graduação como já engenheiros, pela abertura aos debates dentro de sala, pelo cuidado em elaborar o material didático para nós e pela amizade e carinho (Concretos !) com toda a turma, o único defeito dele é que é corintiano, mas ninguém é perfeito, a perfeição existe, mas só no Parque Antárctica.

Ao Prof. Paulo dos Santos Neto pela filosofia guerreira transmitida na sala de aula e pelos ensinamentos e dicas sobre a vida profissional e pela amizade dedicada a nossa turma.

Ao Prof. Cornetti, à Profa. Tânia, à Profa. Maria Olímpia, Prof. Marcio e ao Prof. Brandão da Faculadade de Engenharia Mecânica da UNESP-Guaratinguetá, que tanto contribuíram para minha formação e que tiveram importância fundamental na abertura de meus horizontes para a engenharia e principalmente para a vida.

Aos amigos Sr. Guerrino, Sr. Sebastião e Sr. Hamilton da CONSID detentores de muita sapiência que muito me ensinaram sobre as obras, sobre os solos de São Paulo e cujo respeito ao ser humano é digno de admiração.

Aos amigos do Shopping Interlagos Oseude, Toshio, Urbano, Roberto, Álvaro, Claudia, Adeony, Vanete, Evano, Álvaro, Hisachi e Og.

Aos amigos do grupo Savoy Rami, Cícero, Dr. André .

Ao pessoal do DAP Ribeirão Preto e administração do Novo Shopping.

Aos meus Mestres da engenharia de projetos da Interact Engo ${ }^{\circ}$ Eugênio Pabst, e da Maubertec Eng ${ }^{\circ}$.Carlos Martins, Eng ${ }^{\circ}$ Seije Taira, Eng ${ }^{\circ}$.Yoshida, Eng ${ }^{\circ}$. Marcos Panza, Engo ${ }^{\circ}$ Edson Elias, Engo. Eloy, Engo. Ming, Geólogos Hamilton e Leonardo 
(grande filósofo) e Dr. Luciano A. Borges, muito obrigado pela oportunidade pelos ensinamentos e pelos bons momentos.

Aos amigos Eliseu, Helon, Samantha e Selmo e aos funcionários da Maubertec e Interact.

A todos os amigos da SANASA Campinas .

Ao grandes amigos Zeca, Danhone, Antonio Desena, Henrique Varalta, Clóvis (In Memorian) e Partel (In Memorian), Elisabete, Ana Claudia, Erika, Giane, Dieine, Marcinha, Fábio Guerrini, Luana, Ronaldo, Luiz, Mauro, Bruce, Lívio, Flavio, Leandro, e Émerson (santista) grandes batalhadores da época de graduação cuja ajuda e amizade foram decisivos para a vida.

Aos grandes amigos Thomas N. Shimojo, Flávio e Paulo Yabiku, Wagner Meyer pela grande amizade e pelas alegrias, Deus abençoe a todos vocês !

Ao Gustavo e ao Ricardo que tanto se empenharam para o suporte técnico em meu carro nos dias finais desta dissertação.

À Dona Ângela, Escobar, Mariângela e aos funcionários do EESC-O BAR. 


\section{EPÍGRAFE}

\section{ODE "À ALEGRIA"}

Amigos, basta desses cantos !

Entoemos um outro e mais agradecido :

O cântico do júbilo !

Alegria, brilhante centelha da divindade,

Filha do Elísio.

Adentramos, semblantes ardentes,

Teu glorioso santuário!

Tua força mágica irmana,

O que o mundo separou;

Todos os homens tornam-se irmãos

Onde a tua asa gentil pousou.

Quem atingiu o supremo bem,

De ter por amigo um amigo,

Quem obteve suave esposa,

Esteja conosco no áureo júbilo !

Sim, quem ainda uma só alma

Pôde no mundo sua chamar!

Quem não pôde conduza em pranto

Para longe daqui seu triste caminhar.

Todos os seres bebem da alegria

No seio da natureza;

Bons e maus

Vão por seus floridos caminhos.

Prodigaliza-nos com beijos e vinho,

Amigos fiéis até a morte;

Até o verme pode sentir prazer,

E o querubim permanece diante de Deus!

Alegres como corpos celestiais voam

Sobre o plano rubro dos céus,

Ide, irmãos, a exultar,

Alegres, como heróis rumo à vitória.

Multidões, eu vos abraço.

Esse beijo envio ao mundo inteiro!

Irmãos! Acima desse dossel estrelado

Deve reinar um terno Pai.

Prostrai-vos, multidões?

Sentes o teu Criador, mundo?

Buscai-o então acima dos astros!

Além das estrelas está sua morada. 


\title{
RESUMO
}

Esta dissertação apresenta em primeira etapa o trabalho desenvolvido para averiguar a adequação dos modelos reológicos de Mohr-Coulomb e de Endurecimento de solo, para representar as deformações e distorções que ocorrem no sistema soloestrutura, quando do processo de escavação de valas escoradas. Além disto, em uma segunda etapa fazem-se estimativas de previsão de danos causados em edificações, em decorrência das escavações de uma vala escorada da linha 1 do Metropolitano de São Paulo (Metrô S.P.). A primeira e a segunda etapa foram feitas através de 810 simulações numéricas, em elementos finitos utilizando-se o software PLAXIS, associadas a retroanálise por processo direto do módulo de deformabilidade a $50 \%$ da tensão de ruptura dos solos utilizando-se para isto o processo direto.

Apresenta-se também uma síntese da formação e dos tipos de solos que constituem a bacia sedimentar de São Paulo, onde se localiza a seção experimental $n^{\circ} 1$ objeto de estudo desta dissertação.

Faz-se uma breve revisão bibliográfica a respeito das técnicas de retroanálise.

Apresentam-se critérios para escolha de intervalos de parâmetros geotécnicos que representem o sistema solo-estrutura no processo de escavação.

Foram feitas análises paramétricas para determinar os parâmetros geotécnicos que mais influenciam o sistema solo-estrutura.

Comparam-se os modelos constitutivos de Mohr-Coulomb e de endurecimento na previsão das deformações.

Por fim, faz-se a previsão do nível de danos causados pelas escavações da vala, a um edifício hipotético.

\author{
PALAVRAS CHAVE: Retroanálise, Valas, Escoramentos, Escavações, Metrô, \\ Danos em Edifícios, Interação solo-estrutura, Modelo de Mohr-Coulomb, Modelo \\ de Endurecimento, Elementos finitos
}




\section{SUMMARY}

This dissertation presents, in a first part, the work done to verify how appropriate are the Mohr-Coulomb and Hardening Soil constitutive models to represent the strains and the distortions associated with escavations of braced wall process. In the second part, estimates are made of the damages in constructions due to the braced excavations of line one of Sao Paulo Subway (Metrô S.P.). In the two phases, 810 numeric simulations were made, in finite elements using the software PLAXIS, associated the back analysis for direct process.

It is presented a synthesis of the formation and the types of soils that constitute the basin of the sediments of the city of São Paulo, where is located the section experimental $n^{\circ} .1$, object of study of this dissertation.

It is presented an short bibliographical revision regarding the back analysis techniques.

Criteria for choice of intervals of parameters geotechnical that represent the system soil-structure in the excavation process are presented.

Parametric analyses are made to determine which the parameters have larger influence in the behavior of the system soil-structure.

The behavior of the soil-structure system is simulated using the Mohr-Coulomb and Hardening Soil constitutive models.

The Mohr-Coulomb and Hardening Soil constitutive models are compared in the forecast of the deformations.

Finally, it is made the forecast of the level of damages to a hypothetical building caused by the braced excavations.

WORDS KEY: Back Analysis, Vertical Cuts, Bracing, Excavations, Subway, Damages in Buildings, Soil-structure interaction, Mohr-Coulomb Model, Hardening Soil Model, Finite Elements 


\section{SUMÁRIO}

Capítulo 1 - Introdução................................................................................................................. 1

Capítulo 2 - Tipos de Retroanálise e Objeto de Estudo ................................................................................ 8

2.1 Breve descrição dos principais tipos de retroanálise ...................................................................... 8

2.2 - Retroanálise por processo direto.......................................................................................... 16

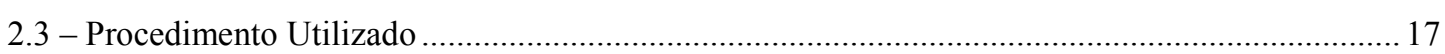

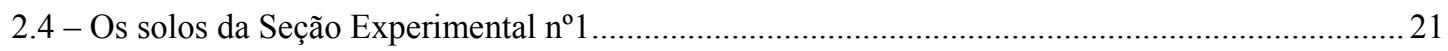

2.5 Características da seção experimental S.E.-1 da linha 1 do Metrô S.P.............................................. 23

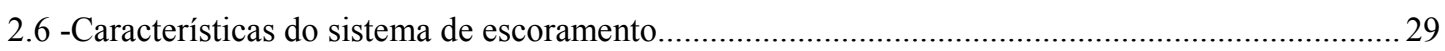

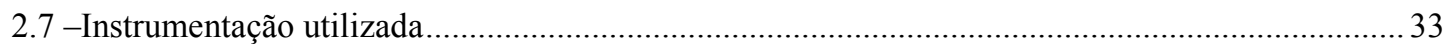

Capítulo 3 - Descrição da Modelagem e Análises Paramétricas ................................................................36

3.1 Limitações da Modelagem e Instrumentação ………………………………………………...... 49

3.2 -Primeira Etapa - modelo constitutivo de Mohr-Coulomb............................................................59

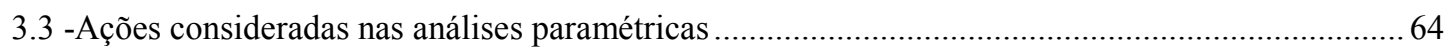

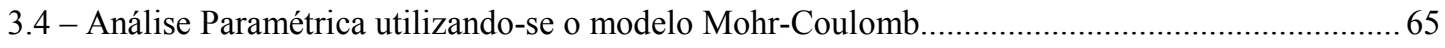

3.5 -Escolha dos intervalos para as retroanálises utilizando-se o modelo Mohr-Coulomb ..................... 72

3.6 -Segunda Etapa - Modelo de Endurecimento de solo ........................................................................ 76

3.7 - Descrição do modelo de Endurecimento de Solo (HS) ………………………………………...... 79

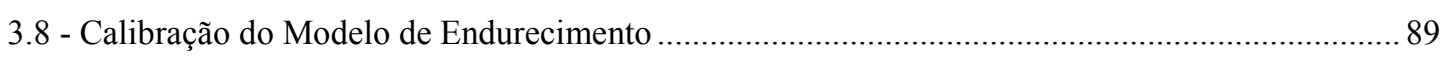

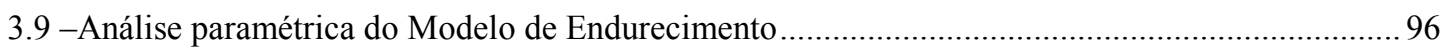

3.9.1 Resultados da variação de deslocamentos horizontais e verticais na variação de $+30 \%$... 98

3.9.2 Resultados da variação das forças nas estroncas variação de $+30 \%$ nos parâmetros ........ 108

3.9.3 Resultados da variação de deslocamentos horizontais e verticais devido à variação de $-30 \%$ nos parâmetros

3.9.4 -Resultados da variação das forças nas estroncas devido à variação de $-30 \%$ nos parâmetros

3.10 - Parâmetros de maior influência nos deslocamentos horizontais e verticais do paramento e nas forças das estroncas

3.10.1 Análise das hierarquias de influências de parâmetros nos deslocamentos horizontais e verticais de paramentos e forças nas estroncas.

3.10.2 -Critério para definição dos intervalos de parâmetros a variar no processo de retroanálise 130

3.10.3 Resultados obtidos com a variação de $+30 \%$ dos valores de referência inicial 2 ........ 132

3.10.4 Resultados obtidos com a variação de $-30 \%$ dos valores de referência inicial 2 .......... 137

3.11 -Escolha dos intervalos para as retroanálises utilizando-se o modelo de Endurecimento............. 142

Capítulo 4 - Aplicação de Retroanálise via Processo Direto a S.E.-1 …………………………………….. 147

4.1 -Influência da variação da temperatura do solo nos deslocamentos de paramento ......................... 147 
4.2 - Correção dos esforços nas estroncas em função do efeito da temperatura 151

4.3 -O problema da Retroanálise baseada somente em erros de deslocamentos do paramento 158

4.4-Resultados obtidos -Modelo de Mohr-Coulomb. 160

4.5 Retroanálise com base em erros de deslocamentos e forças 166

4.6 - Curvas de isovalores dos módulos dos erros para o modelo de Mohr-Coulomb 178

4.7 -Resultados obtidos - Modelo de Endurecimento184

4.8 -Erros em relação aos deslocamentos de paramentos ......................................................... 215

4.9 -Escolha do intervalo de soluções 223

4.10 -Comparação entre os resultados obtidos por retroanálises via Mohr-Coulomb e Endurecimento de solo

Capítulo 5 - Estimativa de danos causados a edifícios pelas escavações da vala da seção experimental $\mathbf{n}^{0} 1$

5.1 -Aspectos da interação solo-estrutura 230

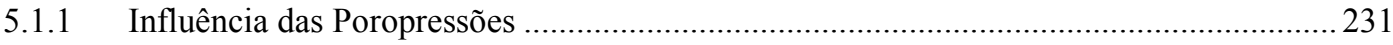

5.1.2 Influência das características de deformação do solo ......................................................2 231

5.1.3 -Influência do estado de tensões in situ ......................................................................... 232

5.2 -Tipos de danos causados à edificações........................................................................... 233

5.3 -Desvio dos elementos em relação à vertical e à horizontal .......................................................... 233

5.4 -Definições dos movimentos das fundações ......................................................................... 233

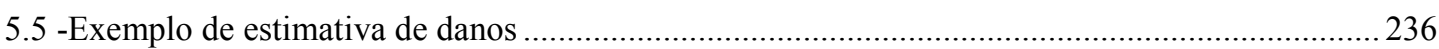

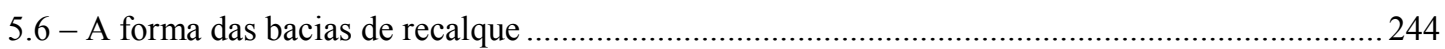

5.6.1 Ajustes de funções polinomiais ........................................................................... 244

5.7 -Relações entre deslocamentos horizontais máximos e profundidade da vala............................247

5.8 -Região de influência dos recalques .......................................................................................... 250

Capítulo 6 - CONSIDERAÇÕES FINAIS E TRABALHOS FUTUROS ..........................................254

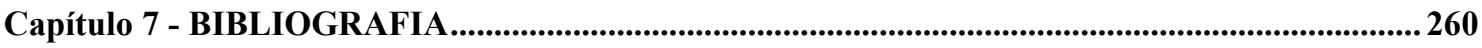

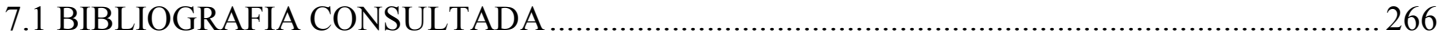




\section{LISTA DE FIGURAS}

Figura 2-1- Determinação do parâmetro desconhecido em situação estaticamente determinada, traduzido de KAVANAGH (1973).

Figura 2-2 Resultados obtidos por retroanálise de Eteórico após 7 estágios (AKUTAGAWA 1991) ........ 19

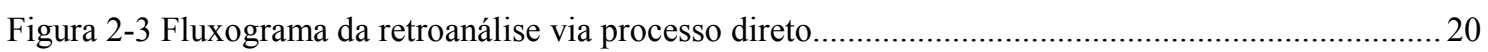

Figura 2-4-Carta Geológica Parcial de São Paulo (Metrô S.P., 1983) ..................................................... 23

Figura 2-5 -Local da Seção Experimental e locação da sondagem (IPT, 1972)....................................24

Figura 2-6 -Boletim de Sondagem No B 162 da Seção experimental no ${ }^{0}$ - (IPT, 1972)...........................25

Figura 2-7- Módulos de Deformabilidade $E_{i}$ e $E_{50}$ (argila porosa vermelha) em função do nível de tensões

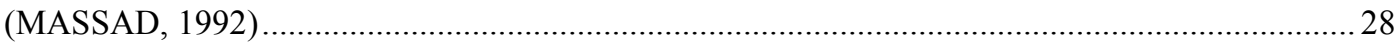

Figura 2-8 - Módulos de Deformabilidade $E_{i}$ e $E_{50}$ (argila rija vermelha) em função do nível de tensões

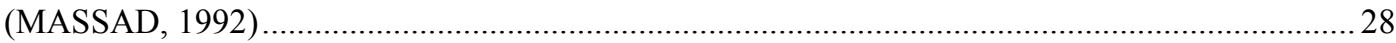

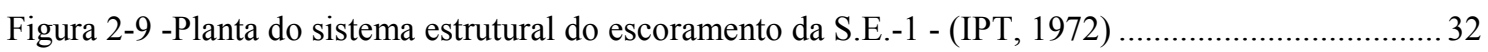

Figura 2-10 - Seção longitudinal do sistema estrutural do escoramento da S.E.-1 - (IPT,1972) .............. 32

Figura 3-1-Elementos finitos com 6 nós e 15 nós e respectivos pontos de tensões, utilizados pelo software

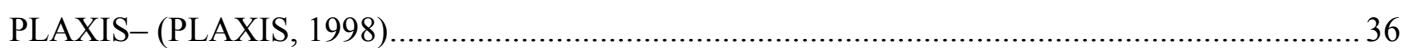

Figura 3-2-Exemplo da opção de malha muito grosseira gerada pelo software PLAXIS ........................3 37

Figura 3-3-Exemplo da opção de malha grosseira gerada pelo software PLAXIS ................................ 38

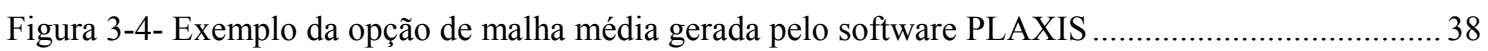

Figura 3-5- Exemplo da opção de malha muito fina gerada pelo software PLAXIS .............................. 39

Figura 3-6-Exemplo da distribuição de nós e pontos de tensão nos elementos de interface e suas conexões com os elementos de solo (PLAXIS, 2002).

Figura 3-7 Picos de distribuições de tensões em bordas de regiões de interface solo-estrutura devido à consideração de pontos inflexíveis (rígidos) (PLAXIS,2002).

Figura 3-8 Distribuições de tensões em bordas de regiões de interface solo-estrutura devido à consideração de pontos flexíveis (PLAXIS, 2002)................................................................... 42

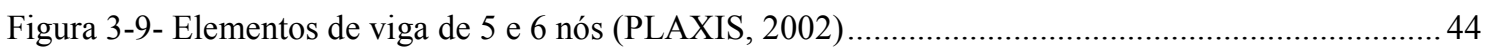

Figura 3-10- Exemplo de critério de cálculo do software PLAXIS (2002) para determinar o coeficiente de segurança para um ponto pré-determinado pelo usuário............................................................... 46

Figura 3-11-Modelo elaborado através software PLAXIS para a S.E.-1 …....................................... 47

Figura 3-12 - Malha de elementos finitos utilizada ................................................................ 48

Figura 3-13 - Deslocamentos de paramento (relacionados às temperaturas) instrumentados para o estágio

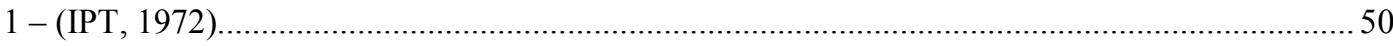

Figura 3-14- Deslocamentos de paramento (relacionados às temperaturas) instrumentados para o estágio 4 (IPT, 1972)

Figura 3-15- Estágios de escavação $\mathrm{n}^{\mathrm{o}} 1$ e 2 (IPT, 1972) ................................................................52

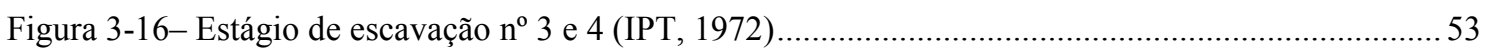

Figura 3-17 -Estágio de escavação no 5 e 6 (IPT, 1972) ................................................................5 


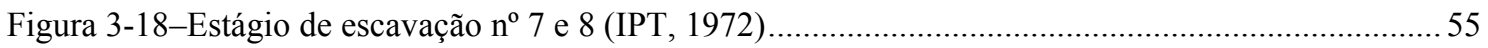

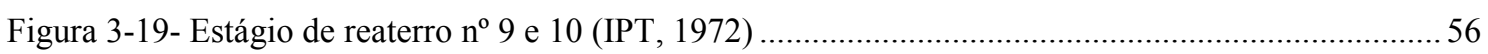

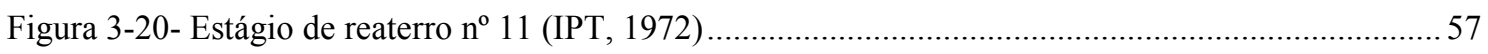

Figura 3-21-Datas de início de escavações dos estágios (IPT, 1972) ….............................................58

Figura 3-22-Datas dos estágios de reaterro e implantação das estruturas de concreto dos túneis (IPT,

Figura 3-23-Superfície de plastificação do Modelo de Mohr-Coulomb para solos não coesivos (PLAXIS, 2002). 60

Figura 3-24 Módulos de deformabilidade a deformações a 1\% e 50\% da tensão de ruptura (PLAXIS, 2002)

Figura 3-25-Módulos de deformabilidade a diferentes deformações (PINTO, 1996). 61

Figura 3-26- Influência do aumento de 30\% dos parâmetros nos deslocamentos horizontais em 3 pontos do paramento para o estágio 3

Figura 3-27- Influência do aumento de 30\% dos parâmetros nos deslocamentos horizontais em 3 pontos do paramento para o estágio 5 .

Figura 3-28- Influência do aumento de 30\% dos valores dos parâmetros nos deslocamentos horizontais em 3 pontos do paramento para o estágio 8

Figura 3-29- Influência do aumento de $30 \%$ dos valores dos parâmetros na força da estronca no nível A para o estágio 3 .

Figura 3-30- Influência do aumento de 30\% dos valores dos parâmetros na força da estronca no nível A para o estágio 5 .

Figura 3-31- Influência do aumento de 30\% dos valores dos parâmetros na força da estronca no nível A

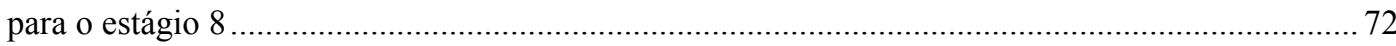

Figura 3-32-Coeficiente de Empuxo em Repouso (Ko) para S.E.1 (MASSAD, 1978).......................... 76

Figura 3-33- Valores obtidos de ensaios oedométricos em areia de Huston e os de simulação utilizando-se o modelo de Endurecimento de solo (PLAXIS,1998) 78

Figura 3-34- Valores obtidos de ensaios triaxiais em areia de Huston e os de simulação utilizando-se o modelo de Endurecimento de solo (PLAXIS,1998)

Figura 3-35 - Representação da superfície de plastificação do modelo de Endurecimento no espaço das tensões principais para um solo não coesivo

Figura 3-36--Relação dos módulos $E_{50}$ e $E_{u r}$ com as tensões desviatórias e as deformações axiais em ensaio triaxial (PLAXIS,2002).

Figura 3-37-Critério para obtenção de $E_{\text {oed }}^{r e f}$ a partir do ensaio oedométrico (PLAXIS,2002)..................85

Figura 3-38-Curvas de plastificação do modelo de Endurecimento para diferentes valores de $m$ (SCHANZ,1999). 87

Figura 3-39-Sondagem do poço experimental Gazeta, (PARREIRA, 1991)

Figura 3-40- Calibração do modelo de Endurecimento via variação do parâmetro $m$ para Argila Porosa

Vermelha $\mathrm{h}=3.5 \mathrm{~m}$ 92

Figura 3-41 - Calibração do modelo de Endurecimento via variação do parâmetro $m$ para Argila Porosa Vermelha $\mathrm{h}=6.5 \mathrm{~m}$ 
Figura 3-42- Calibração do modelo de Endurecimento via variação do parâmetro $m$ para Argila Rija Variegada $h=9.5 \mathrm{~m}$.

Figura 3-43- Calibração do modelo de Endurecimento via variação do parâmetro $m$ para Argila Rija Variegada $h=12.5 \mathrm{~m}$

Figura 3-44-Estágio 1-variação dos deslocamentos horizontais de 3 pontos do paramento em função da variação individual de parâmetros em $+30 \%$.

Figura 3-45 -Estágio 2-variação dos deslocamentos horizontais de 3 pontos do paramento em função da variação individual de parâmetros em $+30 \%$.

Figura 3-46 -Estágio 3-variação dos deslocamentos horizontais de 3 pontos do paramento em função da variação individual de parâmetros em $+30 \%$.

Figura 3-47 -Estágio 4-variação dos deslocamentos horizontais de 3 pontos do paramento em função da variação individual de parâmetros em $+30 \%$. 100

Figura 3-48 -Estágio 5-variação dos deslocamentos horizontais de 3 pontos do paramento em função da variação individual de parâmetros em $+30 \%$.

Figura 3-49 -Estágio 6-variação dos deslocamentos horizontais de 3 pontos do paramento em função da variação individual de parâmetros em $+30 \%$.

Figura 3-50- Estágio 7-variação dos deslocamentos horizontais de 3 pontos do paramento em função da variação individual de parâmetros em $+30 \%$.

Figura 3-51- Estágio 8-variação dos deslocamentos horizontais de 3 pontos do paramento em função da variação individual de parâmetros em $+30 \%$

Figura 3-52 -Estágio 1-variação dos deslocamentos verticais de 3 pontos do paramento em função da variação individual de parâmetros em $+30 \%$.

Figura 3-53- Estágio 2-variação dos deslocamentos verticais de 3 pontos do paramento em função da variação individual de parâmetros em $+30 \%$.

Figura 3-54 -Estágio 3-variação dos deslocamentos verticais de 3 pontos do paramento em função da variação individual de parâmetros em $+30 \%$.

Figura 3-55- Estágio 4-variação dos deslocamentos verticais de 3 pontos do paramento em função da variação individual de parâmetros em $+30 \%$.

Figura 3-56- Estágio 5-variação dos deslocamentos verticais de 3 pontos do paramento em função da variação individual de parâmetros em $+30 \%$.

Figura 3-57 -Estágio 6-variação dos deslocamentos verticais de 3 pontos do paramento em função da variação individual de parâmetros em $+30 \%$.

Figura 3-58- Estágio 7-variação dos deslocamentos verticais de 3 pontos do paramento em função da variação individual de parâmetros em $+30 \%$.

Figura 3-59 -Estágio 8-variação dos deslocamentos verticais de 3 pontos do paramento em função da variação individual de parâmetros em $+30 \%$

Figura 3-60-Estágio 3-variação das forças nas estroncas do nível A em função da variação individual de parâmetros em $+30 \%$

Figura 3-61 Estágio 4-variação das forças nas estroncas do nível A em função da variação individual de parâmetros em $+30 \%$ 
Figura 3-62- Estágio 5-variação das forças nas estroncas do nível A em função da variação individual de parâmetros em $+30 \%$

Figura 3-63- Estágio 6-variação das forças nas estroncas do nível A em função da variação individual de parâmetros em $+30 \%$ 110

Figura 3-64- Estágio 7-variação das forças nas estroncas do nível A em função da variação individual de parâmetros em $+30 \%$ 110

Figura 3-65- Estágio 8-variação das forças nas estroncas do nível A e nível B, em função da variação individual de parâmetros em $+30 \%$.

Figura 3-66- Estágio 1-variação dos deslocamentos horizontais de 3 pontos do paramento em função da variação individual de parâmetros em $-30 \%$.

Figura 3-67 -Estágio 2-variação dos deslocamentos horizontais de 3 pontos do paramento em função da variação individual de parâmetros em $-30 \%$

Figura 3-68-Estágio 3-variação dos deslocamentos horizontais de 3 pontos do paramento em função da variação individual de parâmetros em $-30 \%$

Figura 3-69-Estágio 4-variação dos deslocamentos horizontais de 3 pontos do paramento em função da variação individual de parâmetros em $-30 \%$.

Figura 3-70-Estágio 5-variação dos deslocamentos horizontais de 3 pontos do paramento em função da variação individual de parâmetros em $-30 \%$.

Figura 3-71-Estágio 6-variação dos deslocamentos horizontais de 3 pontos do paramento em função da variação individual de parâmetros em $-30 \%$

Figura 3-72-Estágio 7-variação dos deslocamentos horizontais de 3 pontos do paramento em função da variação individual de parâmetros em $-30 \%$.

Figura 3-73-Estágio 8-variação dos deslocamentos horizontais de 3 pontos do paramento em função da variação individual de parâmetros em $-30 \%$.

Figura 3-74 Estágio 1-variação dos deslocamentos verticais de 3 pontos do paramento em função da variação individual de parâmetros em $-30 \%$.

Figura 3-75 Estágio 2-variação dos deslocamentos verticais de 3 pontos do paramento em função da variação individual de parâmetros em $-30 \%$

Figura 3-76 Estágio 3-variação dos deslocamentos verticais de 3 pontos do paramento em função da variação individual de parâmetros em $-30 \%$

Figura 3-77- Estágio 4-variação dos deslocamentos verticais de 3 pontos do paramento em função da variação individual de parâmetros em $-30 \%$.

Figura 3-78 -Estágio 5-variação dos deslocamentos verticais de 3 pontos do paramento em função da variação individual de parâmetros em $-30 \%$.

Figura 3-79- Estágio 6-variação dos deslocamentos verticais de 3 pontos do paramento em função da variação individual de parâmetros em $-30 \%$.

Figura 3-80 -Estágio 7-variação dos deslocamentos verticais de 3 pontos do paramento em função da variação individual de parâmetros em $-30 \%$.

Figura 3-81- Estágio 8-variação dos deslocamentos verticais de 3 pontos do paramento para o nível A e nível B em função da variação individual de parâmetros em $-30 \%$. 
Figura 3-82- Estágio 3-variação das forças nas estroncas do nível A, em função da variação individual de parâmetros em $-30 \%$

Figura 3-83 -Estágio 4-variação das forças nas estroncas do nível A, em função da variação individual de parâmetros em $-30 \%$

Figura 3-84- Estágio 5-variação das forças nas estroncas do nível A, em função da variação individual de parâmetros em $-30 \%$

Figura 3-85 Estágio 6-variação das forças nas estroncas do nível A, em função da variação individual de parâmetros em $-30 \%$. 122

Figura 3-86- Estágio 7-variação das forças nas estroncas do nível A, em função da variação individual de parâmetros em $-30 \%$

Figura 3-87- Estágio 3-variação das forças nas estroncas do nível A e nível B, em função da variação individual de parâmetros em $-30 \%$

Figura 3-88- Estágio 1 - média dos módulos dos erros de deslocamentos horizontais de paramento por variação individual de $+30 \%$ dos parâmetros de referência inicial 2

Figura 3-89- Estágio 2 - média dos módulos dos erros de deslocamentos horizontais de paramento por variação individual de $+30 \%$ dos parâmetros de referência inicial 2 .

Figura 3-90- Estágio 3 - média dos módulos dos erros de deslocamentos horizontais de paramento e módulo do erro das forças nas estroncas nível $\mathrm{A}$, por variação individual de $+30 \%$ dos parâmetros de referência inicial 2

Figura 3-91- Estágio 4 - média dos módulos dos erros de deslocamentos de paramento e módulos dos erros das forças nas estroncas por variação individual de $+30 \%$ dos parâmetros de referência inicial 2 .

Figura 3-92- Estágio 5-média dos módulos dos erros de deslocamentos de paramento e módulos dos erros das forças nas estroncas nível A por variação individual de $+30 \%$ dos parâmetros de referência inicial 2

Figura 3-93- Estágio 6 - média dos módulos dos erros de deslocamentos de paramento e módulos dos erros das forças nas estroncas nível A por variação individual de $+30 \%$ dos parâmetros de referência inicial 2

Figura 3-94- Estágio 7- média dos módulos dos erros de deslocamentos de paramento e módulos dos erros das forças nas estroncas nível A por variação individual de $+30 \%$ dos parâmetros de referência inicial 2

Figura 3-95- Estágio 8- média dos módulos dos erros de deslocamentos de paramento e módulos dos erros das forças nas estroncas níveis A e B por variação individual de $+30 \%$ dos parâmetros de referência inicial 2

Figura 3-96- Estágio 1-média dos módulos dos erros de deslocamentos de paramento por variação individual de $-30 \%$ dos parâmetros de referência inicial 2

Figura 3-97- Estágio 2-média dos módulos dos erros de deslocamentos de paramento por variação individual de $-30 \%$ dos parâmetros de referência inicial 2 
Figura 3-98- Estágio 3-média dos módulos dos erros de deslocamentos de paramento e módulos dos erros das forças nas estroncas nível A por variação individual de $-30 \%$ dos parâmetros de referência inicial 2

Figura 3-99- Estágio 4-média dos módulos dos erros de deslocamentos de paramento e módulos dos erros das forças nas estroncas nível A por variação individual de $-30 \%$ dos parâmetros de referência inicial 2

Figura 3-100- Estágio 5-média dos módulos dos erros de deslocamentos de paramento e módulos dos erros das forças nas estroncas nível A por variação individual de $-30 \%$ dos parâmetros de referência inicial 2 140

Figura 3-101- Estágio 6-média dos módulos dos erros de deslocamentos de paramento e módulos dos erros das forças nas estroncas nível A por variação individual de $-30 \%$ dos parâmetros de referência inicial 2 140

Figura 3-102- Estágio 7- média dos módulos dos erros de deslocamentos de paramento e módulos dos erros das forças nas estroncas nível A por variação individual de $-30 \%$ dos parâmetros de referência inicial 2

Figura 3-103- Estágio 8 -média dos módulos dos erros de deslocamentos de paramento e módulos dos erros das forças nas estroncas níveis A e B por variação individual de $-30 \%$ dos parâmetros de referência inicial 2

Figura 3-104- Deslocamentos verticais do topo do paramento da seção experimental $n^{\circ} 1$ do MetrôSP em função da variação de $R_{\text {in }}$

Figura 4-1-Condutividade térmicas de solos congelados e não congelados apud MITCHELL (1992) ... 148

Figura 4-2-Curvas deslocamentos do paramento x temperatura nas estroncas para o estágio de escavação n⿳3 $3(\mathrm{IPT}, 1972)$

Figura 4-3-Variações de temperaturas utilizadas na correção das forças nas estroncas nos níveis A e B157

Figura 4-4-Convergência dos deslocamentos para o estágio 2 através de retroanálise de $E_{50}$.....

Figura 4-5 - Deslocamentos horizontais do paramento obtidos para o estágio 3 utilizando-se o valor de $E_{50}$ obtido da retroanálise do estágio 2

Figura 4-6- Deslocamentos horizontais do paramento obtidos para o estágio 5 utilizando-se o valor de $E_{50}$ obtido da retroanálise do estágio 2

Figura 4-7- Média dos módulos dos erros de deslocamentos horizontais de paramento para cada estágio simulado com o parâmetro $E_{50}$ obtido da retroanálise do estágio 2

Figura 4-8- Convergência dos deslocamentos horizontais de paramento através de retroanálise de $E_{50^{-}}$ estágio 3 .

Figura 4-9- Convergência dos módulos dos erros das forças nas estroncas nível A por etapa de retroanálise de $E_{50}$ - estágio3.

Figura 4-10- Convergência da média dos módulos dos erros de deslocamentos horizontais de paramentos para cada etapa de retroanálise de $E_{50}$-estágio 3 168

Figura 4-11- Convergência dos deslocamentos horizontais de paramento através de retroanálise de $E_{50 \text { - }}$ estágio 5 
Figura 4-12-- - Convergência dos módulos dos erros das forças nas estroncas nível A por etapa de retroanálise de $E_{50}$-estágio 5 ......

Figura 4-13 - Convergência da média dos módulos dos erros de deslocamentos horizontais de paramentos para cada etapa de retroanálise de $E_{50}$-estágio 5 .

Figura 4-14- Convergência dos deslocamentos horizontais de paramento através de retroanálise de $E_{50 \text { - }}$ estágio 8 .

Figura 4-15-- Módulo do erro das forças nas estroncas nível A por etapa de retroanálise estágio8

Figura 4-16- Não convergência da média dos módulos dos erros de deslocamentos horizontais de paramentos para cada etapa de retroanálise de $E_{50}$ - estágio 8

Figura 4-17- Média dos módulos dos erros de deslocamentos horizontais de paramento para cada estágio simulado com o parâmetro $E_{50}$ obtido da retroanálise do estágio 3

Figura 4-18- Média dos módulos dos erros de deslocamentos horizontais de paramento para cada estágio simulado com o parâmetro $E_{50}$ obtido da retroanálise do estágio 5

Figura 4-19 - Média dos módulos dos erros de deslocamentos horizontais de paramento para cada estágio simulado com o parâmetro $E_{50}$ obtido da retroanálise do estágio 8

Figura 4-20 -Isovalores de erros de deslocamentos horizontais do paramento - estágio 3. 178

Figura 4-21-Isovalores de erros de deslocamentos horizontais do paramento - estágio 5 . 179

Figura 4-22-Módulo dos erros de deslocamentos horizontais do paramento - estágio 8. 180

Figura 4-23-Isovalores de erros de forças nas estroncas - estágio 3.

Figura 4-24-Isovalores de erros de forças nas estroncas - estágio 5.

Figura 4-25-Módulo dos erros de forças nas estroncas - estágio 8.

Figura 4-26 -Convergência dos deslocamentos horizontais de paramento devido à retroanálise de $E_{50}$ para o Estágio 5 -modelo de endurecimento

Figura 4-27- Módulos dos erros médios para cada etapa de retroanálise de $E_{50}$ apresentados na Tabela 4-12.

Figura 4-28- Média dos módulos dos erros de deslocamentos horizontais de paramento e módulos de forças nas estroncas (A e B) para cada estágio simulado com o parâmetro $E_{50}$ obtido da retroanálise do estágio 5

Figura 4-29-Deslocamentos horizontais instrumentados x simulados através da Retroanálise de $E_{50}$ para o estágio 3 .

Figura 4-30- Deslocamentos horizontais simulados no estágio 2 com a adoção dos valores de $E_{50}$ obtidos da retroanálise do estágio 3 . 195

Figura 4-31- Deslocamentos horizontais simulados no estágio 5 com a adoção dos valores de $E_{50}$ obtidos da retroanálise do estágio 3.

Figura 4-32- Deslocamentos horizontais simulados no estágio 7 com a adoção dos valores de $E_{50}$ obtidos da retroanálise do estágio 3 .

Figura 4-33- Deslocamentos horizontais simulados no estágio 8 com a adoção dos valores de $E_{50}$ obtidos da retroanálise do estágio 3.

Figura 4-34-Deslocamentos horizontais simulados no estágio 2 devido a adoção dos valores de $E_{50}$ obtidos da retroanálise do estágio 5 . 
Figura 4-35- Deslocamentos horizontais simulados no estágio 3 devido a adoção dos valores de $E_{50}$ obtidos da retroanálise do estágio 5 .

Figura 4-36- Deslocamentos horizontais simulados no estágio 6 devido a adoção dos valores de $E_{50}$ obtidos da retroanálise do estágio 5 .

Figura 4-37- Deslocamentos horizontais simulados no estágio 7 devido a adoção dos valores de $E_{50}$ obtidos da retroanálise do estágio 5 .

Figura 4-38- Deslocamentos horizontais simulados no estágio 8 devido a adoção dos valores de $E_{50}$ obtidos da retroanálise do estágio 5 .

Figura 4-39-Ajuste de deslocamentos de paramento simulados x instrumentados obtidos por retroanálise de $E_{50}$ para o estágio 5 .

Figura 4-40--Ajuste de deslocamentos de paramento simulados (para o estágio 2) x instrumentados obtidos por retroanálise de $E_{50}$ para o estágio 5 .

Figura 4-41-Ajuste de deslocamentos de paramento simulados (para o estágio 3) x instrumentados obtidos por retroanálise de $E_{50}$ para o estágio 5 .

Figura 4-42 Ajuste de deslocamentos de paramento simulados (para o estágio 6) x instrumentados obtidos por retroanálise de $E_{50}$ para o estágio 5 .

Figura 4-43 Ajuste de deslocamentos de paramento simulados (para o estágio 7) x instrumentados obtidos por retroanálise de $E_{50}$ para o estágio 5 .

Figura 4-44 Ajuste de deslocamentos de paramento simulados (para o estágio 8) x instrumentados obtidos por retroanálise de $E_{50}$ para o estágio 5 .

Figura 4-45- Módulos dos erros de deslocamentos horizontais do paramento - estágio 3 - Modelo de Endurecimento

Figura 4-46- Módulos dos erros de deslocamentos horizontais do paramento - estágio 5 - Modelo de Endurecimento

Figura 4-47- Módulos dos erros de deslocamentos horizontais do paramento - estágio 8 - Modelo de Endurecimento

Figura 4-48-Módulos dos erros de forças nas estroncas -estágio 3

Figura 4-49- Módulos dos erros das forças nas estroncas -estágio 5.

Figura 4-50- Módulos dos erros de forças nas estroncas nível A -Estágio 8

Figura 4-51- Módulos dos erros de forças nas estroncas nível B-Estágio 8 .

Figura 4-52- Estágio 3- Comparação entre os erros obtidos pelos modelos Mohr-Coulomb e

Endurecimento - erros deslocamentos associados aos erros mínimos de forças nas estroncas ...... 225

Figura 4-53- Estágio 3- Comparação entre os erros obtidos pelos modelos Mohr-Coulomb e

Endurecimento - erros forças estroncas

Figura 4-54- Estágio 5- Comparação entre os erros obtidos pelos modelos Mohr-Coulomb e

Endurecimento -erros deslocamentos associados aos erros mínimos de forças nas estroncas. 226

Figura 4-55 -Estágio 5- Comparação entre os erros obtidos pelos modelos Mohr-Coulomb e

Endurecimento - erros forças estroncas 226

Figura 4-56- Estágio 8-Comparação entre os erros obtidos pelos modelos Mohr-Coulomb e

Endurecimento - erros deslocamentos associados aos erros mínimos de forças nas estroncas. 
Figura 4-57- Estágio 8- Comparação entre os erros obtidos pelos modelos Mohr-Coulomb e

Endurecimento - erros forças estroncas ................................................................................ 227

Figura 5-1-Exemplo de curva tensão $x$ deformação...................................................................2 231

Figura 5-2- Deslocamentos conceituais que ocorrem no solo das fundações de um edifício (ISE, 1989)234

Figura 5-3-Definições de recalque $\delta$, recalque relativo $\delta$ p e rotação $\phi$ e deformação angular $\alpha$ (ISE, 1989)

Figura 5-4-Definições de deflexão relativa $\Delta$, e razão de deflexão $\Delta / L$ (ISE, 1989).............................235

Figura 5-5-Definição de desaprumo $\omega$, rotação relativa (distorção angular) $\beta$ (ISE, 1989)..................235

Figura 5-6- Tipos de deslocamentos de paramentos em balanço (A) e estroncados (B)(ISE, 1989) ....... 236

Figura 5-7- Nível de deslocamentos em função da qualidade construtiva apud O’ROURKE (1990)

(RANZINI, 1996)

Figura 5-8- Nível de danos provocados a edifícios BORCARDIN e CORDING (1989) (RANZINI, 1996)

Figura 5-9-Ajuste da bacia de recalques ajustada por uma relação de polinômios- situação 1 ...............245

Figura 5-10 - Ajuste da bacia de recalques ajustada por uma relação de polinômios -situação 2 ............246

Figura 5-11-Definição das variáveis da escavação utilizadas no método, apud OU et al. (1993)............247

Figura 5-12- instrumentação observações de campo de OU et al. (1993) acrescidas das instrumentações da S.E.-1 Metrô S.P

Figura 5-13-Relação entre o comprimento do paramento e a região de influência dos recalques (OU et al., 1993). 251

Figura 5-14- Proposição de PECK (1969) relacionando recalques e distâncias da escavação com profundidade da escavação, figura traduzida por NC-03 (1980). 253

\section{LISTA DE FOTOGRAFIAS}

Foto 2-1-Foto da vista 1 acima do topo da vala da Seção Experimental n no.1 do Metrô de São Paulo (IPT, 1972).

Foto 2-2- Vista 2 tirada a partir do $2^{\circ}$ nível de estroncas (nível B), no topo as estroncas do $1^{\circ}$ nível (nível

A) da Seção Experimental nº.1 do Metrô de São Paulo (IPT, 1972) .... 31

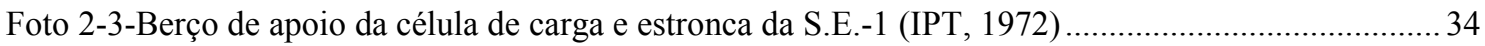

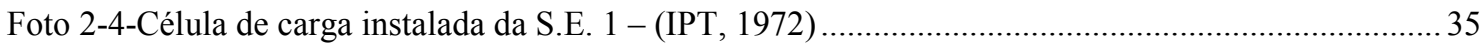




\section{LISTA DE TABELAS}

Tabela 2-1- Resultados obtidos através do algoritmo de minimização Simplex modificado apud GIODA (1980)

Tabela 2-2-Resultados obtidos utilizando-se o algoritmo de minimização de ROSEMBROCK apud

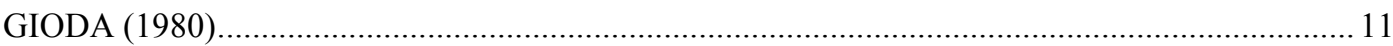

Tabela 2-3- Envoltórias de resistência para tensões efetivas solos da S.E.-1 (IPT, 1972) ......................26

Tabela 2-4 - Características das Argilas Vermelhas de São Paulo (MASSAD, 1992) ...........................27

Tabela 3-1- Diferenças percentuais calculadas (Argilas Vermelhas Porosas) entre os valores máximos, médios e mínimos para parâmetros geotécnicos obtidos de MASSAD (1992) .............................. 66

Tabela 3-2- Diferenças percentuais calculadas (Argilas Rijas Vermelhas) entre os valores máximos, médios e mínimos para parâmetros geotécnicos obtidos dos resultados de MASSAD (1992).

Tabela 3-3- Parâmetros geotécnicos valores de referência inicial 1 e variados em $+30 \%$ utilizados para as simulações com finalidade de análise paramétrica com o modelo de Mohr-Coulomb

Tabela 3-4-Hierarquia de inflûencias sobre os deslocamentos horizontais de 3 pontos do paramento para variações de $+30 \%$.

Tabela 3-5- Hierarquia de inflûencias sobre as forças nas estroncas níveis $A$ e $B$ para variações de $+30 \%$ a $-30 \%$

Tabela 3-6- Valores de deformações calculados pelo modelo de Endurecimento de solo para ensaio triaxial com pressão confinante $\sigma_{3}=294,2 \mathrm{kPa}$ em argila porosa vermelha amostra a $3,5 \mathrm{~m}$ de profundidade $(\operatorname{cota} 808,62)$

Tabela 3-7-Valores de deformações calculados pelo modelo de Endurecimento de solo para ensaio triaxial com pressão confinante $\sigma_{3}=490,3 \mathrm{kPa}$ em argila porosa vermelha amostra a $6,5 \mathrm{~m}$ de profundidade $(\operatorname{cota} 805,62)$

Tabela 3-8- Parâmetros geotécnicos valores de referência inicial 2 e variação de $+30 \%$ e $-30 \%$ em relação aos valores de referência inicial 2 utilizados para as simulações com finalidade de análise paramétrica com o modelo de Endurecimento de Solo

Tabela 3-9- Hierarquia de influências sobre os deslocamentos horizontais de 3 pontos do paramento para variações de $+30 \%$ e $-30 \%$ dos valores de referência inicial 2 .

Tabela 3-10 - Hierarquia de influências sobre os deslocamentos verticais de 3 pontos do paramento para variações e $+30 \%$ e $-30 \%$ dos valores de referência inicial 2 .

Tabela 3-11- Hierarquia de influências sobre as forças nas estroncas níveis $A$ e $B$ para variações e $+30 \%$ e

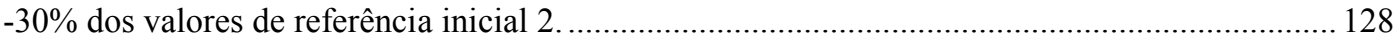

Tabela 3-12-Resumo dos intervalos de parâmetros para erros mínimos por estágio............................... 143

Tabela 4-1-Propriedades térmicas do solo

Tabela 4-2-Descrição das etapas consideradas na simulações das escavações com efeito de temperatura nas estroncas

Tabela 4-3 -Relação de Forças corrigidas em função da variação de temperatura.....

Tabela 4-4- Parâmetros geotécnicos (valores de referência iniciais) adotados para início das retroanálises via Mohr-Coulomb 
Tabela 4-5 -Valores do módulo do erro para retroanálise de $E_{50}$ conduzida para o estágio2 163

Tabela 4-6 -Estágios 3,5 e 8 -Resumo das médias dos módulos dos erros de deslocamentos horizontais de paramentos e forças nas estroncas - Mohr-Coulomb. 174

Tabela 4-7-Resumo das médias dos módulos dos erros de deslocamentos horizontais globais ............... 175

Tabela 4-8-Resumo dos módulos dos erros médios das forças globais nas estroncas. 176

Tabela 4-9 Resumo geral dos resultados de $E_{50}$ e intervalos de $K o$ e $c$ (coesão) que contém a solução para o modelo de Mohr-Coulomb

Tabela 4-10-Exemplo de cálculo de retroanálise de $E_{50}$ demonstrado da etapa 1 (R1) à etapa $3(\mathrm{R} 3) \ldots . .188$

Tabela 4-11- Continuação do exemplo de cálculo de retroanálise de $E_{50}$ demonstrado das etapas 5 e 6 (R5 e R6) saltando para a etapa 10 .

Tabela 4-12 - Módulos dos erros pontuais para cada etapa de retroanálise entre os deslocamentos simulados e os reais. 190

Tabela 4-13- Estágios 3, 5 e 8 - Resumo da média dos módulos dos erros de deslocamentos de paramentos e forças nas estroncas obtidos por retroanálise de $E_{50}$.

Tabela 4-14 - Resumo das médias dos módulos dos erros de deslocamentos globais a partir dos parâmetros obtidos da retroanálise de $E_{50}$ cada um dos estágios isolados (estágios 3, 5 e 8). 200

Tabela 4-15- Resumo das médias dos módulos dos erros de forças globais (estágios 3, 5, 6, 7, 8), obtidos por retroanálise de $E_{50}$

Tabela 4-16-Valores de $\mathrm{E}_{50}$ retroanalisados a partir da mesma combinação de parâmetros em estágios diferentes

Tabela 4-17-Resumo dos parâmetros com os quais ocorreram os erros mínimos de deslocamentos de paramentos e forças nas estroncas

Tabela 5-1-Classificação de danos em edificações BURLAND et al. (1977) (RANZINI, 1996).

Tabela 5-2- Resumo dos danos,da qualidade construtiva a partir deformações horizontais máximas, recalques verticais, distorções angulares da Tabela 4-17. 


\section{LISTA DE SÍMBOLOS}

$\mathbf{\%}<\mathbf{2} \mu$ - percentual de argila

c' - coesão efetiva

Cc - índice de compressão

E.T.N.D.* - Ensaios Triaxiais não drenados

$\boldsymbol{E}_{\text {50ref }}=$ Módulo de deformabilidade de referência, obtido do ponto correspondente a $50 \%$ da tensão de ruptura no ensaio triaxial, relativo a uma tensão $\sigma_{.3}$ definida como tensão de referência.

$\boldsymbol{E}_{5 \boldsymbol{0}=}$ Módulo de deformabilidade de referência, obtido do ponto correspondente a $50 \%$ da tensão de ruptura no ensaio triaxial, relativo a uma tensão $\sigma_{3}$ definida como tensão de referência.

$\boldsymbol{E}_{\boldsymbol{i}}=$ módulo de deformabilidade tangente inicial

$\mathbf{e}_{\text {nat }}$ - índice de vazios natural

Eteórico -Valor teórico do módulo de deformabilidade utlizado por AKUTAGAWA(1991)

$\boldsymbol{E}_{\boldsymbol{u}}=$ Módulo de deformabilidade do solo na situação carregamento/descarregamento h (\%) - percentual de umidade

IP - índice de plasticidade

$\boldsymbol{K} \boldsymbol{a}=$ coeficiente de empuxo do solo no estado ativo

$\boldsymbol{K} \boldsymbol{o}=$ coeficiente de empuxo do solo no estado em repouso

$\boldsymbol{K} \boldsymbol{p}=$ coeficiente de empuxo do solo no estado passivo

LL - limite de liquidez

$\boldsymbol{m}=$ fator de força que indica a aderência ao modelo constitutivo no modelo de endurecimento

$\boldsymbol{q}=$ tensão desviatória

$\boldsymbol{q}_{a}=$ tensão correspondente a assíntota do gráfico tensão x deformação no ensaio triaxial

$\boldsymbol{q}_{f}=$ tensão de ruptura do gráfico tensão x deformação no ensaio triaxial

$\boldsymbol{R}_{\boldsymbol{f}}=$ é a relação entre a tensão assintótica $\left(\boldsymbol{q}_{\boldsymbol{a}}\right)$ e a tensão de ruptura $\left(\boldsymbol{q}_{f}\right)$ obtidas do gráfico de ensaio triaxial

$\boldsymbol{R}_{\text {inter }}=$ Fator de redução da coesão e do ângulo de atrito na interface solo-paramento $\mathbf{S}(\%)$ - percentual de saturação do solo 
$\Delta$ - Deflexão Relativa

$\Delta / \mathbf{L}$ - Razão de Deflexão

$\Phi$ ',$\Phi^{\prime}{ }_{\mathbf{a}}-$ ângulo de atritos efetivos acima e abaixo dos efeitos de pré-adensamento

$\alpha$ - Deformação angular

$\beta$ - Distorção angular ou rotação relativa

$\delta_{\mathbf{p}}$ - Recalque relativo

$\delta$ - Recalque

$\gamma_{\text {nat }}-$ peso específico natural

$\theta-$ Rotação

$\sigma_{\mathbf{a}}$ - tensão de pré adensamento

$\omega$ - Desaprumo

\section{LISTA DE ABREVIATURAS}

AgPoVm- Argila Porosa Vermelha

AgVrgd- Argila Variegada

HSM- Modelo de endurecimento de solo

M.E.F - método dos elementos finitos

M.M.Q.- método dos mínimos quadrados

MC- Mohr Coulomb

S.E.-1 -Seção Experimental n ${ }^{\circ} 1$

SPT- Standard Penetration Test

STBSP - Sedimentos Terciários da Bacia de São Paulo 


\section{Capítulo 1 - Introdução}

Para a previsão do comportamento de um sistema solo-estrutura em escoramentos de vala, o calculista dispõe na etapa de projeto, de intervalos de valores de parâmetros geotécnicos obtidos via ensaios de laboratório e ou in situ. A partir destes intervalos, e do tipo de parâmetro disponível, faz escolhas de valores e de um modelo que represente o sistema solo-estrutura. Este modelo pode ser baseado na analogia de viga unidimensional com molas através do modelo de Wrinkler, ou também num modelo contínuo bi ou tridimensional que utilize, por exemplo, o método dos elementos finitos (M.E.F.). Os métodos disponíveis para escolha são os empíricos, os semi-empíricos e os analíticos.

Em qualquer dos modelos acima que o calculista adotar como representativo do sistema solo-estrutura de contenção, ele terá que fazer simplificações. Se optar por modelos simples precisará de poucos parâmetros geotécnicos. Porém, se escolher modelos mais complexos necessitará de um número maior de parâmetros; isto exigirá um maior conhecimento do solo, visto que o número de simplificações feitas é pequeno.

Por analogia à definição apresentada por AOKI (1999) para fundações, no caso de contenções o paramento é um sistema composto por um elemento estrutural e o solo que o envolve, seja integralmente na ficha ou parcialmente na região escavada. Desta forma, o enfoque dado à estrutura de contenção deve ser o sistêmico, uma vez que a interação solo estrutura é pronunciada.

Segundo MARZIONNA (1979), os parâmetros mais comumente adotados para projeto são coesão e ângulo de atrito que servem de base para muitos modelos simplificados de cálculo. $\mathrm{O}$ mesmo autor cita também que métodos mais sofisticados de cálculo exigem parâmetros como módulo de deformabilidade $(E s)$, coeficiente de Poisson 
$(v)_{2}$ coeficiente de empuxo em repouso (Ko.) ângulo de atrito na interface solo-paramento $\left(\phi_{\text {interface }}\right)$ entre outroṣ, pois levam em conta a interação solo-estrutura.

Devido à carência de espaços livres e à grande demanda por sistemas de Metrôs nos grandes centros é comum que as escavações sejam realizadas muito próximas às fundações de edificações existentes.

Sabe-se que é grande o nível de incertezas envolvidas na avaliação de parâmetros e no comportamento solo-estrutura. Conseqüentemente, a previsão de recalques de superfície e danos causados por eles a edificações também é incerta. A partir das evoluções obtidas nos equipamentos para ensaios in situ espera-se que as incertezas sejam reduzidas.

Ao se analisar vários estudos de caso de escoramentos de vala ao longo do mundo, entre eles o excelente trabalho de LONG (2001), que reuniu casos de vários países, notouse que nos grandes centros houve uma maior tendência à adoção de sistemas de contenção de comportamento rígido. Estes, teoricamente têm o objetivo de restringir os níveis de deformações a limites aceitáveis, e assim causar menores danos quando comparados aos de comportamento flexível.

Foi dada grande ênfase à importância de previsões na prática da engenharia civil por LAMBE (1973). O autor define que o sucesso para o engenheiro não deve ser somente prever, mas o de tomar decisões e agir baseado nestas previsões.

Devido à grande dificuldade em prever-se a variabilidade do solo e reproduzir em laboratório as situações reais do protótipo, surgiu a instrumentação de campo, que aliada a técnicas de retroanálise tem sido de grande utilidade para o engenheiro civil. Estas duas técnicas associadas permitem analisar o estado atual, a evolução do comportamento do sistema, a correção das premissas iniciais de projeto e a previsão de comportamento futuro.

O uso de instrumentação é o melhor dos métodos para refinar o cálculo. Segundo AKAMINE (1985), ela permite obter esforços reais, decorrentes da aplicação de ações reais ao modelo de comportamento real. O mesmo autor cita que a instrumentação para atender ao critério de economia não pode ser aplicada isoladamente. Portanto, deve estar associada a um modelo de cálculo, por exemplo, um modelo bi ou tri-dimensional que utilize o método dos elementos finitos. Assim, através de técnicas de retroanálise será possível reajustar os parâmetros iniciais assumidos em projeto, e se necessário modificar elementos da estrutura de contenção ou alterar o processo construtivo. 
Em outros tipos de obras de escavação como as de túneis, CELESTINO et al. (1987), afirmam que a instrumentação feita por equipes de acompanhamento da construção é de vital importância, tanto para introduzir mudanças rápidas, elevando o nível de segurança, como permitindo reduzir custos.

De acordo com MARZIONNA (1979), a melhor maneira de se avaliar recalques é através da instrumentação e há grande desvantagem em medir os recalques depois de eles terem ocorrido. Desta forma, os danos causados pela existência deles já ocorreram. Para evitar que isto ocorra é necessário que haja forte atuação das equipes de fiscalização e acompanhamento do processo executivo, além disto, é necessário que haja estreita ligação entre equipes de execução e projeto, de forma que os projetistas possam atualizar os parâmetros de projeto rapidamente a partir dos dados de instrumentação aliados a uma técnica de retroanálise. $\mathrm{O}$ mesmo autor cita ainda que os modelos analíticos bidimensionais permitem a obtenção da forma como os recalques ocorrerão à superfície. Isto deve ser feito através de um modelo de cálculo que conduza a resultados mais próximos aos reais. Em sua tese, NIMIR (1979) realizou estudos de paredes diafragma e apresentou como uma das conclusões que os métodos analíticos representam melhor a realidade. Neste ponto, fica claro que uma das opções é associar instrumentação e uma técnica de retroanálise via um modelo analítico.

A retroanálise se divide em duas abordagens, a direta e a inversa. A direta utiliza um modelo que com a entrada direta de um parâmetro (aquele que se quer determinar), fornece um resultado calculado que será comparado com o real (de instrumentação). Para diminuir o erro entre o valor calculado e o real, é necessário alterar o parâmetro de entrada proporcionalmente ao erro obtido na iteração anterior. Após um número de iterações, se as alterações do parâmetro produzirem uma redução do erro, então o processo estará convergindo para solução, desde que não existam pontos de descontinuidade. Assim, o valor de parâmetro que produzir o menor erro será o adotado como próximo ao real.

Já o processo inverso, segundo BERNARDES (2000), utiliza o procedimento contrário ao abordado em análise de estruturas. Neste processo as equações que governam o problema sofrem rearranjo, de forma que as variáveis correspondentes aos parâmetros a identificar apareçam como incógnitas, enquanto que as variáveis relativas aos resultados experimentais surgem como dados do problema. São conhecidas como técnicas de 
identificação de sistemas, ou de parâmetros dos modelos que melhor representem um processo observado ou também como problemas inversos.

$\mathrm{Na}$ abordagem inversa, de acordo com COSTA (2000), é necessário que os parâmetros a identificar tenham relação explícita com as grandezas observadas e que o número de medidas disponíveis seja maior ou igual ao número de parâmetros desconhecidos.

A vantagem da abordagem direta reside na não necessidade de um equacionamento para representar o problema, isto é de grande valia principalmente em problemas complexos e de grande variabilidade construtiva e de materiais, como é o caso de escavações de valas.

Assim pode-se utilizar, por exemplo, um modelo em elementos finitos para representar o fenômeno. A desvantagem é que para se aplicar a retroanálise por processo direto o processo iterativo pode ser longo.

O tempo a ser gasto para obter-se uma solução adequada, dependerá das incertezas que envolvam os parâmetros. Em outras palavras, quando as incertezas sobre os valores de parâmetros são grandes, é necessário estabelecer-se muitas combinações de intervalos de variação dos parâmetros, a fim de restringir-se a busca por possíveis soluções.

O avanço das técnicas de ensaios in situ contribui para a redução das magnitudes dos intervalos de valores de parâmetros a serem combinados. Por conseqüência, há redução do tempo para encontrar os valores de parâmetros que aproximem o comportamento do modelo simulado ao comportamento real.

Além disto, os ensaios in situ não devem se restringir a fase de investigação do solo, mas devem prosseguir em tempo real durante o processo construtivo visando investigar a variação dos parâmetros de solo em função da variação do comportamento do sistema.

A utilização de retroanálise por processo inverso, tem como vantagem a possibilidade de utilização de algoritmos de minimização, por exemplo SIMPLEX e de ROSEMBROCK, para busca das combinações de valores de parâmetros que aproximem os resultados calculados aos reais instrumentados.

Este processo geralmente é rápido, porém necessita de uma formulação para o fenômeno, e obter-se uma formulação adequada pode ser trabalhoso quando as incertezas envolvidas são grandes. Isto não é incomum em problemas de escavações de valas, onde as 
incertezas não só envolvem os materiais, como também a suas distribuições e o comportamento deles ante as variações de fluxos de tensões que ocorrem durante as escavações.

A partir de dados de instrumentação, AKAMINE (1985) e MAFFEI et al. (1987), utilizaram a retroanálise para ajustar os parâmetros geotécnicos de entrada do software evolutivo DEEP inicialmente assumidos em projeto. Assim, puderam prever a partir dos resultados de instrumentação do $3^{\circ}$ nível de tirantes, que poderia ser suprimido o $5^{\circ}$ nível de tirantes de uma estação do Metrô de São Paulo.

Em não bastando a grande variabilidade do solo, associada à grande variabilidade da execução da estrutura de contenção, há também a grande influência e imprevisibilidade da variação da temperatura. Estudos conduzidos por FUJII (1976) atentam para a influência da temperatura, e em IPT (1972) e MASSAD (1978) fica quantificada a grande influência da temperatura na variação das forças nas estroncas.

De acordo com LEITE (1992), “a concepção estrutural dos sistemas de contenção deve levar em conta três fatores: segurança, funcionalidade e custos, sendo que a busca do equilíbrio dos três deve ser a meta". O autor cita a mudança de filosofia que associava o conceito de rigidez ao tipo de parede. Ou seja, escoramentos de perfis-pranhões eram flexíveis e as paredes diafragma eram rígidas, agora este conceito passa a ser função do critério de deformação que depende do tipo e da rigidez da parede, da profundidade de instalação do $1^{\circ}$ nível de apoio, da distância entre os níveis de apoios, da rigidez dos apoios e das condições geológicas e geotécnicas do solo.

O mesmo autor menciona que para atingir a meta dos três pontos citados acima, atuou-se na área de concepção estrutural e funcional. Com isto, pôde-se reduzir o peso dos travamentos que atingiam até $25 \%$ do peso das estroncas e estacas, sendo que pelas normas o travamento deveria atingir em torno de $2 \%$. Após estas alterações, foram implementados dados de instrumentação (da linha leste-oeste do Metrô de São Paulo) a um modelo computacional, que simula o escoramento como uma viga contínua sobre apoios elásticos, associados à forças fictícias. Além disto, LEITE (1992) afirma que após a ruptura ocorrida na parede de contenção da Estação Marechal - Linha Leste-Oeste do Metrô de São Paulohouve uma concentração dos cuidados na concepção do sistema de contenção como um todo, enfocando segurança local e global. 
$\mathrm{Na}$ linha de desenvolvimento desta nova filosofia de projeto onde há grande ênfase na análise estrutural, os modelos em M.E.F. bidimensionais se enquadram bem. A partir do desenvolvimento de pacotes de software bidimensionais evolutivos utilizando o M.E.F., tornou-se possível a consideração de continuidade e também condições de interface soloestrutura, que eram limitadas (dificuldade acoplamento) nos modelos unidimensionais de viga acoplada a molas (Wrinkler). Os modelos bidimensionais evolutivos em M.E.F. produzem resultados mais realistas em relação às deformações do solo e bacias de recalques. De acordo com ESQUÍVEL (1978), se for considerado ou não o atrito entre o solo e a parede não haverá grande diferença entre as tensões normais na interface obtidas pelo modelo unidimensional e pelo bidimensional, mas há diferenças em relação aos momentos fletores. Os modelos unidimensionais evolutivos de mola (Wrinkler), obtiveram resultados satisfatórios quanto a esforços no paramento e nas estroncas, como demonstrou AKAMINE (1985), porém por haver dificuldades em representar a continuidade via acoplamento de molas, o volume de solo deslocado fica mal representado, principalmente no entorno da superfície da vala.

Utilizando-se os dados de instrumentação de deslocamentos horizontais de paramentos e forças nas estroncas, relativos às escavações da Seção Experimental no 1 da linha 1 do Metrô de São Paulo, e um modelo em elementos finitos (softwares bidimensionais PLAXIS (1998 e 2002), aplicou-se a retroanálise por processo direto ao módulo de deformabilidade a $50 \%$ da tensão de ruptura $\left(E_{50}\right)$ dos solos. A partir disto esta dissertação teve como objetivos :

- quantificar a influência dos parâmetros de solo e de interface solo-estrutura, nos deslocamentos do paramento e nas forças das estroncas.

- simular o efeito de temperatura na variação das forças das estroncas

- constatar que a obtenção do intervalo de soluções por retroanálise somente em função da análise de erros de deslocamentos não é confiável

- demonstrar que a análise dos erros de deslocamentos conjuntamente com os erros de esforços nas estroncas conduz a intervalos de soluções mais confiáveis 
- comparar os modelos constitutivos Mohr-Coulomb e Modelo de Endurecimento quanto à representação do comportamento dos solos nos diversos estágios de escavação.

- apresentar a superfície de erros em relação aos deslocamentos do paramento e das forças nas estroncas, para visualizar os intervalos de parâmetros que contenham a solução do problema.

- estimar o nível de danos que seria causado a um edifício hipotético.

Apresenta-se no capítulo 2 uma breve descrição dos tipos de retroanálise, das características dos solos da cidade de São Paulo e da seção experimental n ${ }^{\circ} .1$ (localizada na linha Norte-Sul do Metrô de São Paulo), cujo escoramento foi instrumentado e será objeto de estudo desta dissertação. No capítulo 3 foram feitas a descrição do software, da modelagem utilizada, as análises paramétricas e as descrições dos modelos de MohrCoulomb e de Endurecimento. No capítulo 4 foi feita a aplicação da retroanálise por processo direto à seção experimental $\mathrm{n}^{\circ}$.1, no capítulo 5 a estimativa de danos causados pelas escavações desta seção experimental a um edifício hipotético, no capítulo 6 apresentam-se as considerações finais e recomendações para trabalhos futuros e no capítulo 7 a bibliografia utilizada e a bibliografia consultada e no apêndice A apresenta-se algumas figuras com as telas de entrada e saída do software PLAXIS (2002). 


\section{Capítulo 2 - Tipos de Retroanálise e Objeto de Estudo}

\subsection{Breve descrição dos principais tipos de retroanálise}

Apresenta-se a seguir uma síntese de algumas técnicas de retroanálise, utilizando-se informações obtidas de KAVANAGH (1973), Gioda (1980), GIODA e MAIER (1980), CIVIDINI e GIODA e JURINA (1981), SAKURAI e TAKEUCHI (1983), AKUTAGAWA (1991) e BERNARDES (2000).

Um dos trabalhos iniciais e fundamentais de retroanálise utilizando-se técnicas computacionais foi desenvolvido por KAVANAGH (1973), o algoritmo é apresentado na Figura 2-1-, é uma forma de se determinar constantes elásticas de materiais anisotrópicos. Estas foram determinadas a partir da solução de um grupo de equações não lineares que são influenciadas pelo tipo, número e qualidade dos dados.

$\mathrm{O}$ autor utilizou experimentos que com barras tracionadas, elementos circulares sob torção e cilindros vazados sob ação combinada de torção e pressão interna e vigas sujeitas a flexão. Porém, ele reconheceu que havia limitações no método entre as condições estaticamente determinadas em laboratório e a realidade de indeterminação das tensões in situ. Para isso utilizou dois procedimentos, um quando havia somente medidas de deformações e o problema era estaticamente determinado e outro quando havia indeterminação quanto às tensões internas de campo. 


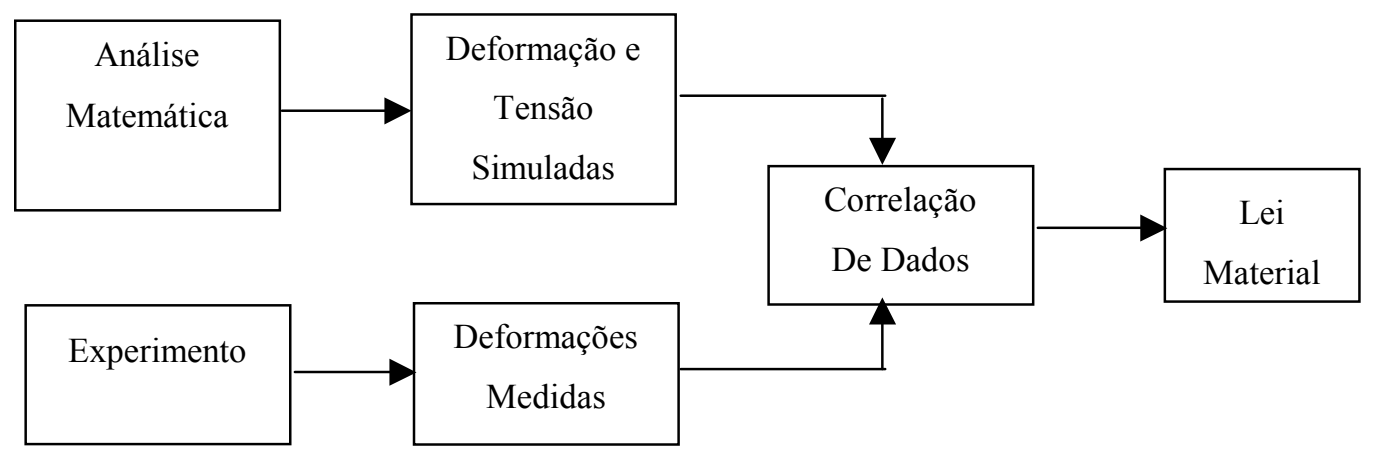

Figura 2-1- Determinação do parâmetro desconhecido em situação estaticamente determinada, traduzido de KAVANAGH (1973)

Ao longo dos estudos numéricos conduzidos e apresentados em KAVANAGH (1973), o autor incluiu análises de sensibilidade e procedimentos para diminuir várias formas de erros. Desta forma, determinou fundamentos de procedimentos computacionais para determinação de parâmetros desconhecidos de materiais utilizando a técnica de retroanálise inversa por elementos finitos.

O referido autor assumiu que há dificuldades na retroanálise numérica quando associada com complexas iterações que envolvem procedimentos numéricos e os erros envolvidos nas medidas.

Após a publicação de KAVANAGH (1973) surgiu o trabalho de KIRSTEN (1976) que apresentava um único algoritmo para a determinação do módulo de Young, baseado em medidas de deslocamentos de campo induzidas por escavações. $\mathrm{O}$ algoritmo não envolvia a inversão direta daquele algoritmo que utilizava elementos finitos que foi desenvolvido por KAVANAGH (1973), podendo ser considerado como um tipo de análise de sensibilidade na qual a resposta do sistema foi pré-calculada, tendo utilizado para determinar os parâmetros desconhecidos as medidas disponíveis.

De acordo com AKUTAGAWA (1991), com o desenvolvimento de técnicas computacionais, chamadas de geomecânica computacional, uma série de estudos teóricos de retroanálise foi desenvolvida pelo grupo de pesquisadores do Politécnico de Milão no início dos anos 80. O primeiro passo foi dado por GIODA (1980) que fez uma modificação no algoritmo de inversão proposto por KAVANAGH (1973). GIODA (1980) explorou o uso da função de minimização e estruturou um método de otimização via elementos finitos. Este método foi chamado de método de busca direta de um problema inverso. Foi construído de tal modo que as discrepâncias entre valores 
medidos e os simulados eram minimizadas por modificação dos parâmetros ativos a cada iteração.

A seleção de parâmetros melhorados pela minimização fez com que a análise do processo de otimização fosse um processo iterativo fechado e feito fora do M.E.F. Este método é mais vantajoso do ponto de vista de programação e utiliza o método Simplex como rotina para minimização de função.

A primeira aplicação do método de busca direta foi utilizada para demonstrar e verificar a capacidade do método de identificar parâmetros elásticos de materiais a partir de medidas de deslocamentos. A partir de GIODA e MAIER (1980) ficou clara a aplicabilidade do método para caracterizar os parâmetros de materiais não lineares e condições de carregamento utilizando um exemplo numérico de um ensaio em um pequeno túnel de seção circular sob pressão. Neste exemplo a pressão $(p)$ aplicada (parâmetro de entrada) era conhecida e o incremento médio. $(\delta)$ do diâmetro do túnel (para um determinado aumento de pressão p), era o parâmetro medido. No procedimento de minimização do erro foram utilizados os métodos simplex modificado e o algoritmo de Rosenbrock e ambos produziram resultados satisfatórios. Isto pode ser observado pela proximidade dos dados obtidos após as iterações, que constam Tabela 2-1 e Tabela 2-2. 
Tabela 2-1- Resultados obtidos através do algoritmo de minimização Simplex modificado apud GIODA (1980)

\begin{tabular}{|c|c|c|c|c|c|c|c|}
\hline $\begin{array}{l}\text { Tipo de } \\
\text { Análise }\end{array}$ & $\begin{array}{c}\text { Erro } \\
\text { mínimo } \\
{\left[\mathrm{e}_{\min } \%\right]}\end{array}$ & $\begin{array}{l}\text { Coesão c } \\
{\left[\mathrm{kg} / \mathrm{cm}^{2}\right]}\end{array}$ & $\begin{array}{c}\text { Ângulo } \\
\text { de Atrito } \\
{\left[\phi^{0}\right]}\end{array}$ & $\begin{array}{c}\text { Tensões in } \\
\text { situ } \\
\sigma_{\mathrm{l}}\left[\mathrm{kg} / \mathrm{cm}^{2}\right]\end{array}$ & $\begin{array}{c}\text { Número } \\
\text { de } \\
\text { Iterações } \\
\text { Simplex }\end{array}$ & $\begin{array}{c}\text { Número } \\
\text { de } \\
\text { Avaliações } \\
\text { de Erro }\end{array}$ & $\begin{array}{c}\text { Tempo } \\
\text { de } \\
\text { CPU }\end{array}$ \\
\hline$\sigma_{\mathrm{t}}=30 \mathrm{~kg} / \mathrm{cm}^{2}$ & 6,34 & 7,41 & 60,01 & - & 41 & 87 & $10 \mathrm{~m} \mathrm{53 \textrm {s }}$ \\
\hline$\sigma_{\iota}=50 \mathrm{~kg} / \mathrm{cm}^{2}$ & 0,04 & 10,00 & 30,00 & - & 52 & 109 & $11 \mathrm{~m} 39 \mathrm{~s}$ \\
\hline$\sigma_{\iota}=70 \mathrm{~kg} / \mathrm{cm}^{2}$ & 5,32 & 12,91 & 24,88 & - & 32 & 65 & $6 \mathrm{~m} 36 \mathrm{~s}$ \\
\hline $\begin{array}{c}\phi ; \sigma_{1} ; \mathrm{c} \mathrm{como} \\
\text { variáveis }\end{array}$ & 0,07 & 10,01 & 29,29 & 49,98 & 72 & 139 & $5 \mathrm{~m} 55 \mathrm{~s}$ \\
\hline
\end{tabular}

Tabela 2-2-Resultados obtidos utilizando-se o algoritmo de minimização de ROSEMBROCK apud GIODA (1980)

\begin{tabular}{|c|c|c|c|c|c|c|c|}
\hline Técnica & $\begin{array}{c}\text { Erro } \\
\text { mínimo } \\
{\left[\mathbf{e}_{\mathbf{m i n}} \%\right]}\end{array}$ & Coesão c & $\begin{array}{c}\text { Angulo de } \\
\text { Atrito } \\
{\left[\mathbf{k g} / \mathbf{c m}^{2}\right]}\end{array}$ & $\begin{array}{c}\text { Tensões } \text { in } \\
\text { situ } \\
{\left[\phi^{0}\right]}\end{array}$ & $\begin{array}{c}\text { Número } \\
\sigma_{\imath}\left[\mathbf{k g} / \mathbf{c m}^{2}\right]\end{array}$ & $\begin{array}{c}\text { Número de Passos } \\
\text { Avaliações } \\
\text { de Erro }\end{array}$ & $\begin{array}{c}\text { Tempo } \\
\text { de CPU }\end{array}$ \\
\hline $\begin{array}{c}\text { Rosenbrock } \\
\text { no jump'; } \gamma=1\end{array}$ & 0,11 & 9,91 & 30,19 & 49,82 & 10 & 219 & $7 \mathrm{~m} 30 \mathrm{~s}$ \\
\hline $\begin{array}{c}\text { Rosenbrock } \\
\text { jump'; } \gamma=1\end{array}$ & 0,42 & 10,30 & 29,43 & 50,61 & 9 & 149 & $4 \mathrm{~m} 56 \mathrm{~s}$ \\
\hline $\begin{array}{c}\text { Rosenbrock } \\
\text { jump'; } \gamma=0,1\end{array}$ & 0,05 & 9,96 & 30,08 & 49,92 & 10 & 148 & $4 \mathrm{~m} 55 \mathrm{~s}$ \\
\hline $\begin{array}{c}\text { Estágio de 1 } \\
\text { ciclo }\end{array}$ & 0,73 & 10,47 & 29,10 & 51,10 & 15 & 223 & $9 \mathrm{~m} 39 \mathrm{~s}$ \\
\hline
\end{tabular}

GIODA e JURINA (1981) alertaram para a necessidade de estudos probabilísticos e ampla investigação quanto aos efeitos dos erros dos dados de instrumentação utilizados como entrada para a solução do problema.

Os pesquisadores do Politécnico de Milão já haviam abordado duas principais vertentes de caracterização de:

- parâmetros de material

- parâmetros de carregamento 
A partir disto, havia o interesse de classificar os vários métodos de solução e a estratégia de formulação da retroanálise com respeito à variedade dos parâmetros desconhecidos.

CIVIDINI e GIODA e JURINA (1981) definiram que os tipos de parâmetros desconhecidos encontrados em processos de retroanálises podem ser divididos em três grupos fundamentais:

- características geométricas : $G$

- propriedades materiais: $M$

- condições de carregamento : $L$

Um exemplo de retroanálise para cada um dos grupos fundamentais de problemas foi feito utilizando-se método de pesquisa direta, o algoritmo de retroanálise padrão para determinar o carregamento e o algoritmo inverso para caracterização dos materiais. A partir destes exemplos o grupo de Milão concluiu que:

- as técnicas de retroanálise têm capacidade de resolver problemas onde os parâmetros desconhecidos pertencem a apenas uma categoria de dados, ou seja, de um só grupo fundamental.

- em casos onde há mais de um grupo fundamental de parâmetros desconhecidos, por exemplo, carregamentos e materiais, somente a medida de deslocamentos não é suficiente para determinar-se uma solução única para o problema.

Foi demonstrado que com 3 algoritmos de retroanálise pode-se resolver uma variedade de problemas se devidamente medidos e providos da precisão das medidas dos dados.

Segundo AKUTAGAWA (1991), a importância primária deste trabalho do grupo de Milão não está relacionada apenas aos fundamentos de classificação da retroanálise, mas também à necessidade de quantificação dos custos envolvidos na obtenção de todos os parâmetros. Estes, conduzem a níveis diferentes de pesquisa para a 
obtenção dos erros das medidas através do método estatístico de estimativa de parâmetros.

A menos do trabalho de GIODA e JURINA (1981) a caracterização de parâmetros de carregamento foi pouco desenvolvida.

SAKURAI e TAKEUCHI (1983) apresentaram um algoritmo de retroanálise para resolver o problema de tensões inicias em problemas de escavações em túneis. $\mathrm{O}$ problema foi formulado para a condição de deformação plana (bi-dimensional), com três parâmetros desconhecidos e três componentes de tensão pré-escavação. Assumiu-se que o coeficiente de Poisson era um dado de entrada. O módulo de Young seria tomado como entrada de dados ou equacionado através de retroanálise. Para a determinação das tensões in-situ um mínimo de três medidas de deslocamentos precisam estar disponíveis. Este algoritmo, entretanto não considera dois fatores cruciais que existem em casos práticos. Em túneis há sempre o problema da tridimensionalidade na frente de escavação e também o tempo de medida dos deslocamentos.

A partir destas limitações no método de SAKURAI e TAKEUCHI (1983) o algoritmo foi estendido por FENG e LEWIS (1987), agora contabilizando também a mudança de direção das tensões de campo, a não linearidade do comportamento do material, e o efeito do avanço da face de escavação do túnel com respeito ao tempo de instalação e monitoramento dos aparelhos.

Em CIVIDINI e MAIER e NAPPI (1983) é formalmente apresentado o método estocástico para aplicações em geomecânica. Neste trabalho os autores evidenciam a importância estatística no processo de medida da informação.

A partir deste ponto, mais pesquisadores lançaram-se nesta área surgindo o método da máxima verossimilhança desenvolvido por GENS et al. (1988) e o método do filtro de Kalman desenvolvido por MURAKAMI e HASEGAWA (1988). Enquanto a experiência era escassa em retroanálise devido ao conhecimento limitado dos erros de engenharia envolvidos, o processo determinístico era utilizado. A partir do momento em que houve inúmeros usos desta técnica e uma melhoria na idéia de erros de medidas, modelagem dos erros, os valores esperados de parâmetros tornaram-se disponíveis e a retroanálise por processos estocásticos pôde ser utilizada.

AKUTAGAWA (1991) fez a partir do trabalho dos autores anteriormente citados, um resumo de todos os métodos existentes e chegou a um grupo de 9 algoritmos distintos. Estes algoritmos foram numerados de 1 a 9, e conjuntamente com o software $C A D A X$ em M.E.F. desenvolvido também por AKUTAGAWA (1991) que o 
autor chamou de Programas de Sistemas de Retroanálise para Aplicações em Geomecânica. Os 9 algoritmos estão descritos sucintamente a seguir:

Algoritmo 1 - representa o $1^{\circ}$ modelo apresentado por KAVANAGH (1973) e utiliza o M.E.F. com análise adiante como processamento central. As relações entre as deformações medidas e a matriz dos componentes desconhecidos são estabelecidas por obtenção de tensão e deformação a partir dos pontos medidos. Estas equações são resolvidas pelo método dos mínimos quadrados (M.M.Q.) para determinar atualizações de parâmetros desconhecidos. O processo se encerra quando a convergência é atingida.

Algoritmo 2 - é o segundo método de KAVANAGH (1973). Este algoritmo utiliza medidas de deslocamentos absolutos como dados de entrada e a formulação baseada no M.E.F. inverso, a partir do qual a equação de rigidez assumida é particionada de acordo com as parcelas medidas e não medidas do vetor de deslocamento. Este particionamento é condensado para simplificar a equação que é submetida ao M.M.Q. para atualização dos parâmetros desconhecidos. Neste ponto o autor cita um fato importante sobre o termo retroanálise, o qual foi primeiramente usado em geomecânica por KIRSTEN (1976). Pode-se ter a impressão de inversão direta para a chamada de análise para adiante. Entretanto, somente o algoritmo 2 é o inverso, todos os outros algoritmos incluindo o de KIRSTEN, usa M.E.F. com análise adiante como processamento central e através de algoritmos especiais associados realizam procedimentos completos de retroanálise.

Algoritmo 3 - é o algoritmo de KIRSTEN - este algoritmo utiliza três simulações com diferentes constantes elásticas, para produzir seis equações das quais seis coeficientes característicos são determinados para cada ponto de referência adotado. A partir da obtenção dos coeficientes característicos, as medidas de deslocamentos absolutos podem ser usadas para determinar as constantes elásticas desconhecidas. Este algoritmo usa portanto, o M.E.F. com análise adiante como processamento central e requer 3 simulações antes de a solução ser obtida.

Algoritmo 4 - é o algoritmo utilizado por SAKURAI e TAKEUCHI (1983) para a determinação de tensões in situ. Neste algoritmo, o M.E.F. com análise adiante também é utilizado como processamento central, que tem grande utilização para gerar a partir de um carregamento unitário, a sensibilidade deformacional da estrutura, conhecida como flexibilidade. A partir da flexibilidade obtida ela é utilizada para definir 
a relação entre os carregamentos desconhecidos e os deslocamentos relativos medidos. O M.M.Q. determina a solução, e o procedimento de iteração não é tão longo como o usado em problemas de elasticidade.

Algoritmo 5 - é o algoritmo proposto por YANG e STERLING (1989), que utiliza B.E.M. (Método dos Elementos de Contorno). Este procedimento expande o tamanho do sistema de equações devido ao número de incógnitas. Por exemplo, quando três componentes de tensões in situ e um módulo de Young são desconhecidos, quatro equações adicionais, três da convergência dos deslocamentos e a última de medida de tensões tangenciais, são adicionadas ao sistema de equações e o grupo de equações é resolvido em uma operação. Este algoritmo tem a particularidade de utilizar todas as equações em uma só matriz e de usar medidas de deslocamentos e tensões simultaneamente.

Algoritmo 6 - é o algoritmo de FENG e LEWIS (1987), utiliza os incrementos não lineares de parâmetros de carregamento. Este algoritmo é baseado no algoritmo 4 com o qual desenvolve o problema de elasticidade linear. Os parâmetros de carregamento são determinados tal qual para o comportamento elástico. Após a $1^{\mathrm{a}}$ solução ter sido obtida, a análise para adiante é conduzida utilizando esta $1^{\mathrm{a}}$. solução e os resultados são comparados com os medidos. Se houver diferenças entre os deslocamentos medidos e simulados, então estas diferenças residuais serão calculadas como medidas residuais as quais serão usadas como próximas medidas (fictícias) para ajustar os parâmetros de carregamento. $\mathrm{O}$ procedimento se repete até que as medidas residuais se tornem menores que uma tolerância.

Algoritmo 7 - chamado de método de pesquisa direta é estruturado com o módulo da análise para adiante. Pode ser utilizado como ferramenta de otimização para casos elásticos, elasto-plásticos ou visco-plásticos e também como ferramenta de otimização matemática, apesar de GIODA (1980) utilizar o método Simplex. Devido a sua estruturação simples e generalista, pode ser largamente utilizado para determinação de propriedades de materiais lineares e não lineares.

Algoritmo 8 - é uma versão diferente do método de pesquisa direta o qual tem a retroanálise como processamento central. Foi utilizado por SAKURAI (1988) para caracterização das tensões in situ e dos parâmetros cisalhantes de materiais anisotrópicos para o problema de cortes em taludes.

Algoritmo 9 - é o método de estimativa Bayesiano desenvolvido por CIVIDINI e MAIER e NAPPI (1983) como $1^{\circ}$ procedimento de retroanálise estocástica para fins 
geomecânicos. Neste algoritmo valores iniciais apropriados são atribuídos a todos os parâmetros desconhecidos. Uma vez que a matriz de sensibilidade está definida, ela é utilizada em conjunto com as medidas de deslocamentos e suas variâncias e valores esperados de variâncias dos parâmetros desconhecidos definidos na primeira estimativa. A solução é dada por atualização da estimativa dos parâmetros desconhecidos e de suas covariâncias. O procedimento continua até que duas sucessivas estimativas sejam consideradas as mesmas. As variâncias finais mostram qual a incerteza dos parâmetros retroanalisados. Na estrutura do algoritmo o M.E.F de análise para adiante tem que ser usado $\mathrm{N}_{\mathrm{p}}+1$ vezes em cada iteração de Bayes, onde $\mathrm{N}_{\mathrm{p}}$ é o número de parâmetros desconhecidos. Devido ao elevado esforço computacional para calcular a matriz de sensibilidade a cada iteração, foi necessário contornar isto. Foi desenvolvido um algoritmo similar por GENS et al. (1988) e MURAKAMI e HASEGAWA (1988) que usaram o método da máxima verossimilhança e o de filtro de KALMAN.

\section{2 - Retroanálise por processo direto}

O grande valor das técnicas de retroanálise é utilizar os dados de instrumentação para atualizar os parâmetros de projeto, fornecendo assim elementos para a previsão de comportamento do sistema solo-estrutura e conseqüentemente sendo grande aliada do engenheiro no planejamento ou em intervenções futuras, permitindo assim a convivência saudável entre economia e segurança.

A retroanálise por processo direto consiste em variar um tipo de parâmetro (e os correlatos a ele) de cada camada de solo e fixar todos os outros. Desta forma, averiguase simultaneamente se os resultados de deslocamentos simulados para cada camada se aproximam ou se distanciam dos obtidos pela instrumentação, que são aceitos como verdadeiros. Aqui cabe enfatizar a fundamental importância da análise racional quanto aos resultados obtidos por retroanálise baseados em instrumentação, uma vez que a instrumentação pode conter erros que se refletirão no parâmetro obtido por retroanálise. Este assunto foi tratado por HACHICH e NEGRO (1990), que argumentam que a retroanálise probabilística permite ajustar cada parâmetro proporcionalmente à sua incerteza. Os autores aplicaram a técnica para interpretação de medidas de convergência em túneis e defendem que o processo direto tende a supervalorizar as informações contidas nas medidas como se não estivessem sujeitas a erro. 


\section{3 - Procedimento Utilizado}

Uma vez que não foi possível obter-se nos relatórios IPT (1972) e IPT2 (1972) as medidas de variabilidades dos parâmetros, descartou-se a abordagem por retroanálise probabilística para este trabalho, apesar de ter sido foco de atenção na fase de revisão bibliográfica.

O relatório IPT (1972), forneceu valores de deslocamentos horizontais de paramentos e forças nas estroncas associadas às temperaturas. Em virtude da não disponibilidade de valores de variabilidades das medidas, este trabalho restringiu-se a comparar os erros entre valores de instrumentação in situ e os correspondentes simulados em elementos finitos. Sendo esses valores as forças nas estroncas e deslocamentos horizontais de paramentos.

O sistema solo-estrutura foi representado através de características geométricas, de materiais (estruturas e solos) e de carregamentos variáveis (variação de forças nas estroncas devido a temperatura) e permanentes (peso próprio dos elementos estruturais).

Considerou-se que a variabilidade é constante para parâmetros de materiais que compõem os elementos estruturais (perfis laminados de aço para as estroncas e paramentos).

Considerou-se que as maiores fontes de variabilidade estão presentes nos solos e nas cargas variáveis (variação de forças nas estroncas por efeito de temperatura e carregamentos devido aos veículos e equipamentos para realizar as escavações e contenções).

Partindo-se do princípio que todos os $n$ parâmetros geotécnicos de cada camada de solo têm influência no comportamento da escavação, e apoiando-se nas conclusões obtidas das análises paramétricas (item 3.10.1) e nos resultados de ensaios de laboratório (Tabela 2-4), optou-se pela fixação de $n-1$ parâmetros e variou-se o parâmetro $E_{50}$ a cada iteração, utilizando-se o modelo de Mohr-Coulomb (item 3.2) e o modelo de Endurecimento (item 3.6).

Isto foi feito seguindo a equação (2.1) que relaciona o parâmetro do modelo com os deslocamentos simulados e os reais (instrumentados). A cada nova iteração faz-se uma nova perturbação do valor do parâmetro $E$ teórico. 
As simulações desta dissertação foram conduzidas primeiramente utilizando-se o modelo de Mohr-Coulomb (item 3.2) e posteriormente o modelo de Endurecimento de solo (item 3.6). Os intervalos de parâmetros foram definidos pela análise paramétrica (item 3.10.1). Considerou-se o efeito de temperatura através das variações de forças das estroncas, metodologia detalhada no Capítulo 4 -.

Foram realizadas 10 iterações para cada combinação, para cada um dos 4 estágios de escavação estudados (estágios 2; 3; 5 e 8) no modelo de Mohr-Coulomb e estágios 3, 5 e 8 para o modelo de Endurecimento.

Quando ocorreu ruptura em uma iteração a combinação foi encerrada e considerou-se como melhor aproximação, a iteração da etapa anterior.

AKUTAGAWA (1991) considerou convergência na $5^{\text {a }}$. etapa de retroanálise para três camadas horizontais de solos com valores diferentes de módulo de

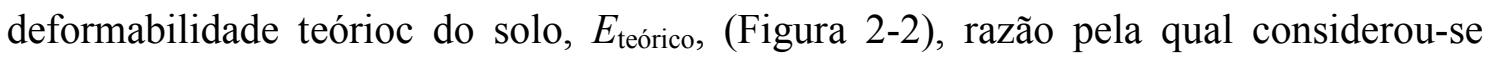
razoável encerrar as iterações na $10^{\mathrm{a}}$ etapa ou antes, quando os erros a cada nova iteração demonstravam-se estacionários.

A equação (2.1) exemplifica como o processo de retroanálise corrige o parâmetro $E_{50}$ em função dos deslocamentos horizontais reais $\left(U_{\text {real }}\right)$ e simulados $\left(U_{\text {simulado }}\right)$ na etapa anterior. Para estes valores de $U_{\text {simulado }}$ obtidos, o erro em relação ao $U_{\text {real }}$ é dado pela equação (2.2)

$$
E_{50, i}=\frac{E_{50, i-1}}{U_{i-1}} \times U_{\text {instrumentado }}
$$

$$
\mid \text { Erro } \%\left|=\left(\frac{U_{\text {instrumentado }}-U_{i-1}}{U_{\text {instrumentado }}}\right) * 100\right|
$$

Sendo :

$U_{\text {instrumentado }}=$ deslocamento horizontal do paramento instrumentado

$U_{i-1}=$ deslocamento horizontal do paramento simulado

$E_{50, i}=$ módulo de deformabilidade a $50 \%$ da tensão de ruptura para a próxima iteração i (atual)

$E_{50, i-1}=$ módulo de deformabilidade a $50 \%$ da tensão de ruptura utilizado para a simulação anterior $i-1$ (passada) 
| Erro \% | = módulo do erro dos deslocamentos horizontais do paramento simulados em relação aos instrumentados

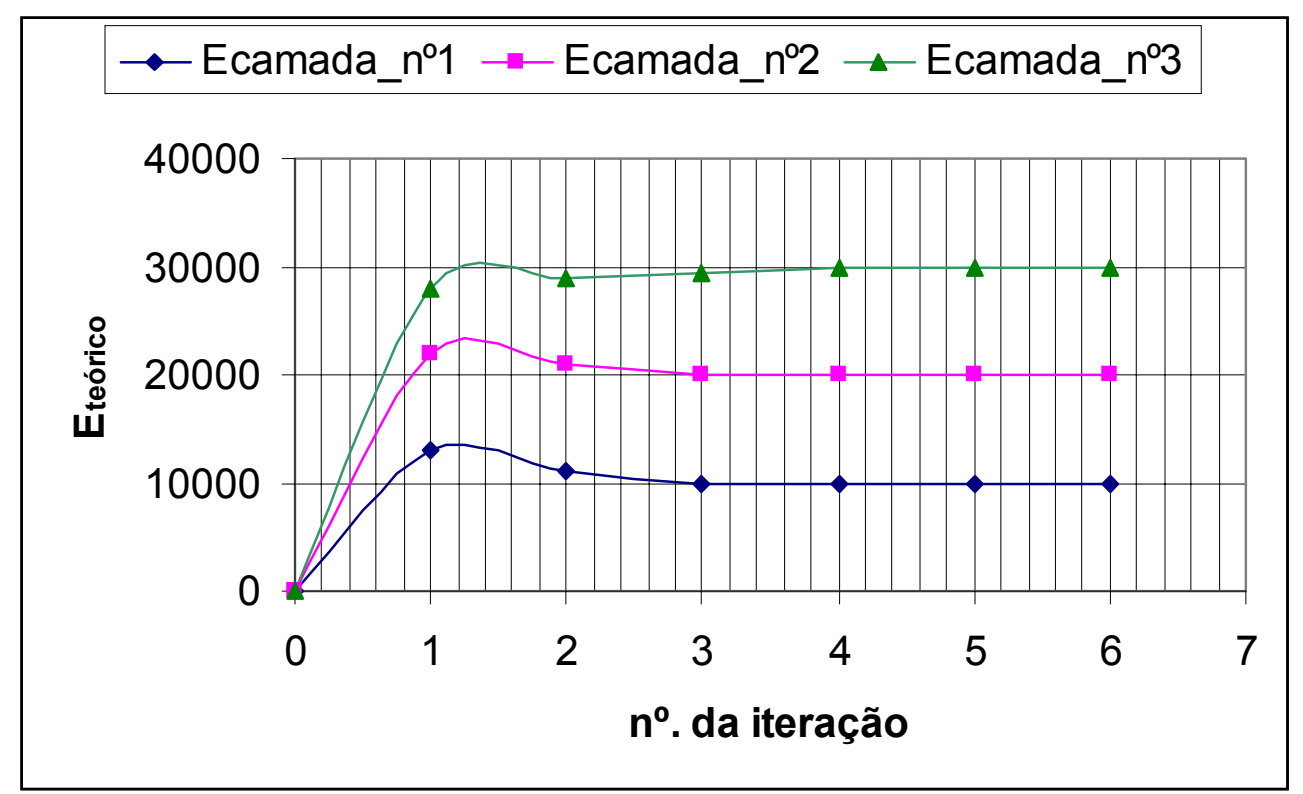

Figura 2-2 Resultados obtidos por retroanálise de $\mathbf{E}_{\text {teórico }}$ após 6 iterações (AKUTAGAWA 1991)

Apresenta-se na Figura 2-3 o fluxograma da retroanálise por processo direto. 


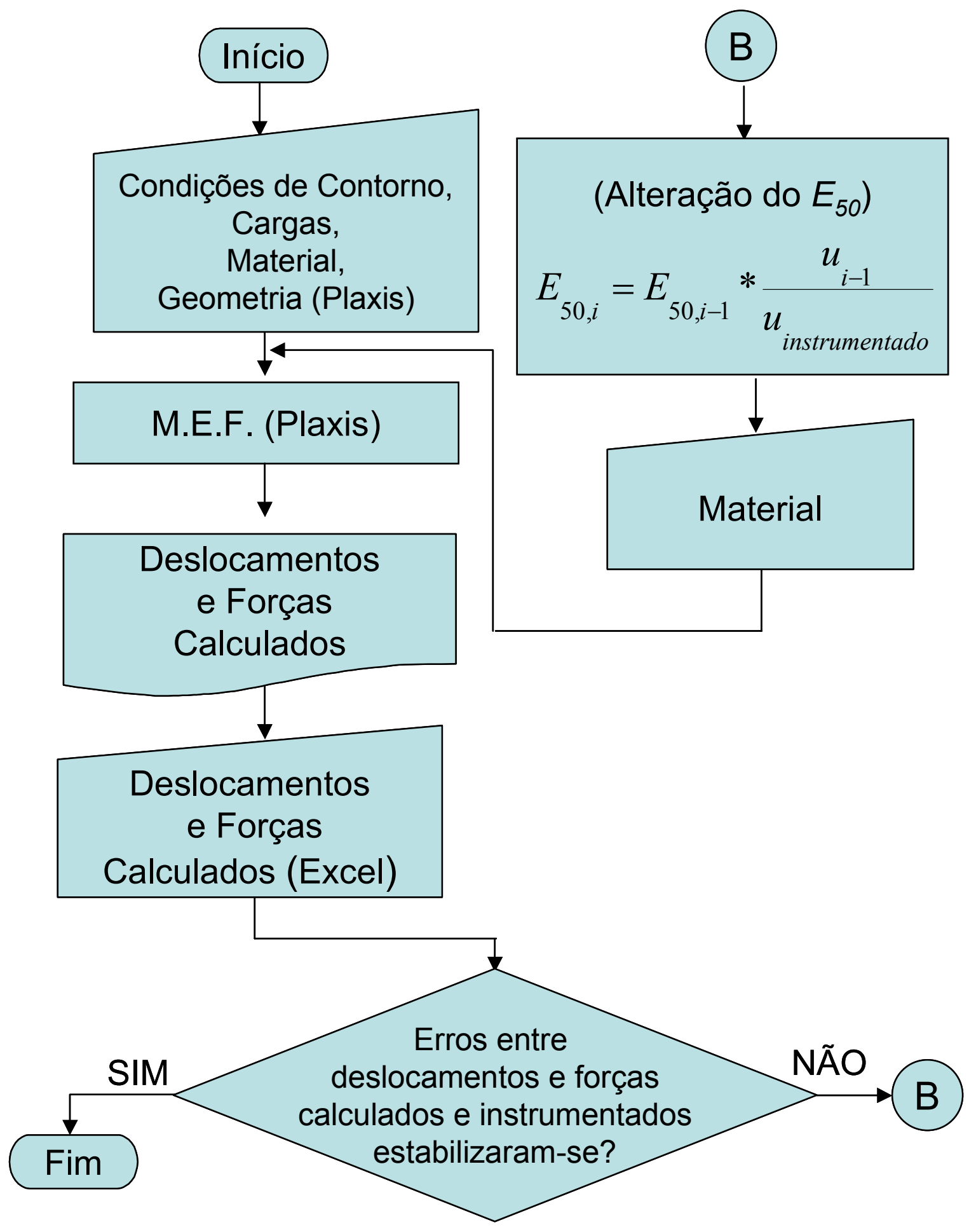

Figura 2-3 Fluxograma da retroanálise via processo direto 


\section{4 - Os solos da Seção Experimental n¹}

A seção experimental $n^{0} .1$ (S.E.-1) da linha Norte-Sul do Metrô S.P., foco de estudo deste trabalho tem como perfil geológico os solos componentes da Bacia de São Paulo.

A Bacia de São Paulo é uma unidade integrante do denominado Rift Continental do Sudoeste do Brasil-RCSB de acordo com RICCOMINI (1989), tendo idade cenozóica, que engloba também de sudoeste para noroeste, as bacias de Curitiba (PR), Graben de Sete Barras e Bacia de Taubaté (SP) entre outras. De acordo com o mesmo autor, o Rift Continental tem uma forma estreita que vai de Curitiba (PR) até Barra de São João (RJ), somando aproximadamente $900 \mathrm{~km}$, seguindo aproximadamente a linha de costa atual com distância aproximada de $70 \mathrm{~km}$, atingindo o Oceano Atlântico a nordeste e se aproximando a sudoeste. O referido Rift desenvolveu-se sobre terrenos policíclicos, que de acordo com RICCOMINI (1992) apud HASUI et al. (1975), é constituído principalmente por rochas metamórficas, migmatitos e granitóides, relacionados em parte ao Ciclo Brasiliano/Pan Africano e, em parte por resultado do retrabalhamento de rochas de ciclos mais antigos. Este conjunto litológico está recortado por denso sistema de falhamentos transcorrentes, de carácter dextral RICCOMINI (1992) apud SADOWSKI (1984), orientados de ENE a EW, que estiveram em atividade até o final do Ciclo Brasiliano.

De acordo com RICCOMINI (1989), reativações dos falhamentos transcorrentes deixaram registros nos sedimentos cenozóicos.

Já no Jurássico Superior, RICCOMINI (1992) apud ALMEIDA (1967), afirma que relacionados à Reativação Wealdeniana, evoluíram para a deriva continental e abertura do Atlântico Sul.

Desta forma, a origem do Rift segundo RICCOMINI (1992) apud MELO et al. (1985) estaria ligada à porção crustal adjacente à Bacia de Santos, como conseqüência da pressão imposta pelos movimentos verticais opostos.

Os solos da cidade de São Paulo localizam-se no chamado Planalto Paulistano. Este compreende uma área de aproximadamente $5000 \mathrm{~km}^{2}$, em sua maior parte entre as níveis de 715 e 900m de acordo com RICOMINI (1992). Segundo o mesmo autor apresenta relevo suavizado, de morros e espigões relativamente baixos, com a drenagem 
fluindo para o Rio Tietê e seus afluentes da Soleira do Barueri, na Serra de Itaqui e também recebem a drenagem os Rios Pinheiros, Tamanduateí e seus tributários.

De uma forma geral são encontrados solos dos sedimentos terciários e quaternários. Quanto aos tipos de rochas são encontradas as graníticas, migmatitos, gnaisses graníticos, filitos e ou meta-arenitos. A ocorrência dos solos e rochas citados está representada na Figura 2-4.

De acordo com PARREIRA (1991) a topografia da bacia sedimentar terciária de São Paulo apresenta um desnível máximo de $113 \mathrm{~m}$ entre as cotas mínimas (718m) na confluência dos Rios Tietê e Pinheiros e a cota máxima $(831 \mathrm{~m})$ no Sumaré.

A espessura média dos sedimentos, segundo o mesmo autor, é de 60 a $80 \mathrm{~m}$ tendo alcançado $202 \mathrm{~m}$ na região da Moóca. As camadas de argilas porosas vermelhas foram detectadas por sondagens acima da cota $750 \mathrm{~m}$ e encontram-se nas partes mais elevadas da cidade, como o Espigão da Avenida Paulista, tendo como características principais serem:

- $\quad$ solos não saturados

- altamente porosas

- de formação laterítica estando presentes óxidos de ferro

- sobreadensadas devido a sucessivos processos de ressecamento e umedecimento durante o processo de formação da bacia sedimentar

- colapsíveis

- inadequadas para o uso de fundações diretas

- apresentarem consistência mole à média

- dispostas verticalmente de uma forma geral, abaixo de uma pequena camada de aterro e acima de uma camada de argila variegada que se inicia junto ao início do lençol freático. 


\subsection{Características da seção experimental S.E.-1 da linha 1 do Metrô S.P.}

A geologia do local da seção experimental no 1 (S.E.-1) da linha Norte-Sul do Metrô de SãoPaulo, inclui-se no grupo dos Sedimentos Terciários da Bacia de São Paulo, Formação São Paulo, Figura 2-4. Na Figura 2-5 apresenta-se o local da seção experimental $\mathrm{n}^{\mathbf{0}} 1$, que esta localizada entre as atuais estações Vila Mariana e Santa Cruz.

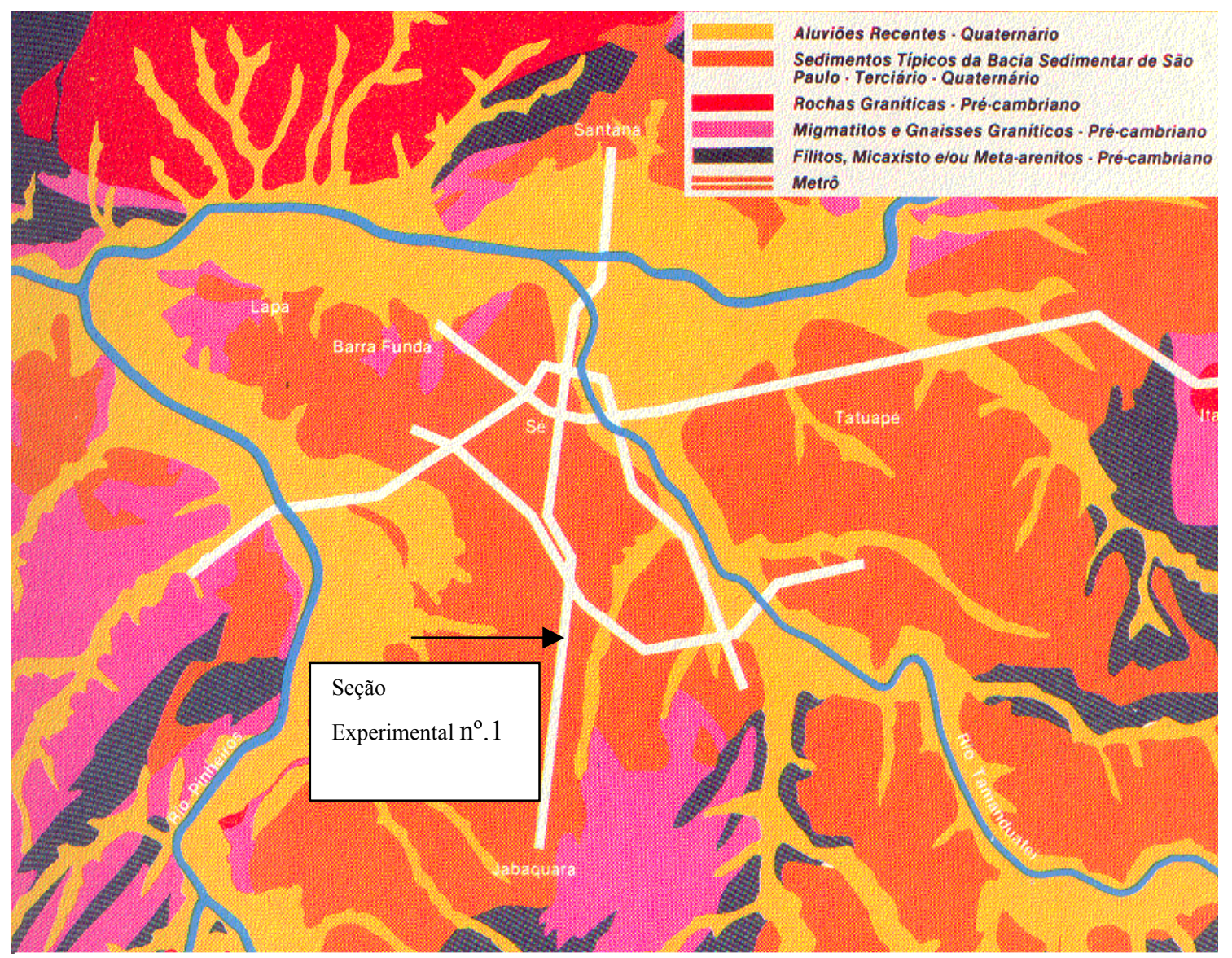

Figura 2-4-Carta Geológica Parcial de São Paulo (Metrô S.P., 1983) 


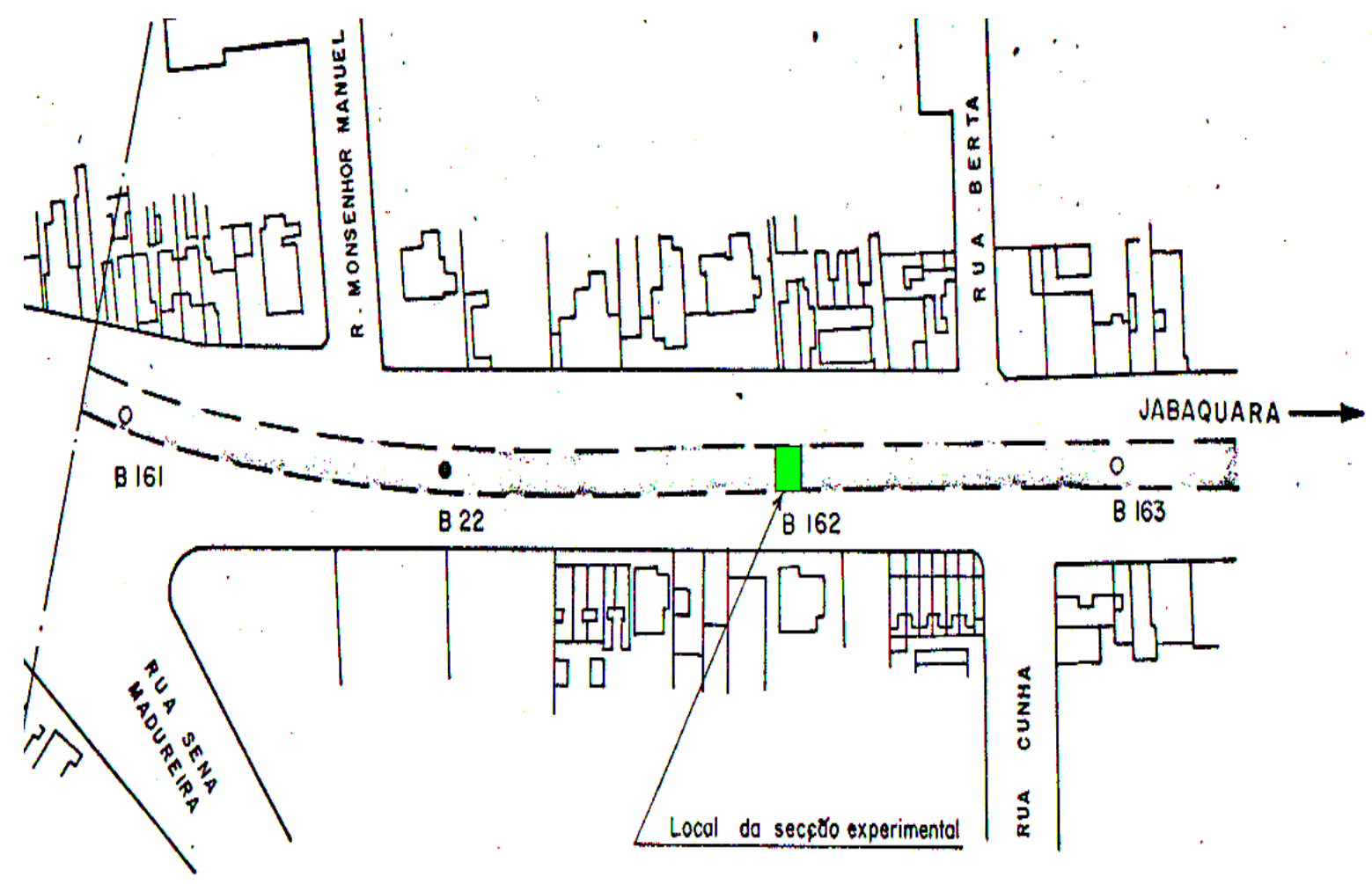

Figura 2-5 -Local da Seção Experimental e locação da sondagem (IPT, 1972)

A escavação de $8,9 \mathrm{~m}$ de profundidade, a partir do nível 800,34m acima do mar, desenvolveu-se totalmente na camada de argila porosa de consistência mole que avança até a profundidade de $11,3 \mathrm{~m}(789,04 \mathrm{~m})$, onde se inicia a camada de argila siltosa rija variegada. Na Figura 2-6 é apresentado um boletim de sondagem típico feito no local da Seção Experimental no 1 (S.E.-1). 


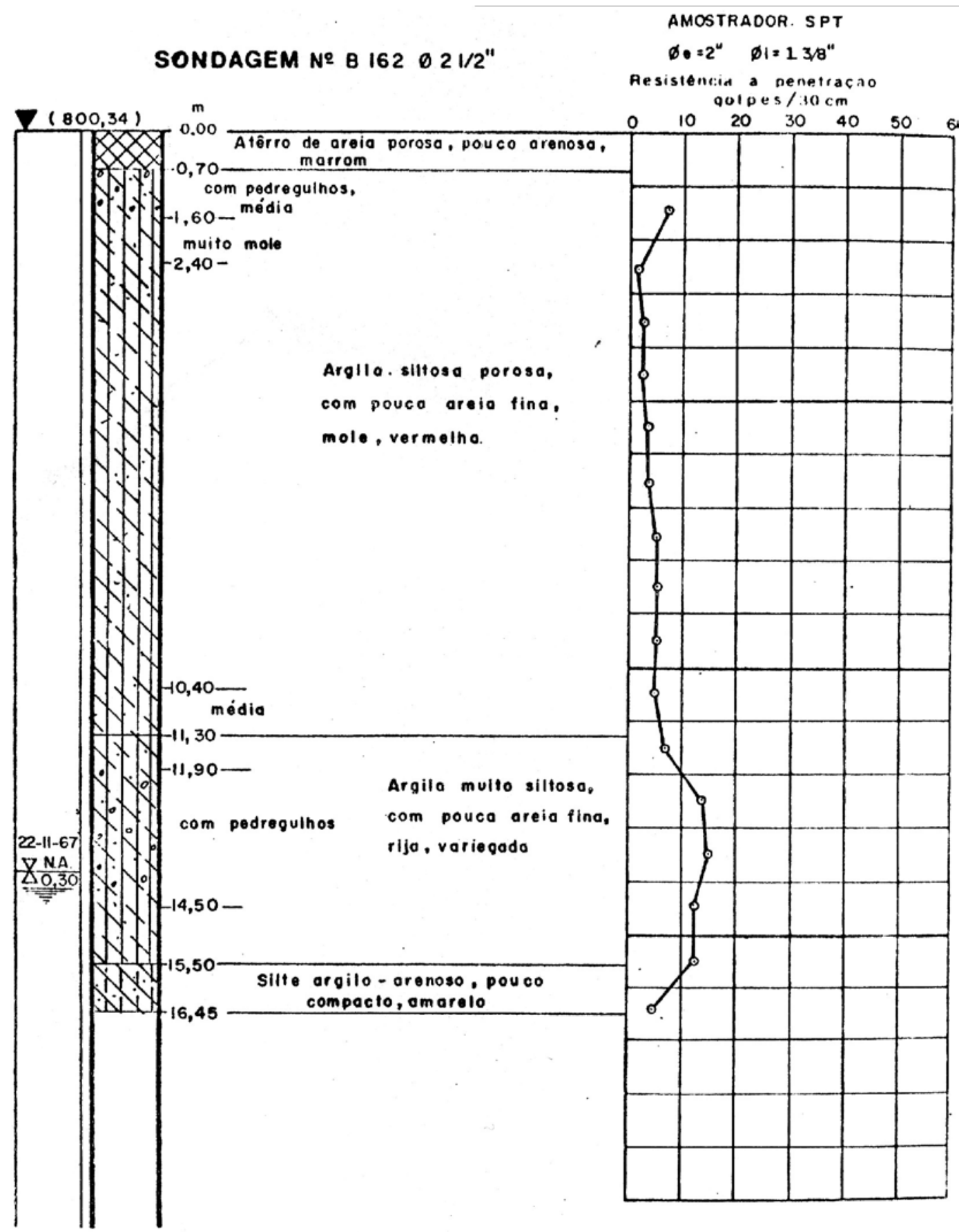

Figura 2-6 -Boletim de Sondagem No B 162 da Seção experimental nº1- (IPT, 1972)

Os solos designados por argilas vermelhas e os solos variegados foram intensamente estudados por vários pesquisadores. Dentre inúmeras pesquisas realizadas, pode-se citar IPT (1972), MASSAD (1978), MASSAD (1982), PENNA (1982) e PARREIRA (1991). A partir dos resultados destes autores selecionaram-se informações de interesse para este trabalho, relativas a parâmetros geotécnicos obtidos. Na Tabela 2-3 estão reproduzidas as envoltórias de resistência para solos do local da seção 
experimental $n^{\circ} 1$ (S.E.-1), localizada entre as atuais estações Vila Mariana e Santa Cruz da linha Norte Sul (linha 1) do Metrô de São Paulo.

Tabela 2-3- Envoltórias de resistência para tensões efetivas solos da S.E.-1 (IPT, 1972)

\begin{tabular}{|c|c|}
\hline $\begin{array}{c}\text { AMOSTRA DE SOLO } \\
\mathrm{N}^{\mathrm{o}}\end{array}$ & $\begin{array}{c}\text { Envoltória de Resistência }\left(\sigma_{3}=196,2 \mathrm{kPa}\right) \\
\mathrm{s}[\mathrm{kPa}]\end{array}$ \\
\hline 1 & $\sigma_{\text {efet. }} * \tan 30^{\circ}$ \\
\hline 2 & $\sigma_{\text {efet. }} * \tan 33^{\circ}$ \\
\hline 3 & $13,7+\sigma_{\text {efet. }} * \tan 30^{\circ}$ \\
\hline 4 & $20,6+\sigma_{\text {efet. }} * \tan 25^{\circ}$ \\
\hline 5 & $39,2+\sigma_{\text {efet. }} * \tan 20^{\circ}$ \\
\hline
\end{tabular}

A Tabela 2-4, a Figura 2-7 e a Figura 2-8 reproduzem dados obtidos por alguns autores, para os mesmos tipos de solos que ocorrem em vários locais da Bacia de São Paulo e são comuns ao local da seção experimental $n^{0} .1$ (S.E.-1) e por isso são de interesse para este trabalho. 
Tabela 2-4 - Características das Argilas Vermelhas de São Paulo (MASSAD, 1992)

Argila Porosa (0 a 6m) Argila Rija (10 a 18m)

Características

Intervalo

Média

Intervalo Média

\begin{tabular}{lcccc}
\hline LL $(\%)$ & 71 a 92 & 82 & 68 a 96 & 82 \\
IP $(\%)$ & 24 a 47 & 38 & 27 a 53 & 39 \\
$\%<2 \mu$ & 50 a 85 & 62 & 45 a 84 & 60 \\
\hline$\sigma_{\mathrm{a}}(\mathrm{kPa})$ & 50 a 350 & 180 & 400 a 1000 & 700
\end{tabular}

Pré-adens.

(Cc) Índice de $\quad 0,41$ a $0,65 \quad 0,49 \quad 0,36$ a $0,67 \quad 0,56$

Compressão

\begin{tabular}{lcccc}
$\mathrm{e}_{\text {nat }}$ & 1,38 a 1,85 & 1,54 & 1,17 a 1,46 & 1,28 \\
\hline $\mathrm{S}(\%)$ & 62 a 88 & 74 & 80 a 96 & 90 \\
$\mathrm{~h}(\%)$ & 33 a 47 & 41 & 35 a 47 & 42 \\
$\gamma_{\text {nat }}\left(\mathrm{kN} / \mathrm{m}^{3}\right)$ & 13,5 a 16,5 & 15,2 & 16,2 a 18 & 17,2 \\
\hline $\mathrm{c}^{\prime}(\mathrm{kPa})$ & 10 a 70 & 32 & 50 a 90 & 69 \\
E.T.N.D.* & & & & \\
$\Phi^{\prime}{ }_{\text {a }}\left({ }^{\circ}\right)$ & 23 a 33 & 27 & 21 a 25 & \\
E.T.N.D.* & & & & 26 \\
$\Phi^{\prime} \quad\left(^{\circ}\right)$ & 26 a 33 & 29 & ----- & \\
E.T.N.D.* & &
\end{tabular}

\section{Legendas :}

LL - limite de liquidez

IP - índice de plasticidade

$\%<2 \mu$ - percentual de argila

$\sigma_{\mathrm{a}-}$ tensão de pré adensamento

$\mathrm{Cc}$ - índice de compressão

$\mathrm{e}_{\text {nat }}$ - índice de vazios natural

$\mathrm{S}(\%)$ - saturação do solo

h $(\%)$ - percentual de umidade

$\gamma_{\text {nat }}-$ peso específico natural

c' - coesão efetiva

$\Phi^{\prime}, \Phi^{\prime}{ }_{\mathrm{a}}$ - ângulo de atritos efetivos acima e abaixo dos efeitos de pré-adensamento

E.T.N.D.* - Ensaios Triaxiais não drenados 

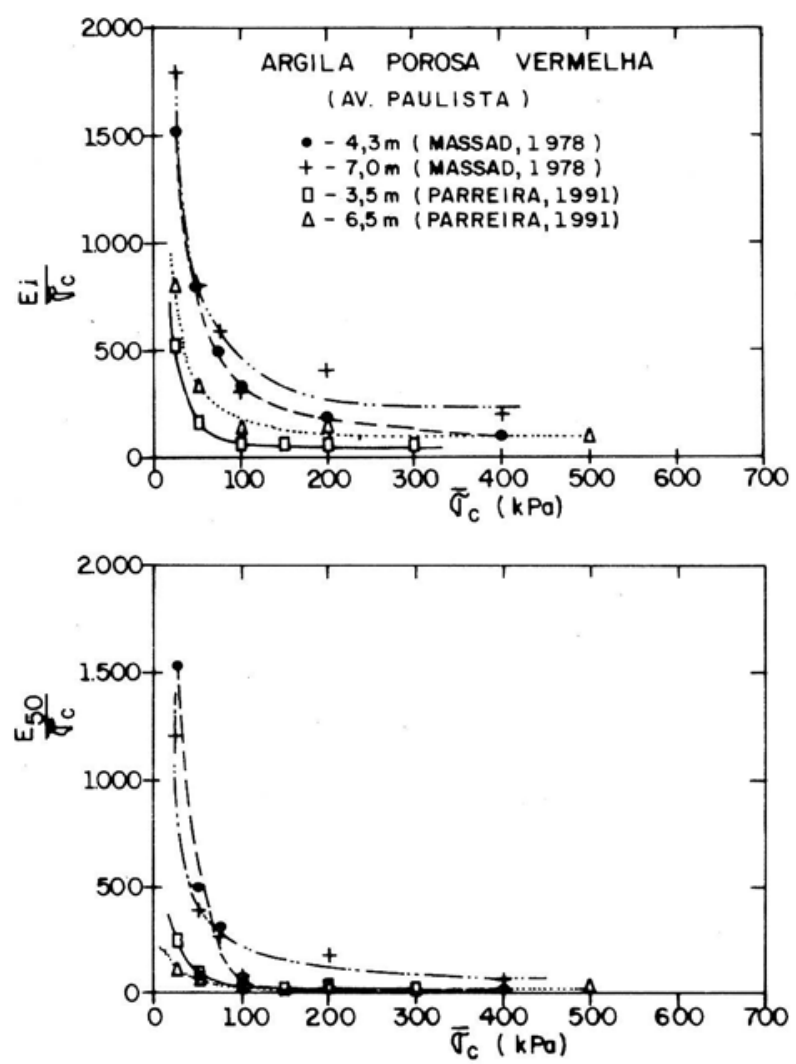

Figura 2-7- Módulos de Deformabilidade $E_{i}$ e $E_{50}$ (argila porosa vermelha) em função do nível de tensões (MASSAD, 1992)
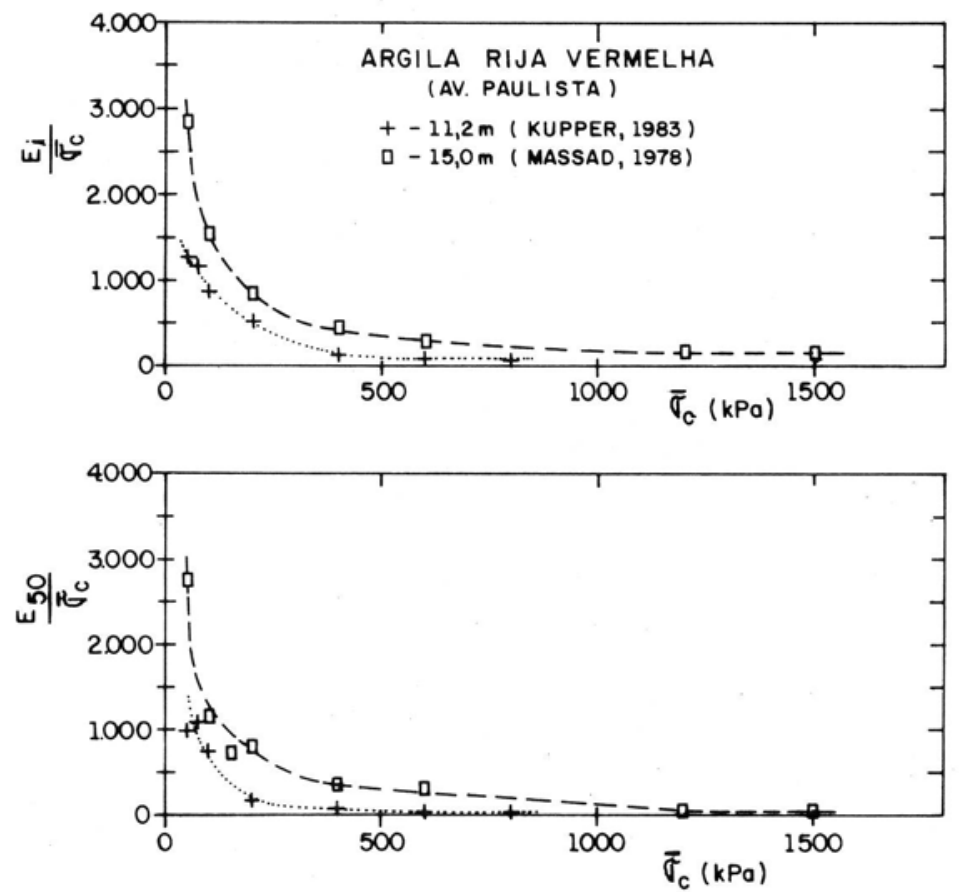

Figura 2-8 - Módulos de Deformabilidade $E_{i}$ e $E_{50}$ (argila rija vermelha) em função do nível de tensões (MASSAD, 1992) 


\section{6 -Características do sistema de escoramento}

A escavação da vala da S.E.-1 teve profundidade $8,9 \mathrm{~m}$, a partir do nível $800,34 \mathrm{~m}$, e $12.9 \mathrm{~m}$ de largura. A estrutura de contenção tem os paramentos constituídos por estacas metálicas de perfis duplo I12”, cravadas a cada 2,5m, ligadas entre si por pranchões de madeira, com ficha de aproximadamente $2,3 \mathrm{~m}$ e dois níveis de estroncas, o $1^{\circ}$ nível a $1,5 \mathrm{~m}$ de profundidade e o $2^{\circ}$ a 5,64m (Figura 2-10), constituídos de perfis metálicos duplo I12", sendo travadas no meio a 6,45m dos paramentos, espaçadas também de 2,5m e ligadas ao paramento por um perfil longitudinal (Figura 2-9). A Foto 2-1e a Foto 2-2 detalham melhor o exposto. 


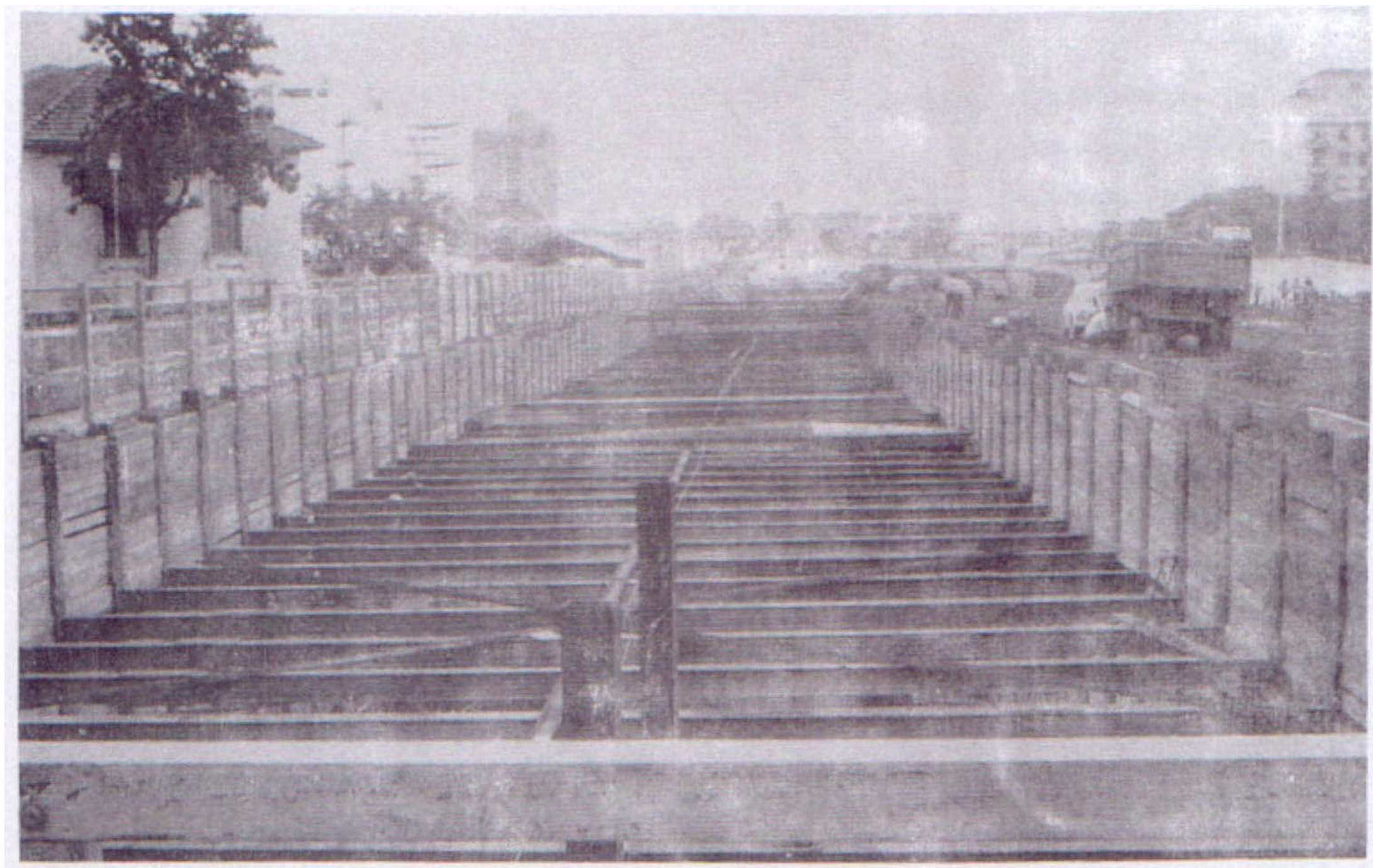

Foto 2-1-Foto da vista 1 acima do topo da vala da Seção Experimental $\mathbf{n}^{0} .1$ do Metrô de São Paulo (IPT, 1972) 


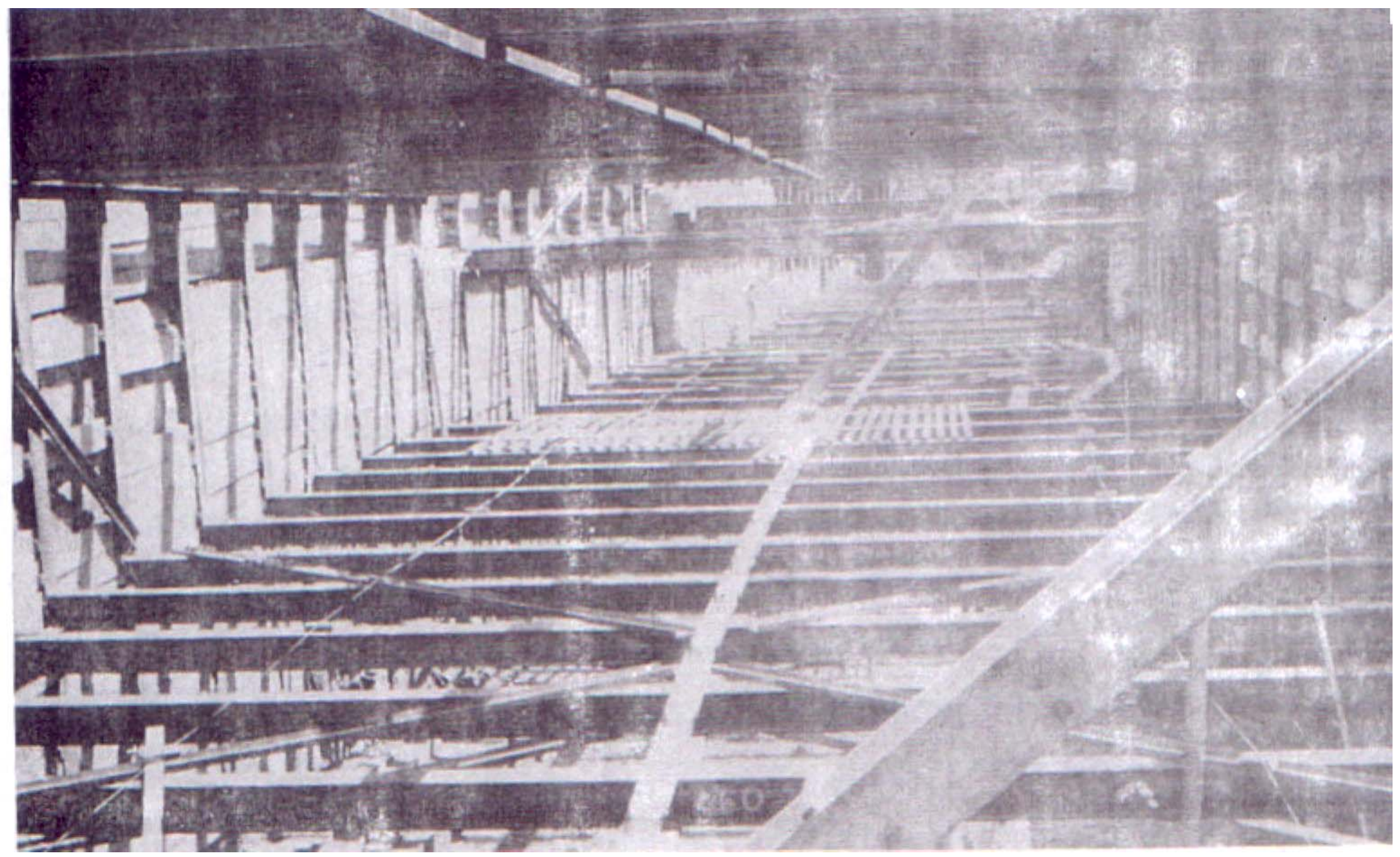

Foto 2-2- Vista 2 tirada a partir do $2^{\circ}$ nível de estroncas (nível B), no topo as estroncas do $1^{\circ}$ nível (nível A) da Seção Experimental $\mathbf{n}^{0} .1$ do Metrô de São Paulo (IPT, 1972) 


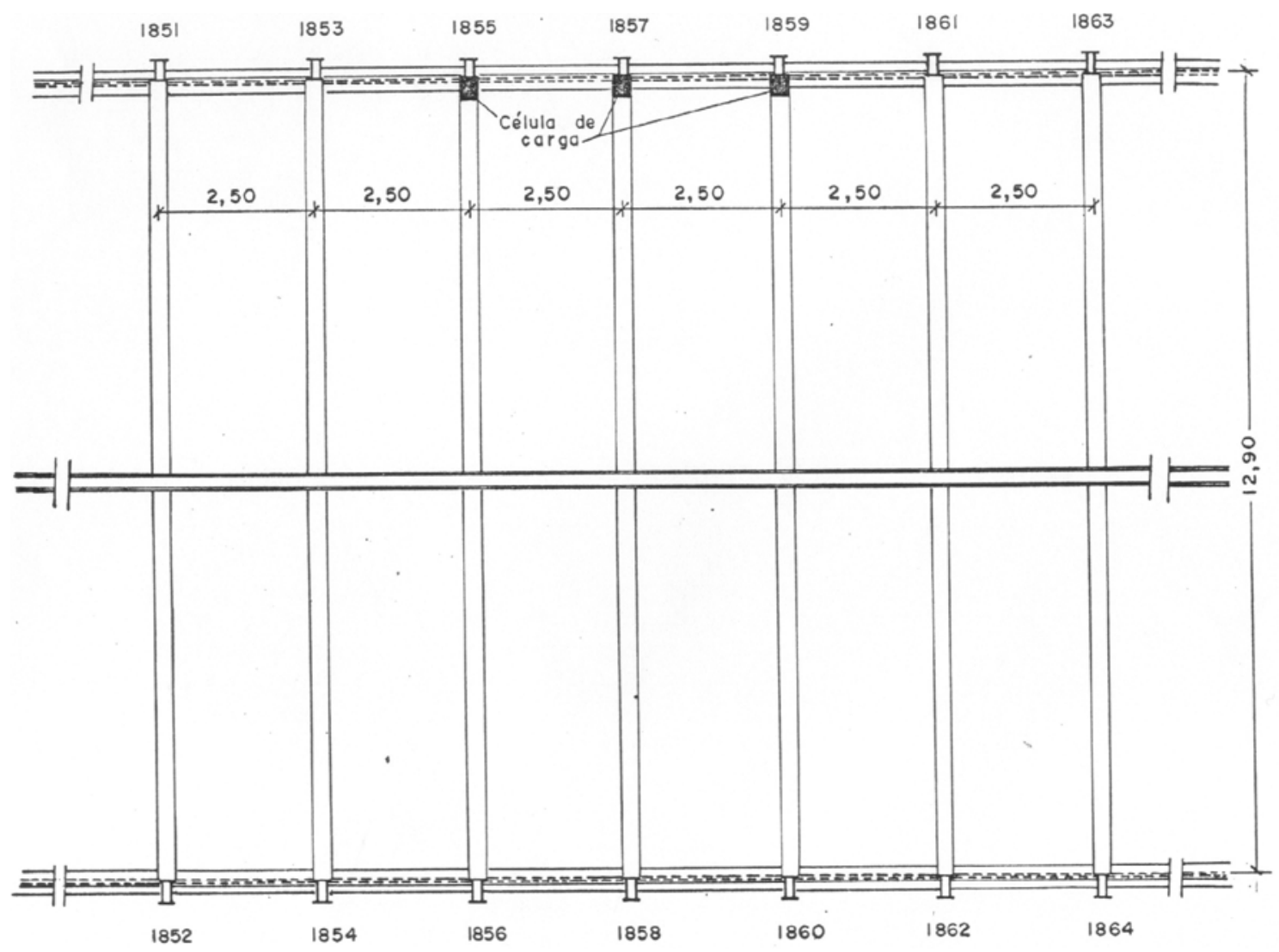

Figura 2-9 -Planta do sistema estrutural do escoramento da S.E.-1 - (IPT, 1972)

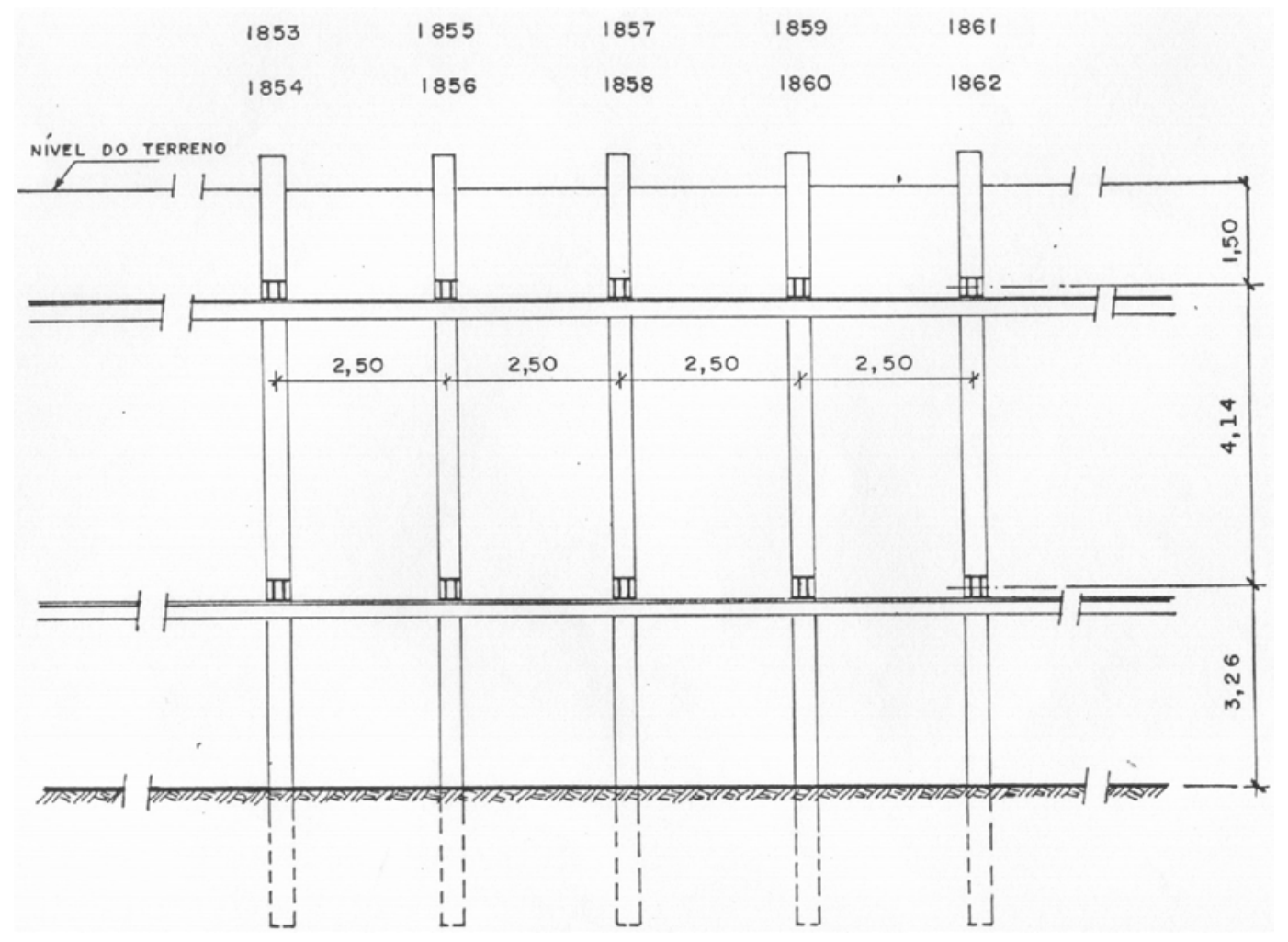

Figura 2-10 - Seção longitudinal do sistema estrutural do escoramento da S.E.-1 (IPT,1972) 


\section{7 -Instrumentação utilizada}

A instrumentação utilizada por IPT (1972) e IPT2 (1972) para a observação do sistema solo escoramento foi composta por:

- Um tubo de inclinômetro Wilson, instalado no interior do furo da estaca 1857 , que foi previamente limpo. O espaço entre o tubo e a estaca foi preenchido com areia compactada

- Seis células de carga de corda vibrante, colocadas entre as estroncas e as estacas metálicas de $\mathrm{n}^{\mathrm{o}} \mathrm{s} .1855,1857,1859$, nos dois níveis de estroncas $(A$ e $B)$.

- As referências para medidas dos alongamentos das estroncas com o Tensotast, nas seis estroncas cujas cargas foram medidas.

- Pares termo-elétricos, para medida das temperaturas, nas seis estroncas cujas cargas foram medidas. Estes pares foram instalados nas partes superiores e inferiores (mesas) das estroncas, adotando-se a média destes valores como a que representava a temperatura média ao longo da estronca.

- A referência instalada na cabeça da estaca $n^{\circ}$. 1857 para a medida de seus deslocamentos horizontais, a serem obtidos por levantamento topográfico.

As observações foram iniciadas em 01/12/1970, com o levantamento topográfico e do inclinômetro da estaca $n^{\circ} 1857$, imediatamente antes do início das escavações. Os demais instrumentos foram instalados à medida que o andamento da escavação o permitia. As diversas medidas foram realizadas com periodicidade variável conforme o andamento da obra:

- diariamente no início e a seguir duas vezes por semana

- diversas vezes foram feitas várias leituras dos aparelhos num mesmo dia

- Pode-se ver detalhes da instrumentação na Foto 2-3 e na Foto 2-4. 


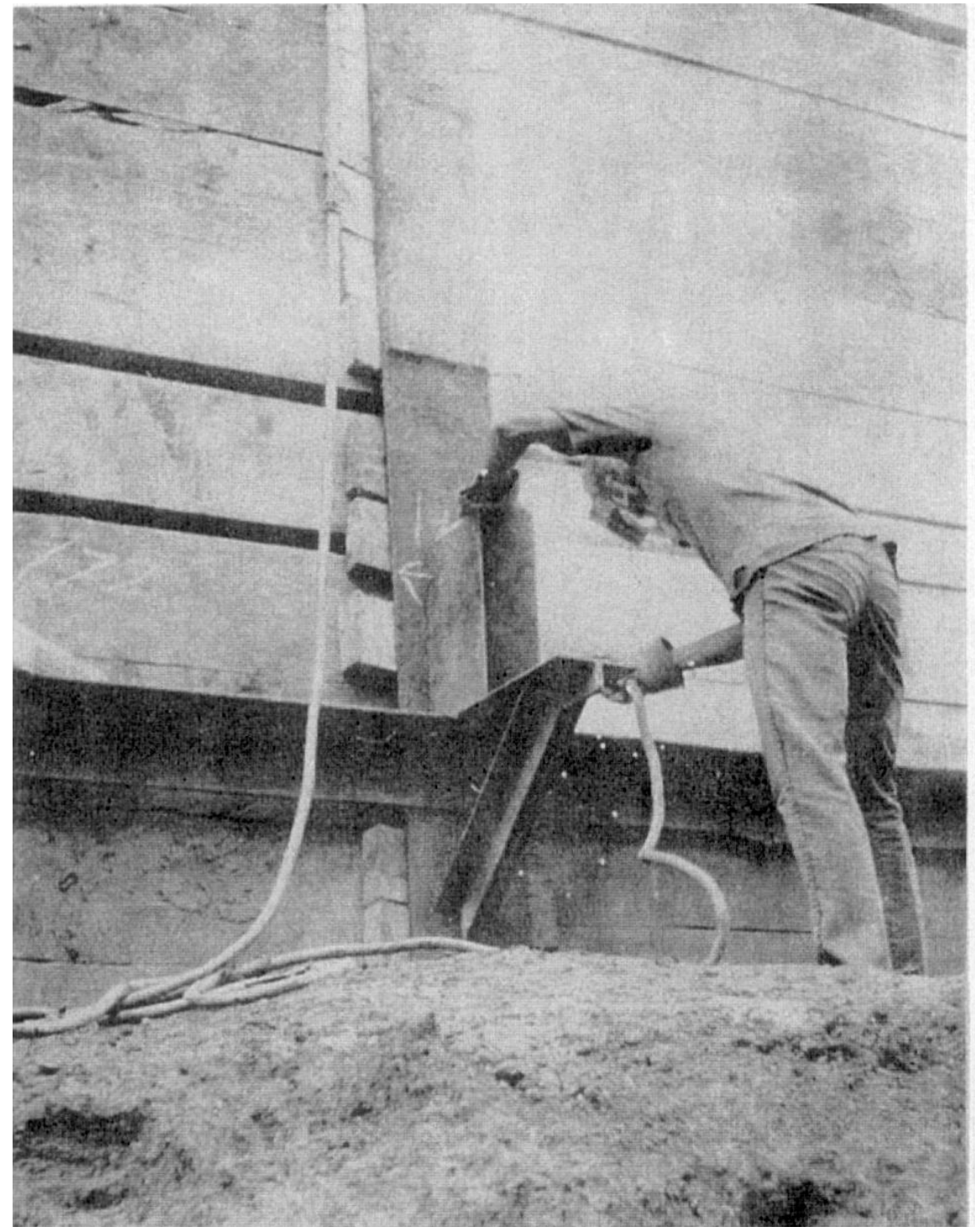

Foto 2-3-Berço de apoio da célula de carga e estronca da S.E.-1 (IPT, 1972) 


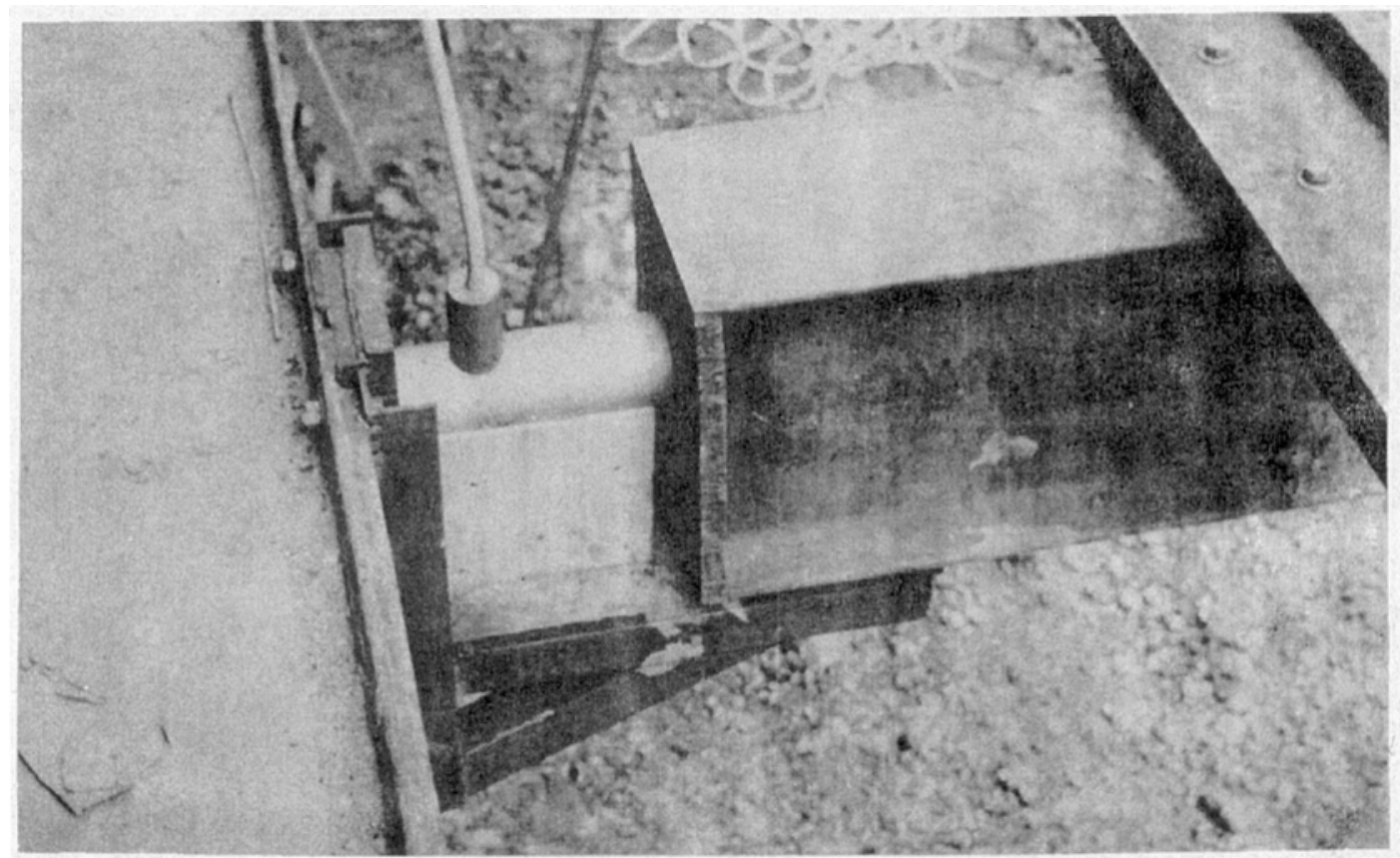

Foto 2-4-Célula de carga instalada da S.E. 1 - (IPT, 1972) 


\section{Capítulo 3 - Descrição da Modelagem e Análises Paramétricas}

Utilizou-se o software PLAXIS (1998) que é fundamentado pelo método dos elementos finitos em duas dimensões para a $1^{\text {a }}$.etapa feita com o modelo constitutivo de Mohr-Coulomb e o software PLAXIS (2002) na $2^{\text {a }}$ etapa de estudos utilizando-se o modelo constitutivo de Endurecimento de solo. A malha de elementos que o software utiliza adota geometria triangular para os elementos, sendo esta geometria a única disponível. Com relação ao numero de nós por elemento triangular pode-se optar por duas configurações. A primeira utiliza 6 nós por elemento e a segunda de 15 nós por elemento. O software calcula as tensões em 3 pontos intermediários para a opção de malha composta por elemento de 6 nós.
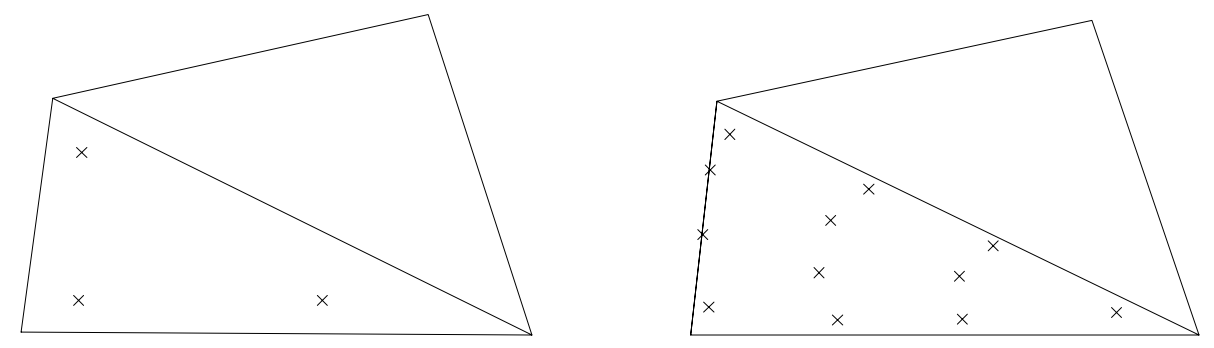

Pontos de tensões
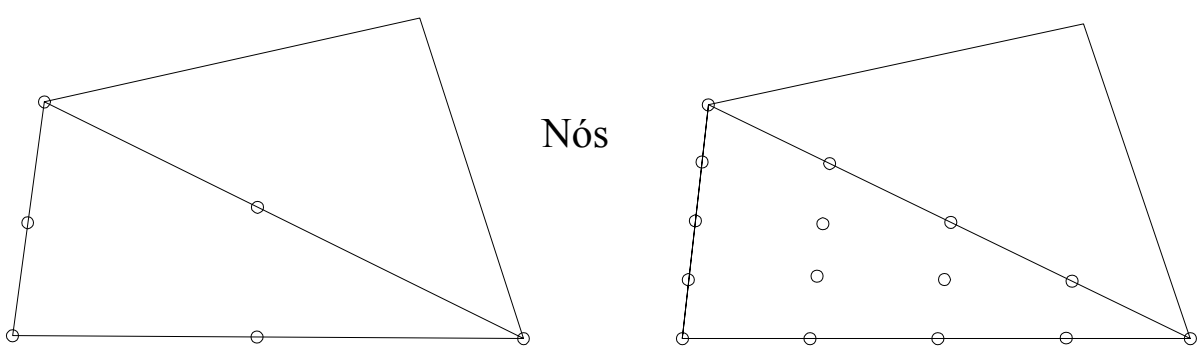

Figura 3-1-Elementos finitos com 6 nós e 15 nós e respectivos pontos de tensões, utilizados pelo software PLAXIS- (PLAXIS, 1998) 
Existem 5 opções de refinamento de malha que são classificadas em muito grosseira, grosseira, média, fina e muito fina. Nas figuras 3.2 a 3.5 pode-se observar como variam as dimensões dos elementos em função da opção de refinamento escolhida.

Há também a opção de refinamento da malha de elementos em torno de uma região de interesse que esteja no solo ou em uma região de interface solo-estrutura. A influência deste recurso na concentração do número de elementos em torno de uma região pode ser notada nas figuras 3.2 a 3.5.

No presente estudo as regiões de interesse para refinamento de linha são três, sendo a primeira à superfície do topo da vala (recalques superficiais), a segunda a interface solo-paramento (deslocamentos horizontais de paramento e forças nas estroncas), e a terceira a linha de fundo de vala (levantamento de fundo de vala).

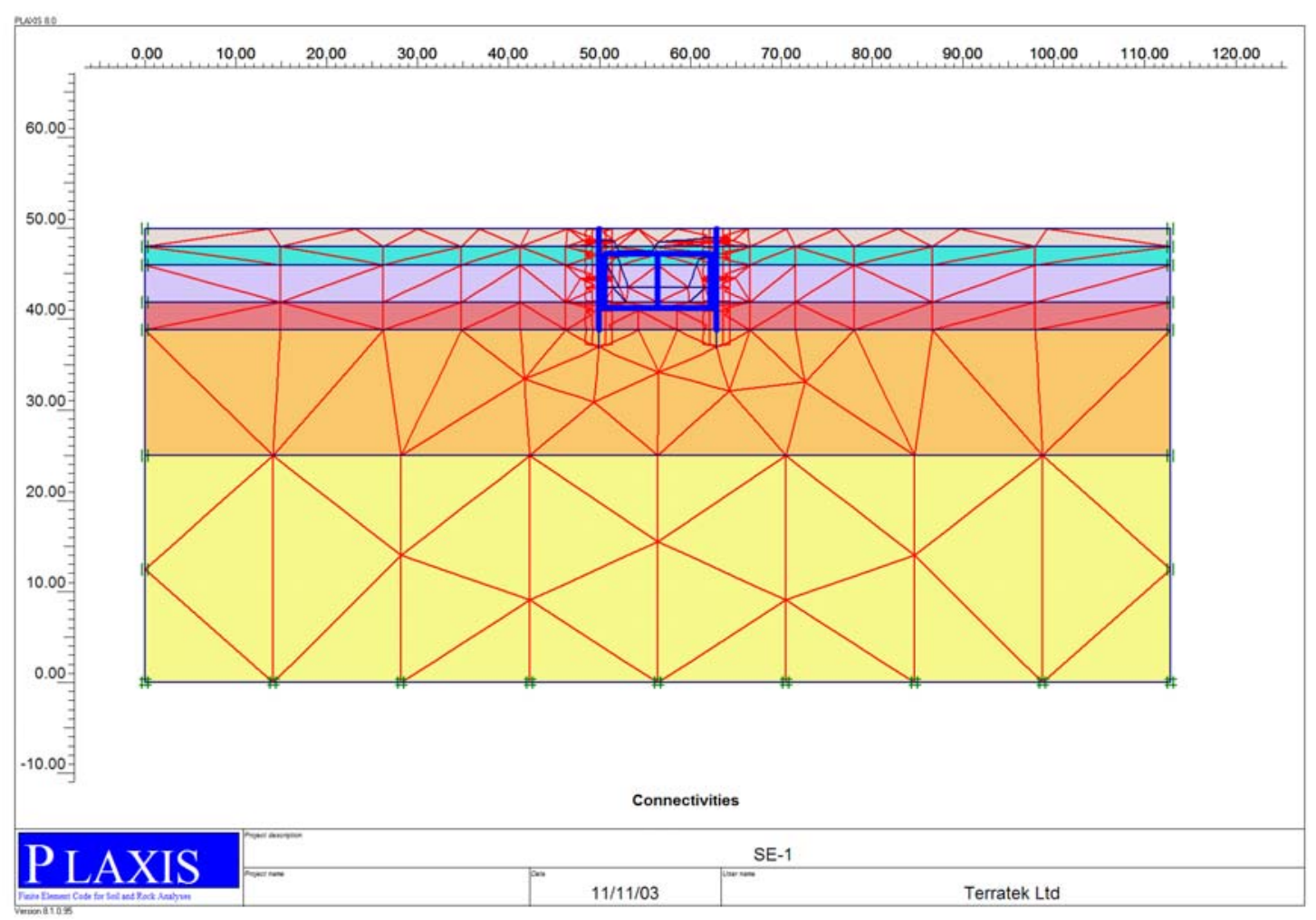

Figura 3-2-Exemplo da opção de malha muito grosseira gerada pelo software PLAXIS 


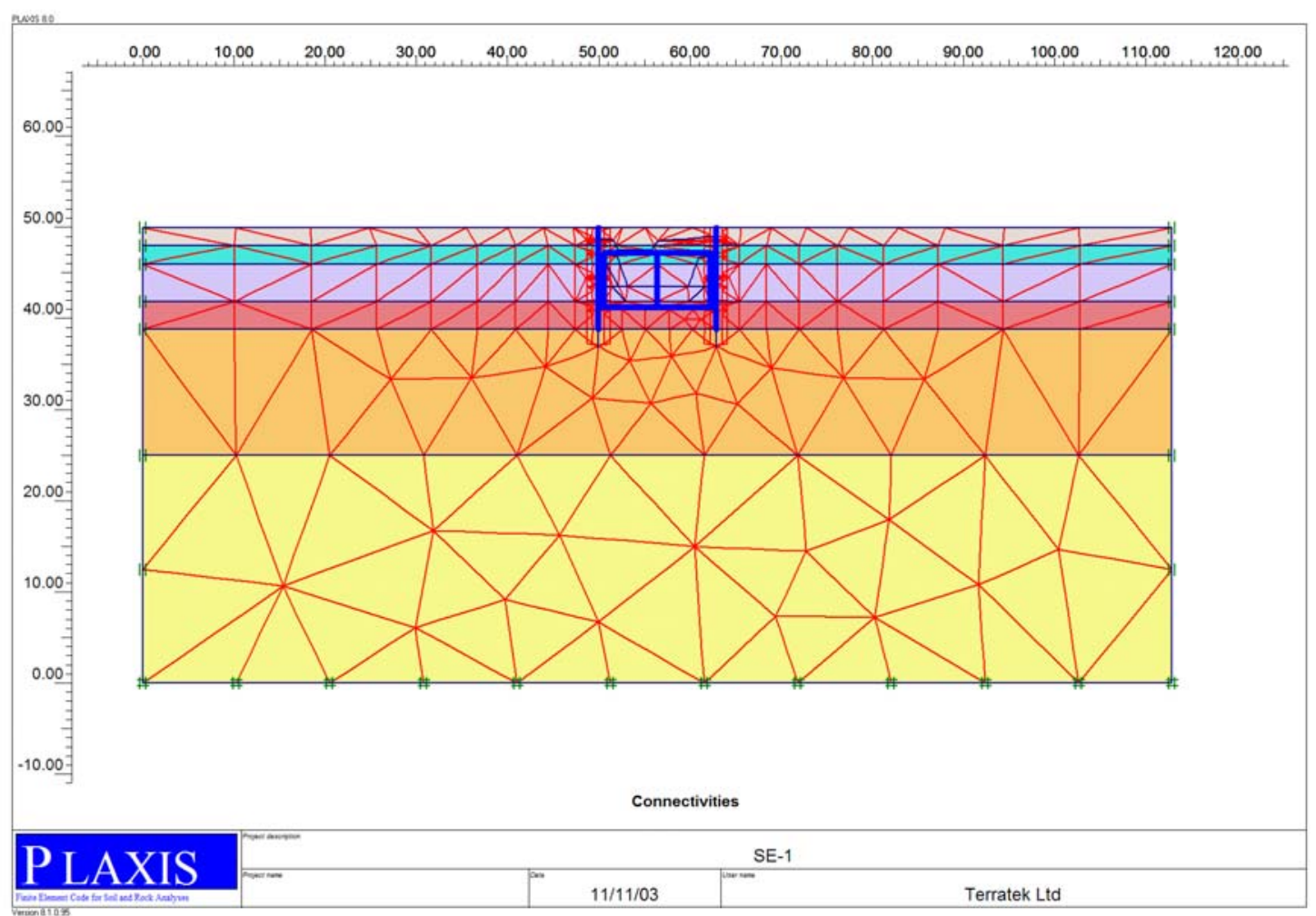

Figura 3-3-Exemplo da opção de malha grosseira gerada pelo software PLAXIS

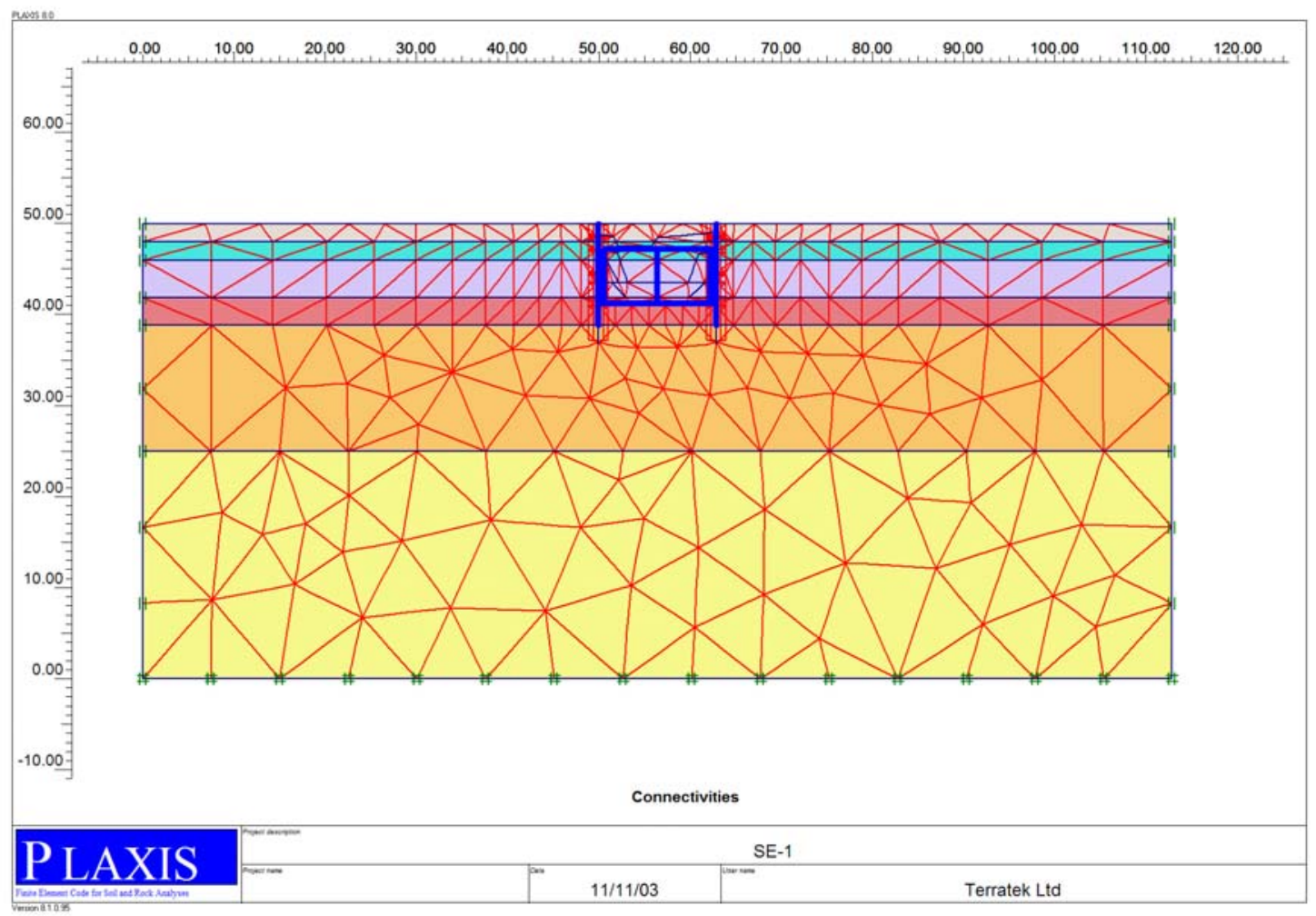

Figura 3-4- Exemplo da opção de malha média gerada pelo software PLAXIS 


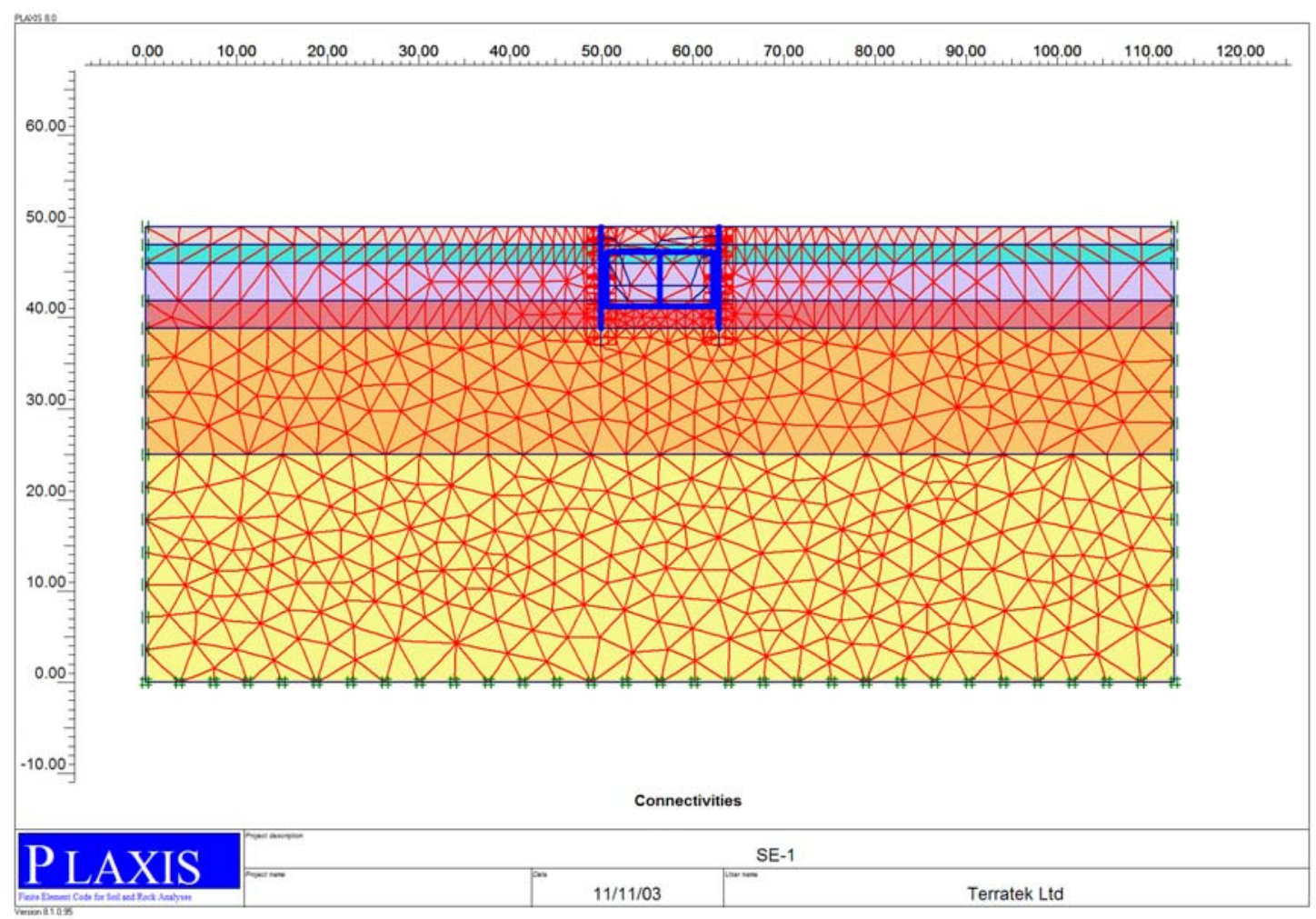

Figura 3-5- Exemplo da opção de malha muito fina gerada pelo software PLAXIS

Notar que há aumento da densidade de elementos e uma redução do tamanho dos elementos finitos nas regiões onde se utilizou o comando de refinamento de linha, ou seja, na superfície do topo da vala, na interface solo-paramento, no fundo de vala onde ocorre uma maior densidade de elementos.

Para realizar as simulações desta dissertação via modelos de Mohr-Coulomb e de Endurecimento, necessárias ao processo de retroanálise, o elemento utilizado foi o de 15 nós e o refinamento global de malha adotado foi o médio, sendo que nas regiões de interesse para este trabalho (superfície, interface solo-paramento e fundo da vala) utilizou-se refinamento de malha, que produziu nestas regiões de interesse elementos de $40 \mathrm{~cm}$ de lado (na superfície próxima a beira da vala) e elementos ainda menores na interface solo-paramento e no fundo da vala.

Para determinar se as dimensões da malha e dos contornos a serem utilizados nos processamentos eram apropriadas, foram feitas verificações dos contornos da malha quanto à ocorrência de pontos de plastificação. Isto foi feito através do comando Plastic points (pontos plastificados), de acordo com o indicado por PLAXIS (2002), este comando faz com que o programa calcule os pontos de plastificação de 
acordo com o critério de Coulomb, que serve entre outras finalidades para checar se a extensão da malha do modelo é suficiente. Se a zona de plasticidade de Coulomb tocar os contornos da malha, isto sugere que a extensão do modelo pode ser muito pequena. Se isto ocorrer o modelo deve ser modificado e os contornos da malha ampliados, ou seja aumenta-se a distância dos contornos em relação à estrutura que está sendo analisada, a partir daí repete-se o processamento e aciona-se novamente o comando Plastic points (pontos plastificados), e assim sucessivamente até que na região dos contornos da malha não existam pontos plastificados. Assim, as dimensões da malha que atenderam a este critério foram :

- na horizontal $112,9 \mathrm{~m}$ (8.8 vezes superior à largura da vala), sendo 50m de extensão entre cada paramento e a linha de contorno vertical mais próxima.

- na vertical $50 \mathrm{~m}$ (5,6 vezes superior à profundidade da vala), sendo $41.1 \mathrm{~m}$ de extensão entre o fundo da vala e a linha de contorno horizontal.

Os erros globais são calculados da seguinte forma:

ERROS GLOBAIS $=: \frac{\Sigma \| \text { forçasdesbalanceadas } \|}{\Sigma \| \text { forçasativas } \|}$

Sendo que as forças desbalanceadas (nodais) são calculadas através da (diferença entre as cargas externas e as forças de equilíbrio (tensões internas).

Para os erros locais são feitas verificações das componentes de tensões pontuais durante o processo iterativo.

\section{Para o modelo de Mohr-Coulomb :}

ERRO LOCAL $=\frac{\left\|\sigma^{e}-\sigma^{c}\right\|}{c^{*} \cos \phi+\frac{1}{2} *\left(\sigma_{x x}^{c}+\sigma_{y y}^{c}\right) * \operatorname{sen} \phi}$

$\sigma^{e}$-tensor de equilibrio de tensões;

$\sigma^{c}$ - tensor de tensões atuantes

$\phi$ - ângulo de atrito do solo 
As interfaces solo-estrutura são constituídas por elementos de interfaces.

Quando o elemento de solo utilizado é o de 15 nós os elementos de interface são constituídos por 5 pares de nós. Por outro lado, se o elemento escolhido para o solo for o de 6 nós, o elemento de interface será constituído por 3 pares de nós.

Nos elementos de interface as tensões são calculadas em três pontos para o elemento de 6 nós e em 5 pontos para elemento de 15 nós. Isto pode ser visto na Figura 3-6.

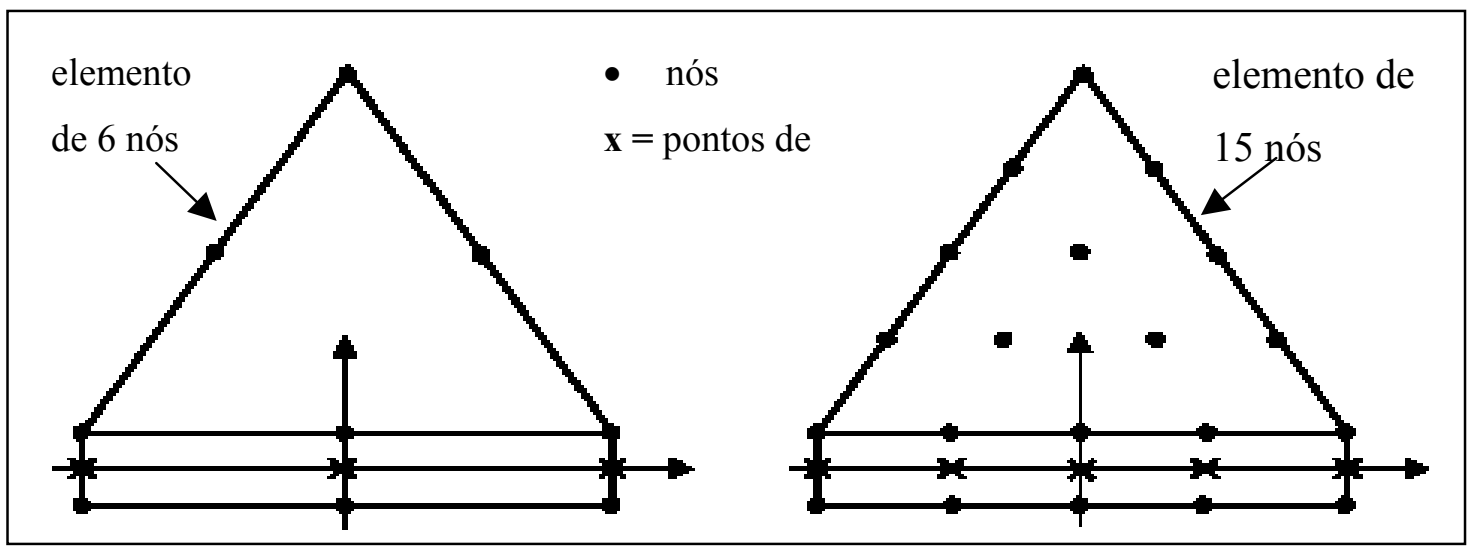

Figura 3-6-Exemplo da distribuição de nós e pontos de tensão nos elementos de interface e suas conexões com os elementos de solo (PLAXIS, 2002)

De acordo com PLAXIS (2002) a cada interface será associada uma espessura virtual. A espessura virtual é uma dimensão imaginária que será utilizada para definir as propriedades do material na interface. Esta é calculada através do fator de espessura virtual vezes o tamanho médio do elemento, sendo este relacionado à opção de refinamento global de malha adotada.

O valor padrão utilizado pelo software PLAXIS (2002) para o fator de espessura virtual é 0,1 , valor que foi adotado para esta dissertação.

O parâmetro de resistência na interface, $R_{\text {inter }}$, é utilizado pelos modelos elastoplásticos para descrever o comportamento das interfaces na modelagem da interação solo-estrutura.

O software PLAXIS (2002) utiliza o critério de Mohr-Coulomb para distinguir se o comportamento solo-estrutura na interface é elástico ou plástico. Para isto duas considerações são feitas : 
- Comportamento elástico quando ocorrem apenas pequenos deslocamentos na região de interface, definido pela equação:

$$
|\tau|\left\langle\sigma_{n} * \tan \phi_{i}+c_{i}\right.
$$

- Comportamento plástico quando ocorre deslizamento relativo permanente.

$$
|\tau|=\sigma_{n} * \tan \phi_{i}+c_{i}
$$

Podem ocorrer picos de tensão nos bordos de regiões de interfaces. Notar a qualidade pobre do diagrama de tensões na Figura 3-7, que apresenta oscilações grandes em regiões próximas.
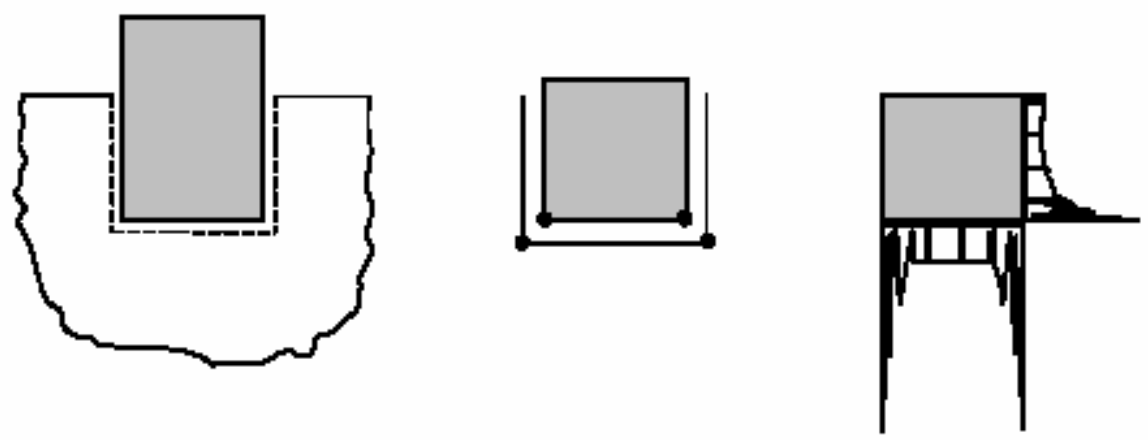

Figura 3-7 Picos de distribuições de tensões em bordas de regiões de interface soloestrutura devido à consideração de pontos inflexíveis (rígidos) (PLAXIS,2002).

O software PLAXIS (2002) permite que este problema seja contornado através do prolongamento da interface que pode ser observado na Figura 3-8. Notar a grande melhoria na qualidade dos diagramas de tensões.

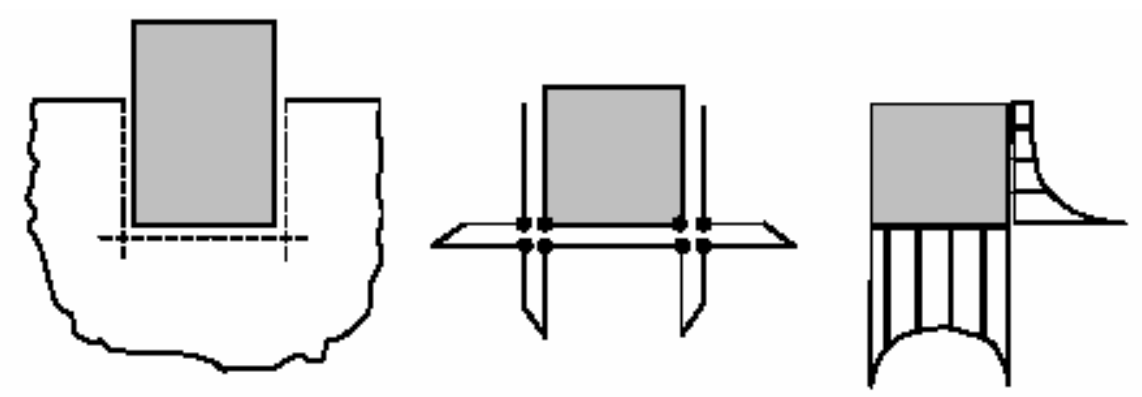

Figura 3-8 Distribuições de tensões em bordas de regiões de interface soloestrutura devido à consideração de pontos flexíveis (PLAXIS, 2002). 
As estroncas são representadas através de um elemento de mola elástica com dois nós tendo como constante de mola (rigidez da mola) o valor de rigidez normal (EA). Este elemento pode estar sujeito à forças de tração (tirantes e chumbadores) bem como forças de compressão (estroncas). Tanto as forças de tração como as de compressão podem ter seus valores limitados na simulação da ruptura dos tirantes e das estroncas. É possível também aplicar protensão aos tirantes.

A seguir faz-se um pequeno resumo das considerações feitas pelo manual do software PLAXIS (2002) com relação aos elementos de placa, viga e critérios de cálculo de distâncias de pontos de tensão e suas distribuições nos elementos, cálculos de espessuras equivalentes de placas.

Os paramentos são representados no PLAXIS (2002) através de placas delgadas. Estas placas delgadas têm como parâmetros mais importantes a rigidez flexural (EI) e a rigidez normal (EA). A partir destas rigidezes o software calcula uma espessura equivalente da placa $\left(\mathrm{d}_{\mathrm{eq}}\right)$ :

$$
d_{e q}=\sqrt{12 * \frac{E^{*} I}{E^{*} A}}
$$

Sendo:

$E=$ módulo de elasticidade do material da placa (paramento)

$I=$ momento de inércia na direção desejada

$A=$ área da seção transversal da placa (paramento)

As placas utilizadas para representar os paramentos são compostas no modelo em elementos finitos bidimensional (2D) por elementos de vigas com três graus de liberdade por nó. Sendo que dois graus de liberdade são translacionais $\left(u_{x}, u_{y}\right)$ e o outro grau de liberdade é rotacional no plano $x-y\left(\phi_{z}\right)$.

Quando se utiliza o elemento de solo de 6 nós então o elemento de viga terá 3 nós, por outro lado se a opção pelo elemento de solo for de 15 nós, o elemento de viga terá cinco nós (Figura 3-9). 


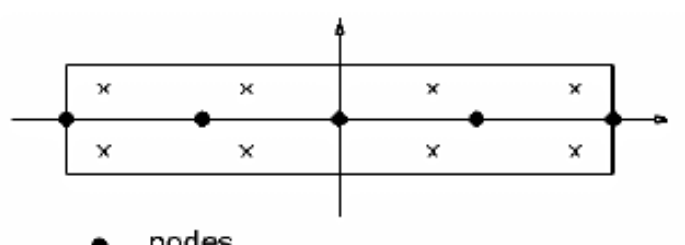

- nodes

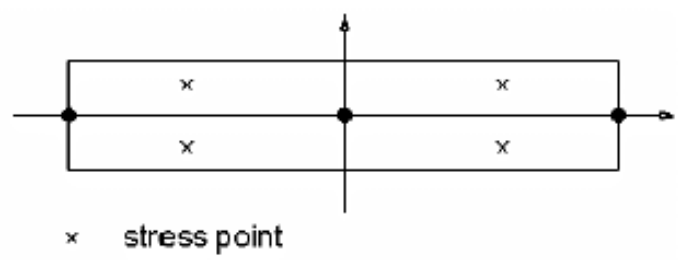

Os momentos fletores e as forças axiais são calculados a partir das tensões nos pontos de tensão. Um elemento de viga de 3 nós contém dois pares de pontos de tensão de Gauss enquanto que elementos de vigas de 5 nós contém quatro pares de pontos de tensão.

Dentro de cada par os pontos de tensão são locados a uma distância de $0.5 * d_{e q} * \sqrt{3}$ acima e abaixo da linha de centro do elemento de placa como pode ser visto na Figura 3-9.

Deve ser notado que uma mudança na relação (EI/EA) induzirá a uma mudança na espessura equivalente $\left(\mathrm{d}_{\mathrm{eq}}\right)$ e por conseqüência alterando também as distâncias dos pontos de tensão. Quando houverem forças aplicadas no elemento de viga, isto causará uma alteração na distribuição dos momentos fletores que poderá ser inadmissível. Por esta razão se as propriedades do material forem alteradas durante uma análise, por exemplo em um estágio de construção, a razão (EI/EA) permanecerá inalterada.

Os erros locais na interface são calculados da seguinte forma para o modelo de MohrCoulomb:

ERRO LOCAL $=\frac{\sqrt{\left(\sigma^{e}-\sigma^{c}\right)+\left(\tau^{e}-\tau^{c}\right)}}{c_{i}+\left(\sigma^{c}\right) * \tan \phi}$

$\sigma^{e}$ - tensor de equilibrio de tensões normais atuante na interface;

$\sigma^{c}$ - tensor de tensões atuantes normais na interface;

$\tau^{e}$ - tensões de cisalhamento de equilíbrio na interface

$\tau^{c}$ - tensões de cisalhamento atuantes na interface 
O encerramento das iterações é determinado em uma etapa de cálculo se forem atendidas as 3 condições abaixo:

\section{ErroGlobal $\leq$ ErroTolerado}

$\mathrm{N}^{\mathrm{o}}$. de pontos no solo imprecisos $\leq 3+\frac{n^{\mathrm{o}} \text { pontosplastificados }}{10}$

$\mathrm{N}^{\mathrm{o}}$. de pontos na interface imprecisos $\leq 3+\frac{n^{\mathrm{o}} \text { pontosplastificados }}{10}$

O usuário do software PLAXIS (2002) define pontos notáveis onde é necessário conhecer os seus coeficientes de segurança.

O coeficiente de segurança é calculado pelo software PLAXIS através de um artifício da comparação das resistências associadas a coesão e a tangente do ângulo de atrito e de sucessivas reduções destes valores até se obter a ruptura, a equação (3.1) exemplifica o exposto e a Figura 3-10 mostra as iterações até a estabilização do valor de coeficiente de segurança.

$$
F . S .=\frac{c}{c_{\text {reduzido }}}=\frac{\tan \phi}{\tan \phi_{\text {reduzido }}}
$$

Sendo

F.S- coeficiente de segurança calculado para um ponto $c$-coesão efetiva

$c$-coesão reduzida pelo software PLAXIS iterativamente

tan $\phi$ - tangente do ângulo de atrito do solo

tan $\phi_{\text {reduzido }}-$ tangente do ângulo de atrito do solo reduzida pelo software PLAXIS iterativamente. 


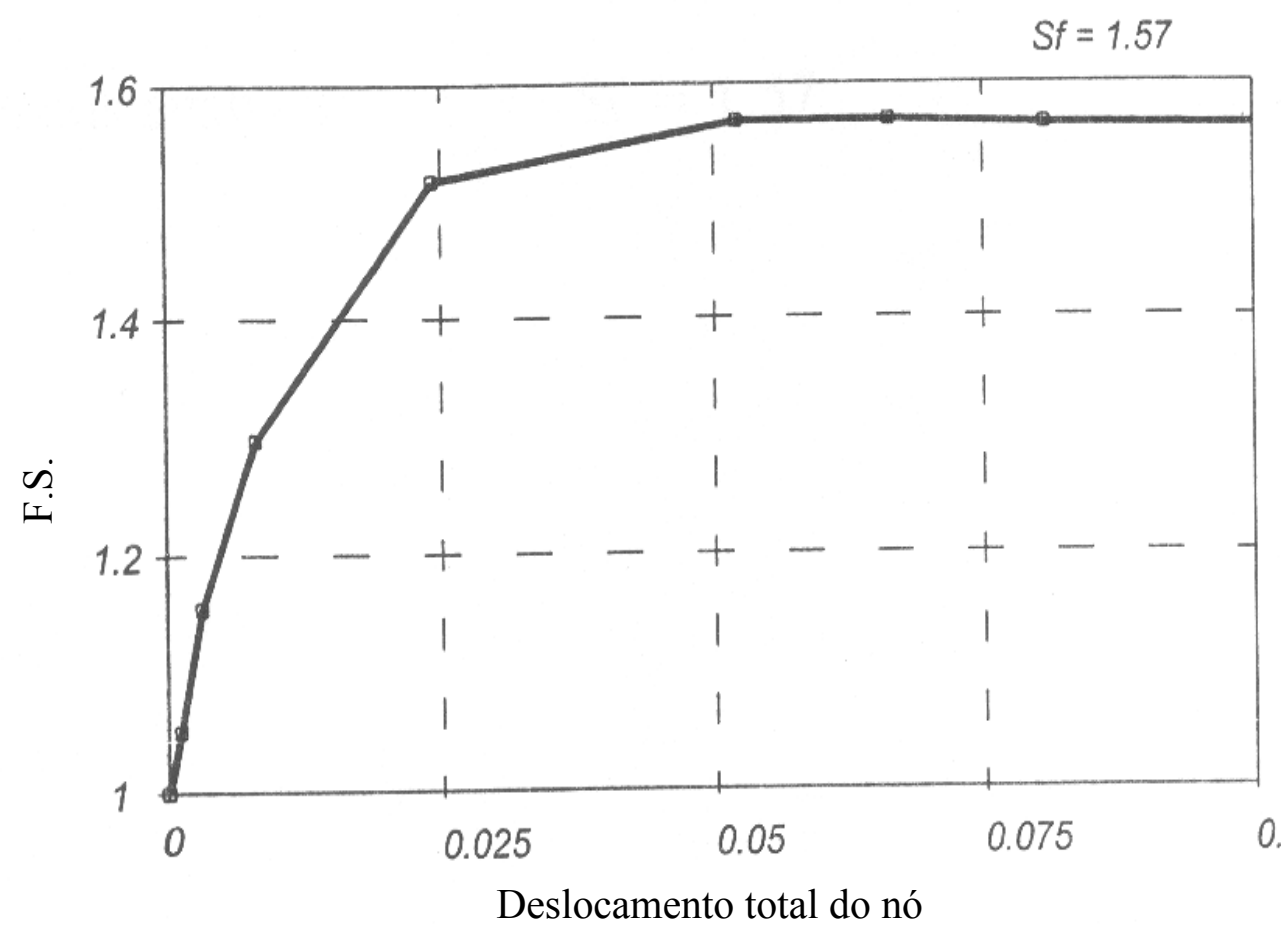

Figura 3-10- Exemplo de critério de cálculo do software PLAXIS (2002) para determinar o coeficiente de segurança para um ponto pré-determinado pelo usuário

Para maiores detalhes sobre os critérios de cálculo e a metodologia utilizada pelo software PLAXIS consultar os mauais do software PLAXIS (2002).

Na Figura 3-11 e Figura 3-12 apresenta-se o modelo adotado para as simulações.

Na Figura 3-11 apresenta-se os pontos de tensões nos elementos.

Na Figura 3-12 apresenta-se a malha de elementos finitos utilizada e aparece uma linha escura horizontal a $1 \mathrm{~m}$ de profundidade que será de interesse para o estudo do capítulo 5, para a estimativa de danos. 


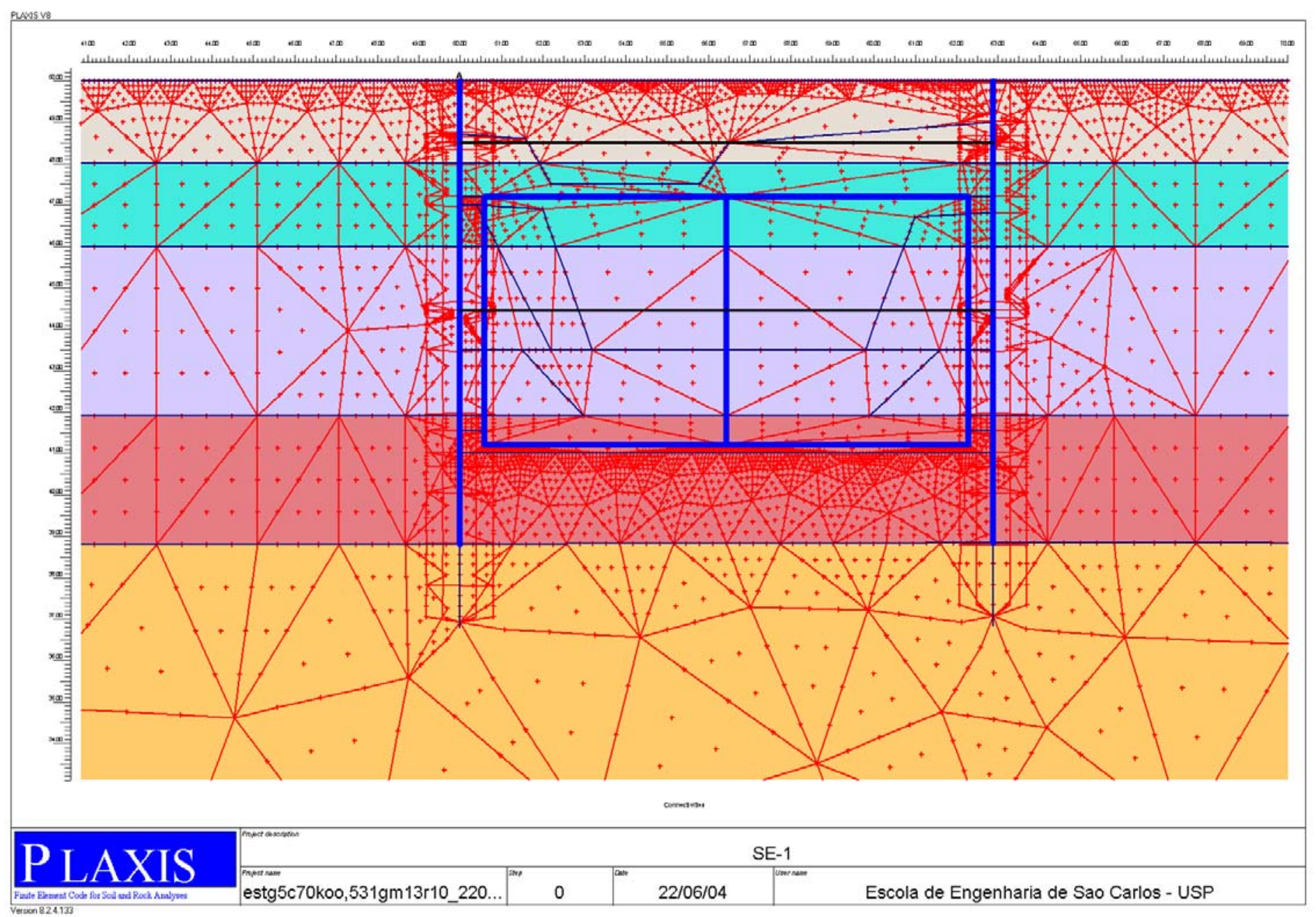

Figura 3-11-Modelo elaborado através software PLAXIS para a S.E.-1 


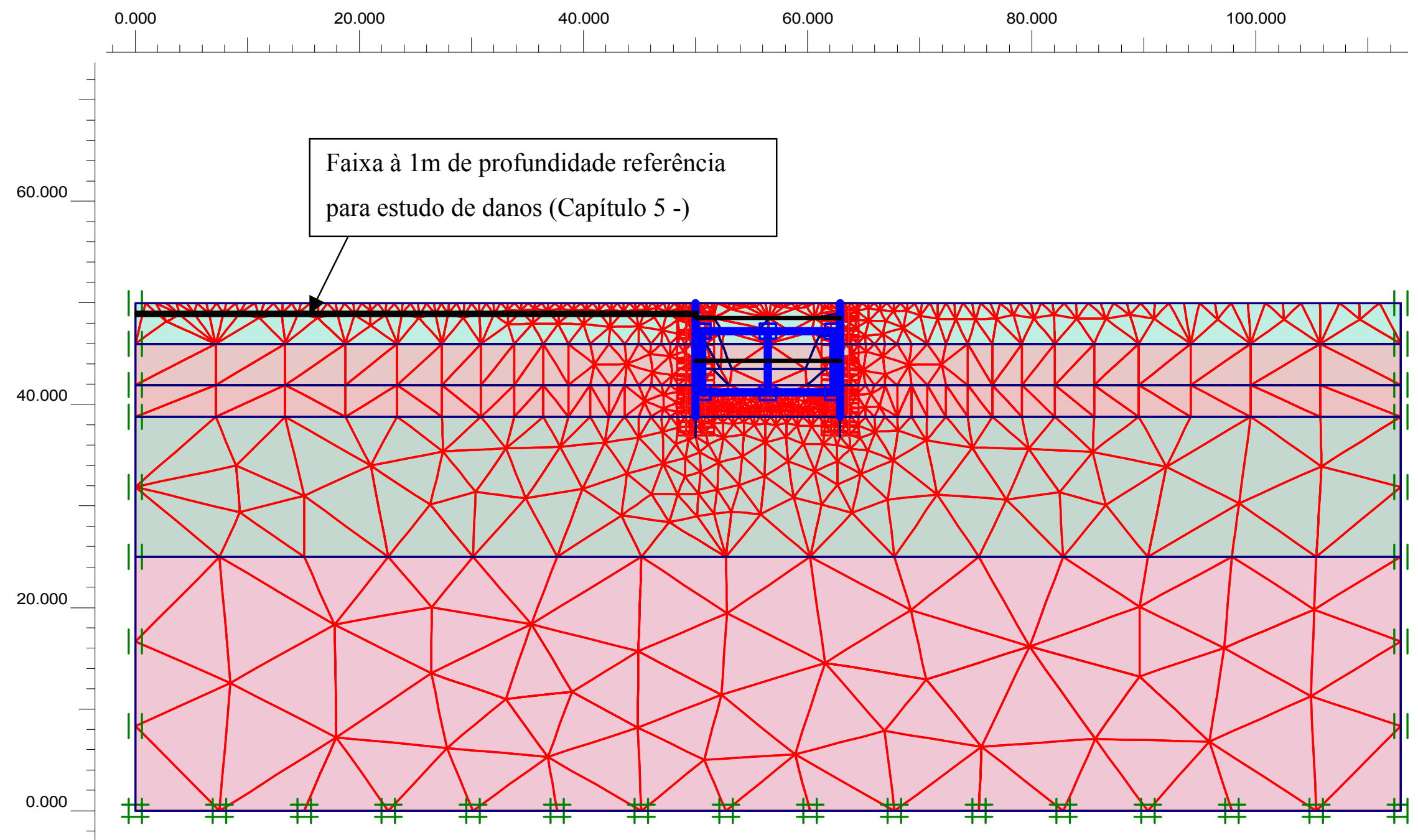

Figura 3-12 - Malha de elementos finitos utilizada 


\subsection{Limitações da Modelagem e Instrumentação}

Para tentar representar o sistema solo-escoramento através do modelo M.E.F, bidimensional foi necessário fazer simplificações.

O paramento real é composto por perfis duplo I 12" espaçados a cada 2,5m e interligados por pranchões de madeira. Nos relatórios de instrumentação não havia menção nem ao tipo de madeira e nem às dimensões dos pranchões. Devido a isto, considerou-se somente as inércias dos perfis metálicos distribuídas ao longo dos 2,5m. Portanto, a rigidez do paramento teórico é inferior a rigidez do paramento real e, os deslocamentos teóricos são maiores que os deslocamentos reais.

A ligação da estronca com o paramento real é feita através da colocação de cunha, que não é infinitamente rígida, portanto sofre deformação. No software esta ligação é feita considerando-se que ela é rigida. Portanto a rigidez da ligação teórica é maior que a rigidez da ligação real.

Sabe-se que o módulo de deformabilidade dos solos é alterado pela trajetória de tensões a que este solo venha a ser submetido. No caso de escavações de valas as situações de descarregamento e recarregamento são freqüentes. O módulo de deformabilidade de alguns solos apresenta aumento de rigidez (endurecimento) após sofrerem recarregamento. Esse novo módulo que teve seu valor aumentado é denominado módulo de descarregamento / recarregamento, e é representado por $E_{u r}$. Em sua tese de doutoramento, MASSAD (1978) aplicou a técnica de retroanálise em dados de instrumentação in situ para argilas vermelhas e obteve valores de $E_{u r} \sim(1,2 \text { a } 2,0)^{*} E_{s}$

O software PLAXIS (2002) não permite no modelo de Endurecimento a consideração de módulo de descarregamento / recarregamento $\left(E_{u r}\right)$ menor que duas vezes o $E_{50}$ (módulo de deformabilidade secante a $50 \%$ da tensão de ruptura).

Em outras palavras, há um limitante inferior representado por $E_{u r} \geq 2 * E_{50}$, que não permite que o processo de retroanálise possa ser conduzido com valores da relação $\left(\frac{E_{u r}}{E_{50}}\right) \angle 2$.

Esta limitação vai contra a própria idéia de retroanálise que durante o processo iterativo é comum o valor teórico de $E_{50}$ apresentar oscilações para cima e para baixo do 
valor real antes de atingir-se a estabilização. A oscilação citada é menor a medida que o valor teórico aproxima-se do real (intrumentado).

Não há menção nos relatórios consultados (IPT,1972 e IPT2,1972) a respeito de dados de instrumentação de deslocamentos verticais de paramentos, fator de fundamental importância para a consideração da adesão solo-paramento na interface.

No estágios 1 e 4 (Figura 3-15 e Figura 3-16) há possíveis erros de instrumentação da deformada dos paramentos. Pode-se verificar isto observando-se para o estágio 1 a Figura 3-13 e para o estágio 4 a Figura 3-14. Notar que no estágio 1 apesar da escavação que tiraria o "apoio" de solo do lado direito da estaca 1857, esta se movimentou para o lado contrário. No estágio 4 onde já há o primeiro nível de estroncas, apesar da dilatação da estronca em relação ao estágio 3 ter sido pequena, houve um deslocamento para a esquerda em torno de $5 \mathrm{~mm}$. Além disto, em relação ao estágio 3 foi escavada parte da berma que apoiava a estaca 1857, ou seja esta deveria sem o apoio ter se deslocado para a direita e não para a esquerda contra o solo.

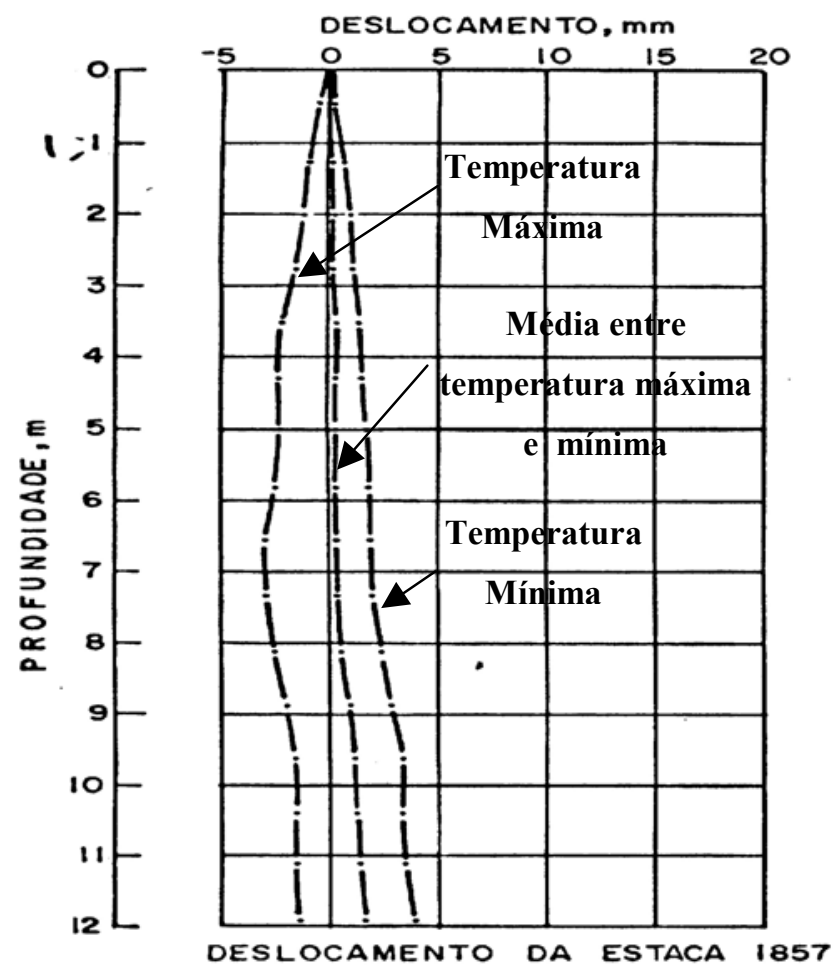

Figura 3-13 - Deslocamentos de paramento (relacionados às temperaturas) instrumentados para o estágio 1 - (IPT, 1972) 


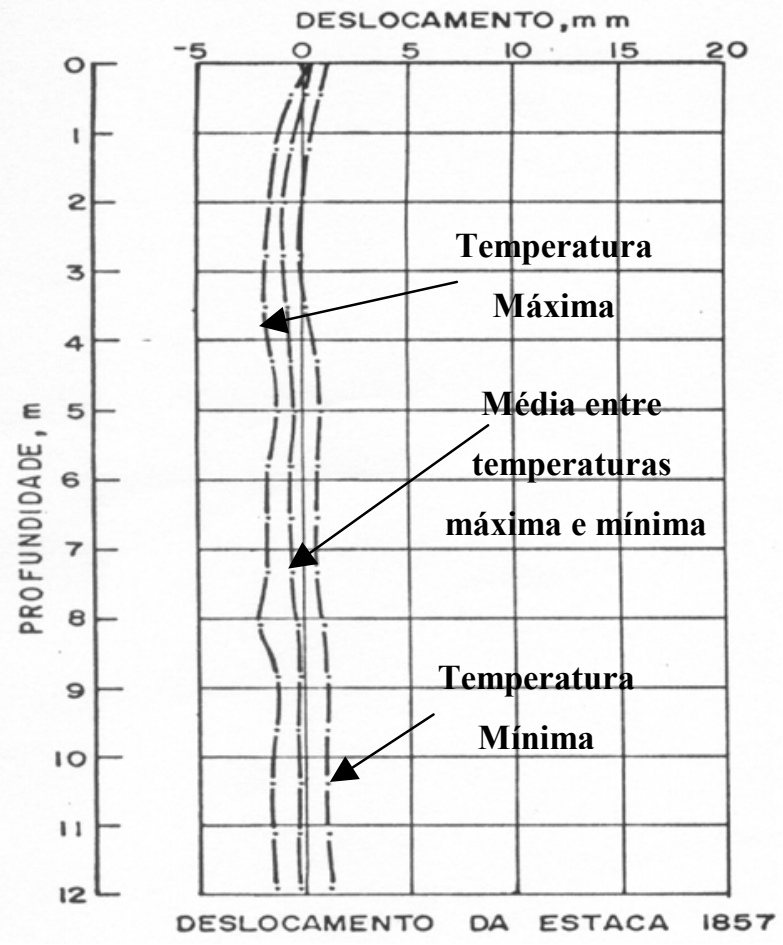

Figura 3-14- Deslocamentos de paramento (relacionados às temperaturas) instrumentados para o estágio 4 (IPT, 1972)

Da Figura 3-15 a Figura 3-22 estão representados os estágios de escavação e reaterro da seção experimental 1 , inclusive com as datas da entrada nos estágios e também da implantação das estruturas de concreto do túnel. 


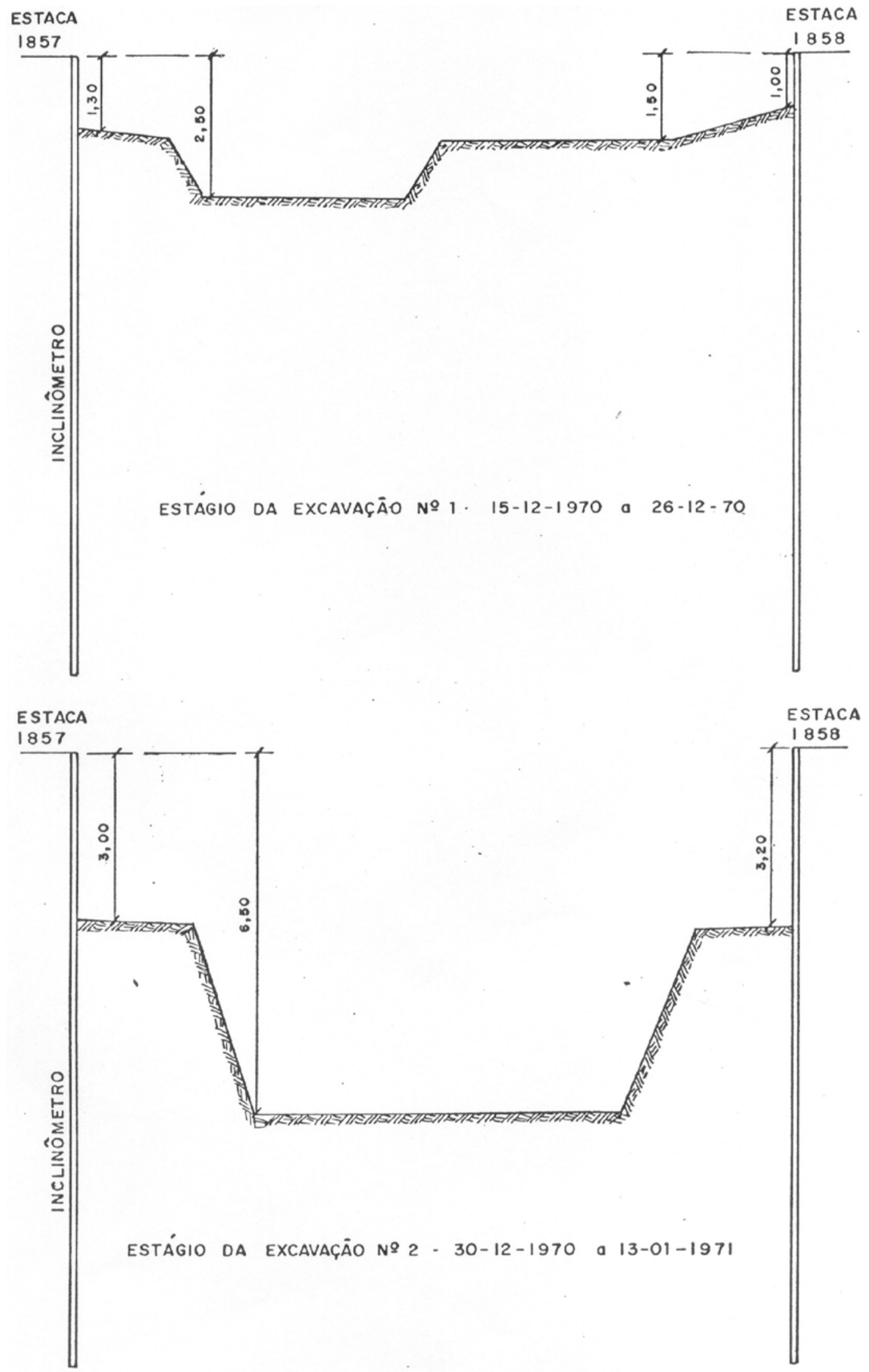

Figura 3-15- Estágios de escavação no 1 e 2 (IPT, 1972) 


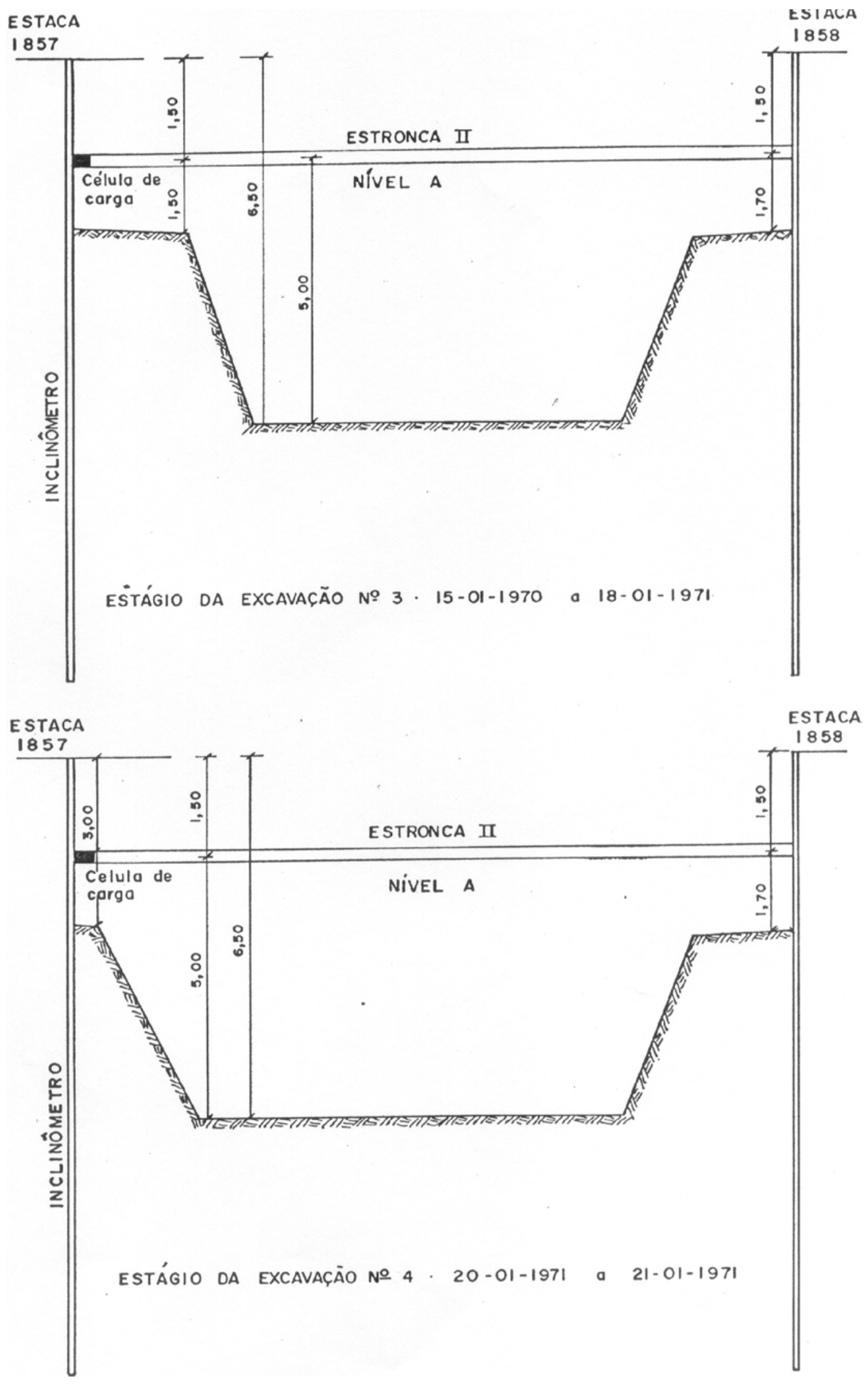

Figura 3-16- Estágio de escavação no 3 e 4 (IPT, 1972) 


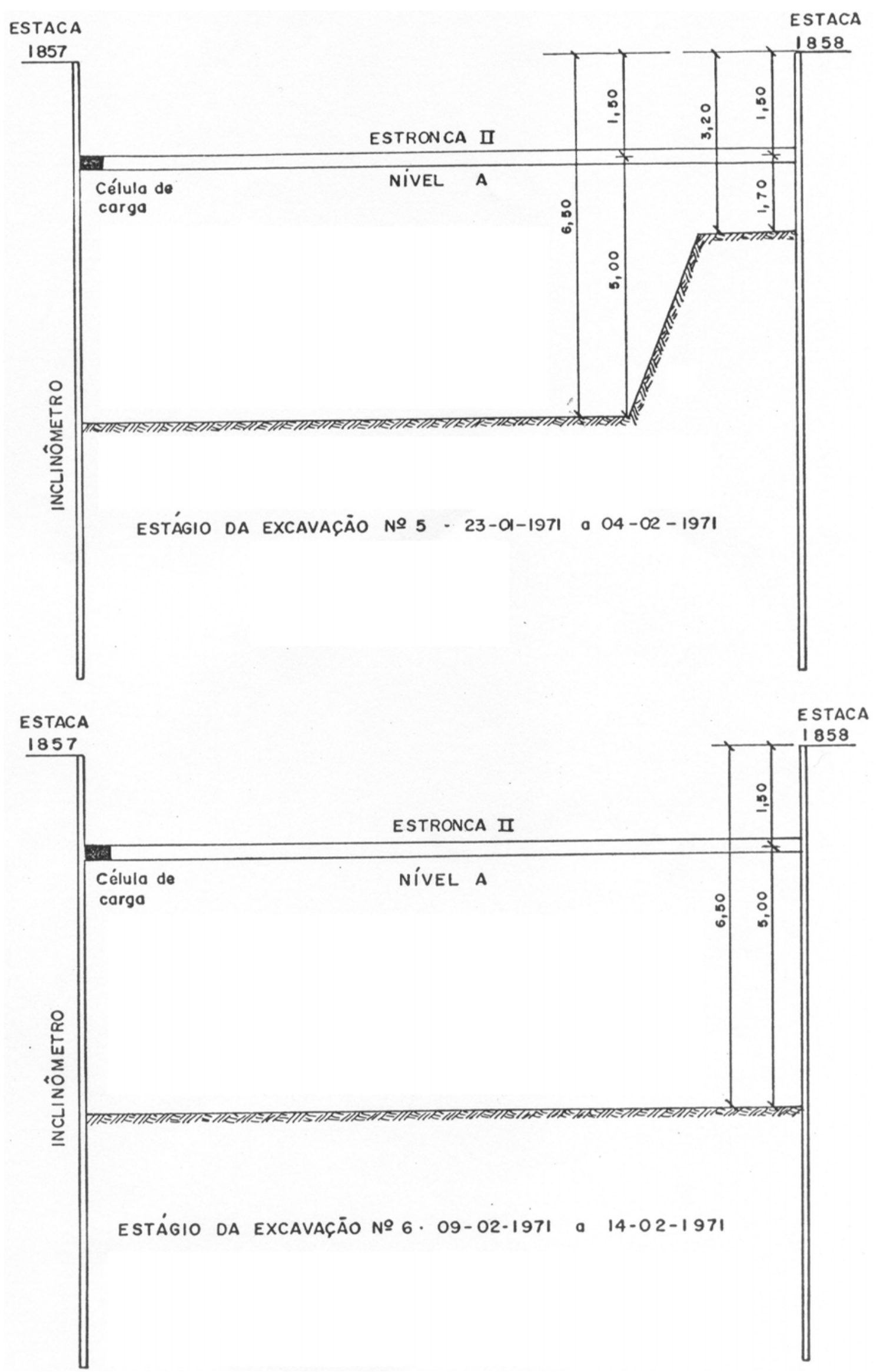

Figura 3-17 -Estágio de escavação no 5 e 6 (IPT, 1972) 


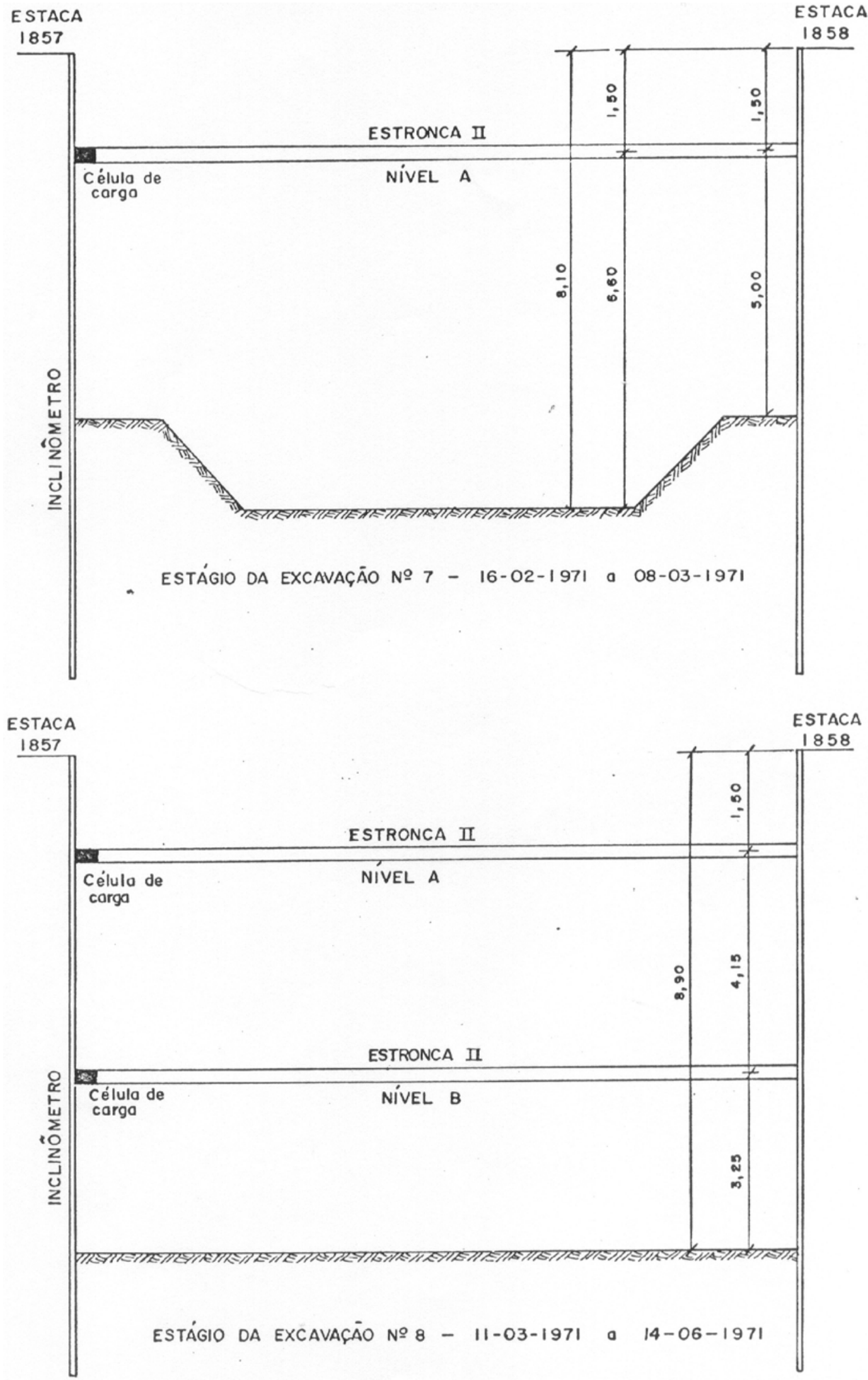

Figura 3-18-Estágio de escavação $n^{0} 7$ e 8 (IPT, 1972) 
Figura 3-19- Estágio de reaterro $\mathrm{n}^{0} 9$ e 10 (IPT, 1972) 


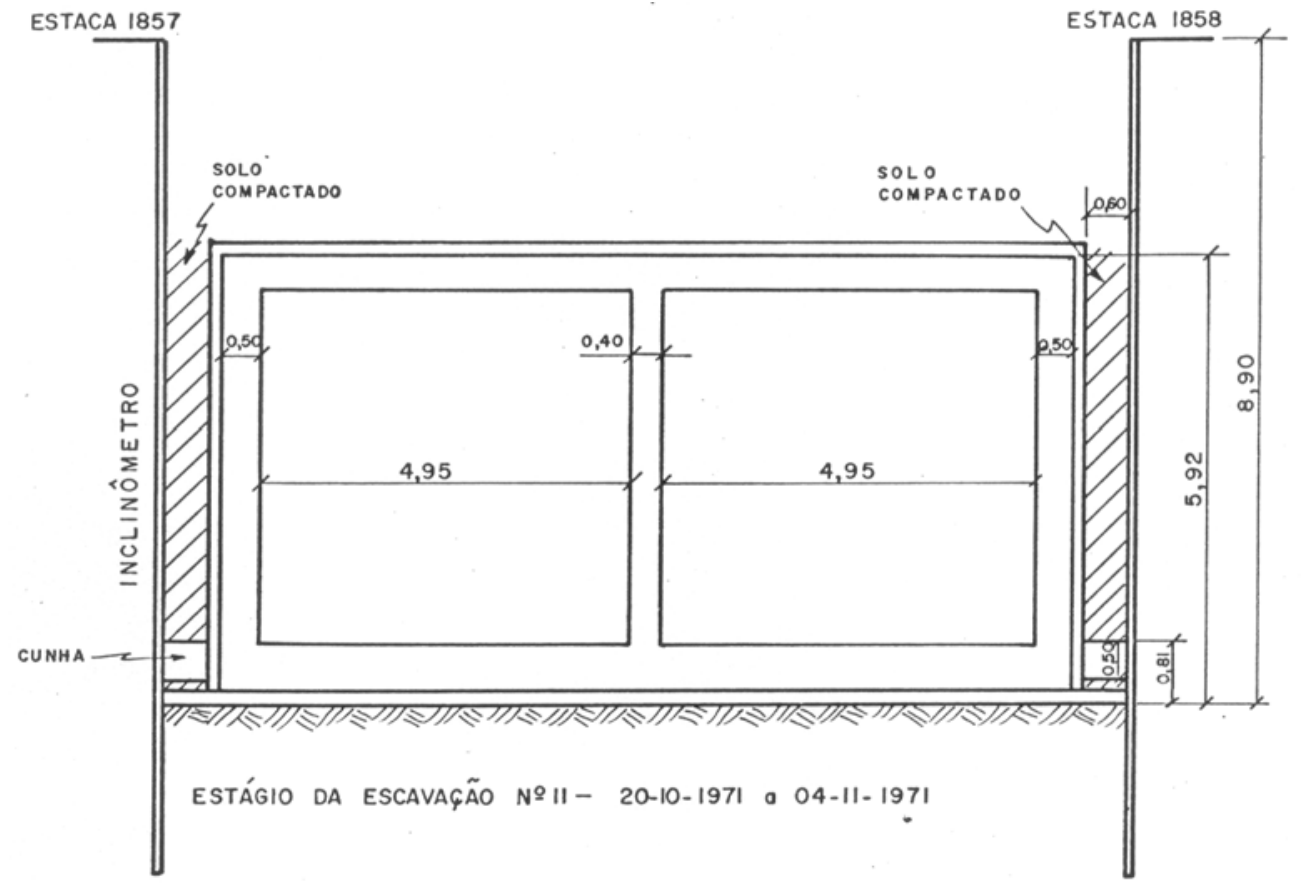

Figura 3-20- Estágio de reaterro $n^{0} 11$ (IPT, 1972) 


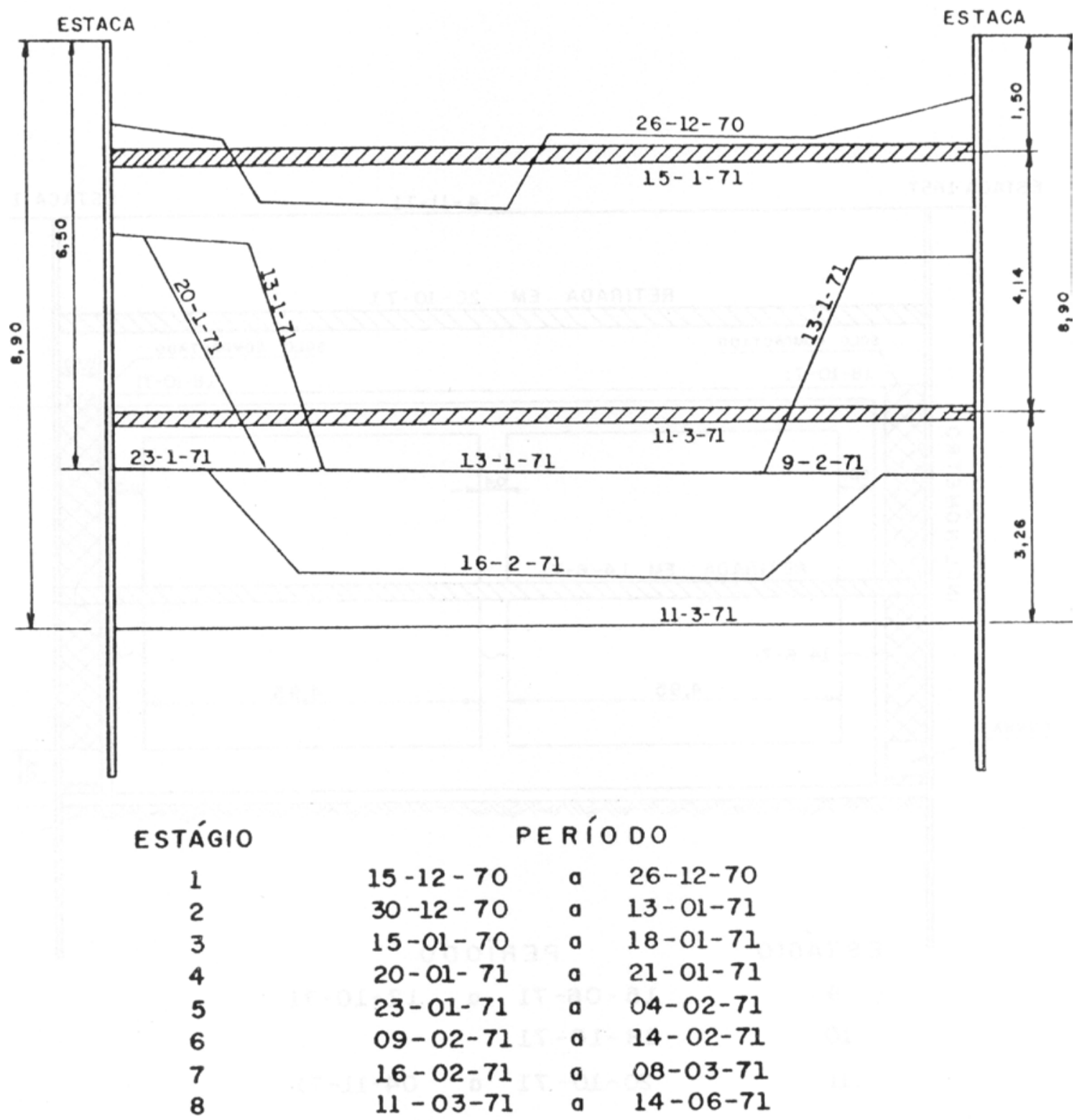

Figura 3-21-Datas de início de escavações dos estágios (IPT, 1972) 


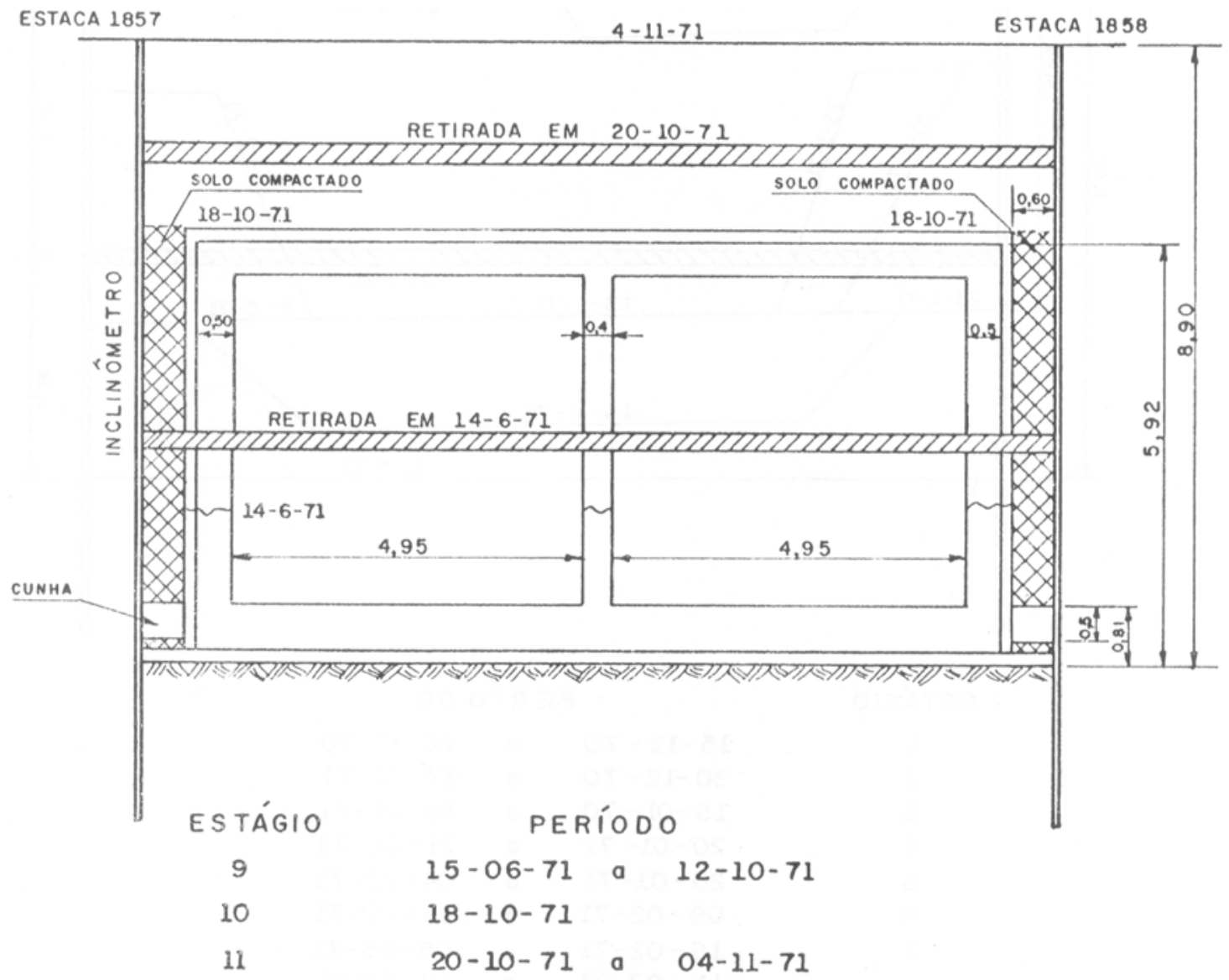

Figura 3-22-Datas dos estágios de reaterro e implantação das estruturas de concreto dos túneis (IPT, 1972)

\section{2 -Primeira Etapa - modelo constitutivo de Mohr-Coulomb}

Uma das grandes diferenças entre as tentativas de modelar o comportamento de estruturas que estão imersas em solos e rochas e outras áreas da engenharia civil, reside no fato da enorme incerteza relacionada tanto aos parâmetros físicos, de resistência e de elasticidade, bem como na distribuição dos materiais dos solos e rochas. Então é de se esperar que seja grande a dificuldade em modelar-se o comportamento dos solos e ou dos sistemas que têm o solo como constituinte.

Um modelo constitutivo ou uma lei constitutiva representa segundo DESAI (1984), um modelo matemático que descreve nossas idéias a respeito do comportamento de um material. 
A formação dos solos envolve inúmeros processos físico-químicos, ocorridos durante as eras geológicas e visto que não se conhece a fundo a totalidade destes processos, nem sua intensidade ou tempo de ocorrência com grande precisão, é muito difícil prever o comportamento dos solos sob todos os aspectos utilizando-se modelos reológicos simples.

De acordo com CHEN (1988) (ANJOS, 1996), nenhum modelo matemático pode prever o comportamento dos solos sob todas as condições. Apesar disto, bons resultados têm sido obtidos na literatura através do uso do modelo de Mohr-Coulomb.

O modelo constitutivo de Mohr-Coulomb que é utilizado na $1^{\text {a }}$ etapa deste estudo é constituído de cinco parâmetros básicos, a saber:

- $\boldsymbol{E}_{50}$ - módulo de deformabilidade a $50 \%$ da tensão de ruptura, teoricamente seria o valor de $E$ que forneceria um coeficiente de segurança 2 à ruptura

- $c$ - coesão

- $\phi$ - ângulo de a atrito

- $\quad \psi$ - ângulo de dilatância

- $\quad v$ - coeficiente de Poisson

A obtenção destes parâmetros é feita a partir de ensaios básicos de laboratório.

A superfície de plastificação do Modelo de Mohr-Coulomb está representada na Figura 3-23.

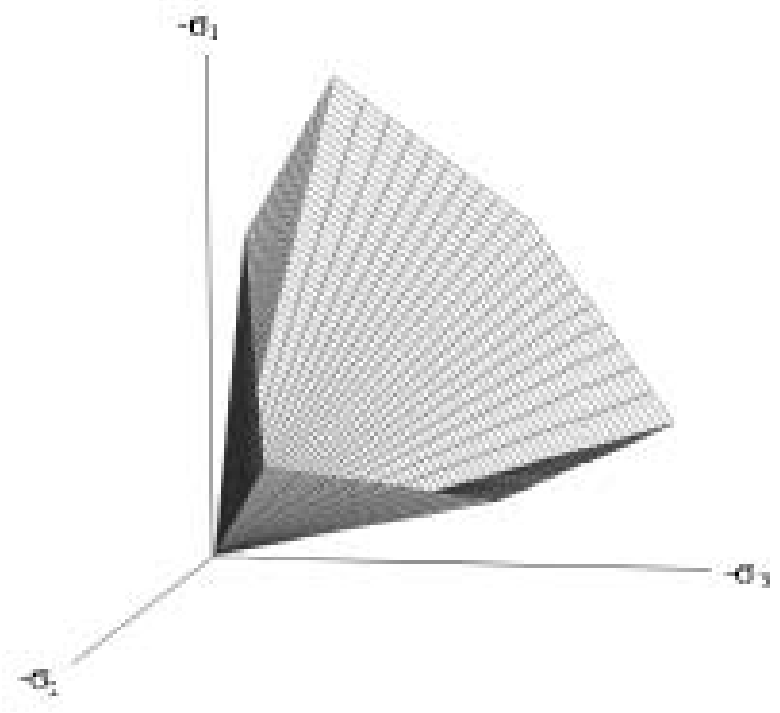

Figura 3-23-Superfície de plastificação do Modelo de Mohr-Coulomb para solos não coesivos (PLAXIS, 2002) 
A Figura 3-25 ilustra os módulos inicial $E_{1 \%}$ e o módulo a $50 \%$ da tensão de ruptura, $\mathrm{E}_{50 \%}$. e a Figura 3-25 ilustra os diversos módulos secantes (a diferentes tensões) e os módulos inicial e tangente.

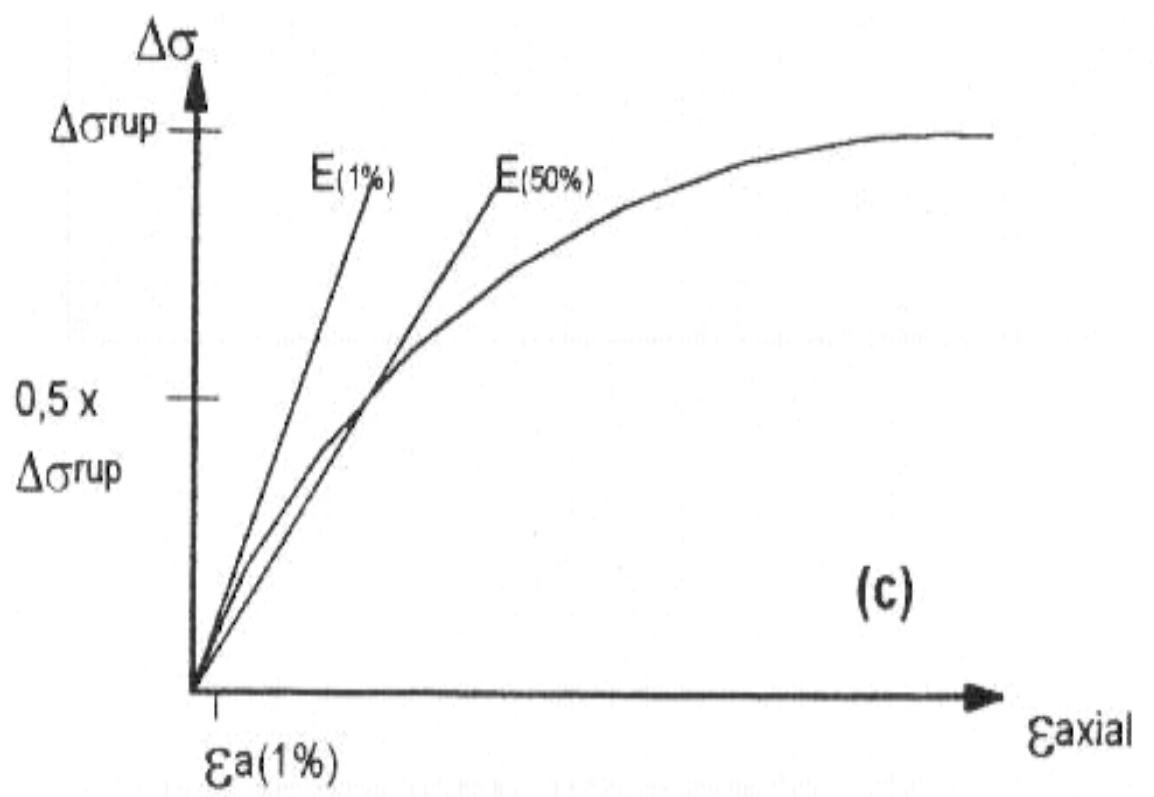

Figura 3-24 Módulos de deformabilidade a deformações a 1\% e 50\% da tensão de ruptura (PLAXIS,2002)

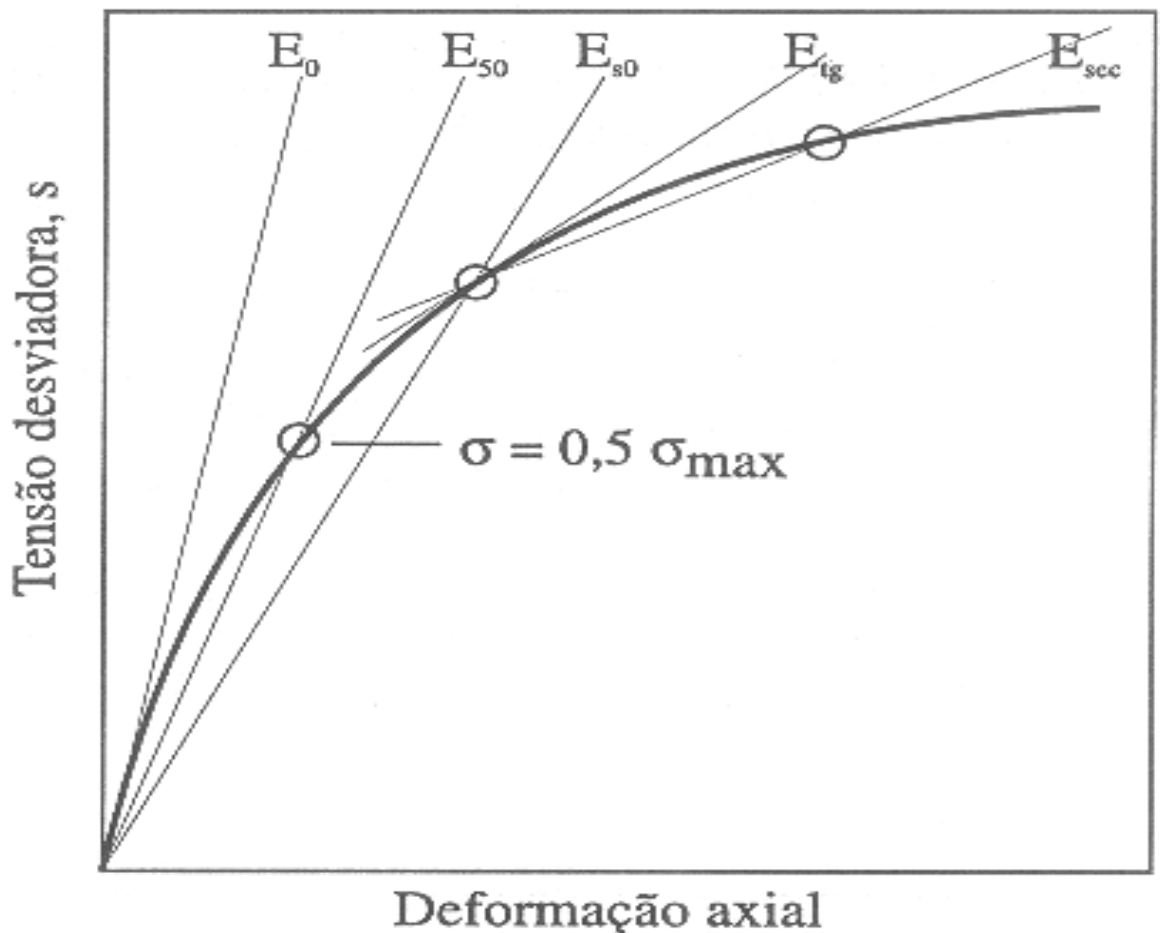

Figura 3-25-Módulos de deformabilidade a diferentes deformações (PINTO, 1996) 
De acordo com PLAXIS (2002), para materiais com comportamento inicial francamente elástico utiliza-se o parâmetro $E_{1 \%}$, porém o mais comum em solos é utilizar-se $E_{50} \%$. Notar apesar de duas nomenclaturas distintas, $E_{50}$ e $E_{50 \%}$ nesta dissertação uniformizaremos a nomenclatura para $E_{50}$. Para o caso de escavações, devido ao fato de haver desconfinamento é mais realista representar o módulo de descarregamento e recarregamento $E_{u r}$ ao invés de $E_{50}$.

Porém, o módulo Eur, não faz parte da formulação do modelo de MohrCoulomb, que utiliza como referência para o trecho elástico $\left(E_{r e f}\right)$ o valor de $E_{50}$, portanto o módulo $E_{u r}$ será utilizado somente na $2^{\text {a }}$. Etapa de estudos que abrangerá simulações com o modelo de Endurecimento que adota $E_{u r}$ nas equações constituintes.

Para a $1^{\text {a }}$ Etapa de estudos será utilizado o modelo de Mohr-Coulomb onde consideraremos como referência (Eref), o valor de módulo secante a 50\% da tensão de ruptura, ou seja, $\mathrm{E}_{50}$.

Por convenção o software PLAXIS considera as tensões de compressão como negativas.

As equações constituintes do modelo de Mohr-Coulomb estão descritas abaixo.

No software PLAXIS v. $8 x$ a condição de plastificação pelo critério de MohrCoulomb obedece a seis funções (3.2 a 3.7) formuladas a partir de tensões efetivas principais $\sigma 1^{\prime}, \sigma 2^{\prime}, \sigma 3^{\prime}$ :

$\mathbf{f}_{1 \mathbf{a}}=\frac{1}{2} *\left(\sigma_{2^{\prime}}-\sigma_{3^{\prime}}\right)+\frac{1}{2} *\left(\sigma_{2^{\prime}}+\sigma_{3^{\prime}}\right) * \operatorname{sen} \phi-c^{*} \cos \phi \leq 0$

$\mathbf{f}_{1 \mathbf{b}}=\frac{1}{2} *\left(\sigma_{3^{\prime}}-\sigma_{2^{\prime}}\right)+\frac{1}{2} *\left(\sigma_{3^{\prime}}+\sigma_{2^{\prime}}\right) * \operatorname{sen} \phi-c * \cos \phi \quad \leq 0$

$\mathbf{f}_{2 \mathbf{a}}=\frac{1}{2} *\left(\sigma_{3^{\prime}}-\sigma_{1^{\prime}}\right)+\frac{1}{2} *\left(\sigma_{3^{\prime}}+\sigma_{1^{\prime}}\right) * \operatorname{sen} \phi-c^{*} \cos \phi \leq 0$

$\mathbf{f}_{\mathbf{2} \mathbf{b}}=\frac{1}{2} *\left(\sigma_{1^{\prime}}-\sigma_{3^{\prime}}\right)+\frac{1}{2} *\left(\sigma_{1^{\prime}}+\sigma_{3^{\prime}}\right) * \operatorname{sen} \phi-c^{*} \cos \phi \leq 0$ 


$$
\begin{aligned}
& \mathbf{f}_{3 \mathbf{a}}=\frac{1}{2} *\left(\sigma_{1^{\prime}}-\sigma_{2^{\prime}}\right)+\frac{1}{2} *\left(\sigma_{1^{\prime}}+\sigma_{2^{\prime}}\right) * \operatorname{sen} \phi-c^{*} \cos \phi \leq 0 \\
& \mathbf{f}_{\mathbf{3} \mathbf{b}}=\frac{1}{2} *\left(\sigma_{2^{\prime}}-\sigma_{1^{\prime}}\right)+\frac{1}{2} *\left(\sigma_{2^{\prime}}+\sigma_{1^{\prime}}\right) * \operatorname{sen} \phi-c^{*} \cos \phi \leq 0
\end{aligned}
$$

Complementando as seis funções de plastificação, há seis funções de potencial de plastificação (3.8 a 3.13) que são dadas por:

$$
\begin{aligned}
& \mathbf{g}_{\mathbf{1} \mathbf{a}}=\frac{1}{2} *\left(\sigma_{2^{\prime}}-\sigma_{3^{\prime}}\right)+\frac{1}{2} *\left(\sigma_{2^{\prime}}+\sigma_{3^{\prime}}\right) * \operatorname{sen} \psi \\
& \mathbf{g}_{\mathbf{1} \mathbf{b}}=\frac{1}{2} *\left(\sigma_{3^{\prime}}-\sigma_{2^{\prime}}\right)+\frac{1}{2} *\left(\sigma_{3^{\prime}}+\sigma_{2^{\prime}}\right) * \operatorname{sen} \psi \\
& \mathbf{g}_{\mathbf{2} \mathbf{a}}=\frac{1}{2} *\left(\sigma_{3^{\prime}}-\sigma_{1^{\prime}}\right)+\frac{1}{2} *\left(\sigma_{3^{\prime}}+\sigma_{1^{\prime}}\right) * \operatorname{sen} \psi \\
& \mathbf{g}_{\mathbf{2} \mathbf{b}}=\frac{1}{2} *\left(\sigma_{1^{\prime}}-\sigma_{3^{\prime}}\right)+\frac{1}{2} *\left(\sigma_{1^{\prime}}+\sigma_{3^{\prime}}\right) * \operatorname{sen} \psi \\
& \mathbf{g}_{\mathbf{3 b}}=\frac{1}{2} *\left(\sigma_{2^{\prime}}-\sigma_{1^{\prime}}\right)+\frac{1}{2} *\left(\sigma_{2^{\prime}}+\sigma_{1^{\prime}}\right) * \operatorname{sen} \psi \\
& \mathbf{g}_{\mathbf{3} \mathbf{a}}=\frac{1}{2} *\left(\sigma_{1^{\prime}}-\sigma_{2^{\prime}}\right)+\frac{1}{2} *\left(\sigma_{1^{\prime}}+\sigma_{2^{\prime}}\right) * \operatorname{sen} \psi
\end{aligned}
$$


As funções de potencial plástico contêm um terceiro parâmetro de plasticidade que é o $\psi$ representando a dilatância. Este parâmetro é necessário para modelar os incrementos de deformações volumétricas plásticas (dilatância), que podem ocorrer em solos densos.

Há ainda a possibilidade de considerar-se o quinhão de resistência à tração que pode haver em alguns solos. Nestes casos o software PLAXIS V.8x considera mais três funções de plastificação (3.14 a 3.16) que se adicionam às seis anteriores para representar o comportamento do solo.

$$
\begin{aligned}
& \mathbf{f}_{\mathbf{4}}=\sigma_{1},-\sigma_{\mathbf{t}} \leq 0 \\
& \mathbf{f}_{\mathbf{5}}=\sigma_{2},-\sigma_{\mathbf{t}} \leq 0 \\
& \mathbf{f}_{\mathbf{6}}=\sigma_{3},-\sigma_{\mathbf{t}} \leq 0
\end{aligned}
$$

Estabeleceu-se que nestes estudos seria adotada a resistência à tração nula dos solos que compõem a Seção Experimental nº 1.

\section{3 -Ações consideradas nas análises paramétricas}

Para realizar as análises paramétricas é necessário reproduzir as etapas de escavação e as cargas permanentes, que influenciarão no comportamento do sistema solo-escoramento.

Em outras palavras, a intenção é determinar-se qual a variação que ocorrerá no sistema provocada por uma variação individual de cada parâmetro, ou variação correlata, se houver parâmetros dependentes.

Assim, serão determinados quais os parâmetros a variar nas etapas de retroanálise, de forma a se obterem intervalos de parâmetros que devem conter a solução do problema procurado. 


\section{4 - Análise Paramétrica utilizando-se o modelo Mohr- Coulomb}

Para realizar uma análise paramétrica com o modelo em M.E.F., idêntico ao que seria utilizado para conduzir as etapas de retroanálise, foi necessário definir-se um valor de variação individual para os parâmetros.

Adotou-se como critério de escolha do valor de variação paramétrica individual, um percentual próximo a máxima variação obtida em laboratório (Tabela 3-1) para os parâmetros $\phi$ ' (ângulo de atrito efetivo), e $\gamma_{\text {nat }}$ (peso específico natural).

Estes dois parâmetros foram escolhidos como referência pois no processo de retroanálise de $E_{50}$ adotou-se fazer variações para c' (coesão efetiva) e $K_{o}$ (coeficiente de empuxo em repouso). com percentuais de variação muito superiores às máximas variações obtidas em laboratório.

A partir dos resultados de MASSAD (1992) apresentados na (Tabela 2-4) e da Figura 2-7 a , fizeram-se estimativas expeditas da ordem de grandeza da variação dos parâmetros nos ensaios de laboratório. Em outras palavras, quanto percentualmente o valor médio foi superior ao valor mínimo e quanto o valor máximo foi superior ao valor médio. Estas estimativas estão apresentadas da Tabela 3-1 a Tabela 3-2, respectivamente para Argilas Porosas Vermelhas, Rijas Vermelhas e Solos Variegados. 
Tabela 3-1- Diferenças percentuais calculadas (Argilas Vermelhas Porosas) entre os valores máximos, médios e mínimos para parâmetros geotécnicos obtidos de MASSAD (1992)

\begin{tabular}{|l|c|c|c|c|}
\hline Características & Mínimo/Máximo & Médio & $\begin{array}{l}\text { \% (mínimo } \\
\text { a médio) }\end{array}$ & $\begin{array}{l}\text { \% (médio a } \\
\text { máximo). }\end{array}$ \\
\hline $\begin{array}{l}\text { c' }(\mathrm{kPa}) \\
\text { E.T.N.D.* }\end{array}$ & 10 a 70 & 32 & $220 \%$ & $118,8 \%$ \\
\hline$\gamma_{\text {nat }}\left(\mathrm{kN} / \mathrm{m}^{3}\right)$ & 13,5 a 16,5 & 15,2 & $12,3 \%$ & $8,5 \%$ \\
\hline $\begin{array}{l}\Phi^{\prime}{ }_{\mathrm{a}}\left({ }^{\circ}\right) \\
\text { E.T.N.D. }\end{array}$ & 23 a 33 & 27 & $17,3 \%$ & $22,2 \%$ \\
\hline$E_{50}(\mathrm{kPa})$ & $* * 20000$ a 50000 & 35000 & $75 \%$ & 42,9 \\
& & & & \\
\hline
\end{tabular}

**Valores calculados a partir da Figura 2-7

Legendas utilizadas :

$\gamma_{\text {nat }}-$ peso específico natural

c' - coesão efetiva

$\phi^{\prime}, \phi_{\mathrm{a}}^{\prime}$ - ângulo de atritos efetivos acima e abaixo dos efeitos de préadensamento.

E.T.N.D.* - Valores obtidos de ensaios triaxiais não drenados 
Tabela 3-2- Diferenças percentuais calculadas (Argilas Rijas Vermelhas) entre os valores máximos, médios e mínimos para parâmetros geotécnicos obtidos dos resultados de MASSAD (1992)

\begin{tabular}{|l|c|c|c|c|}
\hline \multicolumn{1}{|c|}{ Características } & Mínimo / Máximo & Médio & $\begin{array}{c}\text { \% } \\
\text { (mínimo a } \\
\text { médio) }\end{array}$ & $\begin{array}{c}\text { \% (médio a } \\
\text { máximo). }\end{array}$ \\
\hline $\begin{array}{l}\text { c' }(\mathrm{kPa}) \\
\text { E.T.N.D.* }\end{array}$ & 50 a 90 & 69 & $38 \%$ & $30,4 \%$ \\
\hline$\gamma_{\text {nat }}\left(\mathrm{kN} / \mathrm{m}^{3}\right)$ & 16,2 a 18 & 17,2 & $6,2 \%$ & $11,1 \%$ \\
\hline$\Phi^{\prime}{ }_{\mathrm{a}}\left({ }^{\circ}\right)$ & 21 a 25 & 23 & $9,5 \%$ & $8,7 \%$ \\
E.T.N.D.* & $* 105000$ a 160000 & 132500 & $52,4 \%$ & $20,8 \%$ \\
\hline E50 $(\mathrm{kPa})$ & & & & \\
\hline
\end{tabular}

**Os valores de $\boldsymbol{E}_{50}$ foram calculados a partir da Figura 2-8

Da análise da Tabela 3-1 e Tabela 3-2 notou-se que para a argila porosa vermelha (região de escavação da vala). a maior variação de $\phi{ }_{a}{ }_{a}$ acima do valor médio foi de $+22,2 \%$ e de $\gamma_{n a t}$ foi de $12,3 \%$.Para a argila rija (fundo da vala) a maior variação de $\phi{ }_{a}^{\prime}$ acima do valor médio foi de $+8,7 \%$ e de $\gamma_{n a t}$ foi de $11,1 \%$.

Assim resolveu-se adotar para a análise paramétrica do Modelo de Mohr Coulomb valores 30\% acima dos valores definidos como referência inicial 1 (linha 1 da Tabela 3-3).

Os valores de referência inicial 1 são os obtidos de IPT (1972) e estão detalhados na Tabela 3-3 e pertencem ao intervalo de resultados da Tabela 2-4 de MASSAD (1992) .

Na Tabela 3-3 estão apresentados os valores dos parâmetros alterados em $+30 \%$ utilizados em cada uma das combinações para a análise paramétrica. 
Tabela 3-3- Parâmetros geotécnicos valores de referência inicial 1 e variados em $+30 \%$ utilizados para as simulações com finalidade de análise paramétrica com o modelo de Mohr-Coulomb

\begin{tabular}{|c|c|c|c|c|c|c|c|c|}
\hline $\begin{array}{c}\text { Simulação } \\
\mathrm{n}^{\text {o }}\end{array}$ & $\begin{array}{c}\text { Parâmetro } \\
\text { com } \\
\text { aumento } \\
\text { de 30\% }\end{array}$ & $v$ & $\begin{array}{c}\gamma_{\text {nat }} \\
\left(\mathrm{kN} / \mathrm{m}^{3}\right)\end{array}$ & Ko & $\begin{array}{c}\phi^{\prime} \\
\left({ }^{\circ}\right)\end{array}$ & $\mathrm{R}_{\text {inter }}$ & $\begin{array}{c}\mathrm{c}^{\prime} \\
\left(\mathrm{kN} / \mathrm{m}^{2}\right)\end{array}$ & $\begin{array}{c}\mathrm{E}_{50} \\
\left(\mathrm{kN} / \mathrm{m}^{2}\right)\end{array}$ \\
\hline $\begin{array}{c}\text { 1-Valores } \\
\text { de } \\
\text { referência } \\
\text { inicial 1 }\end{array}$ & ----- & $\mathbf{0 . 3 5}$ & $\mathbf{1 5}$ & $\mathbf{0 , 4 5}$ & $\mathbf{2 8}$ & $\mathbf{0 , 5}$ & $\mathbf{3 0}$ & $\mathbf{1 0 0 0 0 0}$ \\
\hline 2 & $\boldsymbol{E}_{50}$ & 0.35 & 15 & 0,45 & 28 & 0,5 & 30 & $\mathbf{1 3 0 0 0 0}$ \\
\hline 3 & $\boldsymbol{c}$ & 0.35 & 15 & 0,45 & 28 & 0,5 & $\mathbf{3 9}$ & 100000 \\
\hline 4 & $\mathbf{R}_{\text {inter }}$ & 0.35 & 15 & 0,45 & 28 & $\mathbf{0 . 6 5}$ & 30 & 100000 \\
\hline 5 & $\Phi$ & 0.35 & 15 & 0,45 & $\mathbf{3 6 . 4}$ & 0,5 & 30 & 100000 \\
\hline 6 & $\boldsymbol{K o}$ & 0.35 & 15 & $\mathbf{0 . 5 9}$ & 28 & 0,5 & 30 & 100000 \\
\hline 7 & $\gamma_{\text {nat }}$ & 0.35 & $\mathbf{1 9 . 5}$ & 0,45 & 28 & 0,5 & 30 & 100000 \\
\hline 8 & $\boldsymbol{v}$ & $\mathbf{0 . 4 6}$ & 15 & 0,45 & 28 & 0,5 & 30 & 100000 \\
\hline
\end{tabular}

Sendo:

- $E_{50}$-Módulo de deformabilidade a $50 \%$ da tensão de ruptura

- $\quad c^{\prime}$ - coesão efetiva

- $R_{\text {inter }}$ - Fator de redução da coesão efetiva e da tangente do ângulo de atrito efetivo que é aplicado pelo software PLAXIS na interface solo paramento, ou seja para interfaces rígidas (sem deslocamento relativo) $R_{\text {inter }}=1$, para as demais situações onde ocorre deslocamento relativo $R_{\text {inter }}<1,0$. Sendo esta redução feita da seguinte forma:

$$
\begin{aligned}
& c_{\text {reduzida }}=R_{\text {inter }} * c^{\prime} \\
& \text { tan } \phi_{\text {reduzido }}=\mathrm{R}_{\text {inter }} * \text { tan } \phi^{\prime}{ }_{\text {reduzido }}
\end{aligned}
$$

- $\quad \phi$. - ângulo de atrito efetivo

- Ko- coeficiente de empuxo em repouso

- $\gamma_{n a t}-$ peso específico natural do solo

- $\quad v$ - coeficiente de Poisson 
A análise paramétrica foi conduzida através de simulações, analisando-se os estágios de escavação 3,5 e 8 .

Utilizou-se como critério de análise impor uma variação de $+30 \%$ sobre os valores dos parâmetros de referência inicial 1 e averiguar as variações induzidas nos deslocamentos horizontais do paramento e nas forças do $1^{\circ}$ nível de estronca em relação aos obtidos sem a variação de $+30 \%$.

Para analisar os deslocamentos horizontais foram observadas três posições na vertical do paramento, sendo elas correspondentes aos pontos extremos superior e inferior e ao ponto médio.

Os resultados estão apresentados da Figura 3-26 a Figura 3-28.

Para estudar a influência sobre as forças nas estroncas induzidas por variações de $+30 \%$ sobre os parâmetros de referência inicial 1, apresentaram-se os resultados na Figura 3-29 até a Figura 3-31.

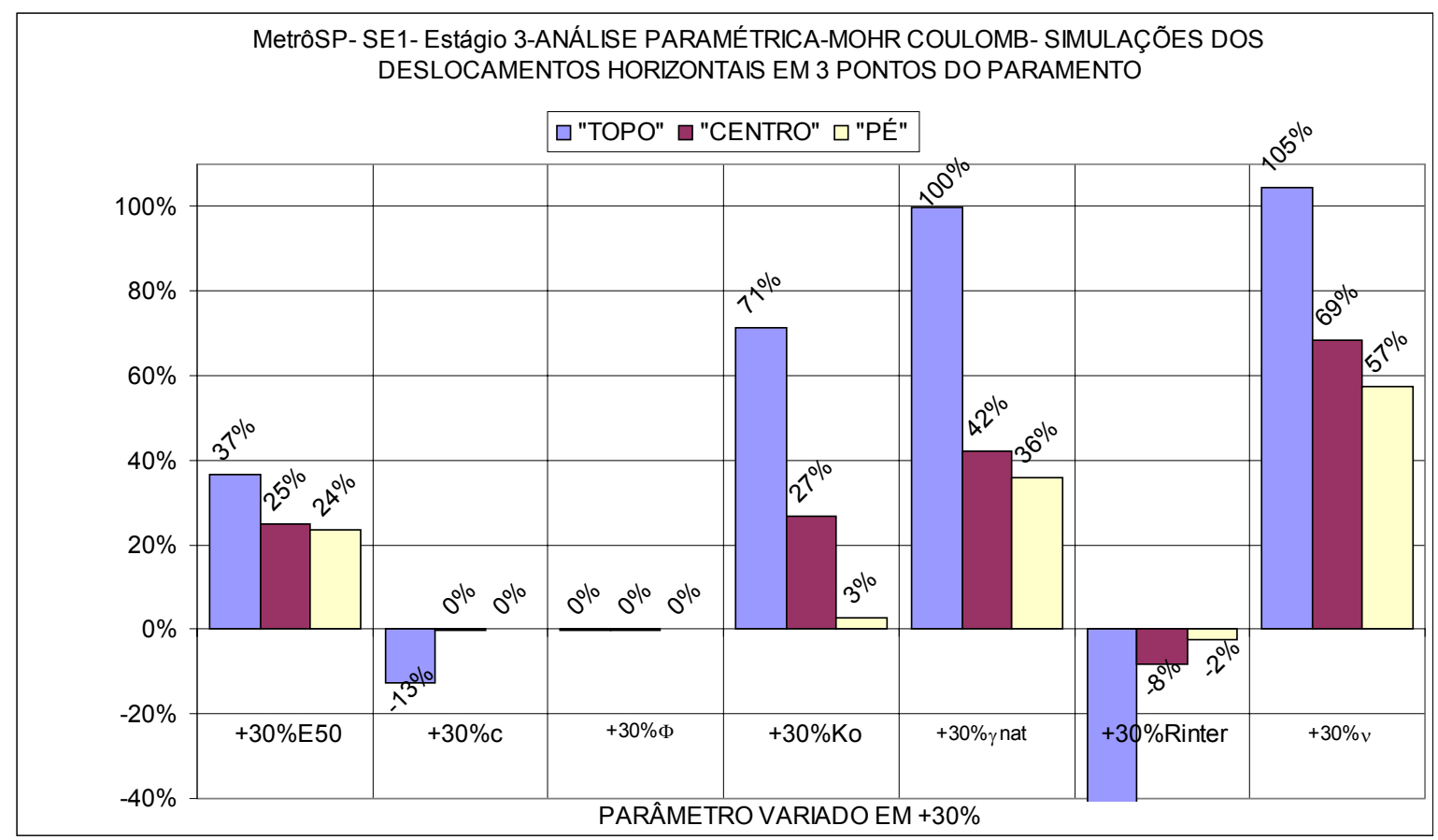

Figura 3-26- Influência do aumento de 30\% dos parâmetros nos deslocamentos horizontais em 3 pontos do paramento para o estágio 3 


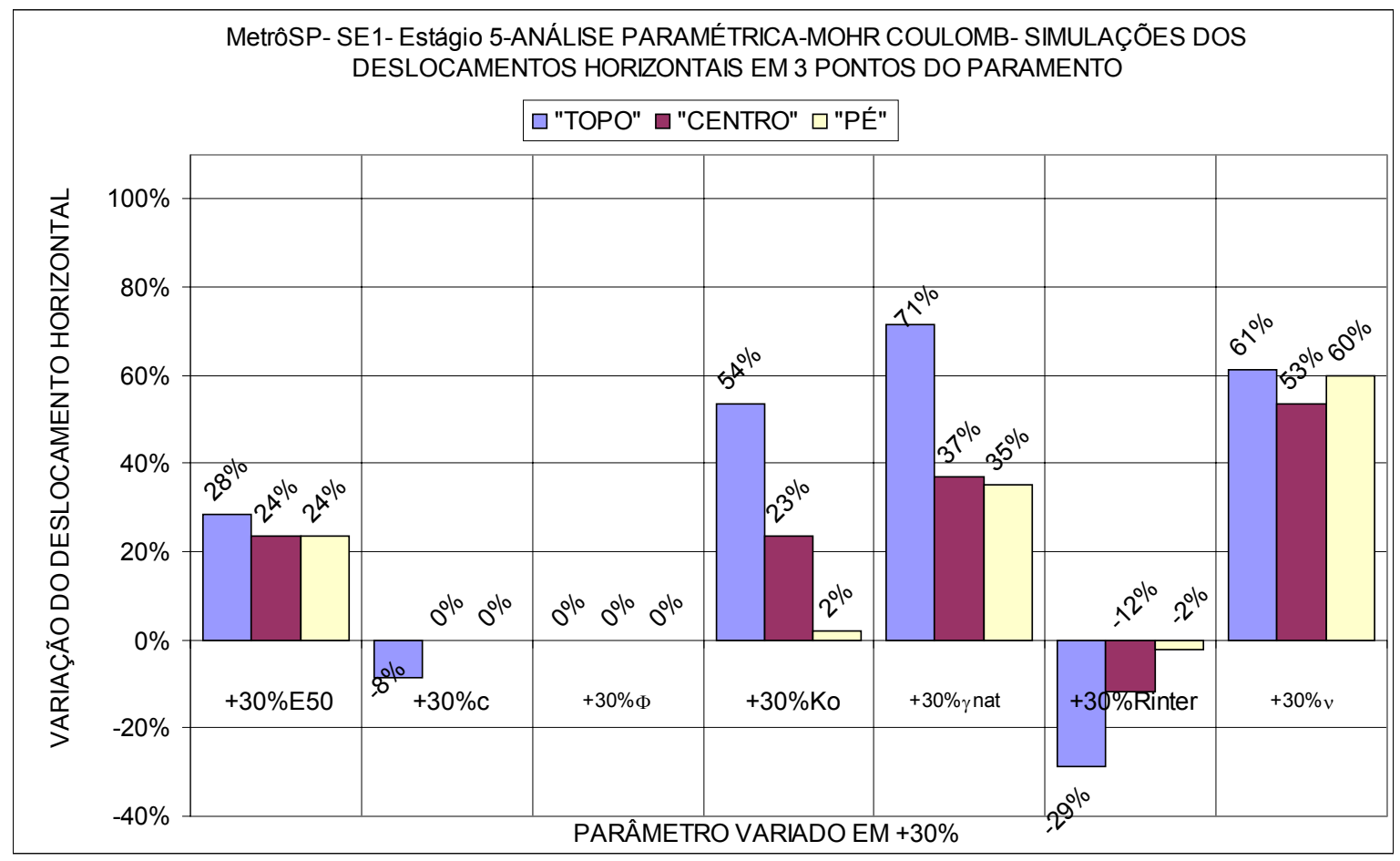

Figura 3-27- Influência do aumento de 30\% dos parâmetros nos deslocamentos horizontais em 3 pontos do paramento para o estágio 5

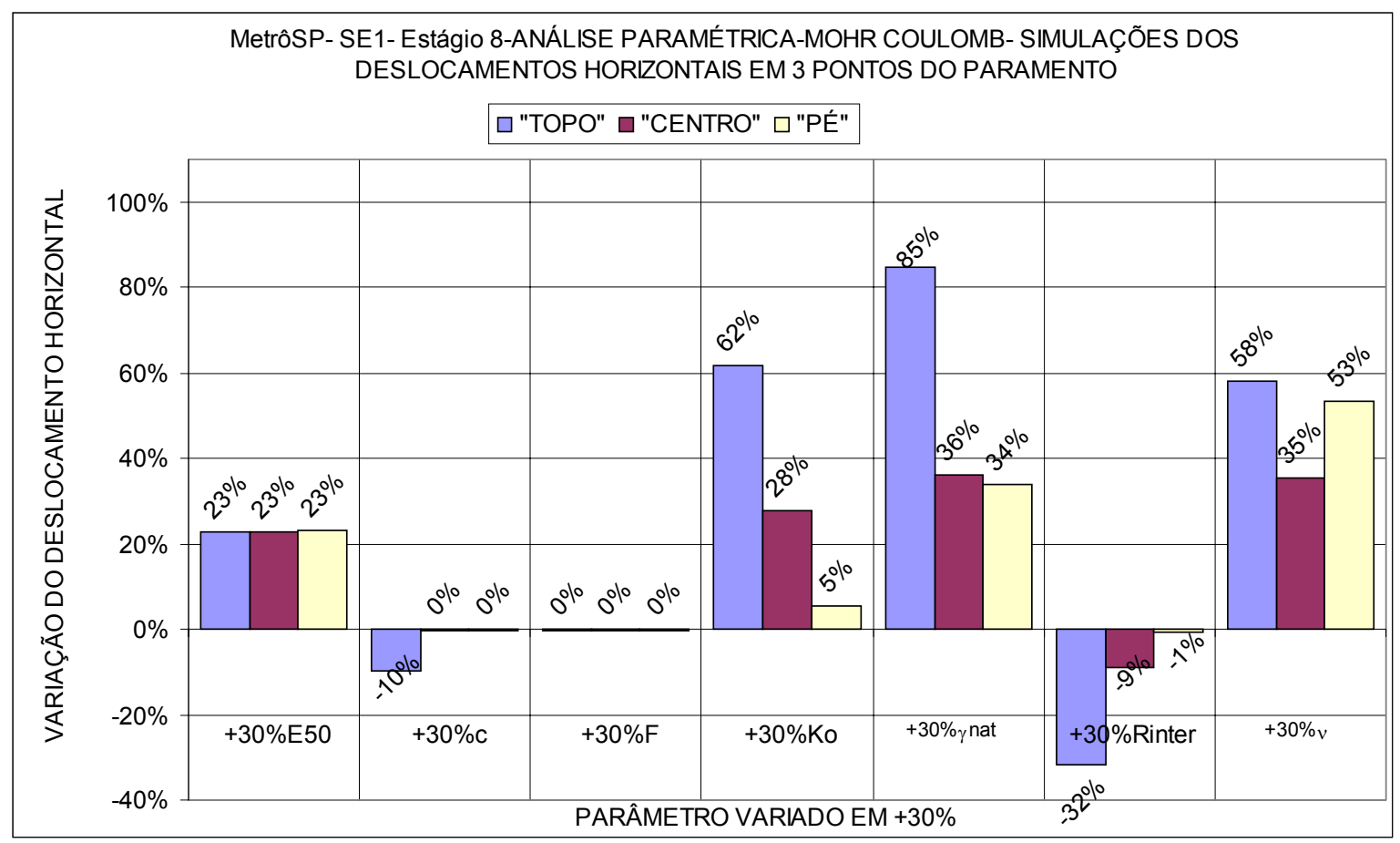

Figura 3-28- Influência do aumento de 30\% dos valores dos parâmetros nos deslocamentos horizontais em 3 pontos do paramento para o estágio 8 


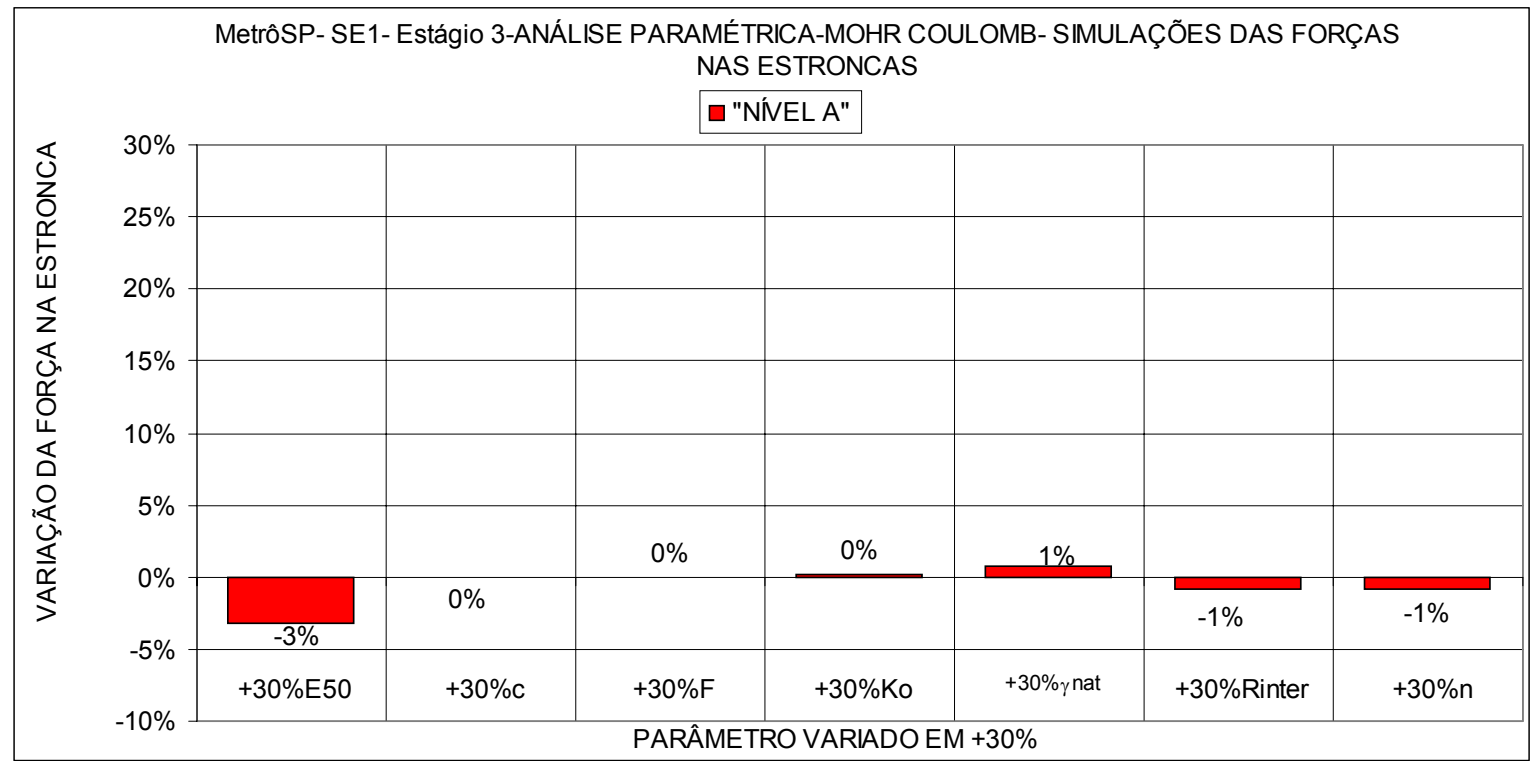

Figura 3-29- Influência do aumento de 30\% dos valores dos parâmetros na força da estronca no nível A para o estágio 3

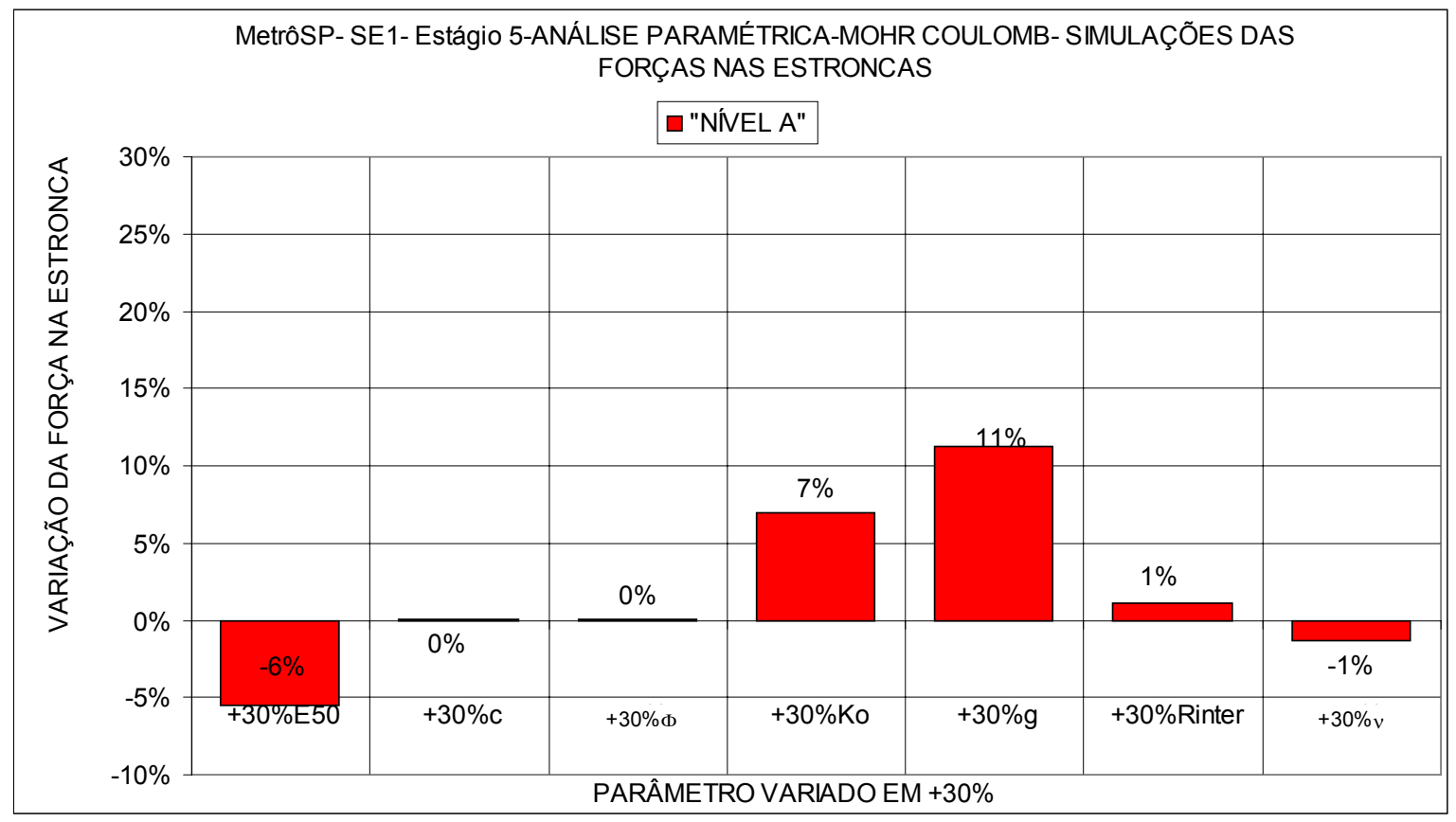

Figura 3-30- Influência do aumento de 30\% dos valores dos parâmetros na força da estronca no nível A para o estágio 5 


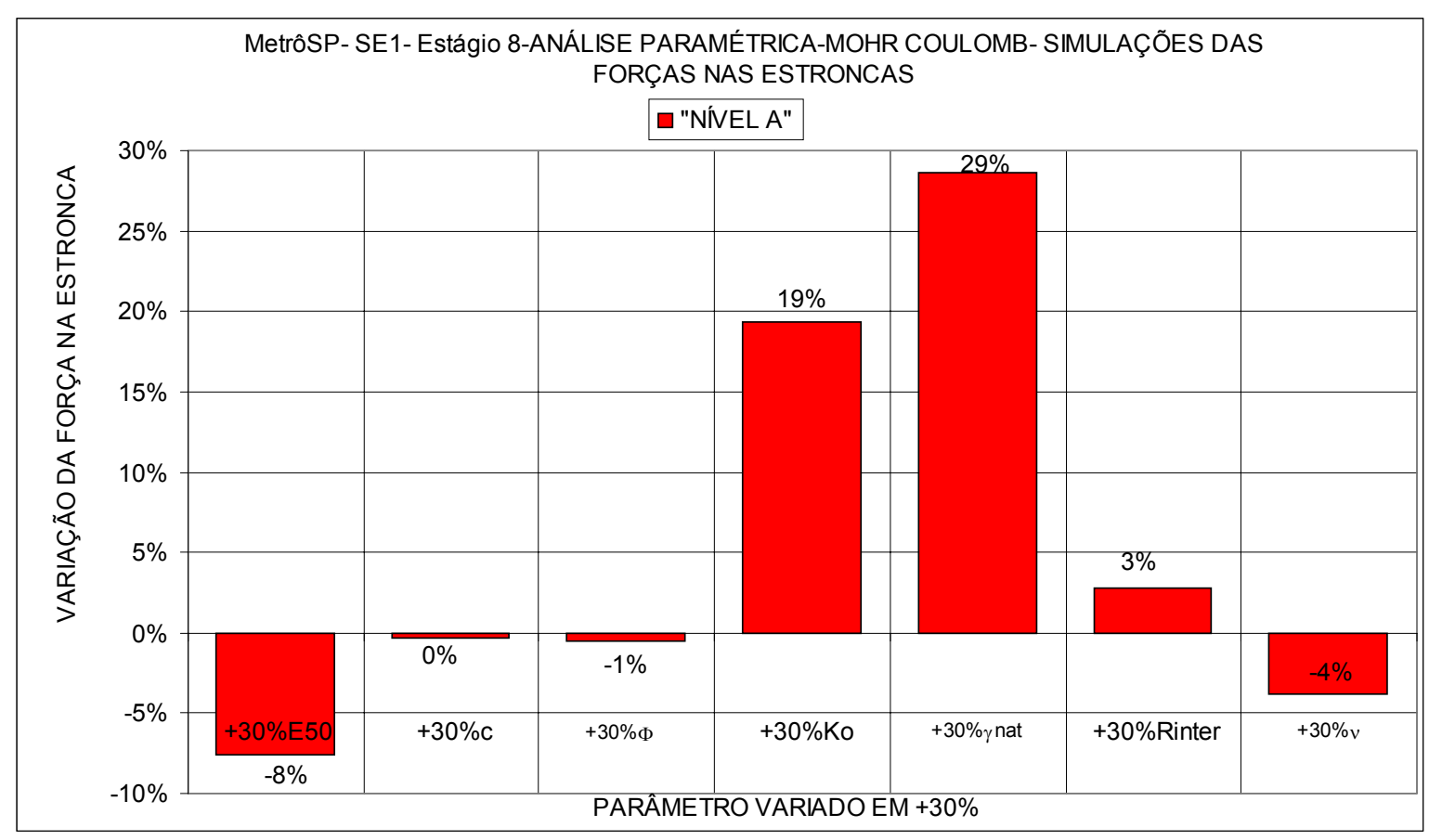

Figura 3-31- Influência do aumento de 30\% dos valores dos parâmetros na força da estronca no nível A para o estágio 8

\section{5 -Escolha dos intervalos para as retroanálises utilizando- se o modelo Mohr-Coulomb}

Da análise da Figura 3-26 a Figura 3-31 obteve-se uma hierarquia de parâmetros com as 3 maiores influências nos deslocamentos horizontais de paramento e forças nas estroncas do nível A .

Os resultados para deslocamentos horizontais foram agrupados na Tabela 3-4 e para forças nas estroncas foram agrupados na Tabela 3-5. 
Tabela 3-4-Hierarquia de inflûencias sobre os deslocamentos horizontais de 3 pontos do paramento para variações de $+30 \%$

\begin{tabular}{|c|c|c|c|c|c|c|c|c|c|c|}
\hline $\mathrm{E}$ & $\mathrm{V}$ & $1^{\mathrm{a}} \cdot$ & $2^{\mathrm{a}} \cdot$ & $3^{\mathrm{a}} \cdot$ & $1^{\mathrm{a}} \cdot$ & $2^{\mathrm{a}} \cdot$ & $2^{\mathrm{a}} \cdot$ & $1^{\mathrm{a}}$ & $2^{\mathrm{a}}$ & $3^{\mathrm{a}} \cdot$ \\
$\mathrm{S}$ & $\mathrm{A}$ & $\mathrm{T}$ & $\mathrm{T}$ & $\mathrm{T}$ & $\mathrm{C}$ & $\mathrm{C}$ & $\mathrm{C}$ & $\mathrm{B}$ & $\mathrm{B}$ & $\mathrm{B}$ \\
$\mathrm{T}$ & $\mathrm{R}$ & $\mathrm{O}$ & $\mathrm{O}$ & $\mathrm{O}$ & $\mathrm{E}$ & $\mathrm{E}$ & $\mathrm{E}$ & $\mathrm{A}$ & $\mathrm{A}$ & $\mathrm{A}$ \\
$\mathrm{A}$ & $\mathrm{I}$ & $\mathrm{P}$ & $\mathrm{P}$ & $\mathrm{P}$ & $\mathrm{N}$ & $\mathrm{N}$ & $\mathrm{N}$ & $\mathrm{S}$ & $\mathrm{S}$ & $\mathrm{S}$ \\
$\mathrm{G}$ & $\mathrm{A}$ & $\mathrm{O}$ & $\mathrm{O}$ & $\mathrm{O}$ & $\mathrm{T}$ & $\mathrm{T}$ & $\mathrm{T}$ & $\mathrm{E}$ & $\mathrm{E}$ & $\mathrm{E}$ \\
$\mathrm{I}$ & $\mathrm{C}$ & & & & $\mathrm{R}$ & $\mathrm{R}$ & $\mathrm{R}$ & & & \\
$\mathrm{O}$ & $\tilde{\mathrm{A}}$ & & & & $\mathrm{O}$ & $\mathrm{O}$ & $\mathrm{O}$ & & & \\
\hline 3 & $\mathrm{O}$ & & & & & & & & & \\
\hline 5 & $+30 \%$ & $\mathrm{v}$ & $\gamma_{\text {nat }}$ & $K o$ & $\mathrm{~V}$ & $\gamma_{\text {nat }}$ & $K o$ & $\mathrm{~V}$ & $\gamma_{\text {nat }}$ & $E_{50}$ \\
\hline
\end{tabular}

A partir da análise isolada da Tabela 3-4, conclui-se que os parâmetros que têm maior influência sobre os deslocamentos horizontais de paramento são:

- $\gamma_{\text {nat }}, K o, E_{50}$

Porém, isto não significa que os outros parâmetros não sejam importantes, uma vez que a análise paramétrica fixou proporções de variação e dependendo das combinações escolhidas pode haver influências de outros parâmetros que não apareceram nesta análise paramétrica, visto que a combinação escolhida foi realizar variações de $+30 \%$ sobre os parâmetros de referência inicial 1 .

Uma análise das variações apresentadas da Figura 3-26 até Figura 3-28 mostra também, que os parâmetros de maior influência sobre os deslocamentos horizontais do paramento dependem do estágio da escavação e do ponto que está sendo analisado.

A mesma afirmação vale para a variação de força no $1^{\circ}$ nível de estroncas.

Porém, se analisarmos em relação ao ponto extremo superior do paramento o fator Rinter que considera a interface entre solo e paramento tem peso maior que $E_{50}$ 
nos estágios 5 e 8, estando na ordem de importância de $K o$. Estes resultados estão de acordo com os estudos de ESQUÍVEL (1978), que concluiu que para modelos bidimensionais o atrito entre o solo e a parede tem grande influência nos deslocamentos.

Tabela 3-5- Hierarquia de inflûencias sobre as forças nas estroncas níveis $A$ e $B$ para variações de $+\mathbf{3 0} \%$ a $\mathbf{- 3 0} \%$

\begin{tabular}{|l|l|c|c|c|}
\hline ESTÁGIO & Variação & $\begin{array}{c}1^{\mathrm{a}} \\
\text { Nível A }\end{array}$ & $\begin{array}{c}2^{\mathrm{a}} \\
\text { Nível A }\end{array}$ & $\begin{array}{c}3^{\mathrm{a}} \\
\text { Nível A }\end{array}$ \\
\hline 3 & $+30 \%$ & $\boldsymbol{E}_{50}$ & $\gamma_{\text {nat }}, \mathrm{v}$ & $\boldsymbol{R}_{\text {inter }}$ \\
\hline 5 & $+30 \%$ & $\gamma_{\text {nat }}$ & $\boldsymbol{K o}$ & $\boldsymbol{E}_{50}$ \\
\hline 8 & $+30 \%$ & $\gamma_{\text {nat }}$ & $\boldsymbol{K o}$ & $\boldsymbol{E}_{50}$ \\
\hline $\begin{array}{l}\text { Parâmetro de maior } \\
\text { Influência }\end{array}$ & $\gamma_{\text {nat }}$ & $\boldsymbol{K o}$ & $\boldsymbol{E}_{50}$ \\
\hline
\end{tabular}

Em relação à variação da força no nível $\mathrm{A}$, para o estágio $3, E_{50}$ teve a maior influência, nos estágio 5 e $8, \gamma_{\text {nat }}$, Ko e $E_{50}$ influenciaram mais.

Análises paramétricas conduzidas por FUJII (1976) que estudou o escoramento de vala junto ao Palácio Monroe e assumiu a hipótese de parede rugosa sem deslizamento relativo com o solo da interface, demonstraram que a rigidez da parede teve pouca influência na variação das forças nas estroncas, bem como v, porém quando o valor se aproxima de $v=0.5$ passa a ter grande influência. Já o parâmetro $E_{50}$ teve grande influência na variação das forças.

Portanto, em virtude de $E_{50}$ ser o parâmetro que mais variou em relação aos resultados de ensaios de laboratório, que constam da Tabela 3-1 a Tabela 3-2, e de ter grande influência na análise paramétrica, e de ser correlato a $E_{50}$, então $E_{50}$ foi adotado como parâmetro a ser retroanalisado.

Os valores de coesão também tiveram grande variação nos ensaios de laboratório, desta forma foram consideradas nas retroanálises simulações com combinações envolvendo intervalos de valores de coesão.

Apesar de $\gamma n a t, v$, Ko e $R_{\text {inter }}$ terem grande peso nas variações de deslocamentos de paramento, em amostras de um mesmo solo em laboratório as variações são pequenas para $\vee$ e $\gamma$ nat. 
Para os valores de $K o$ há uma variação em função da razão de sobreadensamento, de acordo com MASSAD (1978), como pode ser visto na Figura 3-32.

Portanto, estabeleceu-se que os intervalos de parâmetros a abranger nas retroanálises seriam:

- $K o$ utilizar combinações de $K o=0,45 ; 0,73$ e 1,13, valores que foram obtidos por MASSAD (1978), que os apresentou na Figura 3-32, para o local da seção experimental $n^{0} .1$.

- Coesão de 10, 20 e $30 \mathrm{kPa}$ (valores aproximados da Tabela 2-3)

- $R_{\text {inter }}=0,5$ de acordo com o sugerido para a interface argila-aço pela publicação da ASCE (1996).

Quanto aos demais parâmetros utilizaram-se os valores de referência inicial 2 para $\phi=28^{\circ}, \gamma_{n a t}=15 \mathrm{kN} / \mathrm{m}^{3}, E_{50}=100 \mathrm{MPa}, \nu=0.35$, que estão contidos nos intervalos de resultados apresentados na Tabela $2-3$ e na Tabela $2-4$, e o valor de $v=0.35$ foi adotado como a média entre os valores $v=0.30$ (limite superior para argila não saturada) $\mathrm{e}$ $v=0.40$ (limite inferior para argila saturada) sugeridos por TEIXEIRA, A. H. E. ; GODOY, N. S. (1996). 


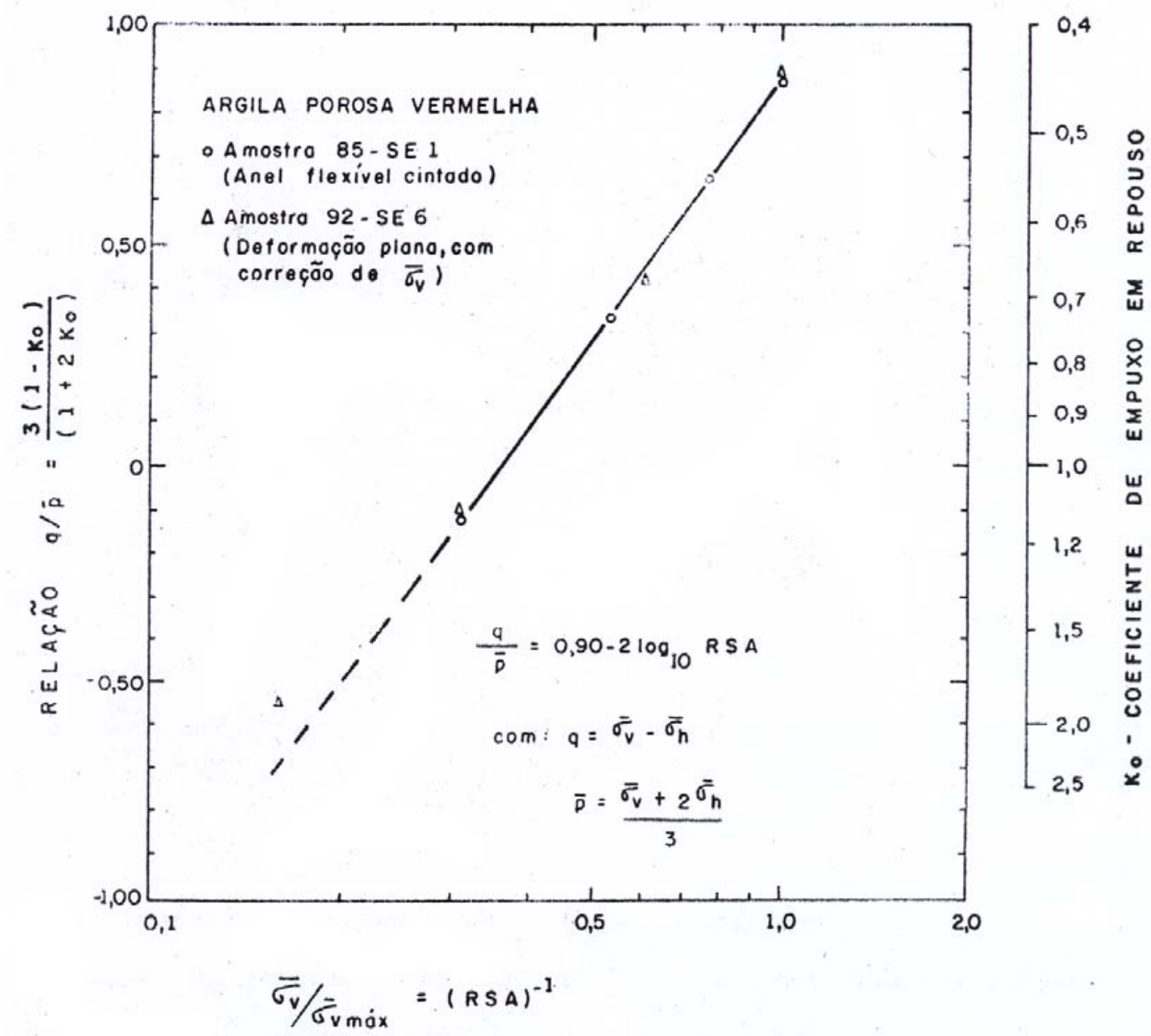

Figura 3-32-Coeficiente de Empuxo em Repouso (Ko) para S.E.1 (MASSAD, 1978)

\section{6 -Segunda Etapa - Modelo de Endurecimento de solo}

Para os solos descritos pelo boletim de sondagem No B162 de 26/04/1971 (Figura 2-6), adotou-se o modelo elasto-plástico de Mohr-Coulomb para a primeira etapa de estudos através de simulações utilizando-se o software PLAXIS (1998) bidimensional.

A partir dos estudos realizados e apresentados nos itens 4.4 a 4.6, percebeu-se que a adoção do modelo de Mohr-Coulomb, não conduziu a resultados satisfatórios quanto à representação do comportamento do sistema solo-estrutura nos avanços de escavações. 
O uso de um modelo reológico adequado traz grande contribuição para a correta previsão das deformações e por conseqüência melhor previsão de danos causados a edificações oriundos das deformações no solo.

Com a finalidade de caracterizar a origem, constituição e o comportamento geotécnico da argila porosa vermelha e da argila variegada, dos sedimentos terciários da bacia de São Paulo, encontrados na região do túnel Paraíso do Metrô S.P., PARREIRA (1991) conduziu uma série de ensaios de laboratório. A partir de ensaios triaxiais convencionais e de compressão isotrópica aquele autor calibrou o modelo elastoplástico de Lade. Com a utilização deste modelo, obteve resultados satisfatórios ao reproduzir as trajetórias de tensão em ensaios de extensão.

Posteriormente, conduziu um estudo em elementos finitos para simular o comportamento do sistema solo-túnel durante as escavações, tendo obtido melhor aproximação à instrumentação de campo ao utilizar o modelo elasto-plástico em comparação aos resultados obtidos pelos modelos elástico-linear e elástico perfeitamente plástico. Devido aos parâmetros necessários para a utilização deste modelo e a necessidade de sua implementação optou-se por buscar outro modelo que atendesse tanto aos parâmetros disponíveis e já estivesse implementado no software PLAXIS.

Em PLAXIS (1998) apresenta-se uma série de resultados de ensaios triaxiais drenados (Figura 3-34) e ensaios oedométricos (Figura 3-33) realizados em areias de Houston e os ótimos ajustes obtidos via simulação destes ensaios. O modelo utilizado foi elementos finitos axissimétrico com o modelo constitutivo de Endurecimento de solo (HS). Apesar dos ensaios apresentados terem utilizado areias e os solos de estudo desta dissertação serem argilas, ficou muito clara a vocação do modelo de Endurecimento em representar o aumento de rigidez com os ciclos de carregamento-descarregamentorecarregamento. 


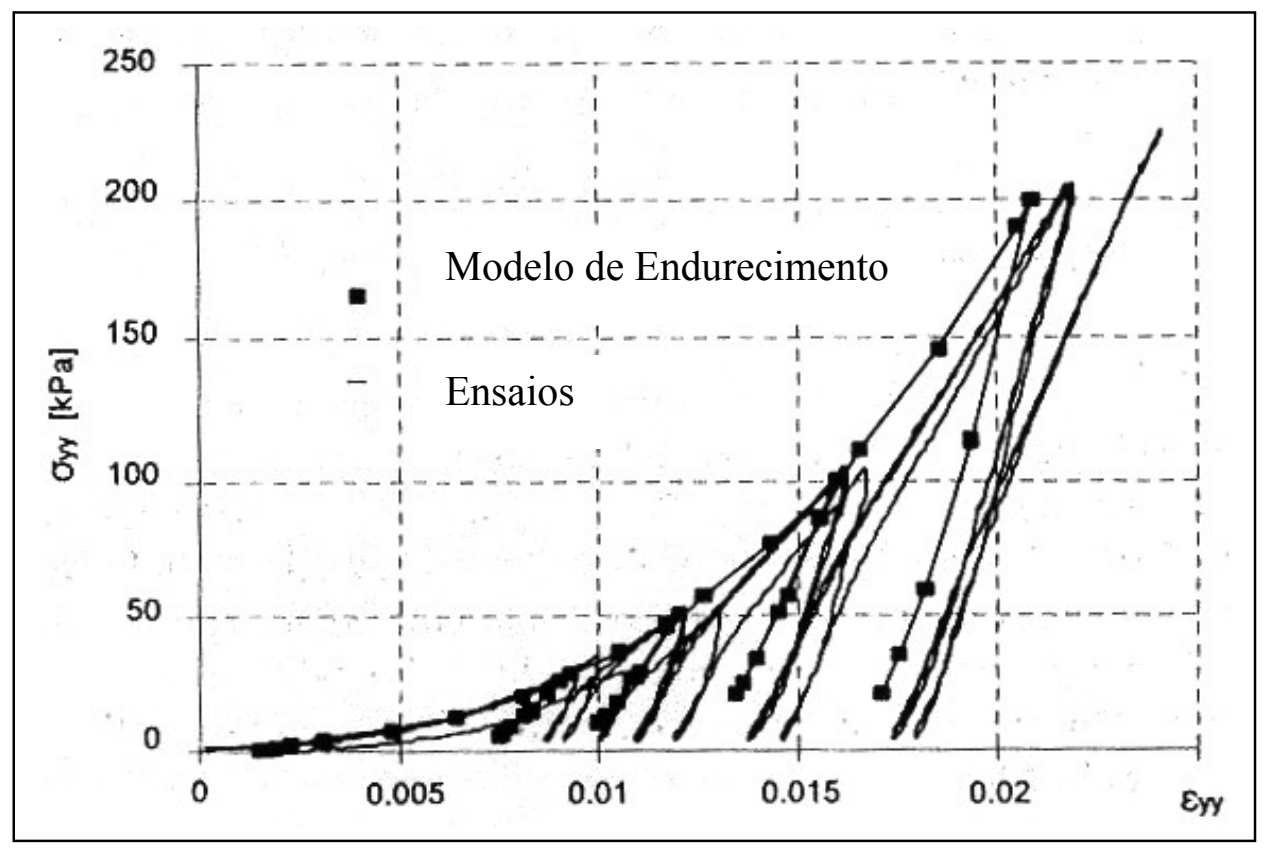

Figura 3-33- Valores obtidos de ensaios oedométricos em areia de Huston e os de simulação utilizando-se o modelo de Endurecimento de solo (PLAXIS,1998)

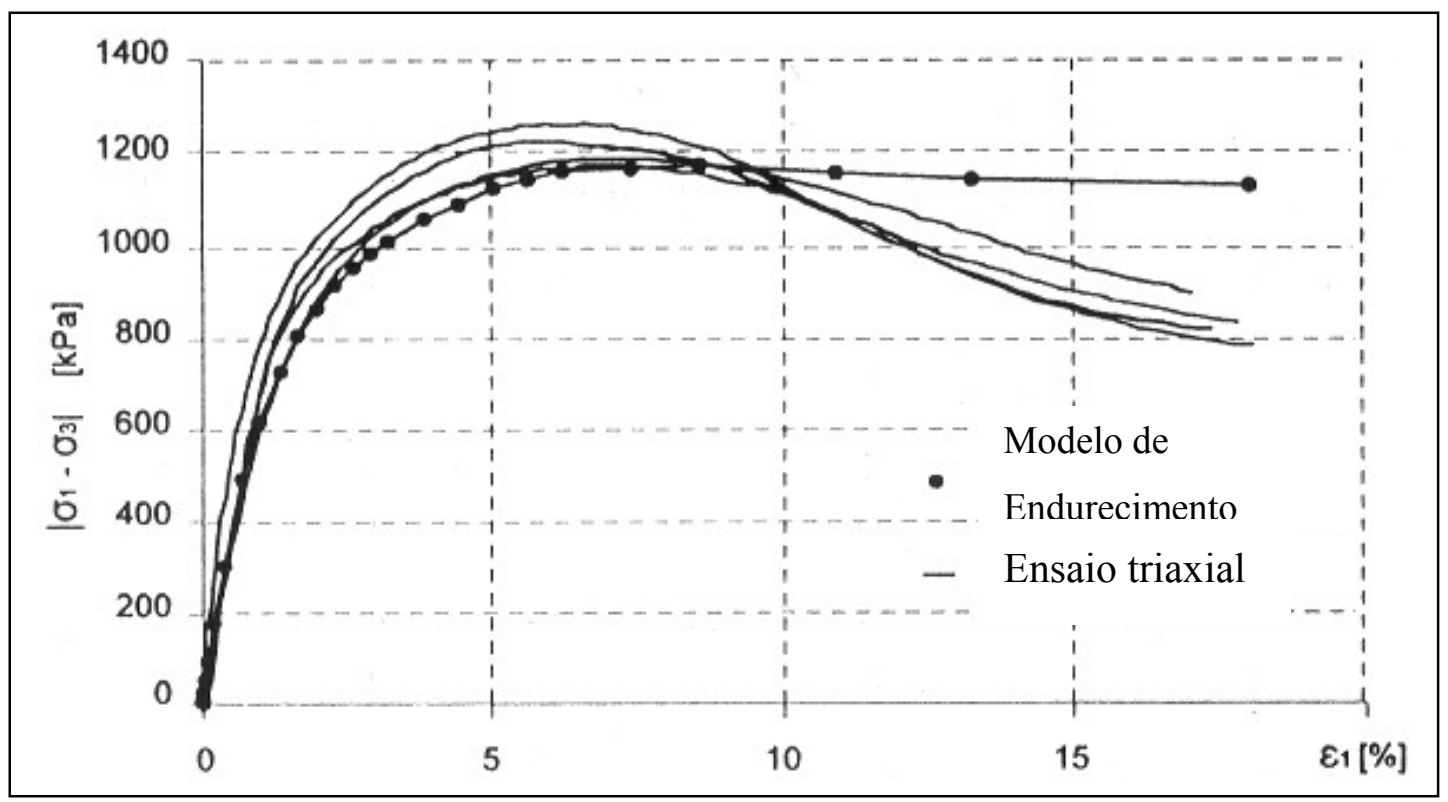

Figura 3-34- Valores obtidos de ensaios triaxiais em areia de Huston e os de simulação utilizando-se o modelo de Endurecimento de solo (PLAXIS,1998)

Desta forma, resolveu-se utilizar o modelo constitutivo de Endurecimento disponível no software PLAXIS. 
Os parâmetros de resistência e deformabilidade adotados foram baseados em ensaios de laboratório realizados por IPT (1972) e MASSAD (1992).

Estabeleceu-se nesta etapa de estudos que também seria adotada a resistência à tração nula dos solos argilosos.

\section{7 - Descrição do modelo de Endurecimento de Solo (HS)}

De acordo com PLAXIS (1998), o modelo de Endurecimento foi proposto por SCHANZ (2000). Este modelo de Endurecimento com a plasticidade tem sua superfície de plastificação não fixada ao espaço de tensões principais, mas pode expandir-se devido a deformações plásticas.

Podem ser feitas distinções entre dois tipos de endurecimento, definidos como endurecimento por cisalhamento e endurecimento por compressão. $\mathrm{O}$ endurecimento por cisalhamento é utilizado para um modelo onde ocorram deformações irreversíveis devido ao carregamento desviatório primário. O endurecimento por compressão é utilizado para deformações plásticas irreversíveis devido à compressão primária no carregamento oedométrico e no carregamento isotrópico e, pode representar, por exemplo, o colapso de solos porosos. Ambos os tipos de endurecimento estão contidos no modelo de endurecimento. Este modelo é considerado avançado para simular o comportamento de diferentes tipos de solo, tanto solos moles como solos rijos, SCHANZ (1998) apud PLAXIS (1998). Quando sujeito ao carregamento desviatório primário, o solo mostra um decréscimo de rigidez e simultaneamente desenvolve deformações plásticas permanentes.

Antes de detalhar o modelo de Endurecimento cabe ressaltar que :

- Se em um material o comportamento não é afetado pela orientação então este material é conhecido como isotrópico.

- Se um material é inicialmente isotrópico ele pode vir a tornar-se anisotrópico durante o processo de deformação, neste caso o comportamento do material sendo anisotrópico é dependente da orientação das tensões.

- Se em um material não ocorre o fenômeno de endurecimento então ele é chamado de perfeitamente plástico.

- Se ocorrer endurecimento o material é considerado plástico com endurecimento. 
Em DESAI \& SIRIWARDANE (1984) enfatiza-se que muitos materiais de engenharia apresentam endurecimento durante as deformações plásticas. $O$ endurecimento destes materiais é descrito utilizando-se critérios que diferenciam se o endurecimento do material ocorre de forma isotrópica ou anisotrópica. Os mesmos autores citam que materiais inicialmente isotrópicos podem exibir anisotropia associada à ocorrência do endurecimento.

No caso especial do ensaio triaxial drenado, observou-se que a relação entre tensões desviatórias e deformações axiais podem ser aproximadas por uma hipérbole. Esta relação foi formulada por KONDNER (1963) e mais tarde utilizada como o conhecido modelo hiperbólico de DUNCAN \& CHANG (1970).

O modelo de Endurecimento difere do modelo hiperbólico, por usar a teoria da plasticidade ao invés da teoria da elasticidade com parâmetros variáveis em diferentes intervalos de deformação, por incluir a dilatância do solo e por introduzir uma "tampa" ou "chapéu" na superfície de plastificação. Na Figura 3-35 apresenta-se a superfície de plastificação do modelo de Endurecimento.

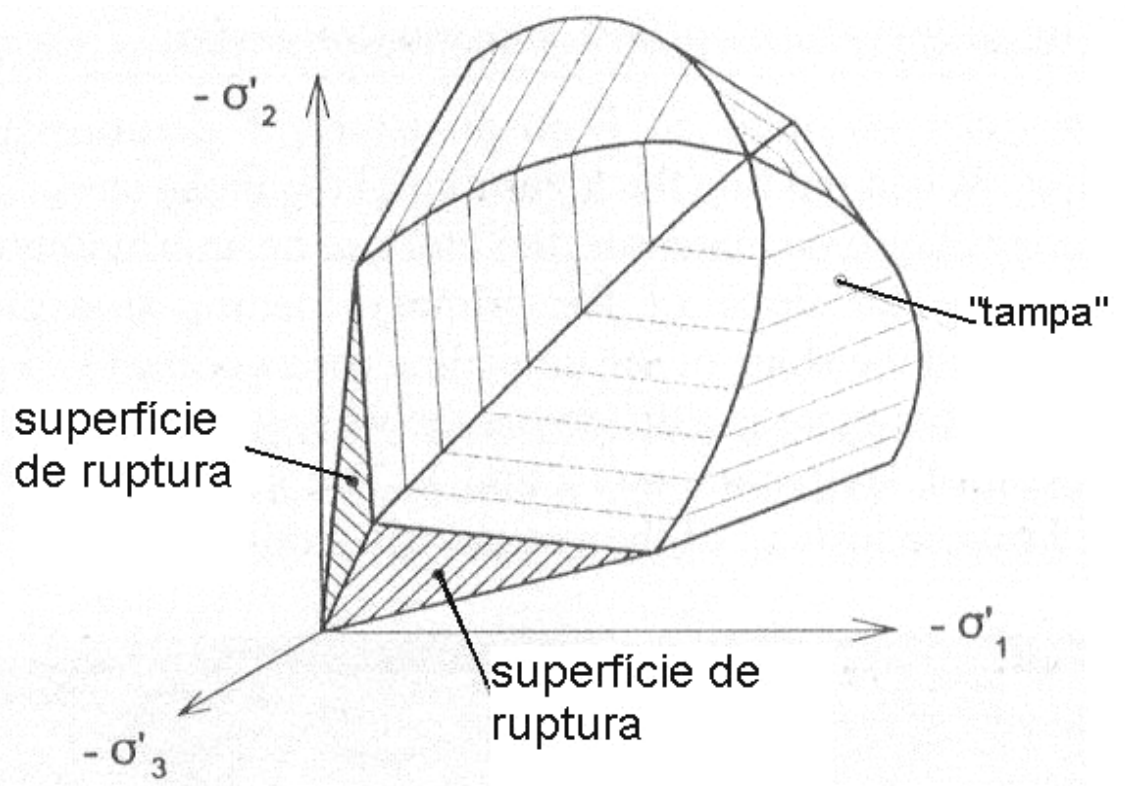

Figura 3-35 - Representação da superfície de plastificação do modelo de Endurecimento no espaço das tensões principais para um solo não coesivo 
Com relação ao ensaio triaxial drenado, o modelo de Endurecimento proposto por SCHANZ (2000), tem como idéia básica de suas equações constitutivas, que há no carregamento desviatório primário uma relação hiperbólica entre deformação vertical $\left(\varepsilon_{1}\right)$ e a tensão desviatória $(q)$.

As curvas de plastificação do modelo de Endurecimento são descritas pelas equações (3.17) e (3.18):

$$
\begin{aligned}
& \varepsilon_{1}=\frac{q_{a}}{2 * E_{50}} *\left(\frac{\sigma_{1}-\sigma_{3}}{q_{a}-\left(\sigma_{1}-\sigma_{3}\right)}\right) \text { para } \mathbf{q}<\mathbf{q f} \\
& q_{f}=\left(\frac{6^{*} \operatorname{sen} \phi_{p}}{3-\operatorname{sen} \phi_{p}}\right) *\left(p^{r e f}+c^{*} \cot \phi_{p}\right)
\end{aligned}
$$

Sendo:

- $q_{\mathrm{a}}=$ tensão correspondente à assintota (Figura 3-36)

- $q_{f}=$ tensão de ruptura

- $\phi_{p}=$ ângulo de atrito na ruptura

- $\quad p^{r e f}=$ pressão de referência para ensaios triaxiais sendo:

$$
\begin{aligned}
& \sigma_{3}=0 \rightarrow p^{r e f}=100 \mathrm{kPa}(\cong 1 \text { atmosfera }) \\
& \sigma_{3} \neq 0 \rightarrow p^{r e f}=\sigma_{3} \text { do ensaio que esta sendo calibrada a curva em } \mathrm{kPa}
\end{aligned}
$$

deve-se ressaltar que para simulações da seção experimental utilizou-se os valores de $p^{r e f}=\sigma_{3}$, para o centro de cada camada, ou seja $\sigma_{3}=K o * \sigma_{v}$

Para a tensão de ruptura $(q f)$ o modelo deriva do critério de ruptura de MohrCoulomb, o qual envolve os parâmetros de resistência $c, \phi_{p}$ sendo que quando ocorre $q=q_{f}$ ocorrem deformações perfeitamente plásticas. A razão entre a tensão de ruptura $\left(q_{f}\right)$ e a tensão correspondente à assintota $\left(q_{a}\right)$ é conhecida como razão de ruptura $R f=\left(\mathrm{q}_{\mathrm{a}} / \mathrm{q}_{\mathrm{f}}\right)$, sendo que SCHANZ (2000) sugere um valor de 0,9 , que obviamente deve ser estudado caso a caso, pois sabe-se que dependendo do tipo de solo estudado e da tensão confinante aplicada, muda a forma da curva e consequentemente as relações entre $q_{a}$ e $q_{f}$ podem ser muito diferentes. 
O comportamento tensão deformação para o carregamento desviatório primário é não linear.

O módulo ( $\left.E_{50}\right)$ (Figura 3-36) para o carregamento desviatório primário utilizado pelo modelo de Endurecimento é dada pela equação (3.19)

$$
E_{50}=E_{50}^{r e f} *\left(\frac{\sigma_{3}+c * \cot \phi_{p}}{p^{r e f}+c * \cot \phi_{p}}\right)^{m}
$$

Notar que $E_{50}$ não depende somente de $E_{i}$, mas é função de $c, \sigma_{3}, \cot \phi_{p}, E_{50}{ }^{r e f}, m$.

Sendo :

$E_{50}=$ módulo de rigidez dependente da tensão para o carregamento primário

$E_{50}{ }^{r e f}=$ módulo de rigidez correspondente a pressão de referência $p^{r e f}$

$\sigma_{3}=$ tensão confinante

$c=$ coesão

$p^{r e f}=$ pressão de referência

$m=$ parâmetro exponencial que relaciona tensão e rigidez, ou seja há dependência da tensão

O parâmetro $m$ tem sua faixa de valores de 0 a 1 , há diversas posições a este respeito, de acordo com PLAXIS (1998) alguns valores propostos foram:

- $m=0,5$ para areias e siltes da Noruega, JANBU (1963)

- $m=0,5$ a 1, VON SOOS (1980)

- $m=1$ argilas moles sugerido pelo manual do PLAXIS (2002)

Deve-se ressaltar que para a argila porosa da seção experimental em estudo, fezse a calibração do modelo de endurecimento (item 3.8) e os melhores ajustes às curvas de laboratório foram obtidas para valores de $m=0,1$. (Figura 3-40 à Figura 3-43). 


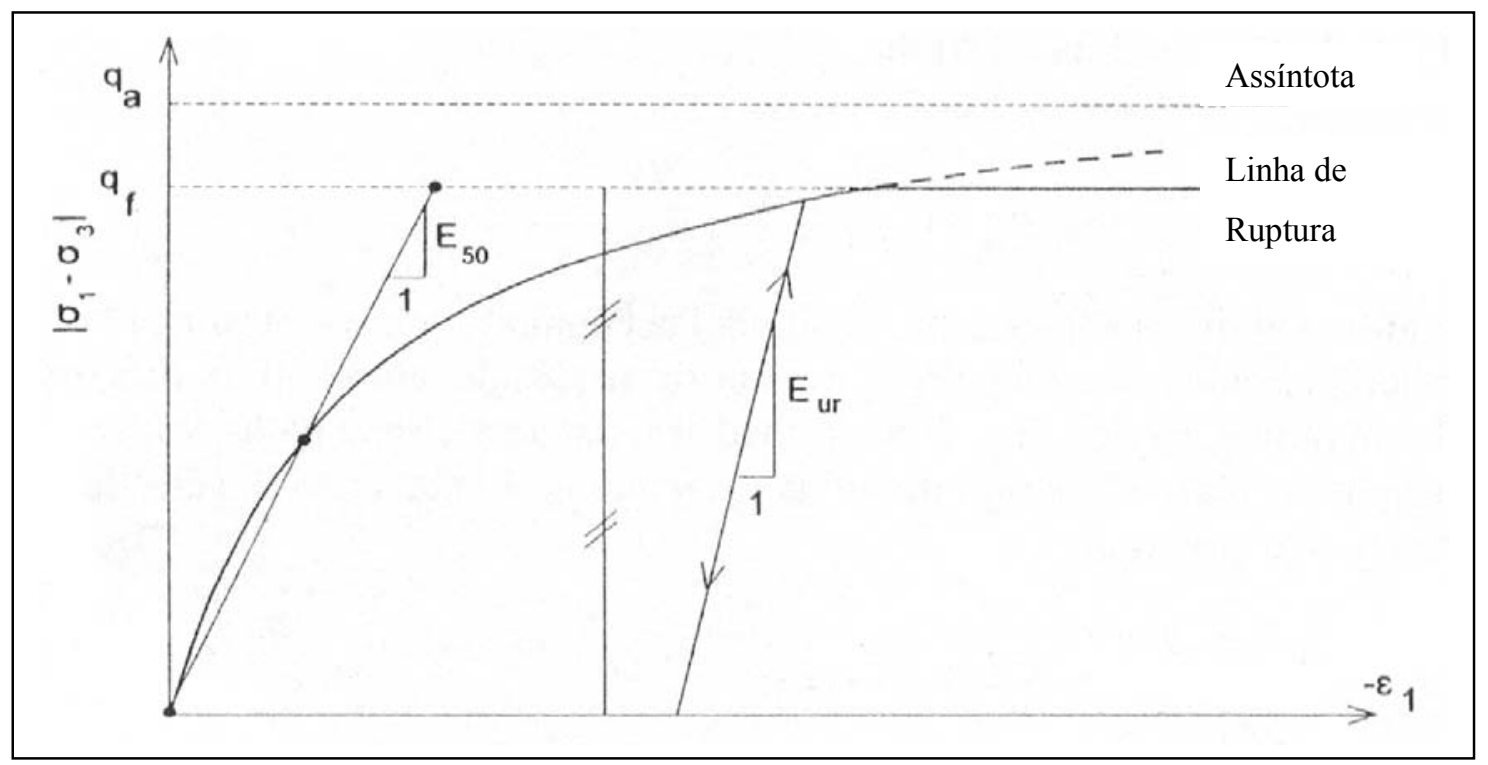

Figura 3-36--Relação dos módulos $E_{50}$ e $E_{u r}$ com as tensões desviatórias e as deformações axiais em ensaio triaxial (PLAXIS,2002).

O módulo de carregamento-descarregamento $\left(E_{u r}\right)$ que é relacionado às trajetórias de carregamento e descarregamento pode ser visto na Figura 3-36, tem relação com as tensões é dado pela equação (3.20) :

$$
E_{u r}=E_{u r}^{r e f} *\left(\frac{\sigma_{3}+c^{*} \cot \phi_{p}}{p^{r e f}+c^{*} \cot \phi_{p}}\right)^{m}
$$

Sendo :

$E_{u r}^{r e f}$ é o módulo de Young de referência para recarregamento e descarregamento, correspondente à pressão de referência $p^{r e f}$.

No software PLAXIS (2002) o valor default de $E u r^{r e f}=3 * E_{50}{ }^{r e f}$, porém considerou-se que este valor é elevado para a seção experimental em estudo, pois MASSAD (1992) cita que "...para incrementos de tensão variando na faixa de 10 a $30 \mathrm{kPa}$, obteve-se um módulo de recarga de 1,2 a 2 vezes o valor do módulo secante.”. Portanto, utilizou-se para as simulações a mínima relação de $E_{u r}{ }^{r e f} \operatorname{com} E_{50}{ }^{r e f}$ permitida pelo software que é dado pela equação (3.21). Já o valor máximo permitido pelo referido software pode ser visto na equação (3.22) : 


$$
E_{u r}^{r e f}=2 * E_{50}^{r e f} \text {. }
$$

$$
E_{u r}^{r e f}=2 * E_{50}^{r e f} \text {. }
$$

O módulo cisalhante transversal do modelo de Endurecimento é dado pela equação (3.23)

$$
G_{u r}=\left(\frac{1}{2 *\left(1+v_{u r}\right)} * E_{u r}\right)
$$

Sendo:

$\mathrm{G}_{\mathrm{ur}}=$ módulo cisalhante transversal na trajetória de carregamento/descarregamento

O termo $v_{u r}$ é o coeficiente de Poisson para carregamento/descarregamento, seu valor utilziado nesta dissertação é $v_{u r}=0,2$ de acordo com PARREIRA (1991).

Para as trajetórias de tensão do ensaio triaxial com $\sigma_{2}=\sigma_{3}=$ constante, o módulo $E_{u r}$ torna-se constante e as deformações são representadas pelas equações (3.24 e 3.25)

$$
\begin{aligned}
& \varepsilon_{1}^{e}=\frac{q}{E_{u r}} \\
& \varepsilon_{2}^{e}=\varepsilon_{3}^{e}=\nu_{u r} * \frac{q}{E_{u r}}
\end{aligned}
$$

Sendo:

$\varepsilon_{1}^{e}=$ deformação axial

$\varepsilon_{2}{ }^{\mathrm{e}}=$ deformação principal na direção 2

$\varepsilon_{3}{ }^{\mathrm{e}}=$ deformação principal na direção 3 
Ao invés de utilizar modelo de rigidez única de Hooke (elasticidade linear) combinado ao de plasticidade ideal de Mohr-Coulomb, o modelo de Endurecimento utiliza uma nova formulação através de um modelo de rigidez dupla para elasticidade em combinação com às deformações isotrópicas com endurecimento.

Em contraste com os modelos baseados em modelos de elasticidade, o modelo de Endurecimento não envolve uma relação fixa entre a rigidez do ensaio triaxial drenado $E_{50}$ e o módulo do ensaio oedométrico $E_{\text {oed }}$. Este módulo é obtido independentemente através da equação (3.26):

$$
E_{\text {oed }}=E_{\text {oed }}^{r e f} *\left(\frac{\sigma_{3}+c * \cot \phi_{p}}{p^{r e f}+c * \cot \phi_{p}}\right)^{m}
$$

Sendo:

$E_{\text {oed }} \cdot{ }^{r e f}=$ obtido da rigidez tangente a tensão vertical $\sigma_{1}$ no gráfico do ensaio edométrico (Figura 3-37).

$P^{r e f}=$ diferentemente do considerado em $E_{u r}$ e $E_{50}$ a pressão de referência é um valor escolhido da tensão vertical $\sigma_{1}$ que deverá ser maior que $\sigma_{3}$.

A Figura 3-37 ilustra o exposto.

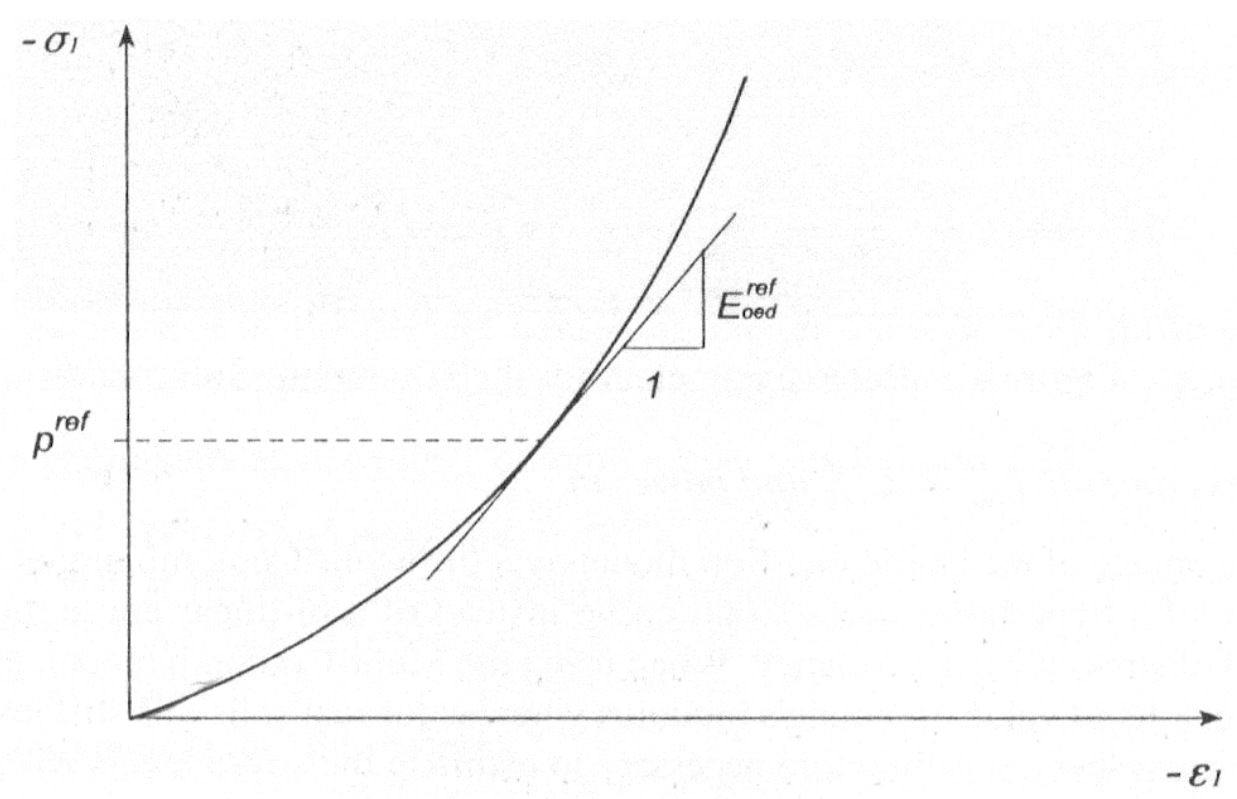

Figura 3-37-Critério para obtenção de $E_{\text {oed }}{ }^{\text {ref }}$ a partir do ensaio oedométrico (PLAXIS, 2002) 
Superfície de plastificação

Para o caso triaxial duas funções de plastificação(3.27 e 3.28) são definidas :

$$
\begin{aligned}
& f_{12}=\frac{q_{a}}{E_{50}} * \frac{\left(\sigma_{1}-\sigma_{2}\right)}{q_{a}-\left(\sigma_{1}-\sigma_{2}\right)}-\frac{2 *\left(\sigma_{1}-\sigma_{2}\right)}{E_{u r}}-\gamma^{p} \\
& f_{13}=\frac{q_{a}}{E_{50}} * \frac{\left(\sigma_{1}-\sigma_{3}\right)}{q_{a}-\left(\sigma_{1}-\sigma_{3}\right)}-2 * \frac{2 *\left(\sigma_{1}-\sigma_{3}\right)}{E_{u r}}-\gamma^{p}
\end{aligned}
$$

Sendo :

- $q_{\mathrm{a}}=$ tensão correspondente à assintota (Figura 3-36)

- $q_{f}=$ tensão de ruptura

- $\phi_{p}=$ ângulo de atrito na ruptura

- $\gamma^{p}=$ deformação plástica por cisalhamento (equação (3.29))

- $\sigma_{1}=$ tensão vertical do ensaio

- $\sigma_{2}=$ tensão principal na direção 2

- $\sigma_{3}=$ tensão principal na direção 3

$$
\gamma^{p}=\varepsilon_{1}^{p}-\varepsilon_{2}^{p}-\varepsilon_{3}^{p}=2 * \varepsilon_{1}^{p}-\varepsilon_{1}^{v} \approx 2 * \varepsilon_{1}^{p}
$$

$\varepsilon_{v}^{p}=$ deformação plástica volumétrica

$\varepsilon_{1}^{p}=$ a deformação axial

A medida de deformação plástica por cisalhamento dada pela equação (3.29) é um parâmetro muito importante para o endurecimento por atrito. Note-se que a deformação plástica volumétrica $\left(\varepsilon_{v}^{p}\right)$ nunca será igual a zero, porém para solos rijos e 
duros esta mudança de volume tende a ser pequena quando comparada com a deformação axial $\left(\varepsilon_{1}^{p}\right)$, de tal forma que a aproximação dada pela equação (3.29) é geralmente precisa.

Segundo SCHANZ(1999) para um dado valor constante do parâmetro de endurecimento, $\gamma^{p}$, a condição de plastificação $f_{12}=f_{13}=0$ pode ser visualizada no plano p'-q, através das curvas de plastificação, que são apresentadas na Figura 3-38 utilizando-se as equações (3.19) e (3.20) para $E_{50}$ e $E_{u r}$ respectivamente. Há forte dependência destas equações $\left(E_{50}\right.$ e $\left.E_{u r}\right)$ do valor do expoente $m$. Para $m=1,0$ obtêm-se um segmento de reta, todos os outros segmentos (levemente curvos) foram obtidos para o valor de $\mathrm{m}=0,5$ que SCHANZ (2000) afirma ser típico de solos rijos.

Na Figura 3-38 o eixo x representa as tensões efetivas normais e o eixo y representa as tensões cisalhantes no plano de máxima tensão cisalhante.

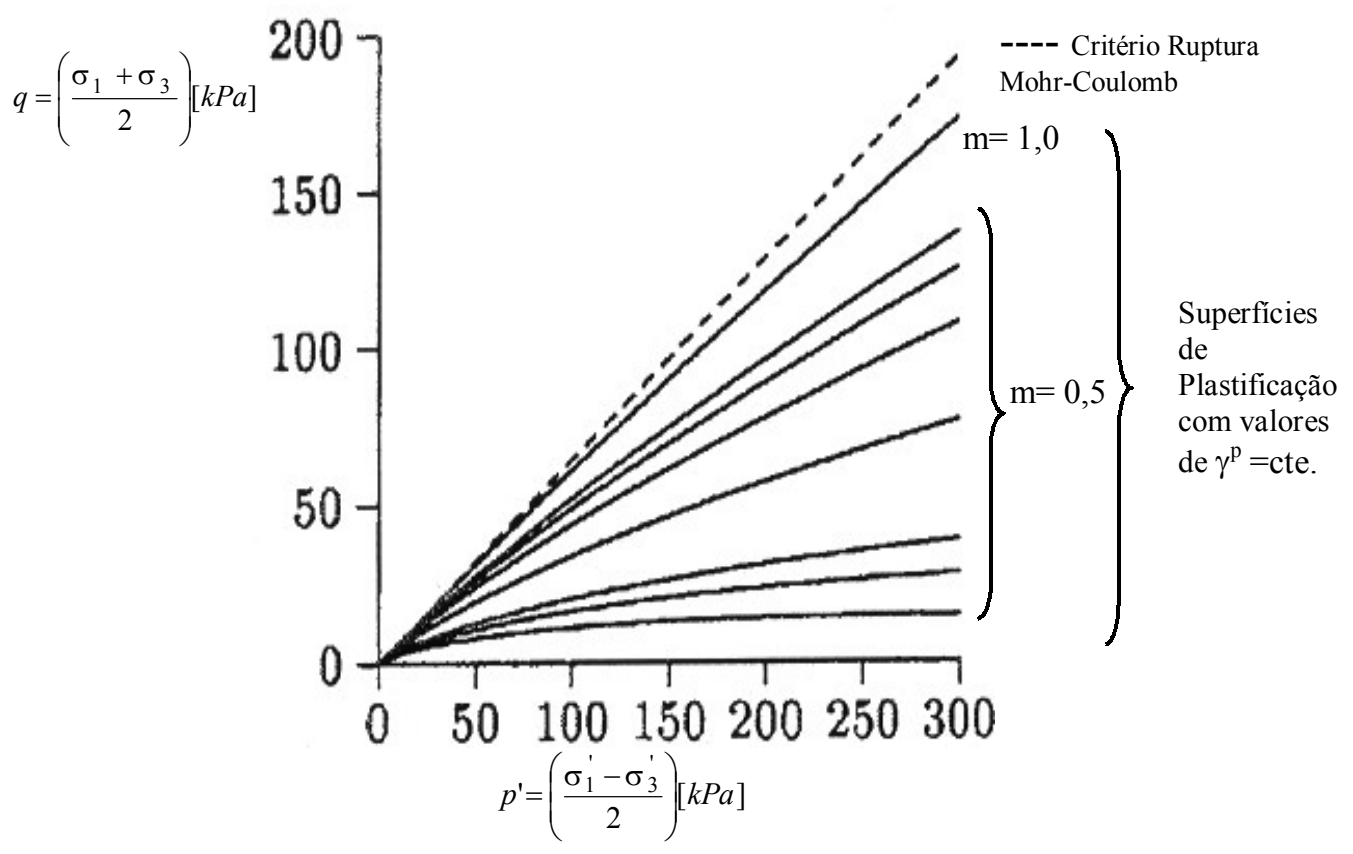

Figura 3-38-Curvas de plastificação do modelo de Endurecimento para diferentes valores de $m$ (SCHANZ,1999) 


\section{Lei de Fluxo Plástico e funções de potenciais plásticos}

O modelo de Endurecimento envolve relações entre as derivadas da deformação plástica por cisalhamento, e da deformação volumétrica.

Estas são representadas respectivamente por :

$\dot{\gamma}^{p} \quad \dot{\varepsilon}_{v}^{p}$ e estão relacionadas nas equações (3.30) e (3.31), fazem parte da teoria de tensão de dilatância de ROWE (1962), SCHANZ (2000) pela lei de fluxo.

$$
\dot{\varepsilon}_{v}^{p}=\operatorname{sen} \psi_{m} *^{p}
$$

$\psi_{m}=$ ângulo de dilatância mobilizado

$$
\operatorname{sen} \psi_{m}=\frac{\operatorname{sen} \phi_{m}-\operatorname{sen} \phi_{c v}}{1-\operatorname{sen} \phi_{m} * \operatorname{sen} \phi_{c v}}
$$

Sendo:

$\phi_{m}=$ ângulo de atrito mobilizado

$\phi_{c v}=$ ângulo de atrito no estado crítico sendo constante e independente do peso específico

A equação (3.32) relaciona as tensões as tensões $\sigma_{1}$ e $\sigma_{3}$ com a cotangente do ângulo de atrito na ruptura $\left(\phi_{p}\right)$ para obter o seno do ângulo de atrito mobilizado $\left(\phi_{m}\right)$.

$$
\operatorname{sen} \phi_{m}=\frac{\left(\sigma_{1}-\sigma_{3}\right)}{\left(\sigma_{1}+\sigma_{3}-2 * c^{*} \cot \phi_{p}\right)}
$$

Na ruptura quando o ângulo de atrito mobilizado $\left(\phi_{m}\right)$ torna-se o ângulo de atrito na ruptura $\left(\phi_{p}\right)$ utilizando-se a equação (3.33) obtém-se o seno do ângulo de dilatância no estado crítico. 


$$
\operatorname{sen} \psi_{c v}=\frac{\operatorname{sen} \phi_{p}-\operatorname{sen} \psi_{p}}{1-\operatorname{sen} \phi_{P} * \operatorname{sen} \psi_{P}}
$$

$\psi_{c v=}$ ângulo de dilatância no estado crítico

Portanto o ângulo $\psi_{c v}$ pode ser calculado através dos ângulos na ruptura, $\phi_{p}$ e $\psi_{p}$. As funções de potencial plástico são calculadas através das equações (3.34 e 3.35):

$$
\begin{aligned}
& g_{12}=\frac{\left(\sigma_{1}-\sigma_{2}\right)}{2}-\frac{\left(\sigma_{1}+\sigma_{2}\right)}{2} * \operatorname{sen} \psi_{m} \\
& g_{12}=\frac{\left(\sigma_{1}-\sigma_{3}\right)}{2}-\frac{\left(\sigma_{1}+\sigma_{3}\right)}{2} * \operatorname{sen} \psi_{m}
\end{aligned}
$$

Uma abordagem mais detalhada do modelo de Endurecimento pode ser encontrada em SCHANZ (2000) e PLAXIS (2002).

\section{8 - Calibração do Modelo de Endurecimento}

A calibração dos parâmetros $m, R_{\text {inter }}, p^{r e f}, E_{u r}, E_{50}{ }^{r e f}$, foi obtida a partir dos ensaios triaxiais realizados por PARREIRA (1991), em solos do Poço Experimental Gazeta, representados no perfil de sondagem da Figura 3-39. Este local da avenida Paulista, tem características geotécnicas similares às da seção experimental $\mathrm{n}^{\circ} 1$, objeto deste estudo.

Em seus estudos, PARREIRA (1991) dividiu a argila porosa vermelha em dois níveis de comportamentos distintos, um no nível $808,62 \mathrm{~m}$ e outro no nível $805,62 \mathrm{~m}$. Da mesma forma, para os solos variegados o referido autor fez divisões nos níveis $802,62 \mathrm{~m}$ (início do nível de água) e 799,62m.

Apresentam-se, da Figura 3-40 a Figura 3-43, os resultados da calibração do modelo para estas amostras de solos extraídas. 
$S P-312$

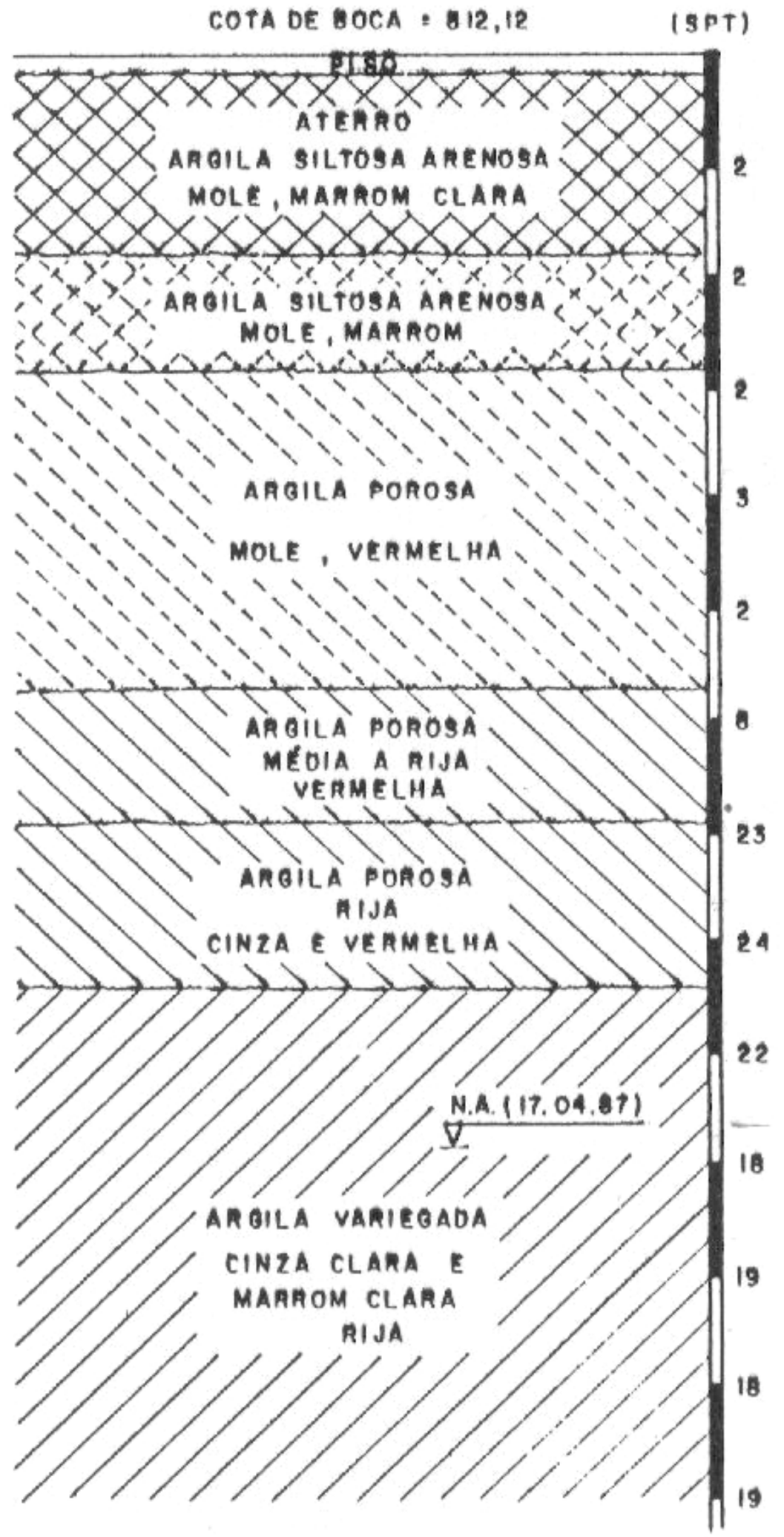

Figura 3-39-Sondagem do poço experimental Gazeta, (PARREIRA, 1991) 
Na seqüência da Figura 3-40 à Figura 3-43 apresentam-se as curvas teóricas calculadas através do modelo de Endurecimento e as curvas experimentais (ensaios triaxiais). As curvas teóricas foram calculadas em função da variação do parâmetro de endurecimento $m$ representada pelos valores $m=0,1 ; 0,3 ; 0,5 ; 0,7 ; 0,9$ e 1,0 .

De acordo com a variação do parâmetro $m$, expoente da relação entre a tensão e a rigidez, pode-se verificar como muda o ajuste das curvas teóricas em relação à curva experimental, para as tensões confinantes, $\sigma_{3}=294,2 \mathrm{kPa}$ e $\sigma_{3}=490,3 \mathrm{kPa}$. para as argilas porosas vermelhas e $\sigma_{3}=784,5 \mathrm{kPa}$ e $\sigma_{3}=470,3 \mathrm{kPa}$, para as argilas rijas variegadas.

Os cálculos das curvas teóricas feitas para a camada de argila porosa vermelha estão representados na Tabela 3-6 e Tabela 3-7 para as tensões confinantes de $\sigma_{3}=294,2 \mathrm{kPa}$ e $\sigma_{3}=490,3 \mathrm{kPa}$. Pode-se observar que apesar dos erros médios terem sido elevados, os menores erros ocorreram para o valor de $m=0,1$.

Pode-se observar da análise da Figura 3-40 à Figura 3-43, que a forma das curvas foi coerente com o ensaios triaxiais para as duas amostras de argilas porosas e fica claro que os melhores ajustes ocorreram com os valores de $m=0,1$. Além disto, mesmo nas curvas de melhor ajuste, as deformações calculadas foram inferiores às obtidas nos ensaios triaxiais. 


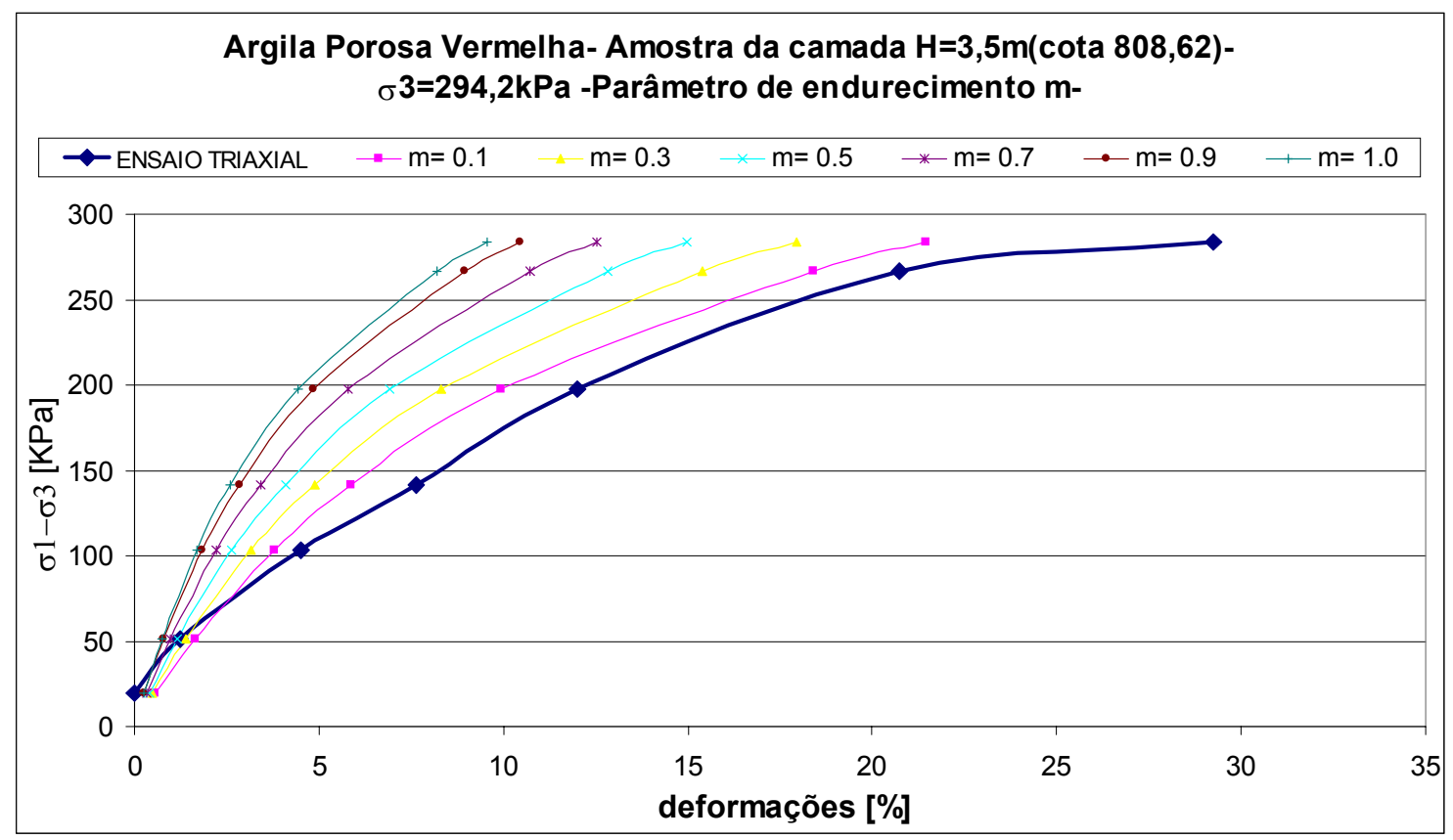

Figura 3-40- Calibração do modelo de Endurecimento via variação do parâmetro $m$ para Argila Porosa Vermelha $\mathrm{h}=\mathbf{3 . 5 m}$

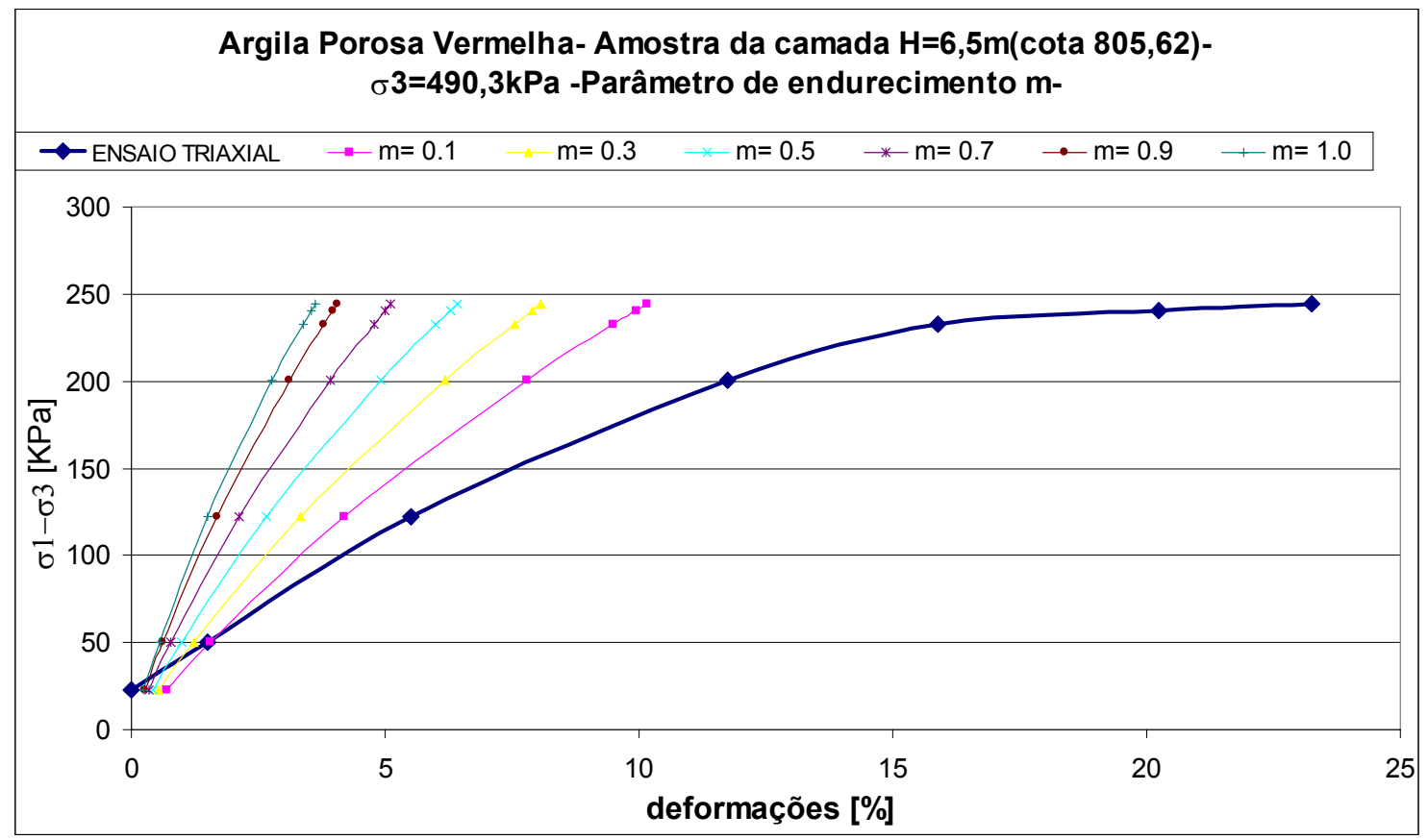

Figura 3-41 - Calibração do modelo de Endurecimento via variação do parâmetro $m$ para Argila Porosa Vermelha $\mathrm{h}=6.5 \mathrm{~m}$ 


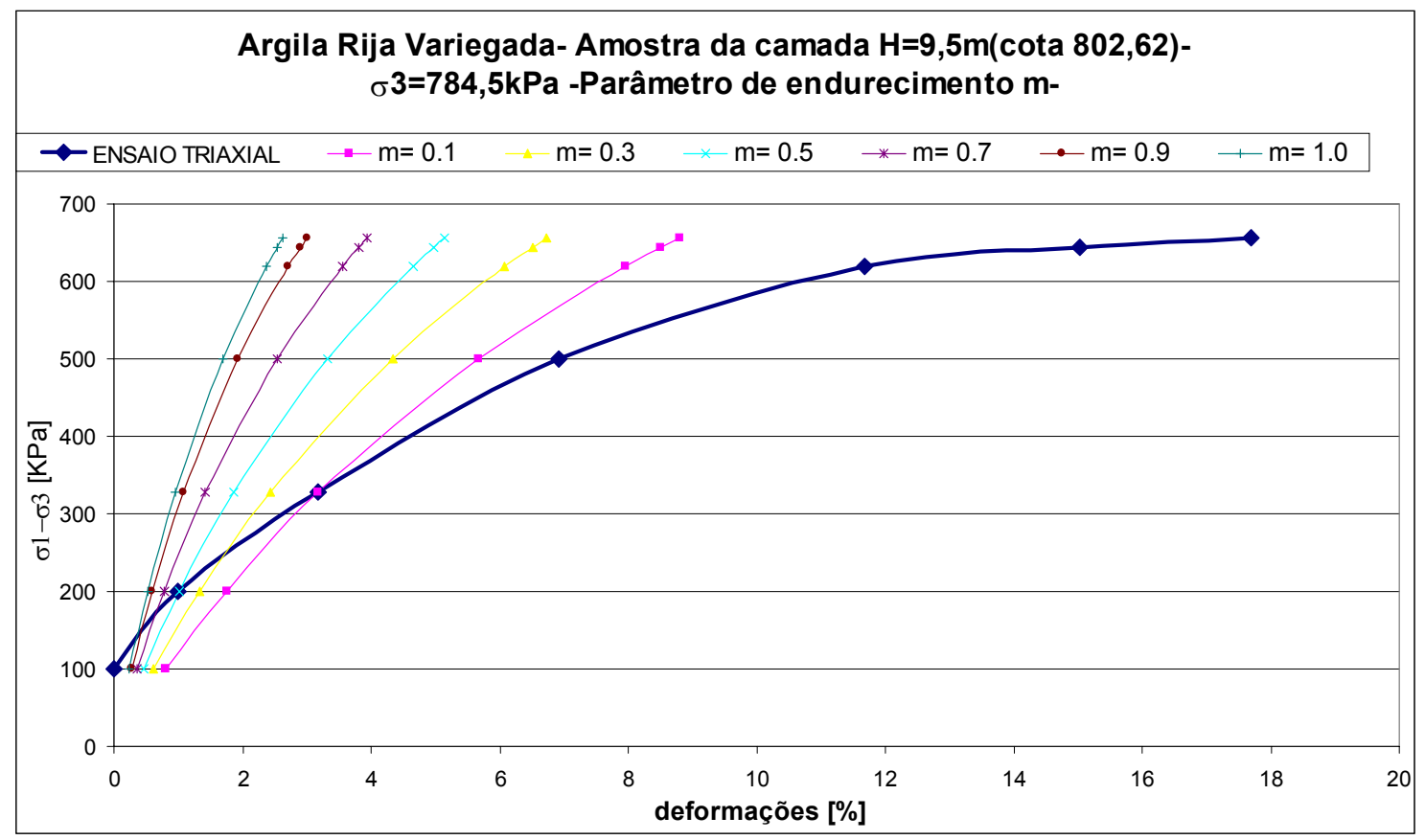

Figura 3-42- Calibração do modelo de Endurecimento via variação do parâmetro $m$ para Argila Rija Variegada $h=9.5 \mathrm{~m}$

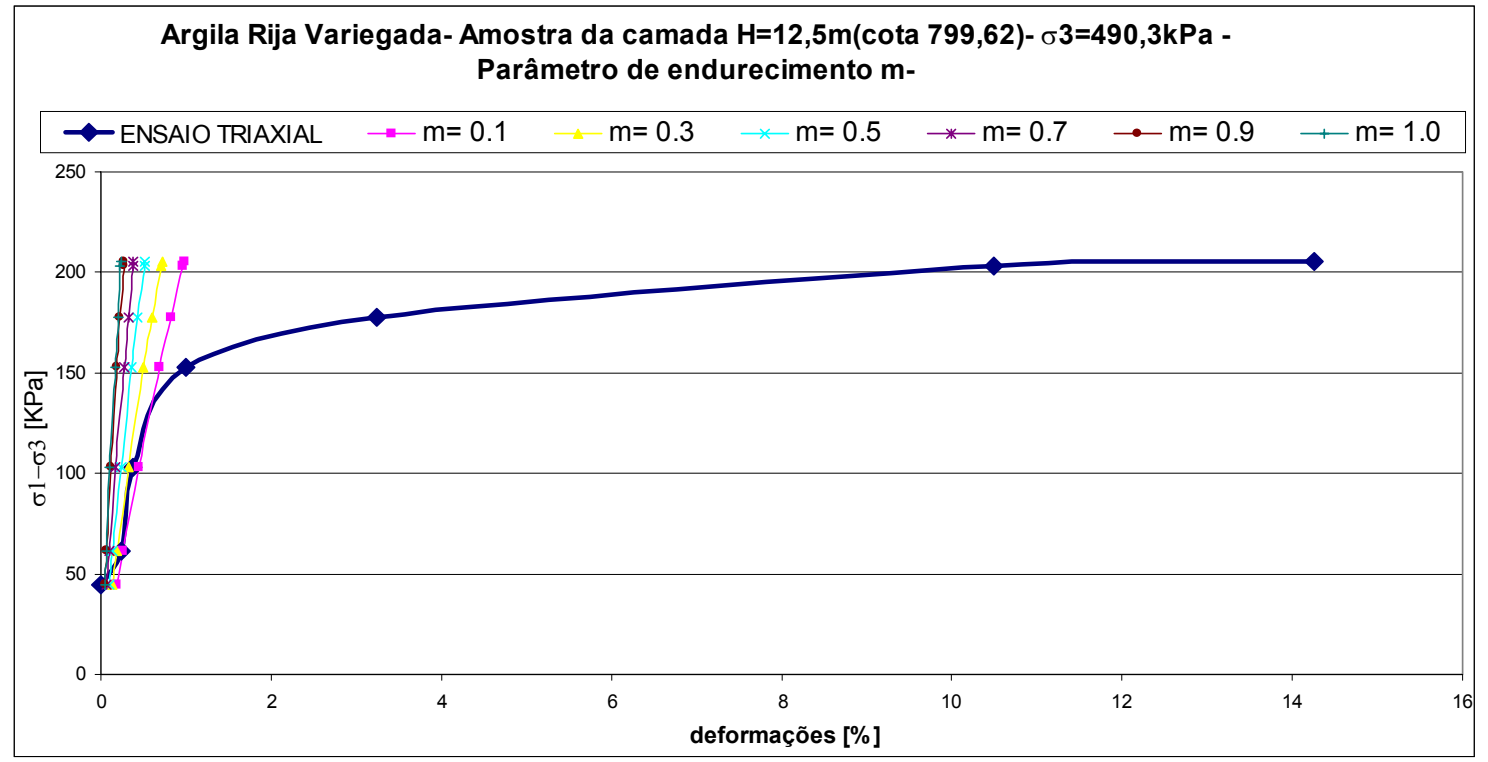

Figura 3-43- Calibração do modelo de Endurecimento via variação do parâmetro $m$ para Argila Rija Variegada $h=12.5 m$ 
Tabela 3-6- Valores de deformações calculados pelo modelo de Endurecimento de solo para ensaio triaxial com pressão confinante $\sigma_{3}=294,2 \mathrm{kPa}$ em argila porosa vermelha amostra a 3,5m de profundidade (cota 808,62)

\begin{tabular}{|c|c|c|c|c|c|c|c|c|c|c|}
\hline$\phi\left({ }^{\circ}\right)$ & $\begin{array}{c}\mathrm{c} \\
{[\mathrm{KPa}]}\end{array}$ & $\begin{array}{c}\sigma 3 \\
{[\mathrm{KPa}]}\end{array}$ & $\begin{array}{l}\text { qf (calculado) } \\
\text { Endurecimento }\end{array}$ & $\begin{array}{c}\text { Rf (adotado) } \\
\text { SCHANZ(1998) }\end{array}$ & $q a=q f / R f$ & $\begin{array}{l}\text { E50ref } \\
\text { (triaxial) }\end{array}$ & $\begin{array}{c}\mathrm{p}^{\mathrm{ref}} \\
{[\mathrm{kPa}]}\end{array}$ & $\mathrm{m}$ & $\begin{array}{l}E 50=f(m) \\
\text { calculado }\end{array}$ & Eur_Ref $=2^{*}$ E50ref \\
\hline 22.61 & 13.9 & -294.2 & 409.20 & 0.9 & 454.66 & 1604 & 100 & $\begin{array}{l}0.1 \\
0.3\end{array}$ & $\begin{array}{l}1755.0 \\
2100.5\end{array}$ & 3208 \\
\hline & & & & & & & & $\begin{array}{c}0.5 \\
0.7 \\
0.9 \\
1 \\
\end{array}$ & $\begin{array}{l}2514.1 \\
3009.0 \\
3601.4 \\
3940.0 \\
\end{array}$ & \\
\hline
\end{tabular}

\begin{tabular}{|c|c|c|c|c|c|c|c|c|c|c|c|c|}
\hline $\begin{array}{c}9=(\sqrt{6}-\sigma 3) \\
{[\mathrm{KPa}]}\end{array}$ & $\begin{array}{r}\mathrm{m}= \\
\mathrm{E} 50[\mathrm{KPa}]\end{array}$ & $\begin{array}{c}0.1 \\
1755.0 \\
\end{array}$ & $\begin{array}{r}\mathrm{m}= \\
\mathrm{E} 50[\mathrm{KPa}]\end{array}$ & $\begin{array}{c}0.3 \\
2100.5 \\
\end{array}$ & $\begin{array}{r}\mathrm{m}= \\
\mathrm{E} 50[\mathrm{KPa}] \\
\end{array}$ & $\begin{array}{c}0.5 \\
2514.1 \\
\end{array}$ & $\begin{array}{r}\mathrm{m=} \\
\mathrm{E50[ \textrm {KPa } ]} \\
\end{array}$ & $\begin{array}{c}0.7 \\
3009.0 \\
\end{array}$ & $\begin{array}{r}\mathrm{m=} \\
\mathrm{E} 50[\mathrm{KPa}] \\
\end{array}$ & $\begin{array}{c}0.9 \\
3601.4 \\
\end{array}$ & $\begin{array}{r}\mathrm{m=} \\
\mathrm{E} 50[\mathrm{KPa}] \\
\end{array}$ & $\begin{array}{c}1.0 \\
3940.0 \\
\end{array}$ \\
\hline & $\begin{array}{c}\varepsilon 1(\%) \\
\text { Endurecimento }\end{array}$ & $\begin{array}{l}\text { erro de } \varepsilon \text { triaxial e modelo } \\
\text { Endurecimento [\%] }\end{array}$ & $\begin{array}{c}\varepsilon 1 \%) \\
\text { Endurecimento }\end{array}$ & $\begin{array}{l}\text { erro de } \varepsilon \text { triaxial e modelo } \\
\text { Endurecimentt [\%] }\end{array}$ & $\begin{array}{c}\varepsilon 1(\%) \\
\text { Endurecimento }\end{array}$ & $\begin{array}{l}\text { erro de } \varepsilon \text { triaxial e modelo } \\
\text { Endurecimento [\%] }\end{array}$ & $\begin{array}{c}\varepsilon 1(\%) \\
\text { Endurecimento }\end{array}$ & $\begin{array}{l}\text { erro de } \varepsilon \text { triaxiale modelo } \\
\text { Endurecimento }[\%]\end{array}$ & $\begin{array}{c}\varepsilon 1 \%) \\
\text { Endurecimento }\end{array}$ & $\begin{array}{l}\text { erro de s triaxiale modelo } \\
\text { Endurecimento [\%] }\end{array}$ & $\begin{array}{c}\varepsilon 1 \%) \\
\text { Endurecimento }\end{array}$ & $\begin{array}{l}\text { erro de } \varepsilon \text { triaxiale modelo } \\
\text { Endurecimento [\%] }\end{array}$ \\
\hline 283.6 & 21.47 & 26.6 & 17.94 & 38.7 & 14.99 & & 12.52 & 57.2 & 10.46 & 64.2 & & 67.3 \\
\hline 266.9 & 18.41 & 37.1 & 15.38 & 47.4 & 12.85 & 56.1 & 10.74 & 63.3 & 8.97 & 69.3 & 8.20 & 72.0 \\
\hline 197.4 & 9.94 & 66.0 & 8.30 & 71.6 & 6.94 & 76.3 & 5.80 & 80.2 & 4.84 & 83.4 & 4.43 & 84.9 \\
\hline 141.8 & 5.87 & 79.9 & 4.90 & 83.2 & 4.10 & 86.0 & 3.42 & 88.3 & 2.86 & 90.2 & 2.61 & 91.1 \\
\hline 102.9 & 3.79 & 87.1 & 3.16 & 89.2 & 2.64 & 91.0 & 2.21 & 92.4 & 1.85 & 93.7 & 1.69 & 94.2 \\
\hline $\begin{array}{l}51.4 \\
195\end{array}$ & 1.65 & 94.4 & 1.38 & 95.3 & 1.15 & 96.1 & 0.96 & 96.7 & 0.81 & 97.2 & 0.74 & 97.5 \\
\hline \multirow[t]{2}{*}{19.5} & 0.58 & 98.0 & 0.48 & 98.3 & 0.40 & 98.6 & 0.34 & 98.8 & 0.28 & 99.0 & 0.26 & 99.1 \\
\hline & ERRO MEDIO [\% & 69.86 & ERRO MEDIO [\%] & 74.82 & ERRO MEDIO [\%] & 78.96 & ERRO MEDIO [\%] & 82.42 & ERRO MEDIO [\%] & 85.31 & ERRO MEDIO [\%] & 86.58 \\
\hline
\end{tabular}


Tabela 3-7-Valores de deformações calculados pelo modelo de Endurecimento de solo para ensaio triaxial com pressão confinante $\sigma_{3}=490,3 \mathbf{k P a}$ em argila porosa vermelha amostra a $6,5 \mathrm{~m}$ de profundidade (cota 805,62$)$

\begin{tabular}{|c|c|c|c|c|c|c|c|c|c|c|}
\hline$\phi\left({ }^{\circ}\right)$ & $\begin{array}{c}\mathrm{c} \\
{[\mathrm{KPa}]}\end{array}$ & $\begin{array}{c}\sigma 3 \\
{[\mathrm{KPa}]}\end{array}$ & $\begin{array}{c}\text { ff (calculado) } \\
\text { Endurecimento }\end{array}$ & $\begin{array}{c}\text { Rf (adotado) } \\
\text { SCHANZ(1998) }\end{array}$ & $q a=q f / R f$ & $\begin{array}{c}\text { E50ref [kPa] } \\
\text { (triaxial) }\end{array}$ & $\begin{array}{c}\mathrm{p}^{\mathrm{ref}} \\
{[\mathrm{kPa}]}\end{array}$ & $m$ & $\begin{array}{c}E 50=f(m) \\
\text { calculado[kPa] }\end{array}$ & Eur_Ref $=2^{*}$ E50ref \\
\hline 23.3 & 35.4 & -490.3 & 749.27 & 0.9 & 832.52 & 1517 & 100 & \multirow{2}{*}{$\begin{array}{l}0.1 \\
0.3 \\
0.5 \\
0.7 \\
0.9 \\
1\end{array}$} & \multirow{2}{*}{$\begin{array}{l}1700.5 \\
2138.1 \\
2688.3 \\
3380.0 \\
4249.8 \\
4765.3\end{array}$} & 3033 \\
\hline & & & & & & & & & & \\
\hline
\end{tabular}

\begin{tabular}{|c|c|c|c|c|c|c|c|c|c|c|c|c|}
\hline $\begin{array}{c}=(61-\sigma 3) \\
{[\mathrm{KPa}]}\end{array}$ & $\begin{aligned} \mathrm{m}= \\
\mathrm{E} 50[\mathrm{KPa}]\end{aligned}$ & $\begin{array}{c}0.1 \\
1700.5 \\
\end{array}$ & $\begin{array}{r}\mathrm{m}= \\
\mathrm{ES0[ \textrm {KPa } ]}\end{array}$ & $\begin{array}{c}0.3 \\
2138.1 \\
\end{array}$ & $\begin{array}{r}\mathrm{m=} \\
\mathrm{E} 50[\mathrm{KPa]}]\end{array}$ & $\begin{array}{c}0.5 \\
2688.3 \\
\end{array}$ & $\begin{array}{r}\mathrm{m=} \\
\mathrm{E} 50[\mathrm{KPa}] \\
\end{array}$ & $\begin{array}{c}0.7 \\
3380.0 \\
\end{array}$ & 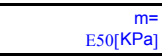 & $\begin{array}{c}0.9 \\
4249.8 \\
\end{array}$ & $\begin{array}{r}m= \\
\text { E50[KPa] }\end{array}$ & $\begin{array}{c}1.0 \\
4765.3 \\
\end{array}$ \\
\hline & $\begin{array}{c}\varepsilon 1(\%) \\
\text { Endurecimento }\end{array}$ & $\begin{array}{l}\text { arro de } \varepsilon \text { traxalale modelo } \\
\text { Endurecimento }[\%]\end{array}$ & $\begin{array}{c}\varepsilon 1(\%) \\
\text { Endurecimento }\end{array}$ & $\begin{array}{l}\text { erro de } \varepsilon \text { triaxiale modelo } \\
\text { Endurecimento [\%] }\end{array}$ & $\begin{array}{c}\varepsilon 1(\%) \\
\text { Endurecimento }\end{array}$ & $\begin{array}{l}\text { erro de } \varepsilon \text { traxiale modelo } \\
\text { Endurecimento [\%] }\end{array}$ & $\begin{array}{c}\varepsilon 1 \%) \\
\text { Endurecimento }\end{array}$ & $\begin{array}{l}\text { erro de } \varepsilon \text { traxaxiale modelo } \\
\text { Endurecimento [\%] }\end{array}$ & $\begin{array}{c}\varepsilon 1 \%) \\
\text { Endurecimento }\end{array}$ & $\begin{array}{l}\text { erro de } \varepsilon \text { triaxiale modelo } \\
\text { Endurecimento [\%] }\end{array}$ & $\begin{array}{c}\varepsilon 1(\%) \\
\text { Endurecimento }\end{array}$ & $\begin{array}{l}\text { erro de } \varepsilon \text { triaxiale modelo } \\
\text { Endurecimento [\%] }\end{array}$ \\
\hline 244.0 & 10.15 & 56.3 & 8.07 & 65.3 & 6.42 & 72.4 & 5.11 & 78.0 & 4.06 & 82.5 & 3.62 & 84.4 \\
\hline 240.6 & 9.95 & 57.2 & 7.91 & 66.0 & 6.29 & 72.9 & 5.01 & 78.5 & 3.98 & 82.9 & 3.55 & 84.7 \\
\hline 232.7 & 9.49 & 59.2 & 7.55 & 67.5 & 6.01 & 74.2 & 4.78 & 79.5 & 3.80 & 83.7 & 3.39 & 85.4 \\
\hline 200.9 & 7.79 & 66.5 & 6.19 & 73.4 & 4.92 & 78.8 & 3.92 & 83.2 & 3.12 & 86.6 & 2.78 & 88.1 \\
\hline 122.0 & 4.20 & 81.9 & 3.34 & 85.6 & 2.66 & 88.6 & 2.11 & 90.9 & 1.68 & 92.8 & 1.50 & 93.5 \\
\hline \multirow{3}{*}{22.7} & 1.56 & 93.3 & 1.24 & 94.7 & 0.99 & 95.8 & 0.79 & 96.6 & 0.63 & 97.3 & 0.56 & 97.6 \\
\hline & 0.69 & 97.0 & 0.55 & 97.7 & 0.43 & 98.1 & 0.35 & 98.5 & 0.27 & 98.8 & 0.24 & 98.9 \\
\hline & ERRO MEDIO [\%] & 73.07 & ERRO MEDIO [\%] & 78.58 & ERRO MEDIO [\%] & 82.96 & ERRO MEDIO [\%] & 86.45 & ERRO MEDIO [\%] & 89.22 & ERRO MEDIO [\%] & 90.39 \\
\hline
\end{tabular}




\section{9 -Análise paramétrica do Modelo de Endurecimento}

A análise paramétrica para o modelo de Endurecimento foi conduzida visando obter os parâmetros de maior influência no comportamento do sistema solo-estrutura. Este comportamento refere-se à variação dos deslocamentos horizontais e verticais do paramento e das forças nas estroncas. A idéia é verificar como variam os deslocamentos de paramento e as forças nas estroncas devido a uma variação isolada de cada um dos sete parâmetros geotécnicos estudados (Tabela 3-8). Para isto, observou-se o comportamento dos pontos de topo, meio e pé do paramento, quanto a deslocamentos horizontais e verticais e também a variação das forças nas estroncas.

Com este intuito foram realizadas 14 simulações para cada um dos oito estágios de escavação. Sendo sete para valores de $+30 \%$ sobre os valores de referência inicial 2 e as outras sete de $-30 \%$, para cada variação individual de parâmetro.Em outras palavras, cada parâmetro foi variado sobre seu valor inicial (parâmetros de referência inicial 2), em $+30 \%$ e $-30 \%$.

A Tabela 3-8 apresenta na $1^{\text {a }}$. linha os valores de referência inicial 2 e nas demais os valores de parâmetros com variações de $+30 \%$ e $-30 \%$.

O parâmetro $R_{\text {inter }}$ representa a redução da coesão (c') e da tan $\phi^{\prime}$ do solo em contato com os paramentos da estrutura de contenção ou seja o parâmetro $R_{\text {inter }}$ varia de 1 (interface rígida) até o valor de 0 . 
Tabela 3-8- Parâmetros geotécnicos valores de referência inicial 2 e variação de $+30 \%$ e $-\mathbf{3 0} \%$ em relação aos valores de referência inicial 2 utilizados para as simulações com finalidade de análise paramétrica com o modelo de Endurecimento de Solo

\begin{tabular}{|c|c|c|c|c|c|c|c|c|}
\hline $\begin{array}{c}\text { Simulação } \\
n^{o}\end{array}$ & $\begin{array}{c}\text { Parâmetro } \\
\text { Variado em } \\
+ \text { ou }-30 \% \\
\text { em relação } \\
\text { ao de } \\
\text { referência } \\
\text { inicial } 2\end{array}$ & $v$ & $\begin{array}{c}\gamma_{\text {nat }} \\
\left(\mathrm{kN} / \mathrm{m}^{3}\right)\end{array}$ & Ko & $\begin{array}{c}\Phi^{\prime} \\
\left({ }^{\mathrm{o}}\right)\end{array}$ & $\mathrm{R}_{\text {inter }}$ & $\begin{array}{c}\mathrm{c}^{\prime} \\
\left(\mathrm{kN} / \mathrm{m}^{2}\right)\end{array}$ & $\begin{array}{c}\mathrm{E}_{50} \\
\left(\mathrm{kN} / \mathrm{m}^{2}\right)\end{array}$ \\
\hline $\begin{array}{c}1 \\
\text { Valores } \\
\text { de } \\
\text { referência } \\
\text { inicial } 2\end{array}$ & ------ & 0.35 & 15 & 0.45 & 28 & 0.5 & 30 & 100000 \\
\hline 2 & $E_{50}(+30 \%)$ & 0.35 & 15 & 0.45 & 28 & 0,5 & 30 & 130000 \\
\hline 3 & $c^{\prime}(+30 \%)$ & 0.35 & 15 & 0.45 & 28 & 0,5 & 39 & 100000 \\
\hline 4 & $\mathrm{R}_{\text {inter }}(+30 \%)$ & 0.35 & 15 & 0.45 & 28 & 0.65 & 30 & 100000 \\
\hline 5 & $\Phi^{\prime}(+30 \%)$ & 0.35 & 15 & 0.45 & 36.4 & 0.5 & 30 & 100000 \\
\hline 6 & $K o(+30 \%)$ & 0.35 & 15 & 0.59 & 28 & 0.5 & 30 & 100000 \\
\hline 7 & $\gamma_{n a t}(+30 \%)$ & 0.35 & 19.5 & 0.45 & 28 & 0.5 & 30 & 100000 \\
\hline 8 & $v(+30 \%)$ & 0.46 & 15 & 0.45 & 28 & 0.5 & 30 & 100000 \\
\hline 9 & $\vee(-30 \%)$ & 0.25 & 15 & 0.45 & 28 & 0.5 & 30 & 100000 \\
\hline 10 & $\gamma_{n a t}(-30 \%)$ & 0.35 & 10.5 & 0.45 & 28 & 0.5 & 30 & 100000 \\
\hline 11 & Ko $(-30 \%)$ & 0.35 & 15 & 0.32 & 28 & 0.5 & 30 & 100000 \\
\hline 12 & $\Phi^{\prime}(-30 \%)$ & 0.35 & 15 & 0.45 & 19.6 & 0.5 & 30 & 100000 \\
\hline 13 & $\mathrm{R}_{\text {inter }}(-30 \%)$ & 0.35 & 15 & 0.45 & 28 & 0.35 & 30 & 100000 \\
\hline 14 & $c^{\prime}(-30 \%)$ & 0.35 & 15 & 0.45 & 28 & 0.5 & 21 & 100000 \\
\hline 15 & $E_{50}(-30 \%)$ & 0.35 & 15 & 0.45 & 28 & 0.5 & 30 & 70000 \\
\hline
\end{tabular}

Os resultados destas simulações estão apresentados da Figura 3-44 à Figura 3-81. 


\subsubsection{Resultados da variação de deslocamentos horizontais e verticais na variação de $+30 \%$}

Apresentam-se da Figura 3-44 à Figura 3-51, os valores de erros em relação aos deslocamentos horizontais de paramentos para 3 pontos do paramento, sendo eles o topo, o centro e o pé do paramento.

Estes resultados foram obtidos por variação individual em $+30 \%$ sobre os valores de referência inicial 2 dos parâmetros $E_{50}, \phi^{\prime}, R_{\text {inter }}, m, c^{\prime}, \gamma_{n a t}, K_{0}$.

Em outras palavras, comparou-se os deslocamentos horizontais de paramentos (para variações de $+30 \%$ e $-30 \%$ dos parâmetros) com os deslocamentos de referência (obtidos a partir das simulações com os valores de referência inicial 2, Tabela 3-8)

Os termos utilizados no eixo horizontal dos gráficos significam:

- $E_{50}$-Módulo de deformabilidade a $50 \%$ da tensão de ruptura

- $c$ - coesão

- $R_{\text {inter }}$ Fator de redução da coesão efetiva e da tangente do ângulo de atrito efetivo que é aplicado pelo software PLAXIS na interface solo paramento, ou seja para interfaces rígidas (sem deslocamento relativo) $R_{\text {inter }}=1$, para as demais situações onde ocorre deslocamento relativo $R_{\text {inter }}<1,0$. Sendo esta redução feita da seguinte forma:

$$
\begin{aligned}
& c_{\text {reduzida }}=R_{\text {inter }} * c \\
& \text { tan }^{\prime}{ }_{\text {reduzido }}=\mathrm{R}_{\text {inter }} * \text { tan } \phi{ }_{\text {reduzido }}
\end{aligned}
$$

- . $\phi$ - ângulo de atrito

- $K_{o^{-}}$coeficiente de empuxo em repouso

- $\gamma_{n a t}-$ peso específico natural do solo 


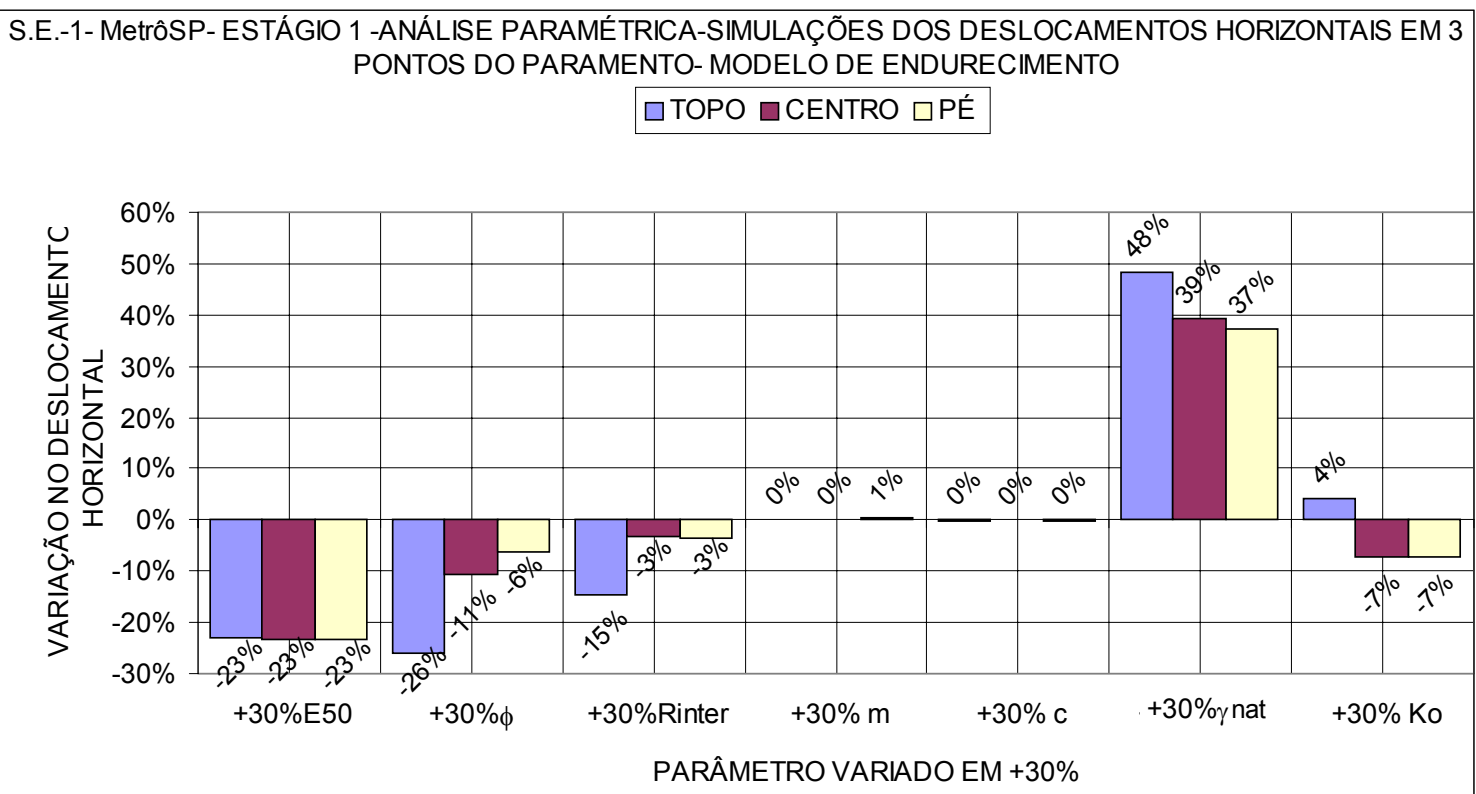

Figura 3-44-Estágio 1-variação dos deslocamentos horizontais de 3 pontos do paramento em função da variação individual de parâmetros em $+30 \%$

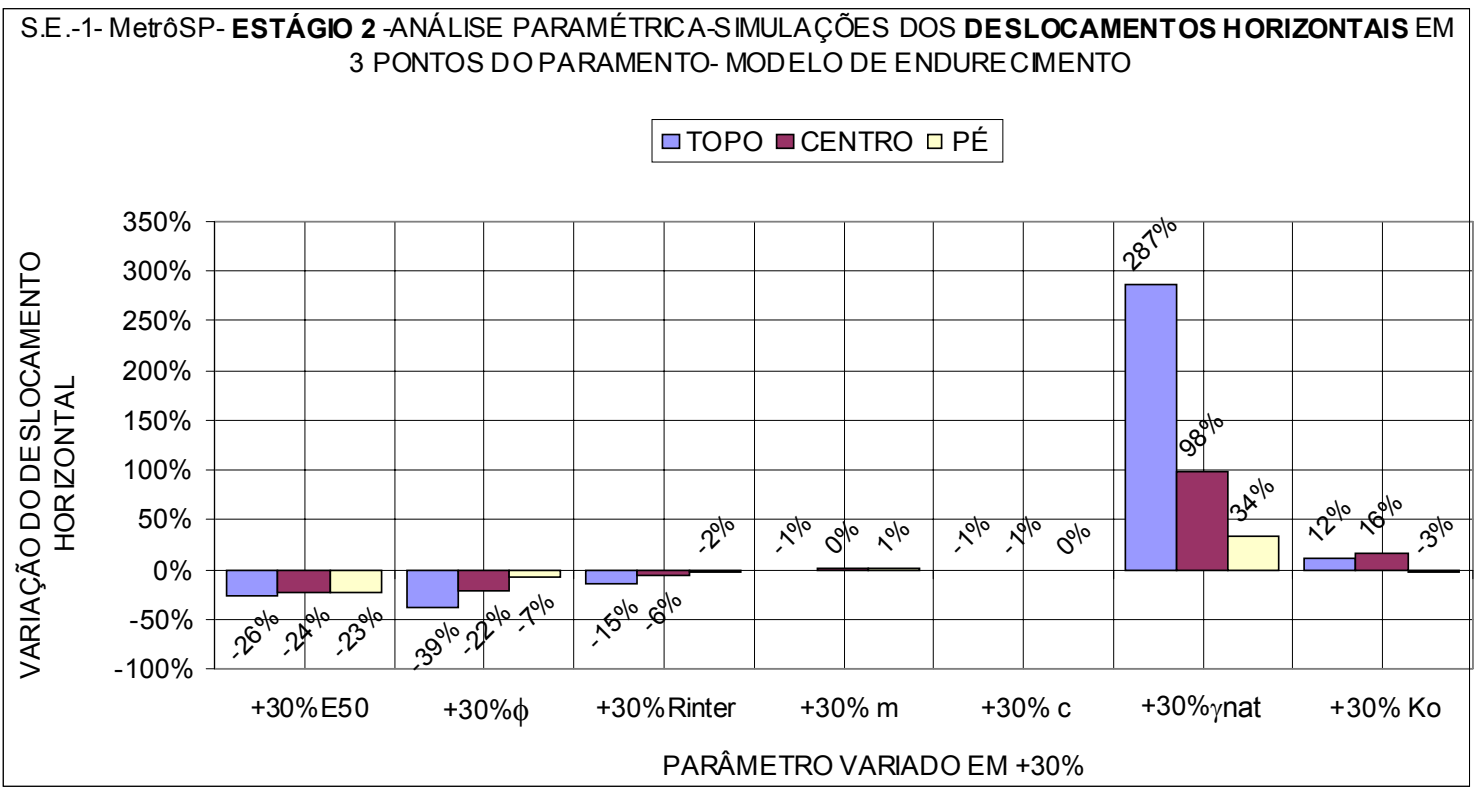

Figura 3-45 -Estágio 2-variação dos deslocamentos horizontais de 3 pontos do paramento em função da variação individual de parâmetros em $+30 \%$ 


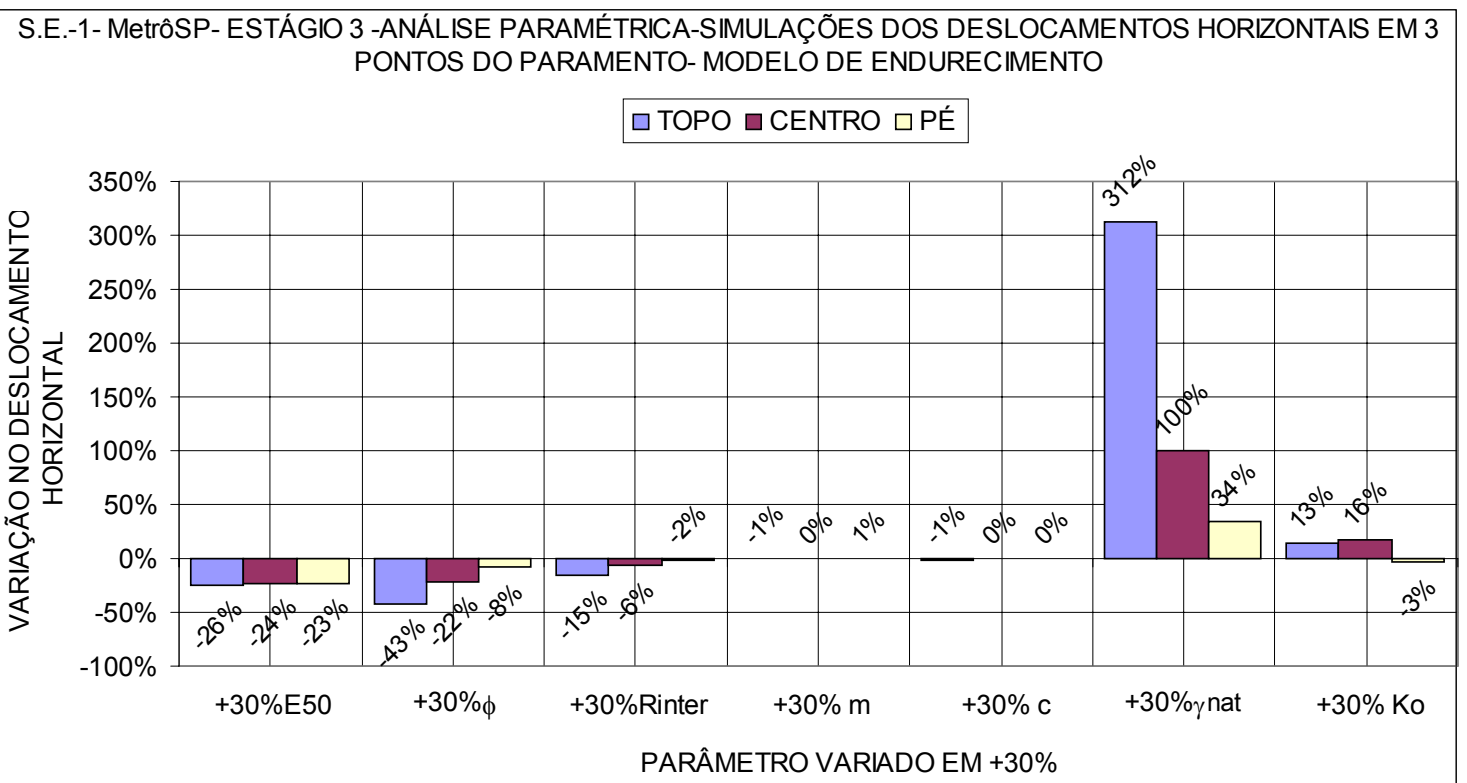

Figura 3-46 -Estágio 3-variação dos deslocamentos horizontais de 3 pontos do paramento em função da variação individual de parâmetros em $+30 \%$

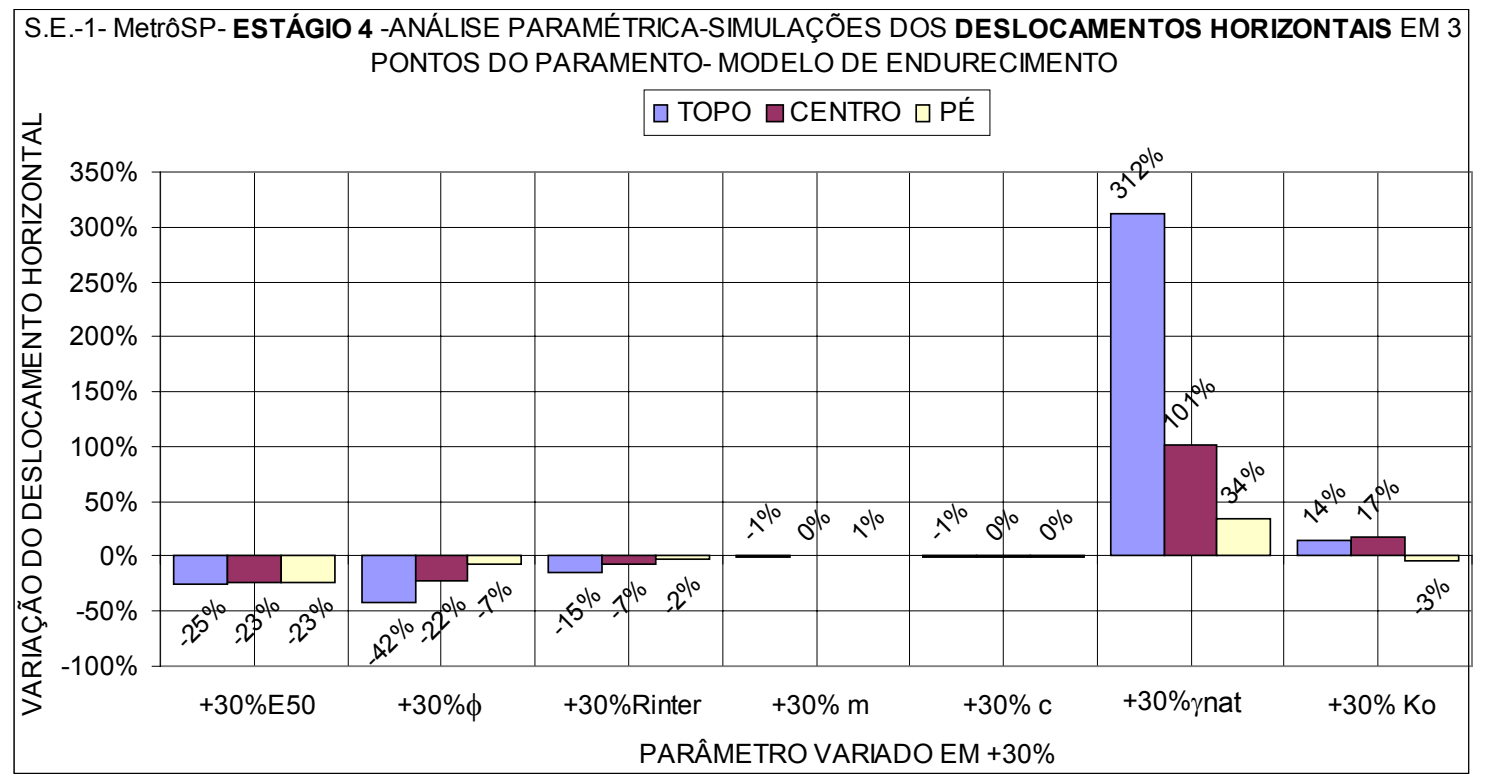

Figura 3-47 -Estágio 4-variação dos deslocamentos horizontais de 3 pontos do paramento em função da variação individual de parâmetros em $+30 \%$ 


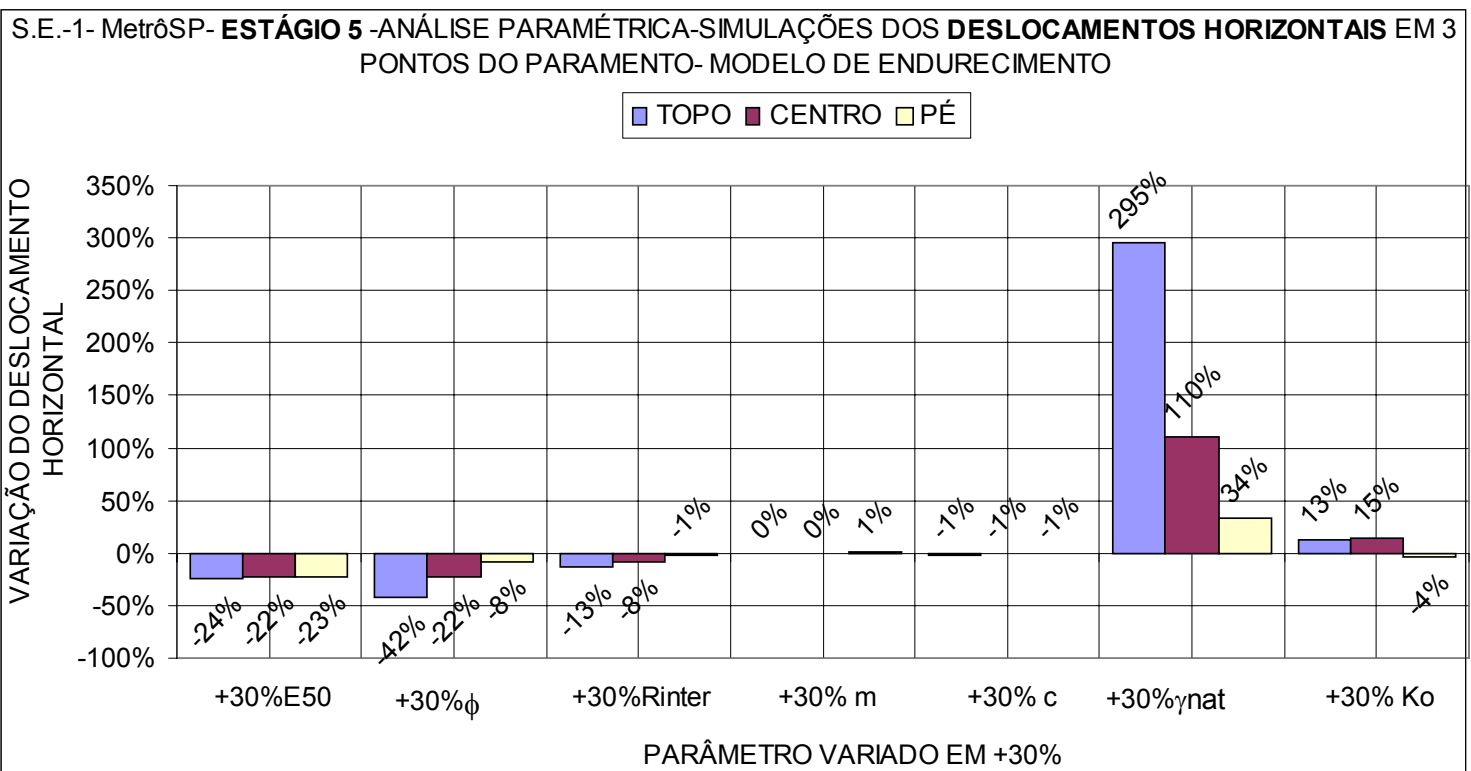

Figura 3-48 -Estágio 5-variação dos deslocamentos horizontais de 3 pontos do paramento em função da variação individual de parâmetros em $+30 \%$

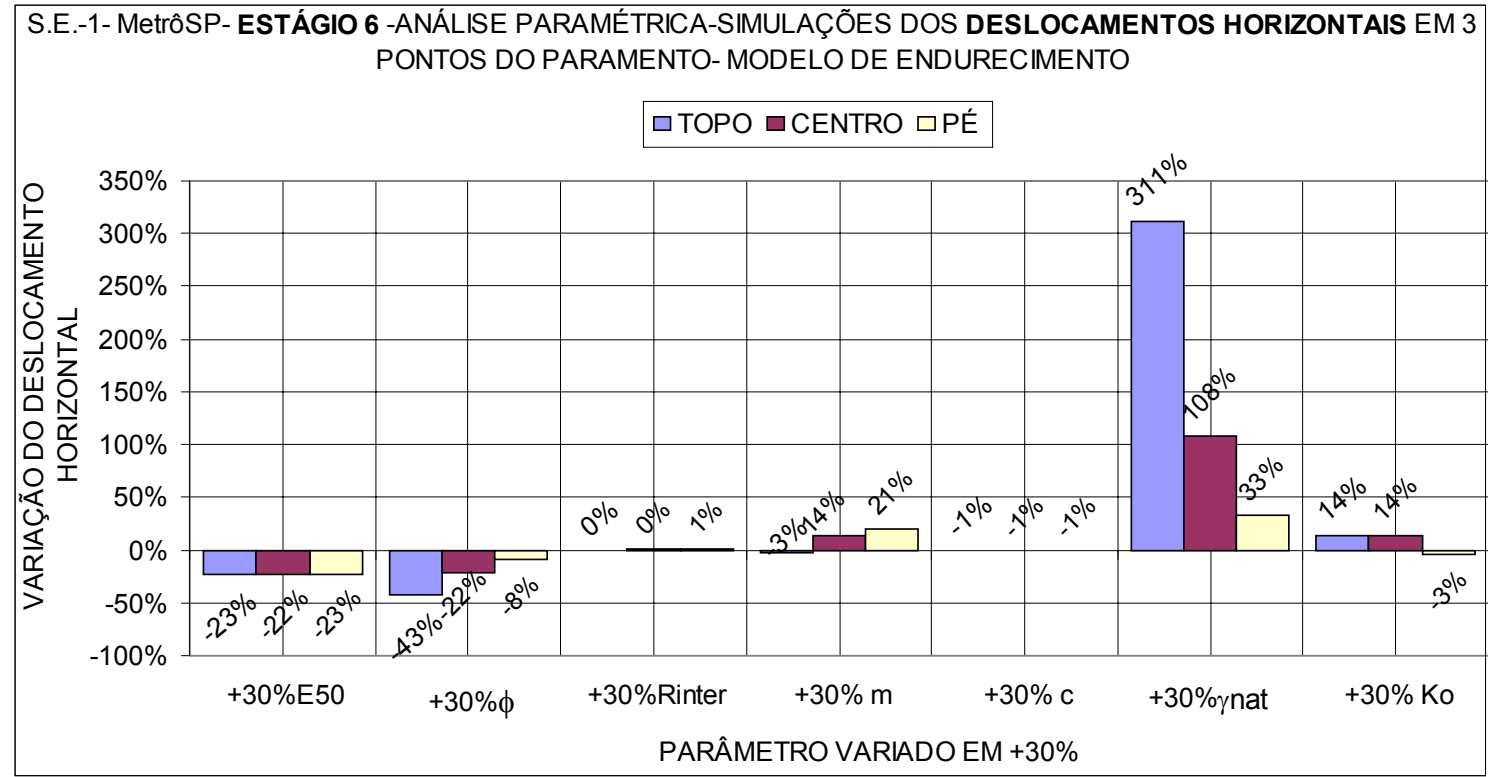

Figura 3-49 -Estágio 6-variação dos deslocamentos horizontais de 3 pontos do paramento em função da variação individual de parâmetros em $+30 \%$ 


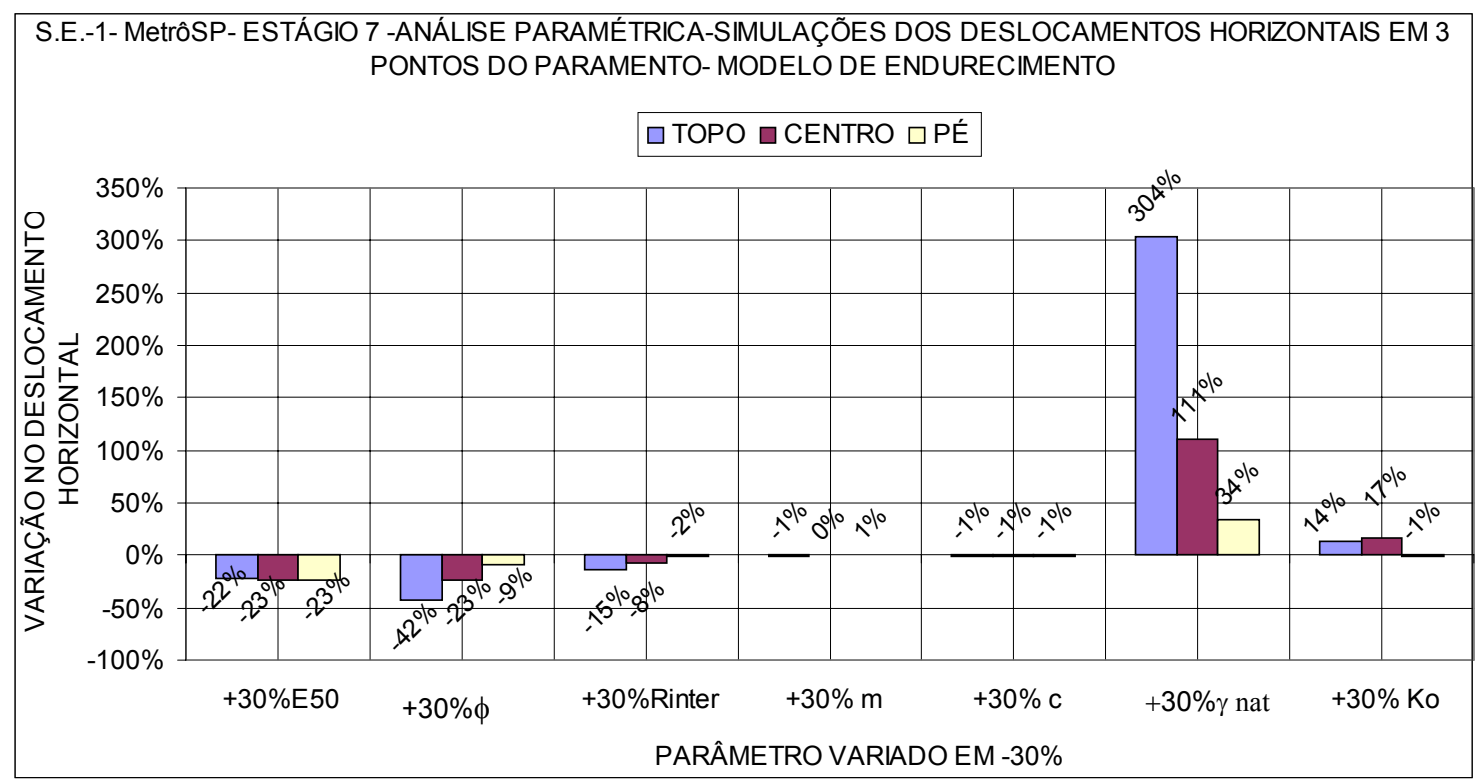

Figura 3-50- Estágio 7-variação dos deslocamentos horizontais de 3 pontos do paramento em função da variação individual de parâmetros em $+30 \%$

$\phi$

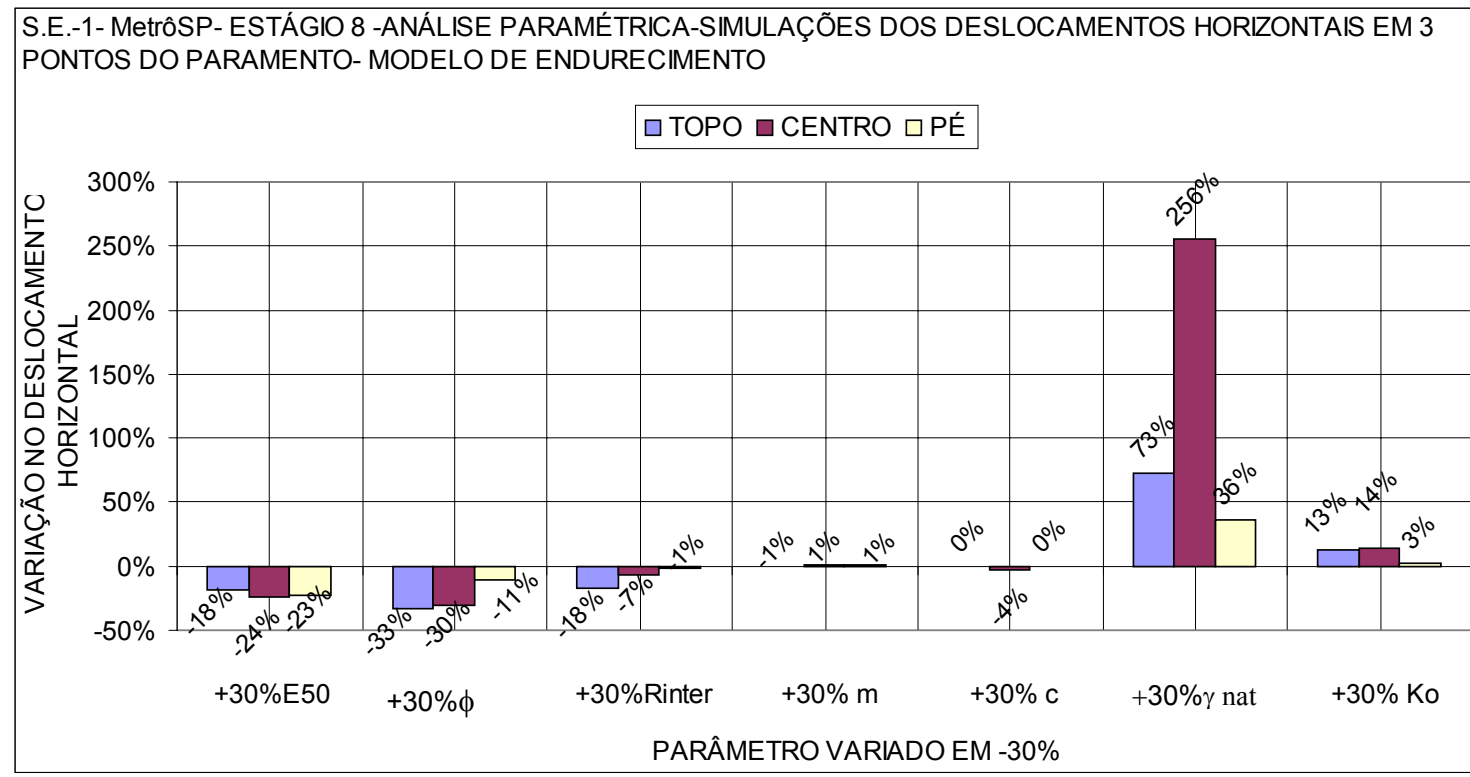

Figura 3-51- Estágio 8-variação dos deslocamentos horizontais de 3 pontos do paramento em função da variação individual de parâmetros em $+30 \%$

Apresentam-se da Figura 3-52 à Figura 3-59, os valores de erros em relação aos deslocamentos verticais de paramentos para 3 pontos do paramento, sendo eles o topo, o centro e o pé do paramento. 
Estes resultados foram obtidos por variação individual em $+30 \%$ sobre os valores de referência inicial 2 dos parâmetros $E_{50}, \phi, R_{\text {inter }}, m, c, \gamma_{\text {nat }}, K_{0}$. 


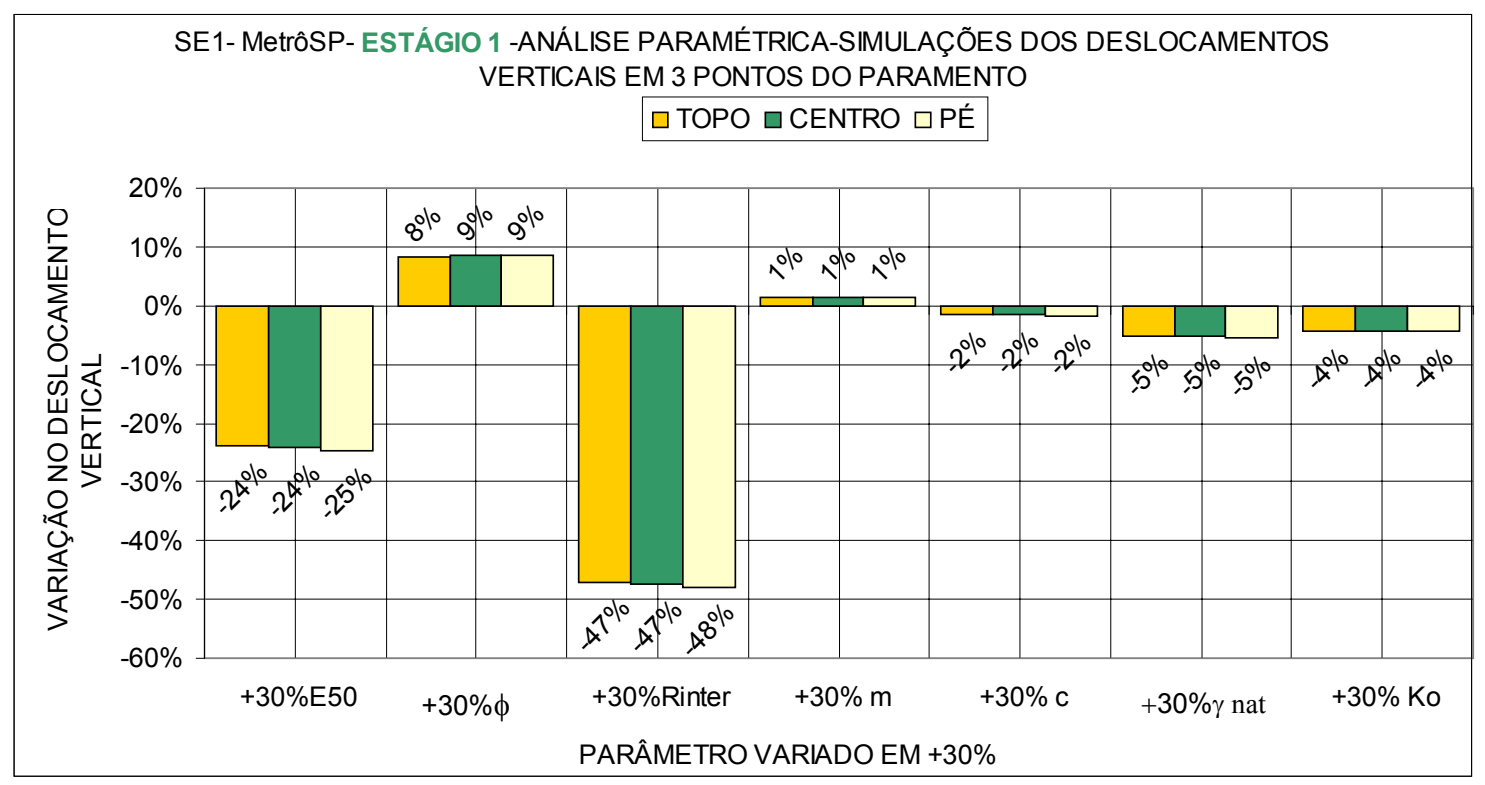

Figura 3-52 -Estágio 1-variação dos deslocamentos verticais de 3 pontos do paramento em função da variação individual de parâmetros em $+30 \%$

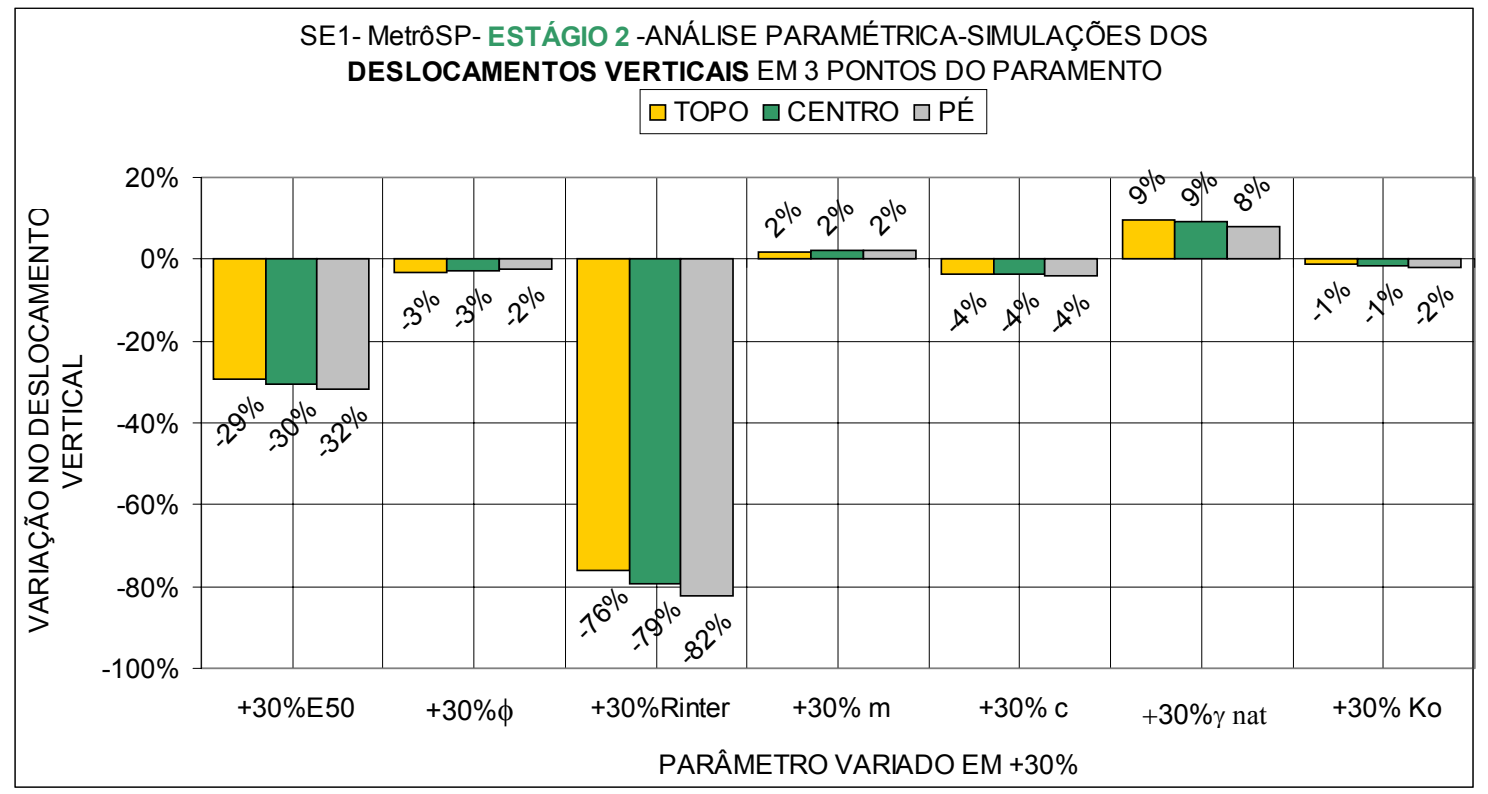

Figura 3-53- Estágio 2-variação dos deslocamentos verticais de 3 pontos do paramento em função da variação individual de parâmetros em $+30 \%$ 


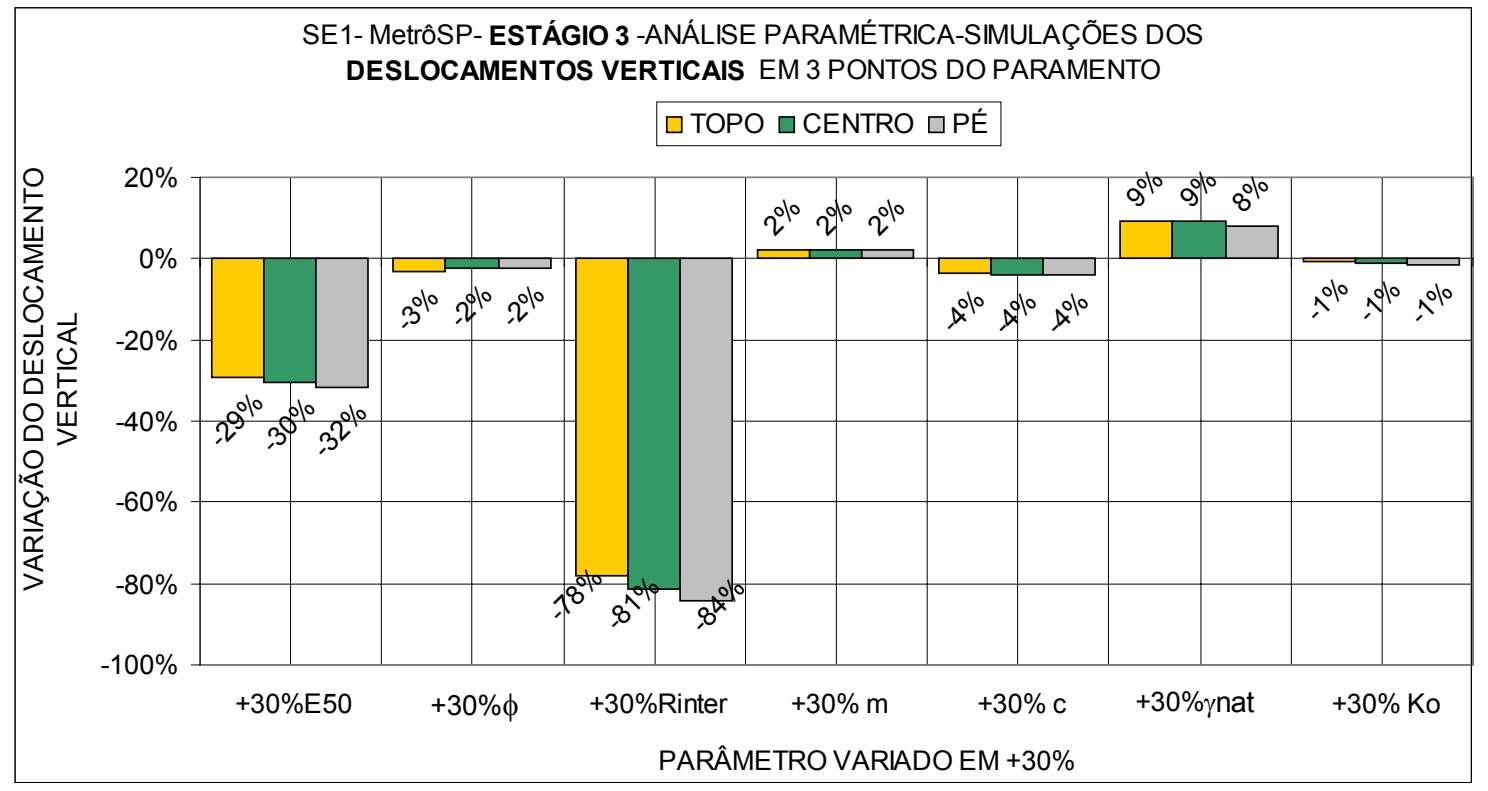

Figura 3-54 -Estágio 3-variação dos deslocamentos verticais de 3 pontos do paramento em função da variação individual de parâmetros em $+30 \%$

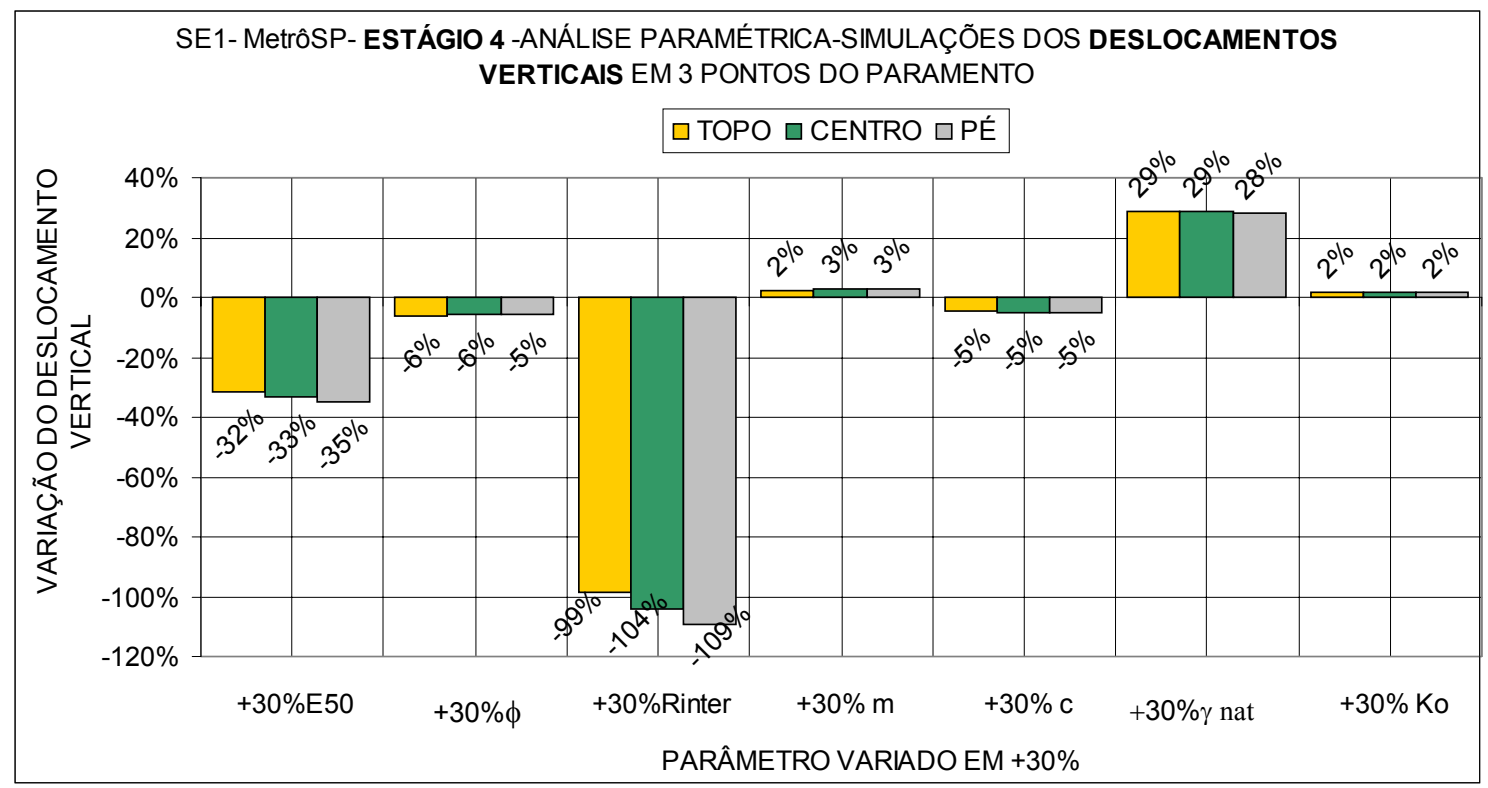

Figura 3-55- Estágio 4-variação dos deslocamentos verticais de 3 pontos do paramento em função da variação individual de parâmetros em $+30 \%$ 


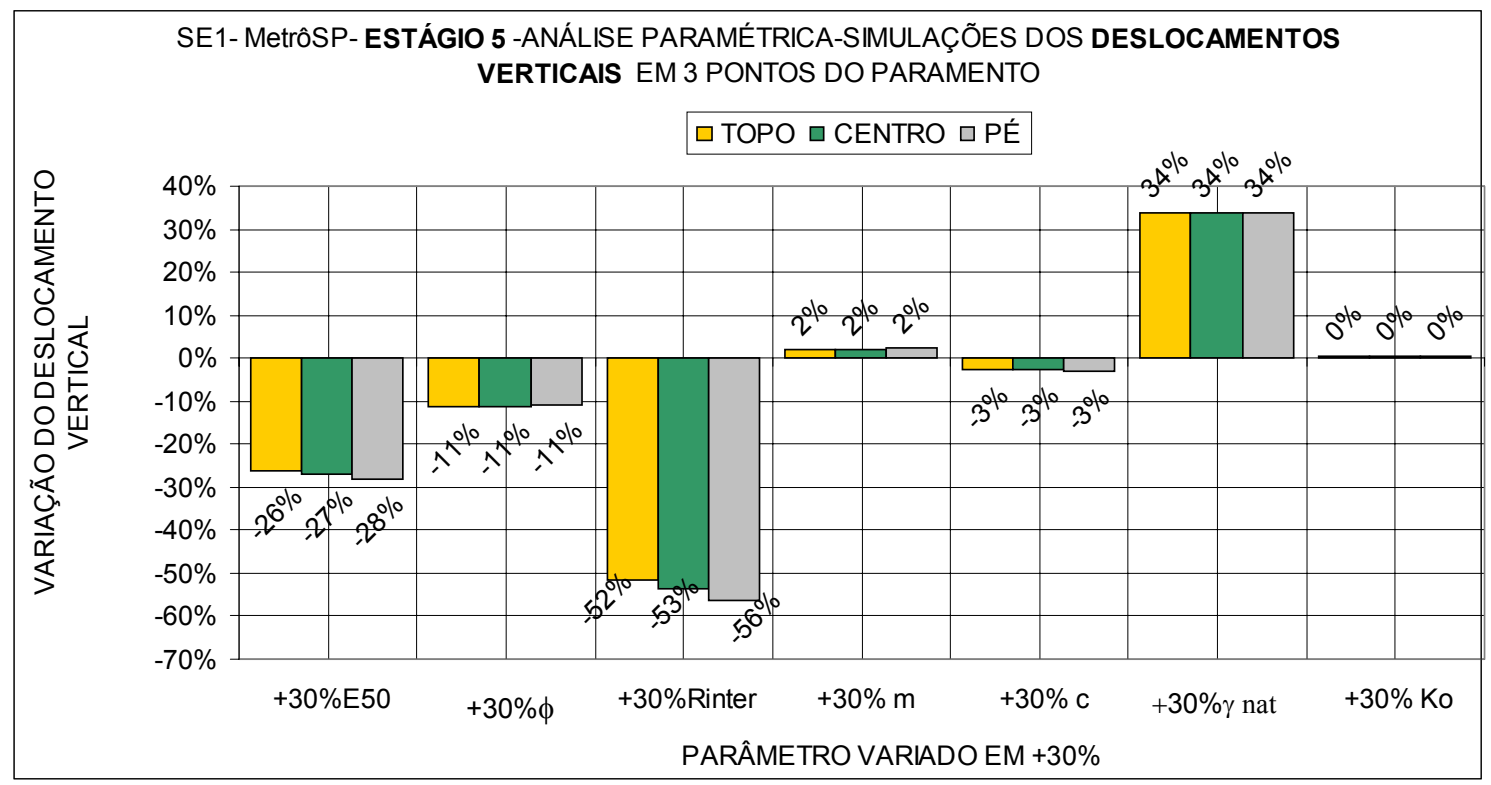

Figura 3-56- Estágio 5-variação dos deslocamentos verticais de 3 pontos do paramento em função da variação individual de parâmetros em $+30 \%$

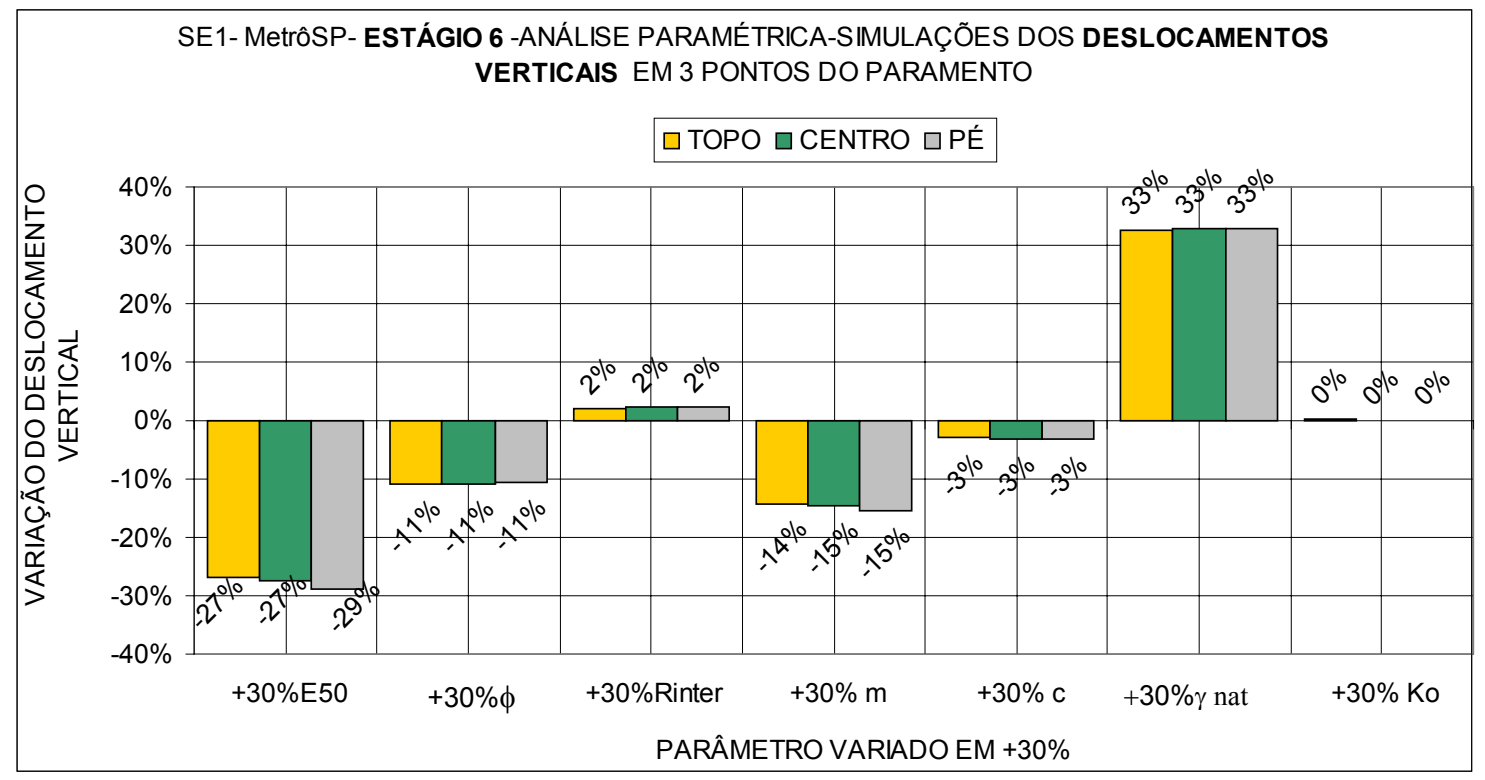

Figura 3-57 -Estágio 6-variação dos deslocamentos verticais de 3 pontos do paramento em função da variação individual de parâmetros em $+30 \%$ 


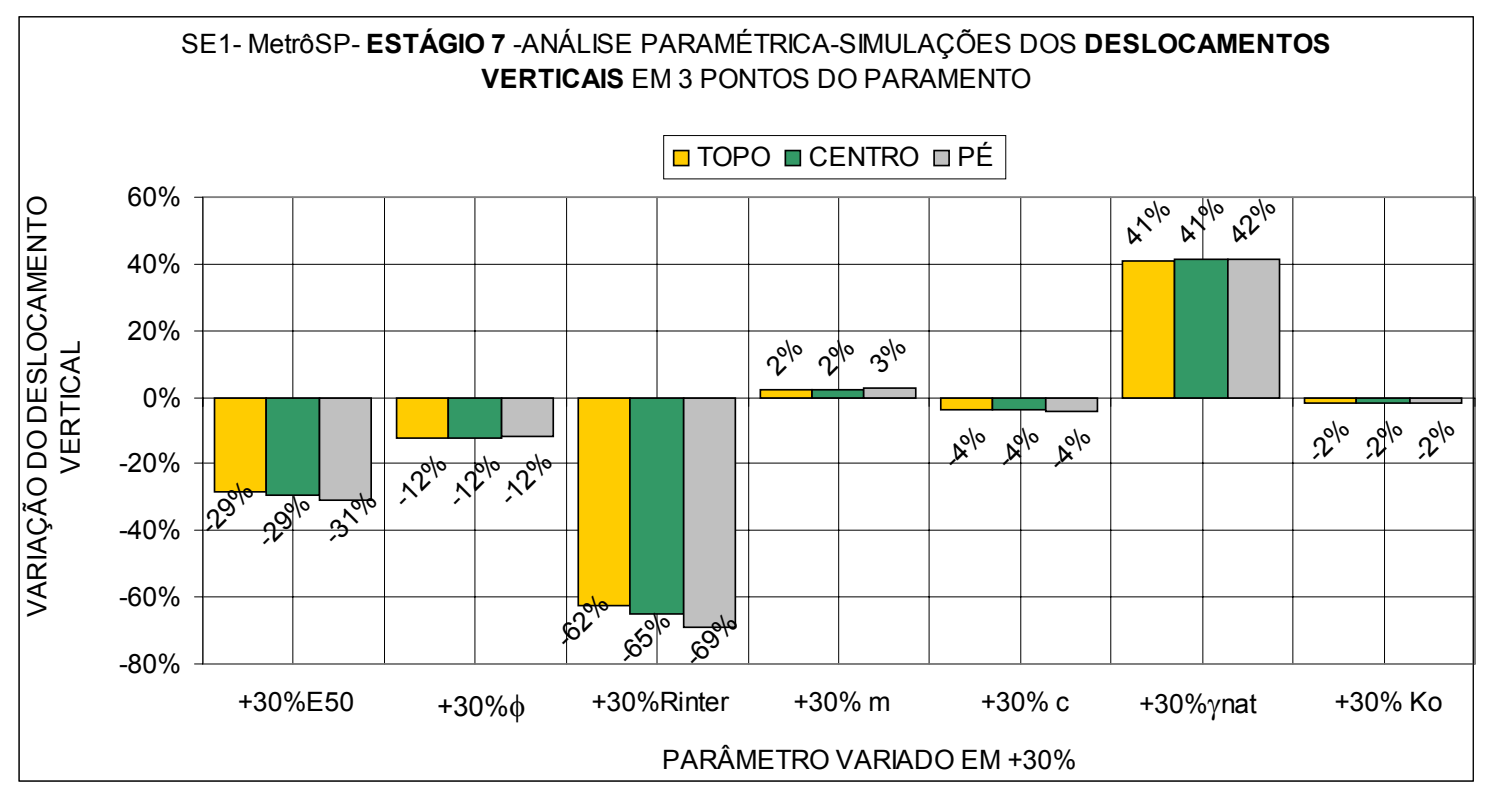

Figura 3-58- Estágio 7-variação dos deslocamentos verticais de 3 pontos do paramento em função da variação individual de parâmetros em $+30 \%$

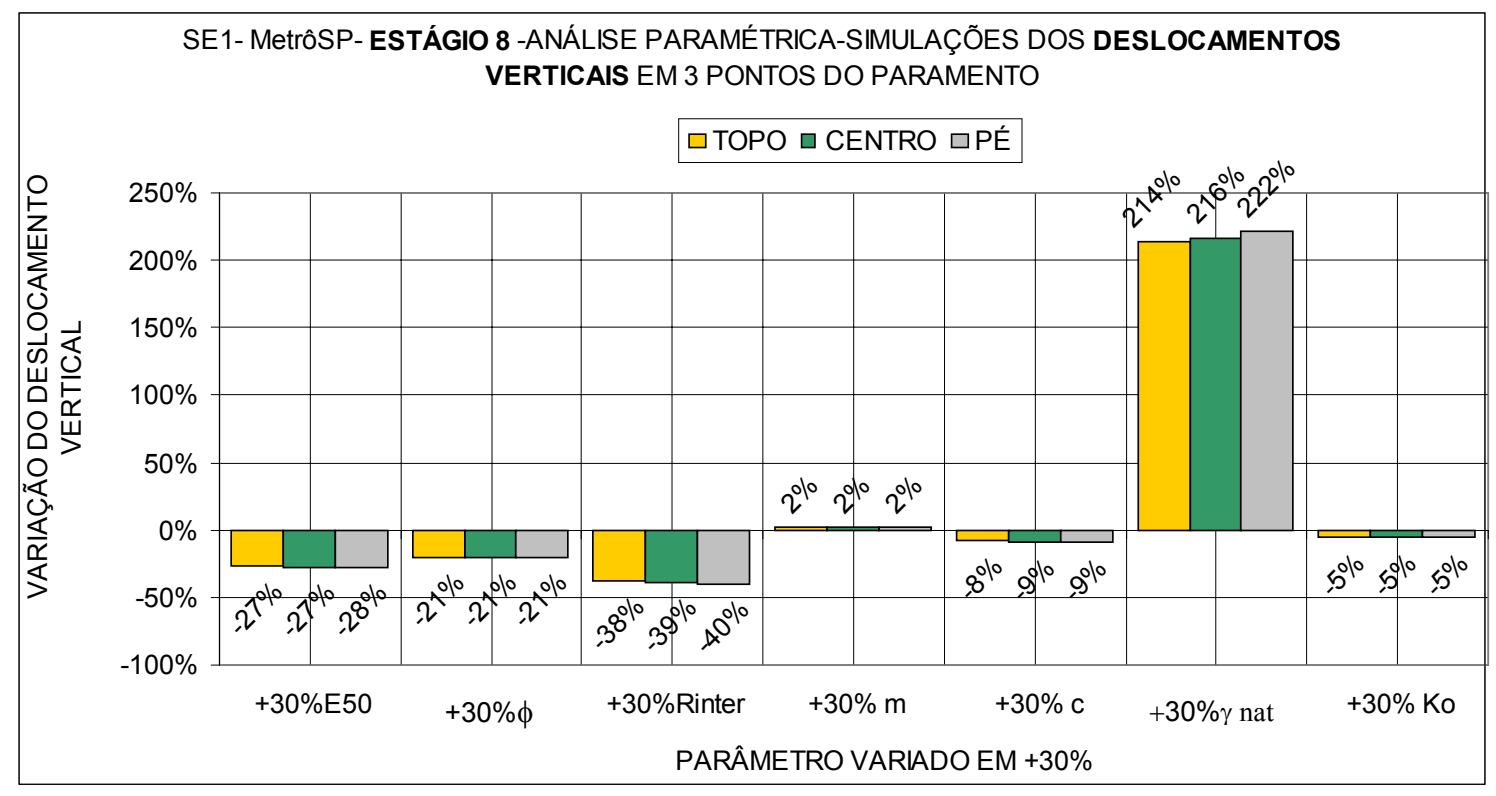

Figura 3-59 -Estágio 8-variação dos deslocamentos verticais de 3 pontos do paramento em função da variação individual de parâmetros em $+30 \%$ 


\subsubsection{Resultados da variação das forças nas estroncas variação de $+30 \%$ nos parâmetros}

Apresentam-se da Figura 3-60 à Figura 3-64, os valores de erros em relação às forças nas estroncas do nível A e na Figura 3-65 em relação também ao nível B.

Estes resultados foram obtidos por variação individual em $+30 \%$ sobre os valores de referência inicial 2 dos parâmetros $E_{50}, \phi, R_{\text {inter }}, m, c, \gamma_{\text {nat }}, K_{0}$.

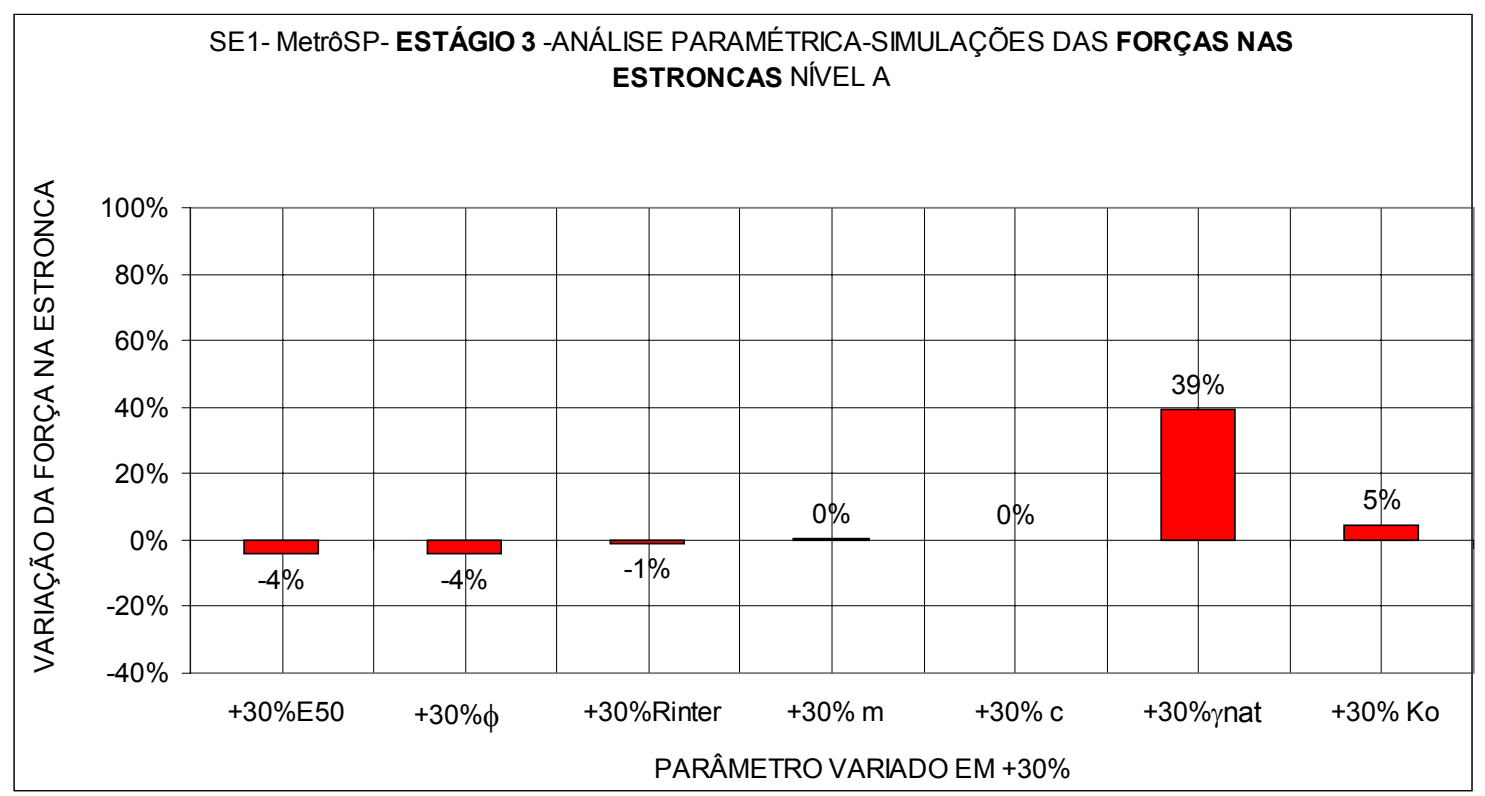

Figura 3-60-Estágio 3-variação das forças nas estroncas do nível A em função da variação individual de parâmetros em $+30 \%$ 


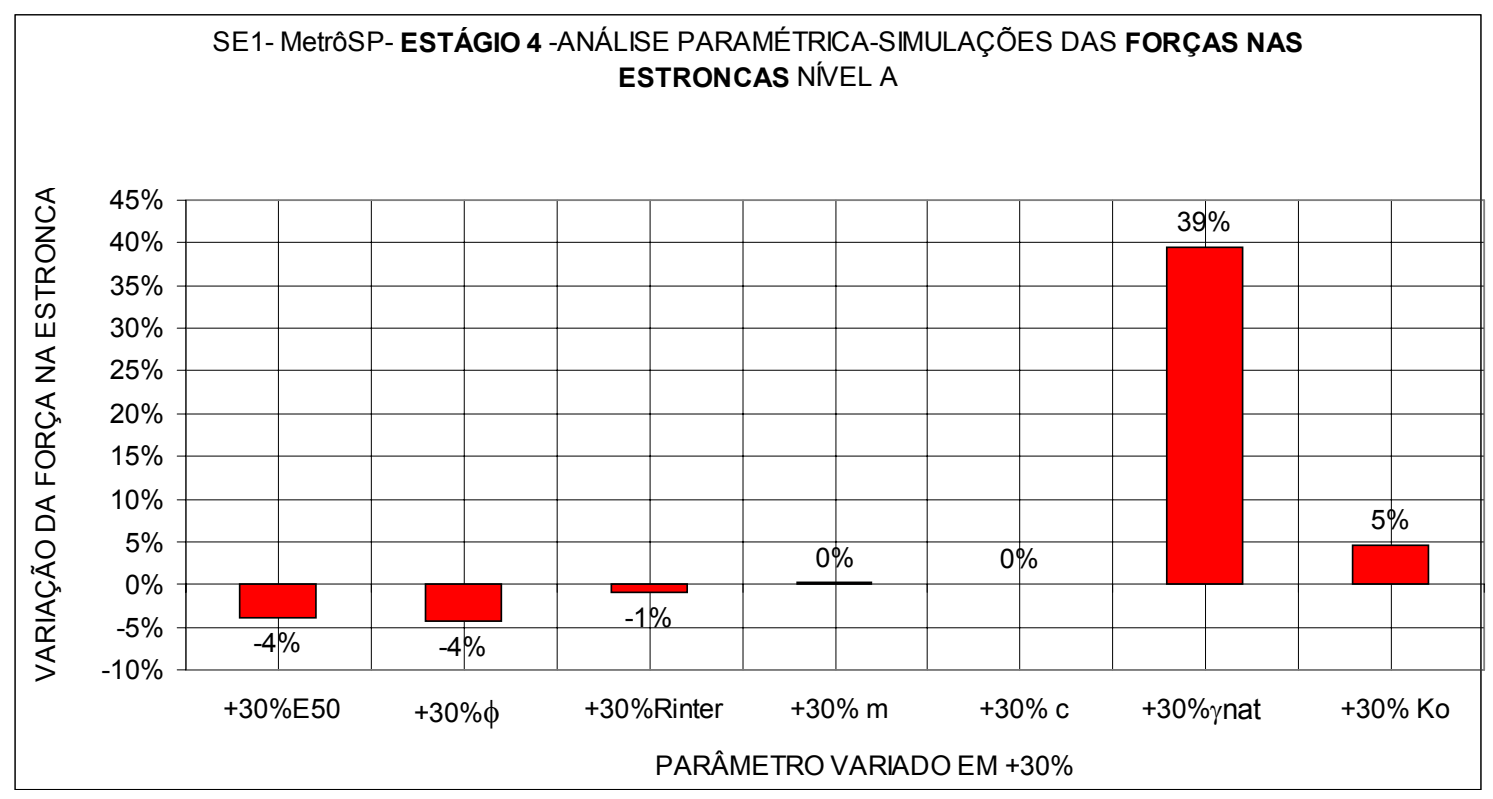

Figura 3-61 Estágio 4-variação das forças nas estroncas do nível A em função da variação individual de parâmetros em $+30 \%$

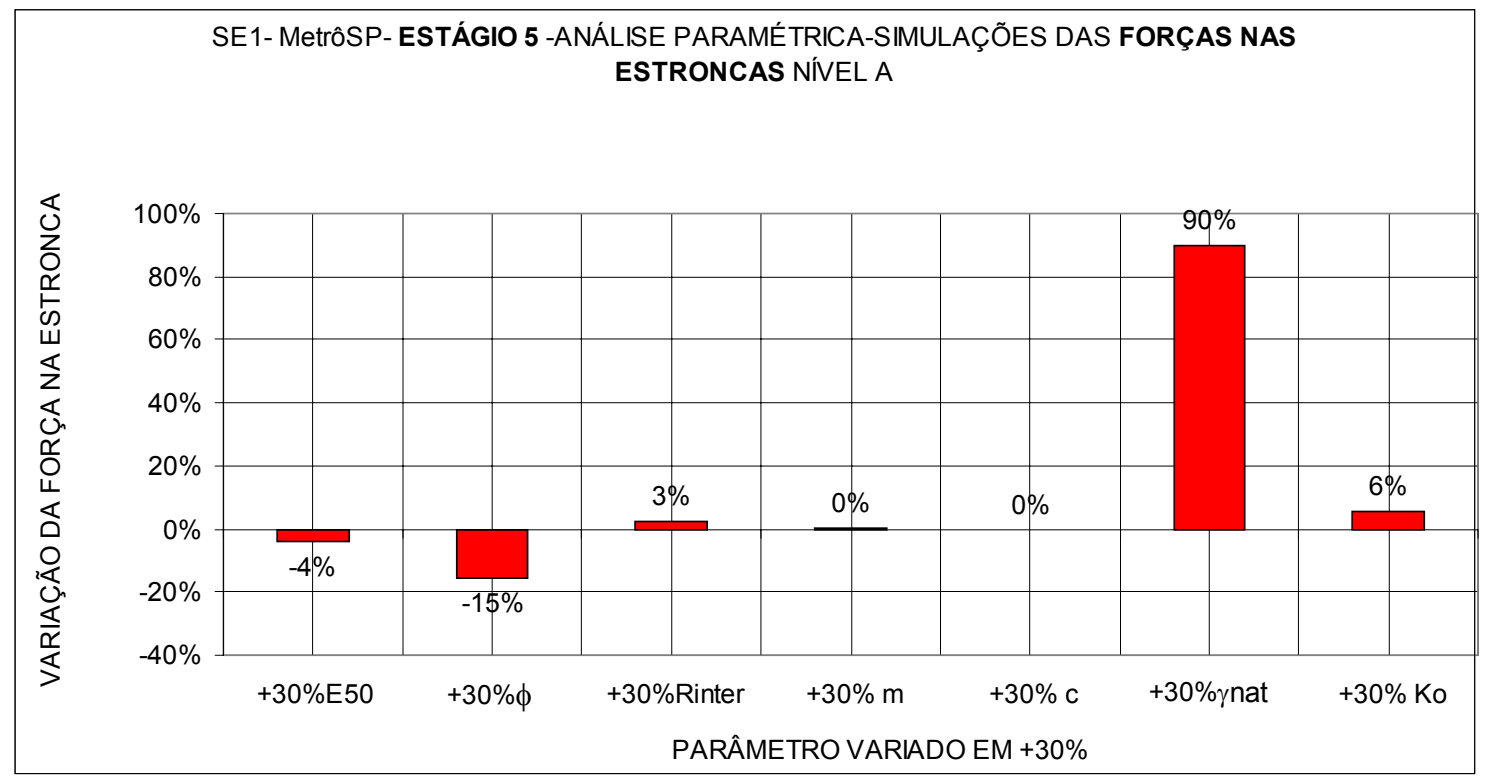

Figura 3-62- Estágio 5-variação das forças nas estroncas do nível A em função da variação individual de parâmetros em $+30 \%$ 


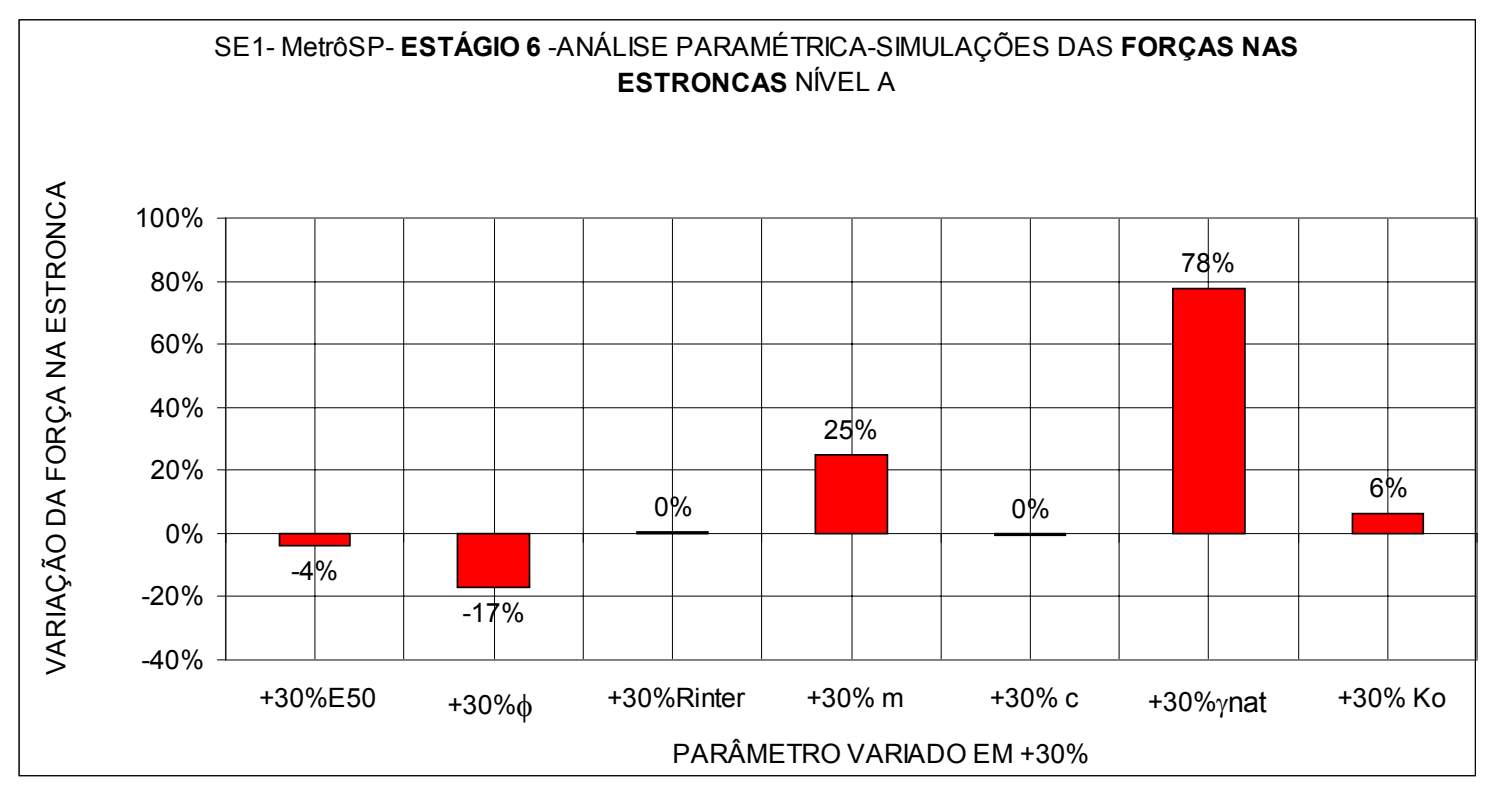

Figura 3-63- Estágio 6-variação das forças nas estroncas do nível A em função da variação individual de parâmetros em $+30 \%$

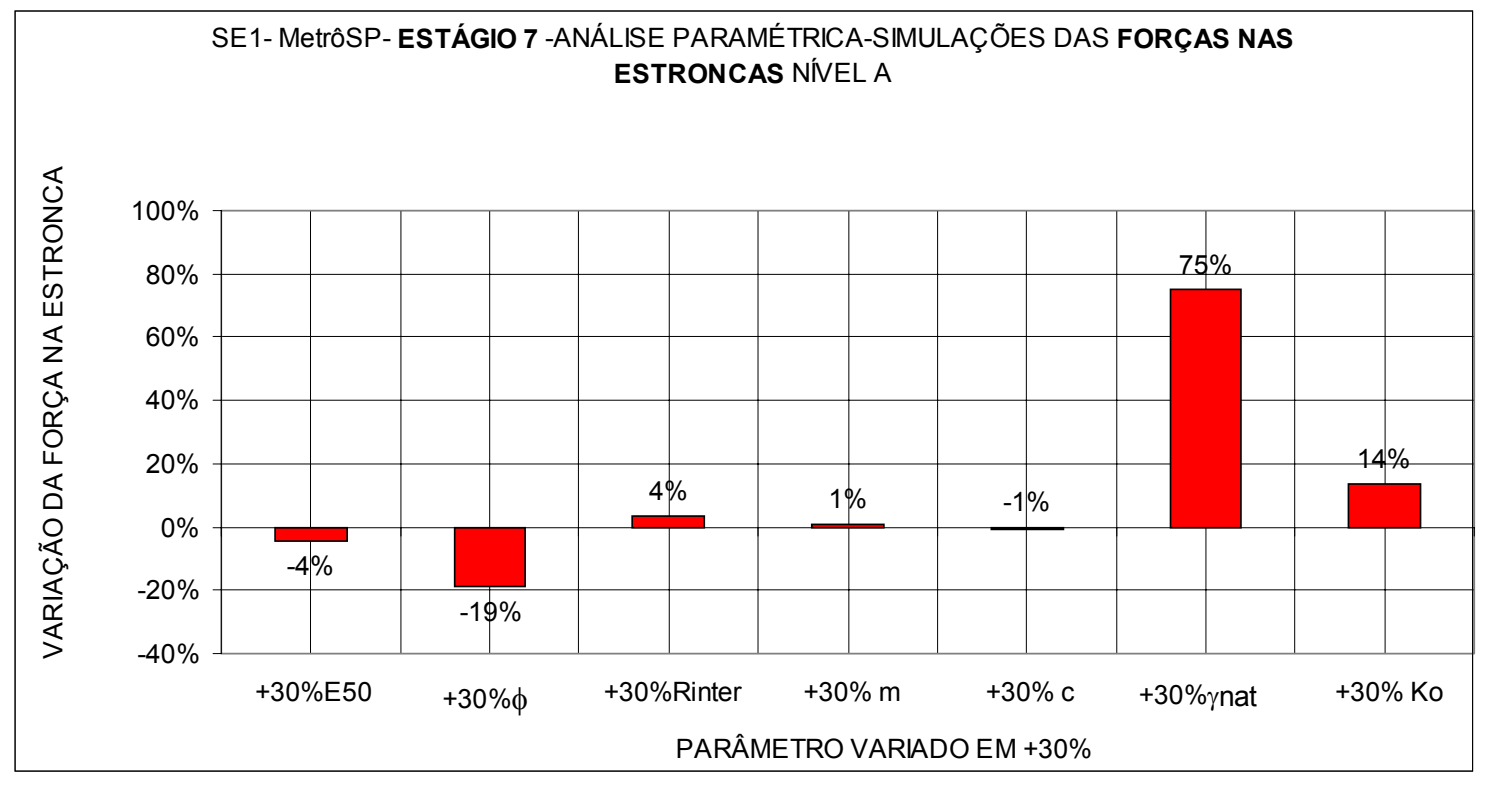

Figura 3-64- Estágio 7-variação das forças nas estroncas do nível A em função da variação individual de parâmetros em $+30 \%$ 


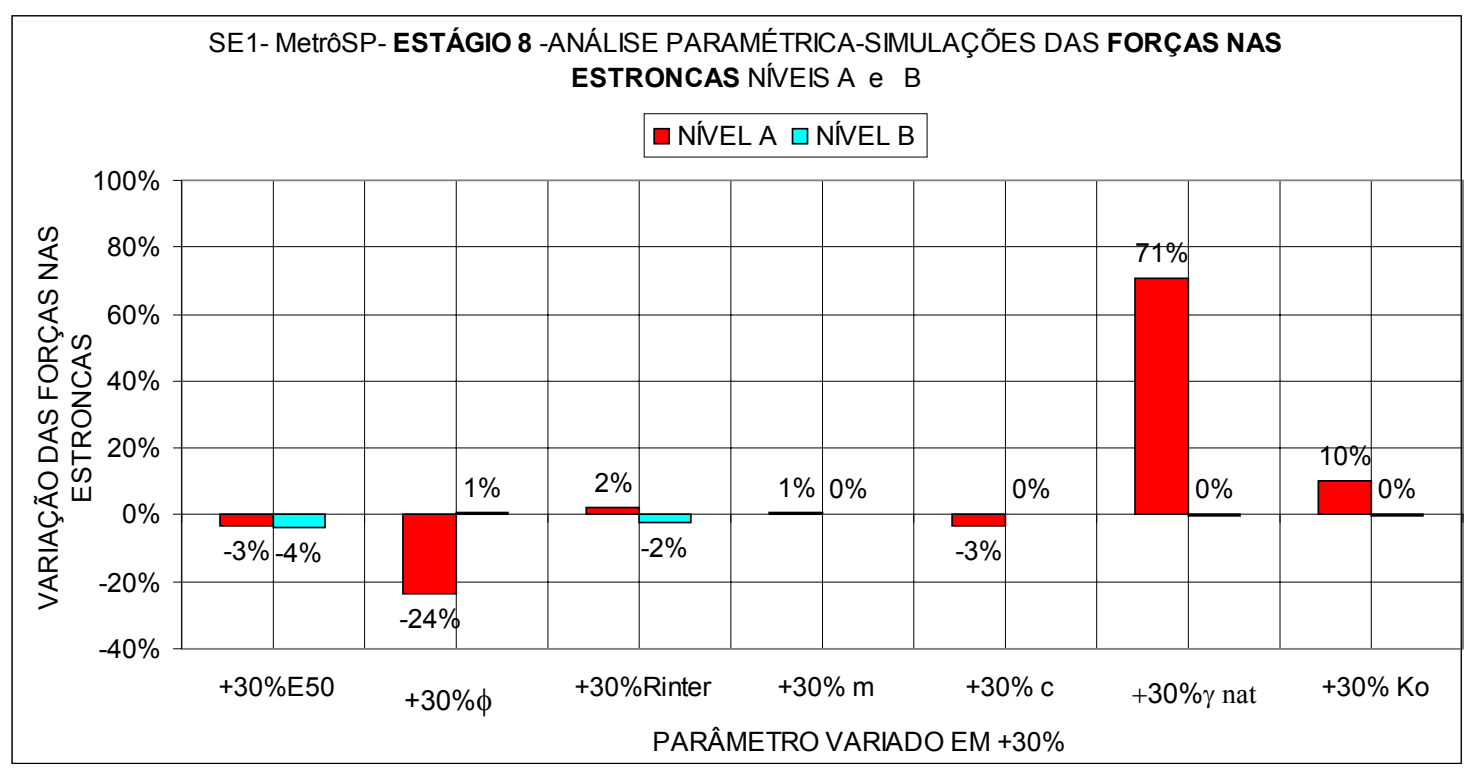

Figura 3-65- Estágio 8-variação das forças nas estroncas do nível A e nível B, em função da variação individual de parâmetros em $+30 \%$

\subsubsection{Resultados da variação de deslocamentos horizontais e verticais devido à variação de $-30 \%$ nos parâmetros}

Apresentam-se da Figura 3-66 à Figura 3-73, os valores de erros em relação aos deslocamentos horizontais de paramentos para 3 pontos do paramento, sendo eles o topo, o centro e o pé do paramento.

Estes resultados foram obtidos por variação individual em -30\% sobre os valores de referência inicial 2 dos parâmetros $E_{50}, \phi, R_{\text {inter }}, m, c, \gamma_{n a t}, K_{o}$. 


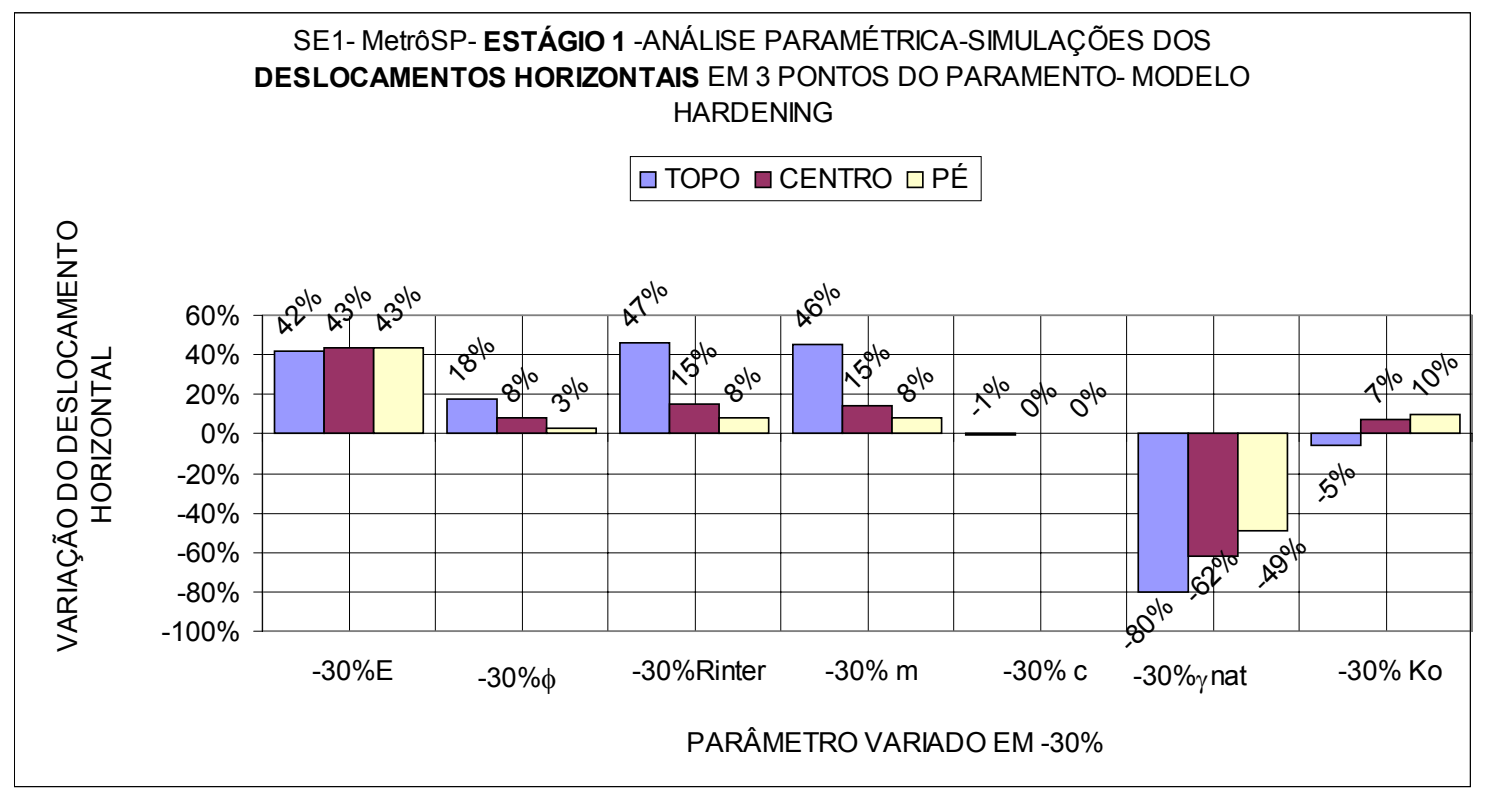

Figura 3-66- Estágio 1-variação dos deslocamentos horizontais de 3 pontos do paramento em função da variação individual de parâmetros em -30\%

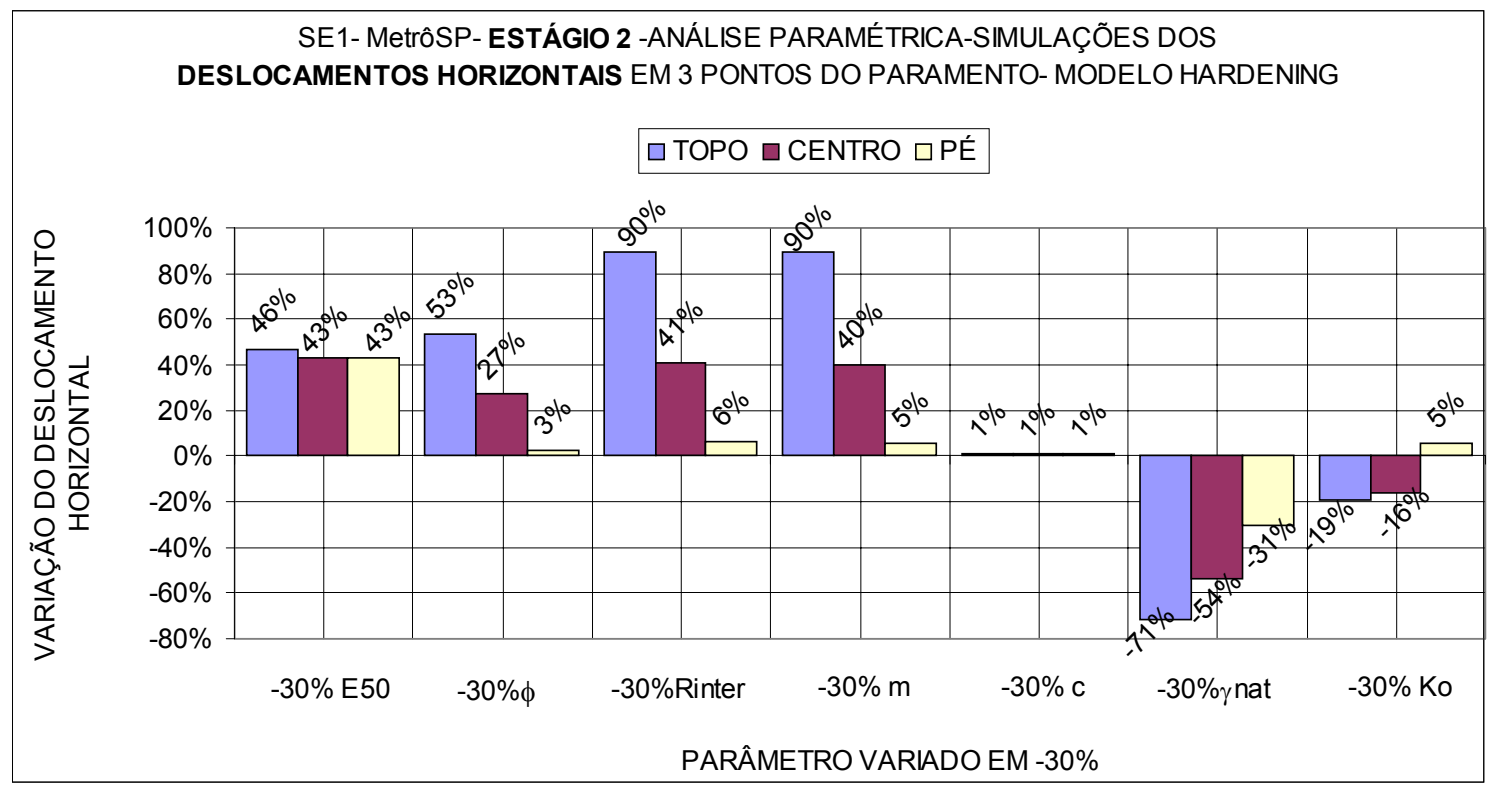

Figura 3-67 -Estágio 2-variação dos deslocamentos horizontais de 3 pontos do paramento em função da variação individual de parâmetros em -30\% 


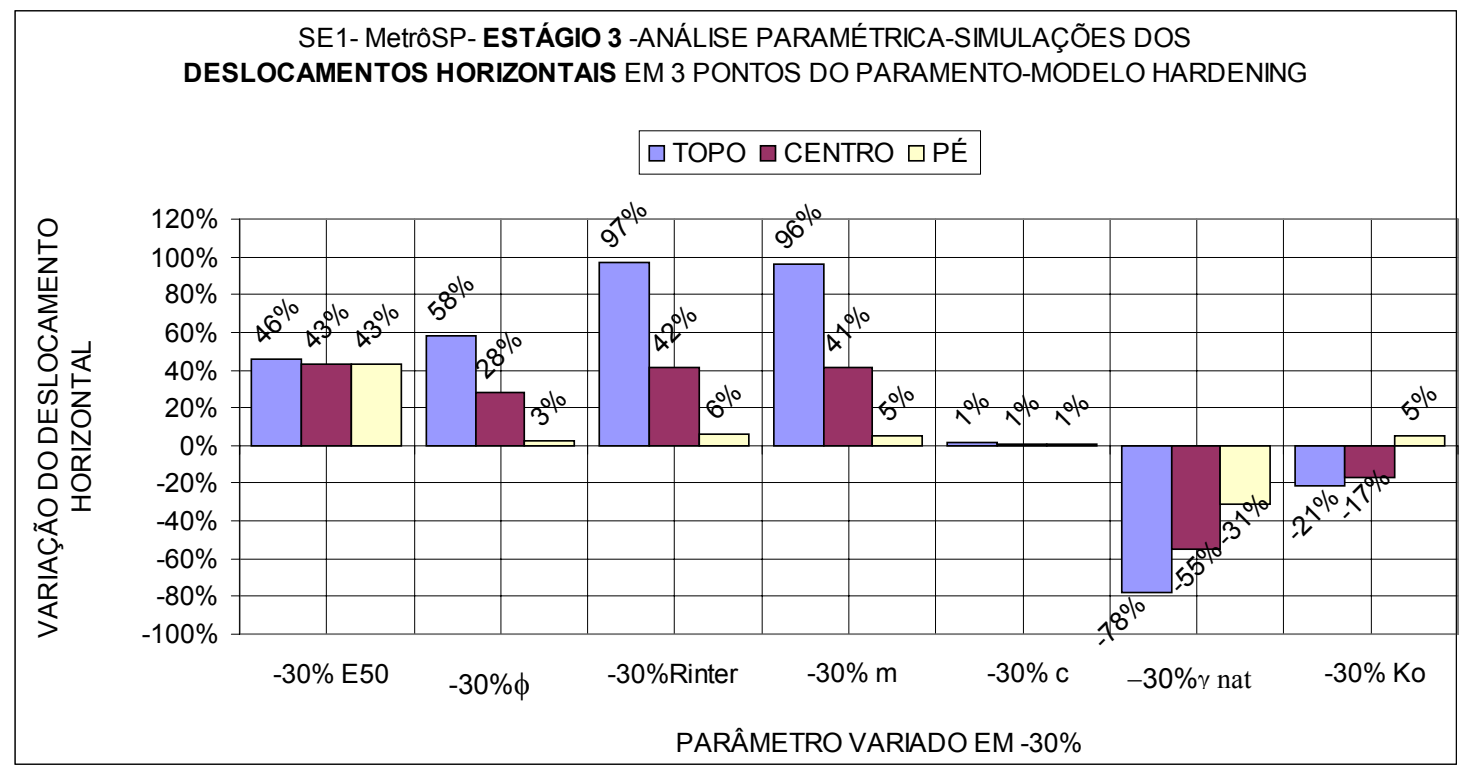

Figura 3-68-Estágio 3-variação dos deslocamentos horizontais de 3 pontos do paramento em função da variação individual de parâmetros em -30\%

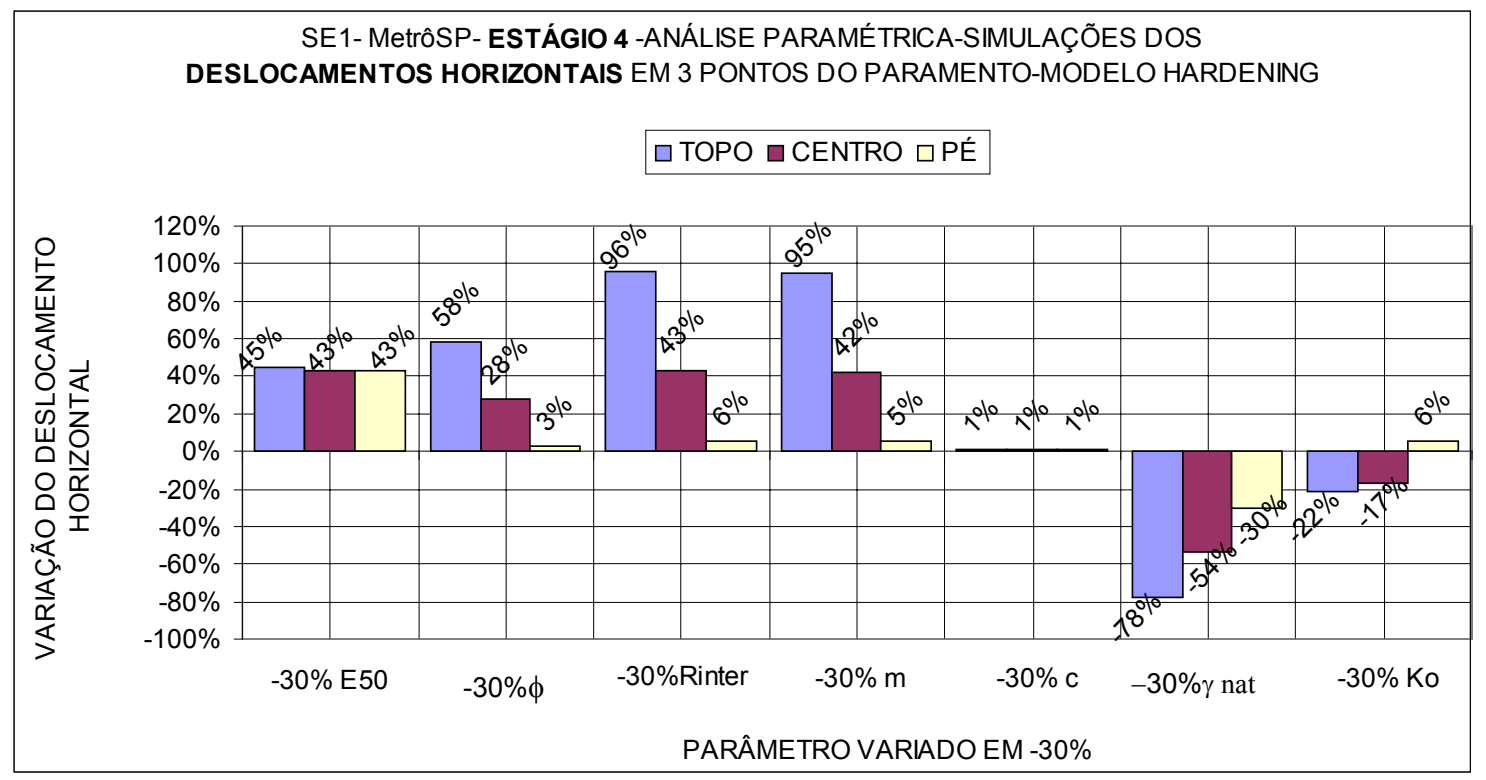

Figura 3-69-Estágio 4-variação dos deslocamentos horizontais de 3 pontos do paramento em função da variação individual de parâmetros em $\mathbf{- 3 0 \%}$ 


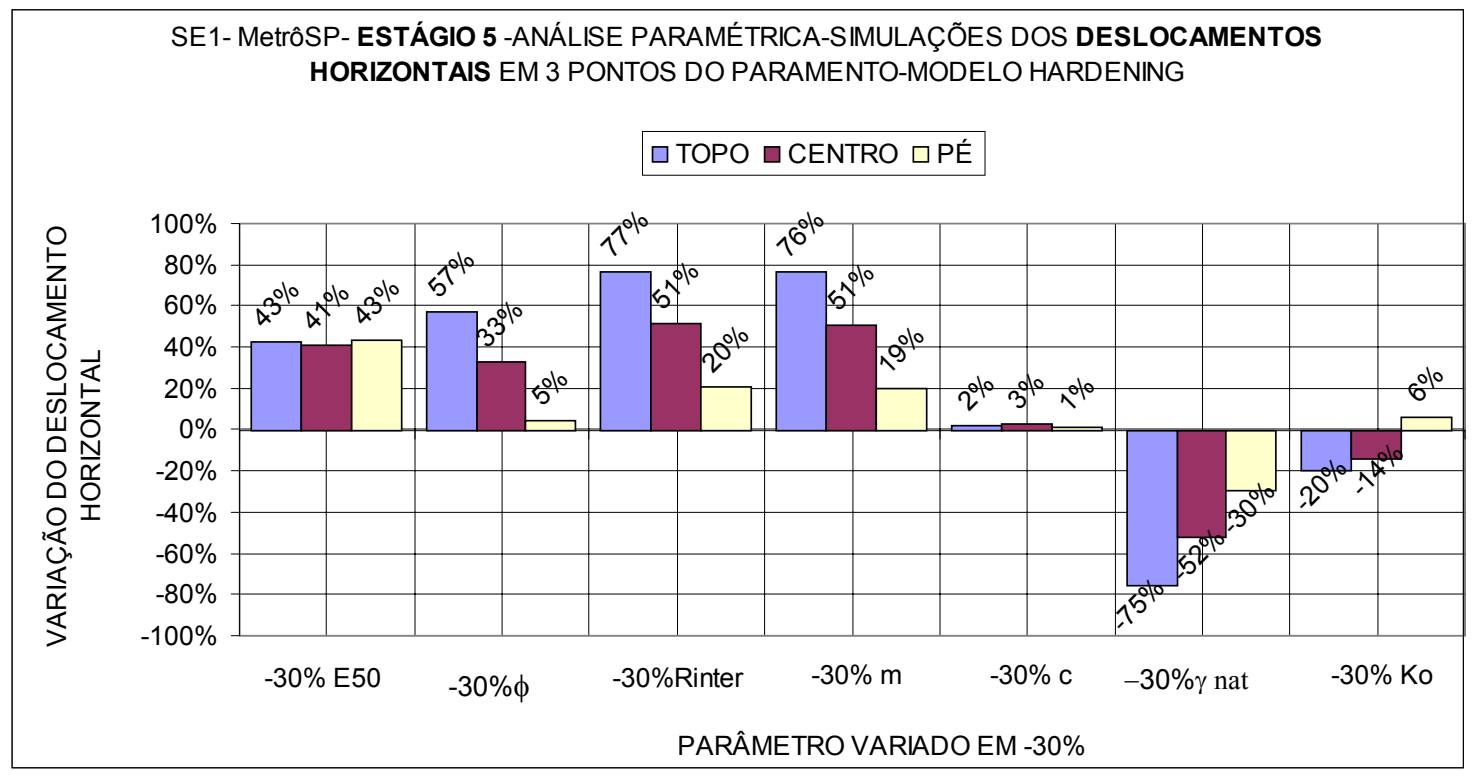

Figura 3-70-Estágio 5-variação dos deslocamentos horizontais de 3 pontos do paramento em função da variação individual de parâmetros em -30\%

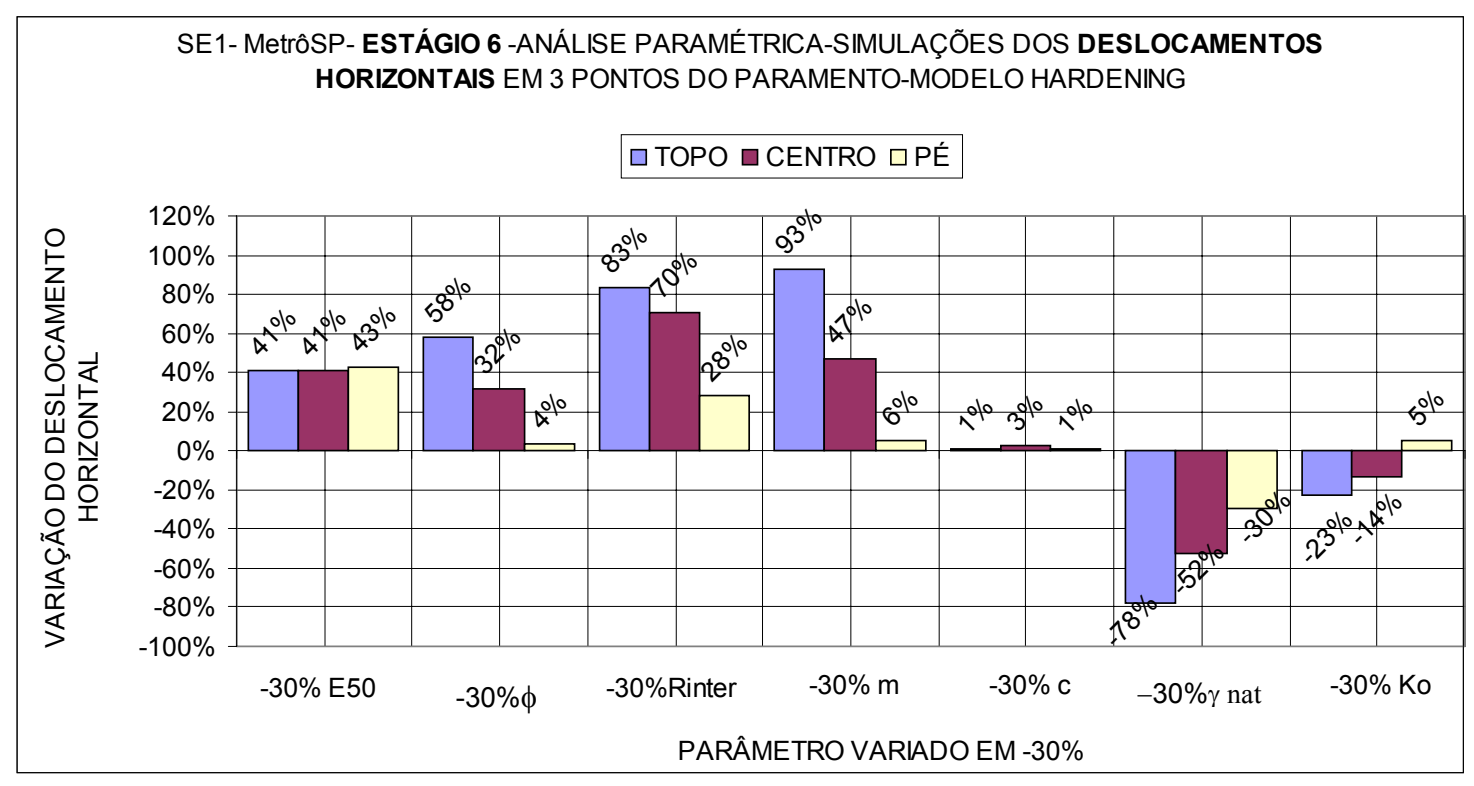

Figura 3-71-Estágio 6-variação dos deslocamentos horizontais de 3 pontos do paramento em função da variação individual de parâmetros em $\mathbf{- 3 0 \%}$ 


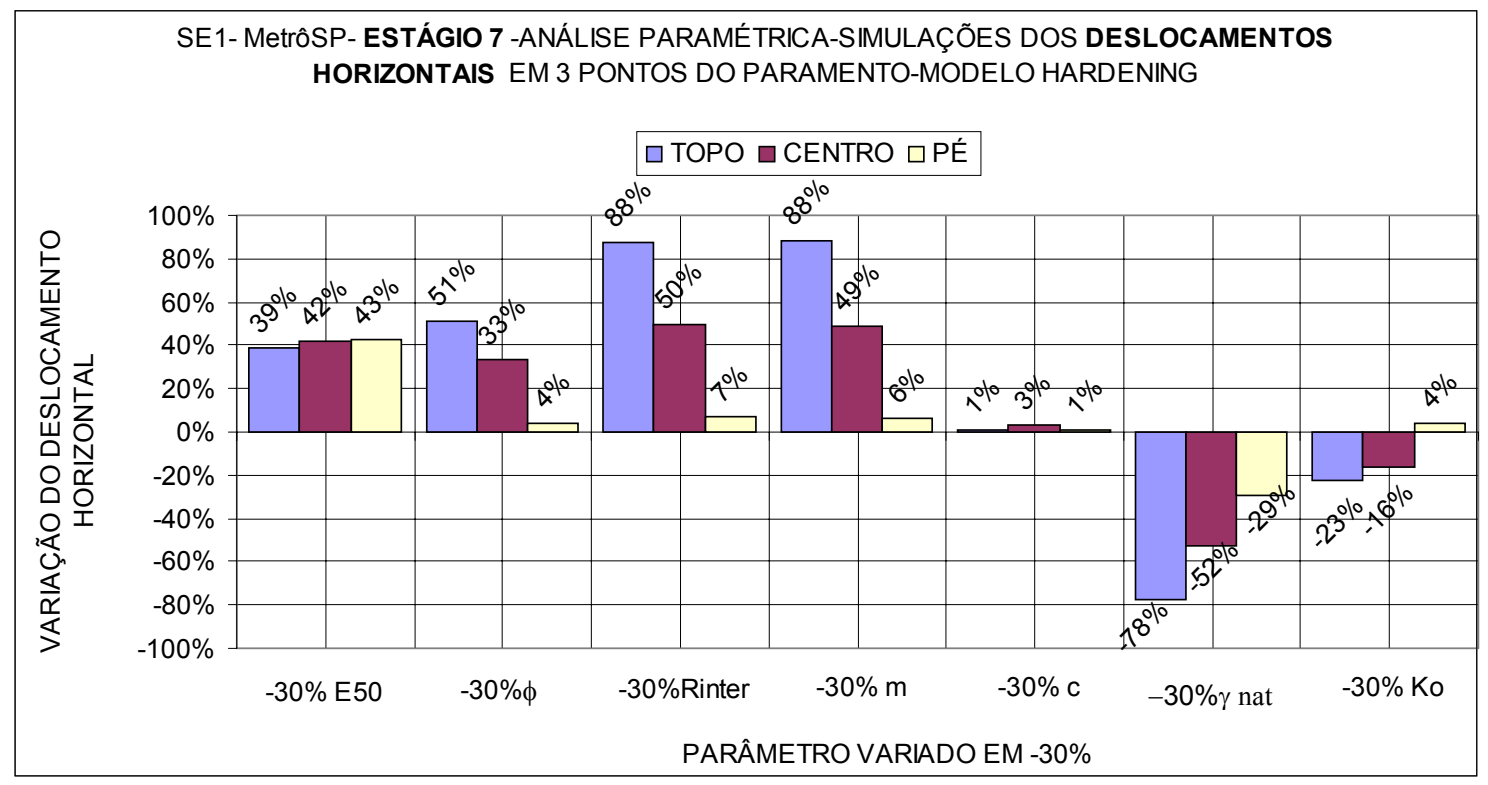

Figura 3-72-Estágio 7-variação dos deslocamentos horizontais de 3 pontos do paramento em função da variação individual de parâmetros em $\mathbf{- 3 0 \%}$

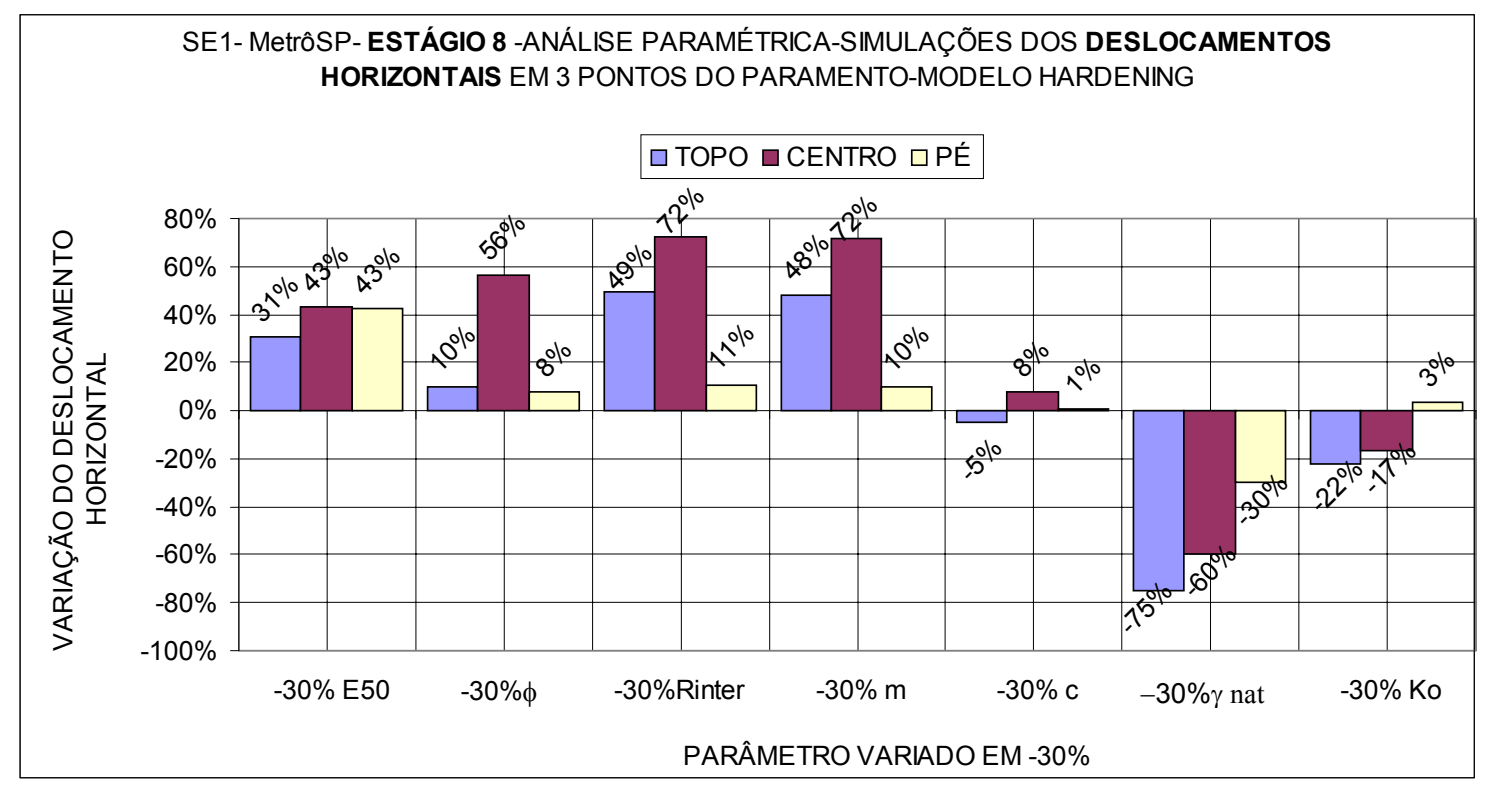

Figura 3-73-Estágio 8-variação dos deslocamentos horizontais de 3 pontos do paramento em função da variação individual de parâmetros em -30\% 
Apresentam-se da Figura 3-74 à Figura 3-81, os valores de erros em relação aos deslocamentos verticais do paramento para 3 pontos, sendo eles o topo, o centro e o pé.

Estes resultados foram obtidos por variação individual em -30\% sobre os valores de referência inicial 2 dos parâmetros $E_{50}, \phi, R_{\text {inter }}, m, c, \gamma_{\text {nat }}, K_{0}$.

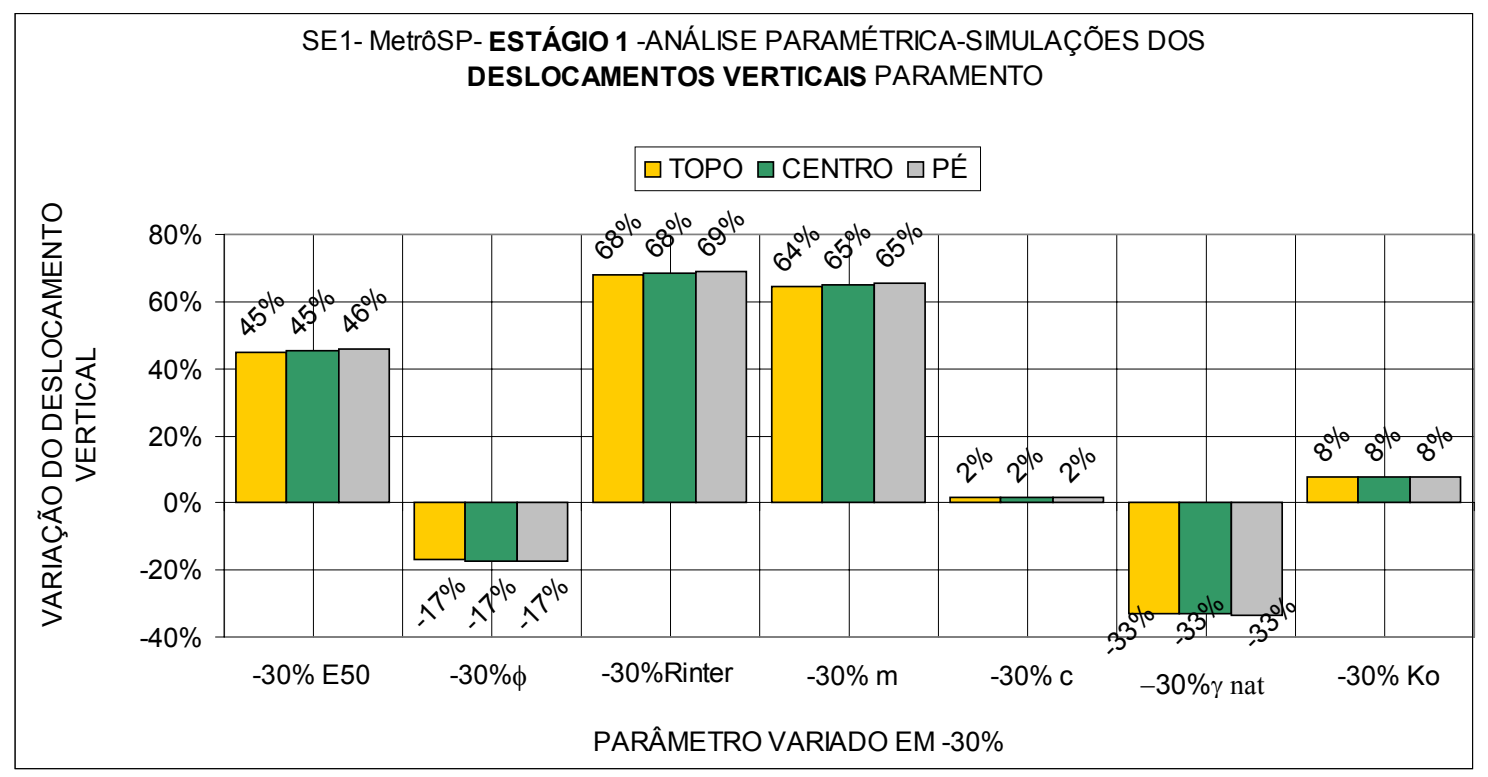

Figura 3-74 Estágio 1-variação dos deslocamentos verticais de 3 pontos do paramento em função da variação individual de parâmetros em -30\% 


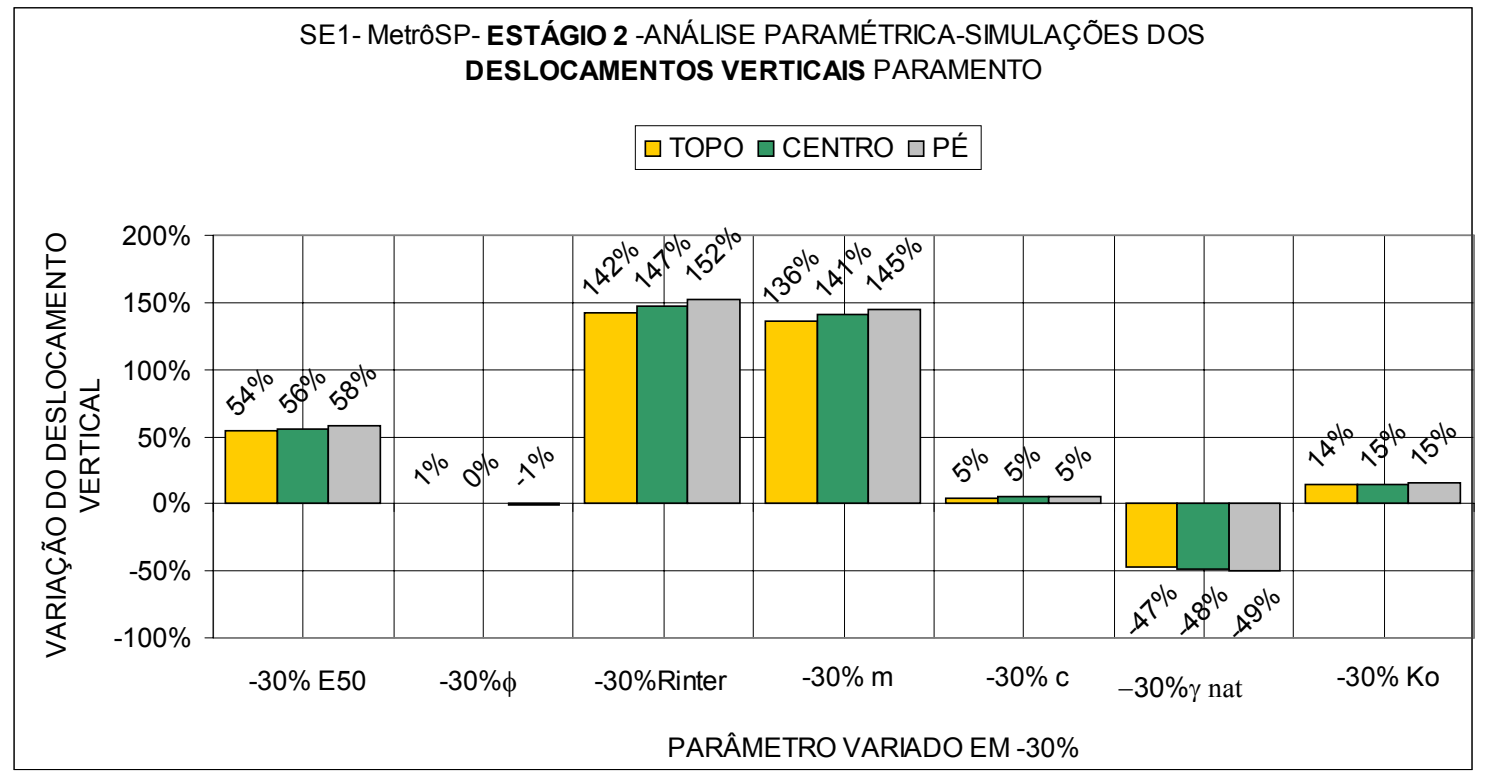

Figura 3-75 Estágio 2-variação dos deslocamentos verticais de 3 pontos do paramento em função da variação individual de parâmetros em $\mathbf{- 3 0 \%}$

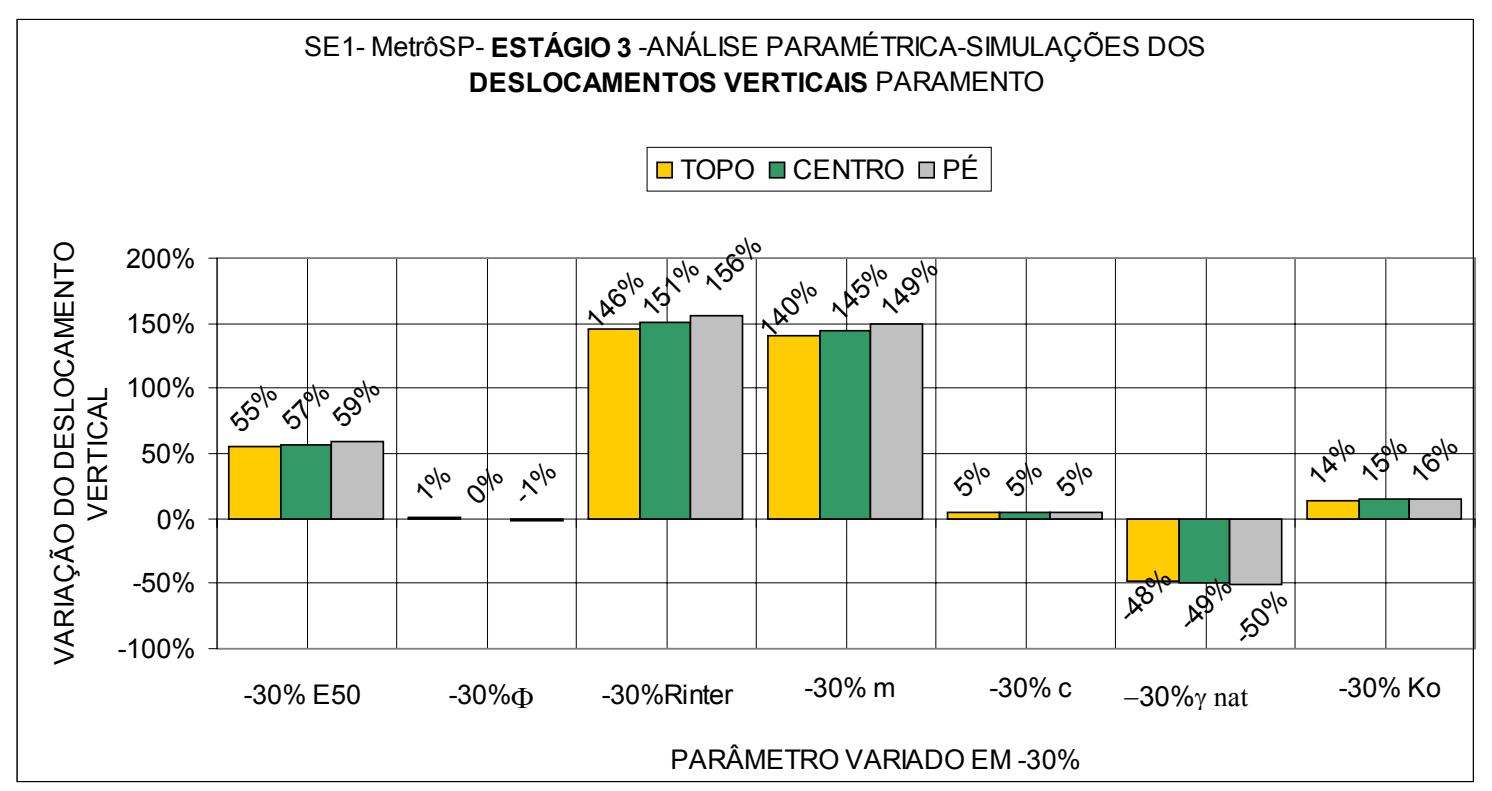

Figura 3-76 Estágio 3-variação dos deslocamentos verticais de 3 pontos do paramento em função da variação individual de parâmetros em -30\% 


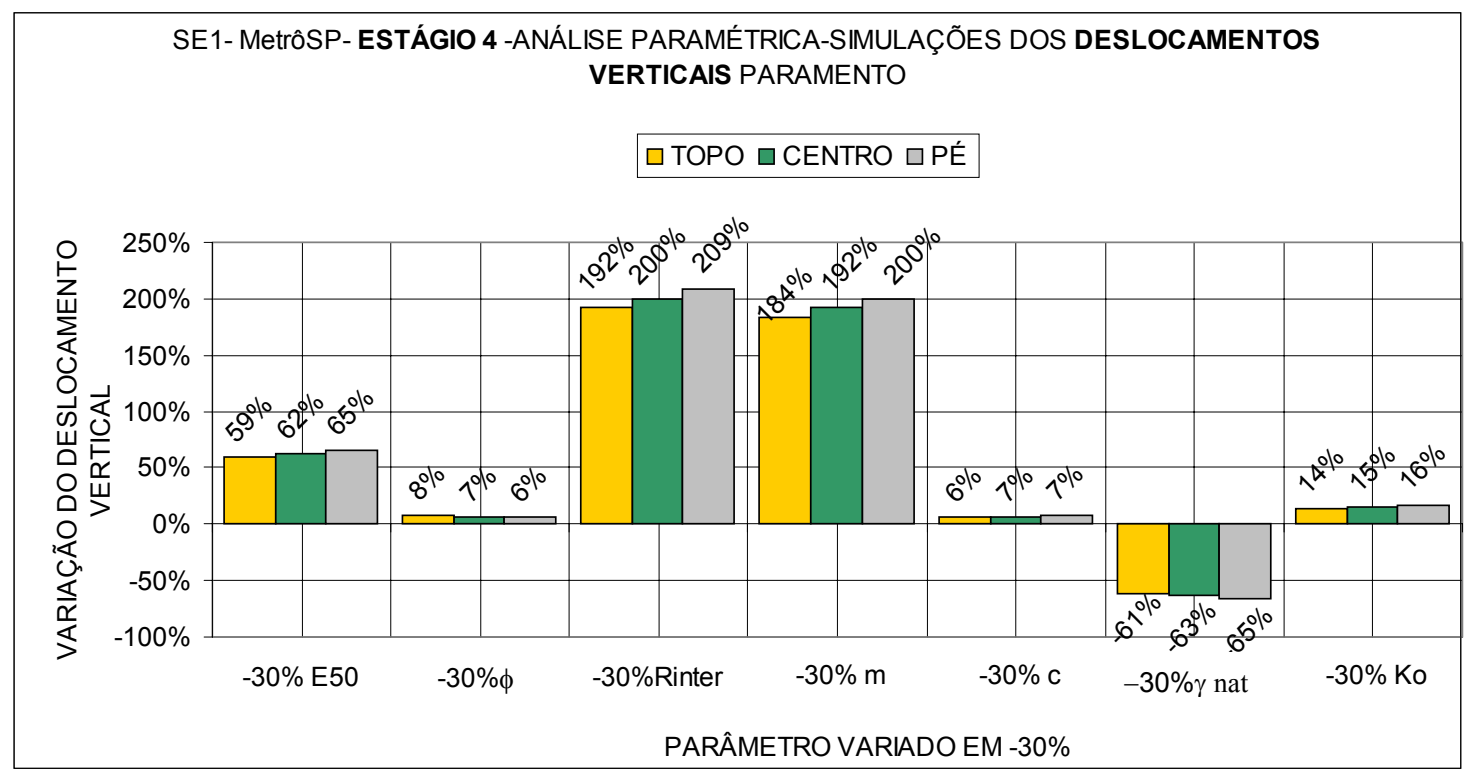

Figura 3-77- Estágio 4-variação dos deslocamentos verticais de 3 pontos do paramento em função da variação individual de parâmetros em $\mathbf{- 3 0 \%}$

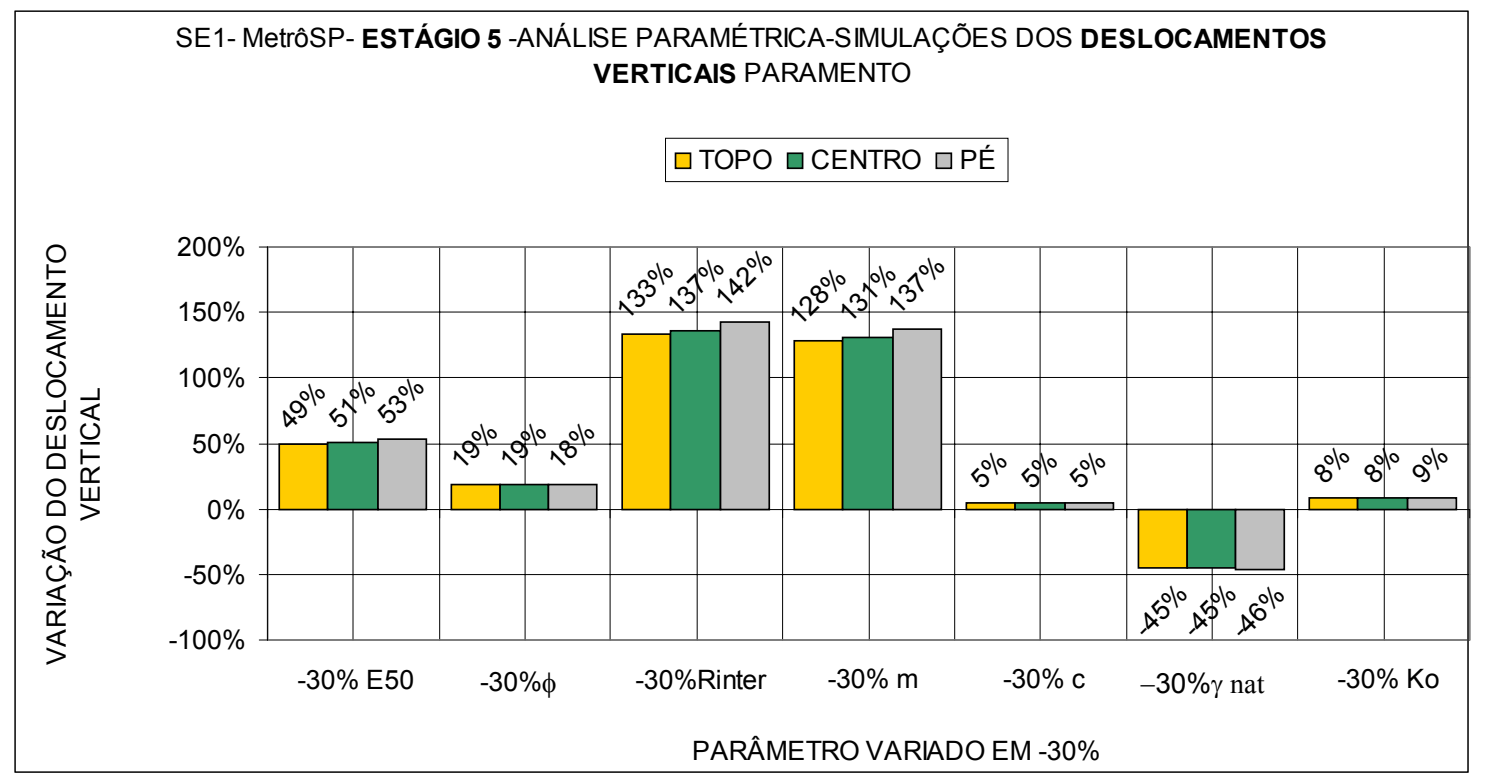

Figura 3-78 -Estágio 5-variação dos deslocamentos verticais de 3 pontos do paramento em função da variação individual de parâmetros em $\mathbf{- 3 0 \%}$ 


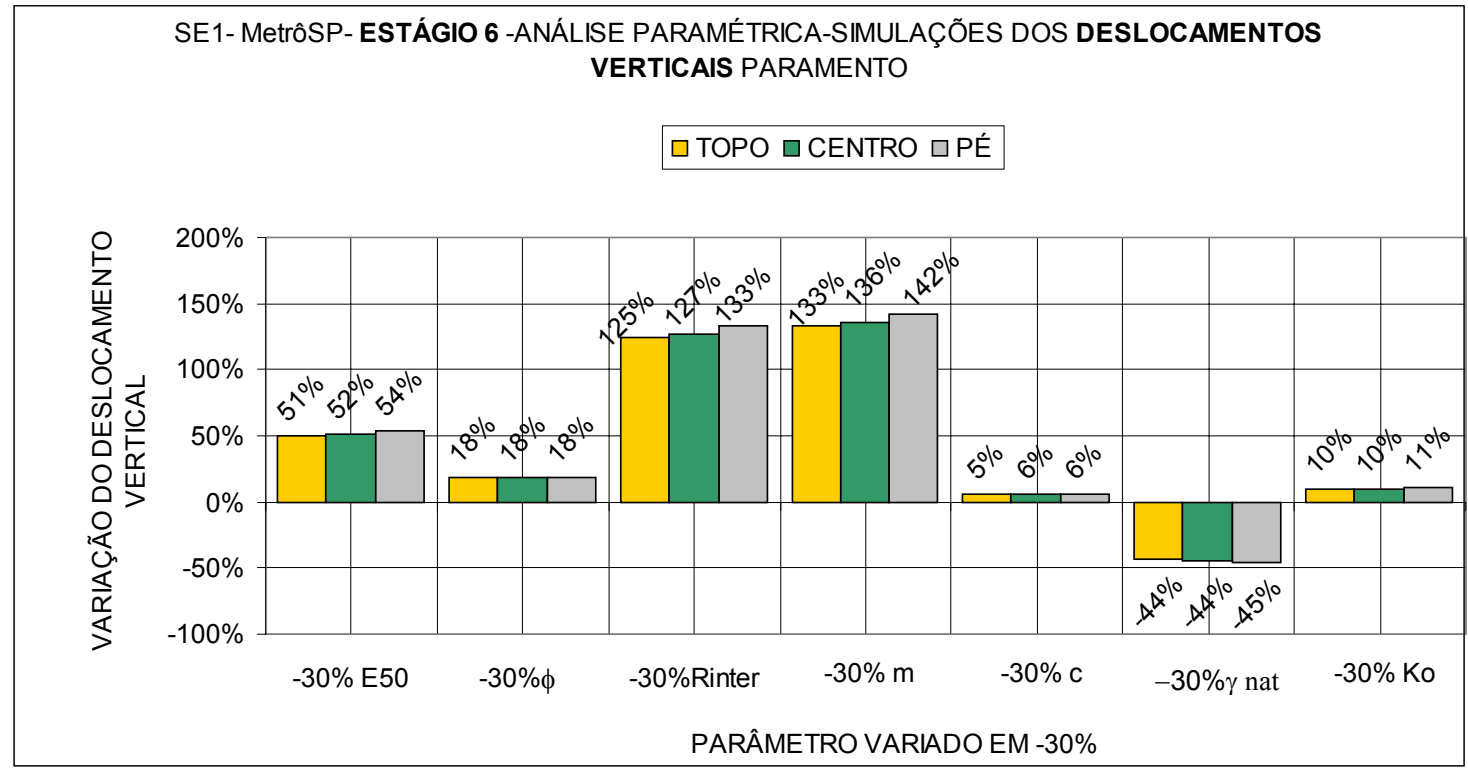

Figura 3-79- Estágio 6-variação dos deslocamentos verticais de 3 pontos do paramento em função da variação individual de parâmetros em $\mathbf{- 3 0 \%}$

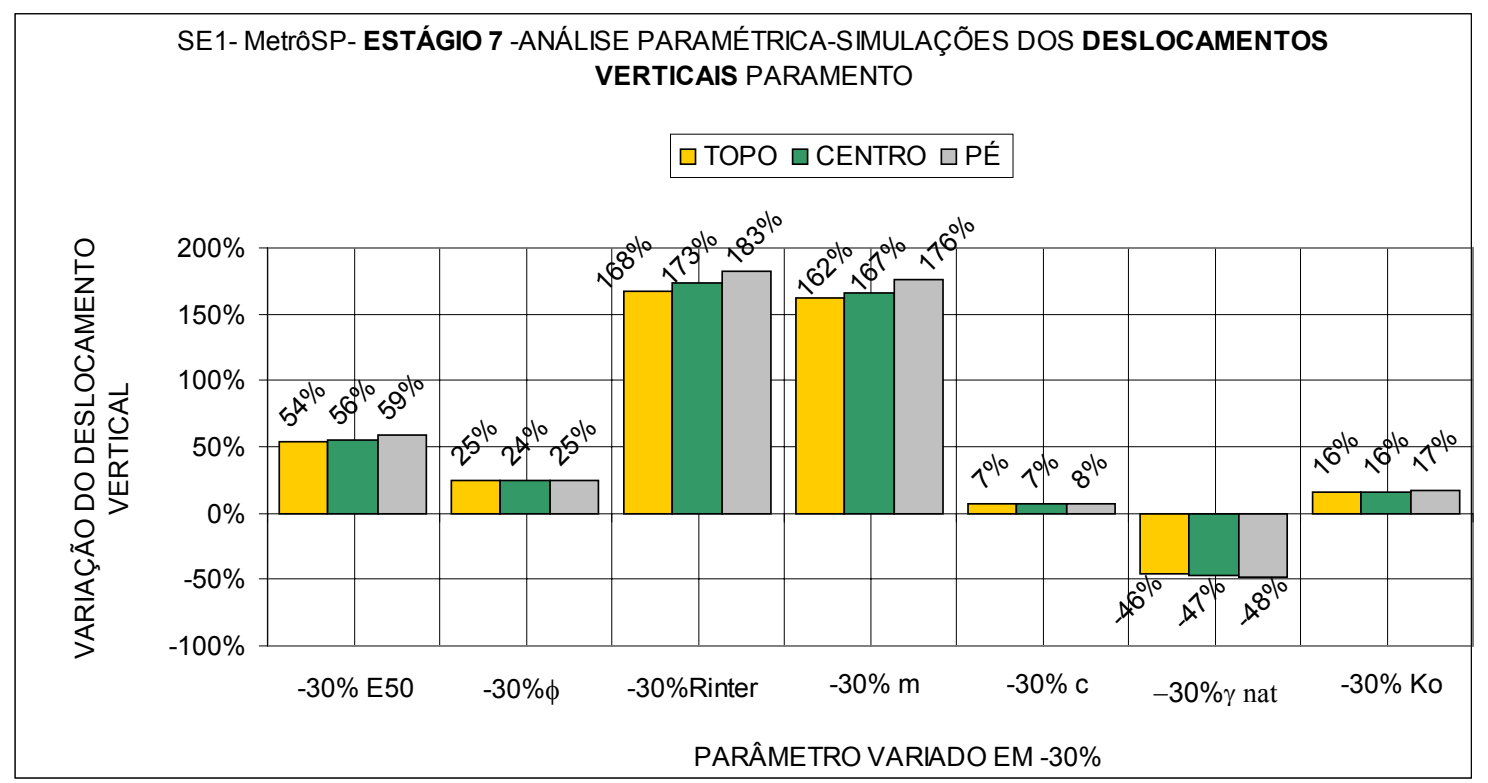

Figura 3-80 -Estágio 7-variação dos deslocamentos verticais de 3 pontos do paramento em função da variação individual de parâmetros em -30\% 


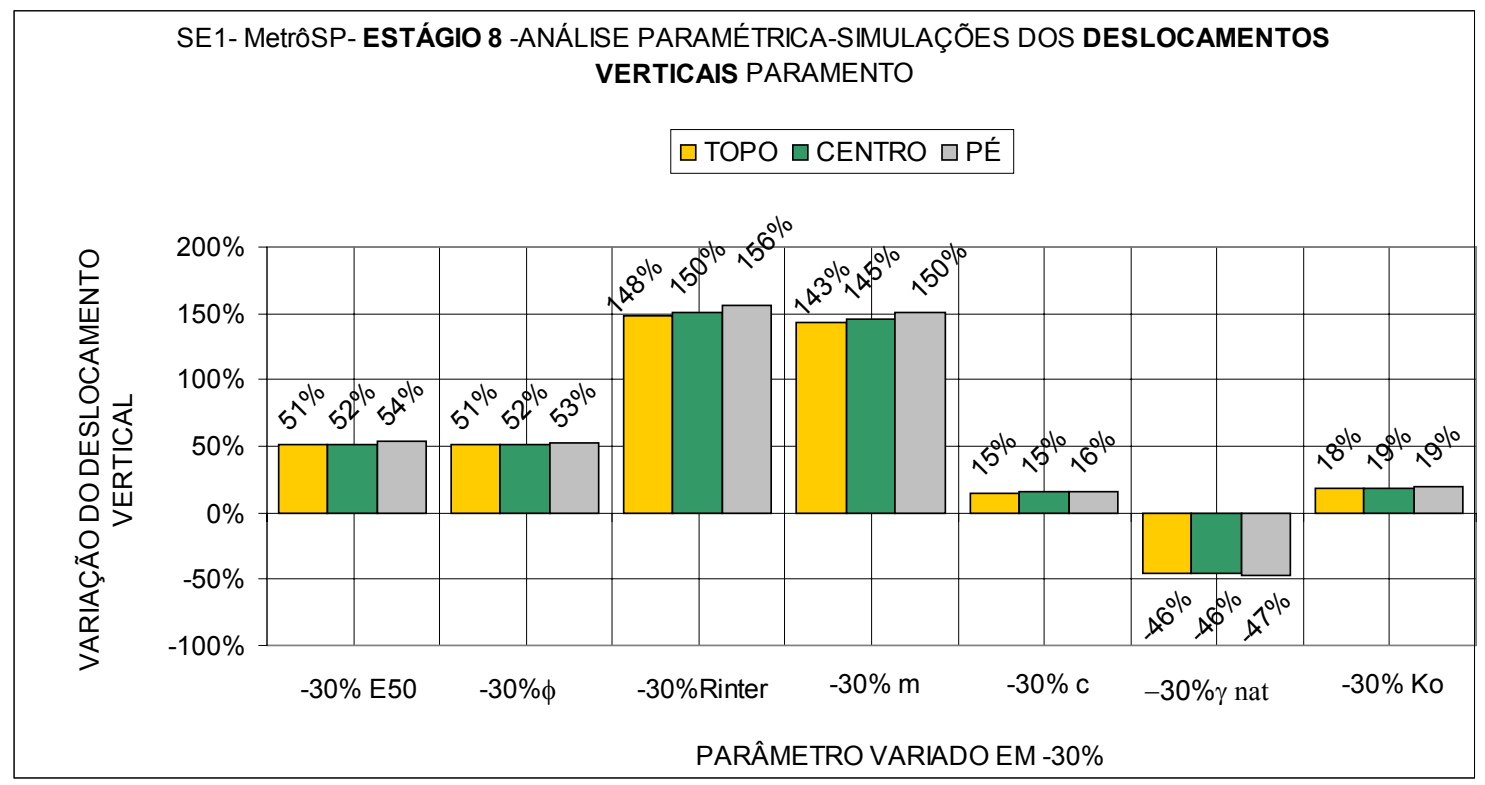

Figura 3-81- Estágio 8-variação dos deslocamentos verticais de 3 pontos do paramento para o nível A e nível B em função da variação individual de parâmetros em $\mathbf{- 3 0 \%}$

\subsection{4 -Resultados da variação das forças nas estroncas devido à variação de $-\mathbf{- 3 0} \%$ nos parâmetros}

Apresentam-se da Figura 3-82 à Figura 3-86, os valores de erros em relação às forças nas estroncas do nível A e na Figura 3-87 em relação também ao nível B.

Estes resultados foram obtidos por variação individual em -30\% sobre os valores de referência inicial 2 dos parâmetros $E_{50}, \phi, R_{\text {inter }}, m, c, \gamma_{\text {nat }}, K_{0}$. 


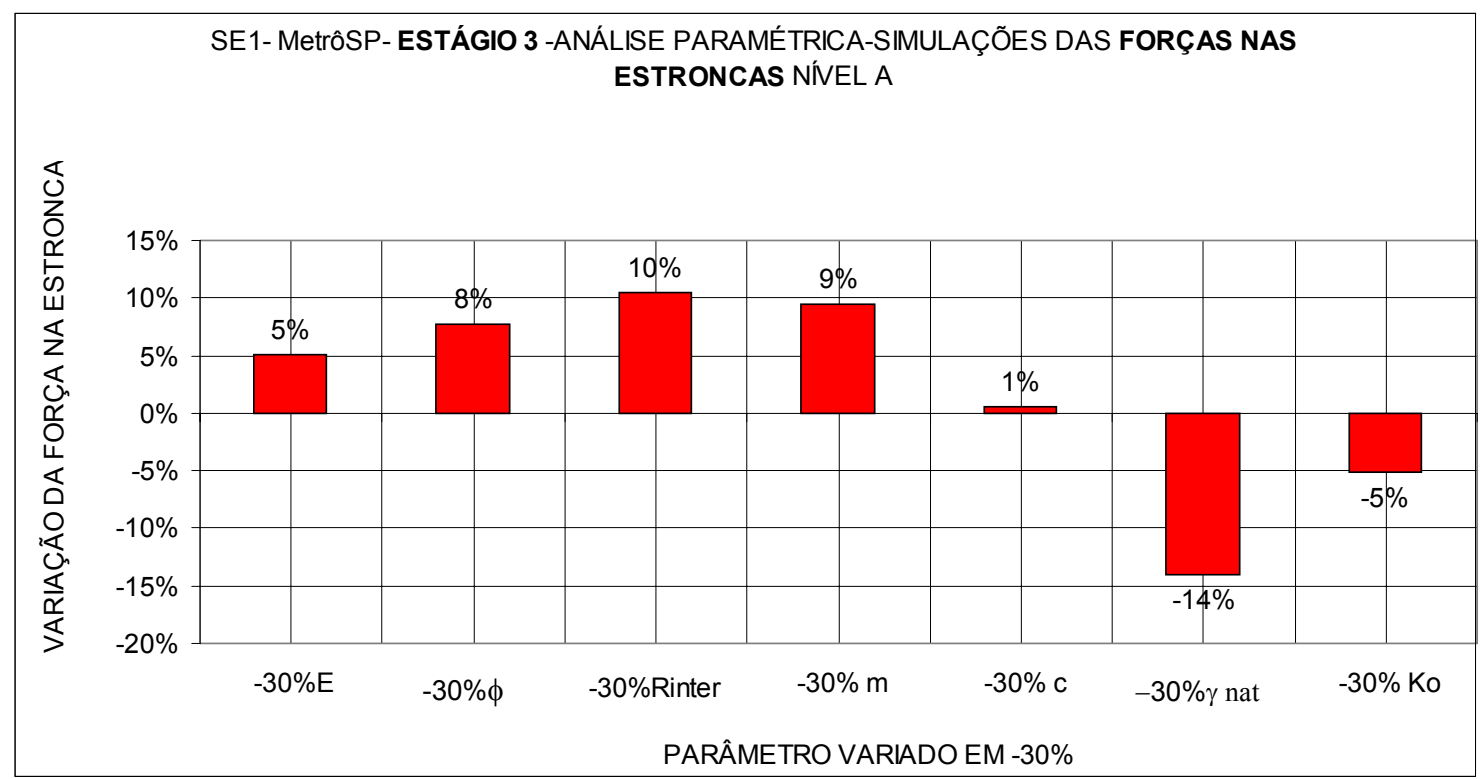

Figura 3-82- Estágio 3-variação das forças nas estroncas do nível A, em função da variação individual de parâmetros em -30\%

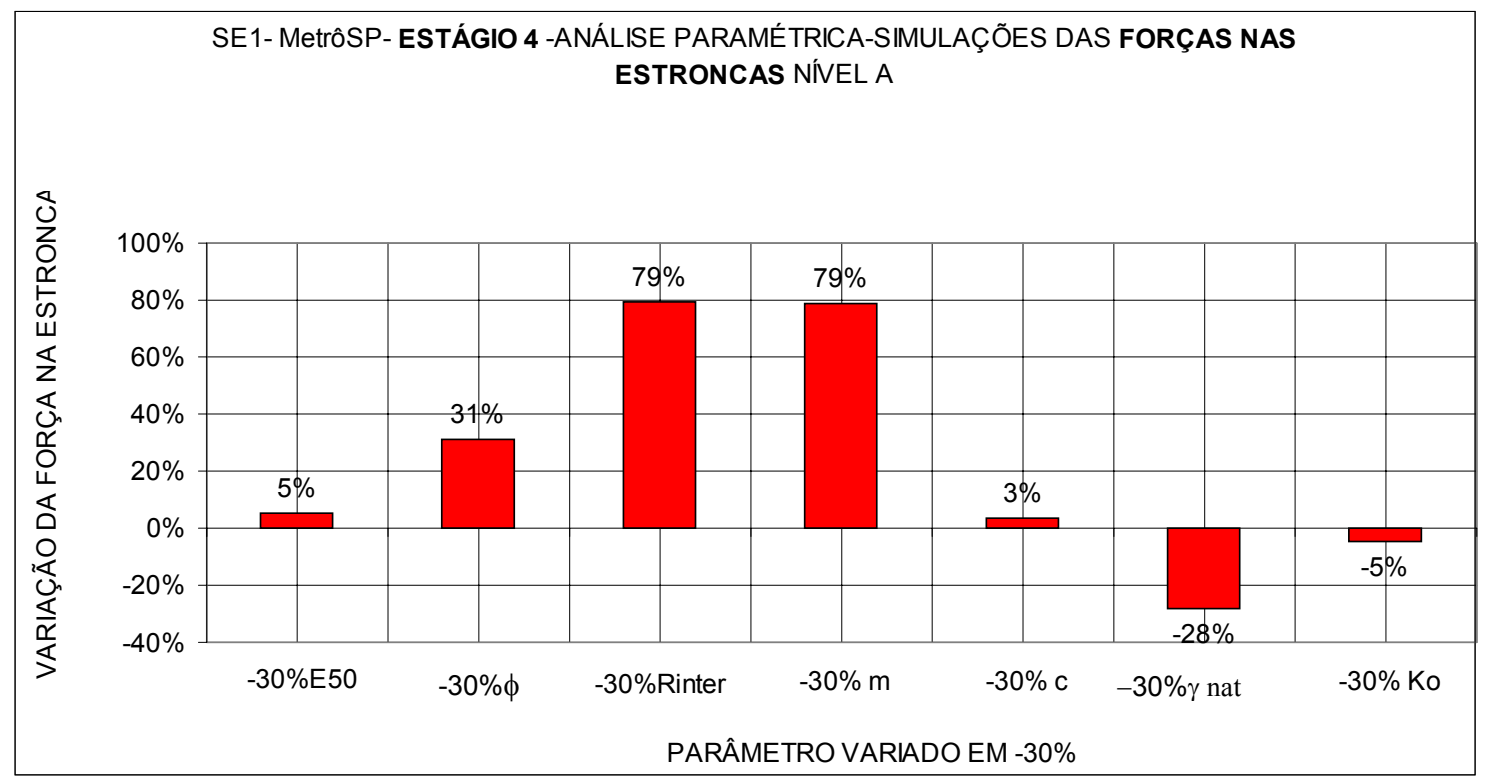

Figura 3-83 -Estágio 4-variação das forças nas estroncas do nível A, em função da variação individual de parâmetros em $\mathbf{- 3 0 \%}$ 


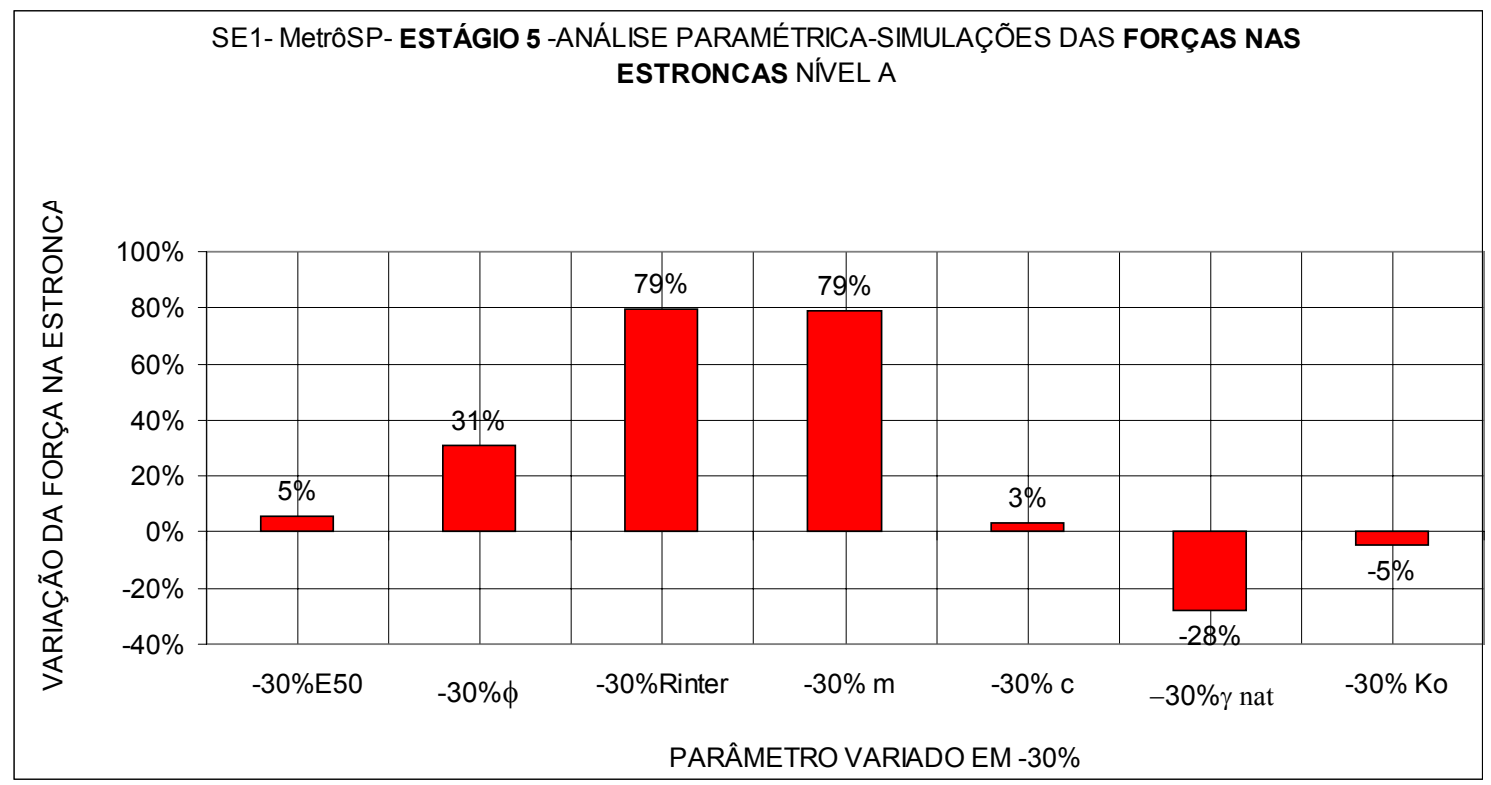

Figura 3-84- Estágio 5-variação das forças nas estroncas do nível A, em função da variação individual de parâmetros em $\mathbf{- 3 0 \%}$

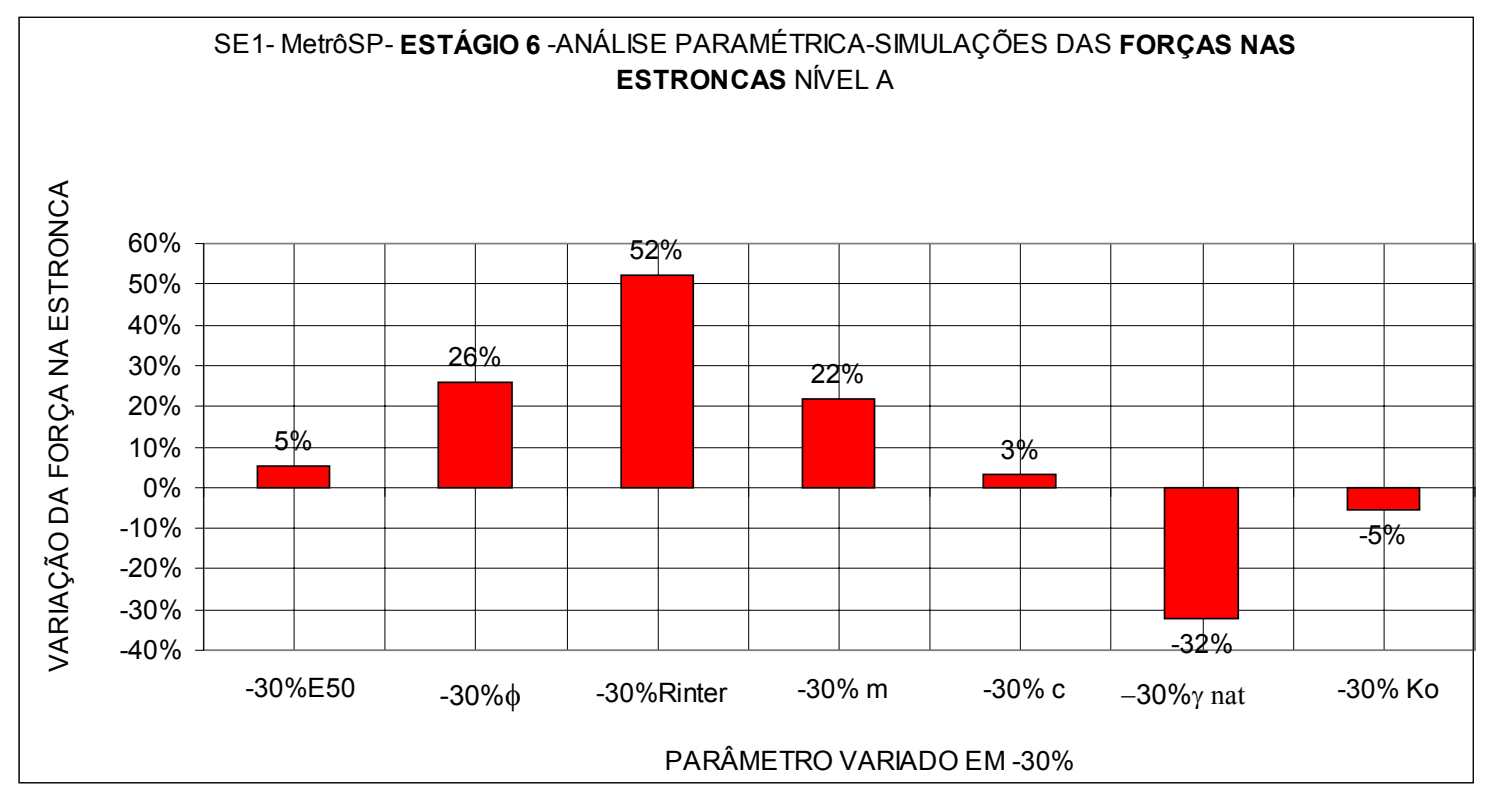

Figura 3-85 Estágio 6-variação das forças nas estroncas do nível A, em função da variação individual de parâmetros em $\mathbf{- 3 0 \%}$ 


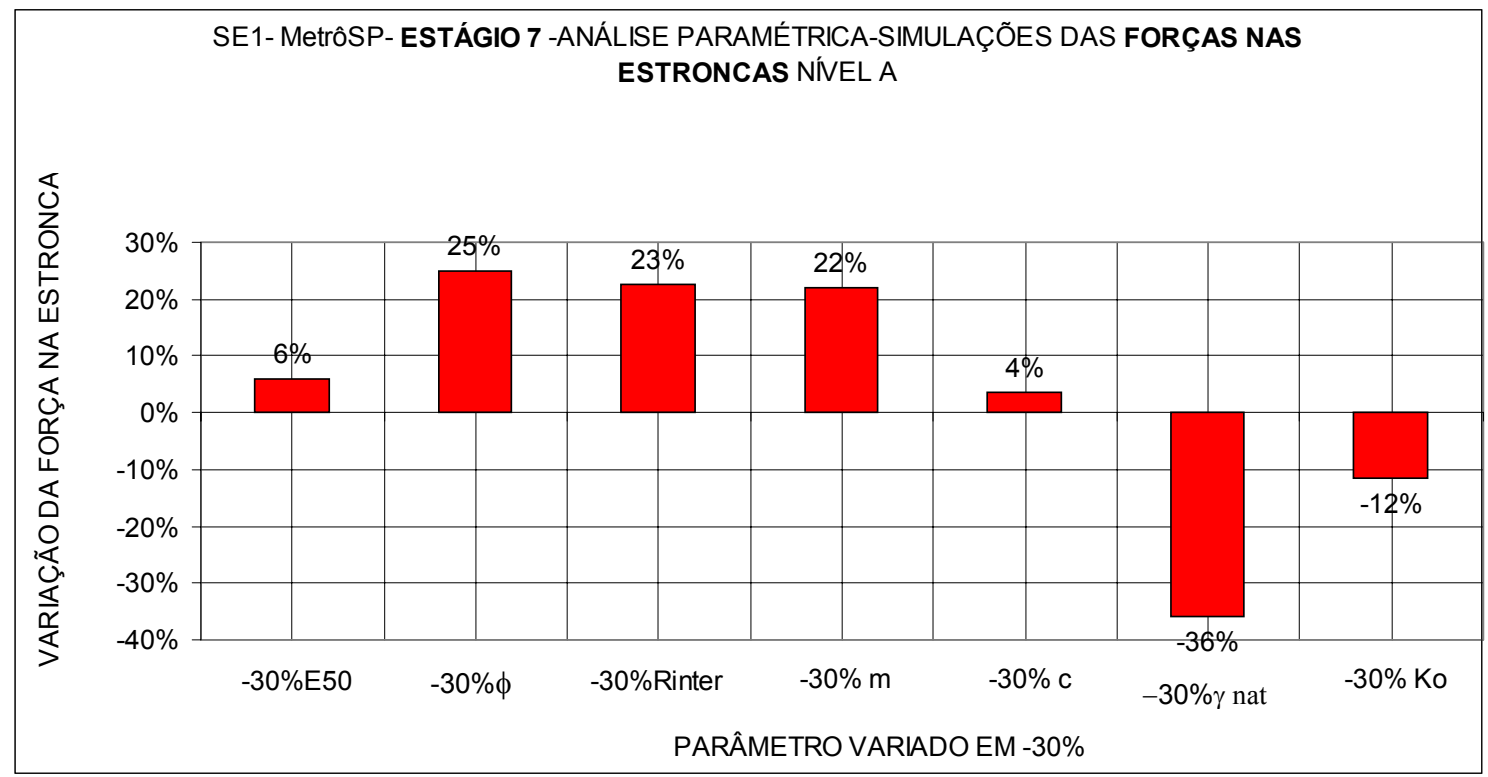

Figura 3-86- Estágio 7-variação das forças nas estroncas do nível A, em função da variação individual de parâmetros em $\mathbf{- 3 0 \%}$

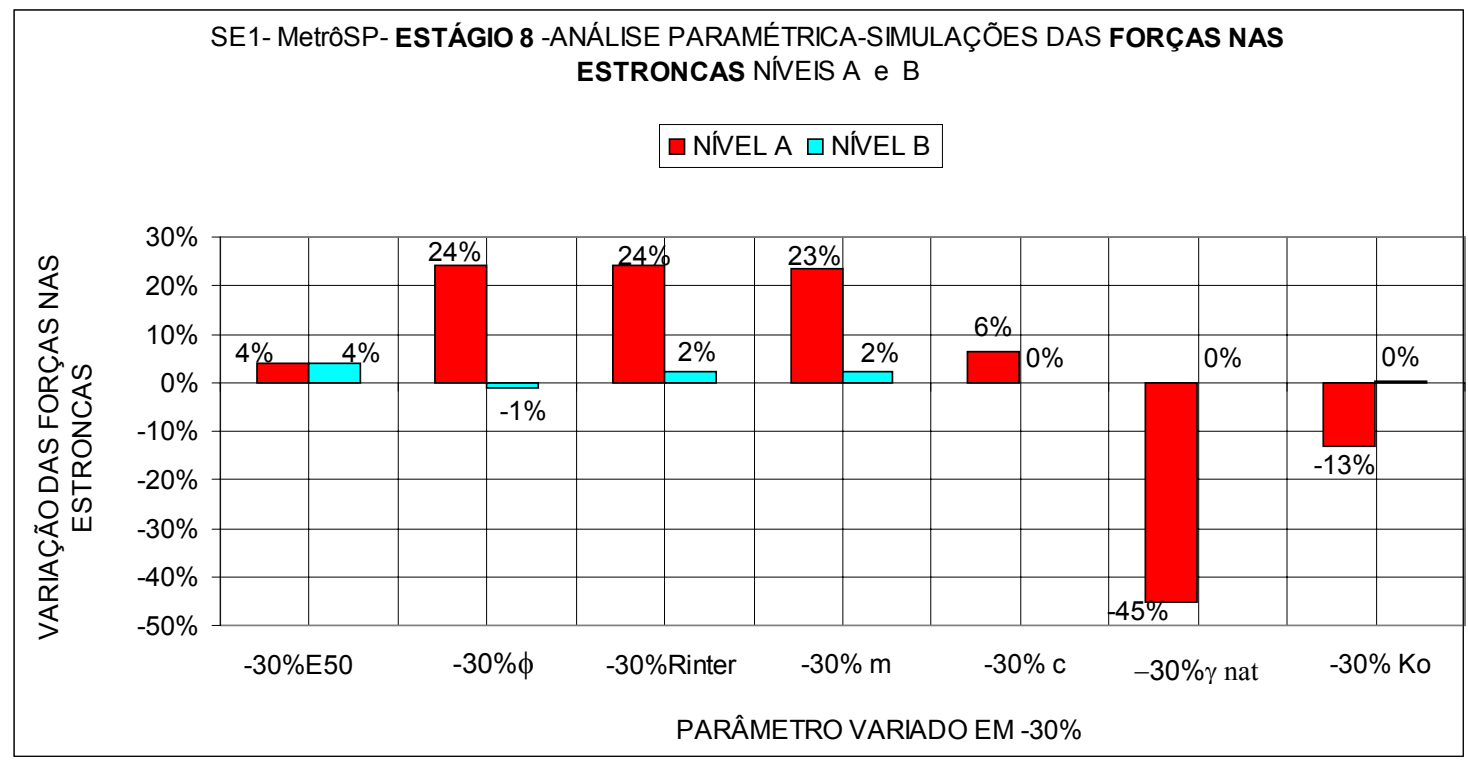

Figura 3-87- Estágio 8-variação das forças nas estroncas do nível A e nível B, em função da variação individual de parâmetros em -30\% 


\subsection{0 - Parâmetros de maior influência nos deslocamentos horizontais e verticais do paramento e nas forças das estroncas}

Da análise da Figura 3-44 à Figura 3-87 obteve-se uma hierarquia de parâmetros com as 3 maiores influências nos deslocamentos verticais e horizontais de paramento e forças nas estroncas dos níveis A e B. A partir desta análise foram feitas 3 tabelas que resumissem esta hierarquia de influência de parâmetros. No conjunto da Tabela 3-9 e Tabela 3-10 relacionadas respectivamente aos deslocamentos horizontais e verticais de paramentos, apresentam-se as hierarquias em relação à três pontos do paramento, a saber topo, centro e base (pé). Na Tabela 3-11 são apresentadas as hierarquias em relação às forças nas estroncas nos níveis $\mathrm{A}$ e $\mathrm{B}$.

Apresenta-se a seguir a nomenclatura utilizada nas tabelas de hierarquia de influência :

$1^{\text {a }}$. TOPO-(Tabela 3-9) parâmetro com a maior influência sobre os deslocamentos horizontais do topo do paramento.

$2^{\text {a }}$. TOPO -(Tabela 3-9) parâmetro com a segunda maior influência sobre os deslocamentos horizontais do topo do paramento.

$1^{\text {a }}$. TOPO (Tabela 3-10) parâmetro com a maior influência sobre os deslocamentos verticais do topo do paramento.

$1^{\text {a }}$. NÍVEL A (Tabela 3-11) parâmetro com a maior influência sobre as forças nas estroncas do nível A 
Tabela 3-9- Hierarquia de influências sobre os deslocamentos horizontais de 3 pontos do paramento para variações de $+30 \%$ e $-30 \%$ dos valores de referência inicial 2.

Hierarquia de Influência

Ponto do Paramento

\begin{tabular}{|c|c|c|c|c|c|c|c|c|c|c|}
\hline$E$ & $\mathrm{~V}$ & $1^{\mathrm{a}}$ & $2^{a}$ & $3^{\mathrm{a}}$ & $1^{\mathrm{a}}$ & $2^{a}$ & $3^{a}$ & $1^{\mathrm{a}}$ & $2^{a}$ & $3^{a}$ \\
\hline$S$ & A & & & & & & & & & \\
\hline $\mathrm{T}$ & $\mathrm{R}$ & $\mathrm{T}$ & $\mathrm{T}$ & $\mathrm{T}$ & C & C & C & B & B & B \\
\hline Á & I & $\mathrm{O}$ & $\mathrm{O}$ & $\mathrm{O}$ & $\mathrm{E}$ & $\mathrm{E}$ & $\mathrm{E}$ & A & A & A \\
\hline $\mathrm{G}$ & A & $\mathrm{P}$ & $\mathrm{P}$ & $\mathrm{P}$ & $\mathrm{N}$ & $\mathrm{N}$ & $\mathrm{N}$ & $\mathrm{S}$ & S & $\mathrm{S}$ \\
\hline I & Ç & $\mathrm{O}$ & $\mathrm{O}$ & $\mathrm{O}$ & $\mathrm{T}$ & $\mathrm{T}$ & $\mathrm{T}$ & E & $\mathrm{E}$ & $\mathrm{E}$ \\
\hline $\mathrm{O}$ & $\tilde{\mathrm{A}}$ & & & & $\mathrm{R}$ & $\mathrm{R}$ & $\mathrm{R}$ & & & \\
\hline & $\mathrm{O}$ & & & & $\mathrm{O}$ & $\mathrm{O}$ & $\mathrm{O}$ & & & \\
\hline 1 & $+30 \%$ & $\gamma_{\text {nat }}$ & $\phi$ & $E$ & $\gamma_{\text {nat }}$ & $E$ & $\phi$ & $\gamma_{\text {nat }}$ & $E$ & $\phi$ \\
\hline 1 & $-30 \%$ & $\gamma_{\text {nat }}$ & $R_{\text {inter }}$ & $m$ & $\gamma_{\text {nat }}$ & $E$ & $R_{\text {inter }}$ & $\gamma_{\text {nat }}$ & $E$ & $K_{o}$ \\
\hline 2 & $+30 \%$ & $\gamma_{\text {nat }}$ & $\phi$ & $E$ & $\gamma_{\text {nat }}$ & $E$ & $\phi$ & $\gamma_{\text {nat }}$ & $E$ & $\phi$ \\
\hline 2 & $-30 \%$ & $M$ & $R_{\text {inter }}$ & $\gamma_{\text {nat }}$ & $\gamma_{\text {nat }}$ & $E$ & $R_{\text {inter }}$ & $E$ & $\gamma_{\text {nat }}$ & $R_{\text {inter }}$ \\
\hline 3 & $+30 \%$ & $\gamma_{\text {nat }}$ & $\phi$ & $E$ & $\gamma_{\text {nat }}$ & $E$ & $\phi$ & $\gamma_{\text {nat }}$ & $E$ & $\phi$ \\
\hline 3 & $-30 \%$ & $R_{\text {inter }}$ & $m$ & $\gamma$ & $\gamma_{\text {nat }}$ & $E$ & $m$ & $E$ & $\gamma_{\text {nat }}$ & $m$ \\
\hline 4 & $+30 \%$ & $\gamma_{\text {nat }}$ & $\phi$ & $E$ & $\gamma_{\text {nat }}$ & $E$ & $\phi$ & $\gamma_{\text {nat }}$ & $E$ & $\phi$ \\
\hline 4 & $-30 \%$ & $m$ & $R_{\text {inter }}$ & $\gamma_{\text {nat }}$ & $\gamma_{\text {nat }}$ & $E$ & $R_{\text {inter }}$ & $E$ & $\gamma_{\text {nat }}$ & $R_{\text {inter }}$ \\
\hline 5 & $+30 \%$ & $\gamma_{\text {nat }}$ & $\phi$ & $E$ & $\gamma_{\text {nat }}$ & $E$ & $\phi$ & $\gamma_{\text {nat }}$ & $E$ & $\phi$ \\
\hline 5 & $-30 \%$ & $R_{\text {inter }}$ & $m$ & $\gamma_{\text {nat }}$ & $\gamma_{\text {nat }}$ & $R_{\text {inter }}$ & $m$ & $E$ & $\gamma_{\text {nat }}$ & $m$ \\
\hline 6 & $+30 \%$ & $\gamma_{\text {nat }}$ & $\phi$ & $E$ & $\gamma_{\text {nat }}$ & $\phi$ & $E$ & $\gamma_{\text {nat }}$ & $E$ & $\phi$ \\
\hline 6 & $-30 \%$ & $\gamma_{\text {nat }}$ & $m$ & $R_{\text {inter }}$ & $R_{\text {inter }}$ & $\gamma_{\text {nat }}$ & $m$ & $E$ & $\gamma_{\text {nat }}$ & $R_{\text {inter }}$ \\
\hline 7 & $+30 \%$ & $\gamma_{\text {nat }}$ & $\phi$ & $E$ & $\gamma_{\text {nat }}$ & $\phi$ & $E$ & $\gamma_{\text {nat }}$ & $E$ & $\phi$ \\
\hline 7 & $-30 \%$ & $m$ & $R_{\text {inter }}$ & $\gamma_{\text {nat }}$ & $\gamma_{\text {nat }}$ & $m$ & $R_{\text {inter }}$ & $E$ & $\gamma_{\text {nat }}$ & $m$ \\
\hline 8 & $+30 \%$ & $\gamma_{\text {nat }}$ & $E$ & $\phi$ & $\gamma_{\text {nat }}$ & $\phi$ & $E$ & $\gamma_{\text {nat }}$ & $E$ & $\phi$ \\
\hline 8 & $-30 \%$ & $R_{\text {inter }}$ & $m$ & $\gamma_{\text {nat }}$ & $m$ & $R_{\text {inter }}$ & $\gamma_{\text {nat }}$ & $E$ & $\gamma_{\text {nat }}$ & $R_{\text {inter }}$ \\
\hline \multicolumn{2}{|c|}{$\begin{array}{l}\text { Parâmetro } \\
\text { de maior } \\
\text { Influência }\end{array}$} & $\gamma_{\text {nat }}$ & $\phi$ & $E$ & $\gamma_{n a t}$ & $E$ & $\phi$ & $\gamma_{\text {nat }}$ & $E$ & $\phi$ \\
\hline
\end{tabular}


Legenda para as tabelas :

$E_{50}$-Módulo de deformabilidade a $50 \%$ da tensão de ruptura $c$ - coesão $R_{\text {inter }}$ - Fator de redução da coesão efetiva e da tangente do ângulo de atrito efetivo que é aplicado pelo software PLAXIS na interface solo paramento, ou seja para interfaces rígidas (sem deslocamento relativo) Rinter $=1$, para as demais situações onde ocorre deslocamento relativo $R_{\text {inter }}<1,0$. Sendo esta redução feita da seguinte forma:

$$
\begin{aligned}
& c_{\text {reduzida }}=R_{\text {inter }} * c \\
& \text { tan } \phi^{\prime}{ }_{\text {reduzido }}=\mathrm{R}_{\text {inter }} * \text { tan } \phi{ }_{\text {reduzido }}
\end{aligned}
$$

$\phi$ - ângulo de atrito; Ko- coeficiente de empuxo em repouso; $\gamma_{n a t}$ - peso específico natural do solo 
Tabela 3-10 - Hierarquia de influências sobre os deslocamentos verticais de 3 pontos do paramento para variações e $+30 \%$ e $-\mathbf{3 0} \%$ dos valores de referência inicial 2.

\begin{tabular}{|c|c|c|c|c|c|c|c|c|c|c|}
\hline & & & $\mathrm{Hi}$ & Irquis & de Infl & ncia - & nto d & Param & nto & \\
\hline $\begin{array}{l}\mathrm{E} \\
\mathrm{S} \\
\mathrm{T} \\
\mathrm{A} \\
\mathrm{G} \\
\mathrm{I} \\
\mathrm{O}\end{array}$ & $\begin{array}{l}\mathrm{V} \\
\mathrm{A} \\
\mathrm{R} \\
\mathrm{I} \\
\mathrm{A} \\
\mathrm{C} \\
\tilde{\mathrm{A}} \\
\mathrm{O}\end{array}$ & $\begin{array}{l}1^{\mathrm{a}} \\
\mathrm{T} \\
\mathrm{O} \\
\mathrm{P} \\
\mathrm{O}\end{array}$ & $\begin{array}{l}2^{\mathrm{a}} \\
\mathrm{T} \\
\mathrm{O} \\
\mathrm{P} \\
\mathrm{O}\end{array}$ & $\begin{array}{l}3^{\mathrm{a}} \\
\\
\mathrm{T} \\
\mathrm{O} \\
\mathrm{P} \\
\mathrm{O}\end{array}$ & $\begin{array}{l}1^{\mathrm{a}} \\
\\
\mathrm{C} \\
\mathrm{E} \\
\mathrm{N} \\
\mathrm{T} \\
\mathrm{R} \\
\mathrm{O}\end{array}$ & $\begin{array}{c}2^{\mathrm{a}} \\
\\
\mathrm{C} \\
\mathrm{E} \\
\mathrm{N} \\
\mathrm{T} \\
\mathrm{R} \\
\mathrm{O}\end{array}$ & $\begin{array}{l}3^{\mathrm{a}} \\
\\
\mathrm{C} \\
\mathrm{E} \\
\mathrm{N} \\
\mathrm{T} \\
\mathrm{R} \\
\mathrm{O}\end{array}$ & $\begin{array}{l}1^{\mathrm{a}} \\
\mathrm{B} \\
\mathrm{A} \\
\mathrm{S} \\
\mathrm{E}\end{array}$ & $\begin{array}{l}2^{\mathrm{a}} \\
\mathrm{B} \\
\mathrm{A} \\
\mathrm{S} \\
\mathrm{E}\end{array}$ & $\begin{array}{l}3^{\mathrm{a}} \\
\mathrm{B} \\
\mathrm{A} \\
\mathrm{S} \\
\mathrm{E}\end{array}$ \\
\hline 1 & $+30 \%$ & $R_{\text {inter }}$ & $E_{50}$ & $\phi$ & $R_{\text {inter }}$ & $E_{50}$ & $\phi$ & $R_{\text {inter }}$ & $E_{50}$ & $\phi$ \\
\hline 1 & $-30 \%$ & $R_{\text {inter }}$ & $m$ & $E_{50}$ & $R_{\text {inter }}$ & $m$ & $E_{50}$ & $R_{\text {inter }}$ & $m$ & $E_{50}$ \\
\hline 2 & $+30 \%$ & $R_{\text {inter }}$ & $E_{50}$ & $\gamma_{\text {nat }}$ & $R_{\text {inter }}$ & $E_{50}$ & $\gamma_{\text {nat }}$ & $R_{\text {inter }}$ & $E_{50}$ & $\gamma_{\text {nat }}$ \\
\hline 2 & $-30 \%$ & $R_{\text {inter }}$ & $m$ & $E_{50}$ & $R_{\text {inter }}$ & $m$ & $E_{50}$ & $R_{\text {inter }}$ & $m$ & $E_{50}$ \\
\hline 3 & $+30 \%$ & $R_{\text {inter }}$ & $E_{50}$ & $\gamma_{\text {nat }}$ & $R_{\text {inter }}$ & $E_{50}$ & $\gamma_{n a t}$ & $R_{\text {inter }}$ & $E_{50}$ & $\gamma$ \\
\hline 3 & $-30 \%$ & $R_{\text {inter }}$ & $m$ & $E_{50}$ & $R_{\text {inter }}$ & $m$ & $E_{50}$ & $R_{\text {inter }}$ & $m$ & $E_{50}$ \\
\hline 4 & $+30 \%$ & $R_{\text {inter }}$ & $E_{50}$ & $\gamma_{\text {nat }}$ & $R_{\text {inter }}$ & $E_{50}$ & $\gamma_{\text {nat }}$ & $R_{\text {inter }}$ & $E_{50}$ & $\gamma_{\text {nat }}$ \\
\hline 4 & $-30 \%$ & $R_{\text {inter }}$ & $m$ & $E_{50}$ & $R_{\text {inter }}$ & $m$ & $E_{50}$ & $R_{\text {inter }}$ & $m$ & $E_{50}$ \\
\hline 5 & $+30 \%$ & $R_{\text {inter }}$ & $\gamma_{\text {nat }}$ & $E_{50}$ & $R_{\text {inter }}$ & $\gamma_{\text {nat }}$ & $E_{50}$ & $R_{\text {inter }}$ & $\gamma_{\text {nat }}$ & $E_{50}$ \\
\hline 5 & $-30 \%$ & $R_{\text {inter }}$ & $m$ & $E_{50}$ & $R_{\text {inter }}$ & $m$ & $E_{50}$ & $R_{\text {inter }}$ & $m$ & $E_{50}$ \\
\hline 6 & $+30 \%$ & $\gamma_{\text {nat }}$ & $E_{50}$ & $m$ & $\gamma_{\text {nat }}$ & $E_{50}$ & $m$ & $\gamma_{\text {nat }}$ & $E_{50}$ & $m$ \\
\hline 6 & $-30 \%$ & $m$ & $R_{\text {inter }}$ & $E_{50}$ & $m$ & $R_{\text {inter }}$ & $E_{50}$ & $m$ & $R_{\text {inter }}$ & $E_{50}$ \\
\hline 7 & $+30 \%$ & $R_{\text {inter }}$ & $\gamma_{\text {nat }}$ & $E_{50}$ & $R_{\text {inter }}$ & $\gamma_{\text {nat }}$ & $E_{50}$ & $R_{\text {inter }}$ & $\gamma_{n a t}$ & $E_{50}$ \\
\hline 7 & $-30 \%$ & $R_{\text {inter }}$ & $m$ & $E_{50}$ & $R_{\text {inter }}$ & $m$ & $E_{50}$ & $R_{\text {inter }}$ & $m$ & $E_{50}$ \\
\hline 8 & $+30 \%$ & $\gamma_{\text {nat }}$ & $R_{\text {inter }}$ & $E_{50}$ & $\gamma_{\text {nat }}$ & $R_{\text {inter }}$ & $E_{50}$ & $\gamma_{\text {nat }}$ & $R_{\text {inter }}$ & $E_{50}$ \\
\hline 8 & $-30 \%$ & $R_{\text {inter }}$ & $m$ & $E_{50}$ & $R_{\text {inter }}$ & $m$ & $E_{50}$ & $R_{\text {inter }}$ & $m$ & $E_{50}$ \\
\hline \multicolumn{2}{|c|}{$\begin{array}{l}\text { Parâmetro } \\
\text { de maior } \\
\text { Influência }\end{array}$} & $\boldsymbol{R}_{\text {inter }}$ & $m$ & $E_{50}$ & $\boldsymbol{R}_{\text {inter }}$ & $m$ & $E_{50}$ & $\boldsymbol{R}_{\text {inter }}$ & $m$ & $E_{50}$ \\
\hline
\end{tabular}


Tabela 3-11- Hierarquia de influências sobre as forças nas estroncas níveis $A$ e $B$ para variações e $+30 \%$ e $-30 \%$ dos valores de referência inicial 2 .

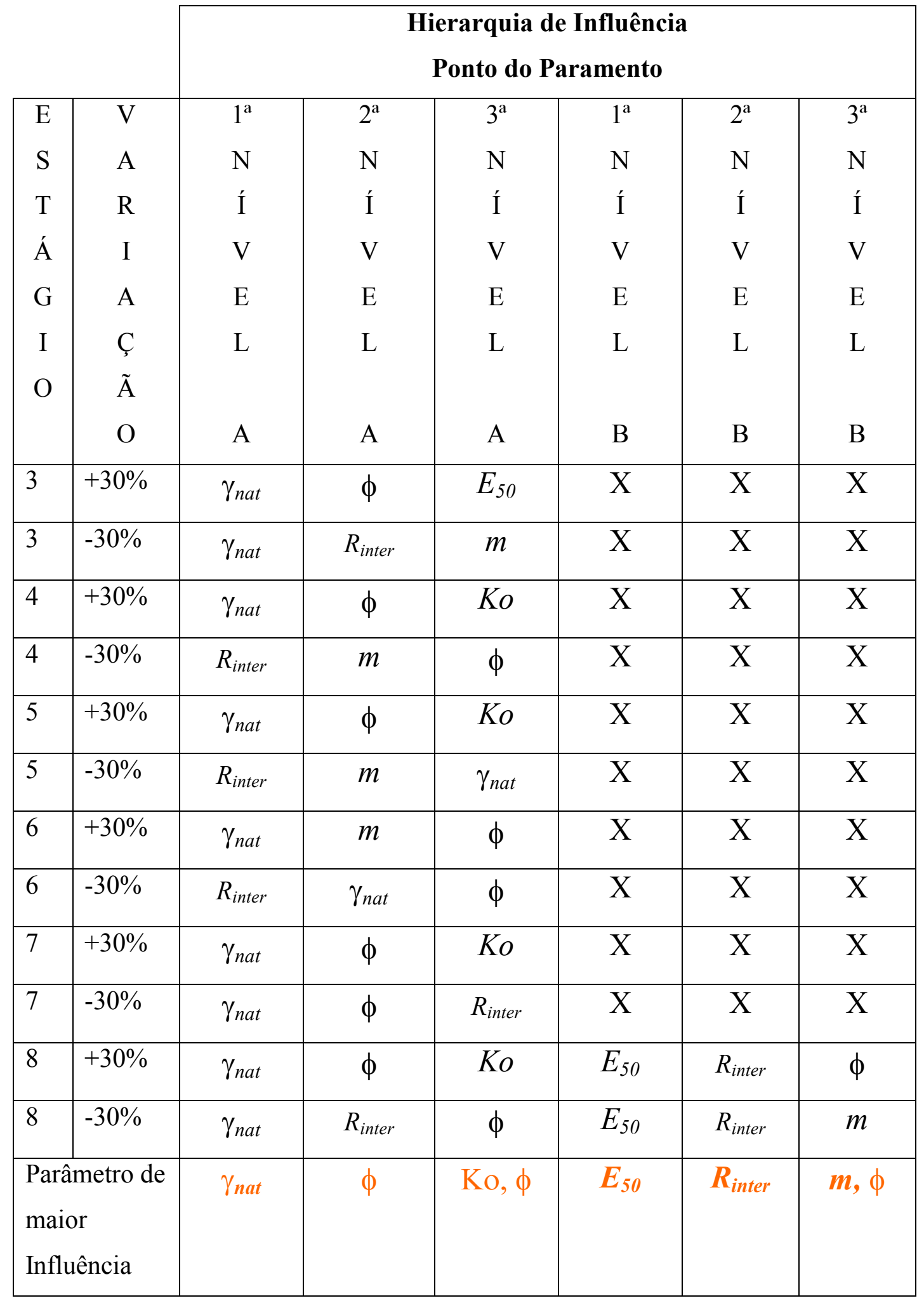




\subsubsection{Análise das hierarquias de influências de parâmetros nos deslocamentos horizontais e verticais de paramentos e forças nas estroncas}

A partir do agrupamento de importância feito da Tabela 3-9 até a

Tabela 3-11 onde se definiu uma hierarquia de importância de parâmetros em relação a deslocamentos horizontais e verticais de 3 pontos de paramento e também em relação à influência sobre as variações de forças nas estroncas, conclui-se:

- os parâmetros de maior importância para deslocamentos horizontais são $\gamma_{n a t}, \phi$ e $E_{50}$

- os parâmetros de maior importância para deslocamentos verticais são $R_{\text {inter }}, m \mathrm{e}$ $E_{50}$

- os parâmetros de maior importância para forças no nível A das estroncas são $\gamma_{n a t}, \phi$ e $K o$ e para o nível B são $E_{50}, R_{\text {inter }}, m$ e $\phi$.

Em virtude de $E_{50}$ ter forte influência tanto nos deslocamentos horizontais e verticais de paramentos e forças nas estroncas, aliado ao fato de ter razoável oscilação (entre os valores mínimos e máximos) verificada em laboratório ( Tabela 3-1 ), e as oscilações de $\phi_{a}$ ' e $\gamma_{n a t}$ serem menores em relação a $E_{50}$ e $c^{\prime}$, determinou-se que o parâmetro a ser retroanalisado é o $E_{50}$.

Apesar da grande variabilidade apresentada por c' em ensaios de laboratório (Tabela 3-1), este parâmetro não foi classificado como de grande influência na análise paramétrica. Porém, resolveu-se incluí-la como parâmetro a ser relacionado ao processo de retroanálise (seção 3.10.2), uma vez que ela está presente na equação de $E_{u r}$ (equação $3.2)$.

Por fim, $R_{\text {inter }}, \gamma_{\text {nat }}$ também farão parte do estudo de intervalos a determinar devido à importância demonstrada na análise paramétrica. 


\subsection{2 -Critério para definição dos intervalos de parâmetros a variar no processo de retroanálise}

A partir de ensaios de laboratório realizados para os solos da linha 1 do Metrô S.P., MASSAD (1978) ao estudar as argilas porosas vermelhas de várias seções experimentais, concluiu que o módulo $E i$ das argilas porosas era aproximadamente constante e propôs a equação 3.36 :

$$
E_{i}=440 * \gamma_{n a t} *\left(\frac{D}{2}\right)\left[\mathrm{tf} / \mathrm{m}^{2}\right]
$$

Sendo:

$\gamma_{\text {nat }}=$ peso específico natural do solo $\left[\mathrm{tf} / \mathrm{m}^{3}\right]$

$\mathrm{D}=$ espessura da camada de argila porosa

Para a seção experimental $\mathrm{n}^{\circ} 1$ em estudo nesta dissertação o boletim de sondagem (Figura 2-6), indica o início da camada de argila porosa vermelha na cota 799,64 e o término na cota 789,04, portanto uma espessura de 10,6m.

Utilizando-se a equação (3.36) e adotando-se $\gamma_{n a l}=15 \mathrm{kN} / \mathrm{m}^{3}$, valor médio obtido por IPT(1972) para o local da seção experimental, transformando-se o resultado para a unidade $k P a$ obtém-se $E i=34980 \mathrm{kPa}$.

Fez-se um conjunto de simulações, com o objetivo de se determinar quais os intervalos de parâmetros a serem adotados para iniciar o processo de retroanálise utilizando-se o modelo de endurecimento.

No software PLAXIS os cálculos são realizados em função da entrada do módulo de deformabilidade a $50 \%$ da tensão de ruptura, $E_{50}$. Apesar dos valores de $E_{i}$ serem sempre superiores ao $E_{50}$ resolveu-se apenas por facilidade numérica, adotar para início das simulações um valor de $E_{50}=40000 \mathrm{kPa}$, isto não tem nenhuma influência nos resultados finais, pois o software considera nos cálculos o valor de $E_{50}$. Além disto o valor teórico de $E_{50}$ será corrigido pelo processo de retroanálise, sendo então sua escolha inicial meramente uma questão de adoção de um valor. Este valor será 
corrigido em função da comparação entre os deslocamentos horizontais de paramentos obtidos das simulações e os reais instrumentados.

Portanto para as simulações citadas adotou-se para toda a camada de argila porosa vermelha os valores de referência inicial 2 (Tabela 3-8), $E_{50}=40000 \mathrm{kPa}, K o=0.531$ (Figura 3-32) e $c=30 \mathrm{kPa}, \phi=28^{\circ}, \gamma_{n a t}=15 \mathrm{kN} / \mathrm{m}^{3}$, (valores próximos aos médios) descritos na Tabela $3-1$, e de $m=0.1$ obtido da calibração do modelo de Endurecimento a partir das curvas de PARREIRA (1991) (Figura 3-40 à Figura 3-43) e $v_{u r}=0.2$ obtido a partir de PARREIRA (1991).

Para obter-se erros mínimos relativos aos parâmetros de referência inicial $2 \mathrm{em}$ relação às variações em $+30 \%$ e $-30 \%$, fez-se gráficos da Figura 3-88 à Figura 3-103.

Sendo que da Figura 3-88 à Figura 3-95: calculou-se os módulos dos erros de deslocamentos horizontais no paramento para os estágios 1 a 8 e de forças nas estroncas para os estágios 3 a 8 , para a variação de $+30 \%$

E no intervalo da Figura 3-96 a Figura 3-103: idem ao exposto para a variação de $-30 \%$. 


\subsubsection{Resultados obtidos com a variação de $+30 \%$ dos valores de referência inicial 2}

Apresenta-se nesta seção, os resultados das simulações feitas com variações de $+30 \%$ em relação aos parâmetros de referência inicial 2 .

Da Figura 3-88 à Figura 3-95, estão representados os valores dos módulos dos erros em relação aos valores instrumentados reais, obtidos em relação aos deslocamentos horizontais de paramentos e às forças nas estroncas (A e B).

Os termos utilizados no eixo horizontal da Figura 3-88 à Figura 3-95 significam:

$E_{50}$-Módulo de deformabilidade a $50 \%$ da tensão de ruptura

$c$ - coesão

$R_{\text {inter }}$ - Fator de redução da coesão efetiva e da tangente do ângulo de atrito efetivo que é aplicado pelo software PLAXIS na interface solo paramento, ou seja para interfaces rígidas (sem deslocamento relativo) $R_{\text {inter }}=1$, para as demais situações onde ocorre deslocamento relativo $R_{\text {inter }}<1,0$. Sendo esta redução feita da seguinte forma:

$$
\begin{aligned}
& c_{\text {reduzida }}=R_{\text {inter }} * c \\
& \text { tan } \phi_{\text {reduzido }}=\mathrm{R}_{\text {inter }} * \text { tan } \phi_{\text {reduzido }}
\end{aligned}
$$

$\phi$ - ângulo de atrito

Ko-coeficiente de empuxo em repouso

$g n a t=\gamma_{n a t}-$ peso específico natural do solo

$\mathrm{f}=\phi=$ ângulo de atrito do solo

Referência inicial 2- são os valores de referência dos parâmetros utilizados (Tabela 3-8) para comparar com os valores das outras simulações (para variações de $+30 \%$ e $-30 \%$ ). 


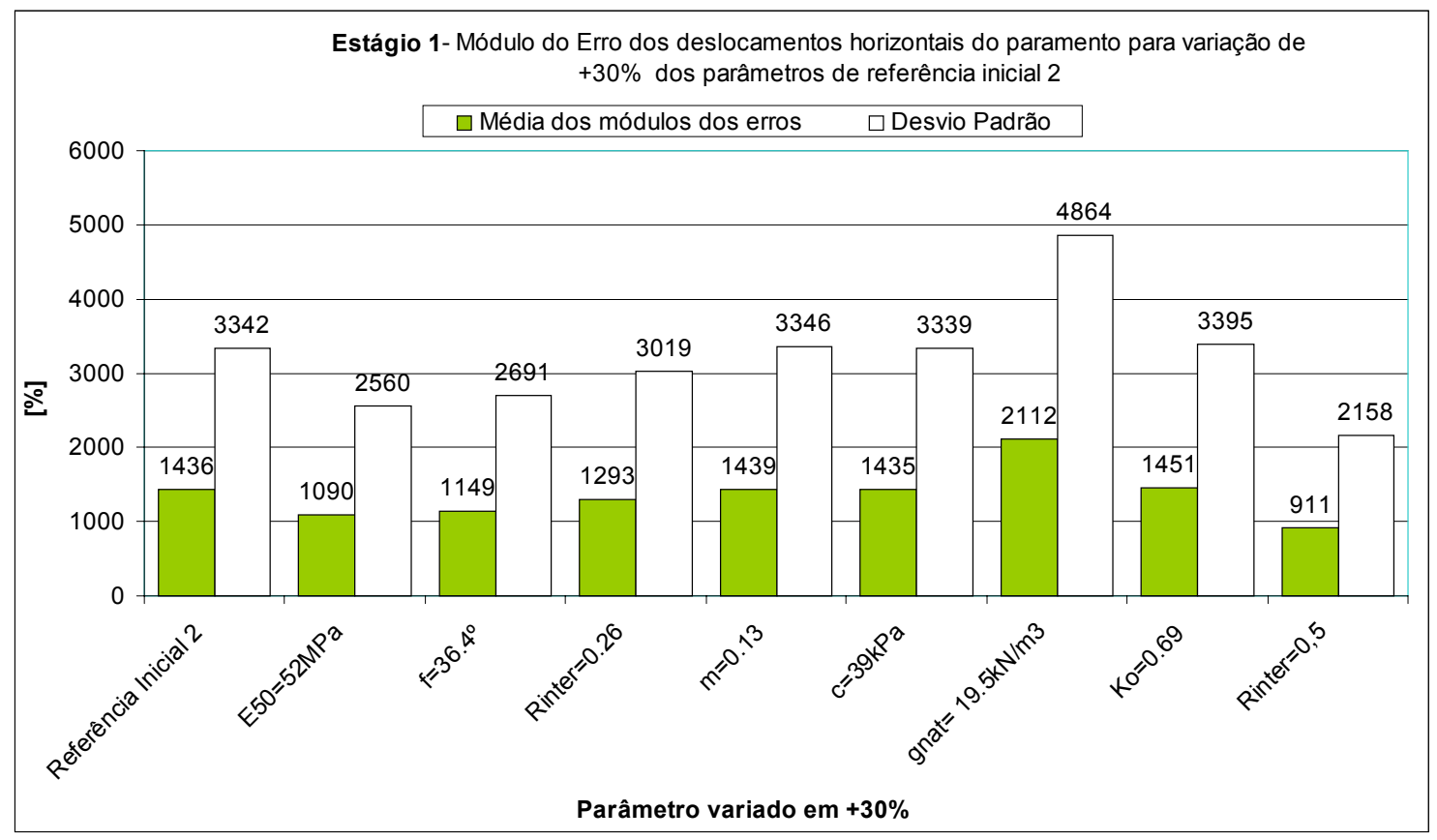

Figura 3-88- Estágio 1 - média dos módulos dos erros de deslocamentos horizontais de paramento por variação individual de $+30 \%$ dos parâmetros de referência inicial 2

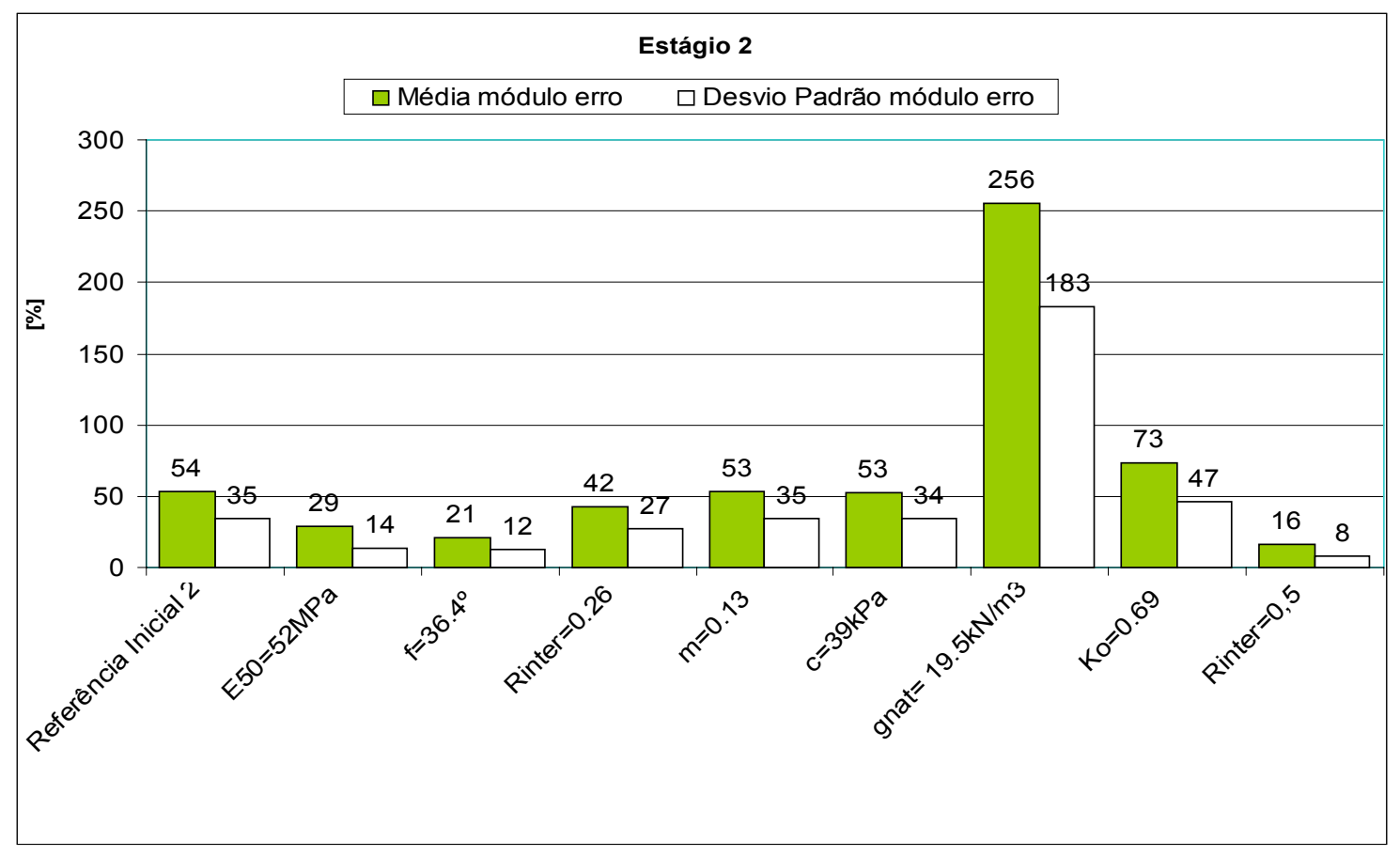

Figura 3-89- Estágio 2 - média dos módulos dos erros de deslocamentos horizontais de paramento por variação individual de $+\mathbf{3 0} \%$ dos parâmetros de referência inicial 2 


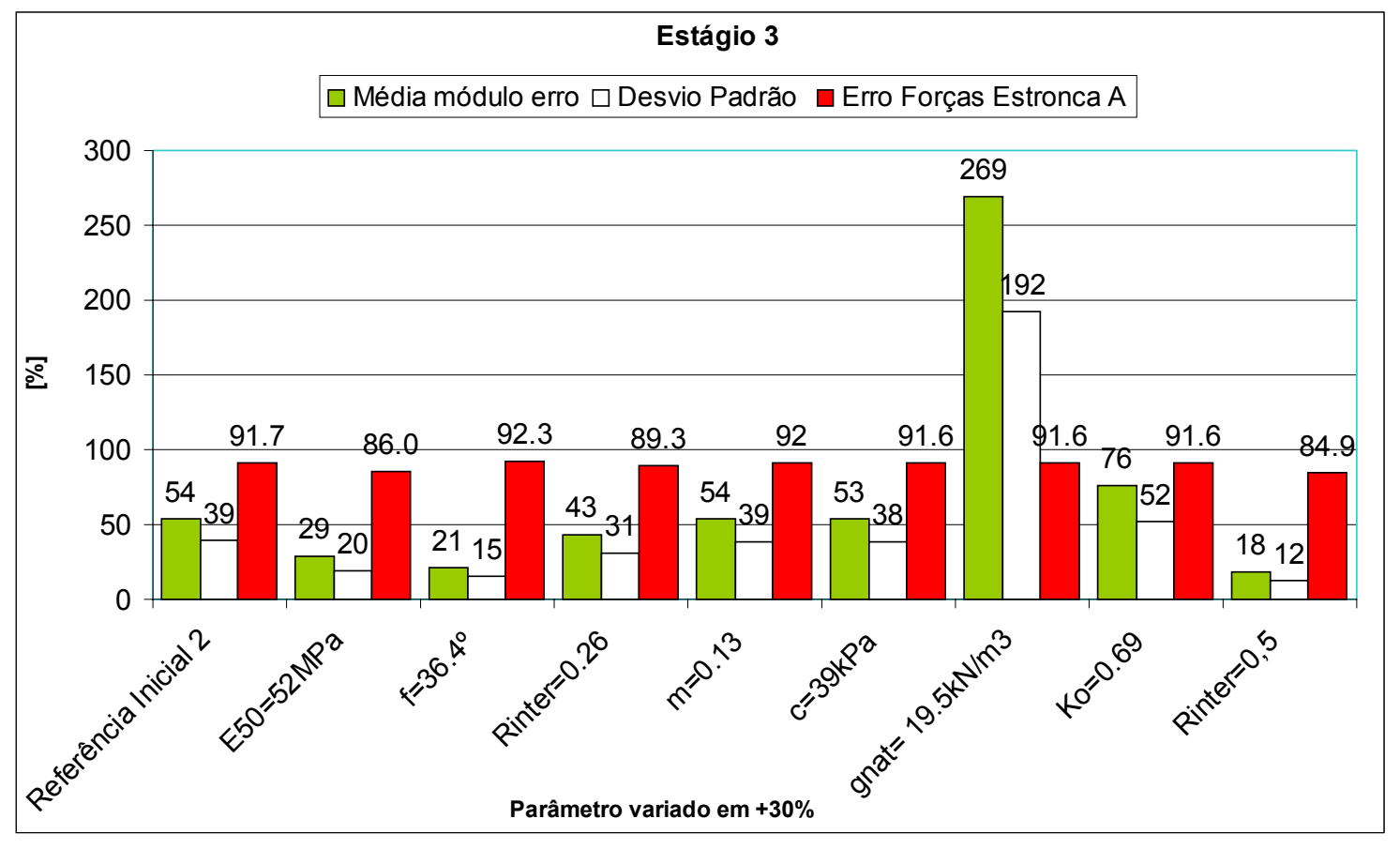

Figura 3-90- Estágio 3 - média dos módulos dos erros de deslocamentos horizontais de paramento e módulo do erro das forças nas estroncas nível $\mathrm{A}$, por variação individual de $+30 \%$ dos parâmetros de referência inicial 2

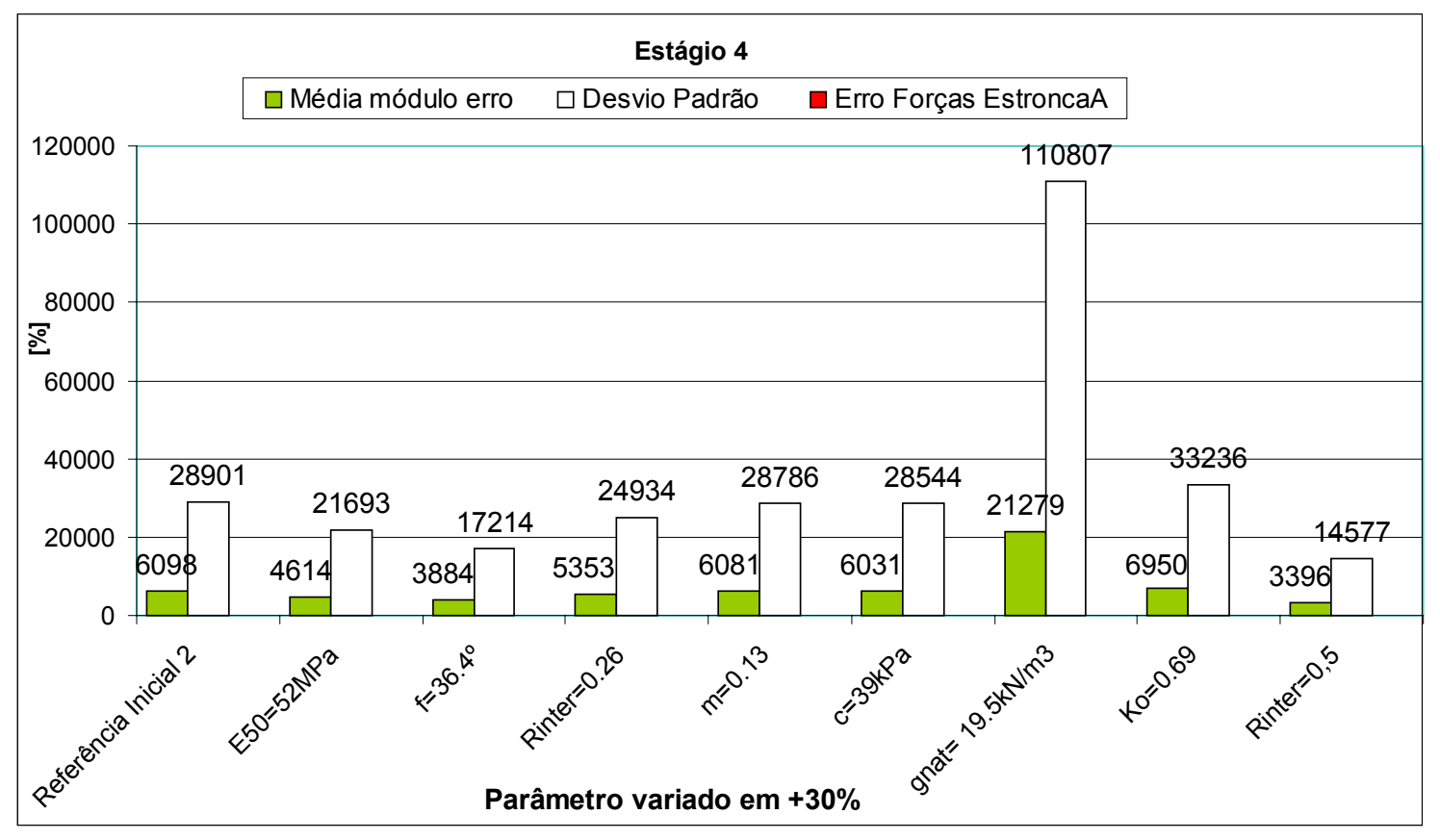

Figura 3-91- Estágio 4 - média dos módulos dos erros de deslocamentos de paramento e módulos dos erros das forças nas estroncas por variação individual de $+30 \%$ dos parâmetros de referência inicial 2 


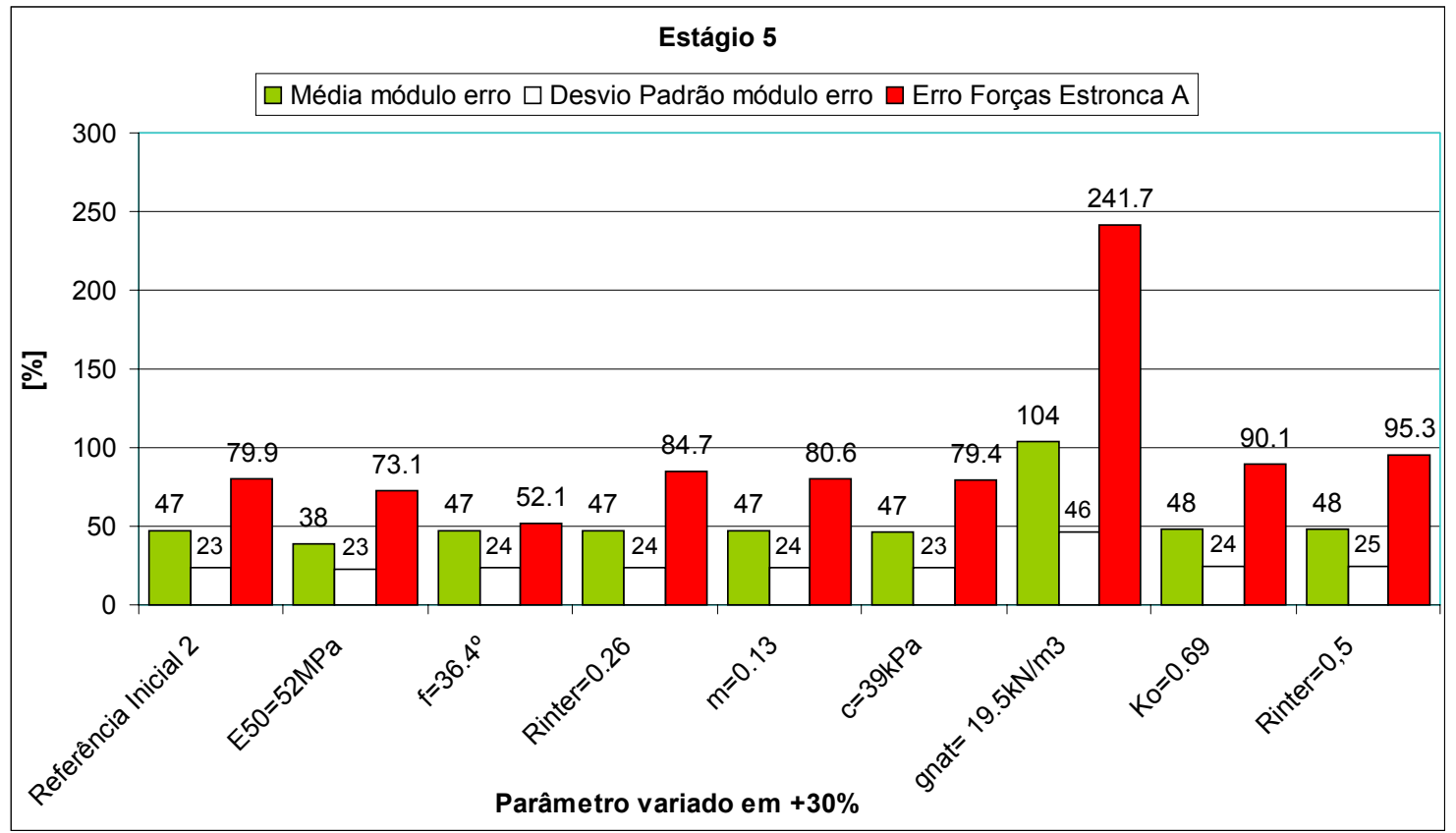

Figura 3-92- Estágio 5-média dos módulos dos erros de deslocamentos de paramento e módulos dos erros das forças nas estroncas nível A por variação individual de $+30 \%$ dos parâmetros de referência inicial 2

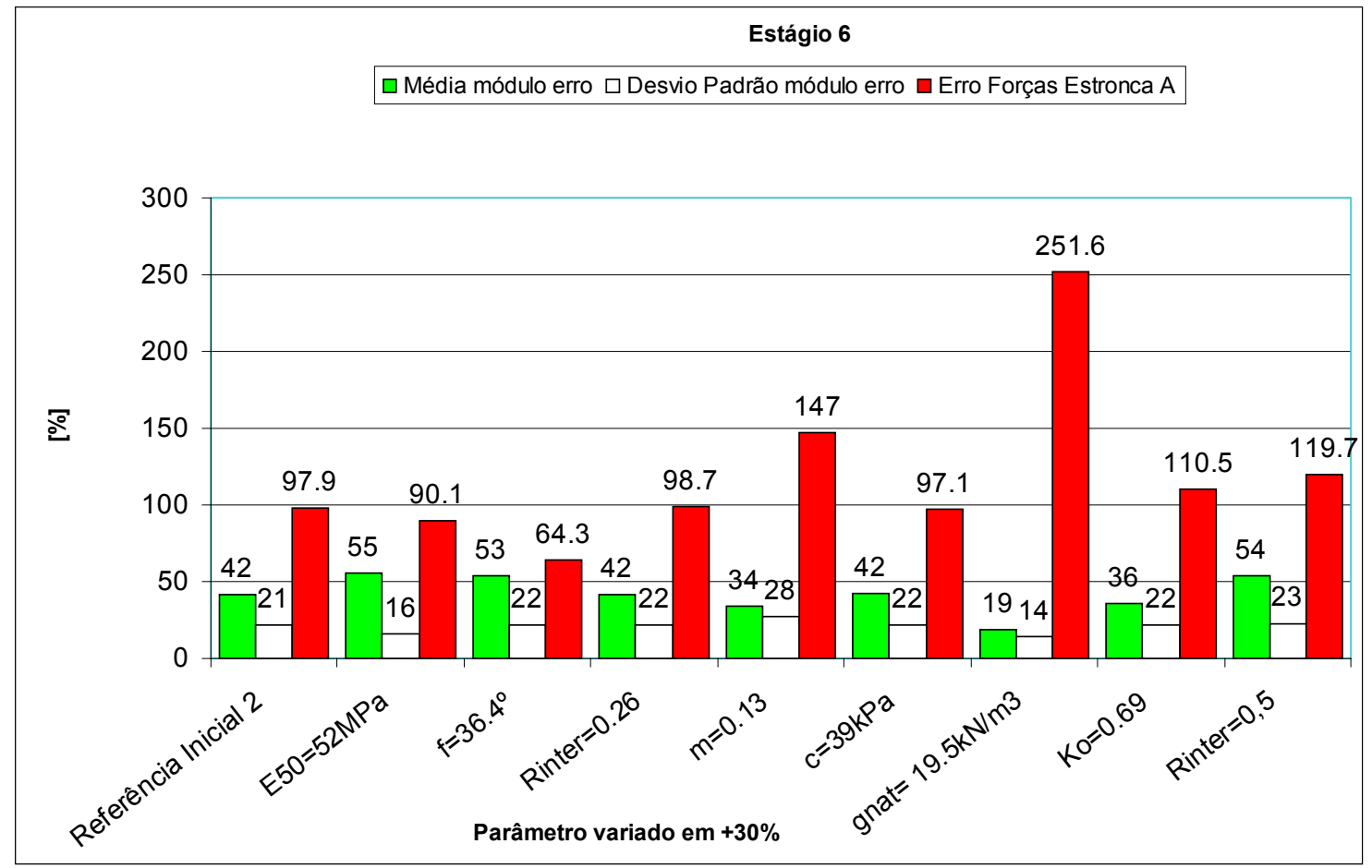

Figura 3-93- Estágio 6 - média dos módulos dos erros de deslocamentos de paramento e módulos dos erros das forças nas estroncas nível A por variação individual de $+30 \%$ dos parâmetros de referência inicial 2 


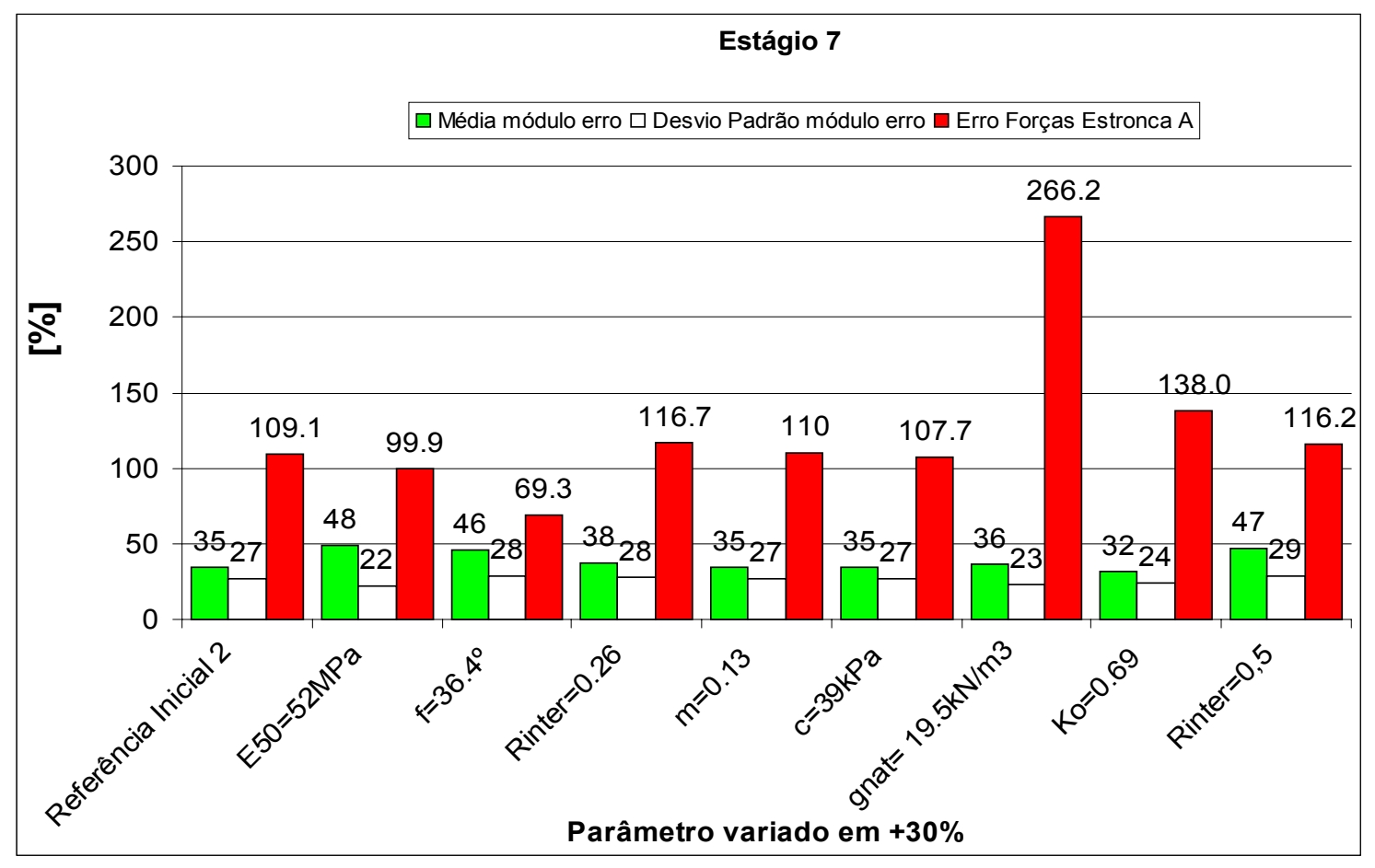

Figura 3-94- Estágio 7- média dos módulos dos erros de deslocamentos de paramento e módulos dos erros das forças nas estroncas nível A por variação individual de $+30 \%$ dos parâmetros de referência inicial 2

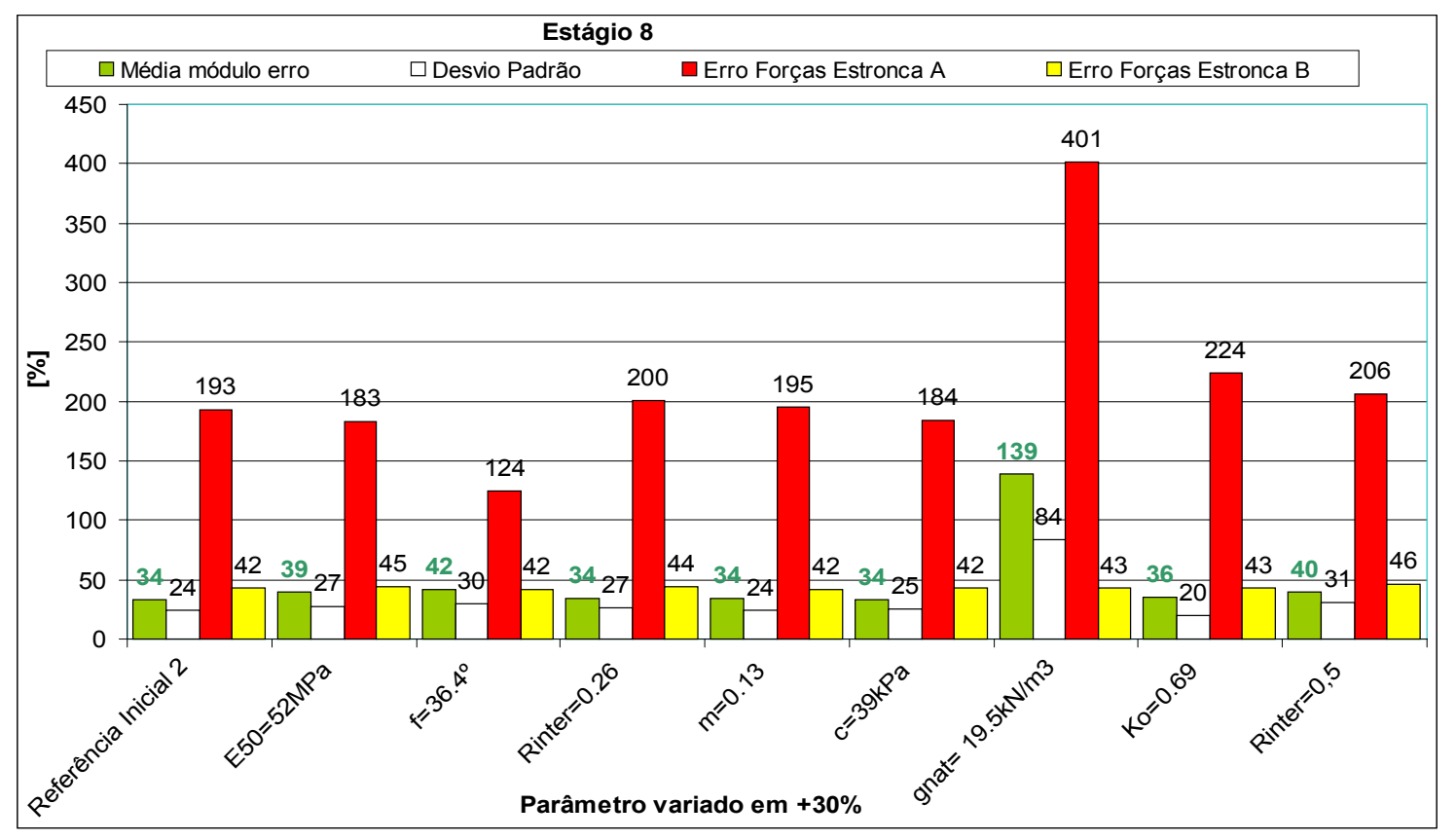

Figura 3-95- Estágio 8- média dos módulos dos erros de deslocamentos de paramento e módulos dos erros das forças nas estroncas níveis A e B por variação individual de $+30 \%$ dos parâmetros de referência inicial 2 


\subsubsection{Resultados obtidos com a variação de $-30 \%$ dos valores de referência inicial 2}

Nesta seção, são apresentados os resultados das simulações feitas com variações de $30 \%$ em relação aos parâmetros de referência inicial 2.

Da Figura 3-96 à Figura 3-103 estão representados os valores de erros em relação aos valores instrumentados reais, obtidos em relação aos deslocamentos horizontais de paramentos e às forças nas estroncas (A e B).

Os termos utilizados no eixo horizontal da Figura 3-96 à Figura 3-103 significam :

$E_{50}-$ Módulo de deformabilidade a $50 \%$ da tensão de ruptura

$c$ - coesão

$R_{\text {inter }}$ - Fator de redução da coesão efetiva e da tangente do ângulo de atrito efetivo que é aplicado pelo software PLAXIS na interface solo paramento, ou seja para interfaces rígidas (sem deslocamento relativo) $R_{\text {inter }}=1$, para as demais situações onde ocorre deslocamento relativo $R_{\text {inter }}<1,0$. Sendo esta redução feita da seguinte forma:

$$
\begin{aligned}
& c_{\text {reduzida }}=R_{\text {inter }} * c \\
& \text { tan } \phi_{\text {reduzido }}^{\prime}=\mathrm{R}_{\text {inter }} * \text { tan } \phi_{\text {reduzido }}
\end{aligned}
$$

$\mathrm{f}=\phi$ - ângulo de atrito

Ko-coeficiente de empuxo em repouso

gnat $=\gamma_{\text {nat }}$ - peso específico natural do solo

Referência inicial 2- são os valores de referência dos parâmetros utilizados (Tabela 3-8) para comparar com os valores das outras simulações (para variações de $+30 \%$ e $-30 \%$ ). 


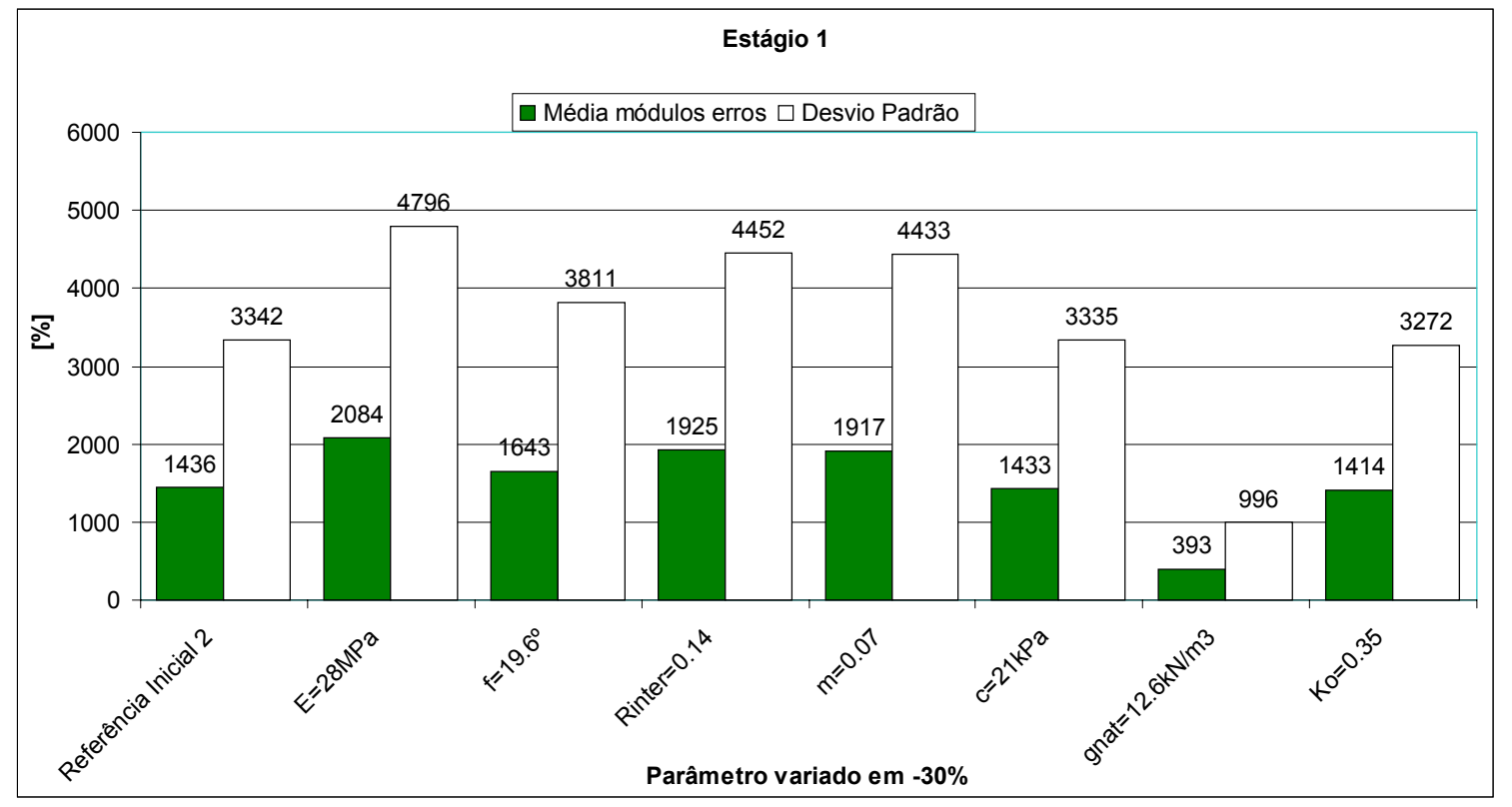

Figura 3-96- Estágio 1-média dos módulos dos erros de deslocamentos de paramento por variação individual de $\mathbf{- 3 0} \%$ dos parâmetros de referência inicial 2

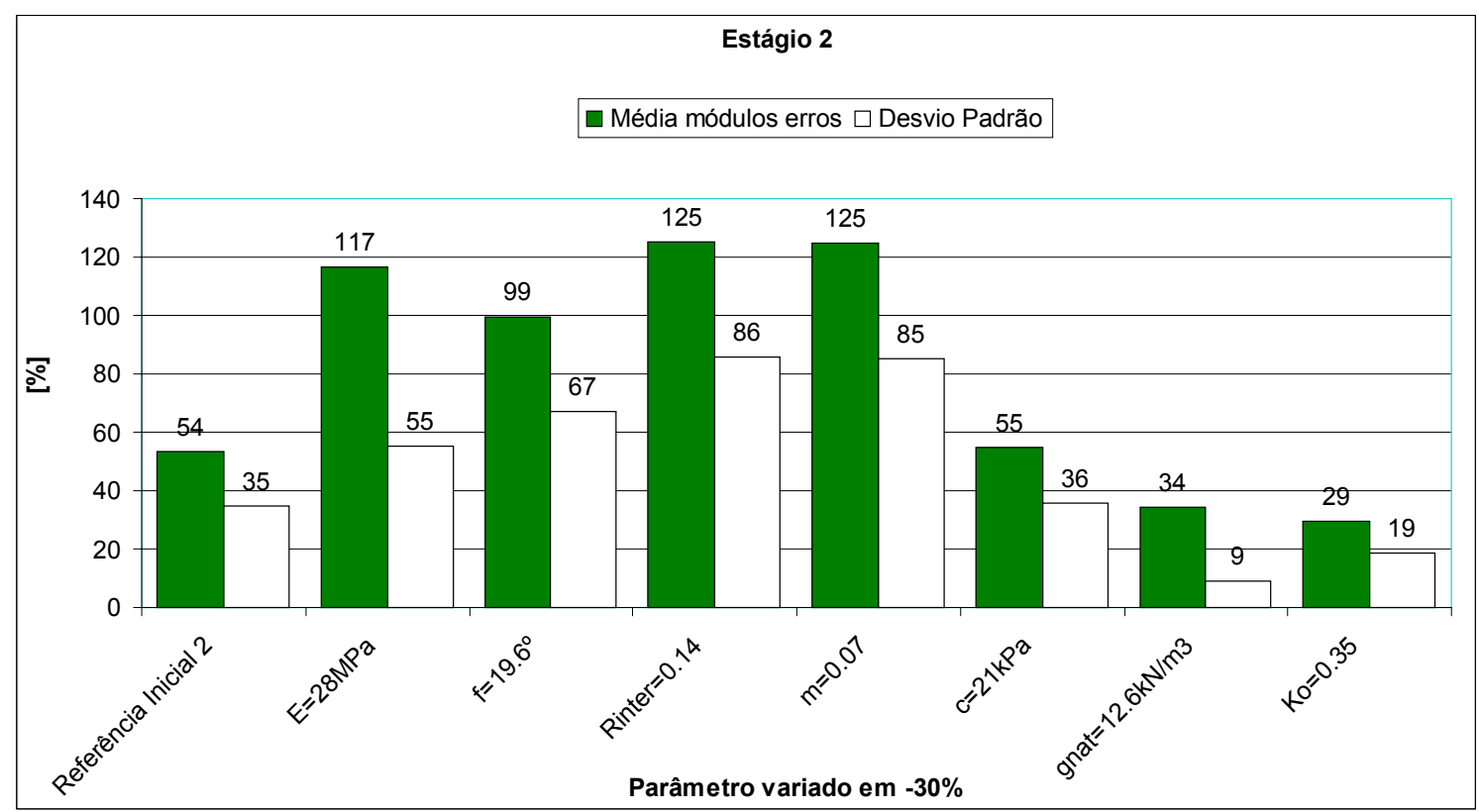

Figura 3-97- Estágio 2-média dos módulos dos erros de deslocamentos de paramento por variação individual de $-\mathbf{3 0} \%$ dos parâmetros de referência inicial 2 


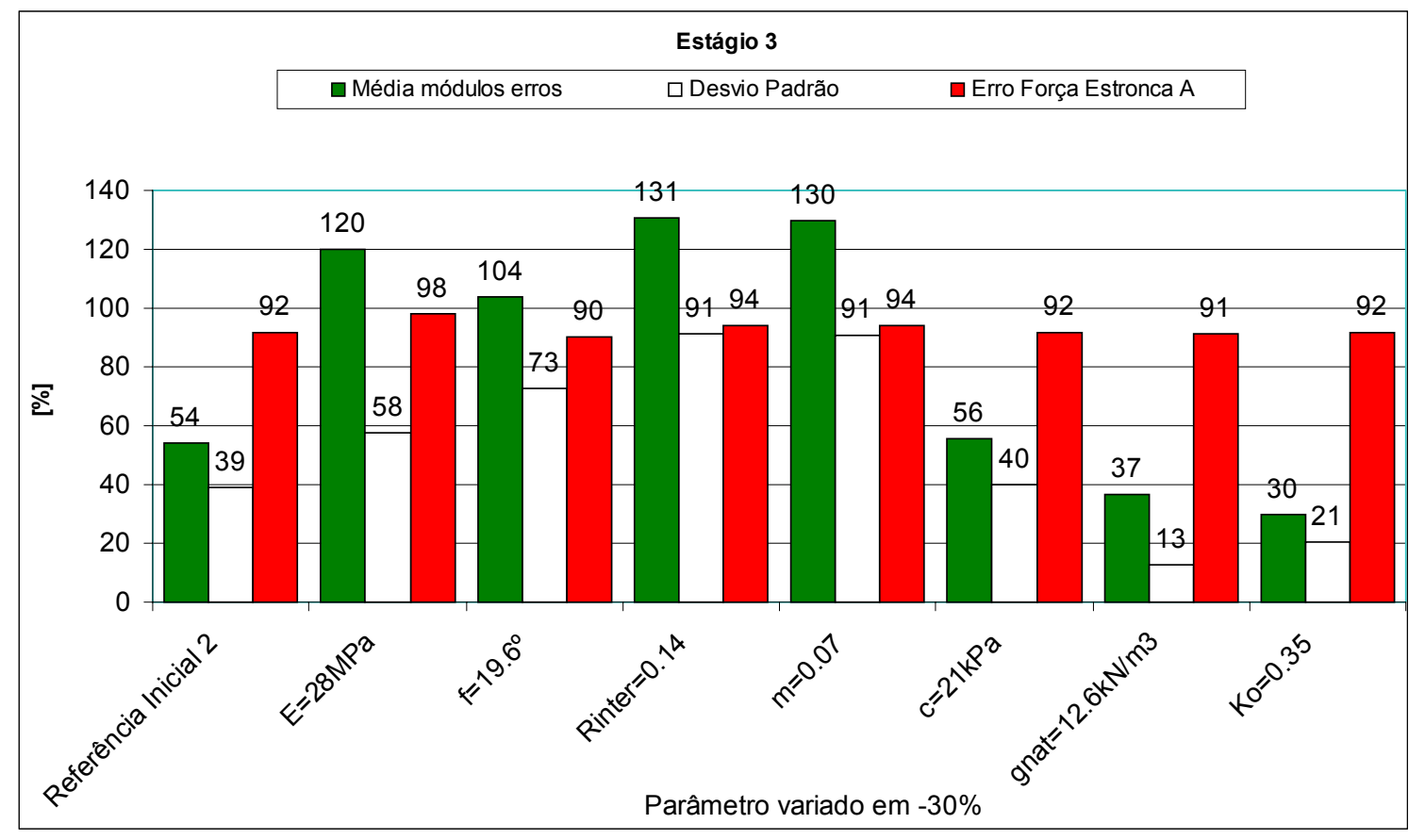

Figura 3-98- Estágio 3-média dos módulos dos erros de deslocamentos de paramento e módulos dos erros das forças nas estroncas nível A por variação individual de $\mathbf{- 3 0} \%$ dos parâmetros de referência inicial 2

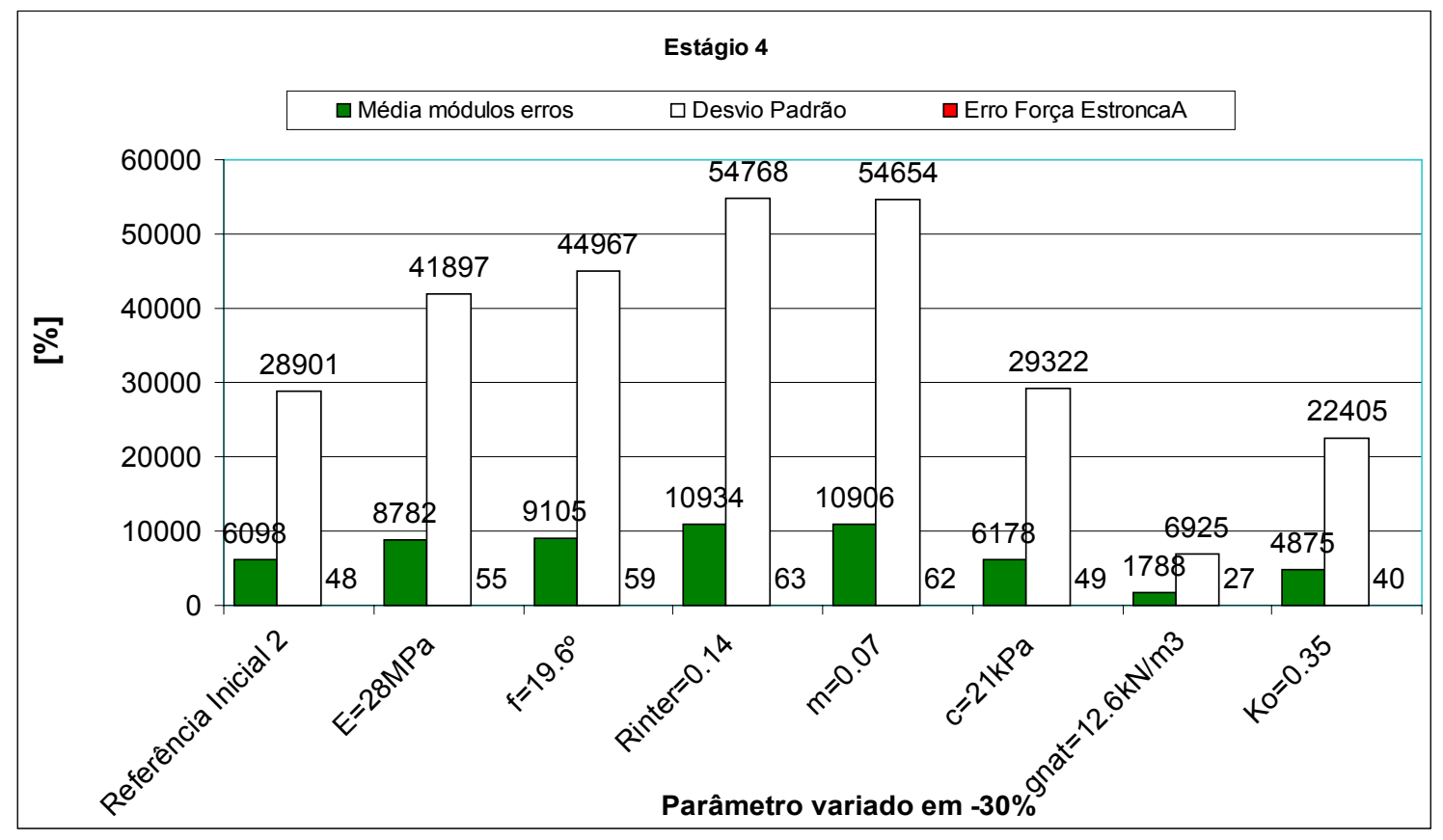

Figura 3-99- Estágio 4-média dos módulos dos erros de deslocamentos de paramento e módulos dos erros das forças nas estroncas nível A por variação individual de $\mathbf{- 3 0 \%}$ dos parâmetros de referência inicial 2 


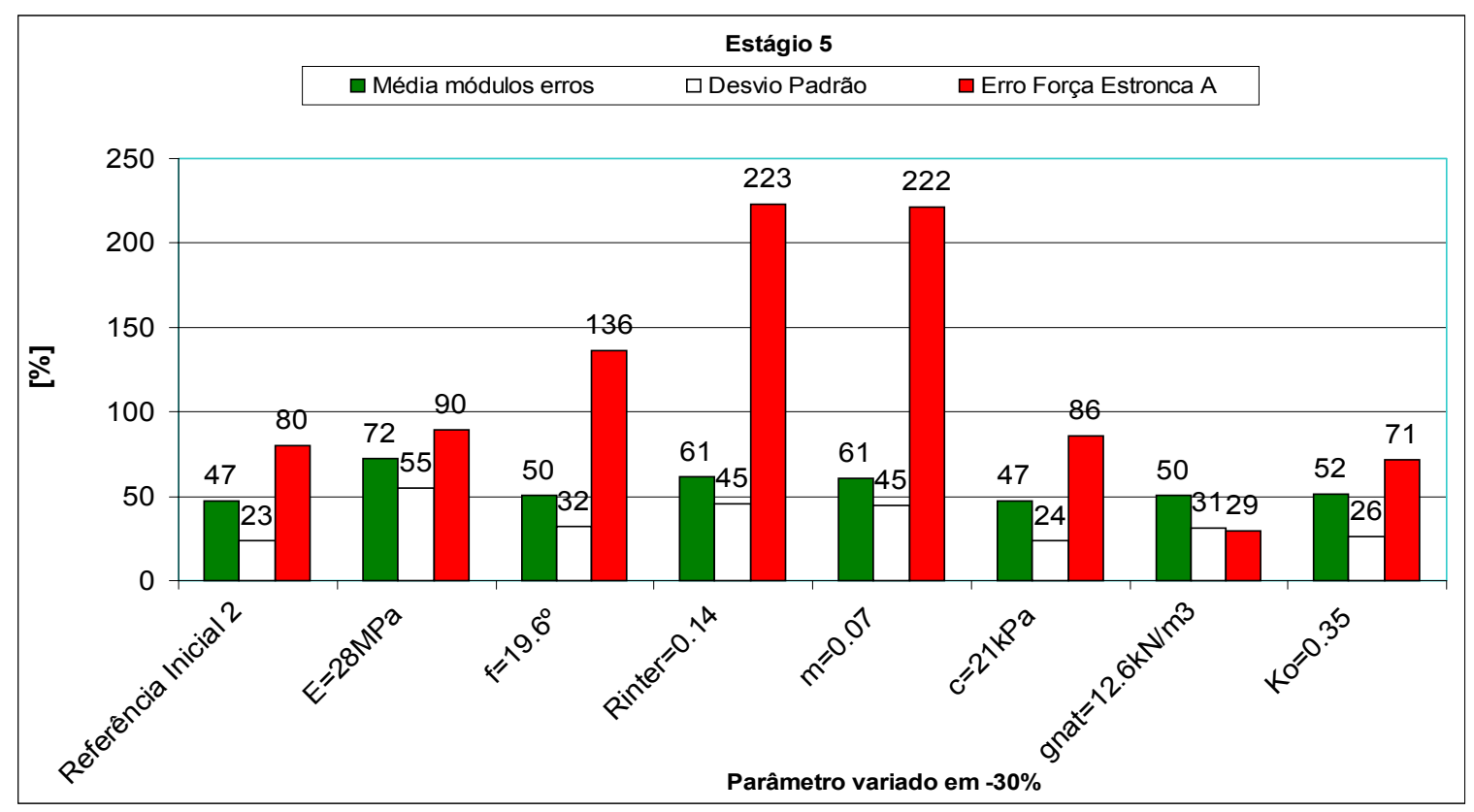

Figura 3-100- Estágio 5-média dos módulos dos erros de deslocamentos de paramento e módulos dos erros das forças nas estroncas nível A por variação individual de $\mathbf{- 3 0 \%}$ dos parâmetros de referência inicial 2

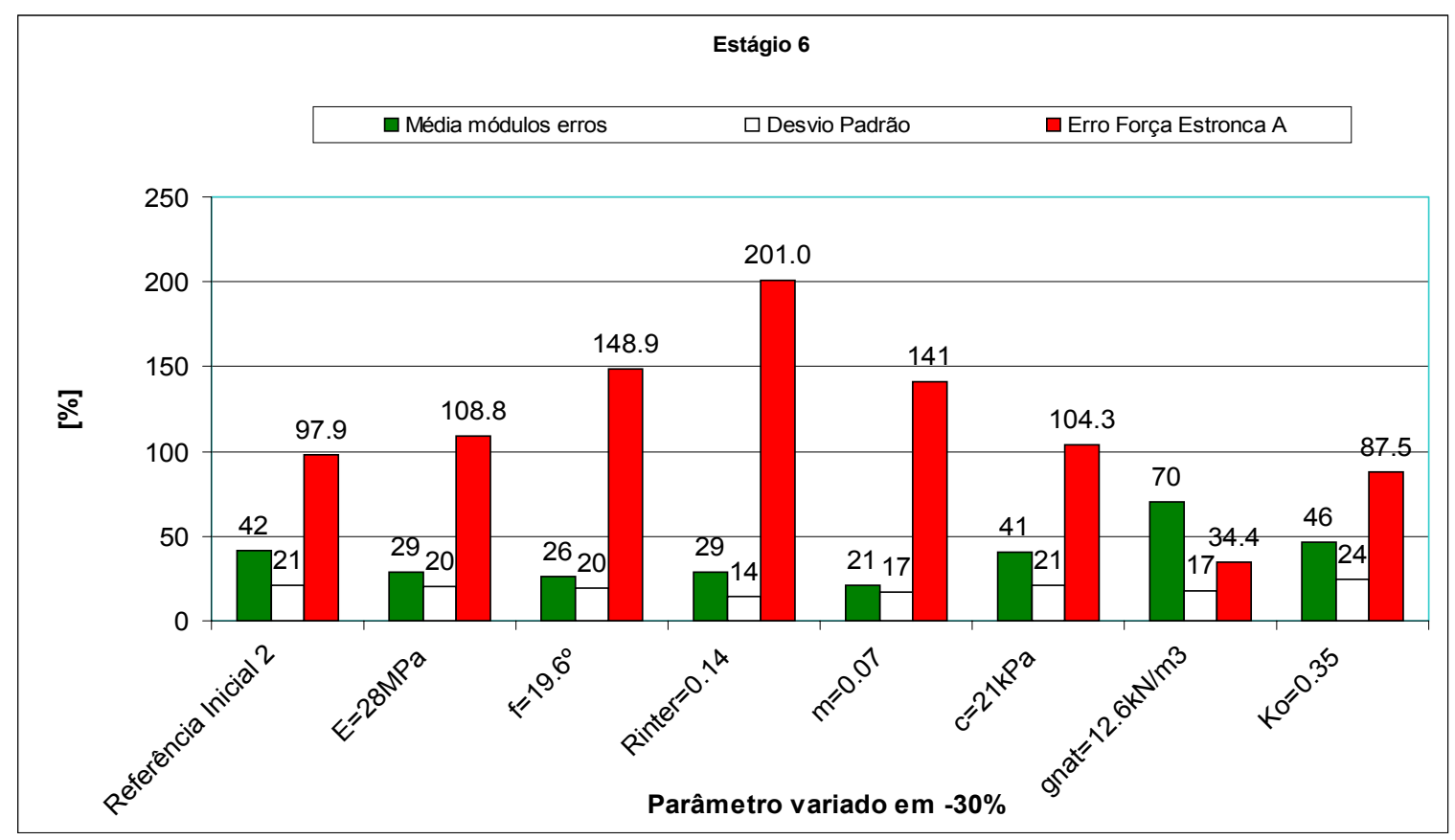

Figura 3-101- Estágio 6-média dos módulos dos erros de deslocamentos de paramento e módulos dos erros das forças nas estroncas nível A por variação individual de $\mathbf{- 3 0 \%}$ dos parâmetros de referência inicial 2 


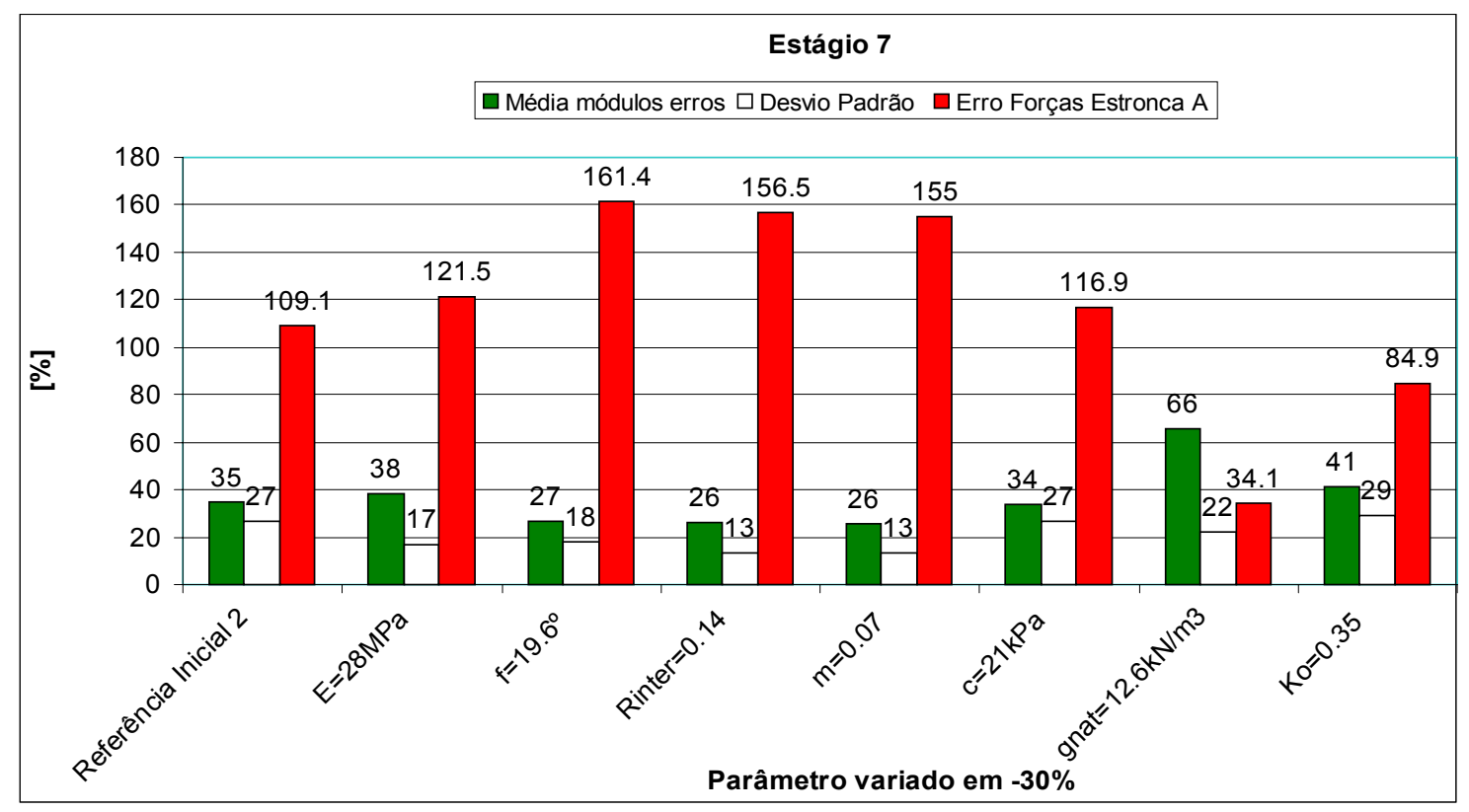

Figura 3-102- Estágio 7- média dos módulos dos erros de deslocamentos de paramento e módulos dos erros das forças nas estroncas nível A por variação individual de $\mathbf{- 3 0} \%$ dos parâmetros de referência inicial 2

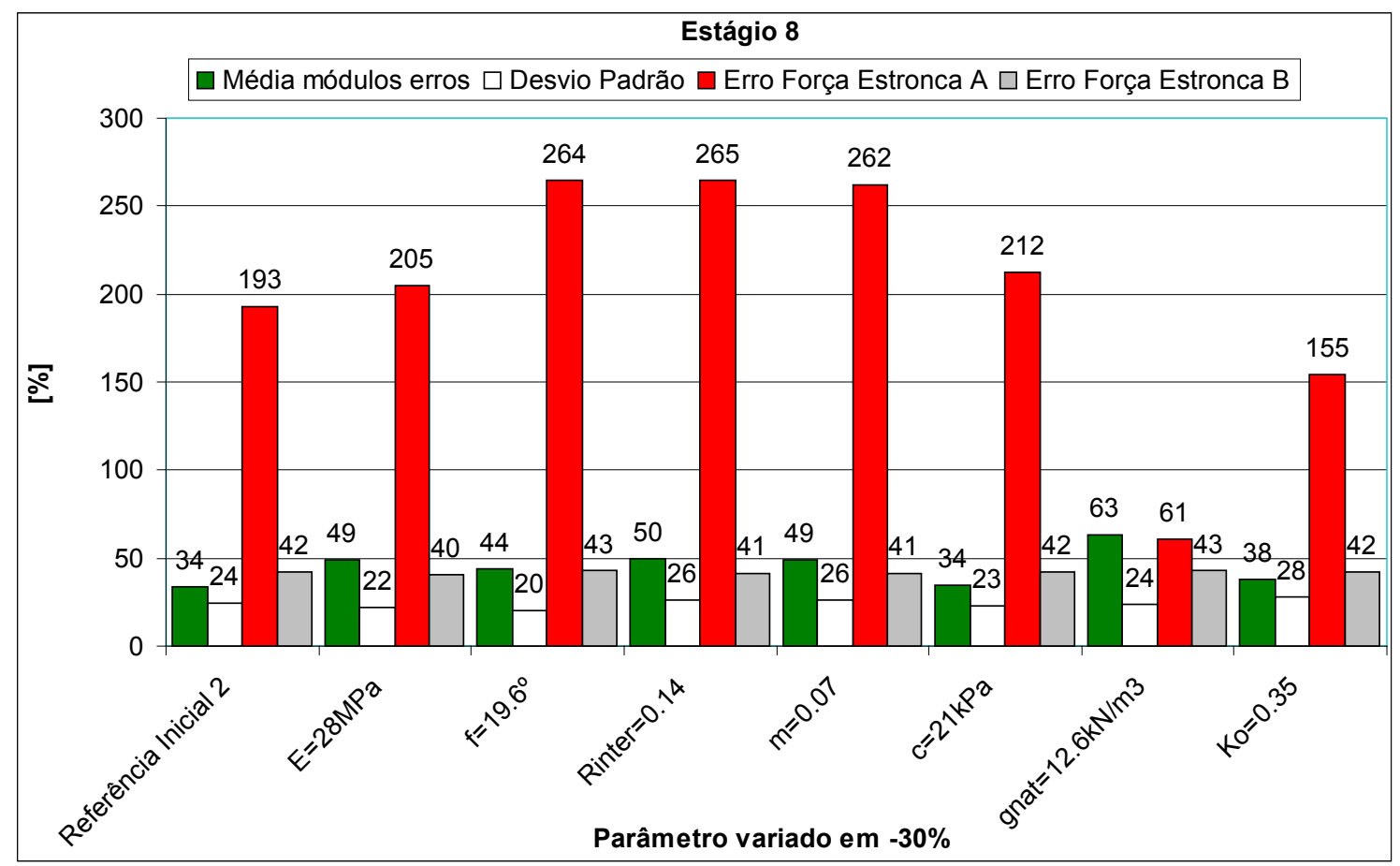

Figura 3-103- Estágio 8 -média dos módulos dos erros de deslocamentos de paramento e módulos dos erros das forças nas estroncas níveis A e B por variação individual de $\mathbf{- 3 0 \%}$ dos parâmetros de referência inicial 2 


\subsection{1 -Escolha dos intervalos para as retroanálises utilizando- se o modelo de Endurecimento}

Para a escolha dos intervalos de combinações de parâmetros para as retroanálises, foi necessário definir um critério. Em outras palavras, encontrar qual o intervalo de cada parâmetro utilizado na análise paramétrica que levará a um erro mínimo para todos os estágios de escavação.

Para isto, analisaram-se os pares de variação $+30 \%$ e $-30 \%$ em relação aos valores de referência inicial 2. Isto foi feito analisando-se os resultados da Figura 3-88 à Figura 3-103.

Por exemplo para o estágio 3, analisaram-se a Figura 3-90 e Figura 3-98. Podese ver nestas figuras que os erros em relação às forças nas estroncas ficou praticamente constante na casa de 84 a 92\%, independente do parâmetro variado, e se a variação foi de + ou $-30 \%$. Quando se analisa o conjunto média o menor erro ocorreu para o parâmetro de interface $\mathrm{R}_{\text {inter }}=0,5$. Em segundo lugar, com magnitudes de erros próximas, estão o valor de $\phi=36,4^{\circ}, E_{50}=52000 \mathrm{kPa}$ para variação de $+30 \%$ e $\gamma_{\text {nat }}=12,6 \mathrm{kN} / \mathrm{m}^{3}$ e $K o=0,35$ e $E_{50}=40000 \mathrm{kPa}$ para a variação de $-30 \%$.

Conclui-se que o valor de $\phi=36,4^{\circ}$ deve ser descartado por ser elevado devido ao solo ser uma argila porosa mole. Além disto, considerou-se baixo o valor de $\gamma_{n a t}=12,6 \mathrm{kN} / \mathrm{m}^{3}$, isto em relação ao mínimo apresentado na Tabela 3-12 Os outros valores citados são todos aceitáveis.

Desta forma, seguindo-se o mesmo raciocínio para os outros estágios elaborouse a Tabela $3-12$ 
Tabela 3-12-Resumo dos intervalos de parâmetros para erros mínimos por estágio

\begin{tabular}{|c|c|c|c|c|c|c|c|}
\hline 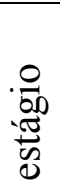 & $\begin{array}{l}\gamma_{\text {nat }} \\
{\left[\mathrm{kN} / \mathrm{m}^{3}\right]}\end{array}$ & $\begin{array}{l}\text { Coesão } \\
{[\mathrm{kPa}]}\end{array}$ & Ko & $\begin{array}{l}\phi \\
{\left[{ }^{\circ}\right\}}\end{array}$ & $\begin{array}{l}\mathrm{E}_{50} \\
{[\mathrm{kPa}]}\end{array}$ & $\mathrm{R}_{\text {inter }}$ & $\mathrm{m}$ \\
\hline 1 & 12.6 a 15 & 30 a 39 & $\begin{array}{c}0.35 \\
\mathrm{a} \\
0.531\end{array}$ & $\begin{array}{c}19.6 \\
\mathrm{a} \\
28\end{array}$ & $\begin{array}{c}40000 \\
a \\
52000\end{array}$ & $\begin{array}{c}0.2 \\
\mathrm{a} \\
0.5\end{array}$ & $\begin{array}{c}0.1 \\
\mathrm{a} \\
0.13\end{array}$ \\
\hline 2 & 12.6 a 15 & 30 a 39 & $\begin{array}{c}0.35 \\
\mathrm{a} \\
0.531\end{array}$ & $\begin{array}{c}19.6 \\
\mathrm{a} \\
28\end{array}$ & $\begin{array}{c}40000 \\
a \\
52000\end{array}$ & $\begin{array}{c}0.2 \\
\mathrm{a} \\
0.5\end{array}$ & $\begin{array}{c}0.1 \\
\mathrm{a} \\
0.13\end{array}$ \\
\hline 3 & $12.6 \mathrm{a} 15$ & 30 a 39 & $\begin{array}{c}0.35 \\
\mathrm{a} \\
0.531\end{array}$ & $\begin{array}{c}19.6 \\
\mathrm{a} \\
28\end{array}$ & $\begin{array}{c}40000 \\
a \\
52000\end{array}$ & $\begin{array}{c}0.2 \\
\mathrm{a} \\
0.5\end{array}$ & $\begin{array}{c}0.1 \\
\mathrm{a} \\
0.13\end{array}$ \\
\hline 4 & 12.6 a 15 & 30 a 39 & $\begin{array}{c}0.35 \\
\mathrm{a} \\
0.531\end{array}$ & $\begin{array}{c}19.6 \\
\mathrm{a} \\
28\end{array}$ & $\begin{array}{c}40000 \\
a \\
52000\end{array}$ & $\begin{array}{c}0.2 \\
\mathrm{a} \\
0.5\end{array}$ & $\begin{array}{c}0.1 \\
\mathrm{a} \\
0.13\end{array}$ \\
\hline 5 & 12.6 a 15 & 30 a 39 & $\begin{array}{c}0.35 \\
\mathrm{a} \\
0.531\end{array}$ & $\begin{array}{c}19.6 \\
\mathrm{a} \\
28\end{array}$ & $\begin{array}{c}40000 \\
a \\
52000\end{array}$ & $\begin{array}{c}0.2 \\
\mathrm{a} \\
0.5\end{array}$ & $\begin{array}{c}0.1 \\
\mathrm{a} \\
0.13\end{array}$ \\
\hline 6 & 12.6 a 15 & 30 a 39 & $\begin{array}{c}0.35 \\
\mathrm{a} \\
0.531\end{array}$ & $\begin{array}{c}19.6 \\
\mathrm{a} \\
28\end{array}$ & $\begin{array}{c}40000 \\
a \\
52000\end{array}$ & $\begin{array}{c}0.2 \\
\mathrm{a} \\
0.5\end{array}$ & $\begin{array}{c}0.1 \\
\mathrm{a} \\
0.13\end{array}$ \\
\hline 7 & $12.6 \mathrm{a} 15$ & 30 a 39 & $\begin{array}{c}0.35 \\
\mathrm{a} \\
0.531\end{array}$ & $\begin{array}{c}19.6 \\
\mathrm{a} \\
28\end{array}$ & $\begin{array}{c}40000 \\
a \\
52000\end{array}$ & $\begin{array}{c}0.2 \\
\mathrm{a} \\
0.5\end{array}$ & $\begin{array}{c}0.1 \\
\mathrm{a} \\
0.13\end{array}$ \\
\hline 8 & 12.6 a15 & 30 a 39 & $\begin{array}{c}0.35 \\
\mathrm{a} \\
0.531\end{array}$ & $\begin{array}{c}19.6 \\
\mathrm{a} \\
28\end{array}$ & $\begin{array}{c}40000 \\
a \\
52000\end{array}$ & $\begin{array}{c}0.2 \\
\mathrm{a} \\
0.5\end{array}$ & $\begin{array}{c}0.1 \\
\mathrm{a} \\
0.13\end{array}$ \\
\hline
\end{tabular}

Na publicação ASCE (1996) há menção ao valor de redução de atrito argila-aço ser Rinter $=0.54$. Nos processamentos foram observadas ocorrências de levantamentos 
de paramentos, ainda que em fases iniciais de escavações, mesmo onde as deformações eram de pequena magnitude.

Estes valores de levantamento por serem de pequena magnitude podem ter passado despercebidos da instrumentação.

O parâmetro do modelo de endurecimento que tem influência direta sobre os deslocamentos verticais de paramento é o $R_{\text {inter }}$.

Enfatizando-se novamente a definição de $R_{\text {inter }}$, é o fator de redução da coesão efetiva e da tangente do ângulo de atrito efetivo que é aplicado pelo software PLAXIS na interface solo-paramento. Para interfaces rígidas (sem deslocamento relativo) $R_{\text {inter }}=1$, para as demais situações onde ocorre deslocamento relativo $R_{\text {inter }}<1,0$. Sendo esta redução feita da seguinte forma:

$$
\begin{aligned}
& c_{\text {reduzida }}=R_{\text {inter }} * c^{\prime} \\
& \text { tan } \phi_{\text {reduzido }}=\mathrm{R}_{\text {inter }} * \text { tan } \phi_{\text {reduzido }}
\end{aligned}
$$

Para tentar elucidar a dúvida sobre qual valor de $R_{\text {inter }}$ seria adotado para as retroanálises, foram feitas simulações com variações de valores de $R_{\text {inter }}$.

A idéia foi identificar a partir de qual valor de redução $\left(\mathrm{R}_{\text {inter }}\right)$ da coesão (c') e da $\tan \phi ’$ na interface solo-paramento, ocorre levantamento de paramento.

Uma vez que nos relatórios disponíveis, a instrumentação não mencionou a ocorrência de deslocamentos verticais de paramento, decidiu-se fazer uma variação de $R_{\text {inter }}$. Foram feitas 10 simulações a partir dos parâmetros de referência inicial 2 (Tabela 3-8), variando-se somente $R_{\text {inter }}$.

A partir das simulações ficou claro que o limite para iniciar-se o levantamento de paramento é com $R_{\text {inter }}$ entre 0,2 e 0,3 (Figura 3-104), portanto adotou-se para as retroanálises $R_{\text {inter }}=0,2$. Porém, não se descartou o conhecimento acumulado pelo ASCE (1996), que sugere um valor de $R_{\text {inter }}=0,54$. Portanto a seqüência de retroanálises foi realizada com $R_{\text {inter }}=0,5$ e $R_{\text {inter }}=0,2$. 


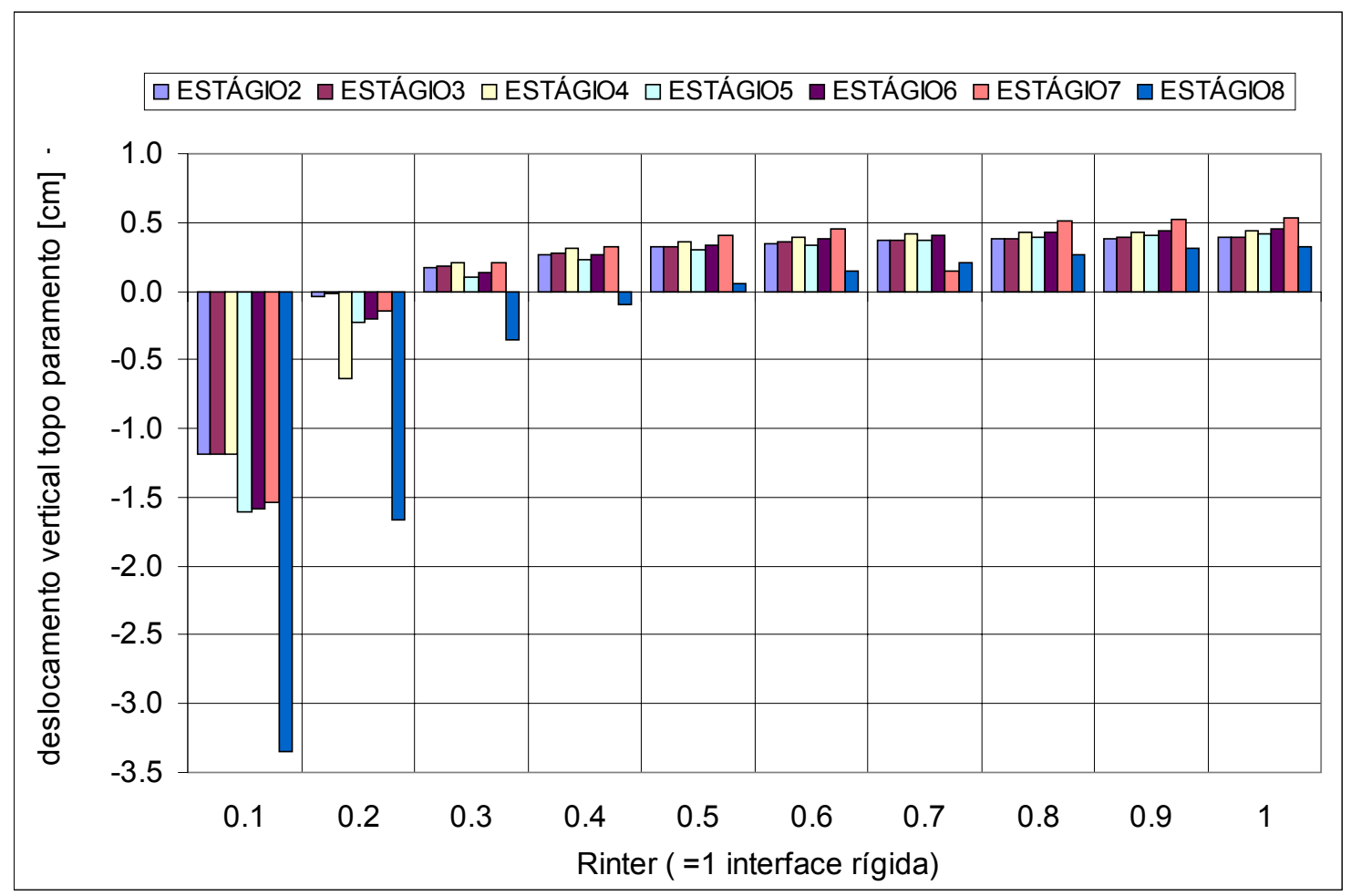

Figura 3-104- Deslocamentos verticais do topo do paramento da seção experimental $\mathrm{n}^{0} 1$ do MetrôSP em função da variação de $\boldsymbol{R}_{\text {inter }}$

Como já foi enfatizado, os relatórios de instrumentação não mencionaram levantamentos de paramento, quem esclarecerá a dúvida sobre qual o fator $R_{\text {inter }}$ mais adequado a estrutura real, será a análise de erros obtidos das etapas de retroanálise (Tabela 4-13), para cada valor de $R_{\text {inter }}$ adotado.

Concluindo, da análise da Tabela 3-12 e da Figura 3-104, adotaram-se os valores de intervalos a variar nas retroanálises, que estão definidos abaixo:

- coesão : duas considerações foram feitas, a de coesão constante para todas as camadas, assumindo-se os valores de $30 \mathrm{kPa}$ e $70 \mathrm{kPa}$, e a consideração de coesão variável em cada camada como função do SPT. TEIXEIRA \& GODOY (1996) sugerem a correlação para coesão não drenada como sendo $c_{u}=10 * \mathrm{~N}_{\mathrm{SPT}}(\mathrm{kPa})$, assim os valores seriam 10,25,35, 55 e 70kPa respectivamente., sendo a quinta camada composta por argila variegada, que aparece na sondagem abaixo do pé do paramento.

- Ângulo de atrito : $\phi=19^{\circ}$ a $28^{\circ}$

- $\gamma_{\mathrm{nat}}=13,5$ a $15 \mathrm{kN} / \mathrm{m}^{3}$

- $K o=0,40$ a 0,531

- $\quad R_{\text {inter }}=0,2$ a 0,5 
- $E_{50}=40000$ a $50000 \mathrm{kPa}$, este parâmetro será retroanalisado, não há grande importância em seus intervalos, uma vez que o próprio processo corrigirá seus valores.

- $m=0,1$ este parâmetro foi adotado da calibração feita dos ensaios de PARREIRA (1991). 


\section{Capítulo 4 - Aplicação de Retroanálise via Processo Direto a S.E.-1}

\section{1 -Influência da variação da temperatura do solo nos deslocamentos de paramento}

Nos relatórios de instrumentação de IPT (1972) não foi mencionado se foram realizadas medidas de temperaturas dos paramentos e do solo.

De acordo com MITCHELL (1992) o fluxo de calor no solo é mais importante pela condução do que pela convecção. A convecção só ocorre se houver elevada taxa de fluxo de água ou ar que pode ocorrer em areias grossas e enrocamentos.

O mesmo autor afirma que a condutividade térmica é a propriedade essencial que controla fluxo de calor nos solos, sendo que o processo de condução se dá principalmente pela fase sólida de uma massa de solo.

A condutividade térmica para minerais que compõem o solo é mais alta do que para a água como desta para o ar. Além disto, a condutividade térmica para solos densos é maior do que do mesmo solo com índice de vazios maior. A condutividade térmica de um solo saturado é maior que um solo não saturado.

O mesmo autor acima afirma ainda que a partir do peso específico do solo e teor de umidade é possível estimar-se a condutividade térmica através da Figura 4-1 para as situações onde há congelamento e onde não há. 

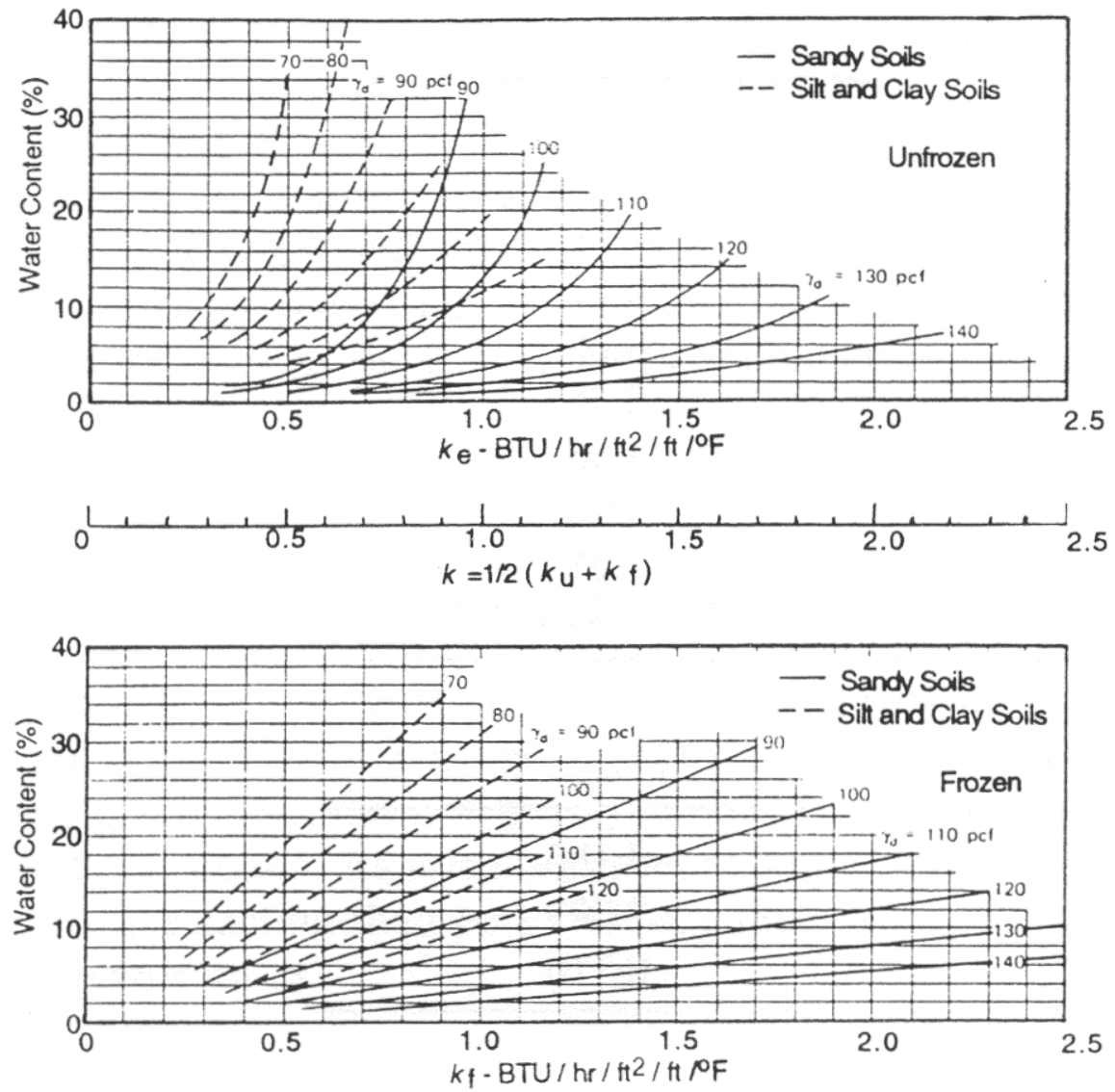

Figura 4-1-Condutividade térmicas de solos congelados e não congelados apud MITCHELL (1992)

Além disto, há outros fatores que influenciam a condutividade térmica que foram alvo de estudos de BRANDON \& MITCHELL (1989) (MITCHELL, 1992). A seguir, citam-se 5 fatores e apresenta-se um apanhado da importância de cada fator no fenômeno da condutividade térmica, baseado no apresentado por MITCHELL (1992).

Mineralogia - a melhor ou pior condutividade térmica depende dos minerais constituintes e de sua concentração. $\mathrm{O}$ autor cita que areias com quartzo têm maior condutividade que areias com alta porcentagem de mica.

Peso específico seco - quanto maior o peso específico seco maior a condutividade térmica

Graduação - solos bem graduados conduzem calor melhor que solos mal graduados. Isto deve-se ao fato de os finos preencherem os espaços intersticiais entre os grãos maiores com isto aumentando o peso específico do conjunto e também fazendo contato mineral-mineral. 
Compactação na presença de água - algumas areias quando compactadas no ramo seco e que posteriormente sofram uma adição de água, mesmo que em pequena quantidade, sofrerão um grande aumento da condutividade em relação a se a areia houvesse sido compactada com este teor de umidade.

Tempo - solos que contenham altas porcentagens de sílica, carbonatos ou outros materiais podem desenvolver cimentações entre as partículas. Com isto pode haver um aumento da condutividade térmica com o decorrer do tempo.

Temperatura - todos os minerais cristalinos nos solos apresentam queda da condutividade térmica com o aumento da temperatura, contudo a condutividade térmica da água aumenta levemente com o aumento da temperatura e a condutividade térmica dos poros saturados de ar aumenta notoriamente com o aumento da temperatura. A combinação de efeitos faz com que a condutividade térmica de areias úmidas aumente com o incremento da temperatura.

A Tabela 4-1 foi traduzida de MITCHELL (1992) e nela são apresentados alguns valores de condutividade térmica para alguns materiais. 
Tabela 4-1-Propriedades térmicas do solo

\begin{tabular}{|c|c|c|c|}
\hline \multirow{8}{*}{$\begin{array}{l}\text { Condutividade } \\
\text { térmica }\end{array}$} & Material & BTU/ hr $/ \mathrm{ft}^{2} /{ }^{\circ} \mathbf{F} / \mathbf{f t}$ & $\mathbf{W} / \mathbf{m} / \mathbf{K}$ \\
\hline & $\mathrm{Ar}$ & 0.014 & 0.024 \\
\hline & Água & 0.30 & 0.60 \\
\hline & Gelo & 1.30 & 2.25 \\
\hline & Xisto & 0.90 & 1.56 \\
\hline & Granito & 1.60 & 2.76 \\
\hline & Cobre & 225 & 389 \\
\hline & Solo & 0.15 a $1.5(\sim 1.0)$ & 0.25 a $2.5(\sim 1.7)$ \\
\hline \multirow{4}{*}{$\begin{array}{l}\text { Capacidade } \\
\text { calorífica }\end{array}$} & Material & $\mathbf{B T U} / \mathbf{l b} /{ }^{\mathbf{o}} \mathbf{F}$ & kJ / kg / K \\
\hline & Água & 1.0 & 4.186 \\
\hline & Gelo & 0.5 & 2.093 \\
\hline & Minerais & 0.17 & 0.710 \\
\hline \multirow[t]{2}{*}{$\begin{array}{l}\text { Volume } \\
\text { calorífico }\end{array}$} & $\begin{array}{l}\text { Material } \\
\text { Solo Não } \\
\text { congelado }\end{array}$ & $\begin{array}{c}\mathbf{B T U} / \mathbf{f t}^{\mathbf{3}} /{ }^{\mathbf{o}} \mathbf{F} \\
\gamma_{\mathrm{d}}(0.17+\mathrm{w} / 100)\end{array}$ & $\begin{array}{l}\mathbf{k J} / \mathbf{~ m}^{3} / \mathbf{K} \\
\gamma_{\mathrm{d}}\left(72.4+427^{*} \mathrm{w} / 100\right)\end{array}$ \\
\hline & $\begin{array}{c}\text { Solo } \\
\text { Congelado }\end{array}$ & $\gamma_{\mathrm{d}}\left(0.17+0.5^{*} \mathrm{~W} / 100\right)$ & $\gamma_{\mathrm{d}}(72.4+213 * \mathrm{w} / 100)$ \\
\hline $\begin{array}{l}\text { Calor de } \\
\text { Fusão }\end{array}$ & $\begin{array}{l}\text { Material } \\
\text { Água } \\
\text { Solo }\end{array}$ & $\begin{array}{c}143.4 \mathrm{BTU} / \mathrm{lb} \\
143.4(\mathrm{w} / 100) \gamma_{\mathrm{d}} \\
\mathrm{BTU} / \mathrm{ft}^{3}\end{array}$ & $\begin{array}{l}333 \mathrm{~kJ} / \mathrm{kg} \\
3.40 * 10^{4}(\mathrm{w} / 100) \gamma_{\mathrm{d}} \mathrm{kJ} / \mathrm{m}^{3}\end{array}$ \\
\hline $\begin{array}{l}\text { Calor de } \\
\text { Vaporização }\end{array}$ & $\begin{array}{l}\text { Material } \\
\text { Água } \\
\text { Solo }\end{array}$ & $\begin{array}{c}970 \mathrm{BTU} / \mathrm{lb} \\
970(\mathrm{w} / 100) \gamma_{\mathrm{d}} \mathrm{BTU} / \mathrm{ft}^{3}\end{array}$ & $\begin{array}{l}2.26 \mathrm{MJ} / \mathrm{kg} \\
230(\mathrm{w} / 100) \gamma_{\mathrm{d}} \mathrm{MJ} / \mathrm{m}^{3}\end{array}$ \\
\hline
\end{tabular}

Nota do autor : $\gamma_{\mathrm{d}}=$ peso específico do solo seco deve ser utilizado na $2^{\mathrm{a}}$. coluna $\mathrm{em} \mathrm{lb} / \mathrm{ft}^{3}$ para unidades inglesas, e na $3^{\mathrm{a}}$. coluna $\mathrm{em} \mathrm{kN} / \mathrm{m}^{3}$ para o Sistema Internacional de unidades, $\mathrm{w}=$ teor de umidade $\%$ 
Uma vez que não se dispõe de dados sobre as variações de temperatura ao longo dos paramentos não foi possível fazer-se uma estimativa da influência da dilatação e contração do solo sobre os deslocamentos de paramento. Por esta razão considerou-se que a temperatura do solo não foi alterada ao longo do processo e não teve influência sobre os deslocamentos de paramento.

\section{2 -Correção dos esforços nas estroncas em função do efeito da temperatura}

Em IPT (1972) e MASSAD (1978) menciona-se que para um determinado aumento de temperatura nas estroncas ocorre uma dilatação e uma variação na força da estronca. Além disto, afirma-se que estes dois fatores estão relacionados a duas situações de vinculação entre a estronca e o paramento:

i) Considera-se que as extremidades das estroncas estão livres para deslocamento axial.

ii) Considera-se que as extremidades das estroncas estão bloqueadas para deslocamento axial.

A NC-03 (1980) recomenda a inclusão dos efeitos de temperatura nas forças das estroncas em projetos de escoramentos de vala com estroncas de comprimento maior que $20 \mathrm{~m}$.

Nos relatórios de IPT (1972) menciona-se que para a condição i) (extremidades livres) o aquecimento de $1^{\circ} \mathrm{C}$ imposto à estronca causaria um acréscimo de comprimento nas estroncas de :

$\Delta \mathrm{L}=\mathrm{L} * \alpha * \Delta \mathrm{t}$

Para o aço ASTM-A36 $\alpha=1,1 * 10^{-5} /{ }^{\circ} \mathrm{C}$, com uma estronca de $12,90 \mathrm{~m}$ de comprimento (dimensão da estronca da seção experimental $n^{\circ} .1$ ).

$\Delta \mathrm{L}=1,42 * 10^{-2} \mathrm{~cm}$ 
Considerando-se a condição ii) (extremidades bloqueadas) o aquecimento de $1^{\circ} \mathrm{C}$ imposto à estronca causaria um acréscimo de tensão devido ao bloqueio da deformação $(\Delta \mathrm{L} / \mathrm{L})$ :

$\Delta \sigma=\mathrm{E}_{\mathrm{aço}} *(\Delta \mathrm{L} / \mathrm{L})$

Sendo $\Delta \mathrm{L}=\mathrm{L} * \alpha * \Delta \mathrm{t}$

Para o aço ASTM-A36 $\mathrm{E}_{\text {aço }}=210.000 \mathrm{MPa}$

Portanto o acréscimo de tensão para $1^{\circ} \mathrm{C}$ é:

$\Delta \sigma=2,3 \mathrm{MPa}$

A área de uma estronca é $154,6 \mathrm{~cm}^{2}$, logo o acréscimo de força devido a um aumento de $1^{\circ} \mathrm{C}$ será:

$\Delta \mathrm{F}=34,89 \mathrm{kN}$

Por exemplo, o resfriamento ocorrido entre o encunhamento da estronca A aos $26^{\circ} \mathrm{C}$ e a medida dos deslocamentos intermediários aos $21,25^{\circ} \mathrm{C}, \Delta \mathrm{t}=-4,75^{\circ} \mathrm{C}$, provocou um encurtamento da estronca e uma redução da força incorporada quando de seu encunhamento. Esta redução de força para a condição de estremidades bloqueadas seria:

$$
\Delta \mathrm{F}=-165,6 \mathrm{kN}
$$

Porém nas observações relatadas em IPT (1972), salientou-se que os acréscimos de carga verificados devidos a acréscimos de temperatura não superaram $10 \%$ do acréscimo de força que ocorreria se as estroncas fossem bloqueadas à dilatação. Em virtude das observações acima, adotou-se por analogia que o decréscimo de força provocado pela variação da temperatura de $26^{\circ} \mathrm{C}$ a $21,3^{\circ} \mathrm{C}$ foi de $10 \%$ de $-165.6 \mathrm{kN}$, ou seja, $-16,6 \mathrm{kN}$ 
Finalmente, o valor utilizado para simular a força incorporada à estronca na temperatura de $21,25^{\circ} \mathrm{C}$ é de $-18,5 \mathrm{kN}$

Portanto, nas simulações das etapas de escavações, os efeitos de temperatura sobre as forças nas estroncas e sobre os deslocamentos horizontais dos paramentos, foram considerados:

- no instante da instalação das estroncas.

- nos instantes em que foram feitas as leituras sob temperaturas máximas e mínimas em cada estágio de escavação.

A estronca do nível $\mathrm{A}$ foi encunhada com $35,1 \mathrm{kN}$ à temperatura de $26^{\circ} \mathrm{C}$, que ocorreu no dia 14/01/1971 às $17 \mathrm{~h}$, esta foi à única medida de temperatura e força registrada neste dia por IPT (1972). Portanto a simulação do $3^{\circ}$ estágio de escavação considerou a carga de encunhamento de $35,1 \mathrm{kN}$ para o nível $A$ das estroncas.

Nos dois dias seguintes (15 e 16/01), mediu-se às $9 \mathrm{~h}$ respectivamente $21,5^{\circ} \mathrm{C}$ e $16,6 \mathrm{kN}$ e $17^{\circ} \mathrm{C}$ e $14,3 \mathrm{kN}$. No dia $19 / 01$ às $9: 30 \mathrm{~h}$ mediu-se $27^{\circ} \mathrm{C}$ e força de $25,4 \mathrm{kN}$.

Na Figura 4-2 apresenta-se as curvas deslocamentos e cargas nas estroncas em função das temperaturas lidas nas estroncas. Em IPT (1972) não há menção para quais temperaturas foram traçadas as curvas de deslocamentos médios, inferiores e superiores de paramento. Inferiu-se que para a temperatura mínima indicada $\left(17^{\circ} \mathrm{C}\right)$ a correspondente curva de deslocamentos é a de máximos deslocamentos (contração das estroncas que puxaria o paramento para dentro da vala) e por coerência, a correspondente à de máxima temperatura $\left(25,5^{\circ} \mathrm{C}\right)$ seria a de mínimos deslocamentos (dilatação da estronca empurraria o paramento contra o solo). Desta forma a curva média de deslocamentos seria obtida pela média das curvas de deslocamentos máximos (mínima temperatura) e deslocamentos mínimos (máxima temperatura).

Procedeu-se a retroanálise de $E_{50}$ para o estágio 3 em função da curva média de deslocamentos horizontais do paramento e da força na estronca para a temperatura média de $21,3^{\circ} \mathrm{C}$. A simulação do estágio 3 (Figura 3-16) foi iniciada com a aplicação de uma força de $35,1 \mathrm{kN}$ concentrada para representar a força de encunhamento. Após isto, fez-se uma redução desta força para $18,2 \mathrm{kN}$, que representa o valor instrumentado no nível $\mathrm{A}$ na temperatura média de $21,3^{\circ} \mathrm{C}$, sendo relacionada à curva média de deslocamentos do paramento.

Para os estágios consideram-se como carregamento devido à dilatação e contração das estroncas as variações de temperatura descritas na Tabela 4-2 
Tabela 4-2-Descrição das etapas consideradas na simulações das escavações com efeito de temperatura nas estroncas

\begin{tabular}{|c|c|}
\hline $\begin{array}{l}\text { Posição da } \\
\text { escavação }\end{array}$ & DESCRIÇÃO \\
\hline Inicial & Instalação de paramentos \\
\hline Estágio 1 & Escavação 1 \\
\hline Estágio 2 & Escavação 2 \\
\hline Estágio 3 & Macaco hidráulico empurra paramento \\
\hline Estágio 3 & Instalação do $1^{\circ}$. Nível de estroncas e retirada do macaco \\
\hline Estágio 3 & Contrai Estronca nível A temperatura de $26 \mathrm{p} / 21,3^{\circ} \mathrm{C}$ \\
\hline Estágio 4 & Escavação 3 \\
\hline Estágio 4 & Dilatação Estronca nível A 21,3 p/ 29, $8^{\circ} \mathrm{C}$ \\
\hline Estágio 5 & Escavação 4 \\
\hline Estágio 5 & Contração Estronca nível A 29,8 p/ $28,3^{\circ} \mathrm{C}$ \\
\hline Estágio 6 & Escavação 5 \\
\hline Estágio 6 & Contração Estronca nível A 28,3 p/ $25^{\circ} \mathrm{C}$ \\
\hline Estágio 7 & Escavação 6 \\
\hline Estágio 7 & Dilatação Estronca nível A 25 p $/ 25,3^{\circ} \mathrm{C}$ \\
\hline Estágio 8 & Escavação 7 \\
\hline Estágio 8 & Contração Estronca nível A 25,3 p/ $21,5^{\circ} \mathrm{C}$ \\
\hline Estágio 8 & Macaco hidráulico empurra nível B do paramento \\
\hline Estágio 8 & Instalação de Estroncas nível B ( a $22^{\circ} \mathrm{C}$ ) e retirada do macaco \\
\hline Estágio 8 & $\begin{array}{l}\text { Dilatação nível } \boldsymbol{A} \text { de } 21,5 \text { a } 21,8^{\circ} \mathrm{C} \text { e contração nível } \boldsymbol{B} 22 \mathrm{p} / \\
18,3^{\circ} \mathrm{C}\end{array}$ \\
\hline
\end{tabular}

As simulações desta seção foram conduzidas em relação à curva média de deslocamentos horizontais de paramentos e analisadas em função dos erros entre as forças calculadas e as forças instrumentadas nas estroncas com inclusão do efeito de temperatura. Os valores de variação de forças nas estroncas devido à variação de temperatura estão apresentados na Figura 4-2 e as respectivas temperaturas na Tabela 4-3 e na Figura 4-3. 


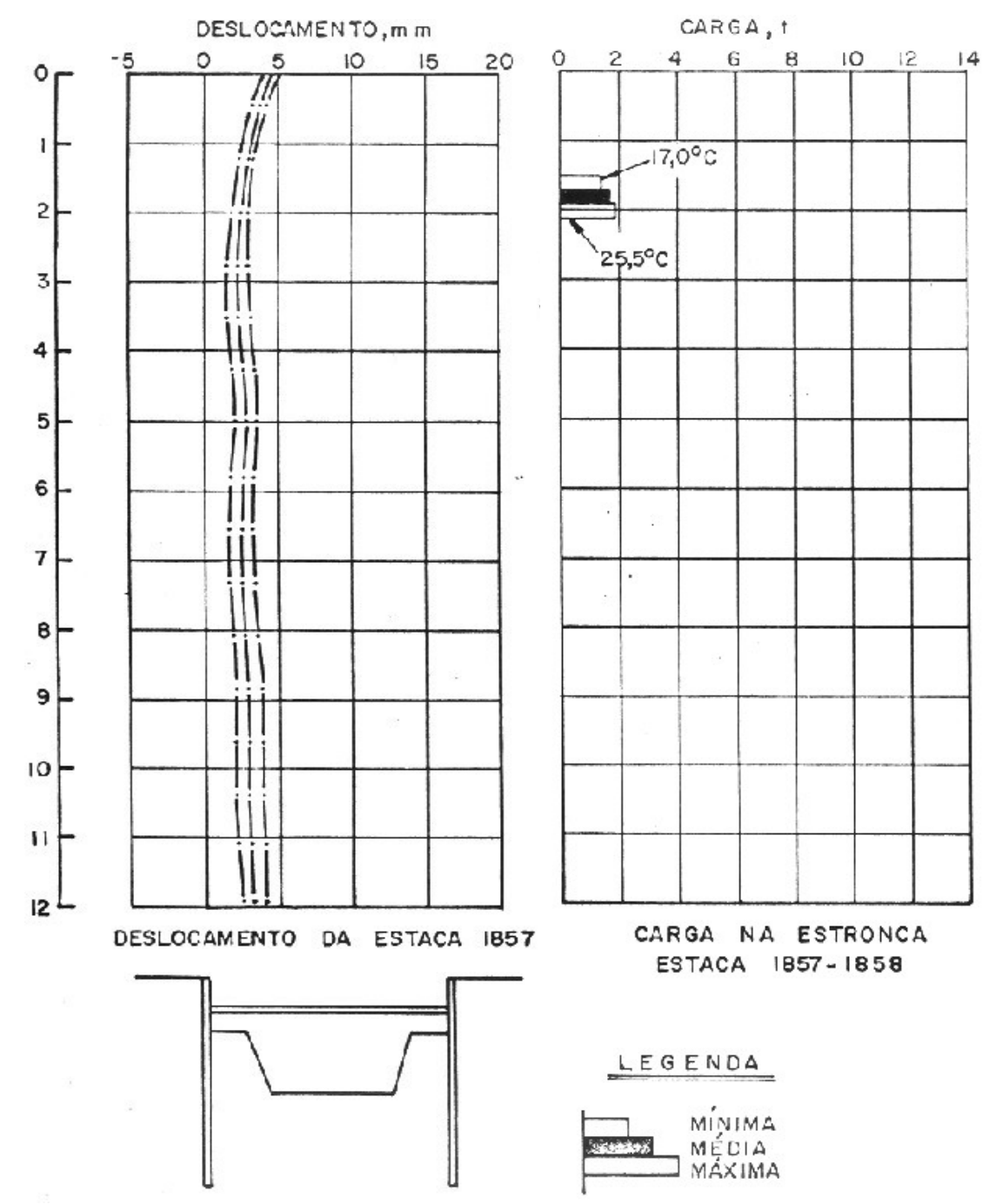

Figura 4-2-Curvas deslocamentos do paramento $x$ temperatura nas estroncas para o estágio de escavação n⿳3 (IPT,1972) 
Tabela 4-3 -Relação de Forças corrigidas em função da variação de temperatura

\begin{tabular}{|c|c|c|c|c|c|c|c|c|c|c|}
\hline & \multirow{2}{*}{\multicolumn{3}{|c|}{ FORÇAS INSTRUMENTADAS TEMPERATURAS }} & \multirow{3}{*}{$\begin{array}{c}{[1]} \\
\text { Forças de } \\
\text { encunhamento } \\
\text { (instrumentada) } \\
{[\mathrm{kN}]}\end{array}$} & \multirow{3}{*}{$\begin{array}{c}{[2]} \\
\text { Temperatura } \\
\text { encunhamento } \\
\text { (instrumentada) } \\
{\left[{ }^{\circ} \mathrm{C}\right]}\end{array}$} & \multirow{3}{*}{$\begin{array}{c}{[3]} \\
\text { Temperatura } \\
\text { de cálculo } \\
\text { do estágio anterior } \\
{\left[{ }^{\circ} \mathrm{C}\right]}\end{array}$} & {$[4]=([5]+[6]) / 2$} & \begin{tabular}{|c|}
{$[5]$} \\
\end{tabular} & [6] \\
\hline & & & & & & & & \multicolumn{3}{|c|}{ TEMPERATURAS } \\
\hline & & $\begin{array}{l}\text { MINIMA } \\
{[\mathrm{kN}]}\end{array}$ & $\begin{array}{c}\text { MEDIA } \\
{[\mathrm{kN}]}\end{array}$ & $\begin{array}{c}\text { MAXIMA } \\
{[\mathrm{kN}]}\end{array}$ & & & & $\begin{array}{c}\text { MEDIA } \\
\text { estágio atual } \\
{\left[{ }^{\circ} \mathrm{C}\right]}\end{array}$ & $\begin{array}{c}\text { MINIMA } \\
\text { (instrumentada) } \\
{\left[{ }^{\circ} \mathrm{C}\right]}\end{array}$ & $\begin{array}{c}\text { MAXIMA } \\
\text { (instrumentada) } \\
{\left[{ }^{\circ} \mathrm{C}\right]} \\
\end{array}$ \\
\hline FORÇA ESTR. A & ESTÁGIO 3 & 14.3 & 16.2 & 18.0 & 35.1 & 26.0 & 26.00 & 21.25 & 17 & 25.5 \\
\hline FORÇA ESTR. A & ESTÁGIO 4 & 18.50 & 28.9 & 39.3 & & & 21.25 & 29.75 & 28 & 31.5 \\
\hline FORÇA ESTR. A & ESTÁGIO 5 & 41.60 & 62.9 & 84.1 & & & 29.75 & 28.25 & 20.5 & 36 \\
\hline FORÇA ESTR. A & ESTÁGIO 6 & 49.90 & 57.1 & 64.2 & & & 28.25 & 25.00 & 23 & 27 \\
\hline FORÇA ESTR. A & ESTÁGIO 7 & 49.40 & 67.0 & 84.6 & & & 25.00 & 25.25 & 21.5 & 29 \\
\hline FORÇA ESTR. A & ESTÁGIO 8 & 61.91 & 72.7 & 83.5 & & 21.5 & 25.25 & 21.75 & 13 & 30.5 \\
\hline FORÇA ESTR. B & ESTÁGIO 8 & 75.75 & 45.6 & 15.4 & 78.8 & 22 & 21.75 & 18.25 & 10.5 & 26 \\
\hline
\end{tabular}

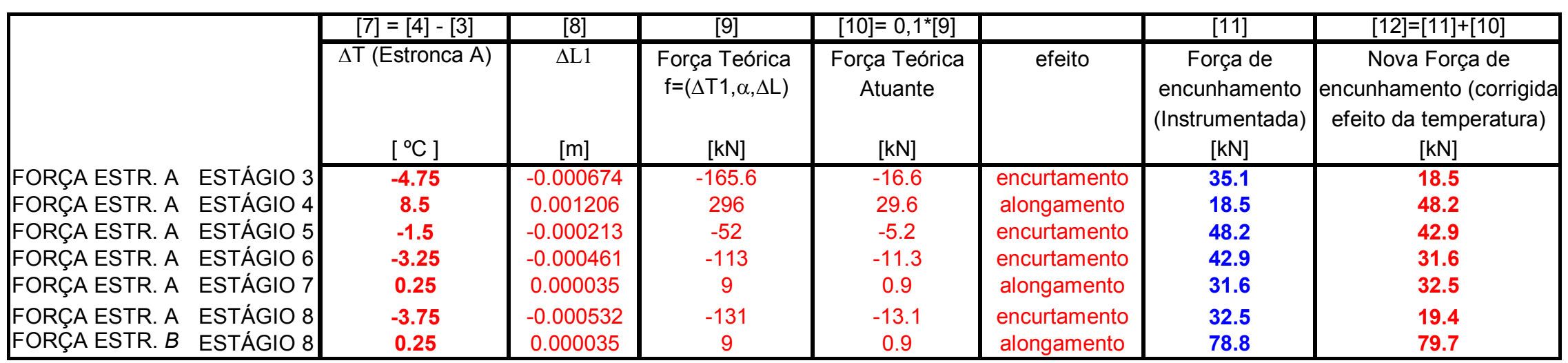




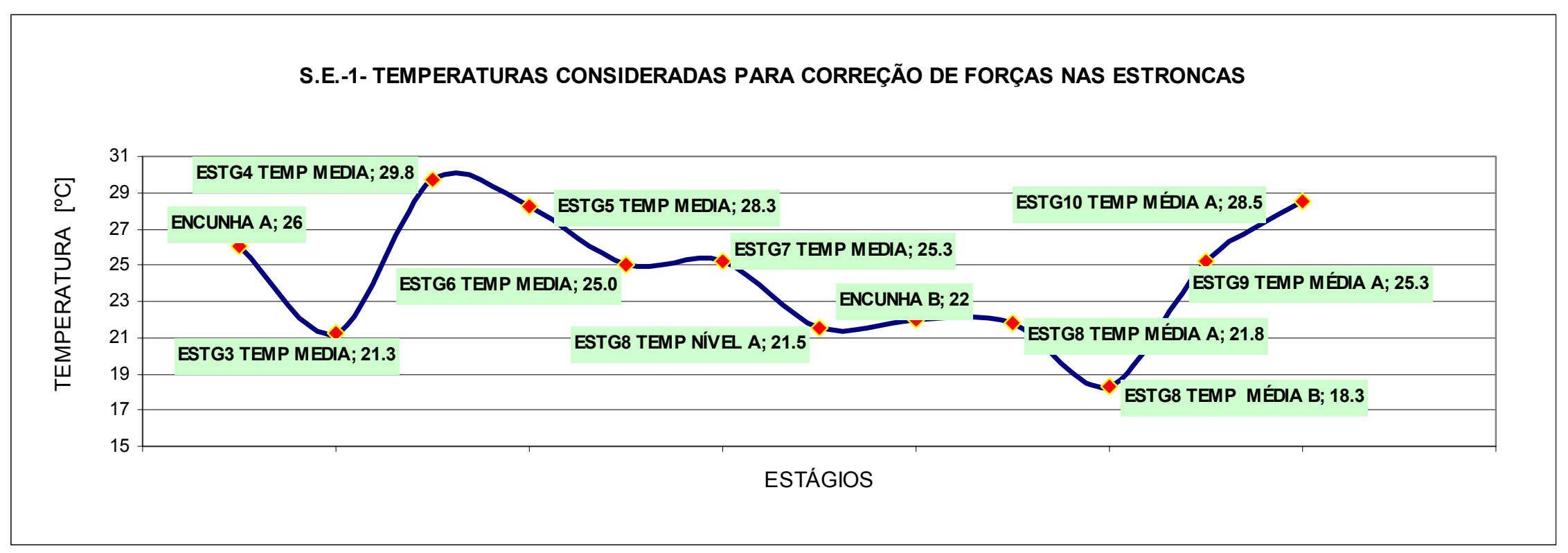

Figura 4-3-Variações de temperaturas utilizadas na correção das forças nas estroncas nos níveis A e B 


\section{3 -O problema da Retroanálise baseada somente em erros de deslocamentos do paramento}

Um dos problemas que podem advir da retroanálise por processo direto reside no fato de haver várias combinações possíveis de parâmetros geotécnicos que podem conduzir a mesmos valores de deslocamentos de paramentos. Fica então a questão: qual das combinações é a mais correta?

A partir da utilização do modelo em M.E.F. já descrito no capítulo 3, e adotando-se o modelo constitutivo de Mohr-Coulomb, fez-se uma seqüência de 90 retroanálises por processo direto, para o estágio 2 de escavação (Figura 4-4).

Neste estágio de escavação ainda não foram instaladas as estroncas. Desta forma, todo o critério de parada dos processos de retroanálise fica baseado somente nos erros entre os deslocamentos horizontais do paramento simulados em relação aos instrumentados. Sem a comparação dos valores de forças nas estroncas simuladas com a leitura de instrumentação nas estroncas reais, fica muito difícil determinar-se o correto valor do módulo de deformabilidade do conjunto.

O exemplo desenvolvido a seguir neste tópico demonstra o exposto acima.

A partir da técnica de retroanálise por processo direto via método dos elementos finitos (M.E.F.), com o modelo constitutivo de Mohr-Coulomb, determinaram-se os valores de módulo de deformabilidade $\left(E_{50}\right)$ e intervalos de coesão e coeficiente de empuxo em repouso $(K o)$ que conduzissem a resultados simulados visando erro mínimo, para os solos da seção experimental $n^{\circ} 1$ do Metropolitano de São Paulo.

A partir de parâmetros de solo obtidos em MASSAD (1978), IPT (1972) e parâmetros de interação solo estrutura obtidos em PLAXIS (1998), PLAXIS (2002) e ASCE (1996) iniciou-se o processo de retroanálise com os parâmetros que constam na Tabela 4-4. 
Tabela 4-4- Parâmetros geotécnicos (valores de referência iniciais) adotados para início das retroanálises via Mohr-Coulomb

\begin{tabular}{|c|c|c|c|c|c|c|c|c|c|}
\hline Solo & $\begin{array}{c}\text { Início/Fim } \\
\text { [m] }\end{array}$ & $\begin{array}{c}\gamma_{\text {nat }} \\
{\left[\mathbf{k N} / \mathbf{m}^{3}\right]}\end{array}$ & $\begin{array}{c}\gamma_{\mathrm{sat}} \\
{\left[\mathrm{kN} / \mathrm{m}^{3}\right]}\end{array}$ & $v$ & $\begin{array}{c}\mathrm{c}^{\prime} \\
\mathrm{kPa}\end{array}$ & $\begin{array}{l}\phi^{\prime} \\
{\left[{ }^{\circ}\right]}\end{array}$ & $\begin{array}{c}\mathbf{E}_{50} \\
{[\mathrm{MPa}]}\end{array}$ & Ko & $\begin{array}{c}\text { Rinter. } \\
* *\end{array}$ \\
\hline $\mathrm{AgPoVm} 1$ & 0 a 4,4 & 15 & 18 & 0,35 & 10 a 30 & 28 & 40 & $\begin{array}{c}0,45 \\
0,73 \\
\text { e } \\
1,13\end{array}$ & 0,5 \\
\hline $\mathrm{AgPoVm} 2$ & 4,4 a 8 & 15 & 18 & 0,35 & 10 a 30 & 28 & 40 & $\begin{array}{c}0,45 \\
0,73 \\
\mathrm{e} \\
1,13\end{array}$ & 0,5 \\
\hline $\mathrm{AgPoVm} 3$ & 8 a 11,20 & 15 & 18 & 0,35 & 10 a 30 & 28 & 40 & $\begin{array}{c}0,45 \\
0,73 \\
\text { e } \\
1,13\end{array}$ & 0,5 \\
\hline AgSiVrgd & 11,20 & 15,3 & 18,4 & 0,35 & 70 & 26 & 40 & $\begin{array}{c}0,45 \\
0,73 \\
\mathrm{e} \\
1,13\end{array}$ & 0,5 \\
\hline SiAgArAm & $15.50 \mathrm{~m}$ & 15,3 & 18,4 & 0,35 & 70 & 26 & 336 & $\begin{array}{c}0,45 \\
0,73 \\
\mathrm{e} \\
1,13\end{array}$ & 0,5 \\
\hline
\end{tabular}

$* *$ (ASCE ,1996)

Legendas:

AgPoVm1-Subdivisão 1 da camada de Argila Porosa Vermelha

AgPoVm2-Subdivisão 2 da camada de Argila Porosa Vermelha

AgPoVm3- Subdivisão 3 da camada de Argila Porosa Vermelha

AgSiVrgd- Camada de Argila Siltosa Variegada

SiAgArAm- Camada de Silte argilo arenoso pouco compacto amarelo 
Para os solos descritos na Figura 2-6 adotou-se o modelo elasto-plástico de Mohr-Coulomb para a primeira etapa de estudos, que foram realizados através de simulações utilizando-se o software PLAXIS (1998) bidimensional.

Durante as escavações dos estágios 1 e 2, somente o paramento fez a contenção, desta forma não houve medidas de temperaturas nem de forças nas estroncas, que apenas viriam a ser instaladas no estágio 3.

\section{4 -Resultados obtidos -Modelo de Mohr-Coulomb}

Conduziu-se retroanálises de $E_{50}$ baseando-se na curva intermediária de deslocamentos do estágio 2.

Distinção deve ser feita entre o termo simulação e o termo retroanálise.

Neste texto convencionou-se que simulação é o processo de cálculo com a finalidade de modelar o comportamento do sistema solo-escoramento nas diversas fases de escavação. Sendo realizada através do software PLAXIS com parâmetros geotécnicos adotados a partir de parâmetros de laboratório. Estes parâmetros já foram definidos anteriormente como parâmetros de referência inicial 1, para o modelo de Mohr-Coulomb, e parâmetros de referência inicial 2 para o modelo de Endurecimento.

A partir da $1^{\text {a }}$. simulação obtém-se valores calculados pelo software (teóricos) de deslocamentos de paramentos e forças nas estroncas.

A partir da comparação entre estes valores teóricos de deslocamentos horizontais de paramentos (calculados na simulação) e os valores reais instrumentados em campo, altera-se um dos parâmetros de referência inicial, que nesta dissertação foi o $E_{50}$. Realiza-se nova simulação com o novo valor de $E_{50}$.

$\mathrm{O}$ procedimento de correção do valor de $E_{50}$ associado à nova simulação realizada com o valor corrigido de $E_{50}$ convencionou-se aqui chamar de retroanálise $\mathrm{n}^{\mathrm{o}} .1$. Procede-se assim sucessivamente até última retroanálise $\mathrm{n}^{\mathrm{o}} . N$. Nesta última etapa de retroanálise realizada, os deslocamentos e forças nas estroncas calculados pelo software podem ser considerados equivalentes aos reais instrumentados.

Para aquela última etapa de retroanálise $n^{\circ} . N$ de um estágio de escavação, o modelo em elementos finitos (agora com $\mathrm{E}_{50}$ corrigido), é considerado equivalente ao sistema solo-escoramento real (para um estágio de escavação específico). 
Se ao avançar do processo de escavação o modelo retroanalisado conseguir representar os novos deslocamentos de paramentos e forças nas estroncas, então se considera que o modelo representa o comportamento do sistema solo-escoramento em todas as etapas de escavação subseqüentes ao estágio onde foi realizada a retroanálise.

Caso contrário o modelo constitutivo adotado para representar o solo deverá ser substituído por outro que possa representar melhor os avanços de escavação. Este é um dos desafios que o engenheiro geotécnico encontra quando tenta representar o sistema solo-escoramento sujeito a um processo de escavação e reaterro.

Os termos utilizados apresentados da Figura 4-4 à Figura 4-19 significam:

- Xreal_MÉDIO -Valores de instrumentação dos deslocamentos horizontais médios de paramento.

- S_inicial- simulação inicial feita com os valores de referência inicial 1 (Tabela 3-3) adotados para as análises paramétricas.

- R1- $1^{\mathrm{a}}$. iteração de retroanálise de $E_{50}$, realizada a partir das diferenças entre os valores de deslocamentos horizontais de paramento simulados em S_inicial e os correspondentes instrumentados (Xreal_médio).

- $\mathrm{R} 2-2^{\mathrm{a}}$. iteração de retroanálise de $E_{50}$, realizada a partir das diferenças entre os valores de deslocamentos simulados em R1 e os correspondentes instrumentados (Xreal_médio).

- Idem para R3 a R10.

- RETRO2_ESTG3 - Erros entre os deslocamentos horizontais de paramento instrumentados no estágio 3 e os calculados com os $E_{50}$ obtidos da convergência da retroanálise do estágio 2 .

- RETRO2_ESTG5 - Erros entre os deslocamentos horizontais de paramento instrumentados no estágio 5 e os calculados com os $E_{50}$ obtidos da convergência da retroanálise do estágio 2 .

- Na forma geral, RETROn_ESTG $p$ - $p$ é estágio onde se calcula o erro entre os deslocamentos instrumentados e os calculados utilizando-se os $E_{50}$ do estágio $n$ (obtido anteriormente por retroanálise).

Da Figura 4-4 à Figura 4-19 são apresentados os resultados da convergência da retroanálise para os diversos estágios de escavação obtidos para a combinação $\mathrm{Ko}=0.45$ e coesão $=20 \mathrm{kPa}$. 


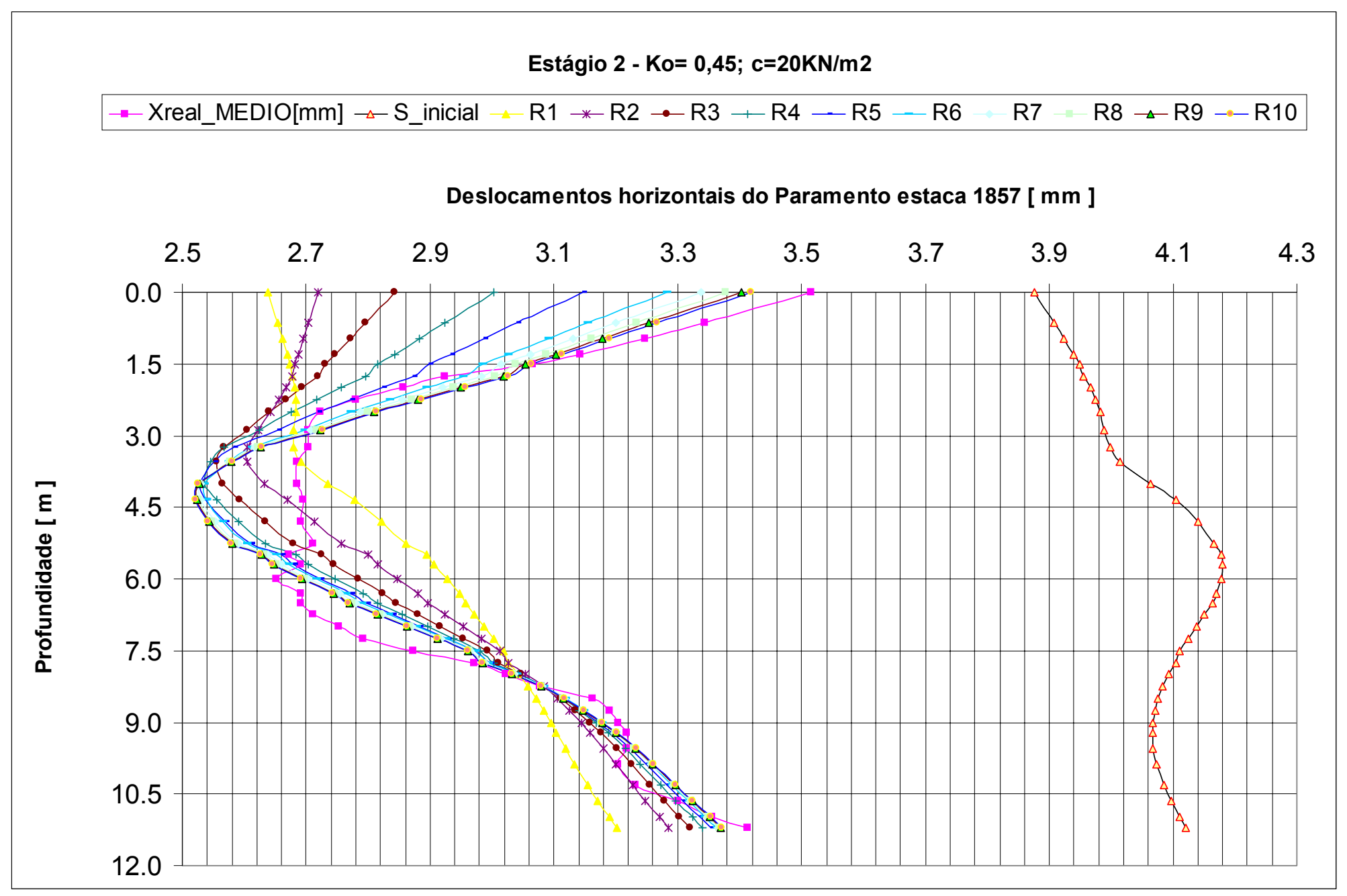

Figura 4-4-Convergência dos deslocamentos para o estágio 2 através de retroanálise de $E_{50}$ 
Analisando-se a Figura 4-4, percebe-se que de uma forma geral houve boa aderência entre a curva obtida da convergência da retroanálise de $E_{50}$ e a curva instrumentada.

Obteve-se desta forma o módulo do erro entre os valores simulados para o estágio 2 e os instrumentados para a curva média de deslocamentos, que estão apresentados na Tabela 4-5

Tabela 4-5 -Valores do módulo do erro para retroanálise de $E_{50}$ conduzida para o estágio2

\begin{tabular}{|c|c|c|c|c|}
\cline { 3 - 5 } \multicolumn{2}{|c|}{} & \multicolumn{3}{c|}{$\begin{array}{c}\text { MÓDULO DOS ERROS DE } \\
\text { DESLOCAMENTOS }\end{array}$} \\
\cline { 3 - 5 } \multicolumn{2}{c|}{} & Ko & Ko & Ko \\
\cline { 3 - 5 } Coesão[kPa] & 0.45 & 0.73 & 1.13 \\
\hline 10 & Erro [\%] & 3.1 & 4.7 & 5.8 \\
& Desvio [\%] & 3.0 & 4.4 & 4.9 \\
\hline 20 & Erro [\%] & $\mathbf{2 . 3 3}$ & 2.78 & 6.1 \\
& Desvio [\%] & $\mathbf{1 . 7 2}$ & 2.34 & 4.6 \\
\hline 30 & Erro [\%] & $\mathbf{2 . 7 1}$ & $\mathbf{2 . 6 8}$ & 6.0 \\
& Desvio [\%] & $\mathbf{2 . 3 0}$ & $\mathbf{1 . 8 5}$ & 3.6 \\
\hline
\end{tabular}

Analisando-se isoladamente os resultados apresentados na Tabela 4-5 e na Figura 4-4, pode-se acreditar que a solução encontra-se no intervalo de valores de coesão 20 a 30 e valores de coeficiente de empuxo em repouso Ko 0,45 a 0,73, pois os três menores erros e desvios ocorrem nestes intervalos.

Se houvessem valores de erros em relação às forças nas estroncas, a dúvida sobre o intervalo de $K o$ estaria esclarecida, pois de acordo com a análise paramétrica realizada $K o$ tem influência média, e isto forneceria pistas sobre o intervalo correto a adotar-se.

Portanto, há necessidade de também averiguar os erros relacionados às forças nas estroncas e quando na ausência destas (estágios 1 e 2), as análises feitas a partir dos erros em relação aos deslocamentos não devem ser assumidas como sendo conclusivas se os valores de erros estiverem muito próximos. Se isto ocorrer deve-se refinar mais o intervalo de parâmetros. 
Utilizando-se os valores de $E_{50}$ obtidos por retroanálise para deslocamentos horizontais do paramento do estágio 2, simularam-se os outros dois estágios de escavações $\left(n^{0} 3 ; n^{\circ} 5\right)$. Na Figura 4-5 e Figura 4-6 apresentam-se os resultados destas simulações.

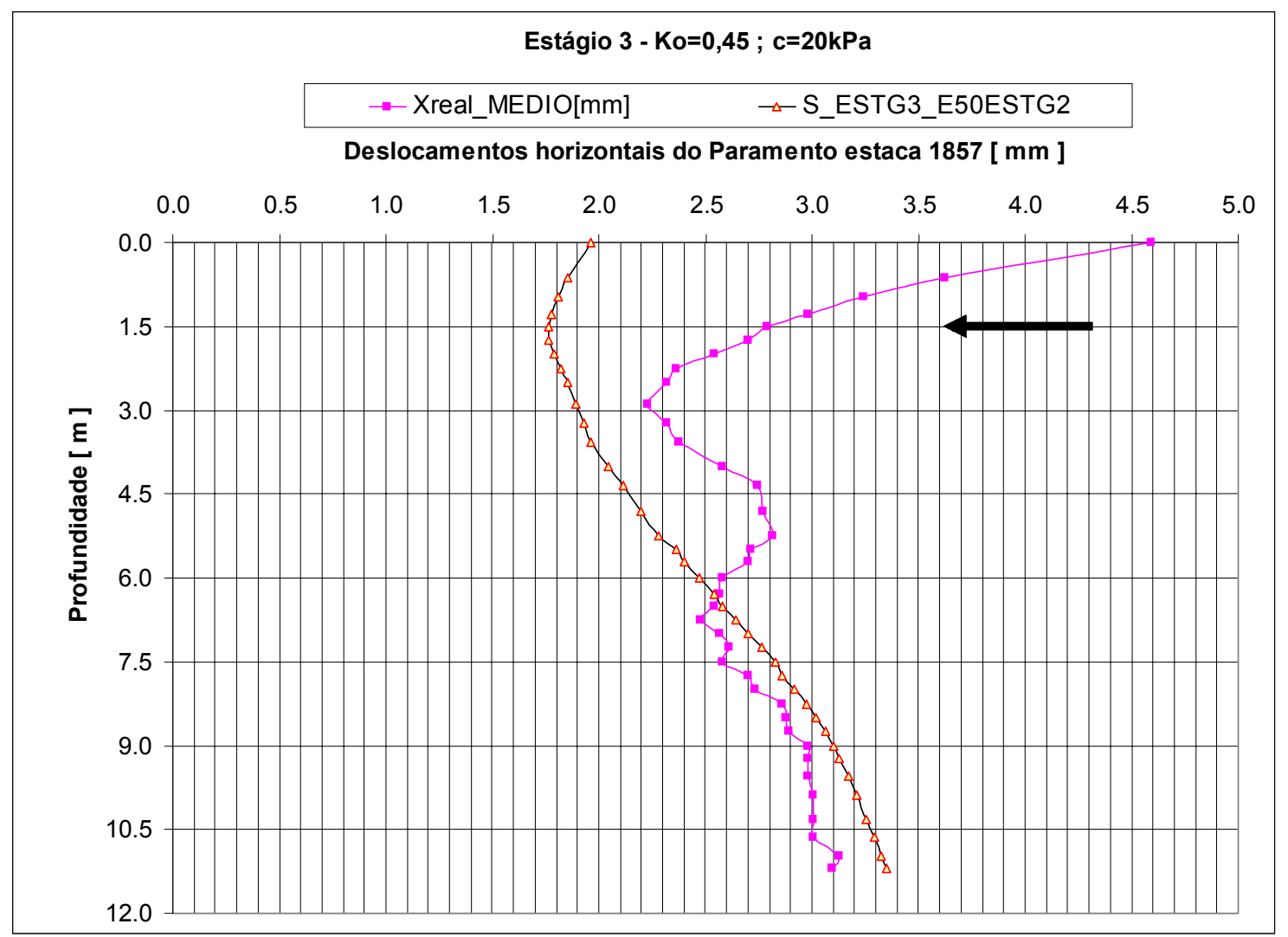

Figura 4-5 - Deslocamentos horizontais do paramento obtidos para o estágio 3 utilizando-se o valor de $E_{50}$ obtido da retroanálise do estágio 2 


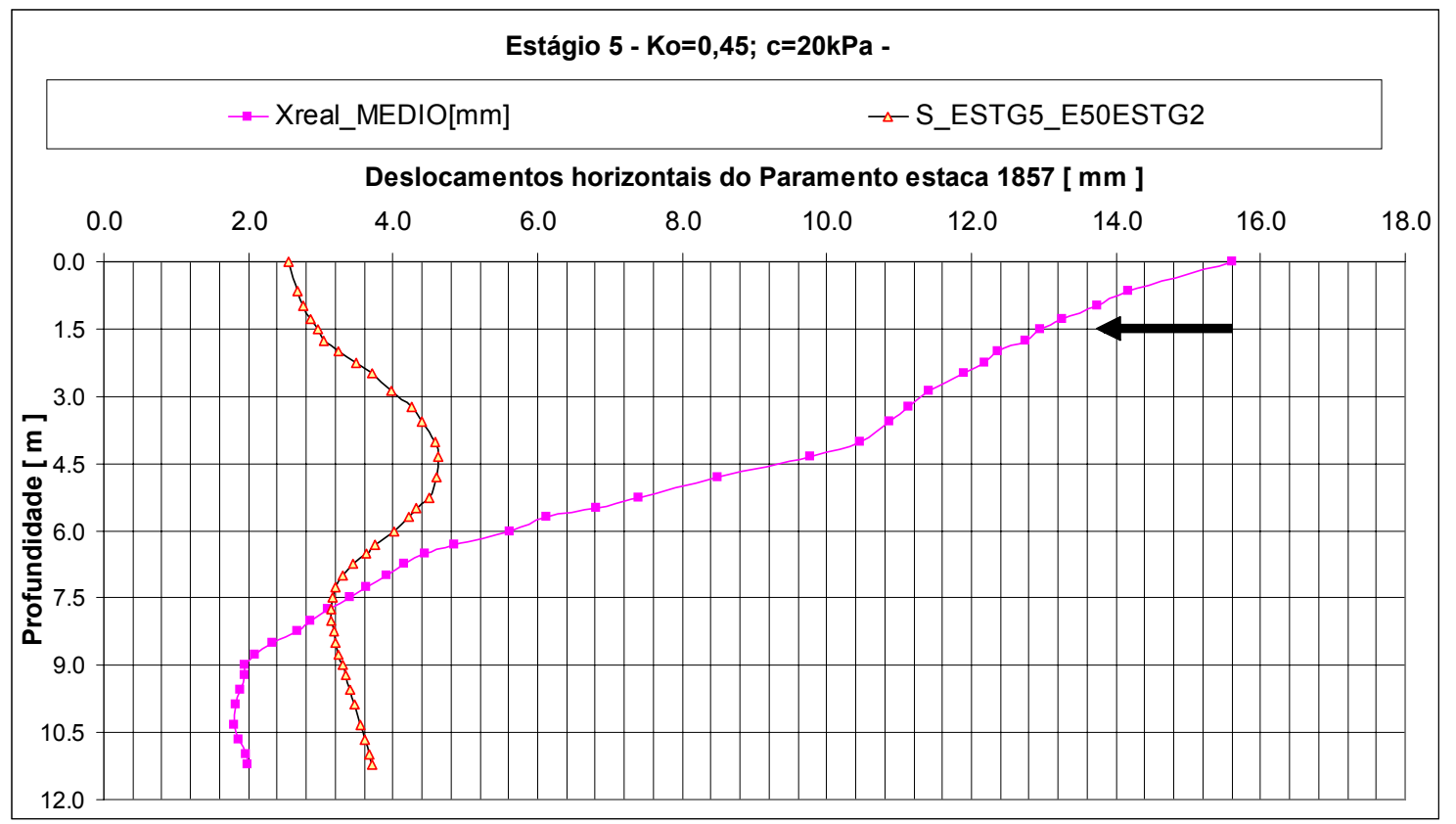

Figura 4-6- Deslocamentos horizontais do paramento obtidos para o estágio 5 utilizando-se o valor de $E_{50}$ obtido da retroanálise do estágio 2

Da análise da Figura 4-5 a Figura 4-7, fica claro que, apesar da simulação do estágio 2 ter se ajustado à instrumentação com erro e desvio padrão em torno de $3 \%$, o mesmo não ocorreu com os outros estágios de escavação. Desta forma, a cada avanço da escavação, o erro aumentou, ficando evidente que o modelo retroanalisado através dos deslocamentos do estágio 2 não é equivalente ao sistema solo estrutura instrumentado. A Figura 4-7 elucida a argumentação. 


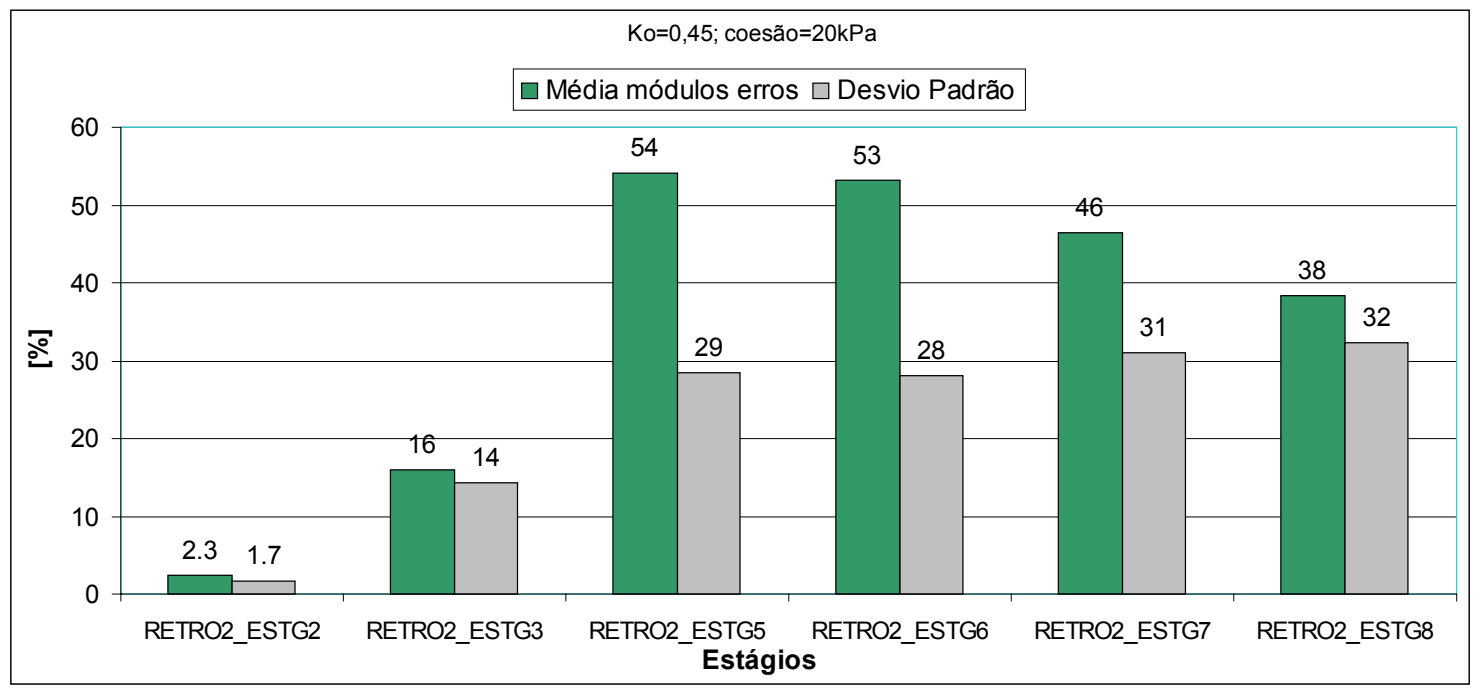

Figura 4-7- Média dos módulos dos erros de deslocamentos horizontais de paramento para cada estágio simulado com o parâmetro $E_{50}$ obtido da retroanálise do estágio 2

O critério como foram calculados as médias dos erros de deslocamentos horizontais de paramentos em função dos dados de instrumentação está exemplificado da Tabela 4-10 à Tabela 4-12 que foram feitas para o modelo de endurecimento mas a metologia utilizada nesta seção (modelo de Mohr-Coulomb) é a mesma.

Notar que os valores constantes nestas tabelas citadas (modelo de endurecimento) não são os referentes à Figura 4-7(modelo de Mohr-Coulomb).

\subsection{Retroanálise com base em erros de deslocamentos e forças}

Da Figura 4-8 à Figura 4-19, apresentam-se para a combinação Ko=0,45 e $\mathrm{c}=20 \mathrm{kN} / \mathrm{m} 2$, (estágios 3,5 e 8 ), as curvas de:

- deslocamentos horizontais de paramentos por etapa de retroanálise

- módulos dos erros em relação a estes deslocamentos

- erros em relação às forças nas estroncas

- erros gerais em estágios posteriores por adoção de parâmetros da convergência de estágios anteriores. 


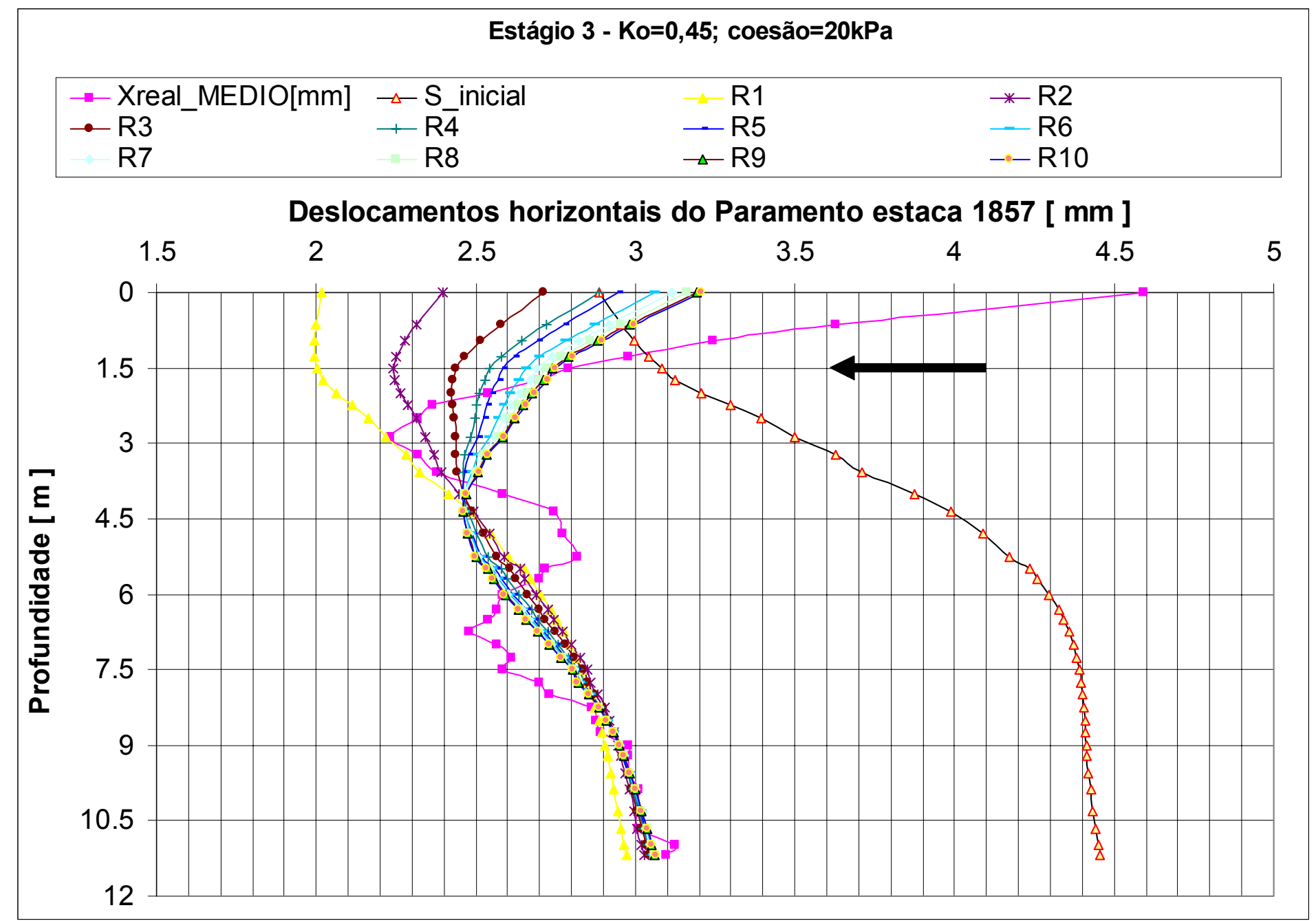

Figura 4-8- Convergência dos deslocamentos horizontais de paramento através de retroanálise de $E_{50}$-estágio 3 


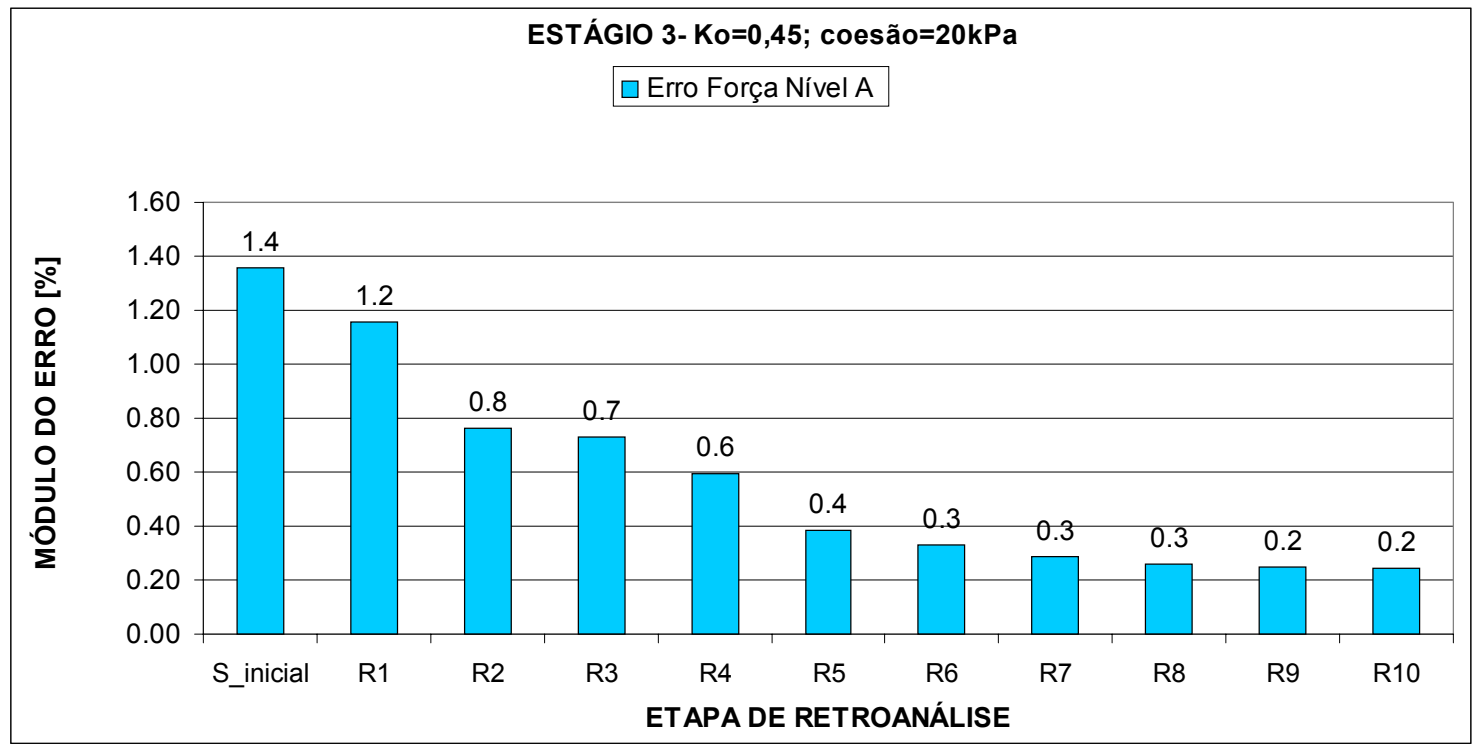

Figura 4-9- Convergência dos módulos dos erros das forças nas estroncas nível A por etapa de retroanálise de $E_{50}$ - estágio3

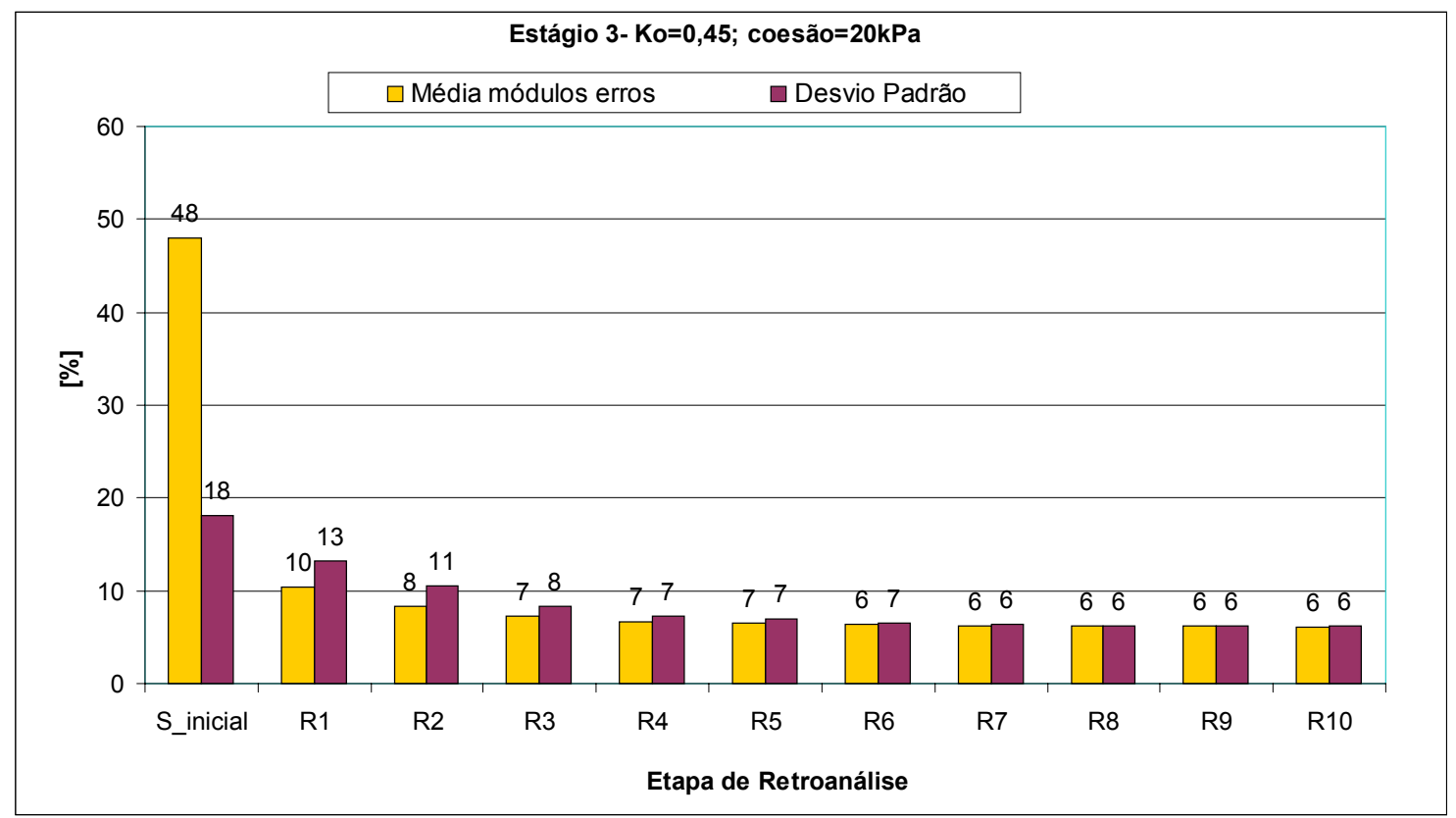

Figura 4-10- Convergência da média dos módulos dos erros de deslocamentos horizontais de paramentos para cada etapa de retroanálise de $E_{50}$-estágio 3 


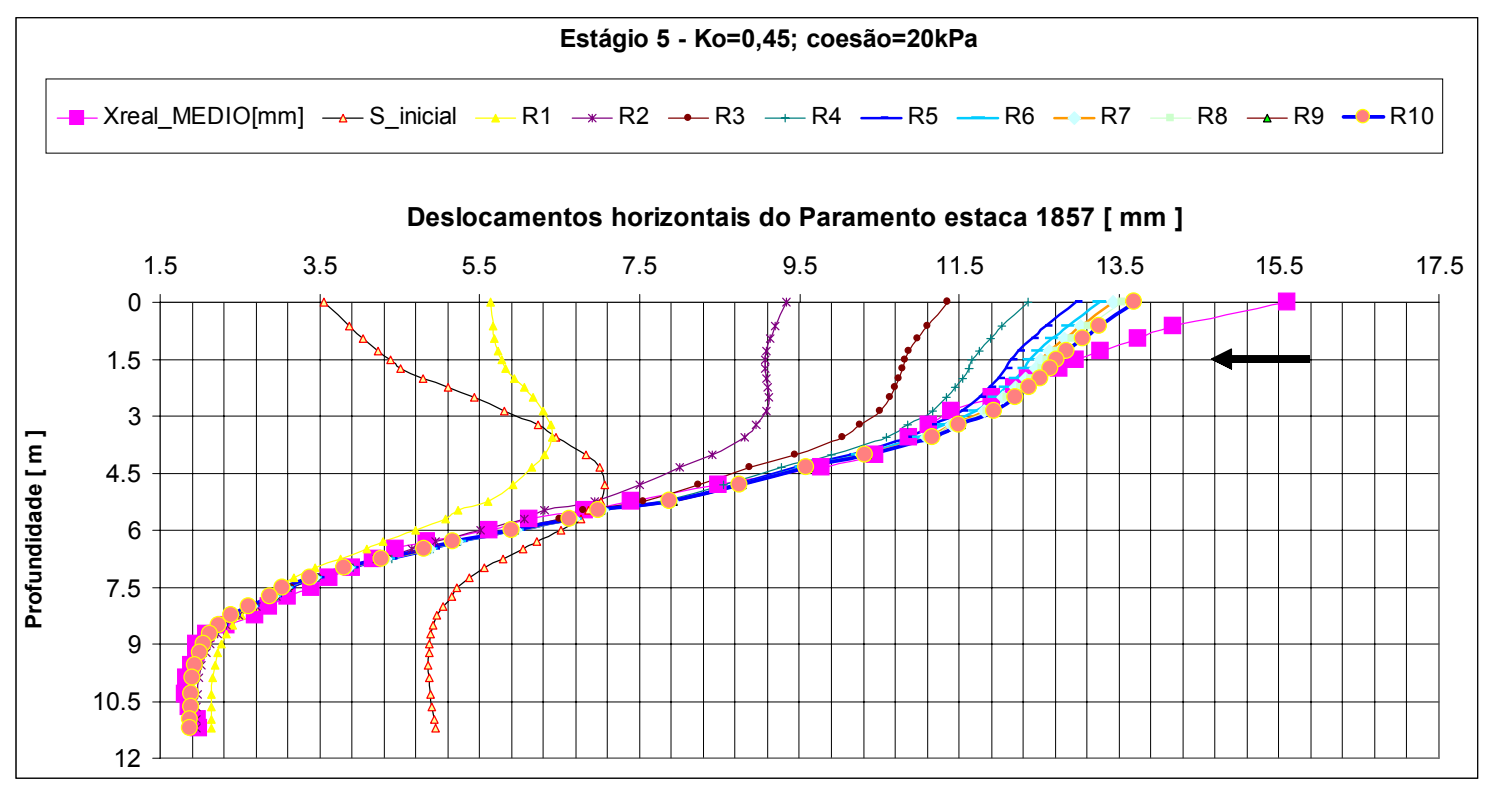

Figura 4-11- Convergência dos deslocamentos horizontais de paramento através de retroanálise de $E_{50-}$ estágio 5

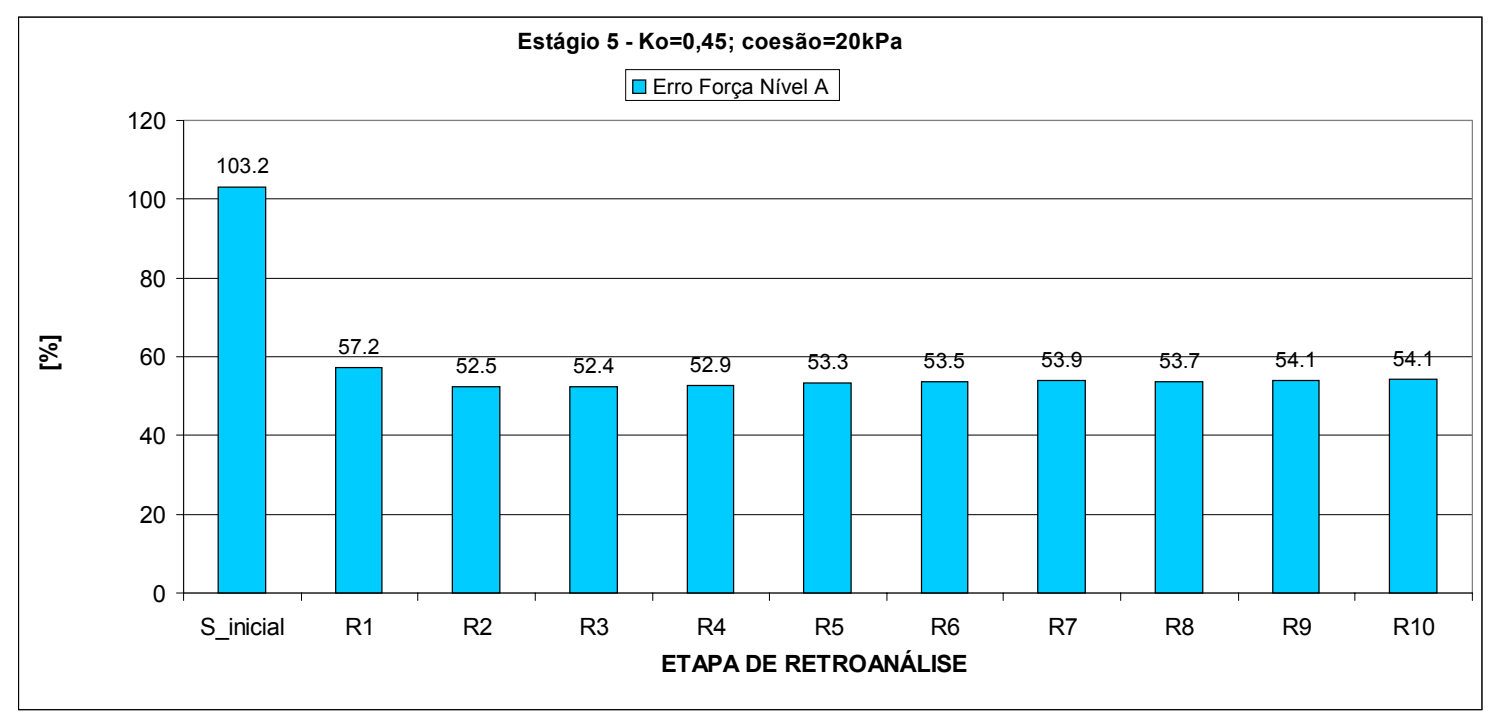

Figura 4-12-- - Convergência dos módulos dos erros das forças nas estroncas nível A por etapa de retroanálise de $E_{50}$-estágio 5 


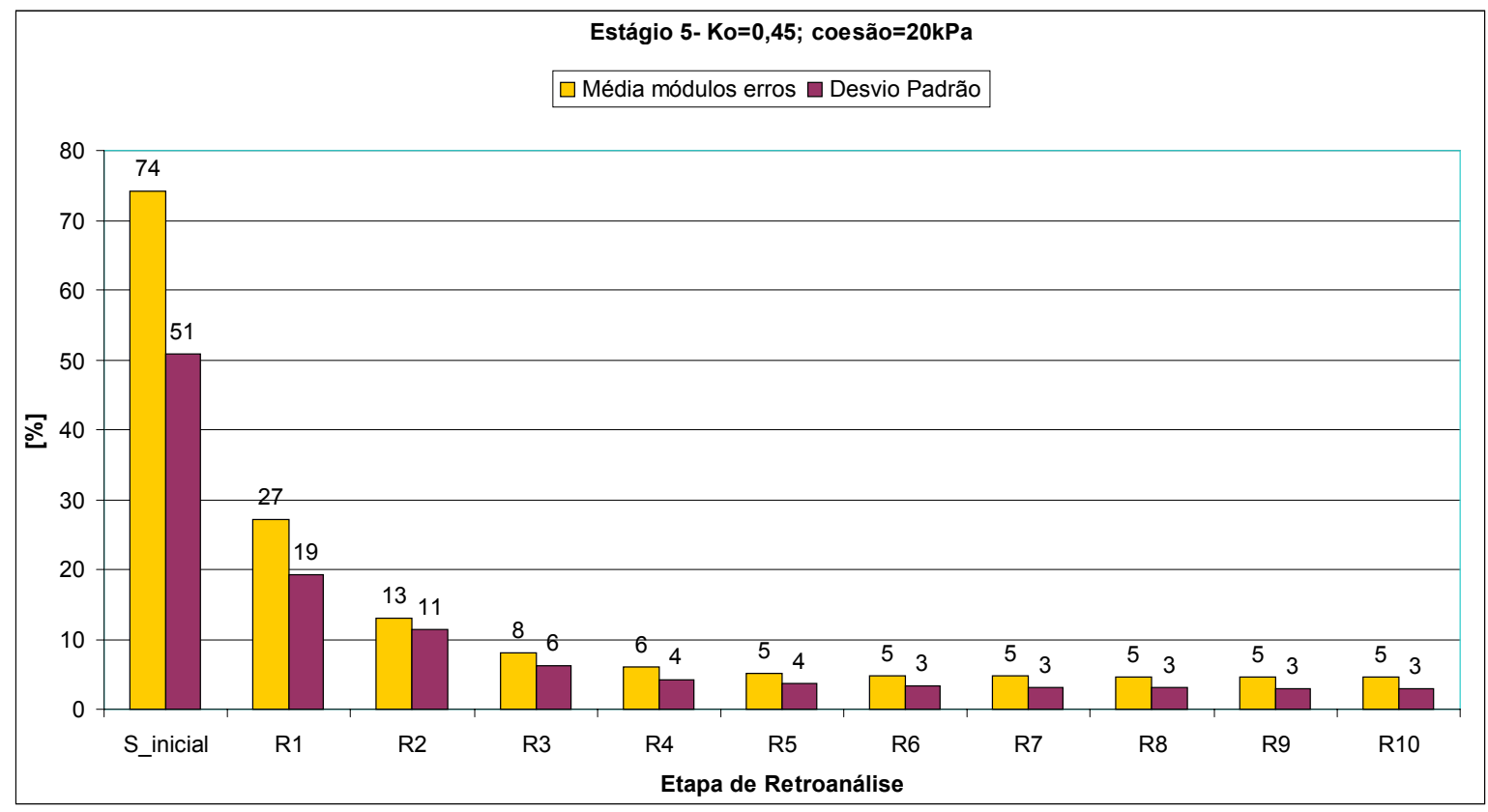

Figura 4-13 - Convergência da média dos módulos dos erros de deslocamentos horizontais de paramentos para cada etapa de retroanálise de $E_{50}$-estágio 5

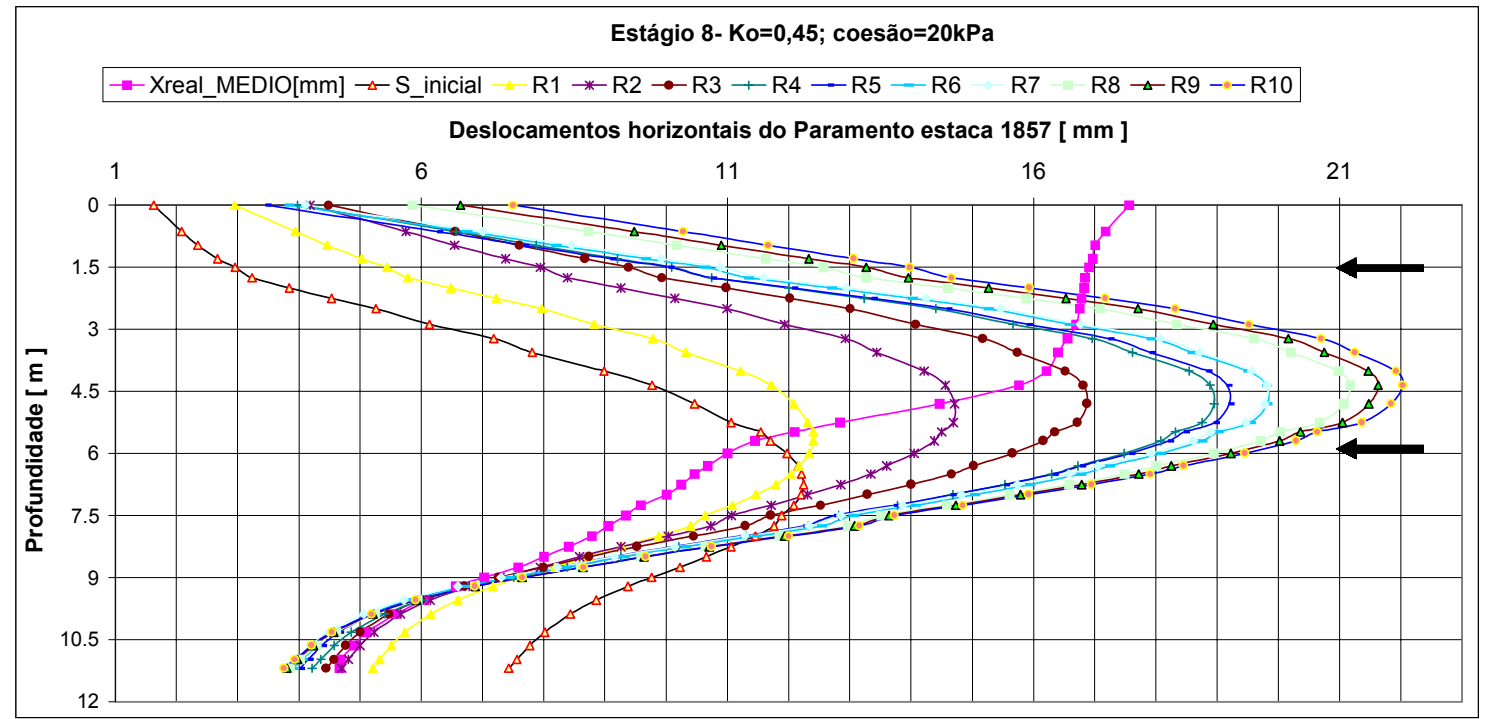

Figura 4-14- Convergência dos deslocamentos horizontais de paramento através de retroanálise de $E_{50 \text { - }}$ estágio 8 


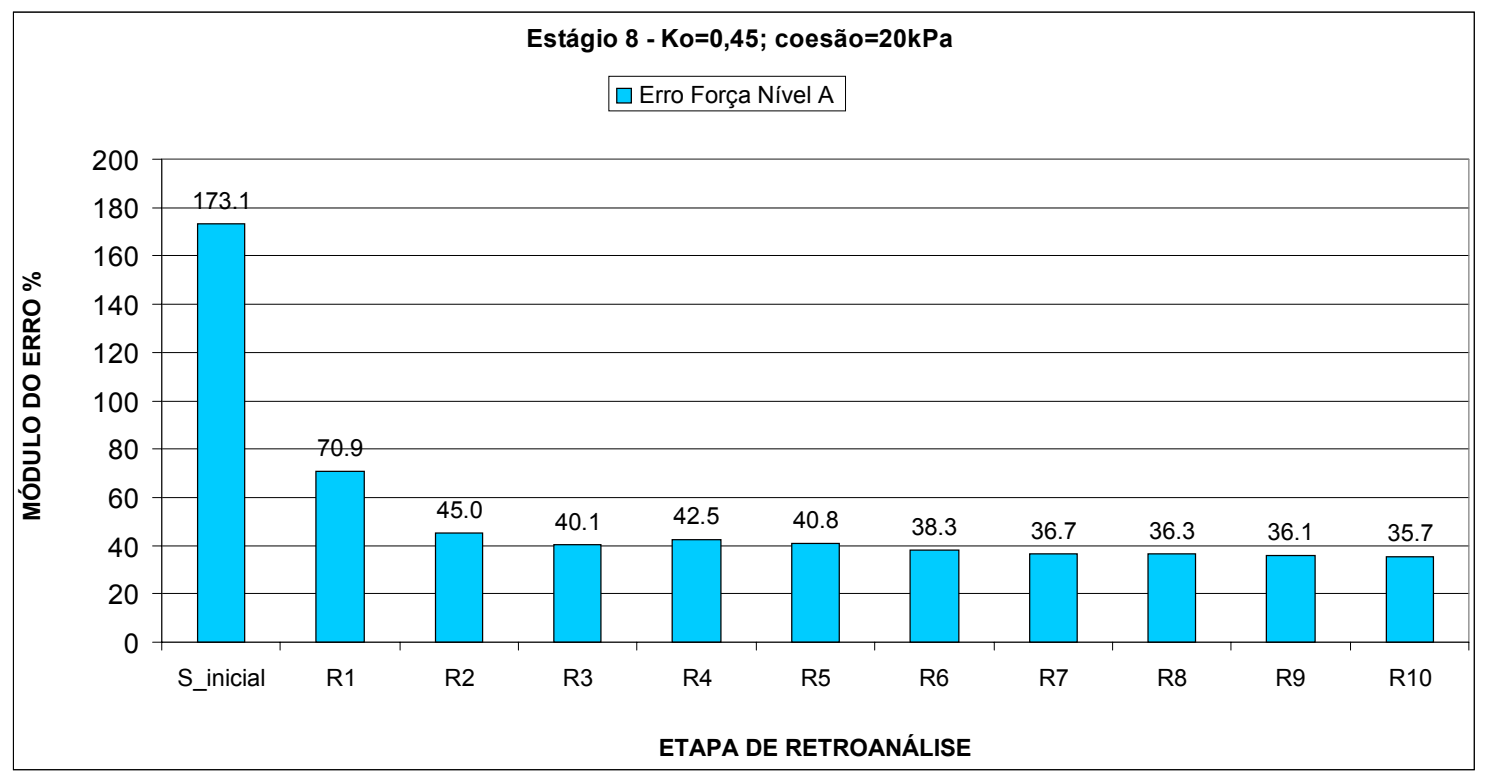

Figura 4-15-- Módulo do erro das forças nas estroncas nível A por etapa de retroanálise estágio8

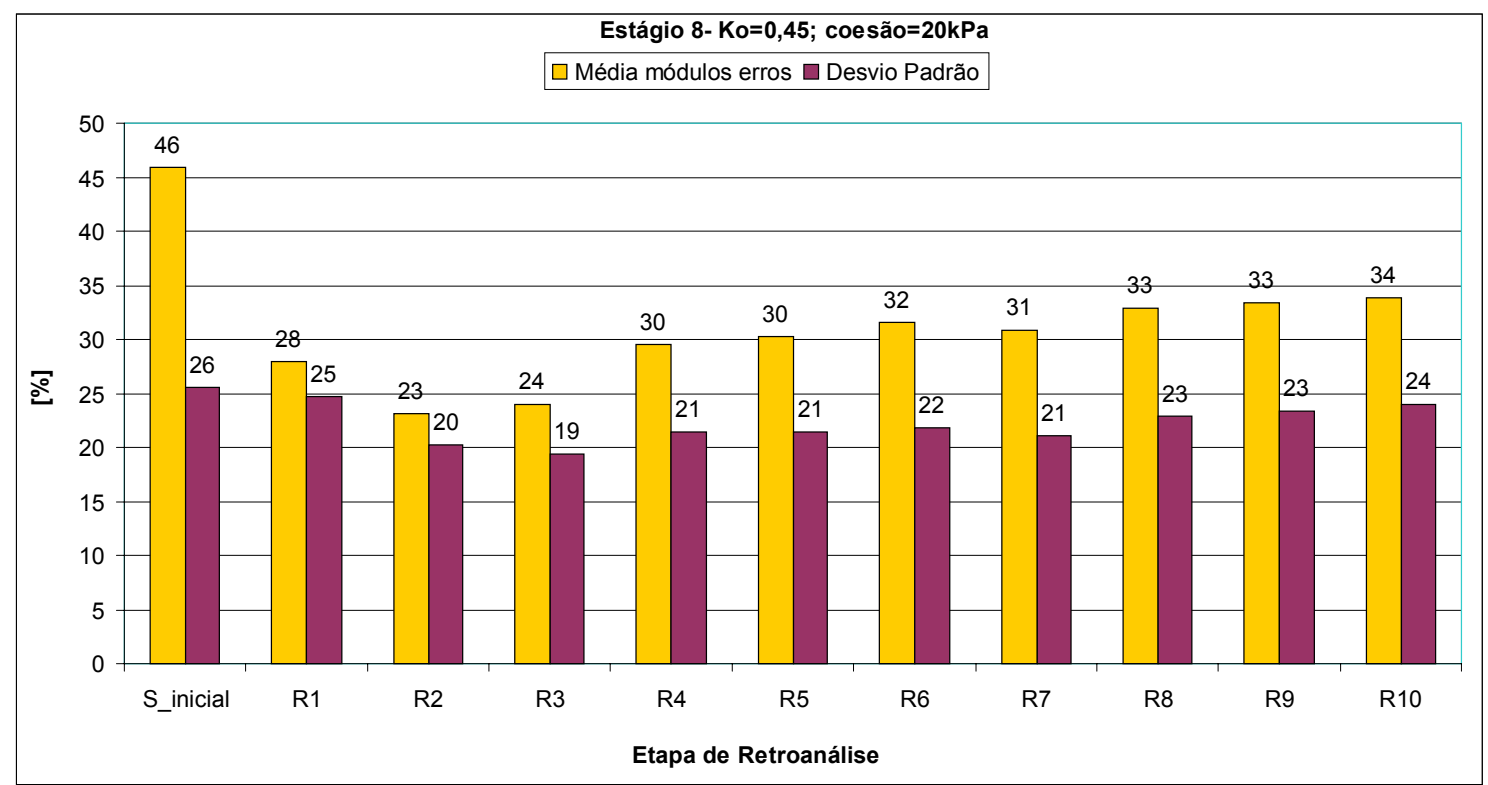

Figura 4-16- Não convergência da média dos módulos dos erros de deslocamentos horizontais de paramentos para cada etapa de retroanálise de $E_{50}$ - estágio 8 


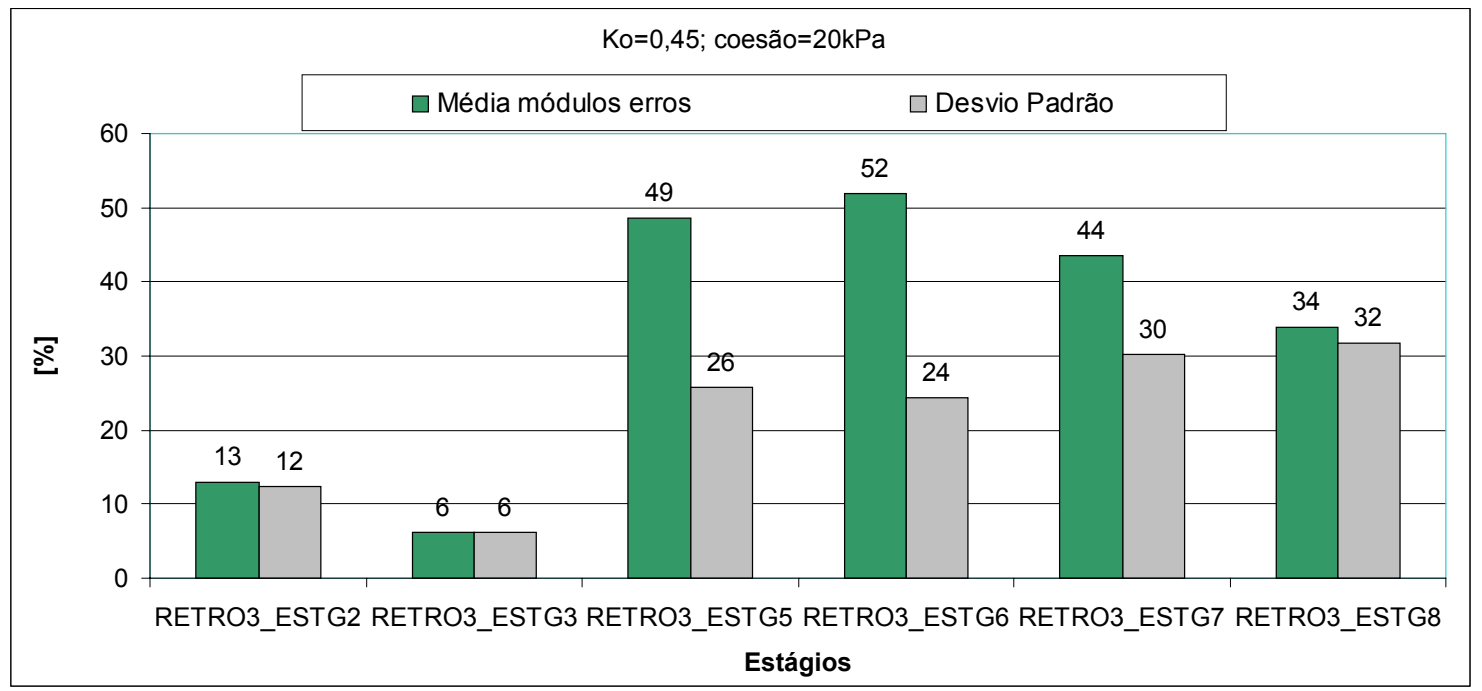

Figura 4-17- Média dos módulos dos erros de deslocamentos horizontais de paramento para cada estágio simulado com o parâmetro $E_{50}$ obtido da retroanálise do estágio 3

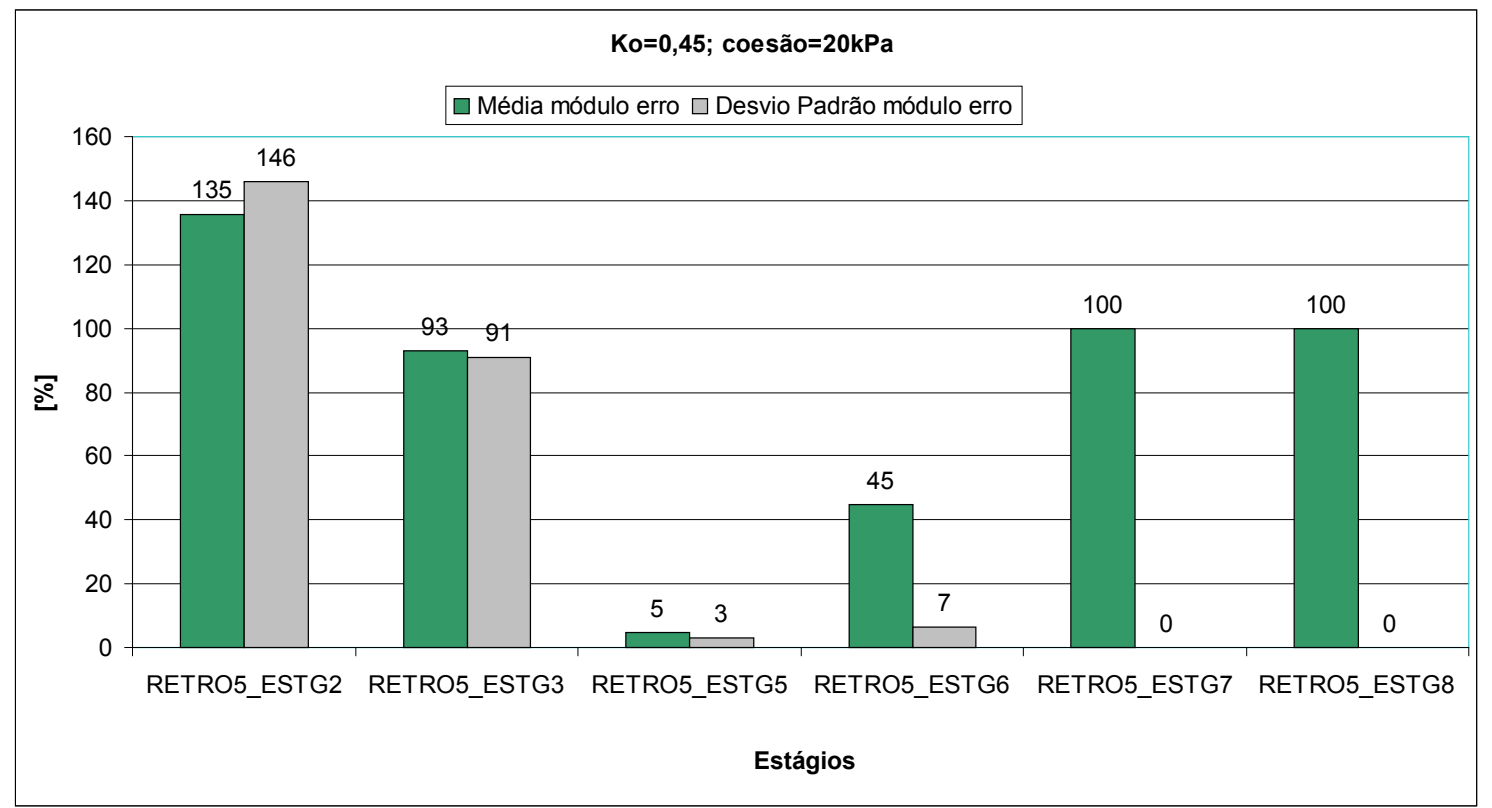

Figura 4-18- Média dos módulos dos erros de deslocamentos horizontais de paramento para cada estágio simulado com o parâmetro $E_{50}$ obtido da retroanálise do estágio 5 


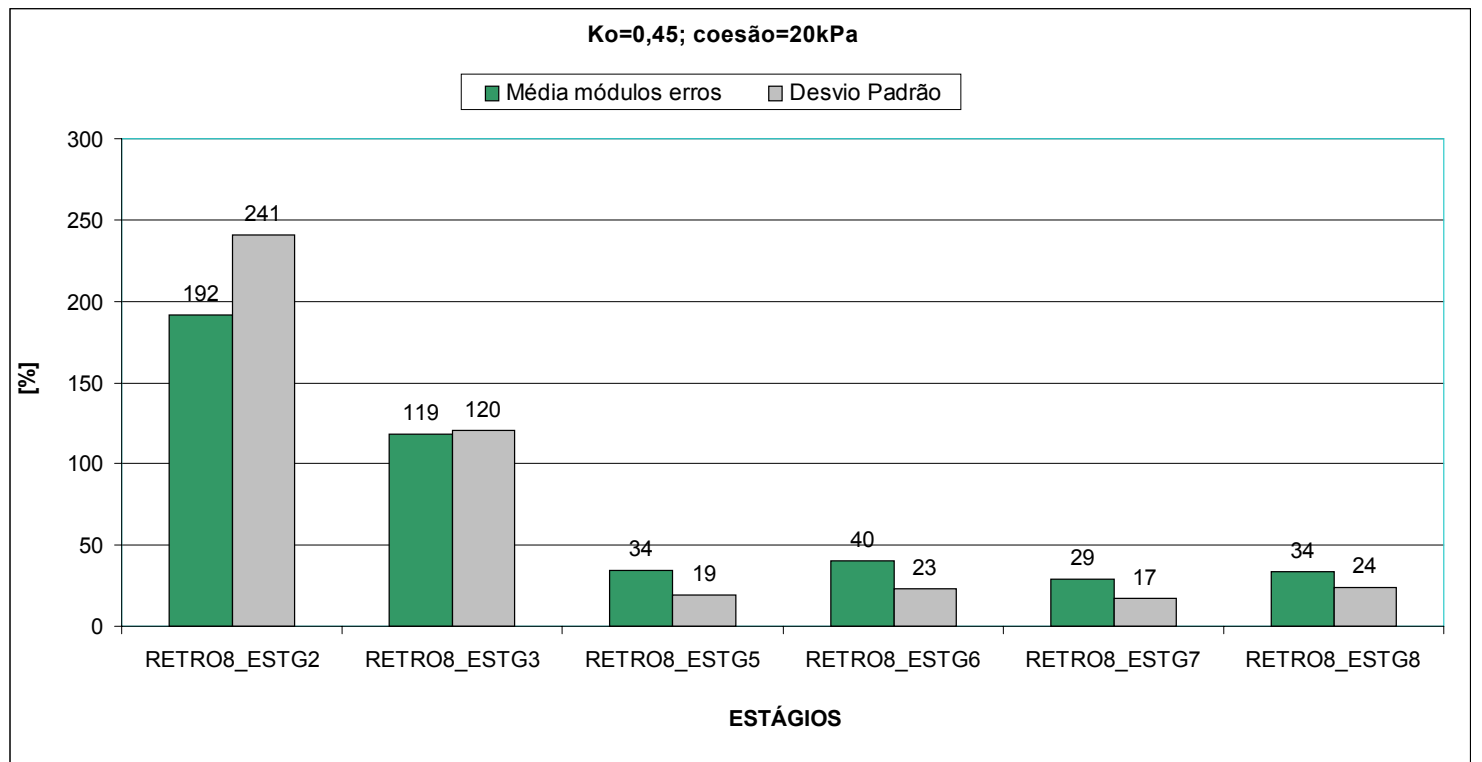

Figura 4-19 - Média dos módulos dos erros de deslocamentos horizontais de paramento para cada estágio simulado com o parâmetro $E_{50}$ obtido da retroanálise do estágio 8

Da Tabela 4-6 à Tabela 4-8, apresentam-se os resultados de erros para todas as combinações de parâmetros consideradas no modelo de Mohr-Coulomb. 
Tabela 4-6 -Estágios 3,5 e 8 -Resumo das médias dos módulos dos erros de deslocamentos horizontais de paramentos e forças nas estroncas - Mohr-Coulomb

\begin{tabular}{|c|c|c|c|c|}
\hline \multicolumn{2}{|c|}{ estagio 3} & \multicolumn{4}{c|}{ MÉDIA DOS MÓDULOS DOS ERROS DE DESLOCAMENTOS } \\
\cline { 3 - 5 } & & Ko & Ko & Ko \\
\cline { 1 - 4 } C [kPa] & 0.45 & 0.73 & 1.13 \\
\hline 10 & erro [\%] & 6.25 & 7.8 & 9.5 \\
& desvio [\%] & 7.81 & 8.7 & 8.8 \\
\hline \multirow{2}{*}{20} & erro [\%] & 6.16 & 5.5 & 9.5 \\
& desvio [\%] & 6.19 & 1.8 & 8.1 \\
\hline \multirow{2}{*}{30} & erro [\%] & 6.29 & 9.1 & 9.2 \\
& desvio [\%] & 6.12 & 6.8 & 6.9 \\
\hline
\end{tabular}

\begin{tabular}{|c|c|c|c|c|}
\hline \multirow{2}{*}{ estagio 3 } & \multicolumn{3}{|c|}{ Erros Forças Estronca A } \\
\cline { 3 - 5 } & & $\begin{array}{c}\text { Ko } \\
\text { No.45 }\end{array}$ & 0.73 & 1.13 \\
\hline C [kPa] & & 2.1 & 10.1 & 13.2 \\
\hline 20 & erro [\%] & & & 5.8 \\
\hline 30 & erro [\%] & 0.24 & 8.8 & \\
\hline & erro [\%] & 11.4 & 1.2 & 0.16 \\
\hline
\end{tabular}

\begin{tabular}{|c|c|c|c|c|}
\hline \multirow{2}{*}{ estagio 5 } & \multicolumn{4}{c|}{ MÉDIA DOS MÓDULOS DOS ERROS DE DESLOCAMENTOS } \\
\cline { 3 - 5 } \multicolumn{1}{|c|}{} & & Ko & Ko & Ko \\
\cline { 1 - 4 } C [kPa] & 0.45 & 0.73 & 1.13 \\
\hline 10 & erro [\%] & 7.9 & 19.1 & 6.9 \\
& desvio [\%] & 5.7 & 14.9 & 5.5 \\
\hline 20 & erro [\%] & 4.61 & 6.4 & 9.8 \\
& desvio [\%] & 2.96 & 3.8 & 5.4 \\
\hline \multirow{2}{*}{30} & erro [\%] & 4.57 & 4.9 & 8.2 \\
& desvio [\%] & 3.01 & 3.3 & 7.0 \\
\hline
\end{tabular}

\begin{tabular}{|c|c|c|c|c|}
\hline \multirow[t]{2}{*}{ estagio 5} & & \multicolumn{3}{|c|}{ Erros Forças Estronca A } \\
\hline & & $\mathrm{Ko}$ & Ko & Ko \\
\hline $\mathrm{C}[\mathrm{kPa}]$ & & 0.45 & 0.73 & 1.13 \\
\hline 10 & erro [\%] & 2.4 & 116.2 & 122.9 \\
\hline 20 & erro [\%] & 54.1 & 76.2 & 113.3 \\
\hline 30 & erro [\%] & 51.8 & 114.5 & 117.1 \\
\hline
\end{tabular}

\begin{tabular}{|c|c|c|c|c|}
\hline \multirow[t]{2}{*}{ estagio 8} & \multicolumn{4}{|c|}{ MÉDIA DOS MÓDULOS DOS ERROS DE DESLOCAMENTOS } \\
\hline & & Ko & Ko & Ko \\
\hline $\mathrm{C}[\mathrm{kPa}]$ & & 0.45 & 0.73 & 1.13 \\
\hline 10 & $\begin{array}{c}\text { erro [\%] } \\
\text { desvio [\%] }\end{array}$ & $\begin{array}{l}36.7 \\
26.0\end{array}$ & Ruptura & Ruptura \\
\hline 20 & $\begin{array}{c}\text { erro [\%] } \\
\text { desvio [\%] }\end{array}$ & $\begin{array}{l}33.8 \\
23.9 \\
\end{array}$ & Ruptura & Ruptura \\
\hline 30 & $\begin{array}{c}\text { erro [\%] } \\
\text { desvio [\%] }\end{array}$ & $\begin{array}{l}18.5 \\
20.8\end{array}$ & $\begin{array}{l}22.2 \\
23.0\end{array}$ & Ruptura \\
\hline
\end{tabular}

\begin{tabular}{|c|c|c|c|c|}
\hline \multicolumn{2}{|c|}{ estagio 8 } & \multicolumn{5}{|c|}{ Erros Forças Estronca A , Estronca B } \\
\cline { 3 - 5 } & & $\begin{array}{c}\text { Ko } \\
\text { C [kPa] }\end{array}$ & Ko 0.73 & 1.13 \\
\hline 10 & erro A [\%] & 184.4 & Ruptura & Ruptura \\
& erro B [\%] & 100.0 & & Ruptura \\
\hline 20 & erro A [\%] & 35.7 & Ruptura & Ruptura \\
\hline 30 & erro A [\%] & 22.1 & 134.3 & \\
\hline
\end{tabular}

$C$ - coesão $[\mathrm{kPa}] ; K o-$ coeficiente de empuxo em repouso 
A partir da retroanálise de $E_{50}$ (em função dos deslocamentos horizontais de paramentos) obtem-se valores de $E_{50}$ (um valor para cada camada de solo) para cada estágio de escavação.

A partir da utilização dos valores de $E_{50}$ de um estágio de escavação, calcula-se os deslocamentos horizontais ocorridos em todos os outros estágios, estes deslocamentos obtidos foram nomeados deslocamentos globais. Por analogia as forças nas estroncas obtidas foram nomeadas forças globais.

A Tabela 4-7 apresenta os valores dos módulos dos erros de deslocamentos globais horizontais de paramentos obtidos quando utiliza-se os valores de $E_{50}$ (obtidos por retroanálise) dos estágios 3, 5 e 8 de escavação.

Tabela 4-7-Resumo das médias dos módulos dos erros de deslocamentos horizontais globais

\begin{tabular}{|c|c|c|c|c|}
\hline \multicolumn{2}{|c|}{ estagio 3} & \multicolumn{4}{c|}{ MÉDIA DOS MÓDULOS DOS ERROS DESL.GLOBAIS } \\
\cline { 3 - 5 } & & Ko & Ko & Ko \\
\cline { 1 - 4 } C [KN/m2] & 0.45 & 0.73 & 1.13 \\
\hline 10 & erro [\%] & 29.2 & 29.2 & 31.4 \\
& desvio [\%] & 16.3 & 16.7 & 16.0 \\
\hline \multirow{2}{*}{20} & erro [\%] & 32.9 & 5.5 & 30.6 \\
& desvio [\%] & 21.8 & 1.8 & 15.7 \\
\hline \multirow{2}{*}{30} & erro [\%] & 33.2 & 7.2 & 7.3 \\
& desvio [\%] & 21.8 & 5.7 & 5.8 \\
\hline
\end{tabular}

\begin{tabular}{|c|c|c|c|c|}
\hline \multirow{2}{*}{ estagio 5 } & \multicolumn{4}{|c|}{ MÉDIA DOS MÓDULOS DOS ERROS DESL.GLOBAIS } \\
\cline { 3 - 5 } & & Ko & Ko & Ko \\
\hline C [KN/m2] & & 0.45 & 0.73 & 1.13 \\
\hline 10 & erro [\%] & 63.7 & 50.4 & 66.8 \\
& desvio [\%] & 54.2 & 22.8 & 57.7 \\
\hline 20 & erro [\%] & 64.5 & 72.4 & 64.0 \\
& desvio [\%] & 50.6 & 42.6 & 50.4 \\
\hline 30 & erro [\%] & 70.0 & 64.6 & 69.1 \\
& desvio [\%] & 61.7 & 56.8 & 57.4 \\
\hline
\end{tabular}

\begin{tabular}{|c|c|c|c|c|}
\hline \multicolumn{2}{|c|}{ estagio 8} & \multicolumn{4}{|c|}{ MÉDIA DOS MÓDULOS DOS ERROS DESL.GLOBAIS } \\
\cline { 3 - 5 } & & Ko & Ko & Ko \\
\cline { 3 - 5 } C [KN/m2] & 0.45 & 0.73 & 1.13 \\
\hline 10 & erro [\%] & 38.9 & Ruptura & Ruptura \\
& desvio [\%] & 17.3 & & \\
\hline 20 & erro [\%] & 91.4 & Ruptura & Ruptura \\
& desvio [\%] & 98.1 & & \\
\hline 30 & erro [\%] & 47.6 & 41.8 & Ruptura \\
& desvio [\%] & 43.4 & 29.1 & \\
\hline
\end{tabular}


Da análise da Tabela 4-7 percebe-se que os menores erros de deslocamentos globais ocorrem quando se adota os $E_{50}$, obtidos das retroanálises do estágio 3.

O mesmo não ocorre para os erros globais das forças nas estroncas do nível A, sendo os valores de $E_{50}$ das retroanálises do estágio 8 , os que conduziram aos menores erros globais como pode ser observado na Tabela 4-8.

Tabela 4-8-Resumo dos módulos dos erros médios das forças globais nas estroncas

\begin{tabular}{|c|c|c|c|c|}
\hline \multirow{2}{*}{ estagio 3 } & \multicolumn{3}{|c|}{ Módulo dos erros médios forças globais nível $A$} \\
\cline { 3 - 5 } \multicolumn{2}{|c|}{} & $\begin{array}{c}\text { Ko } \\
\text { C [kPa] }\end{array}$ & $\begin{array}{c}\text { Ko } \\
1.13\end{array}$ \\
\hline 10 & erro [\%] & 27.0 & $\begin{array}{c}72.3 \\
\text { ruptura estg7 }\end{array}$ & $\begin{array}{c}46.9 \\
\text { ruptura estg7 }\end{array}$ \\
\hline 20 & erro [\%] & 36.9 & $\begin{array}{c}81.8 \\
\text { ruptura estg5 }\end{array}$ & $\begin{array}{c}79.4 \\
\text { ruptura estg5 }\end{array}$ \\
\hline 30 & erro [\%] & 62.4 & 80.0 & $\begin{array}{c}59.8 \\
\text { ruptura estg5 }\end{array}$ \\
\hline
\end{tabular}

\begin{tabular}{|c|c|c|c|c|}
\hline \multirow[t]{2}{*}{ estagio 5} & & \multicolumn{3}{|c|}{ Módulo dos erros médios forças globais nível $A$} \\
\hline & & Ko & Ko & Ko \\
\hline $\mathrm{C}[\mathrm{kPa}]$ & & 0.45 & 0.73 & 1.13 \\
\hline 10 & erro [\%] & $\begin{array}{c}31.7 \\
\text { ruptura estg7 }\end{array}$ & $\begin{array}{c}76.2 \\
\text { ruptura estg7 }\end{array}$ & $\begin{array}{c}98.4 \\
\text { ruptura estg7 }\end{array}$ \\
\hline 20 & erro [\%] & $\begin{array}{c}43.0 \\
\text { ruptura estg7 }\end{array}$ & $\begin{array}{c}61.6 \\
\text { ruptura estg6 }\end{array}$ & $\begin{array}{c}83.1 \\
\text { ruptura estg6 }\end{array}$ \\
\hline 30 & erro [\%] & $\begin{array}{c}32.1 \\
\text { ruptura estg6 }\end{array}$ & $\begin{array}{c}61.6 \\
\text { ruptura estg6 }\end{array}$ & $\begin{array}{c}75.4 \\
\text { ruptura estg6 }\end{array}$ \\
\hline
\end{tabular}

\begin{tabular}{|c|c|c|c|c|}
\hline \multicolumn{2}{|l|}{ estagio 8 } & \multicolumn{3}{|c|}{ Módulo dos erros médios forças globais nível $A$} \\
\cline { 3 - 5 } \multicolumn{2}{|c|}{} & $\begin{array}{c}\text { Ko } \\
\text { C }[\mathrm{kPa}]\end{array}$ & $\begin{array}{c}\text { Ko } \\
\text { no.45 }\end{array}$ & $\begin{array}{c}\text { Ko } \\
1.13\end{array}$ \\
\hline 10 & erro [\%] & 61.1 & Ruptura & Ruptura \\
\hline 20 & erro [\%] & 20.7 & Ruptura & Ruptura \\
\hline 30 & & & & \\
\hline & erro [\%] & 19.8 & 77.5 & Ruptura \\
\hline
\end{tabular}

Na Tabela 4-9 apresentam-se os valores de $E_{50}$ obtidos para os intervalos escolhidos em função dos menores erros globais de deslocamentos e forças nas estroncas. Da Figura 4-20 a Figura 4-25 apresentam-se as curvas de isovalores para as tabelas 4.6 a 4.8 . 
Tabela 4-9 Resumo geral dos resultados de $E_{50}$ e intervalos de $K o$ e $c$ (coesão) que contém a solução para o modelo de Mohr-

\section{Coulomb}

\begin{tabular}{|c|c|c|c|c|c|}
\hline & $\begin{array}{c}\text { Norma NC-03 } \\
\text { MetrôS.P.Es[kPa] }\end{array}$ & $\begin{array}{c}\text { Valores de } E_{50}[\mathrm{kPa}] \\
\text { ( Figura 2-7 e Figura 2-8) }\end{array}$ & $\begin{array}{c}\text { RETROANALISE } \\
\mathbf{E}_{50}[\mathrm{kPa}]\end{array}$ & Intervalo de Ko & $\begin{array}{c}\text { Intervalo de coesão } \\
{[\mathrm{kPa}]}\end{array}$ \\
\hline $\begin{array}{c}\text { Estágio } 3 \text { camada } 1 \\
\text { Argila Porosa } \\
\text { Vermelha }\end{array}$ & 10000 & 20000 a 50000 & 25100 & 0,40 a 0,73 & 10 a 30 \\
\hline $\begin{array}{c}\text { Estágio } 3 \text { camada } 2 \\
\text { Argila Porosa } \\
\text { Vermelha }\end{array}$ & 10000 & 20000 a 50000 & 72210 & 0,40 a 0,73 & 10 a 30 \\
\hline $\begin{array}{c}\text { Estágio } 3 \text { camada } 3 \\
\text { Argila Rija }\end{array}$ & 30000 & 105000 a 160000 & 57450 & 0,40 a 0,73 & 10 a 30 \\
\hline $\begin{array}{c}\text { Estágio } 5 \text { camada } 1 \\
\text { Argila Porosa } \\
\text { Vermelha }\end{array}$ & 10000 & 20000 a 50000 & 3990 & 0,40 a 0,73 & 10 a 30 \\
\hline $\begin{array}{c}\text { Estágio } 5 \text { camada } 2 \\
\text { Argila Porosa } \\
\text { Vermelha }\end{array}$ & 10000 & 20000 a 50000 & 43280 & 0,40 a 0,73 & 10 a 30 \\
\hline $\begin{array}{c}\text { Estágio } 5 \text { camada } 3 \\
\text { Argila Rija }\end{array}$ & 30000 & 105000 a 160000 & 11244 & 0,40 a 0,73 & 10 a 30 \\
\hline $\begin{array}{c}\text { Estágio } 8 \text { camada } 1 \\
\text { Argila Porosa } \\
\text { Vermelha }\end{array}$ & 10000 & 20000 a 50000 & 410 & 0,40 a 0,73 & 10 a 30 \\
\hline $\begin{array}{c}\text { Estágio } 8 \text { camada } 2 \\
\text { Argila Porosa } \\
\text { Vermelha }\end{array}$ & 10000 & 20000 a 50000 & 220970 & 0,40 a 0,73 & 10 a 30 \\
\hline $\begin{array}{c}\text { Estágio } 8 \text { camada } 3 \\
\text { Argila Rija }\end{array}$ & 30000 & 105000 a 160000 & 68820 & 0,40 a 0,73 & 10 a 30 \\
\hline
\end{tabular}




\section{6 -Curvas de isovalores dos módulos dos erros para o modelo de Mohr-Coulomb}

Neste ítem serão apresentadas as curvas de isovalores dos módulos dos erros de deslocamentos horizontais de paramentos e das forças nas estroncas, para os estágios de escavações 3,5 e 8 .

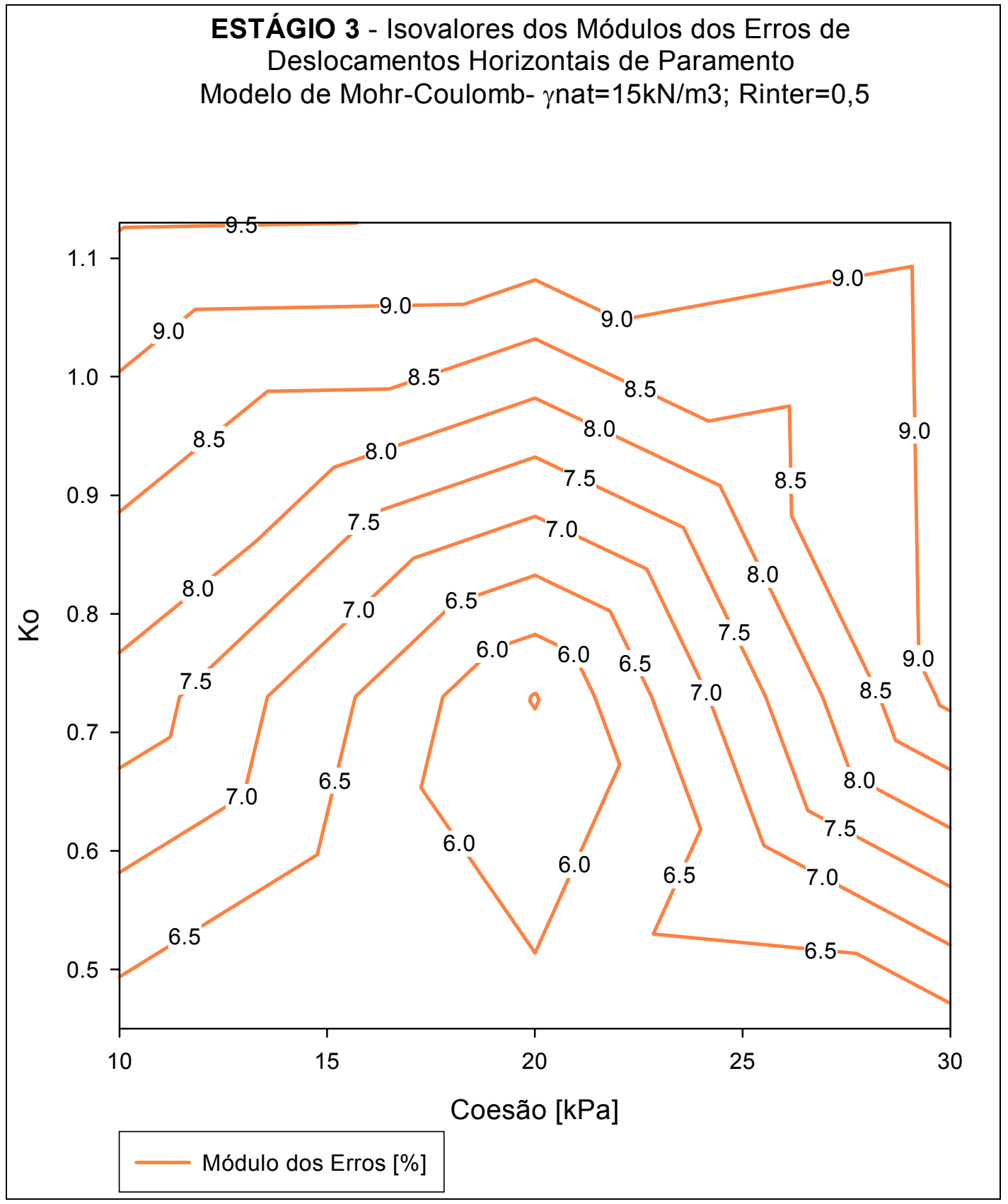

Figura 4-20 -Isovalores de erros de deslocamentos horizontais do paramento estágio 3 


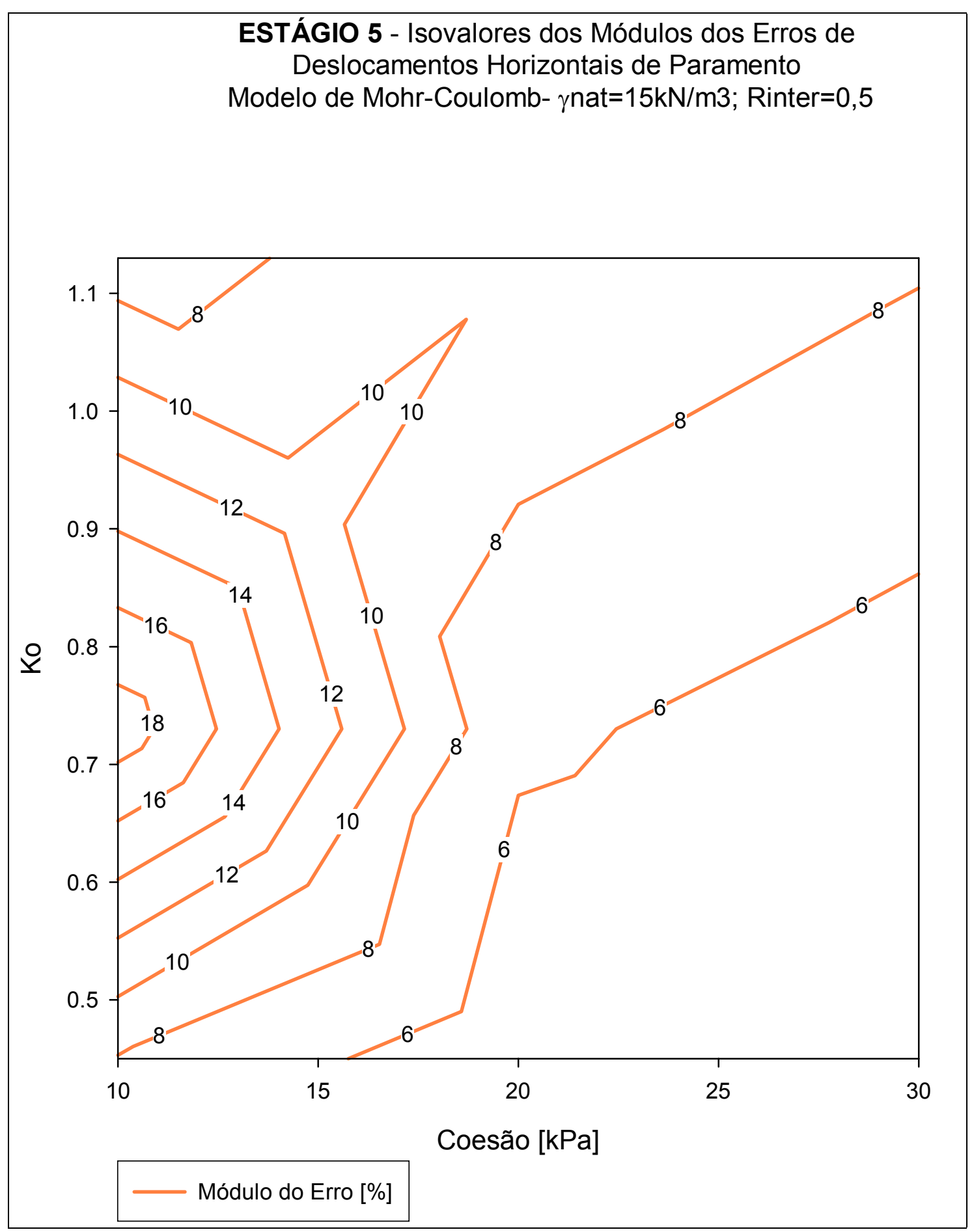

Figura 4-21-Isovalores de erros de deslocamentos horizontais do paramento estágio 5 


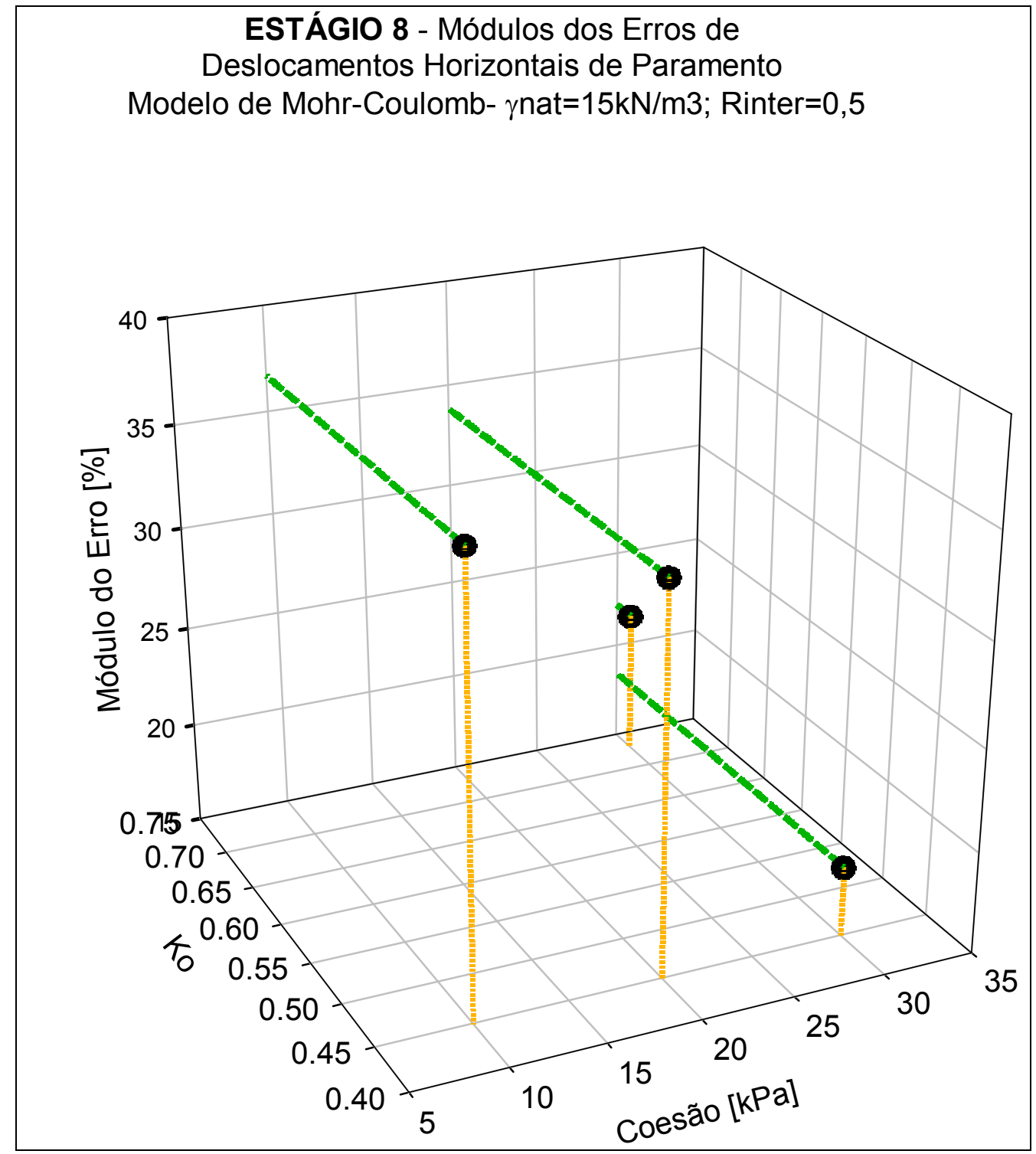

Figura 4-22-Módulo dos erros de deslocamentos horizontais do paramento estágio 8 


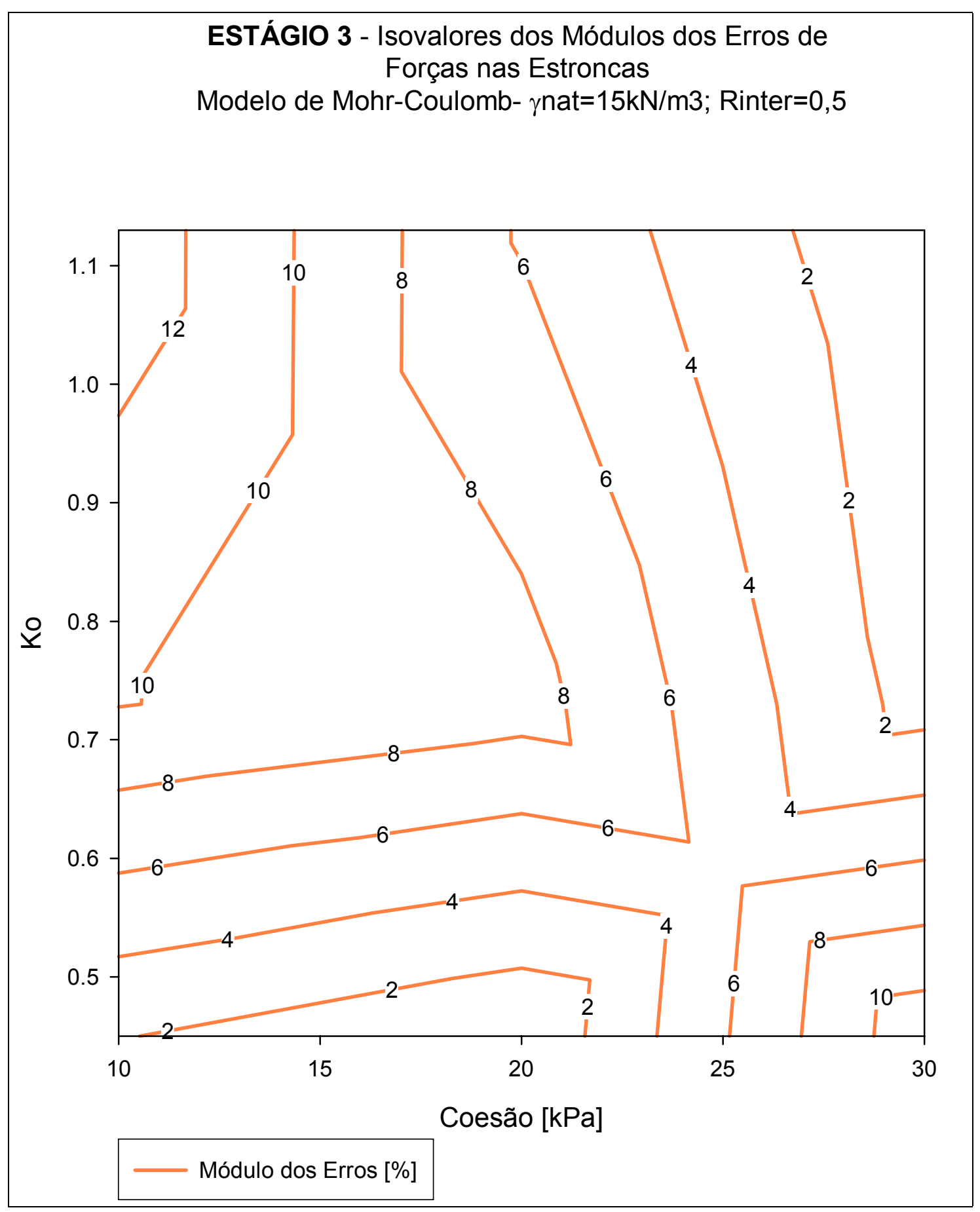

Figura 4-23-Isovalores de erros de forças nas estroncas - estágio 3 


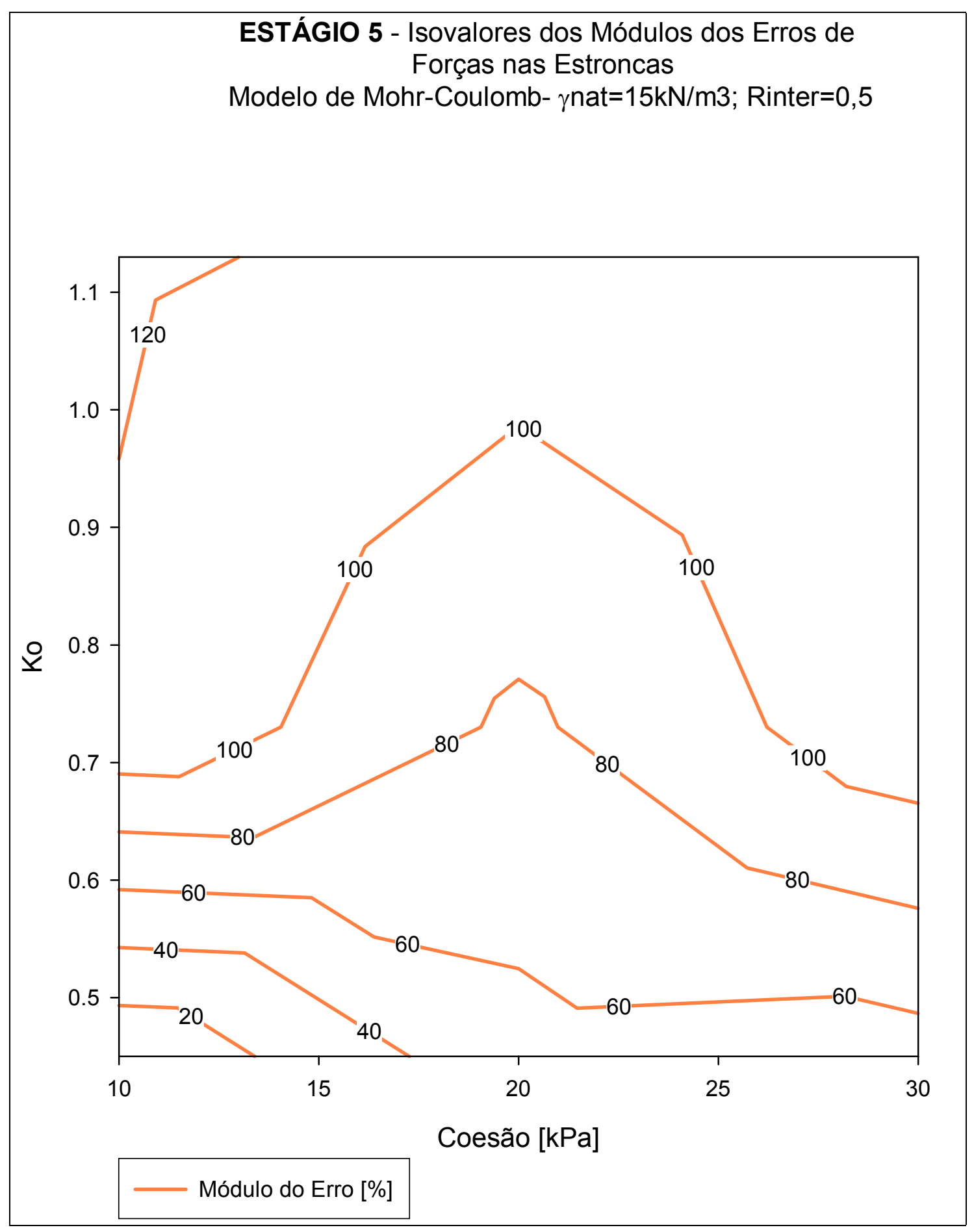

Figura 4-24-Isovalores de erros de forças nas estroncas - estágio 5 


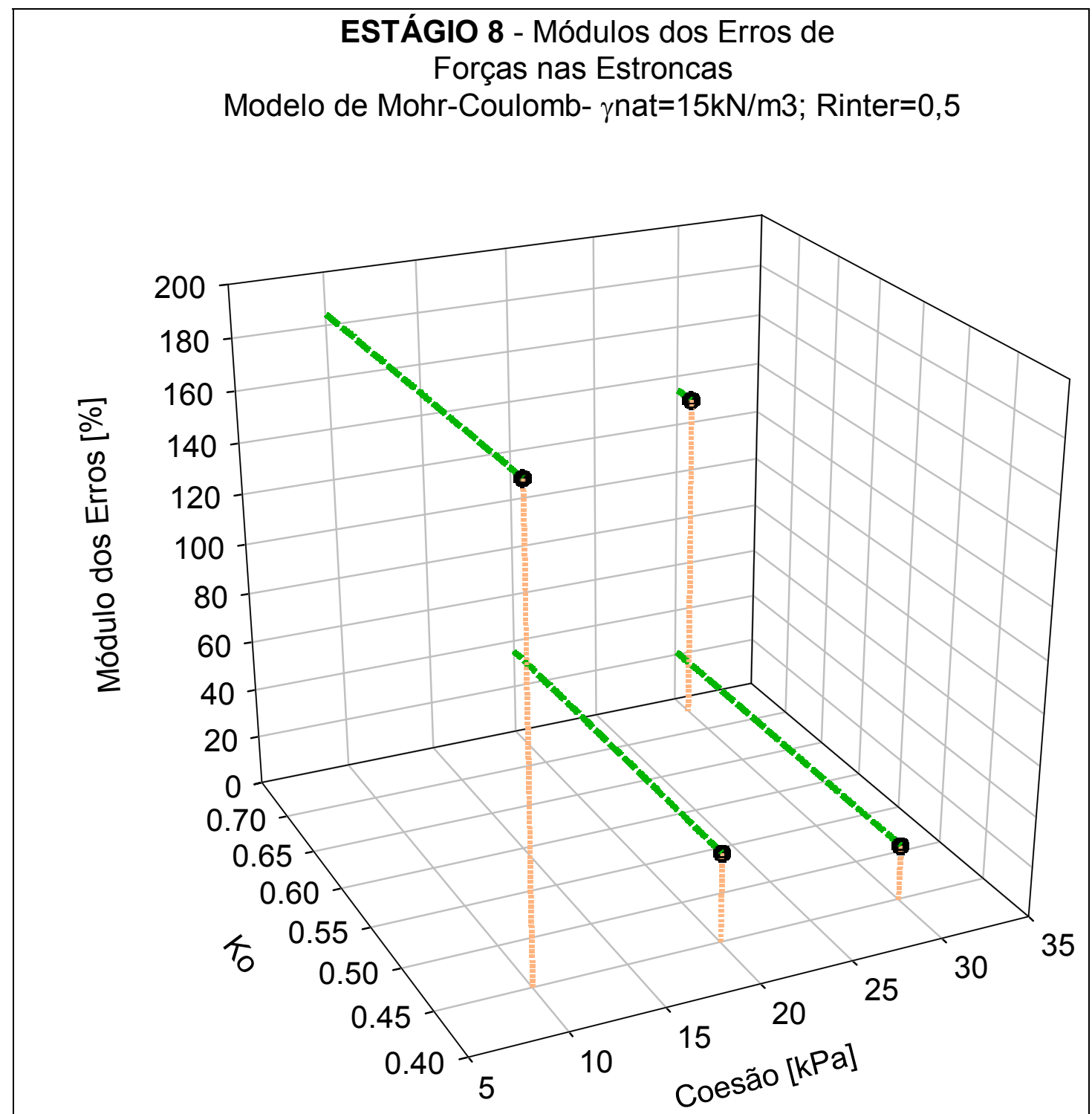

Figura 4-25-Módulo dos erros de forças nas estroncas - estágio 8

O modelo constitutivo de Mohr-Coulomb não representou bem o comportamento do sistema solo-estrutura durante os estágios de escavações desta seção experimental $\mathrm{n}^{\mathrm{o}}$.1. É necessário investigar em trabalhos futuros, se este modelo é adequado ou não para representar o comportamento do sistema solo-estrutura de outras seções experimentais.

Para dirimir esta dúvida quanto a esta seção experimental resolveu-se estudar outro modelo disponível no software PLAXIS (2002), definido como modelo de Endurecimento.

No item 4.7 apresentam-se os resultados obtidos utilizando-se o modelo de Endurecimento. 


\section{7 -Resultados obtidos - Modelo de Endurecimento-}

Na Figura 4-26 apresenta-se um exemplo com o melhor ajuste obtido para as curvas de deslocamentos horizontais de paramentos, que foi obtido para o estágio 5 de escavação, utilizando-se o modelo de Endurecimento. É possível notar que a cada nova etapa de retroanálise há uma aproximação maior dos valores simulados em direção aos reais (instrumentados). Os símbolos apresentados significam:

Xreal_médio -valores de instrumentação dos deslocamentos horizontais médios de paramento.

S_inicial- simulação feita com os valores de referência inicial 2 (Tabela 3-8)

R1- $1^{\mathrm{a}}$. iteração de retroanálise de $E_{50}$, realizada a partir das diferenças entre os valores de deslocamentos horizontais de paramento simulados em S_inicial e os correspondentes instrumentados (Xreal_médio).

R2-2 $2^{\mathrm{a}}$. iteração de retroanálise de $E_{50}$, realizada a partir das diferenças entre os valores de deslocamentos simulados em R1 e os correspondentes instrumentados (Xreal_médio).

Idem para R3 a R10.

Da Tabela 4-10 à

Tabela 4-11 apresentam-se para exemplificar, utilizando-se o estágio 5, os valores calculados de $E_{50}$ em função das diferenças entre valores de deslocamentos horizontais simulados e instrumentados.

Na Tabela 4-12 apresentam-se os resultados dos módulos dos erros pontuais entre deslocamentos reais e simulados e no fim de cada coluna os valores médios destes módulos de erros. Estes serão considerados como representativos do erro da correspondente etapa de retroanálise.

As nomenclaturas utilizadas na Tabela 4-10 à Tabela 4-12 significam:

Ux_S_inicial- Deslocamentos horizontais de paramento calculados na simulação S_inicial com os parâmetros de referência inicial 2. 
Ux_R1-Deslocamentos horizontais de paramento calculados pela $1^{\mathrm{a}}$. iteração de retroanálise de $E_{50}(\mathrm{R} 1)$ em função dos deslocamentos horizontais de paramento obtidos na simulação anterior (S_inicial).

Ux_R2- Deslocamentos horizontais de paramento calculados pela $2^{\mathrm{a}}$. iteração de retroanálise de $E_{50}(\mathrm{R} 2)$ em função dos deslocamentos horizontais de paramento obtidos na simulação anterior (R1).

Idem para Ux_Rn com n variando de 3 a 10.

E50_S_inicial- valor de $E_{50}$ utilizado na simulação inicial S_inicial (Entrada Plaxis) E50_R1 - novo módulo $E_{50}$ obtido $1^{\text {a }}$. iteração de retroanálise envolvendo o valor E50_S_inicial com os deslocamentos horizontais calculados Ux_inicial (Saída Plaxis).

média_E50_R1 (Entrada Plaxis)- média dos valores obtidos E50_R1 utilizados no próximo cálculo para obter os deslocamentos horizontais de paramento Ux_R1 (Saída Plaxis)

E50_R2 - novo módulo $E_{50}$ obtido $2^{\mathrm{a}}$. iteração de retroanálise envolvendo o valor média_E50_R1 com os deslocamentos horizontais calculados Ux_R1 (Saída Plaxis). média_E50_R2 (Entrada Plaxis)- média dos valores obtidos E50_R1 a utilizar no próximo cálculo para obter os deslocamentos horizontais de paramento Ux_R1 (Saída Plaxis)

Idem do E50_R3 ao E50_Idem do E50_R3 ao E50_R10.

Os erros por etapa de retroanálise estão também apresentados em forma gráfica por etapa na Figura 4-27.

Na Figura 4-28 estão representados os erros em relação às forças nas estroncas e aos deslocamentos horizontais de paramento, de todos os estágios, devido à adoção dos parâmetros obtidos por retroanálise de $E_{50}$, para o estágio 5 . 


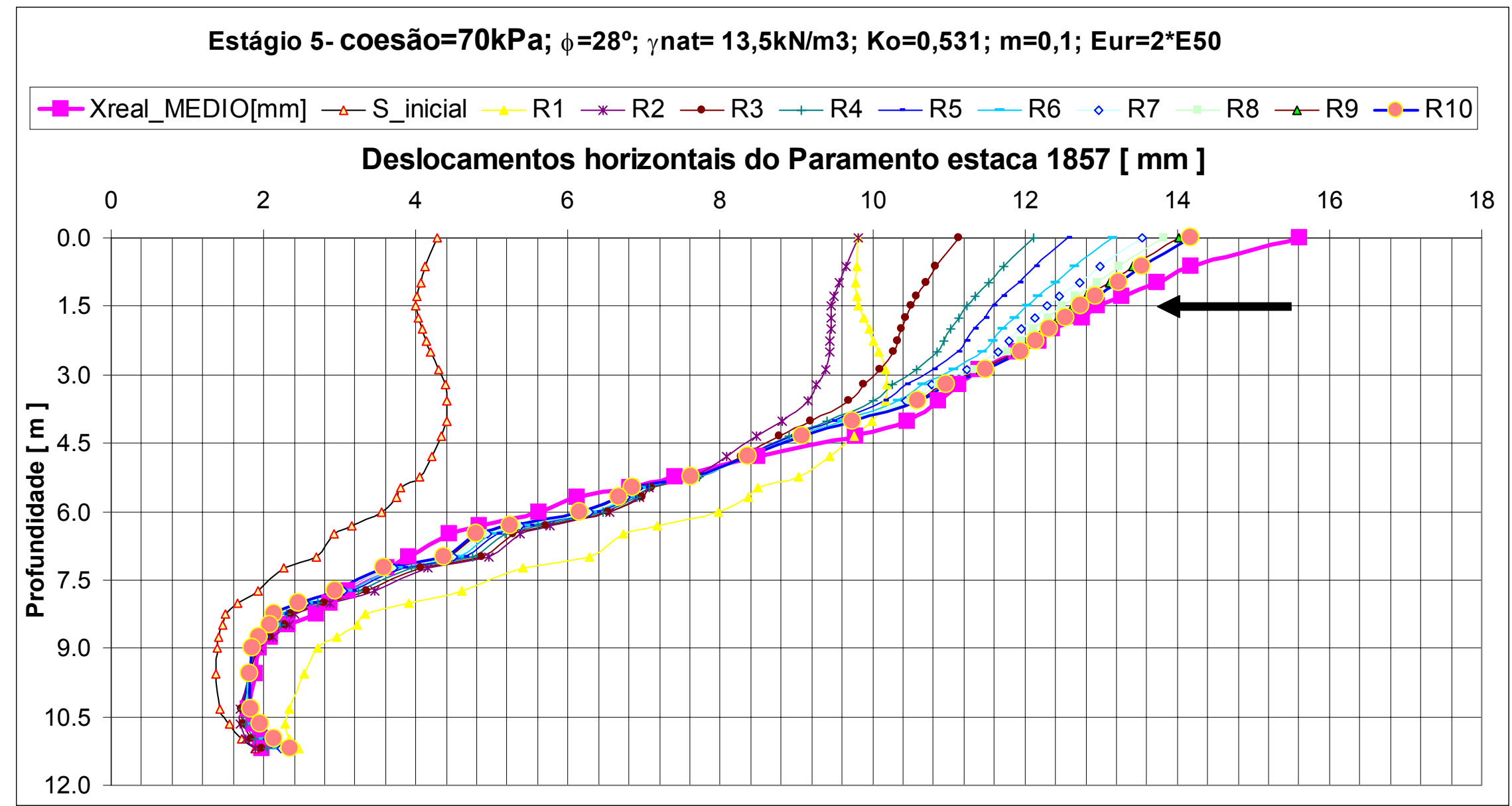

Figura 4-26 -Convergência dos deslocamentos horizontais de paramento devido à retroanálise de $E_{50}$ para o Estágio 5 -modelo de endurecimento 
Por clareza de visualização da Figura 4-26 que é o melhor ajuste obtido neste trabalho será repetida para a última etapa de retroanálise (R10).

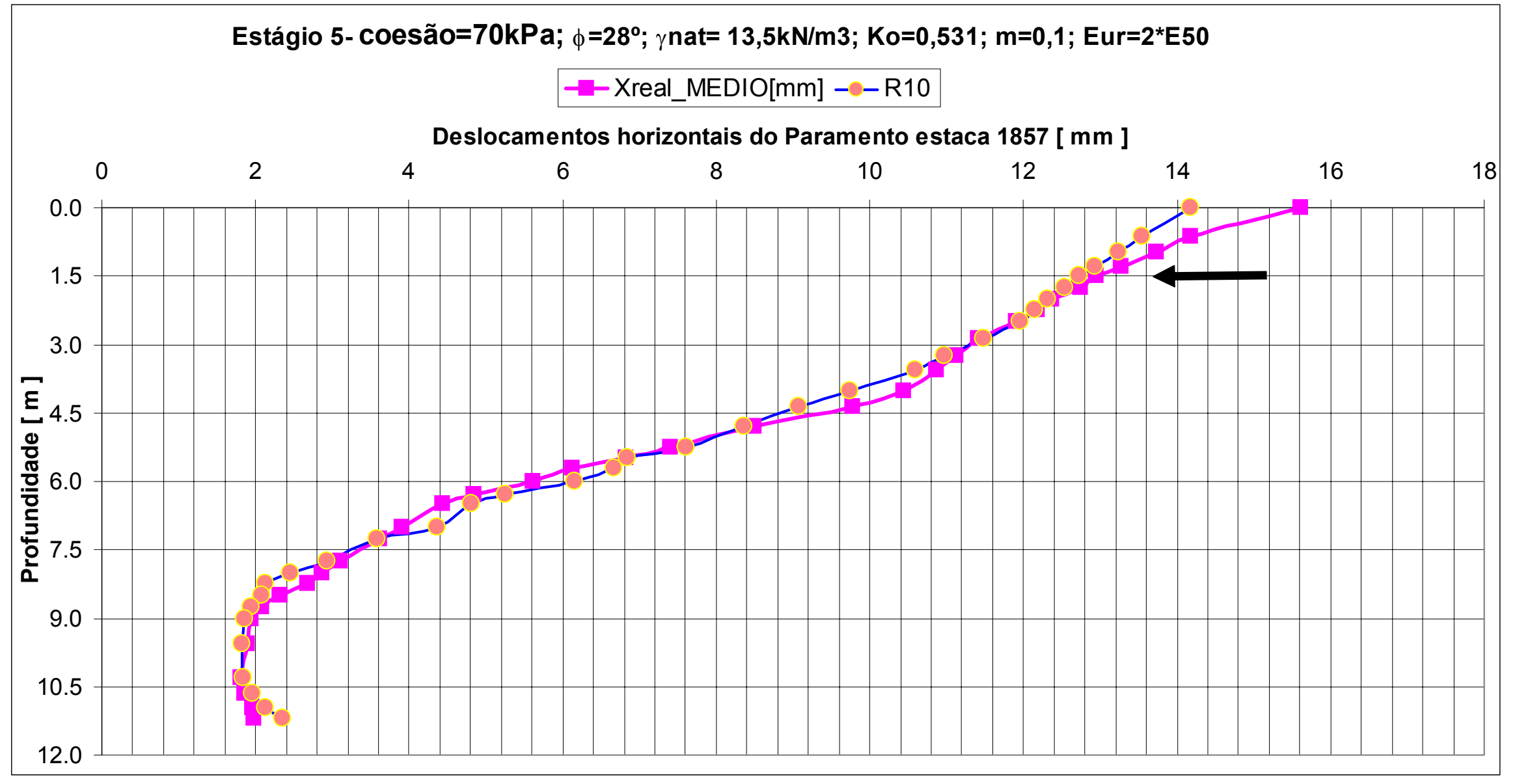


Tabela 4-10-Exemplo de cálculo de retroanálise de $E_{50}$ demonstrado da etapa 1 (R1) à etapa 3 (R3)

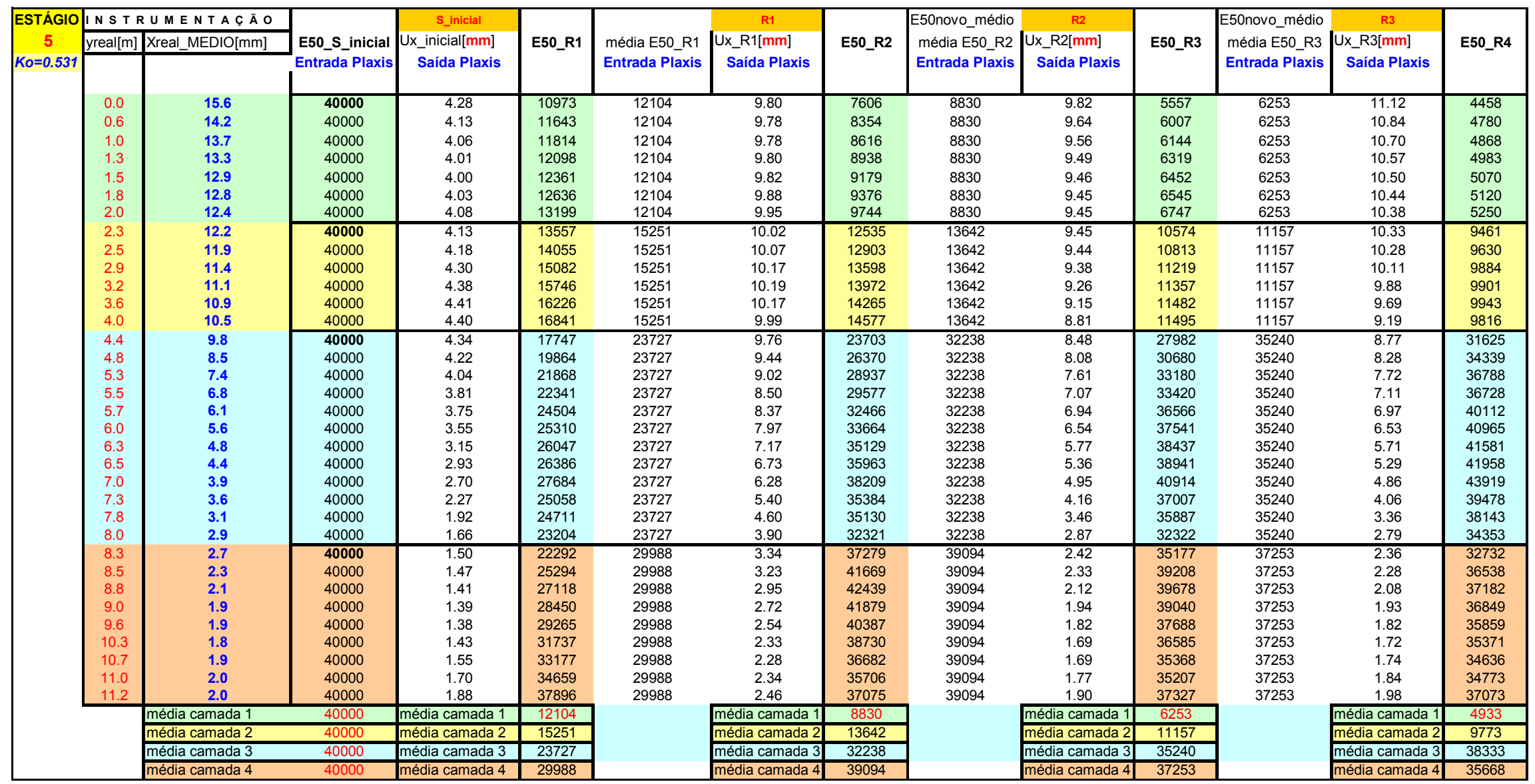


Tabela 4-11- Continuação do exemplo de cálculo de retroanálise de $E_{50}$ demonstrado das etapas 5 e 6 (R5 e R6) saltando para a etapa 10

\begin{tabular}{|c|c|c|c|c|c|c|c|c|c|}
\hline & E50novo_médio & R5 & & retro $2 \mathrm{E} 1$ & R6 & R9 & & E50novo_médio & R10 \\
\hline E50_R5 & $\begin{array}{l}\text { média E50_R5 } \\
\text { Entrada Plaxis }\end{array}$ & $\begin{array}{l}\text { Ux_R5[mm] } \\
\text { Saída Plaxis }\end{array}$ & E50_R6 & $\begin{array}{l}\text { média E50_R6 } \\
\text { Entrada Plaxis }\end{array}$ & $\begin{array}{c}\text { Ux_Retro6[mm] } \\
\text { Saída Plaxis }\end{array}$ & $\begin{array}{l}\text { Ux_Retro9[mm] } \\
\text { Saída Plaxis }\end{array}$ & E50_R10 & \begin{tabular}{|c} 
média E50_R10 \\
Entrada Plaxis
\end{tabular} & $\begin{array}{l}\text { Ux_R10[mm] } \\
\text { Saída Plaxis }\end{array}$ \\
\hline 3831 & 4179 & 12.56 & 3365 & 3654 & 13.16 & 14.02 & 2630 & 2803 & 14.18 \\
\hline 4079 & 4179 & 12.13 & 3575 & 3654 & 12.65 & 13.41 & 2768 & 2803 & 13.55 \\
\hline 4139 & 4179 & 11.91 & 3624 & 3654 & 12.40 & 13.11 & 2792 & 2803 & 13.23 \\
\hline 4219 & 4179 & 11.71 & 3689 & 3654 & 12.16 & 12.82 & 2827 & 2803 & 12.93 \\
\hline 4280 & 4179 & 11.58 & 3739 & 3654 & 12.02 & 12.63 & 2854 & 2803 & 12.74 \\
\hline 4307 & 4179 & 11.46 & 3758 & 3654 & 11.87 & 12.44 & 2855 & 2803 & 12.54 \\
\hline 4398 & 4179 & 11.33 & 3830 & 3654 & 11.71 & 12.23 & 2894 & 2803 & 12.32 \\
\hline 8771 & 8919 & 11.23 & 8218 & 8293 & 11.58 & 12.06 & 7321 & 7239 & 12.15 \\
\hline 8897 & 8919 & 11.11 & 8323 & 8293 & 11.44 & 11.88 & 7381 & 7239 & 11.96 \\
\hline 9057 & 8919 & 10.79 & 8440 & 8293 & 11.06 & 11.42 & 7405 & 7239 & 11.48 \\
\hline 9004 & 8919 & 10.43 & 8358 & 8293 & 10.64 & 10.92 & 7259 & 7239 & 10.97 \\
\hline 8997 & 8919 & 10.15 & 8329 & 8293 & 10.33 & 10.56 & 7185 & 7239 & 10.59 \\
\hline 8790 & 8919 & 9.48 & 8090 & 8293 & 9.60 & 9.72 & 6881 & 7239 & 9.74 \\
\hline 34913 & 41092 & 8.94 & 37576 & 43399 & 9.01 & 9.07 & 45085 & 49694 & 9.08 \\
\hline 37631 & 41092 & 8.33 & 40316 & 43399 & 8.37 & 8.37 & 47853 & 49694 & 8.36 \\
\hline 40027 & 41092 & 7.68 & 42684 & 43399 & 7.69 & 7.63 & 50104 & 49694 & 7.62 \\
\hline 39688 & 41092 & 6.99 & 42133 & 43399 & 6.97 & 6.87 & 48903 & 49694 & 6.84 \\
\hline 43283 & 41092 & 6.84 & 45905 & 43399 & 6.81 & 6.70 & 53153 & 49694 & 6.67 \\
\hline 44021 & 41092 & 6.37 & 46558 & 43399 & 6.32 & 6.19 & 53524 & 49694 & 6.16 \\
\hline 44373 & 41092 & 5.50 & 46710 & 43399 & 5.44 & 5.29 & 53041 & 49694 & 5.25 \\
\hline 44631 & 41092 & 5.07 & 46877 & 43399 & 5.00 & 4.84 & 52919 & 49694 & 4.81 \\
\hline 46574 & 41092 & 4.64 & 48817 & 43399 & 4.56 & 4.40 & 54802 & 49694 & 4.37 \\
\hline 41653 & 41092 & 3.84 & 43516 & 43399 & 3.77 & 3.61 & 48416 & 49694 & 3.58 \\
\hline 40136 & 41092 & 3.16 & 41879 & 43399 & 3.10 & 2.97 & 46430 & 49694 & 2.94 \\
\hline 36174 & 41092 & 2.64 & 37812 & 43399 & 2.59 & 2.48 & 42100 & 49694 & 2.46 \\
\hline 30483 & 34174 & 2.25 & 28625 & 32923 & 2.22 & 2.15 & 24312 & 29885 & 2.13 \\
\hline 34081 & 34174 & 2.18 & 32053 & 32923 & 2.15 & 2.09 & 27332 & 29885 & 2.08 \\
\hline 34879 & 34174 & 2.01 & 32982 & 32923 & 1.99 & 1.96 & 28513 & 29885 & 1.95 \\
\hline 34814 & 34174 & 1.89 & 33136 & 32923 & 1.88 & 1.87 & 29125 & 29885 & 1.86 \\
\hline 34145 & 34174 & 1.81 & 32725 & 32923 & 1.81 & 1.82 & 29271 & 29885 & 1.82 \\
\hline 34198 & 34174 & 1.76 & 33209 & 32923 & 1.78 & 1.82 & 30694 & 29885 & 1.84 \\
\hline 33894 & 34174 & 1.82 & 33245 & 32923 & 1.85 & 1.94 & 31511 & 29885 & 1.95 \\
\hline 34304 & 34174 & 1.95 & 33867 & 32923 & 2.00 & 2.11 & 32650 & 29885 & 2.14 \\
\hline 36770 & 34174 & 2.12 & 36460 & 32923 & 2.18 & 2.32 & 35558 & 29885 & 2.35 \\
\hline 4179 & & média camada 1 & 3654 & & médias & & 2803 & & \\
\hline 8919 & & média camada 2 & 8293 & & & & 7239 & & \\
\hline 41092 & & média camada 3 & 43399 & & & & 49694 & & \\
\hline 34174 & & média camada 4 & 32923 & & & & 29885 & & \\
\hline
\end{tabular}


Tabela 4-12—Módulos dos erros pontuais para cada etapa de retroanálise entre os deslocamentos simulados e os reais.

\begin{tabular}{|c|c|c|c|c|c|c|c|c|c|c|c|}
\hline \\
\hline
\end{tabular}




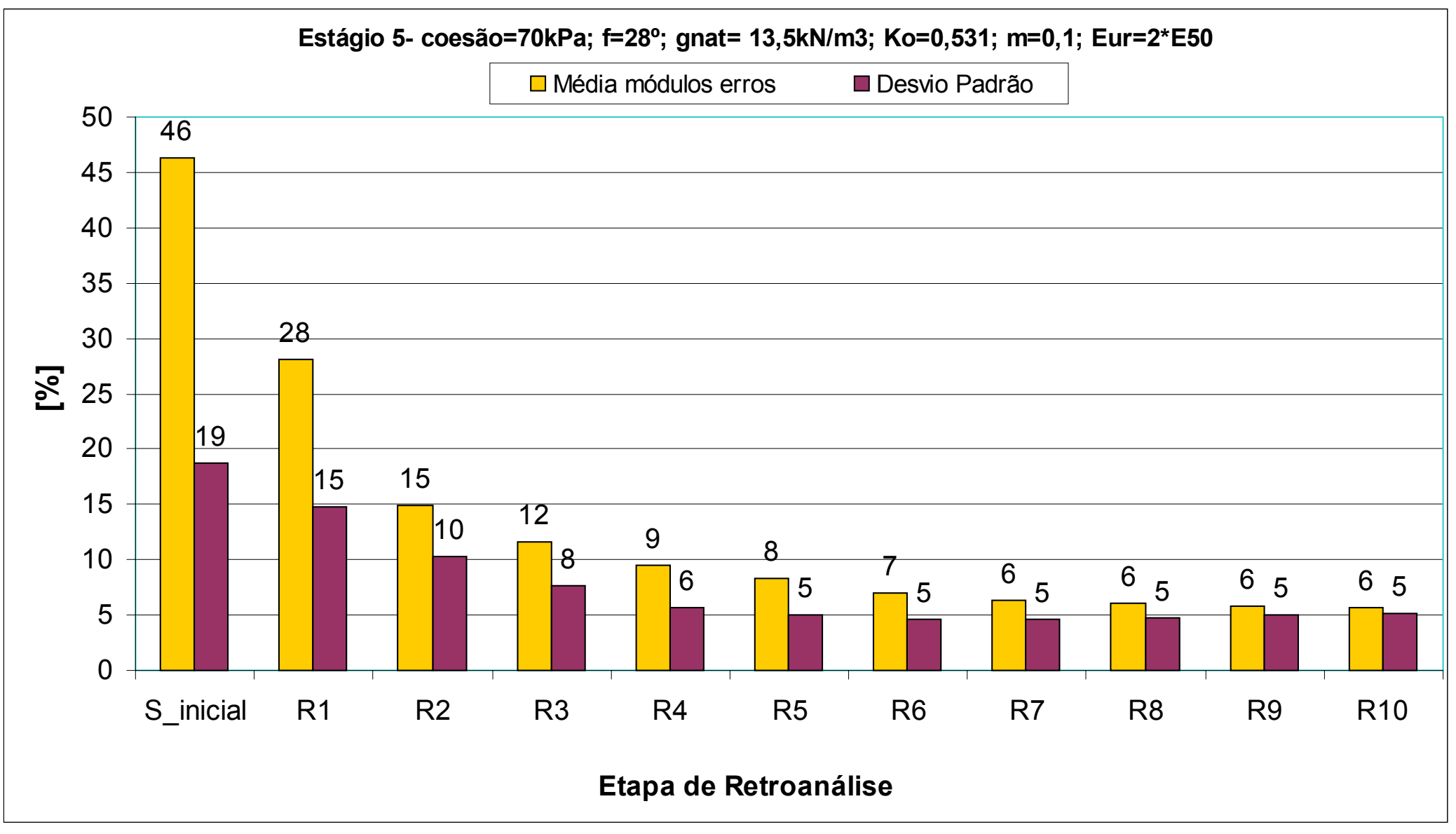

Figura 4-27- Módulos dos erros médios para cada etapa de retroanálise de $E_{50}$ apresentados na Tabela 4-12 


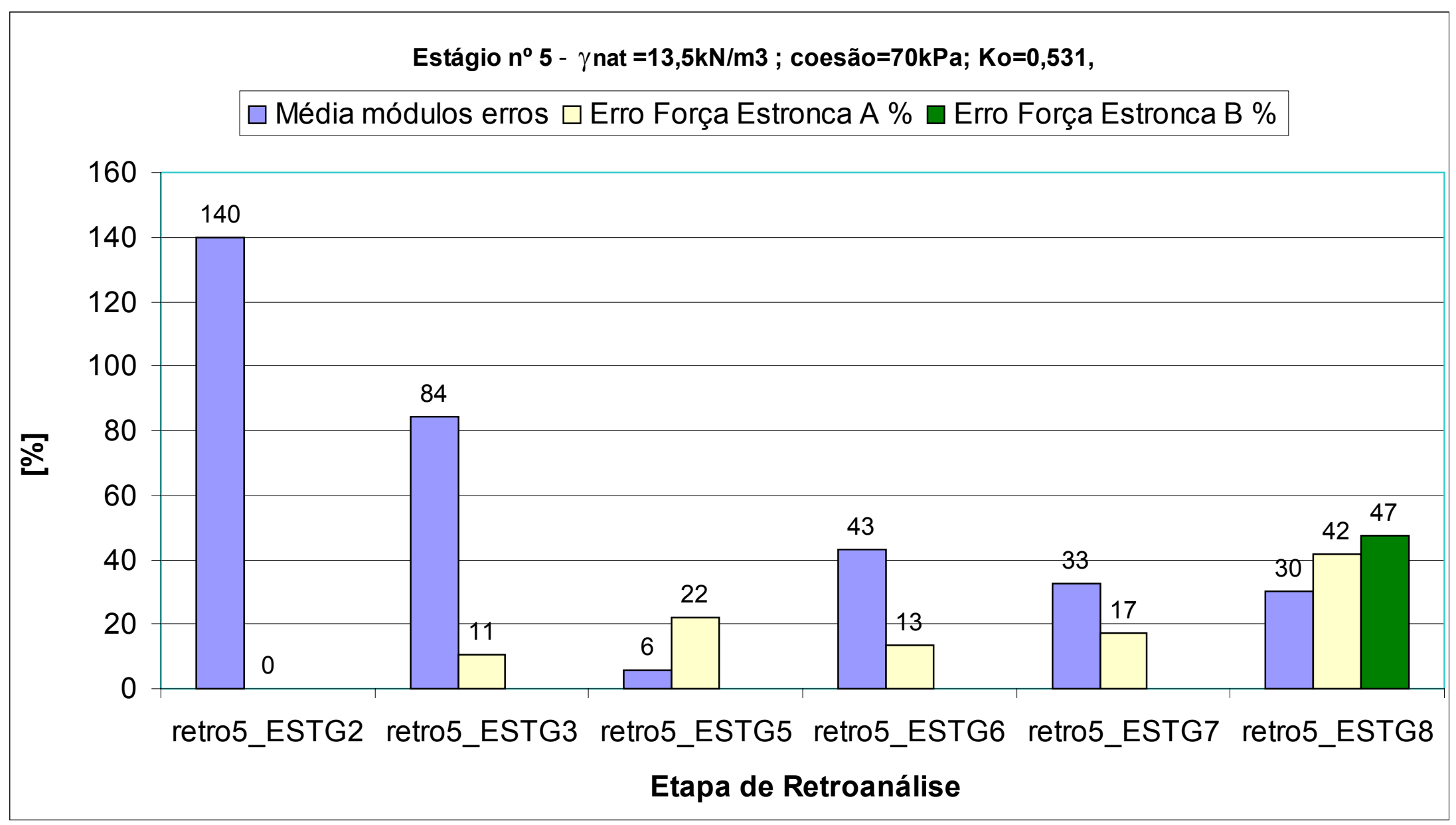

Figura 4-28- Média dos módulos dos erros de deslocamentos horizontais de paramento e módulos de forças nas estroncas (A e B) para cada estágio simulado com o parâmetro $E_{50}$ obtido da retroanálise do estágio 5 
O ótimo ajuste obtido para os deslocamentos de paramento através da retroanálise do estágio 5 , não se repetiu para os estágios 3 e 8 , razão pela qual resolveuse averiguar onde poderia estar a causa desta deficiência.

Pode-se confirmar o exposto acima analisando-se da Figura 4-29 à Figura 4-33, que estão relacionadas às previsões de deslocamentos de paramentos nos estágios 2, 5, 7 e 8, utilizando-se para isto os valores de $E_{50}$ obtidos das retroanálises do estágio 3. 


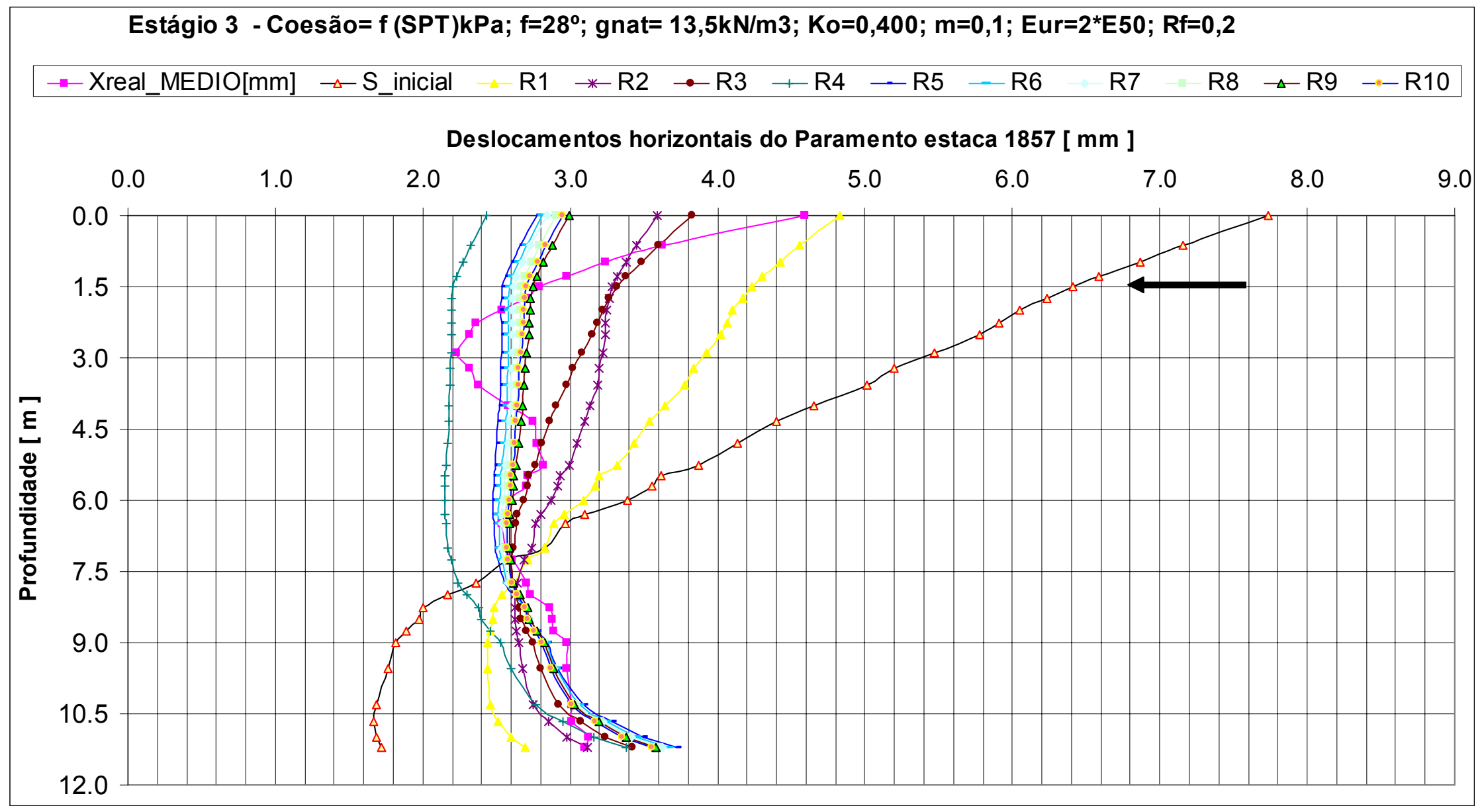

Figura 4-29-Deslocamentos horizontais instrumentados $x$ simulados através da Retroanálise de $E_{50}$ para o estágio 3 


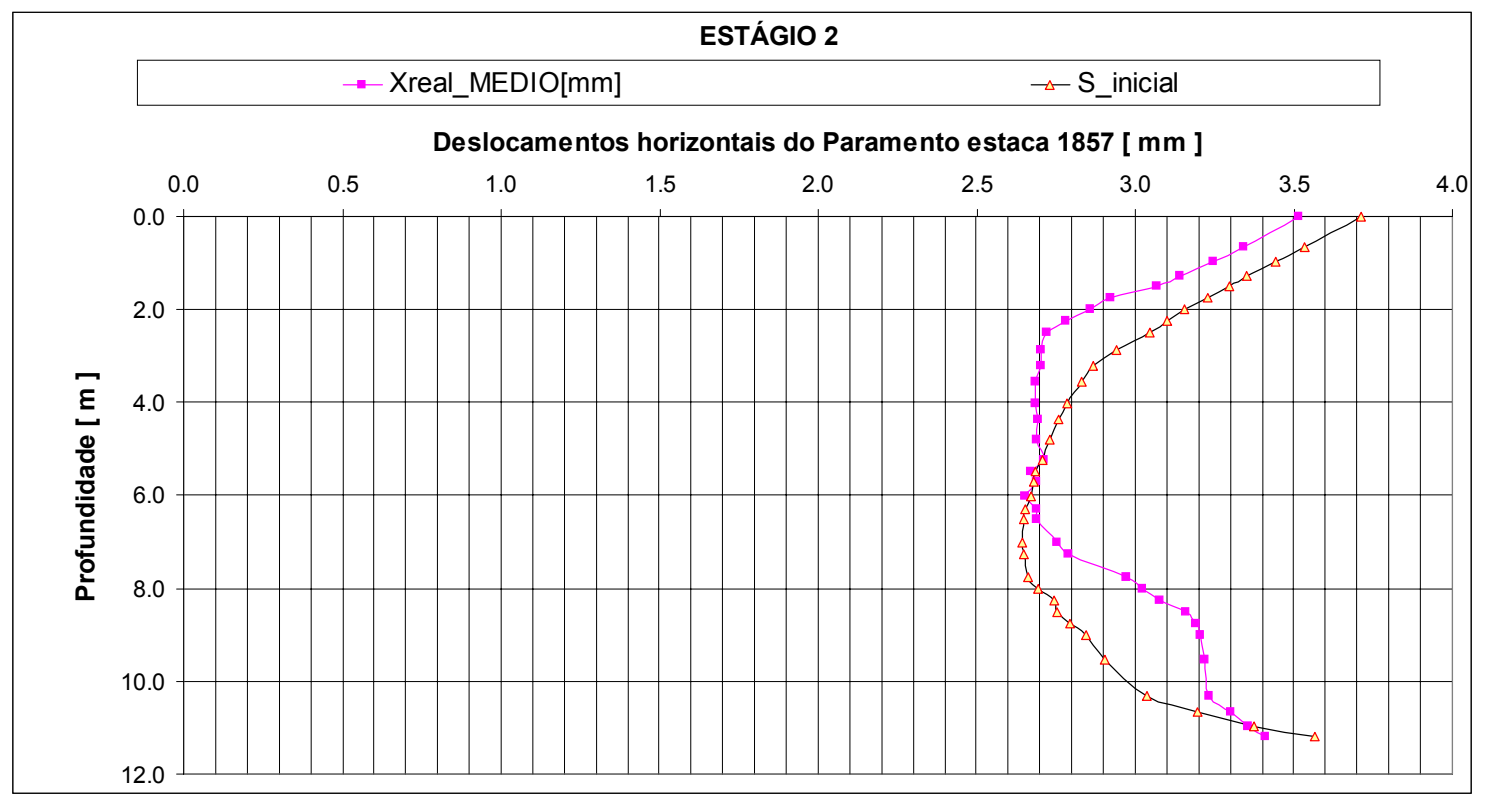

Figura 4-30- Deslocamentos horizontais simulados no estágio 2 com a adoção dos valores de $E_{50}$ obtidos da retroanálise do estágio 3

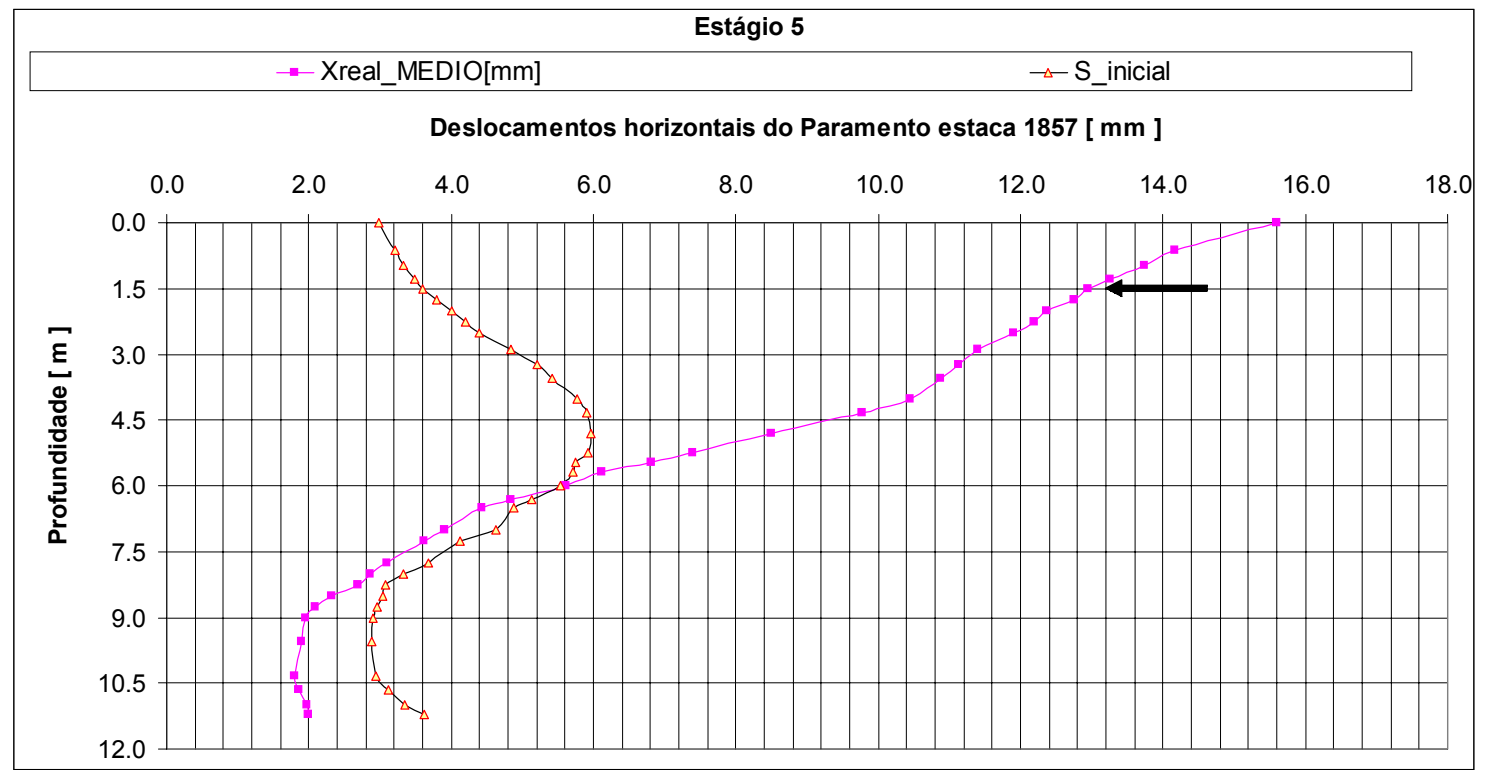

Figura 4-31- Deslocamentos horizontais simulados no estágio 5 com a adoção dos valores de $E_{50}$ obtidos da retroanálise do estágio 3. 


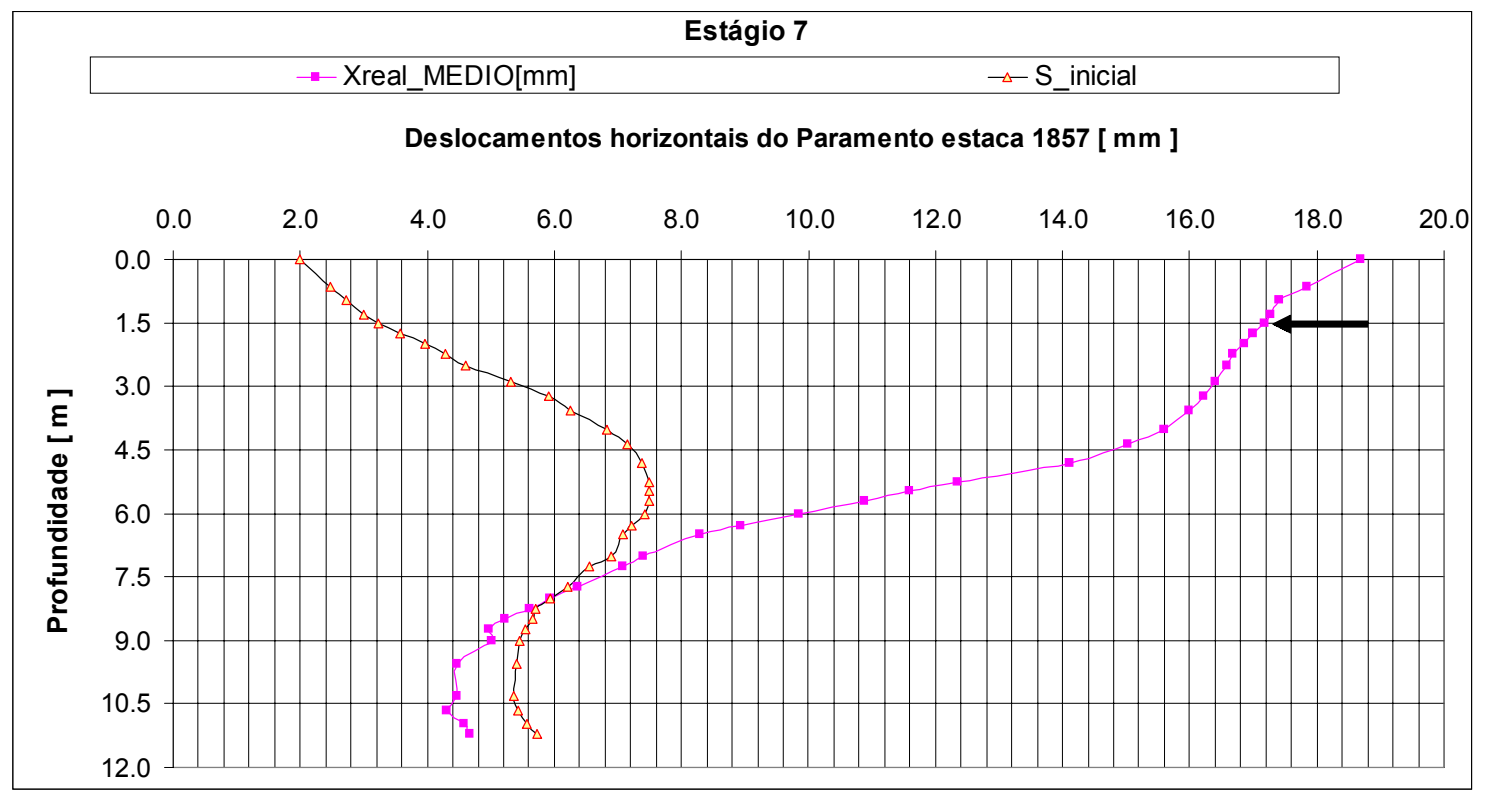

Figura 4-32- Deslocamentos horizontais simulados no estágio 7 com a adoção dos valores de $E_{50}$ obtidos da retroanálise do estágio 3.

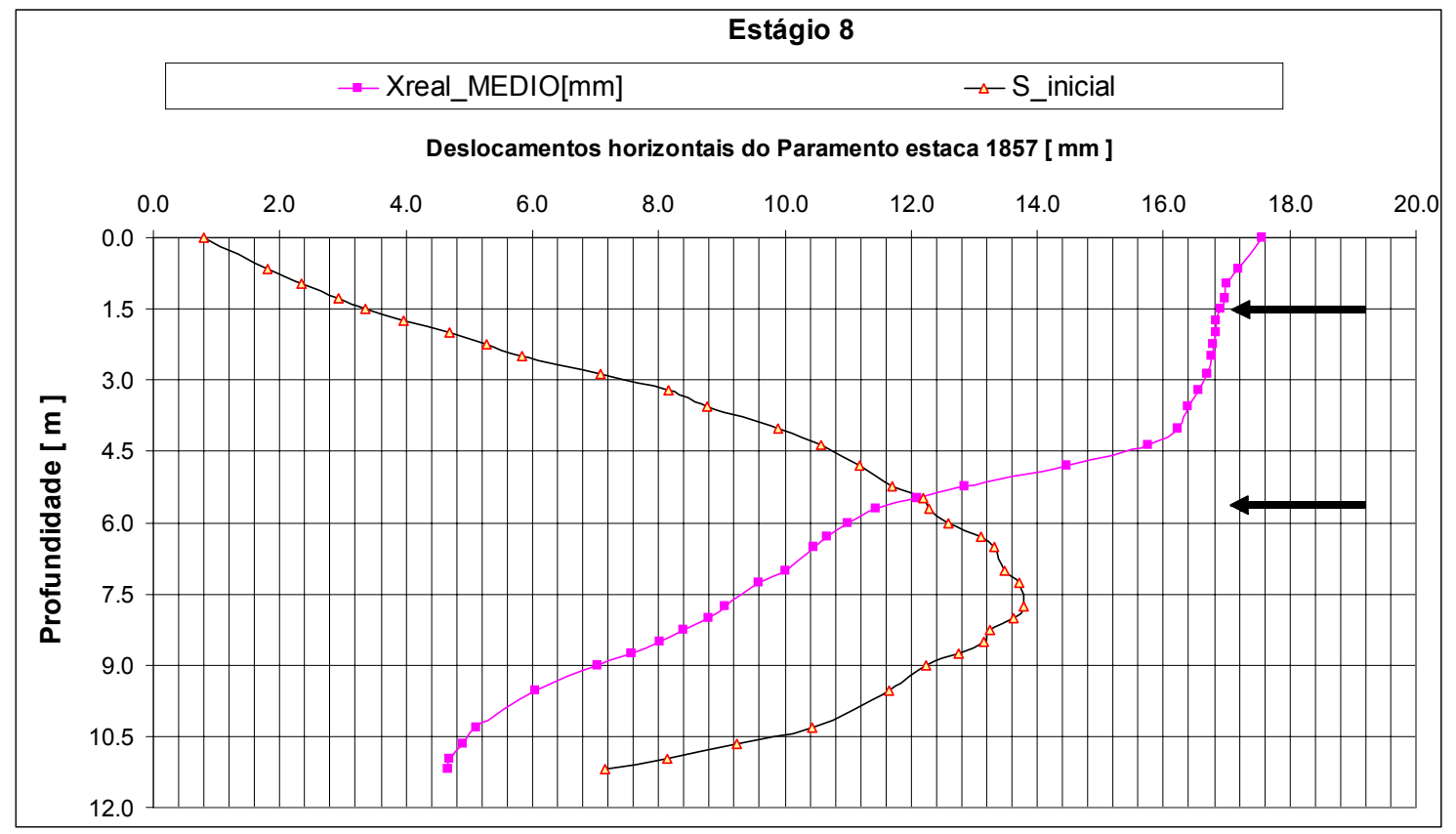

Figura 4-33- Deslocamentos horizontais simulados no estágio 8 com a adoção dos valores de $E_{50}$ obtidos da retroanálise do estágio 3.

Ao analisar-se a Figura 4-29, percebe-se que o solo simulado no estágio 3 apresenta de 0 a 4,5m de profundidade um maior endurecimento que o solo real. Para a 
Figura 4-30 isto ocorre abaixo dos $6 \mathrm{~m}$ de profundidade, sendo que de 0 a $6 \mathrm{~m}$ o solo simulado teve menor endurecimento que o solo real.

Com relação aos estágios 5, 7 e 8 (simulados com $\mathrm{E}_{50}$ obtidos da retroanálise do estágio 3),os solos simulados apresentam maior endurecimento que os solos simulados na faixa que varia de :

- 0 a $6 \mathrm{~m}$ para o estágio 5

- 0 a 7,6m para o estágio 7

- 0 a $5,8 \mathrm{~m}$ para o estágio 8 .

Destas observações, fez-se as afirmações abaixo.

Os valores de $E_{50}$ obtidos por retroanálise do estágio 3 têm representação razoável para os deslocamentos de paramento dos estágios 2 e 3 .

Para os estágios 5, 6, 7 e 8, de uma forma geral, o modelo de Endurecimento não consegue reduzir o $E_{u r}$ do solo com o avanço das escavações. Isto ocorre de 0 a 6 ou $7,5 \mathrm{~m}$ de profundidade, dependendo do estágio.

Quando se atinge o estágio 8 nota-se que o solo simulado abaixo dos $6 \mathrm{~m}$ de profundidade fica com Eur menor que o solo real, diferença que era menos sentida nos outros estágios anteriores. Durante a implantação do segundo nível de estroncas (nível B), acredita-se que o software PLAXIS (2002) não conseguiu representar a variação de rigidez do paramento e a consequente variação do $E_{u r}$ do solo. Além disto, pode ter havido algum fato que passou despercebido pela instrumentação.

Ao se obterem erros satisfatórios em relação aos deslocamentos de paramento e em relação às forças nas estroncas, para um determinado estágio então o modelo ajustado deveria representar bem a realidade, não só para aquele estágio como também para os outros. Isto ocorreria se o modelo reológico utilizado tivesse a capacidade de representar a variação dos módulos de carregamento e descarregamento (Eur). A partir deste raciocínio, percebe-se que o modelo de Endurecimento não foi capaz de corrigir os módulos Eur, para os estágios subseqüentes ao estágio 3 .

A partir desta última constatação de deficiência do modelo de Endurecimento, resolveu-se analisar separadamente os estágios 5 e 8 , através de retroanálises de $E_{50}$. Eles foram escolhidos, uma vez que representavam os estágios médio e final de escavações.

Na Tabela 4-13 à Tabela 4-15, estão representados os valores de módulos dos erros entre valores simulados e valores instrumentados de deslocamentos de paramento 
e forças nas estroncas, para os estágios 3, 5 e 8 . Estes valores foram obtidos a partir das retroanálises de $E_{50}$ que foram corrigidas etapa a etapa em função das relações e diferenças entre deslocamentos reais e simulados.

Deve-se notar na Tabela 4-13 à Tabela 4-15 que há uma linha destinada à coesão em função de SPT, isto representa que a coesão é variável em cada uma das camadas em que a argila porosa foi subdividida.

De acordo com TEIXEIRA \& GODOY (1996) a correlação para coesão não drenada em função do número de golpes do ensaio SPT, é $c_{u}-10^{*} \mathrm{~N}_{\mathrm{SPT}}(\mathrm{kPa})$, assim os valores para as cinco camadas seriam 10, 25, 35, 55 e $70 \mathrm{kPa}$. Os primeiros quatro valores são da camada de argila porosa e o quinto para a camada composta por argila rija, que aparece na sondagem (Figura 2-6) abaixo do pé do paramento . 
Tabela 4-13- Estágios 3, 5 e 8 - Resumo da média dos módulos dos erros de deslocamentos de paramentos e forças nas estroncas obtidos por retroanálise de $E_{50}$

\begin{tabular}{|c|c|c|c|c|c|c|c|}
\hline \multicolumn{8}{|c|}{ Estágio 3-Módulos dos erros Médios de Deslocamentos Horizontais $\left(\mathrm{u}_{\mathrm{n}}\right)$} \\
\hline & & Rinter $=0$ & & & & & nter $=0,5$ \\
\hline & & \multicolumn{3}{|c|}{$\gamma \mathrm{n}=13.5 \mathrm{kN} / \mathrm{m}^{3}$} & \multicolumn{3}{|c|}{$\gamma n=15 \mathrm{kN} / \mathrm{m}^{3}$} \\
\hline & & Ko & Ko & Ko & Ko & Ko & Ko \\
\hline $\mathrm{C}\left[\mathrm{KN} / \mathrm{m}^{2}\right]$ & & 0.4 & 0.4 & 0.531 & 0.4 & 0.531 & 0.4 \\
\hline \multirow{2}{*}{30} & erro médio[\%] & & 11.3 & 11.6 & 13.6 & 13.4 & \\
\hline & $\begin{array}{l}\text { desvio[\%] } \\
\text { dio] }\end{array}$ & & 10.9 & 11.3 & 13.2 & 12.2 & \\
\hline \multirow[t]{2}{*}{70} & erro médio[\%] & 7.1 & 7.2 & 13.8 & 8.1 & 12.1 & 6.6 \\
\hline & desvio[\%] & 8.6 & 7.2 & 11.5 & 8.3 & 10.3 & 7.9 \\
\hline & erro médio[ ${ }^{\circ}$ & 9.7 & 11.1 & 14.1 & 17.6 & 19.4 & 10.5 \\
\hline SPT & desvio[\%] & 12.7 & 11.8 & 12.0 & 17.5 & 17.1 & 11.1 \\
\hline
\end{tabular}

\begin{tabular}{|c|c|c|c|c|c|c|c|}
\hline \multicolumn{8}{|c|}{ Estágio 3 -Módulos dos erros de Forças nas Estroncas Nível A } \\
\hline & & Rinter=c & & inter $=0$ & & & inter $=0,5$ \\
\hline & & \multicolumn{3}{|c|}{$\gamma \mathrm{n}=13.5 \mathrm{kN} / \mathrm{m}^{3}$} & \multicolumn{3}{|c|}{$\gamma \mathrm{n}=15 \mathrm{kN} / \mathrm{m}^{3}$} \\
\hline & & Ko & Ko & Ko & Ko & Ko & Ko \\
\hline $\mathrm{C}\left[\mathrm{KN} / \mathrm{m}^{2}\right]$ & & 0.4 & 0.4 & 0.531 & 0.4 & 0.531 & 0.4 \\
\hline 30 & $\begin{array}{l}\text { erro nivel A [\%] } \\
\text { desvio[\%] }\end{array}$ & & 1.2 & 0.6 & 0.1 & 0.3 & \\
\hline 70 & \begin{tabular}{|l} 
erro nivel A [\%] \\
desvio[\%]
\end{tabular} & 9.0 & 3.1 & 1.2 & 1.0 & 1.1 & 8.3 \\
\hline SPT & $\begin{array}{l}\text { erro nivel A [\%] } \\
\text { desvio[\%] }\end{array}$ & 4.7 & 0.7 & 1.7 & 0.3 & 0.8 & 1.5 \\
\hline
\end{tabular}

\begin{tabular}{|c|c|c|c|c|c|c|c|}
\hline \multicolumn{8}{|c|}{ Estágio 5- Módulos dos erros Médios de Deslocamentos Horizontais $\left(u_{n}\right)$} \\
\hline & & Rinter $=0,5$ & & & & & $\overline{R \text { Rinter }=0,5}$ \\
\hline & & \multicolumn{3}{|c|}{$\gamma \mathrm{n}=13.5 \mathrm{kN} / \mathrm{m}^{3}$} & \multicolumn{3}{|c|}{$\gamma \mathrm{n}=15 \mathrm{kN} / \mathrm{m}^{3}$} \\
\hline & & Ko & Ko & Ko & Ko & Ko & Ko \\
\hline $\mathrm{C}\left[\mathrm{KN} / \mathrm{m}^{2}\right]$ & & 0.4 & 0.4 & 0.531 & 0.4 & 0.531 & 0.4 \\
\hline 30 & erro médio[\%] & & 7.4 & 16.5 & 7.9 & 6.0 & \\
\hline & $\begin{array}{l}\text { desvio[\%] } \\
\text { dio] }\end{array}$ & & 6.0 & 10.5 & 6.3 & 5.4 & \\
\hline 70 & erro médio[\%] & $\overline{6.2}$ & 7.9 & 5.7 & 8.4 & 7.1 & 5.9 \\
\hline & |desvio[\%] & 4.5 & 5.8 & 5.1 & 5.5 & 5.9 & 4.5 \\
\hline & erro médio[\%] & 6.4 & 7.0 & 6.6 & 7.7 & 7.2 & 7.6 \\
\hline SPT & desvio[\%] & 4.3 & 5.1 & 5.4 & 6.1 & 5.4 & 5.2 \\
\hline
\end{tabular}

\begin{tabular}{|c|c|c|c|c|c|c|c|}
\hline \multicolumn{8}{|c|}{ Estágio 5 -Módulos dos erros de Forças nas Estroncas Nivel A } \\
\hline & & Rinter $=0,5$ & \multicolumn{3}{|c|}{ Rinter $=0.2$} & & Rinter $=0,5$ \\
\hline & & \multicolumn{3}{|c|}{$\gamma \mathrm{n}=13.5 \mathrm{kN} / \mathrm{m}^{3}$} & \multicolumn{3}{|c|}{$\gamma \mathrm{n}=15 \mathrm{kN} / \mathrm{m}^{3}$} \\
\hline & & Ko & Ko & Ko & Ko & Ko & Ko \\
\hline $\mathrm{C}\left[\mathrm{KN} / \mathrm{m}^{2}\right]$ & & 0.4 & 0.4 & 0.531 & 0.4 & 0.531 & 0.4 \\
\hline 30 & \begin{tabular}{|l} 
erro nivel A [\%] \\
desvio[\%]
\end{tabular} & & 23.9 & 27.5 & 29.7 & 28.1 & \\
\hline 70 & \begin{tabular}{|l}
$\begin{array}{l}\text { erro nivel A [\%] } \\
\text { desvio[\%] }\end{array}$ \\
\end{tabular} & 20.3 & 24.2 & 22.2 & $\overline{27.2}$ & 39.5 & 22.9 \\
\hline SPT & \begin{tabular}{|l} 
erro nivel A [\%] \\
desvio[\%]
\end{tabular} & 16.3 & 22.5 & 33.1 & 31.6 & 37.6 & 19.9 \\
\hline
\end{tabular}

\begin{tabular}{|c|c|c|c|c|c|c|c|}
\hline \multicolumn{8}{|c|}{ Estágio 8- Módulos dos erros Médios de Deslocamentos Horizontais $\left(u_{n}\right)$} \\
\hline & & Rinter $=0,5$ & & & & & Rinter $=0,5$ \\
\hline & & \multicolumn{3}{|c|}{$\gamma \mathrm{n}=13.5 \mathrm{kN} / \mathrm{m}^{3}$} & \multicolumn{3}{|c|}{$\gamma \mathrm{n}=15 \mathrm{kN} / \mathrm{m}^{3}$} \\
\hline & & Ko & Ko & Ko & Ko & Ko & Ko \\
\hline $\mathrm{C}\left[\mathrm{KN} / \mathrm{m}^{2}\right]$ & & 0.4 & 0.4 & 0.531 & 0.4 & 0.531 & 0.4 \\
\hline \multirow[t]{2}{*}{30} & erro médio[\%] & & 21.8 & 19.1 & 27.4 & 25.2 & \\
\hline & desvio[\%] & & 15.3 & 11.1 & 16.3 & 13.3 & \\
\hline \multirow[t]{2}{*}{70} & erro médio[\%] & 19.8 & 24.4 & 16.2 & 21.7 & 23.4 & 20.6 \\
\hline & desvio[\%] & 17.1 & 17.3 & 9.4 & 15.0 & 13.1 & 16.9 \\
\hline & erro médio[\%] & 26.8 & 20.7 & 22.5 & 22.3 & 23.7 & 23.7 \\
\hline SPT & desvio[\%] & 20.7 & 13.7 & 12.1 & 12.7 & 12.6 & 18.2 \\
\hline
\end{tabular}

\begin{tabular}{|c|c|c|c|c|c|c|c|}
\hline \multicolumn{8}{|c|}{ Estágio 8 -Módulos dos erros de Forças nas Estroncas Nivel A } \\
\hline & & Rinter $=0,5$ & & Rinter $=0$. & & & Rinter $=0,5$ \\
\hline & & \multicolumn{3}{|c|}{$\gamma \mathrm{n}=13.5 \mathrm{kN} / \mathrm{m}^{3}$} & \multicolumn{3}{|c|}{$\gamma \mathrm{n}=15 \mathrm{kN} / \mathrm{m}^{3}$} \\
\hline & & Ko & Ko & Ko & Ko & Ko & Ko \\
\hline $\mathrm{C}\left[\mathrm{KN} / \mathrm{m}^{2}\right]$ & & 0.4 & 0.4 & 0.531 & 0.4 & 0.531 & 0.4 \\
\hline \multirow[t]{2}{*}{30} & erro nivel A [\%] & & $\overline{30.2}$ & 39.3 & $\overline{56.3}$ & 55.3 & \\
\hline & erro nivel B [\%] & & 48.6 & 49.8 & 48.5 & 48.9 & \\
\hline \multirow[t]{2}{*}{70} & erro nivel A [\%] & 31.7 & 32.3 & 38.7 & 36.4 & 62.2 & 39.6 \\
\hline & erro nivel B [\%] & 48.3 & 49.0 & 49.1 & 49.7 & 48.9 & 49.0 \\
\hline & erro nivel A [\%] & 41.4 & 30.9 & 52.6 & 38.0 & 68.3 & 44.2 \\
\hline SPT & erro nível B [\%] & 48.2 & 49.1 & 48.6 & 48.7 & 49.1 & 49.5 \\
\hline
\end{tabular}

$C=$ coesão $\left[\mathrm{kN} / \mathrm{m}^{2}\right] ;$ Rinter $=$ coeficiente de redução da tan $\phi$ e da coesão; $K o=$ coeficiente de empuxo em repouso;

$\gamma$ nat= peso específico natural do solo $\left[\mathrm{kN} / \mathrm{m}^{3}\right]$; SPT= Coesão $(\mathrm{C})$ em função dos SPT médio de cada camada 
Tabela 4-14 - Resumo das médias dos módulos dos erros de deslocamentos globais a partir dos parâmetros obtidos da retroanálise de $E_{50}$ cada um dos estágios isolados (estágios 3, 5 e 8).

\begin{tabular}{|c|c|c|c|c|c|c|c|}
\hline & 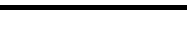 & Rinter $=0,5$ & \multicolumn{4}{|c|}{ Rinter $=0.2$} & Rinter $=0,5$ \\
\hline & & \multicolumn{3}{|c|}{$\gamma \mathrm{n}=13.5 \mathrm{kN} / \mathrm{m}^{3}$} & \multicolumn{3}{|c|}{$\gamma \mathrm{n}=15 \mathrm{kN} / \mathrm{m}^{3}$} \\
\hline & & Ko & Ko & Ko & Ko & Ko & Ko \\
\hline $\mathrm{C}\left[\mathrm{KN} / \mathrm{m}^{2}\right]$ & & 0.4 & 0.4 & 0.531 & 0.4 & 0.531 & 0.4 \\
\hline 30 & $\begin{array}{l}\text { erro médio[\%] } \\
\text { desvio[\%] }\end{array}$ & & $\begin{array}{l}39.4 \\
28.5\end{array}$ & $\begin{array}{l}39.4 \\
27.0\end{array}$ & $\begin{array}{l}37.7 \\
26.7\end{array}$ & $\begin{array}{l}38.0 \\
25.5\end{array}$ & \\
\hline 70 & $\begin{array}{l}\text { erro médio[\%] } \\
\text { desvio[\%] }\end{array}$ & $\begin{array}{l}40.3 \\
31.6\end{array}$ & $\begin{array}{l}37.8 \\
27.7\end{array}$ & $\begin{array}{l}36.6 \\
24.5\end{array}$ & $\begin{array}{l}36.8 \\
26.4\end{array}$ & $\begin{array}{l}35.4 \\
23.9\end{array}$ & $\begin{array}{l}52.7 \\
42.8\end{array}$ \\
\hline SPT & $\begin{array}{l}\text { erro médio[\%] } \\
\text { desvio[\%] }\end{array}$ & $\begin{array}{l}52.9 \\
26.0\end{array}$ & $\begin{array}{l}37.8 \\
27.3\end{array}$ & $\begin{array}{l}36.3 \\
24.0\end{array}$ & $\begin{array}{l}37.9 \\
27.0\end{array}$ & $\begin{array}{l}37.9 \\
25.7\end{array}$ & $\begin{array}{l}43.6 \\
36.1\end{array}$ \\
\hline \multicolumn{8}{|c|}{ Estágio 5- Médias dos Módulos dos Erros Globais de Deslocamentos Horizontais $\left(\mathrm{u}_{\mathrm{h}}\right)$} \\
\hline & & Rinter $=0,5$ & \multicolumn{4}{|c|}{ Rinter $=0.2$} & Rinter $=0,5$ \\
\hline & & \multicolumn{3}{|c|}{$\gamma \mathrm{n}=13.5 \mathrm{kN} / \mathrm{m}^{3}$} & \multicolumn{3}{|c|}{$\gamma \mathrm{n}=15 \mathrm{kN} / \mathrm{m}^{3}$} \\
\hline & & & Ko & Ko & Ko & Ko & Ko \\
\hline $\mathrm{C}\left[\mathrm{KN} / \mathrm{m}^{2}\right]$ & & & 0.4 & 0.531 & 0.4 & 0.531 & 0.4 \\
\hline 30 & $\begin{array}{l}\text { erro médio[\%] } \\
\text { desvio[\%] }\end{array}$ & & $\begin{array}{l}55.6 \\
43.9\end{array}$ & $\begin{array}{l}50.1 \\
30.1\end{array}$ & $\begin{array}{l}54.8 \\
42.2\end{array}$ & $\begin{array}{l}55.5 \\
45.8\end{array}$ & \\
\hline 70 & $\begin{array}{l}\text { erro médio[\%] } \\
\text { desvio[\%] }\end{array}$ & $\begin{array}{l}54.6 \\
43.1 \\
\end{array}$ & $\begin{array}{l}54.4 \\
41.3 \\
\end{array}$ & $\begin{array}{l}56.0 \\
45.8\end{array}$ & $\begin{array}{l}53.0 \\
39.8 \\
\end{array}$ & $\begin{array}{l}53.6 \\
44.1\end{array}$ & $\begin{array}{l}53.8 \\
43.9 \\
\end{array}$ \\
\hline SPT & \begin{tabular}{|l} 
erro médio[\%] \\
desvio[\%]
\end{tabular} & $\begin{array}{l}55.8 \\
44.1\end{array}$ & $\begin{array}{l}55.0 \\
43.1\end{array}$ & $\begin{array}{l}54.8 \\
44.9\end{array}$ & $\begin{array}{l}54.1 \\
41.4\end{array}$ & $\begin{array}{l}53.5 \\
42.8\end{array}$ & $\begin{array}{l}54.5 \\
41.3\end{array}$ \\
\hline \multicolumn{8}{|c|}{ Estágio 8- Médias dos Módulos dos Erros Globais de Deslocamentos Horizontais $\left(u_{h}\right)$} \\
\hline & & Rinter $=0,5$ & \multicolumn{4}{|c|}{ Rinter $=0.2$} & Rinter $=0,5$ \\
\hline & & \multicolumn{3}{|c|}{$\gamma \mathrm{n}=13.5 \mathrm{kN} / \mathrm{m}^{3}$} & \multicolumn{3}{|c|}{$\gamma \mathrm{n}=15 \mathrm{kN} / \mathrm{m}^{3}$} \\
\hline & & Ko & Ko & Ko & Ko & Ko & Ko \\
\hline $\mathrm{C}\left[\mathrm{KN} / \mathrm{m}^{2}\right]$ & & 0.4 & 0.4 & 0.531 & 0.4 & 0.531 & 0.4 \\
\hline 30 & $\begin{array}{l}\text { erro médio[\%] } \\
\text { desvio[\%] }\end{array}$ & & $\begin{array}{l}74.4 \\
60.2\end{array}$ & $\begin{array}{l}77.0 \\
68.8\end{array}$ & $\begin{array}{l}62.7 \\
45.9\end{array}$ & $\begin{array}{l}61.5 \\
47.5\end{array}$ & \\
\hline 70 & $\begin{array}{l}\text { erro médio[\%] } \\
\text { desvio[\%] }\end{array}$ & $\begin{array}{l}63.1 \\
53.5\end{array}$ & $\begin{array}{l}69.6 \\
54.8\end{array}$ & $\begin{array}{l}31.3 \\
16.9\end{array}$ & $\begin{array}{l}70.8 \\
58.3\end{array}$ & $\begin{array}{l}61.0 \\
47.1\end{array}$ & $\begin{array}{l}60.9 \\
50.9\end{array}$ \\
\hline SPT & $\begin{array}{l}\text { erro médio[\%] } \\
\text { desvio[\%] }\end{array}$ & $\begin{array}{l}53.4 \\
40.1\end{array}$ & $\begin{array}{l}71.4 \\
60.0\end{array}$ & $\begin{array}{l}69.2 \\
57.3\end{array}$ & $\begin{array}{l}73.7 \\
65.3\end{array}$ & $\begin{array}{l}61.9 \\
48.1\end{array}$ & $\begin{array}{l}57.1 \\
44.6\end{array}$ \\
\hline
\end{tabular}


Tabela 4-15- Resumo das médias dos módulos dos erros de forças globais (estágios $3,5,6,7,8)$, obtidos por retroanálise de $E_{50}$

\begin{tabular}{|c|c|c|c|c|c|c|c|}
\hline & & Rinter $=0,5$ & \multicolumn{4}{|c|}{ Rinter $=0.2$} & Rinter $=0,5$ \\
\hline & & \multicolumn{3}{|c|}{$\gamma \mathrm{n}=13.5 \mathrm{kN} / \mathrm{m}^{3}$} & \multicolumn{3}{|c|}{$\gamma \mathrm{n}=15 \mathrm{kN} / \mathrm{m}^{3}$} \\
\hline & & Ko & Ko & Ko & Ko & Ko & $\mathrm{Ko}$ \\
\hline $\mathrm{C}\left[\mathrm{KN} / \mathrm{m}^{2}\right]$ & & 0.4 & 0.4 & 0.531 & 0.4 & 0.531 & 0.4 \\
\hline 30 & $\begin{array}{l}\text { erro médio[\%] } \\
\text { desvio[\%] }\end{array}$ & & $\begin{array}{c}107.8 \\
47.4\end{array}$ & $\begin{array}{c}116.3 \\
47.8\end{array}$ & $\begin{array}{c}120.9 \\
47.8\end{array}$ & $\begin{array}{l}116.3 \\
47.8\end{array}$ & \\
\hline 70 & $\begin{array}{l}\text { erro médio[\%] } \\
\text { desvio[\%] }\end{array}$ & $\begin{array}{l}41.0 \\
47.2\end{array}$ & $\begin{array}{l}95.6 \\
47.2\end{array}$ & $\begin{array}{c}135.5 \\
47.9\end{array}$ & $\begin{array}{c}113.4 \\
47.7\end{array}$ & $\begin{array}{c}135.0 \\
48.5\end{array}$ & $\begin{array}{l}41.3 \\
47.9\end{array}$ \\
\hline SPT & $\begin{array}{l}\text { erro médio[\%] } \\
\text { desvio[\%] }\end{array}$ & $\begin{array}{l}91.4 \\
47.9 \\
\end{array}$ & $\begin{array}{c}132.6 \\
48.5 \\
\end{array}$ & $\begin{array}{c}110.2 \\
47.6 \\
\end{array}$ & $\begin{array}{c}122.8 \\
48.0 \\
\end{array}$ & $\begin{array}{c}134.6 \\
48.7 \\
\end{array}$ & $\begin{array}{c}145.3 \\
48.5 \\
\end{array}$ \\
\hline \multicolumn{8}{|c|}{ Estágio 5- Médias dos Módulos dos erros das Forças Nível A Globais } \\
\hline & & Rinter $=0,5$ & \multicolumn{3}{|c|}{ Rinter $=0.2$} & & Rinter $=0,5$ \\
\hline & & \multicolumn{3}{|c|}{$\gamma \mathrm{n}=13.5 \mathrm{kN} / \mathrm{m}^{3}$} & \multicolumn{3}{|c|}{$\gamma \mathrm{n}=15 \mathrm{kN} / \mathrm{m}^{3}$} \\
\hline & & Ko & Ko & Ko & Ko & Ko & Ko \\
\hline $\mathrm{C}\left[\mathrm{KN} / \mathrm{m}^{2}\right]$ & & 0.4 & 0.4 & 0.531 & 0.4 & 0.531 & 0.4 \\
\hline 30 & $\begin{array}{l}\text { erro médio[\%] } \\
\text { desvio[\%] }\end{array}$ & & 24.4 & 30.8 & 32.2 & 32.6 & \\
\hline 70 & $\begin{array}{l}\text { erro médio[\%] } \\
\text { desvio[\%] }\end{array}$ & 21.2 & 22.3 & 21.0 & 26.8 & 42.2 & 21.6 \\
\hline SPT & $\begin{array}{l}\text { erro médio[\%] } \\
\text { desvio[\%] }\end{array}$ & 17.5 & 22.0 & 36.0 & 32.9 & 41.7 & 22.2 \\
\hline \multicolumn{8}{|c|}{ Estágio 8- Médias dos Módulos dos erros das Forças Nível A Globais } \\
\hline & & Rinter $=0,5$ & \multicolumn{3}{|c|}{ Rinter $=0.2$} & & Rinter $=0,5$ \\
\hline & & \multicolumn{3}{|c|}{$\gamma \mathrm{n}=13.5 \mathrm{kN} / \mathrm{m}^{3}$} & \multicolumn{3}{|c|}{$\gamma \mathrm{n}=15 \mathrm{kN} / \mathrm{m}^{3}$} \\
\hline & & Ko & Ko & Ko & Ko & Ko & Ko \\
\hline $\mathrm{C}\left[\mathrm{KN} / \mathrm{m}^{2}\right]$ & & 0.4 & 0.4 & 0.531 & 0.4 & 0.531 & 0.4 \\
\hline 30 & $\begin{array}{l}\text { erro médio[\%] } \\
\text { desvio[\%] }\end{array}$ & & 16.0 & 19.2 & 25.4 & 25.1 & \\
\hline 70 & $\begin{array}{l}\text { erro médio[\%] } \\
\text { desvio[\%] }\end{array}$ & 16.0 & 17.9 & 23.1 & 21.4 & 32.2 & 19.5 \\
\hline SPT & $\begin{array}{l}\text { erro médio[\%] } \\
\text { desvio[\%] }\end{array}$ & 15.3 & 15.6 & 26.3 & 19.4 & 32.6 & 18.2 \\
\hline
\end{tabular}

A partir destes valores de erros obtidos adotou-se que o estágio 5 seria o foco de atenção desta etapa, uma vez que foi obtido um ajuste muito bom da deformada de paramento simulada em relação à instrumentada, Figura 4-26.

Com relação ao estágio 3 o elevado valor de $E_{50}$ obtido para a $2^{\text {a }}$. camada de argila porosa vermelha (Tabela 4-16), causou incerteza pois este valor superou em 20 vezes o $E_{50}$ obtido para a camada de argila rija (5 . camada). Em MASSAD (1992) mencionou-se que “... as relações $\left(\mathrm{E}_{50} / \mathrm{Su}\right)$ foram muito elevadas e próximas entre si, para cada horizonte, entre 500 e 600 para Argilas Porosas e entre 400 e 500 para Argilas Rijas, fato que foi atribuído à cimentação entre partículas destes solos lateríticos".

Apesar da citação acima, ainda considerou-se elevado o valor obtido para $E_{50}$ para a $2^{\mathrm{a}}$. Camada no estágio 3 , e duas hipóteses foram ponderadas: 
- há a possibilidade de algum fato ter passado despercebido pela instrumentação (apesar de pouco provável)

- os resultados obtidos em laboratório não avaliam o comportamento do sistema solo-estrutura, mas apenas o material solo. Sendo assim, não é possível comparar dois sistemas que não tem equivalência entre si. Ficando portanto esta conclusão indeterminada até que futuras pesquisas que considerem o sistema solo-estrutura, possam avaliar se o valor de $E_{50}$ obtido para a $2^{\mathrm{a}}$. camada é realmente elevado ou não.

O bom ajuste para o estágio 5 foi obtido ao se adotarem os valores de parâmetros $K o=0,531$, $\gamma$ nat $=13,5 \mathrm{kN} / \mathrm{m} 3$, coesão $=70 \mathrm{kPa}$, Rinter $=0,2$ e $m=0,1$, oriundos do menor erro obtido em relação aos deslocamentos horizontais de paramento $(5,7 \%)$ e às forças nas estroncas (22,2\%). Porém, a adoção destes parâmetros não conduziu a bons ajustes de deslocamentos de paramentos para os estágios posteriores e anteriores.

Os ajustes de deslocamentos de paramentos dos estágios 2, 3, 6, 7 e 8, obtidos pela adoção dos valores de parâmetros para o estágio 5 acima citados, estão representados no intervalo entre a Figura 4-34 e a Figura 4-38.

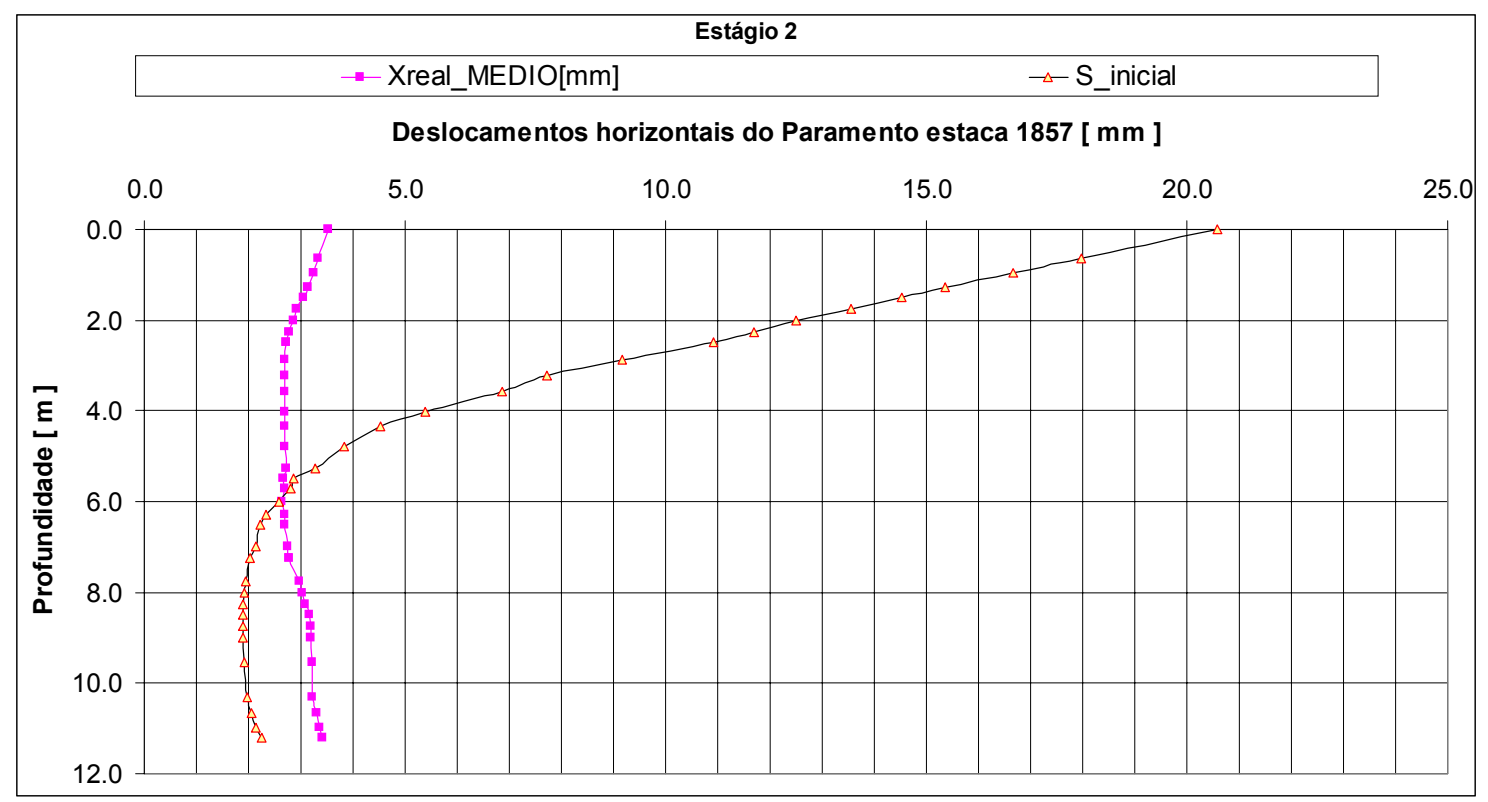

Figura 4-34-Deslocamentos horizontais simulados no estágio 2 devido a adoção dos valores de $E_{50}$ obtidos da retroanálise do estágio 5 


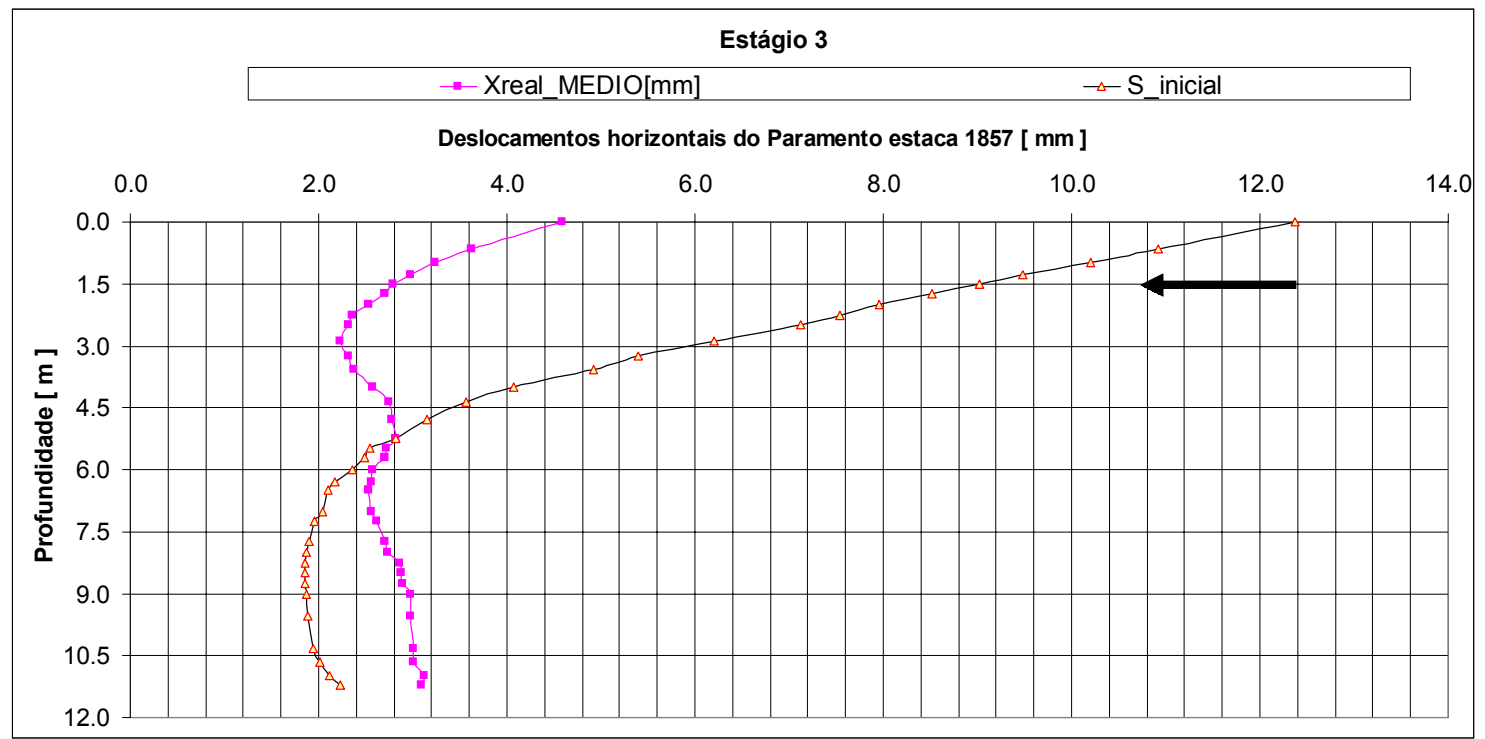

Figura 4-35- Deslocamentos horizontais simulados no estágio 3 devido a adoção dos valores de $E_{50}$ obtidos da retroanálise do estágio 5

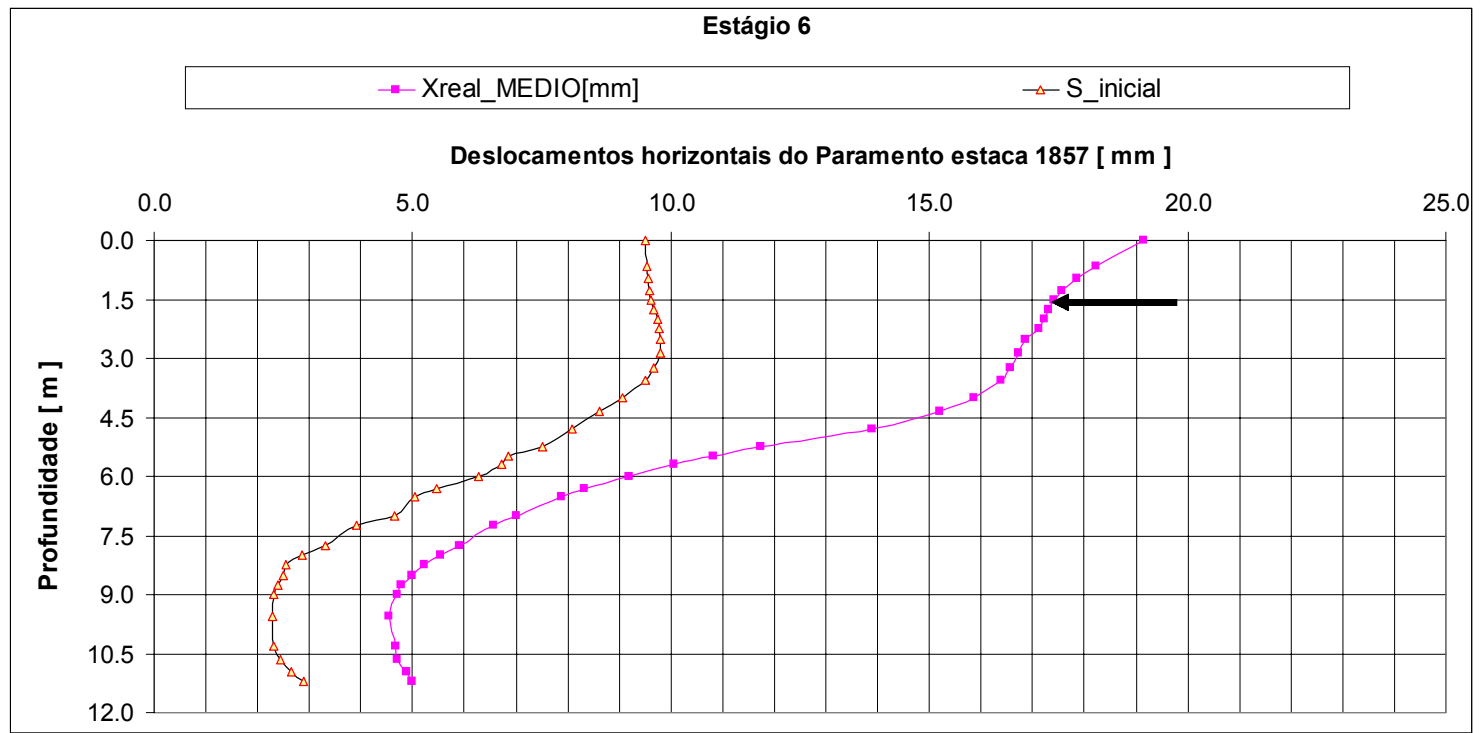

Figura 4-36- Deslocamentos horizontais simulados no estágio 6 devido a adoção dos valores de $E_{50}$ obtidos da retroanálise do estágio 5 


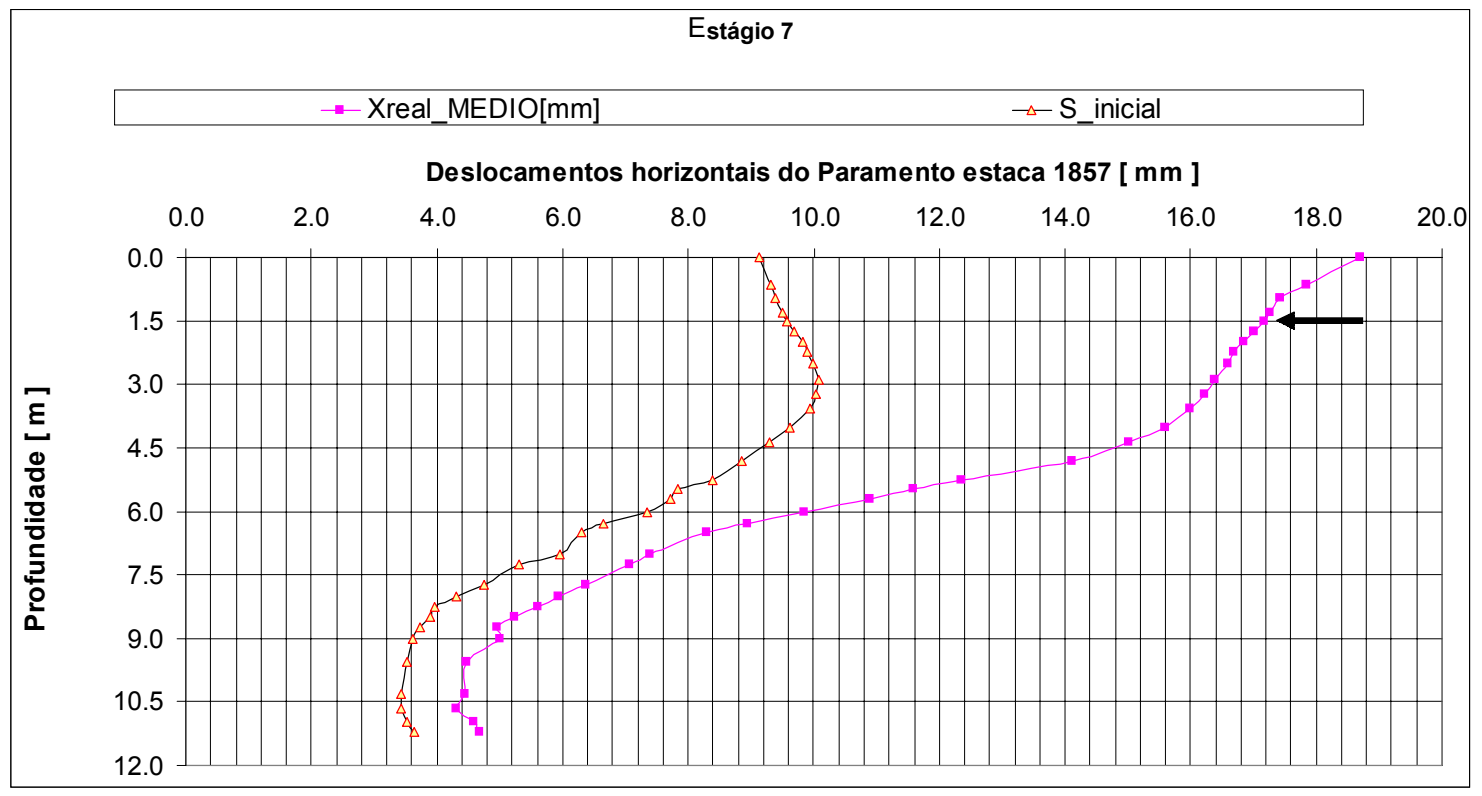

Figura 4-37- Deslocamentos horizontais simulados no estágio 7 devido a adoção dos valores de $E_{50}$ obtidos da retroanálise do estágio 5

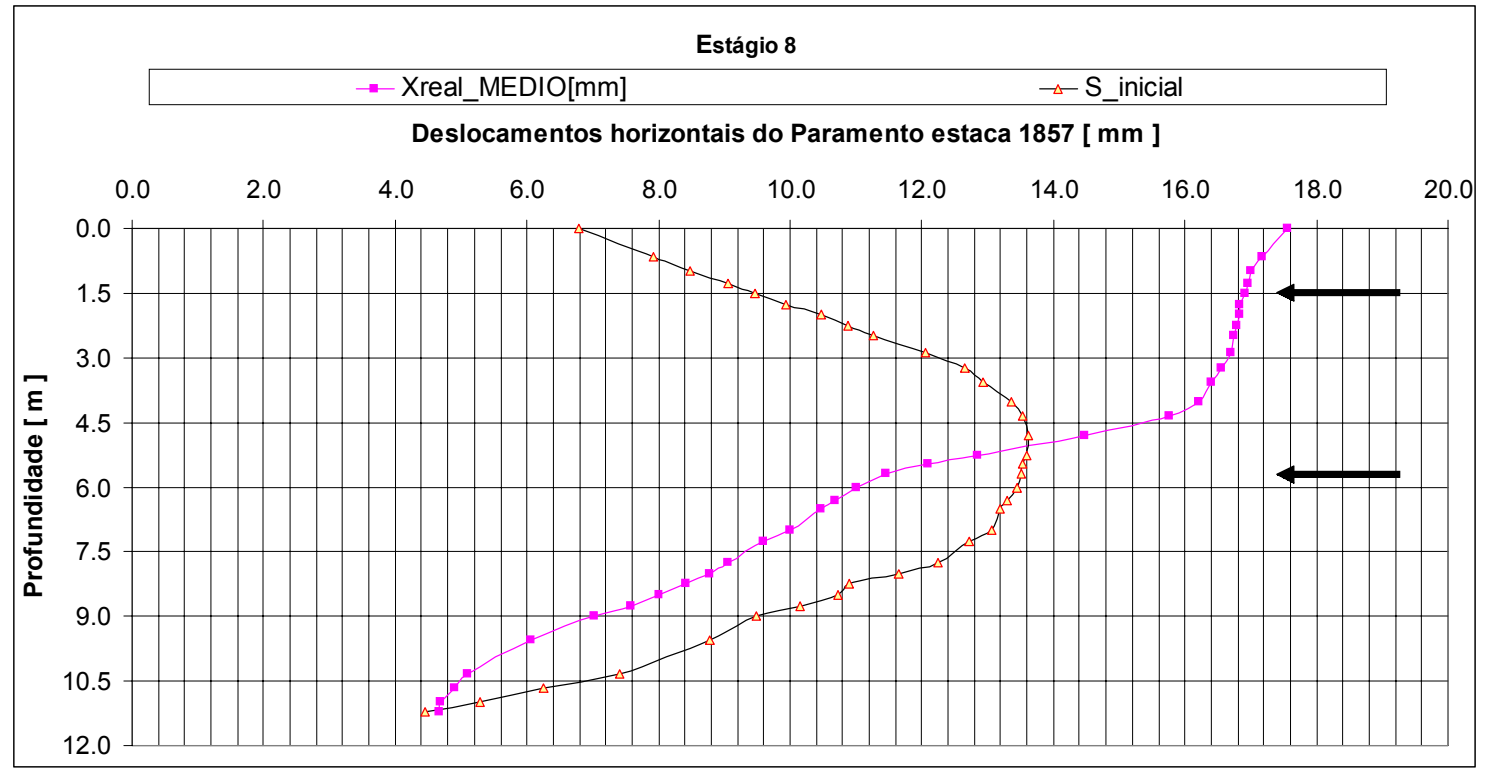

Figura 4-38- Deslocamentos horizontais simulados no estágio 8 devido a adoção dos valores de $E_{50}$ obtidos da retroanálise do estágio 5

Ao analisar-se o comportamento das curvas nos estágios 2 e 3, (Figura 4-34 e Figura 4-35), percebe-se que o valor teórico de $E_{50}$ adotado do estágio 5 foi menos rígido que o real na profundidade de 0 a $6 \mathrm{~m}$, para os estágios 2 e 3 , e ligeiramente mais rígido que o real abaixo dos $6 \mathrm{~m}$ de profundidade. Isto significa que os valores reais de $E_{50}$ de 0 a $6 \mathrm{~m}$ para os estágios 2 e 3 , são maiores que os obtidos para o estágio 5 . Em 
outras palavras, há um decréscimo da rigidez do solo $\left(\mathrm{E}_{50}\right)$ entre o estágio 3 e o estágio 5 que conceitualmente deveria ter sido representado pelo modelo de Endurecimento. É importante neste ponto ressaltar que a retroanálise de $E_{50}$ feita no estágio 3 conduziu a valores maiores que os obtidos para o estágio 5 .

A Tabela 4-16 apresenta os diferentes valores de $E_{50}$ obtidos por retroanálise para cada deformada de paramento dos estágios 3 e 5 respectivamente.

Tabela 4-16-Valores de $E_{50}$ retroanalisados a partir da mesma combinação de parâmetros em estágios diferentes

\begin{tabular}{|c|c|c|}
\hline Camada & Estágio 3 [kPa] & Estágio 5 [kPa] \\
\hline 1 & 37331 & 2803 \\
\hline 2 & 361635 & 7239 \\
\hline 3 & 51349 & 49694 \\
\hline 4 & 17800 & 29885 \\
\hline
\end{tabular}

A partir da análise da Tabela 4-16 percebe-se que houve uma variação significativa de $E_{50}$ nas camadas 1 e 2 e menos significativa nas camadas 3 e 4 que estão a maiores profundidades, tendo sofrido portanto menores deslocamentos que o topo do paramento.

Fica claro então que o processo de retroanálise utilizado para os estágios 3 e 5 está coerente, pairando a dúvida já exposta anteriormente sobre o valor considerado elevado de $E_{50}$ para a camada 2 no estágio 3.

Ao analisarmos o comportamento das curvas simuladas referentes aos estágios 6 e 7, que estão representadas da Figura 4-36 à Figura 4-37, percebe-se que as formas das curvas teóricas são coerentes as da instrumentação e acredita-se que o software não conseguiu reduzir os valores de $E_{u r}$ à medida que o processo de escavação avançou.

Um fato interessante ocorre quando analisamos o ocorrido com a curvas do estágio 8, Figura 4-38. Neste estágio, contrariamente ao que vinha ocorrendo nos estágios 6 e 7, o $E_{u r}$ simulado é menor que o real para as camadas mais profundas que $5 \mathrm{~m}$. Deve ser notado que isto só pode ocorrer do estágio 7 para o estágio 8 se houver um forte enfraquecimento das camadas inferiores do solo simulado, o que não vinha acontecendo nos estágios 6 e 7, sendo portanto uma incoerência, pois acima dos cinco metros a rigidez simulada continuou maior que a do solo real., de forma coerente com o que vinha ocorrendo com os estágios anteriores (6 e 7). A partir do exposto uma 
hipótese é levantada, que é a do aumento real da rigidez relativa do solo-escoramento devido à instalação de nova estronca, rigidez não compensada pela equivalente instalação da estronca teórica no programa em M.E.F.

Há também outras hipóteses que poderiam justificar esta deficiência do modelo simulado em corrigir os valores de $E_{50}$, que ocorrem na realidade :

- os valores do parâmetro $m$, que relaciona tensão com $E_{u r}$ de forma exponencial, são maiores no modelo simulado do que seriam na realidade, ou seja, o solo seria mais para intermediário entre solos com endurecimento e solos fofos, do que para solos tendendo ao extremo do endurecimento

- os valores do módulo de carregamento/descarregamento (Eur) seriam menores que os valores mínimos impostos pelo software, ou seja, Eur $<$ $\left(2 * E_{50}\right)$. Por limitação do software isto não pôde ser investigado.

Para dirimir a dúvida quanto ao valor de $m$, resolveu-se realizar algumas simulações variando-se este parâmetro, uma vez que o valor $(m=0,1)$ até então utilizado, foi obtido a partir da calibração feita sobre as curvas dos ensaios de laboratório de PARREIRA (1991).

A partir do melhor ajuste obtido por retroanálise (estágio 5), foram feitas simulações com valores de $m=0,5$ e $m=0,7$, ou seja desta forma o solo estaria se afastando do comportamento de endurecimento e se aproximando do comportamento de solos fofos e moles. Os resultados destas variações podem ser vistos da Figura 4-39 à Figura 4-44. 


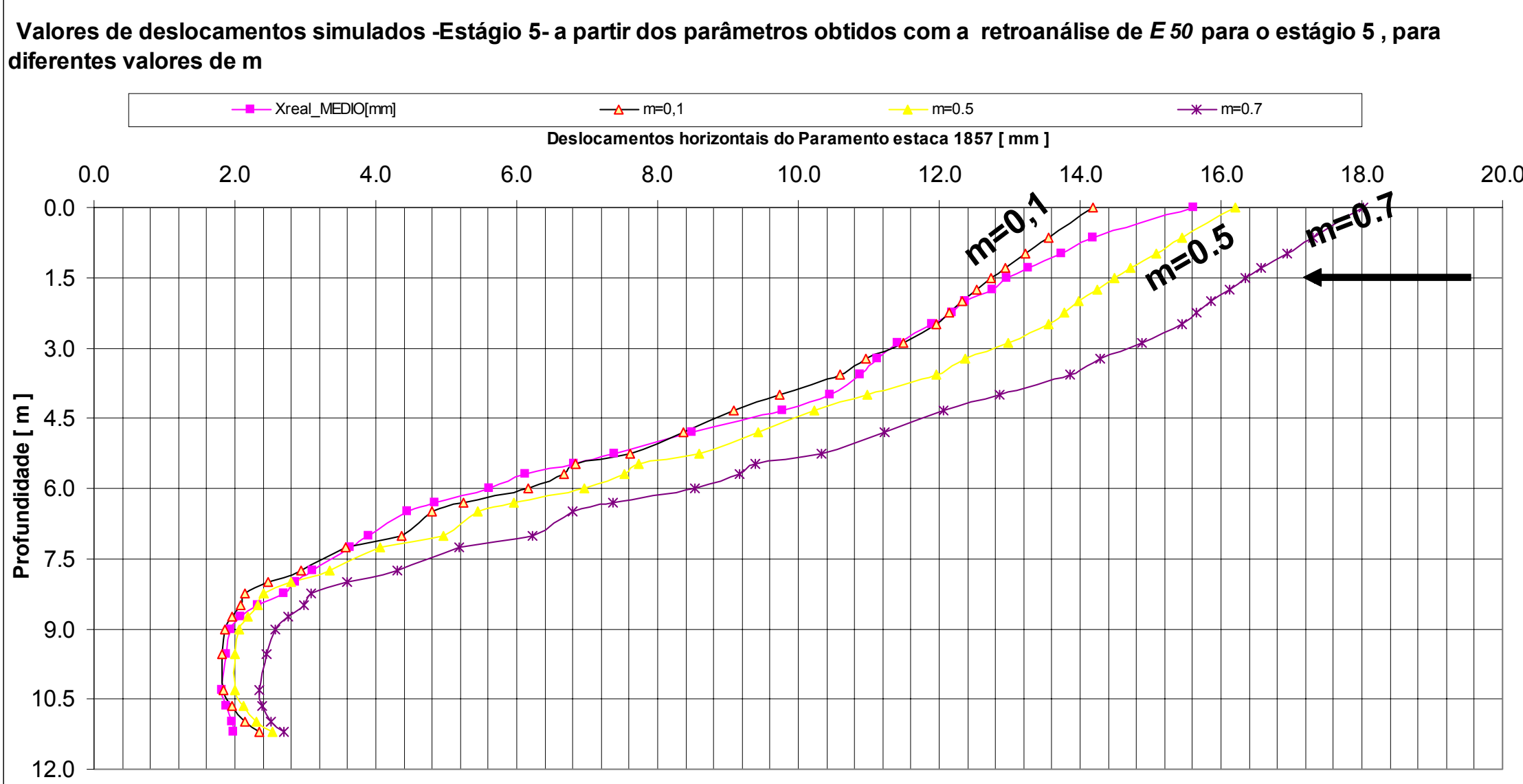

Figura 4-39-Ajuste de deslocamentos de paramento simulados x instrumentados obtidos por retroanálise de $E_{50}$ para o estágio 5 


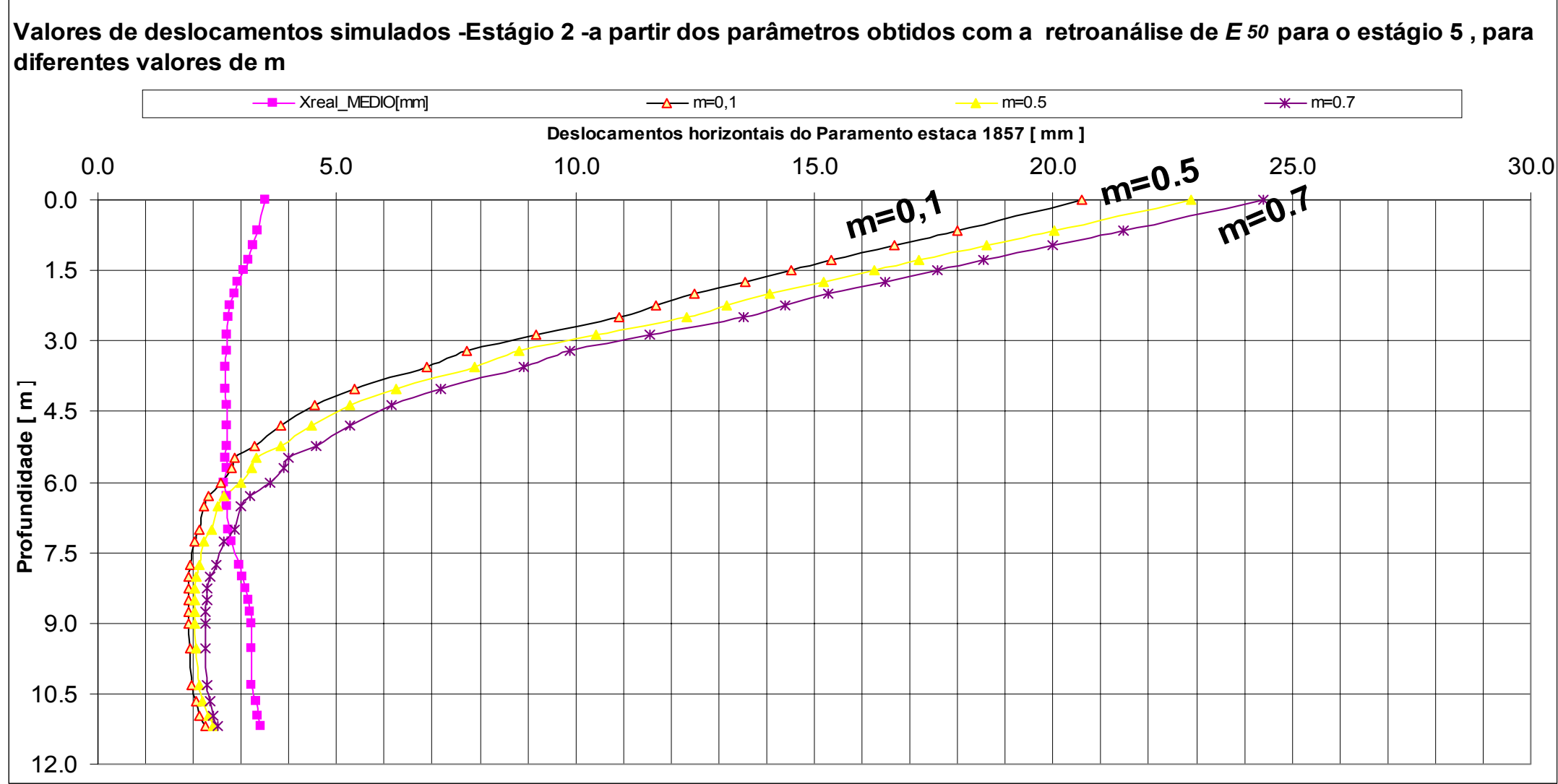

Figura 4-40--Ajuste de deslocamentos de paramento simulados (para o estágio 2) $x$ instrumentados obtidos por retroanálise de $E_{50}$ para o estágio 5 


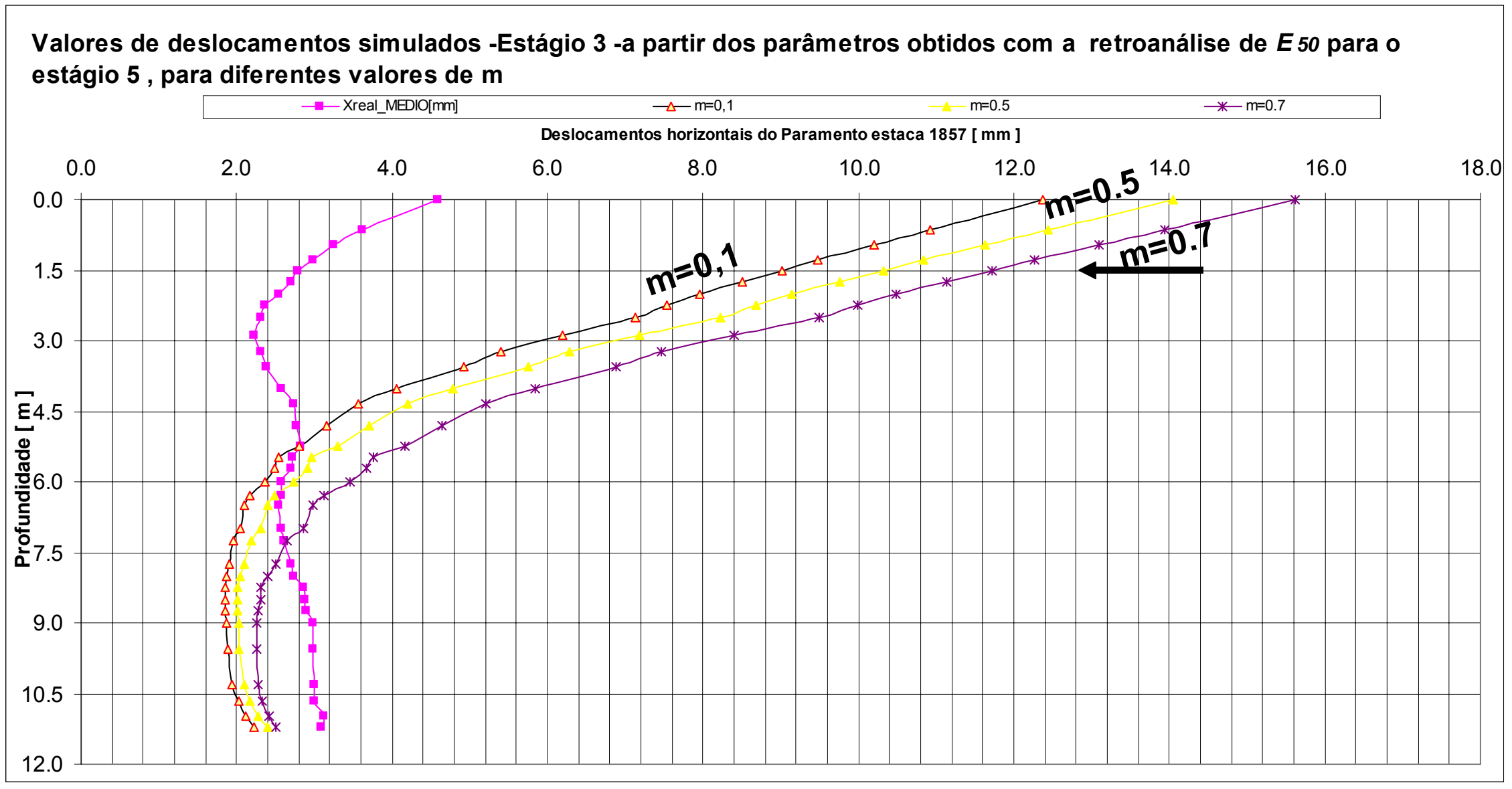

Figura 4-41-Ajuste de deslocamentos de paramento simulados (para o estágio 3) x instrumentados obtidos por retroanálise de $E_{50}$ para 0 estágio 5 


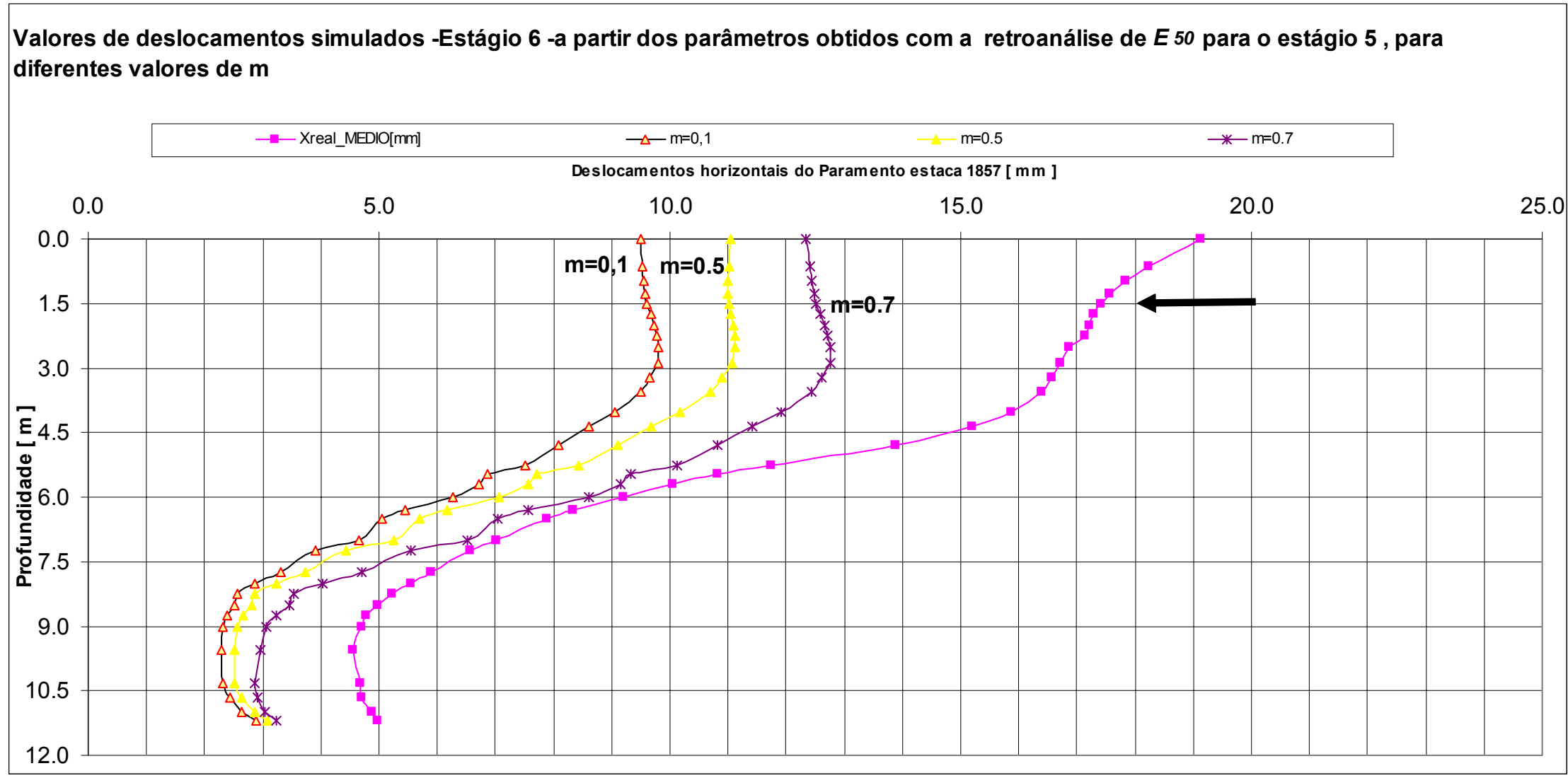

Figura 4-42 Ajuste de deslocamentos de paramento simulados (para o estágio 6) $\mathrm{x}$ instrumentados obtidos por retroanálise de $E_{50}$ para o estágio 5 


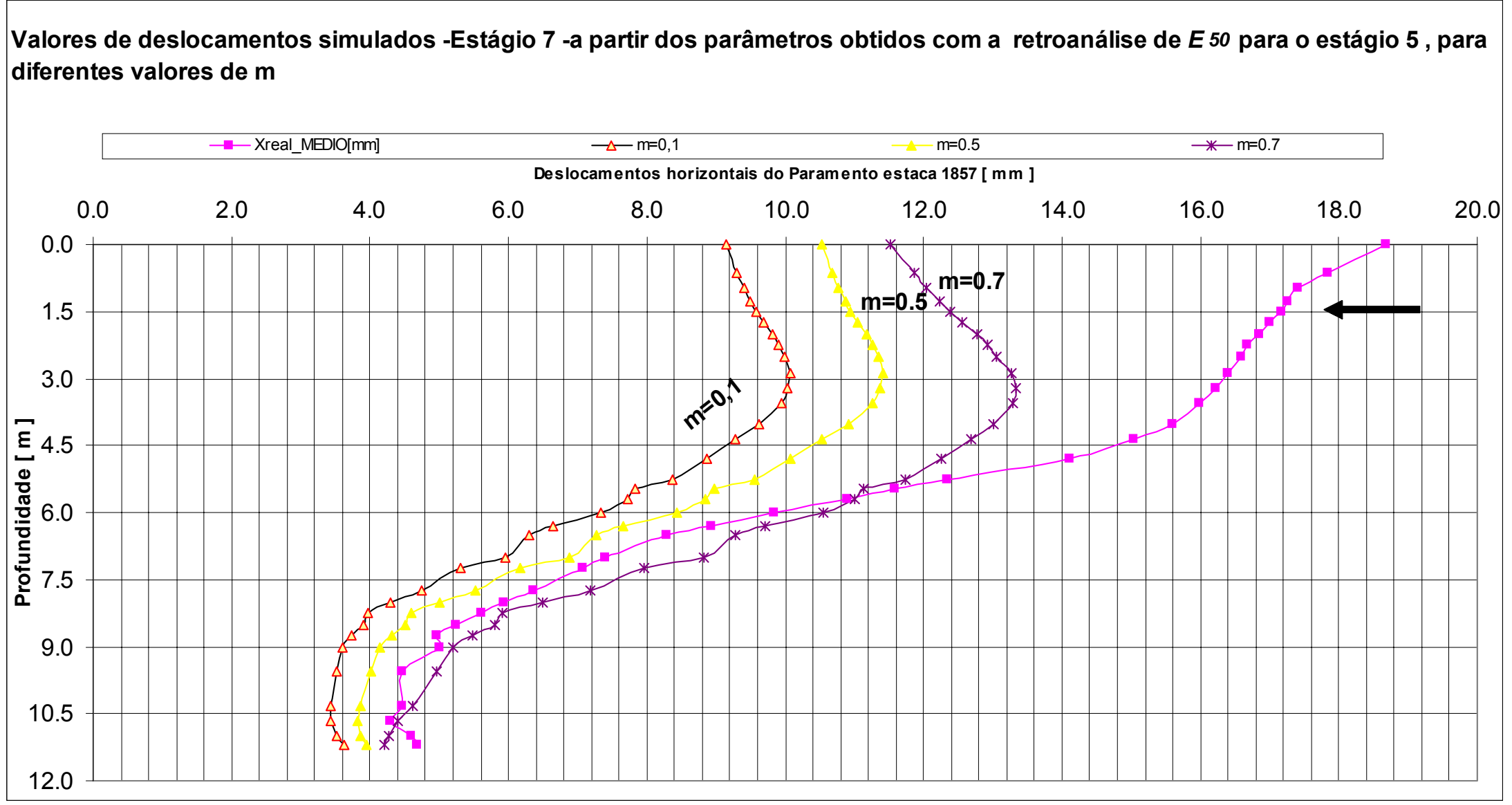

Figura 4-43 Ajuste de deslocamentos de paramento simulados (para o estágio 7) x instrumentados obtidos por retroanálise de $E_{50}$ para o estágio 5 


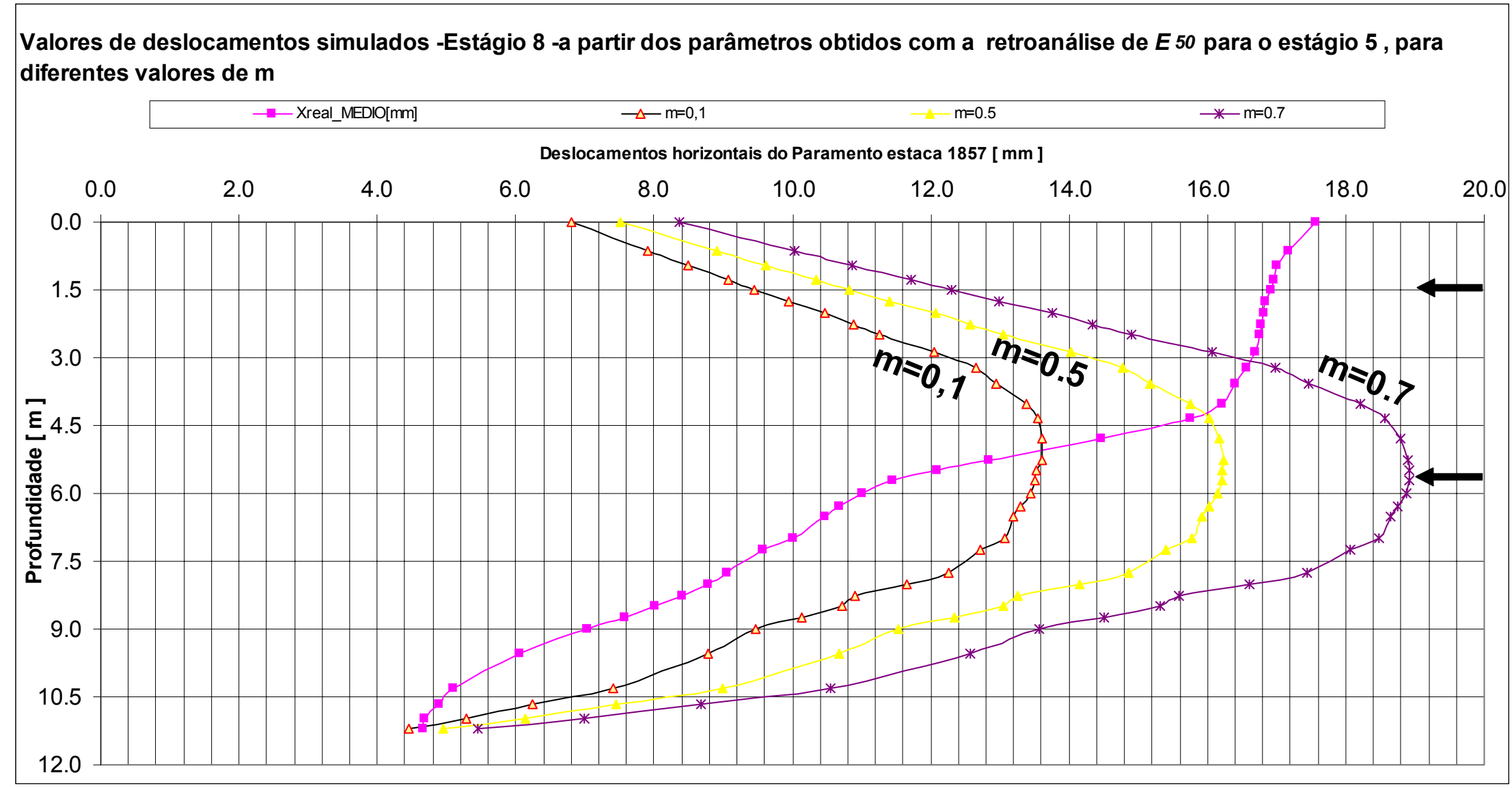

Figura 4-44 Ajuste de deslocamentos de paramento simulados (para o estágio 8) $\mathrm{x}$ instrumentados obtidos por retroanálise de $E_{50}$ para o estágio 5 
Ao analisarem-se as curvas da Figura 4-39 à Figura 4-44 depreende-se que:

- no melhor ajuste obtido para a curva do estágio 5, Figura 4-39, o parâmetro $m=0,1$ demonstrou-se mais adequado.

- o comportamento das curvas obtidas para os estágios 2 e 3 - (Figura 4-40 e Figura 4-41) - de 0 a $5 \mathrm{~m}$ indica que o parâmetro $m$ deveria ser menor que 0,1 , porém abaixo dos $5 \mathrm{~m}$ de profundidade ele deveria ser maior que 0,7, se afastando do comportamento de endurecimento. Este fato é estranho uma vez que os deslocamentos ocorridos no pé do paramento são pequenos quando comparados ao topo e centro de paramento, portanto não deveria ter ocorrido uma redução da rigidez a ponto de o solo afastar-se do comportamento de endurecimento.

A análise das curvas da Figura 4-42 à Figura 4-43, relativas aos estágios 6 e 7 respectivamente, mostra que o valor de $m$ adequado ao ajuste das curvas deveria ser maior que $m=0,1$ e menor que 0,7 , ou seja o solo definitivamente se afastaria do comportamento de endurecimento, aproximando-se do comportamento de solos moles.

Por fim, ao se analisar os ajustes obtidos para o estágio 8 em função das variações de $m$ obtidas, nota-se que o solo de 0 a $5 \mathrm{~m}$ de profundidade tem comportamento de solo mole, indicando um valor de $m$ maior ainda que o de $m=0,7$. Por outro lado, abaixo dos $5 \mathrm{~m}$ o solo tem comportamento fortemente de endurecimento, ou seja, pede um valor de $m$ menor que o utilizado nas retroanálises $(m=0,1)$. Este fato pode ter ocorrido por ter havido aumento da rigidez relativa do sistema solo escoramento devido à instalação de nova estronca, rigidez não compensada plenamente pela equivalente instalação no programa em M.E.F.

Da análise feita para o comportamento das curvas ao variar-se o parâmetro $m$ conclui-se que:

- os valores de $m=0,1$, adotados a partir da calibração das curvas de PARREIRA (1991) são coerentes com os ajustes para a maioria dos estágios

- os valores de $E_{u \mathrm{r}}=2 * E_{50}$ (relação mínima permitida por PLAXIS (2002)) são elevados para este solo, sendo esta afirmação também apoiada em MASSAD (1992) que obteve valores de Eur de 1,2 a 2 vezes maior que $E_{50}$. Fica claro que há uma deficiência do software em corrigir o módulo $E_{u r}$, tanto para o avanço como para o retrocesso da escavação. 
Em função do exposto considera-se que o modelo de Endurecimento pode ser adequado às previsões de avanços e retrocessos de escavação desta seção experimental, porém só se podendo concluir com certeza em trabalhos futuros onde seja possível utilizarem-se valores menores que 2, para relacionar $E_{u r}$ ao $E_{50}$.

Em função dos erros obtidos considera-se que os parâmetros que representam melhor o estágio 5, onde se obteve melhor ajuste são:

$K o=0,531, \gamma_{n a t}=13,5 \mathrm{kN} / \mathrm{m}^{3}, c=70 \mathrm{kPa}$, Rinter $=0,2$ e $m=0,1$. 


\section{8 -Erros em relação aos deslocamentos de paramentos}

A partir dos resultados obtidos das simulações, que estão apresentados da Tabela 4-13 à Tabela 4-15, elaborou-se um conjunto de figuras tridimensionais que são apresentados no intervalo que compreende a Figura 4-45 à Figura 4-51.

Em todas as figuras são apresentados os erros em relação aos deslocamentos horizontais dos paramentos. Estes erros estão apresentados para dois grupos distintos de $\gamma_{\text {nat }}$, sendo de 13,5 e de $15 \mathrm{kN} / \mathrm{m}^{3}$.

Foram feitas duas considerações quanto à coesão nas retroanálises. A $1^{\mathrm{a}}$. consideração abrangeu valores de coesão constante para toda a camada, sendo assim, foram feitos um grupo de simulações para coesão constante $30 \mathrm{kPa}$ e outro grupo para coesão constante de $70 \mathrm{kPa}$. A segunda consideração foi a de considerar que a coesão variava ao longo da profundidade. Assim, a camada foi subdividida em subcamadas. E ao invés de utilizar-se um único valor de coesão por retroanálise, utilizou-se 5 valores distintos, a saber, 10, 25, 35, 55, e $70 \mathrm{kPa}$. (um para cada camada).

Não é possível representar este grupo de coesão variável por camadas nas figuras citadas. Portanto para contornar esta dificuldade, adotou-se que o valor de coesão de $80 \mathrm{kPa}$ (somente nas figuras), representaria o erro para o grupo de coesão variável. Assim, quando for lido no gráfico o erro com relação ao ponto de coesão igual a $80 \mathrm{kPa}$, deve-se interpretar que esta coesão representa o grupo de 5 valores distintos de coesão, sendo meramente um artifício para poder comparar com os outros valores de erros (onde as coesões foram constantes para todas as camadas).

Desta forma, não há sentido em representar os erros através de superfícies, como foi feito para o modelo de Mohr-Coulomb, pois daria uma idéia errônea de comportamento.

As legendas utilizadas nas figuras a seguir (Figura 4-45 à Figura 4-51) representam:

$R_{\text {inter }}$ - fator de redução da coesão efetiva e da tangente do ângulo de atrito efetivo que é aplicado pelo software PLAXIS na interface solo paramento, ou seja para interfaces rígidas (sem deslocamento relativo) $R_{\text {inter }}=1$, para as demais situações onde ocorre deslocamento relativo $R_{\text {inter }}<1,0$. Sendo esta redução feita da seguinte forma:

$$
\begin{aligned}
& c_{\text {reduzida }}=R_{\text {inter }} * c^{\prime} \\
& \text { tan }^{\prime}{ }_{\text {reduzido }}=\mathrm{R}_{\text {inter }} * \tan \phi_{\text {reduzido }}
\end{aligned}
$$


$\gamma_{\text {nat }}=$ peso específico natural do solo.

Estágio 3 - Módulos dos Erros de deslocamentos horizontais de paramento Modelo de Endurecimento de Solo

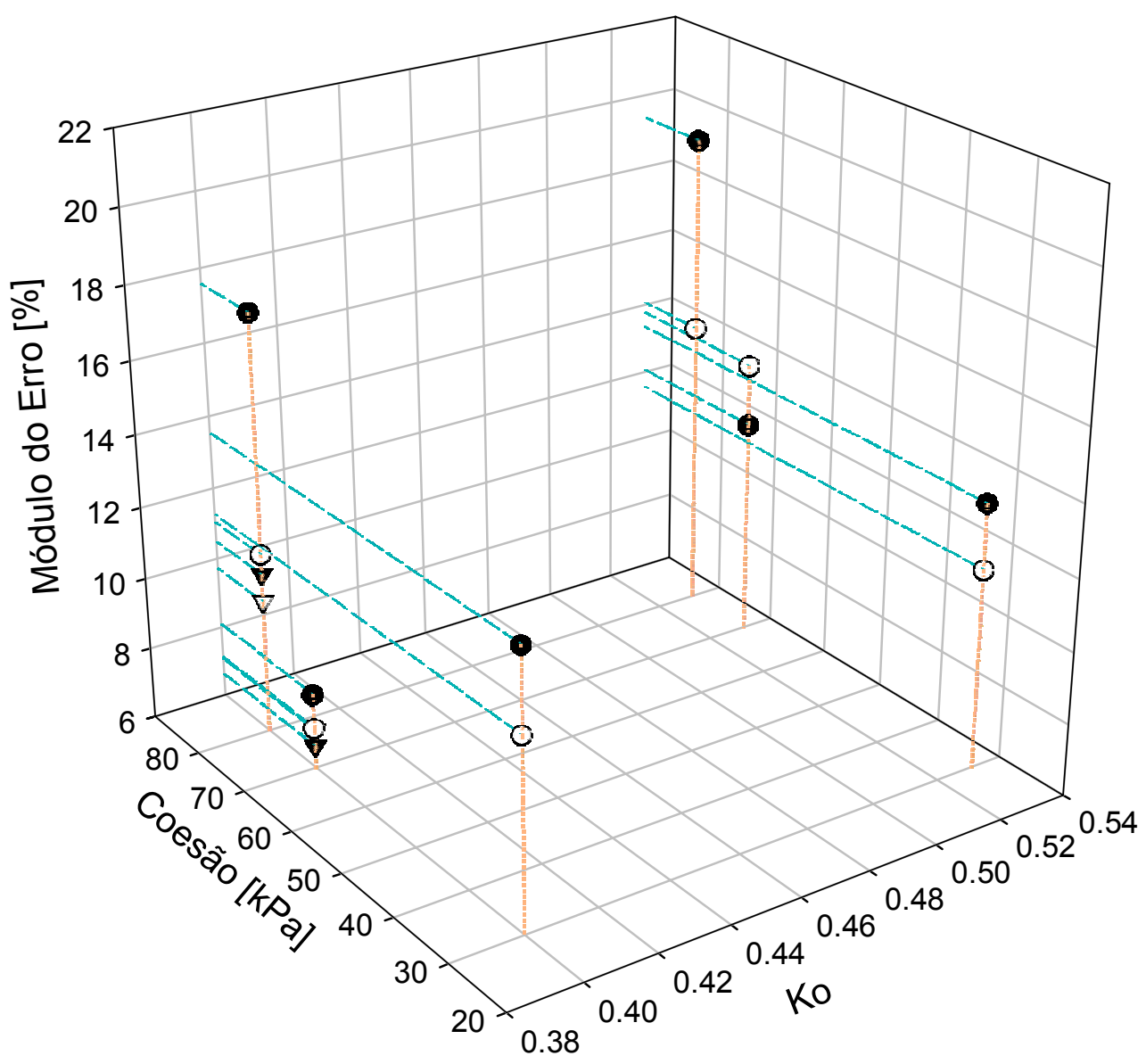

- gama_nat $=15 \mathrm{kN} / \mathrm{m} 3 ;$ Rintern $=0,2$

gama_nat $=13,5 \mathrm{kN} / \mathrm{m} 3 ;$ Rintern $=0,2$

$\nabla$ gama_nat $=15 \mathrm{kN} / \mathrm{m} 3 ;$ Rintern $=0,5$

$\nabla$ gama_nat $=13,5 \mathrm{kN} / \mathrm{m} 3 ;$ Rintern $=0,5$ gama_nat=peso específico do solo

Figura 4-45- Módulos dos erros de deslocamentos horizontais do paramento estágio 3 - Modelo de Endurecimento 
Estágio 5 - Módulos dos Erros de deslocamentos horizontais de paramento Modelo de Endurecimento de Solo

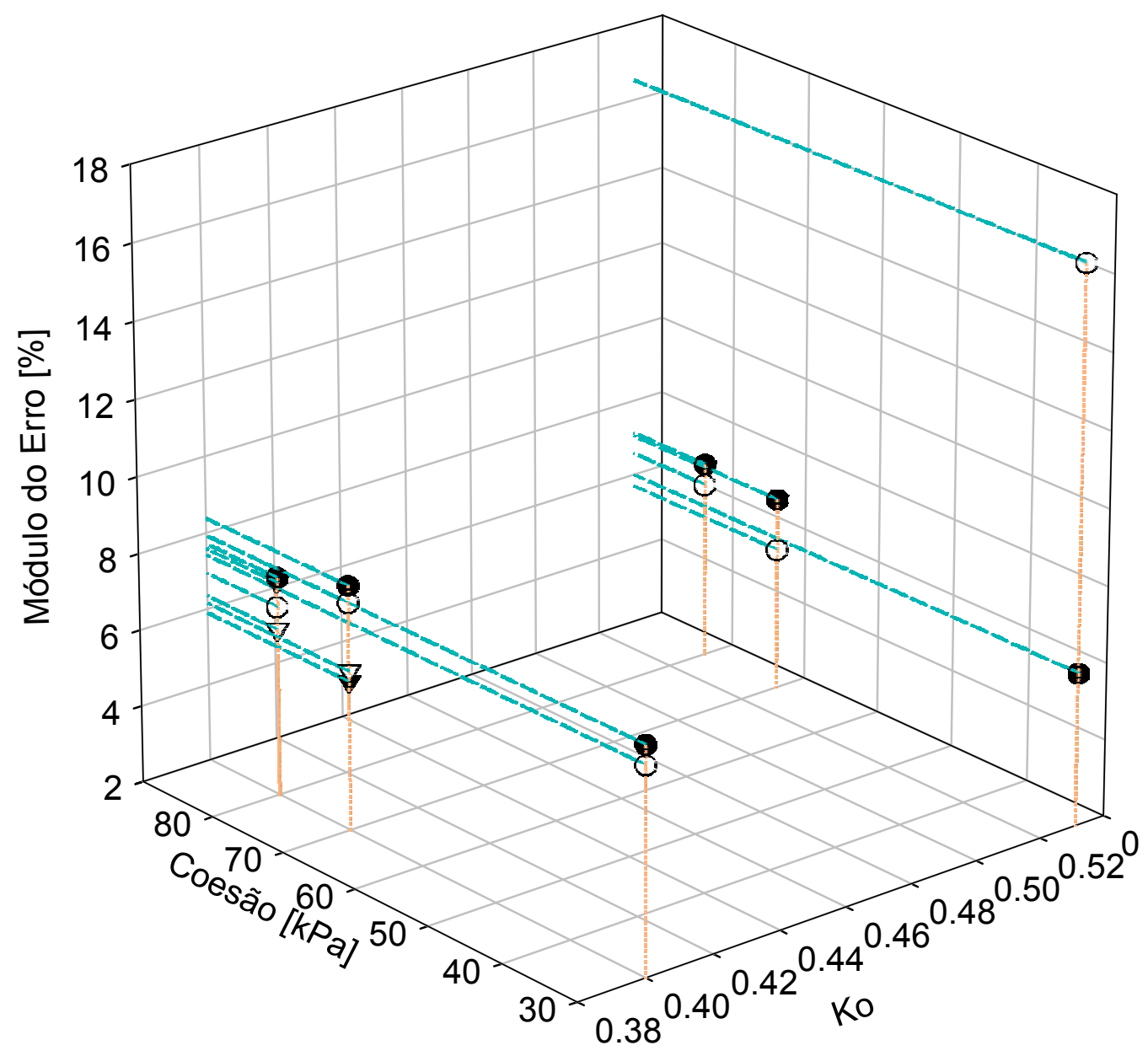

$\begin{array}{ll}\text { - } & \text { gama_nat }=15 \mathrm{kN} / \mathrm{m} 3 ; \text { Rintern }=0,2 \\ \bigcirc & \text { gama_nat }=13,5 \mathrm{kN} / \mathrm{m} 3 ; \text { Rintern }=0,2 \\ \nabla & \text { gama_nat }=15 \mathrm{kN} / \mathrm{m} 3 ; \text { Rintern }=0,5 \\ \nabla & \text { gama_nat }=13,5 \mathrm{kN} / \mathrm{m} 3 ; \text { Rintern }=0,5 \\ & \text { gama_nat }=\text { peso especifico do solo }\end{array}$

Figura 4-46- Módulos dos erros de deslocamentos horizontais do paramento estágio 5 - Modelo de Endurecimento 
Estágio 8 - Módulos dos Erros de deslocamentos horizontais de paramento Modelo de Endurecimento de Solo

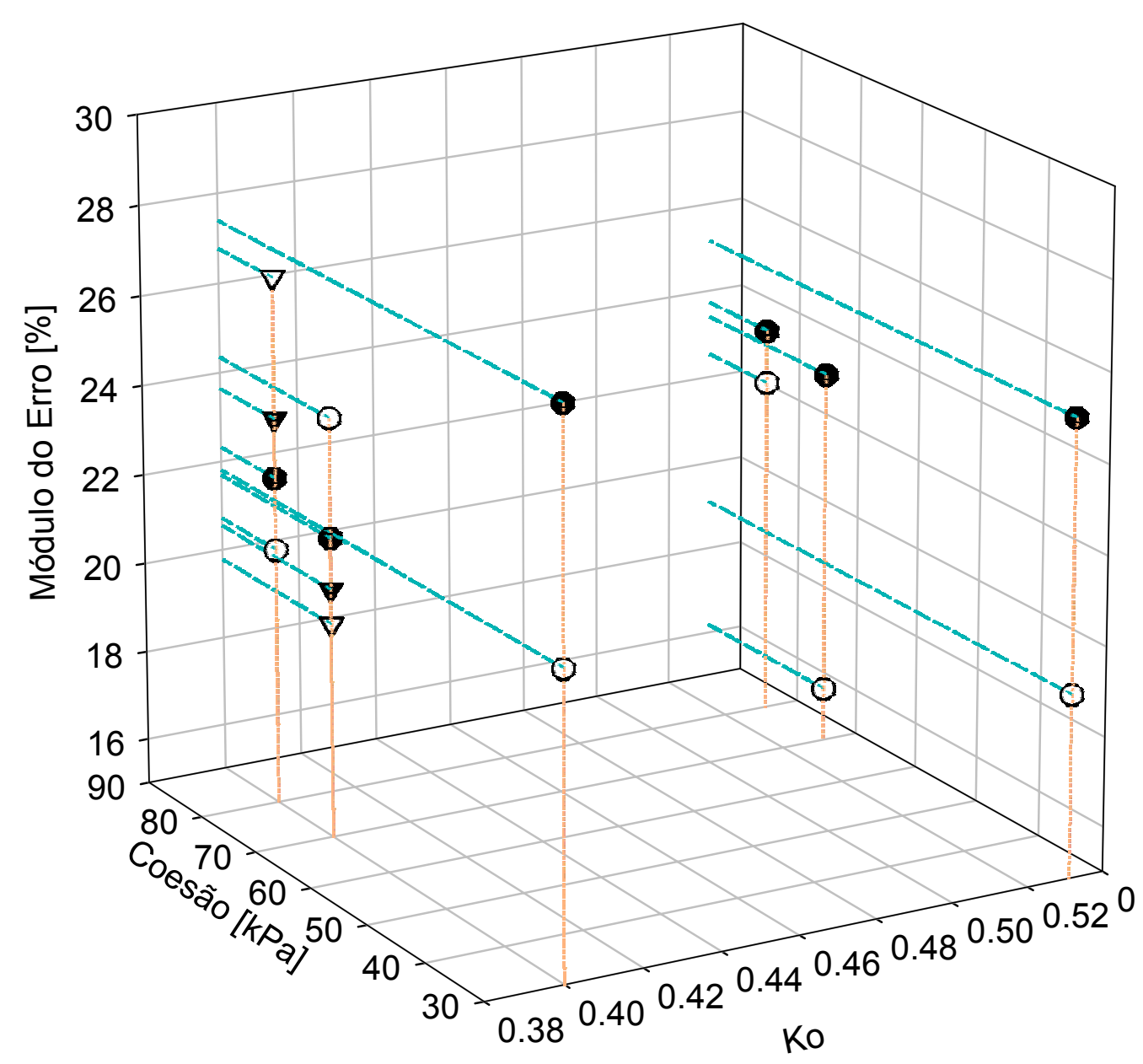

\footnotetext{
- gama_nat $=15 \mathrm{kN} / \mathrm{m} 3 ;$ Rintern $=0,2$

O gama_nat $=13,5 \mathrm{kN} / \mathrm{m} 3 ;$ Rintern $=0,2$

$\nabla$ gama_nat $=15 \mathrm{kN} / \mathrm{m} 3 ;$ Rintern $=0,5$

$\nabla$ gama_nat $=13,5 \mathrm{kN} / \mathrm{m} 3 ;$ Rintern $=0,5$ gama_nat=peso específico do solo
}

Figura 4-47- Módulos dos erros de deslocamentos horizontais do paramento estágio 8 - Modelo de Endurecimento 
Estágio 3 - Módulos dos Erros das Forças nas Estroncas Modelo de Endurecimento de Solo

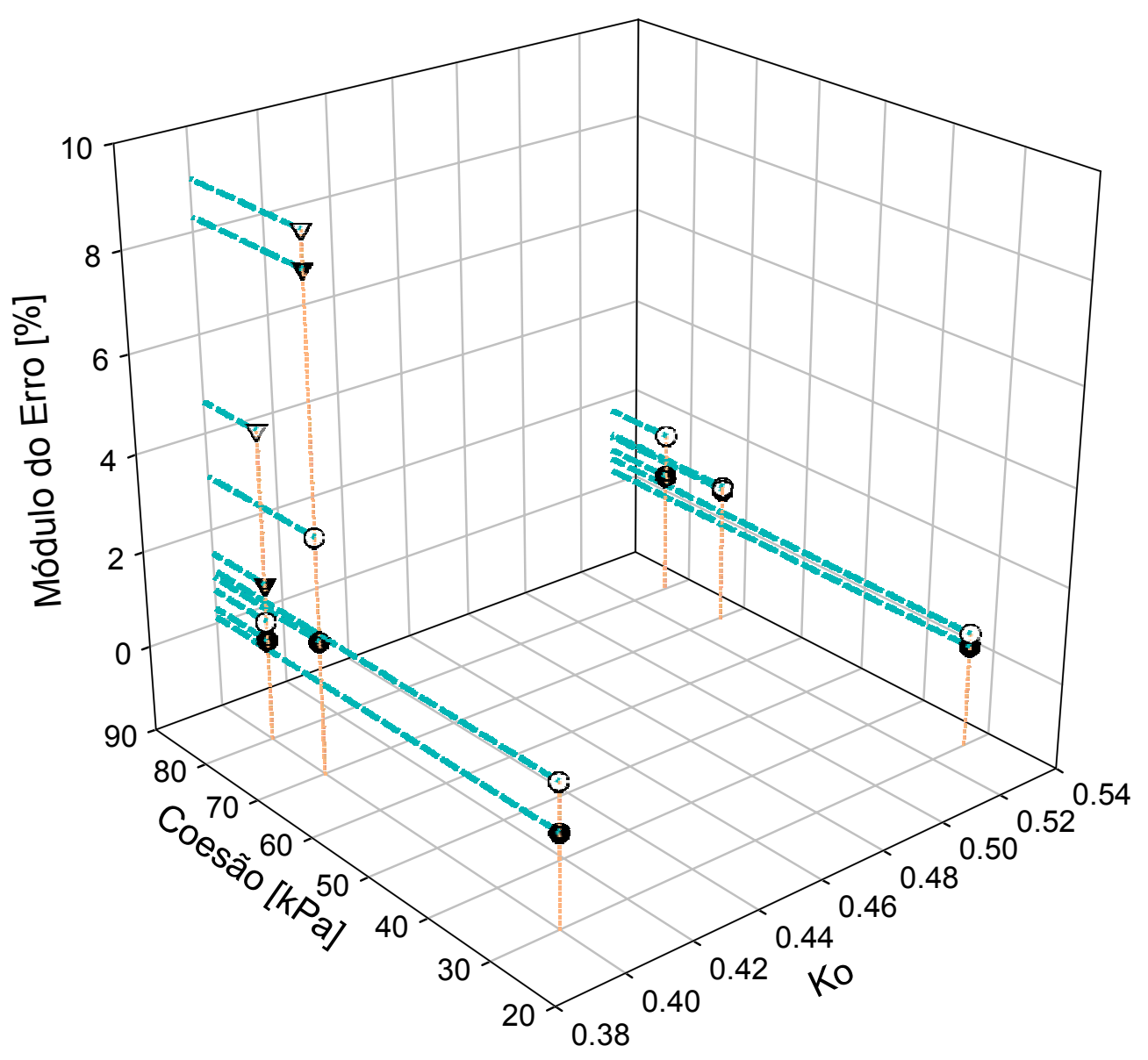

- gama_nat $=15 \mathrm{kN} / \mathrm{m} 3 ;$ Rintern $=0,2$

O gama_nat $=13,5 \mathrm{kN} / \mathrm{m} 3 ;$ Rintern $=0,2$

$\nabla$ gama_nat $=15 \mathrm{kN} / \mathrm{m} 3 ;$ Rintern $=0,5$

$\nabla \quad$ gama_nat $=13,5 \mathrm{kN} / \mathrm{m} 3 ;$ Rintern $=0,5$ gama_nat=peso específico do solo

Figura 4-48-Módulos dos erros de forças nas estroncas -estágio 3 
Estágio 5 - Módulos dos Erros das Forças nas estroncas Modelo de Endurecimento de Solo

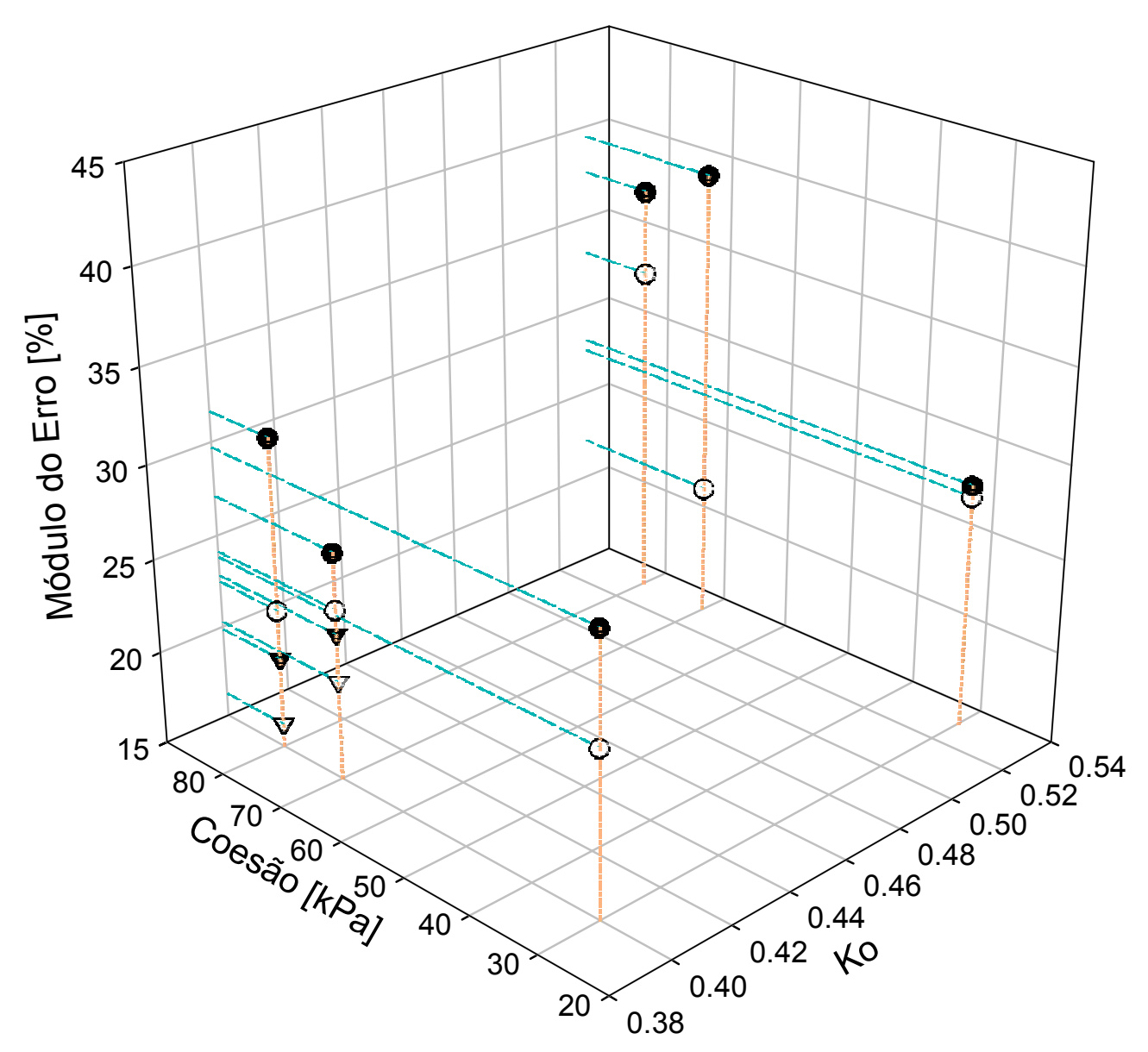

- gama_nat $=15 \mathrm{kN} / \mathrm{m} 3 ;$ Rintern $=0,2$

O gama_nat $=13,5 \mathrm{kN} / \mathrm{m} 3 ;$ Rintern $=0,2$

$\nabla$ gama_nat $=15 \mathrm{kN} / \mathrm{m} 3 ;$ Rintern $=0,5$

$\nabla$ gama_nat $=13,5 \mathrm{kN} / \mathrm{m} 3 ;$ Rintern $=0,5$ gama_nat=peso específico do solo

Figura 4-49- Módulos dos erros das forças nas estroncas -estágio 5 
Estágio 8 - Módulos dos Erros das Forças nas estroncas nível A Modelo de Endurecimento de Solo

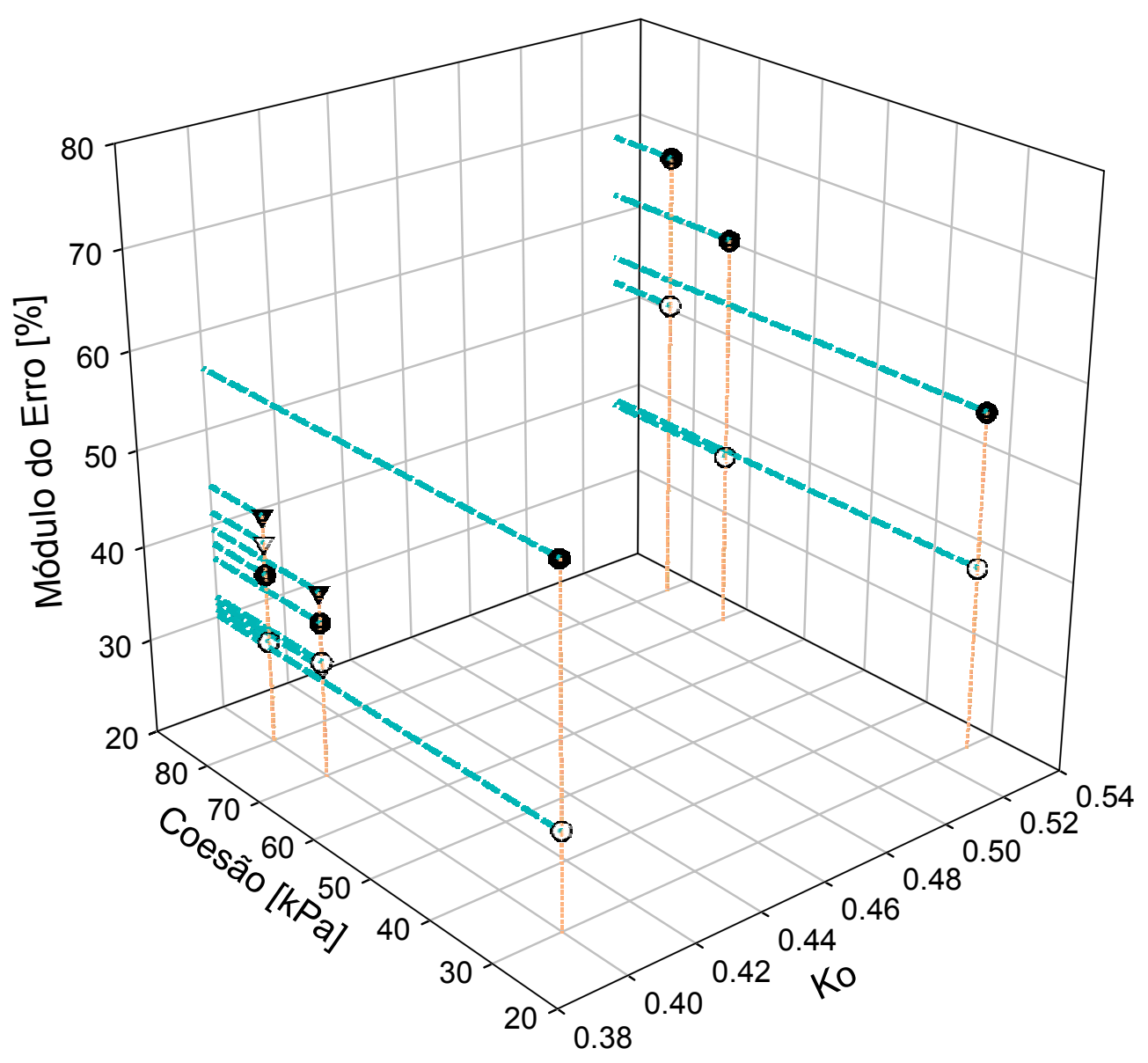

\footnotetext{
- gama_nat $=15 \mathrm{kN} / \mathrm{m} 3 ;$ Rintern $=0,2$

O gama_nat $=13,5 \mathrm{kN} / \mathrm{m} 3 ;$ Rintern $=0,2$

$\boldsymbol{\nabla}$ gama_nat $=15 \mathrm{kN} / \mathrm{m} 3 ;$ Rintern $=0,5$

$\nabla$ gama_nat $=13,5 \mathrm{kN} / \mathrm{m} 3 ;$ Rintern $=0,5$ gama_nat=peso específico do solo
}

Figura 4-50- Módulos dos erros de forças nas estroncas nível A -Estágio 8 
Estágio 8 - Módulos dos Erros das Forças nas Estroncas nível B Modelo de Endurecimento de Solo

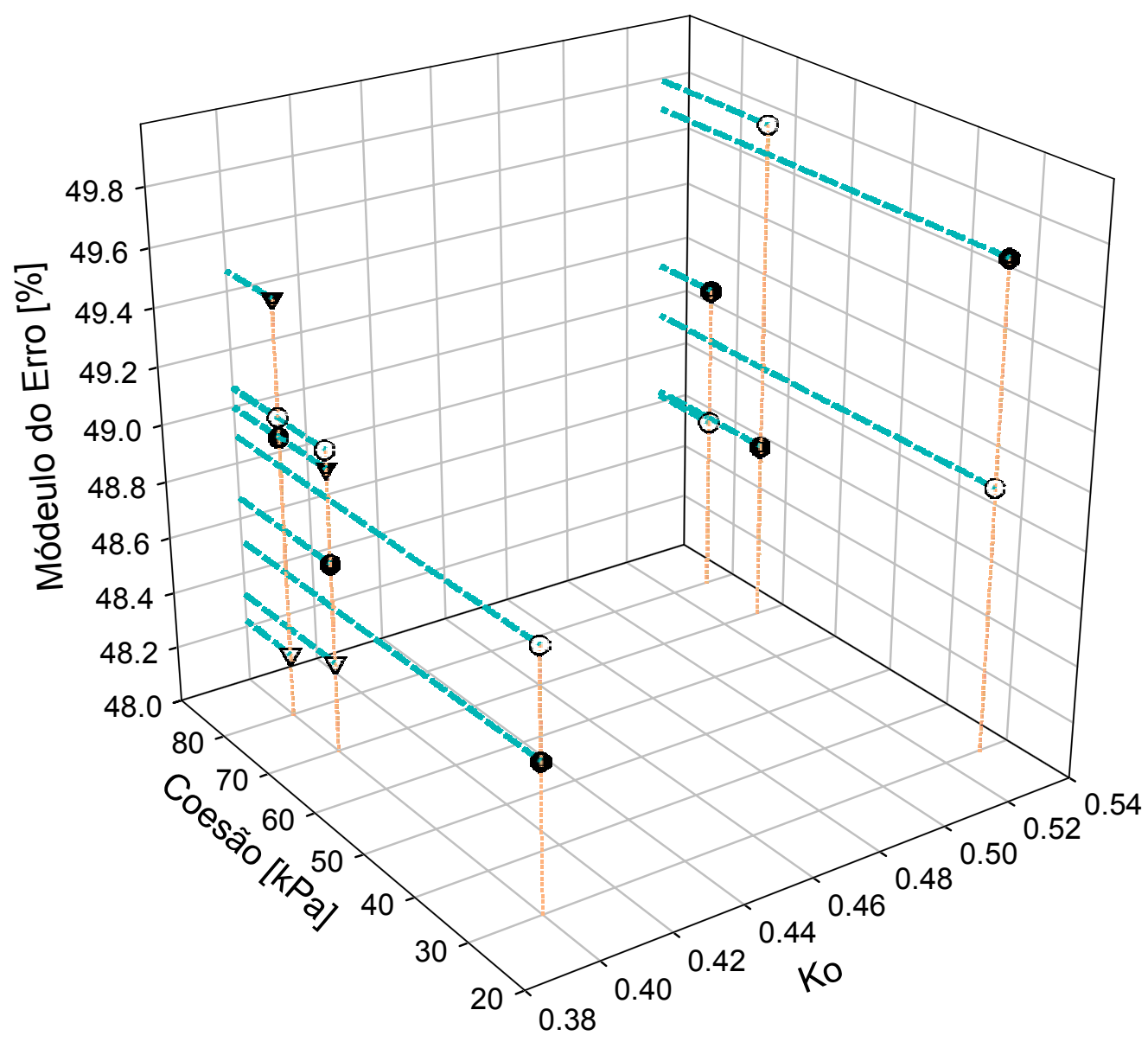

- gama_nat $=15 \mathrm{kN} / \mathrm{m} 3 ;$ Rintern $=0,2$

O gama_nat $=13,5 \mathrm{kN} / \mathrm{m} 3 ;$ Rintern $=0,2$

$\boldsymbol{\nabla}$ gama_nat $=15 \mathrm{kN} / \mathrm{m} 3 ;$ Rintern $=0,5$

$\nabla$ gama_nat $=13,5 \mathrm{kN} / \mathrm{m} 3 ;$ Rintern $=0,5$ gama_nat=peso específico do solo

Figura 4-51- Módulos dos erros de forças nas estroncas nível B-Estágio 8 


\section{9 -Escolha do intervalo de soluções}

A partir dos resultados obtidos com o modelo constitutivo de Endurecimento, determinou-se um intervalo de parâmetros geotécnicos que conduzissem a valores de erros mínimos de deslocamentos horizontais de paramentos ou forças nas estroncas que estão apresentados na Tabela 4-17

Tabela 4-17-Resumo dos parâmetros com os quais ocorreram os erros mínimos de deslocamentos de paramentos e forças nas estroncas

\begin{tabular}{|l|c|c|c|c|c|}
\hline $\begin{array}{l}\text { ERRO MÍNIMO PARA } \\
\text { [situação n }\end{array}$ ] & Estágio & Ko & $\begin{array}{c}\gamma_{\mathbf{n a t}} \\
{\left[\mathbf{k N} / \mathbf{m}^{\mathbf{3}}\right]}\end{array}$ & $\begin{array}{c}\mathbf{c} \\
{[\mathbf{k P a}]}\end{array}$ & $\mathbf{R}_{\text {inter }}$ \\
\hline [1] Deslocamentos de & 3 & 0,400 & 13,5 & $\mathrm{f}(\mathrm{SPT})$ & 0,5 \\
paramentos & 5 & 0,531 & 13,5 & 70 & 0,2 \\
\cline { 2 - 6 } & 8 & 0,531 & 13,5 & 70 & 0,2 \\
\hline \multirow{2}{*}{ [2]Forças nas estroncas $\boldsymbol{A}$} & 3 & 0,400 & 13,5 & $\mathrm{f}(\mathrm{SPT})$ & 0,2 \\
\cline { 2 - 6 } & 5 & 0,400 & 13,5 & $\mathrm{f}(\mathrm{SPT})$ & 0,5 \\
\cline { 2 - 6 } & 8 & 0,400 & 13,5 & $\mathrm{f}(\mathrm{SPT})$ & 0,2 \\
\hline
\end{tabular}

C- coesão ; Ko-coeficiente de empuxo em repouso; $\mathrm{R}_{\text {inter }}$ - fator de redução da tan $\phi$ e da coesão na interface.

\subsection{0-Comparação entre os resultados obtidos por retroanálises via Mohr-Coulomb e Endurecimento de solo}

A idéia de utilizar os modelos constitutivos de Mohr-Coulomb e de Endurecimento foi verificar qual dos modelos era mais adequado para representar o comportamento do sistema solo-escoramento durante o processo de escavação. Assim, seria conhecido também o modelo que representaria melhor as forças nas estroncas 
conjuntamente com os recalques de superfície, que são fundamentais para realizar estimativas de danos que poderão vir a ocorrer nas edificações lindeiras a vala.

Em função das observações relativas às solicitações de carregamento e descarregamento impostas aos solos durante o processo de escavação e contenção, bem como pelo "efeito pulsante" devido às variações de temperatura, que foram amplamente estudadas por MASSAD (1978), havia a expectativa do modelo de Endurecimento viesse a representar de forma mais precisa o processo de escavação do que o modelo de Mohr-Coulomb. Isto devido ao fato do modelo de Endurecimento permitir em sua formulação a consideração do módulo de carregamento -descarregamento ( $\left.\mathrm{E}_{\mathrm{ur}}\right)$.

A partir dos resultados obtidos da retroanálise utilizando-se os modelos de Mohr-Coulomb e de Endurecimento, adotou-se como critério :

- comparar para os dois modelos constitutivos os 3 menores erros em relação às forças nas estroncas e os correspondentes erros de deslocamentos associados àqueles erros de forças nas estroncas, obtidos da retroanálise de $E_{50}$ para cada um dos estágios $(3,5,8)$ que constam na Tabela 4-6 e Tabela 4-13. Ou seja, para uma combinação de parâmetros geotécnicos que conduza a mínimos erros de forças nas estroncas estão associados os erros de deslocamentos horizontais de paramentos.

Da Figura 4-52 à Figura 4-57 apresentam-se os resultados das comparações entre os modelos de Mohr-Coulomb e de Endurecimento, com relação aos erros obtidos para as forças nas estroncas e deslocamentos horizontais de paramentos, para os estágios de escavação 3,5 e 8.

A notação (nas figuras de forças nas estroncas) $1^{\circ}$ significa que foi o menor erro encontrado para as forças nas estroncas naquele estágio de escavação, sendo portanto o $1^{\mathrm{o}}$ na hierarquia de erros mínimos, raciocínio análogo deve ser feito para as notações $2^{\circ}$ e $3^{\circ}$.

A notação média significa a média dos módulos dos erros em relação aos deslocamentos horizontais de paramentos associados a hierarquia da força da estronca e desv.pad significa o desvio padrão do erro mínimo. (Figura 4-52 à Figura 4-57) 


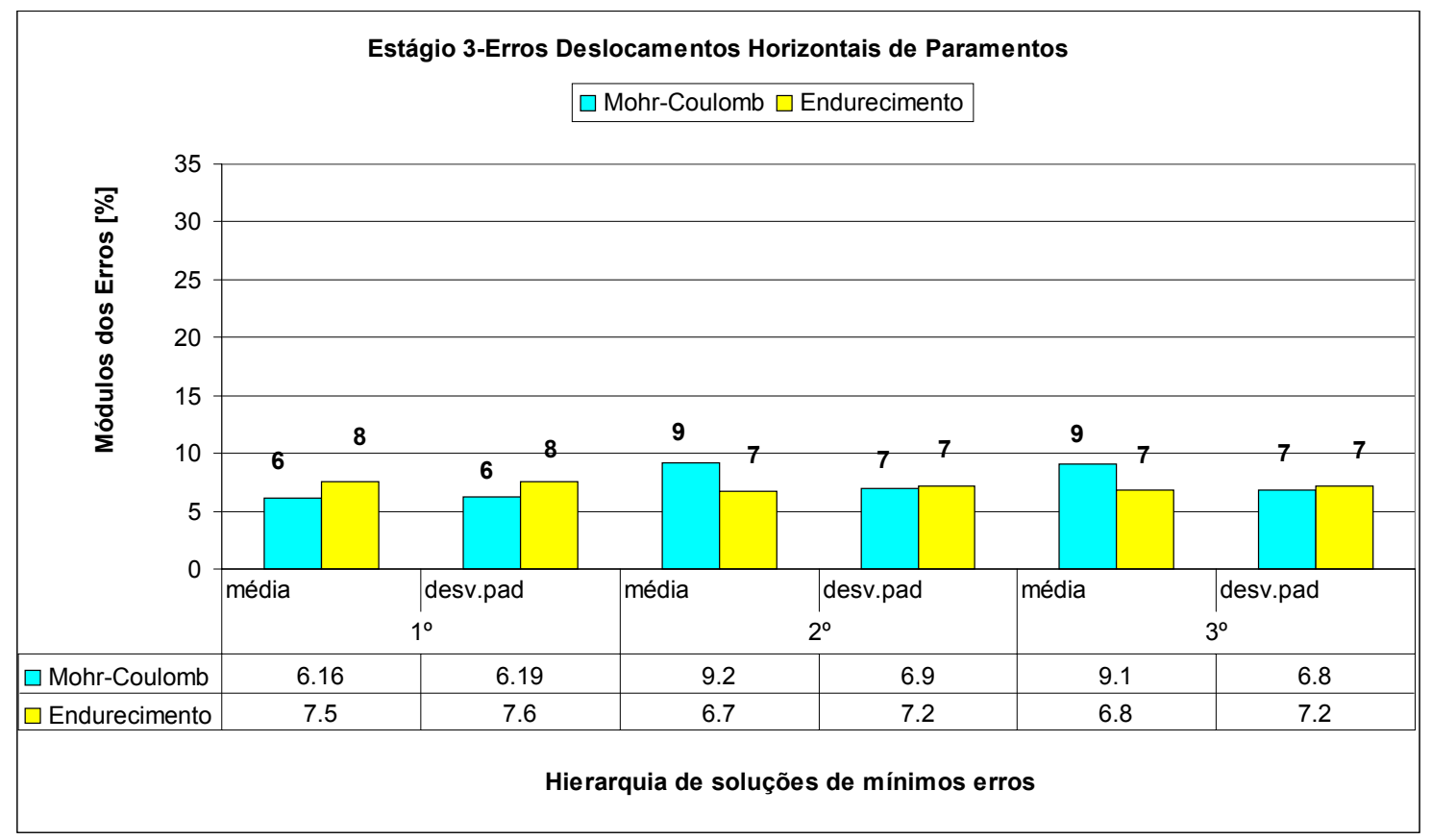

Figura 4-52- Estágio 3- Comparação entre os erros obtidos pelos modelos MohrCoulomb e Endurecimento - erros deslocamentos associados aos erros mínimos de forças nas estroncas

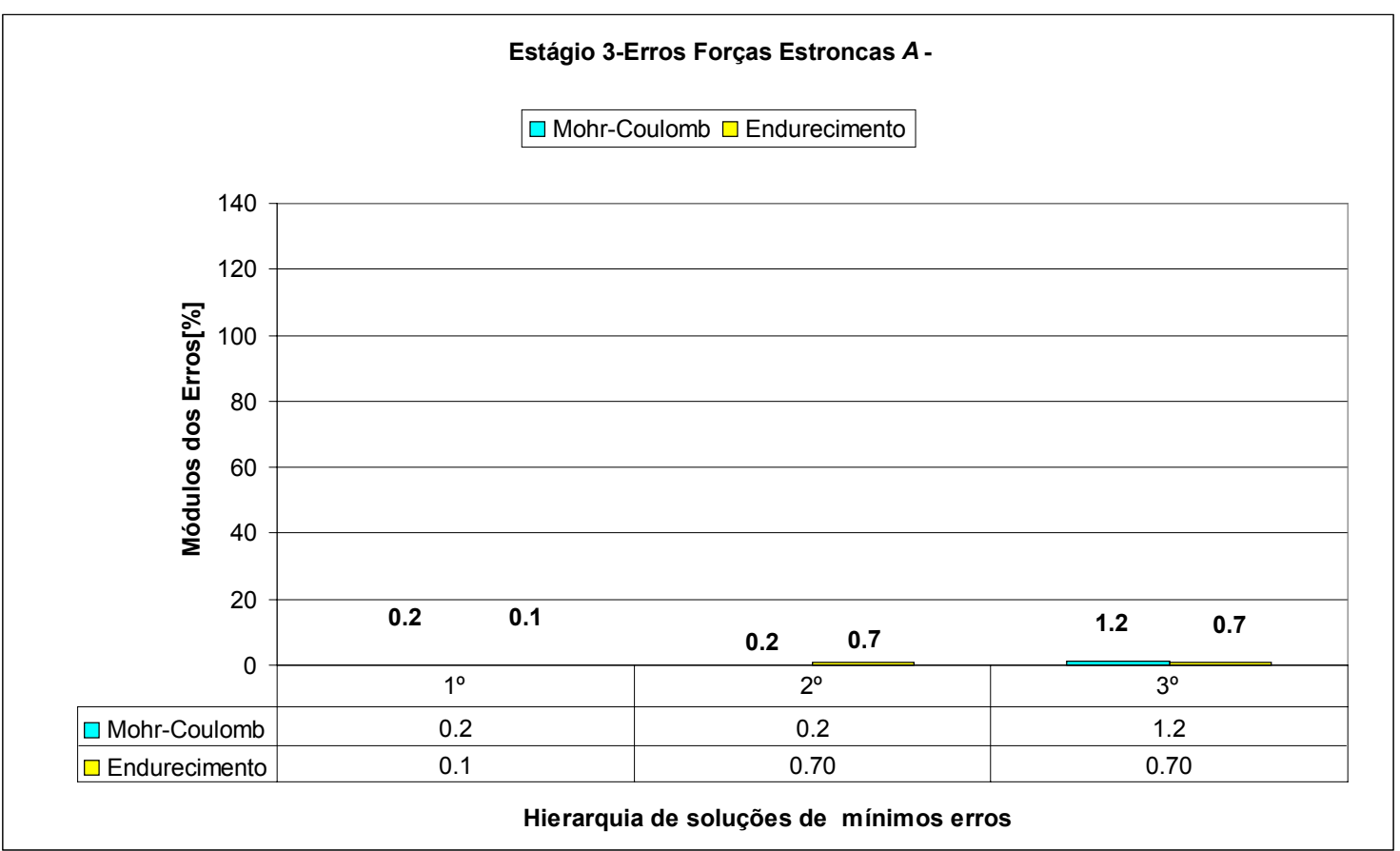

Figura 4-53- Estágio 3- Comparação entre os erros obtidos pelos modelos MohrCoulomb e Endurecimento - erros forças estroncas 


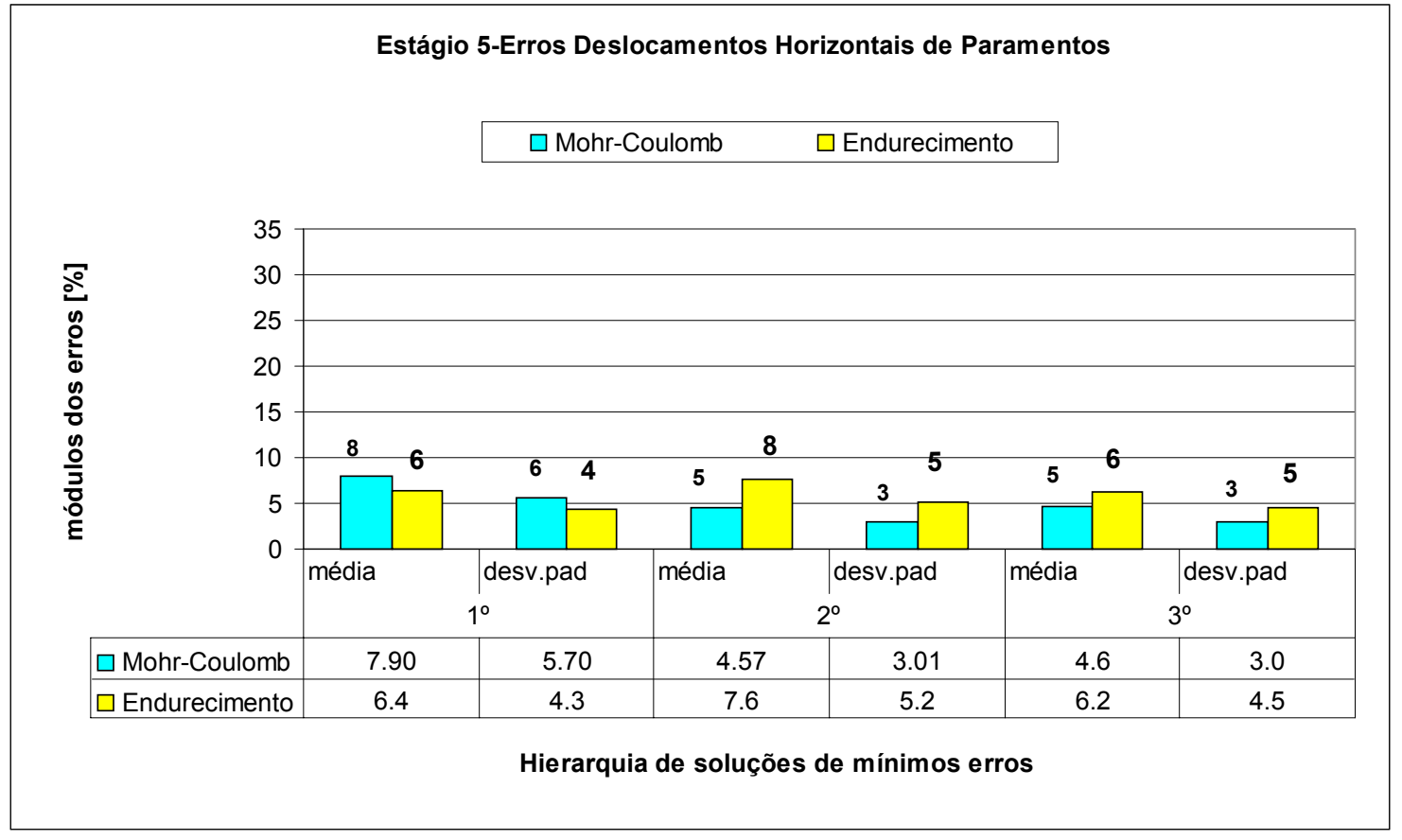

Figura 4-54- Estágio 5- Comparação entre os erros obtidos pelos modelos MohrCoulomb e Endurecimento -erros deslocamentos associados aos erros mínimos de forças nas estroncas

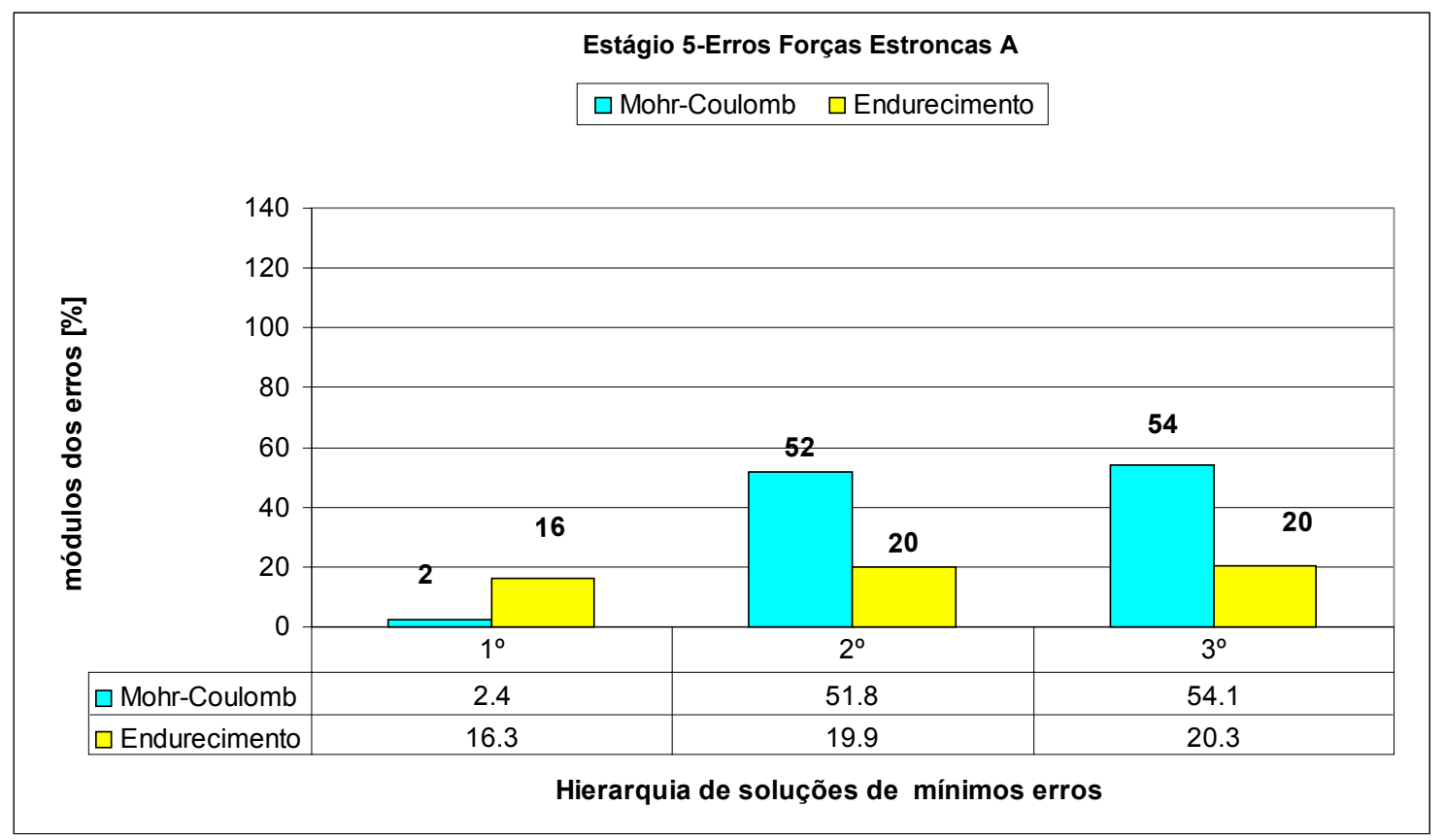

Figura 4-55 -Estágio 5- Comparação entre os erros obtidos pelos modelos MohrCoulomb e Endurecimento - erros forças estroncas 


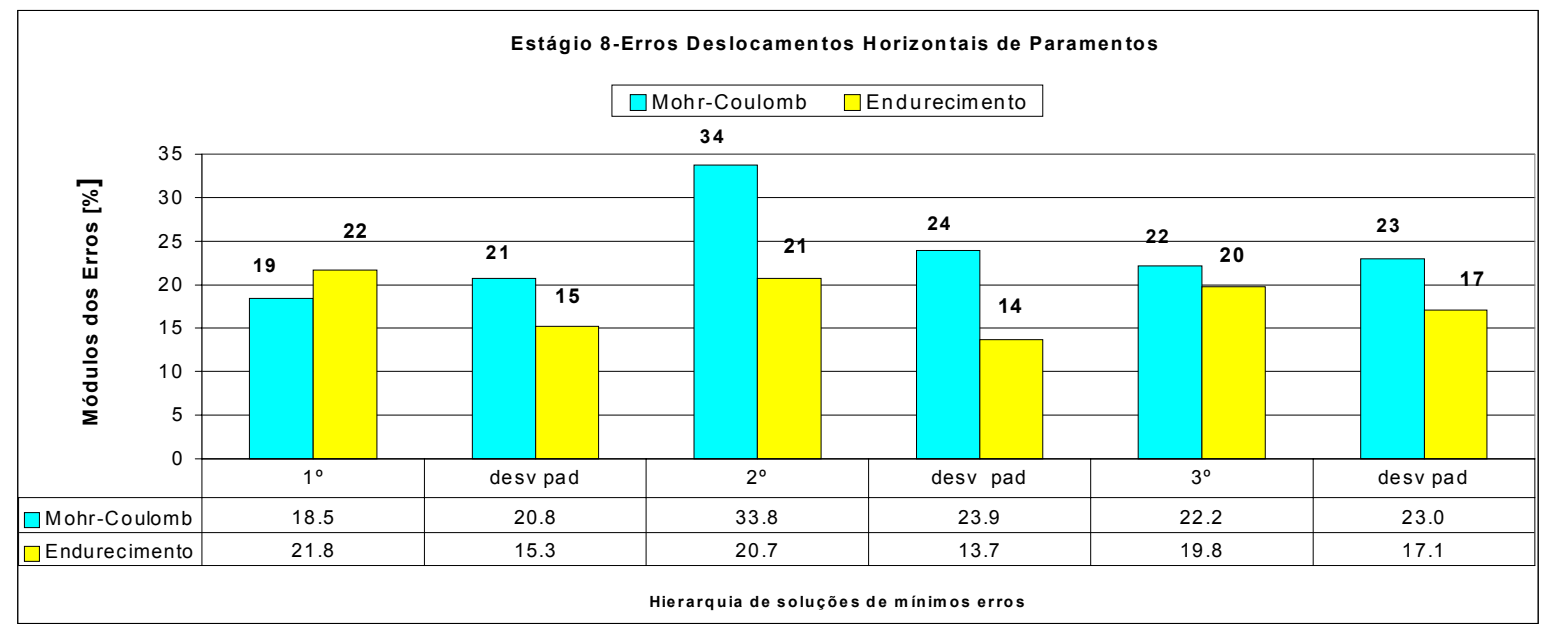

Figura 4-56- Estágio 8-Comparação entre os erros obtidos pelos modelos MohrCoulomb e Endurecimento - erros deslocamentos associados aos erros mínimos de forças nas estroncas

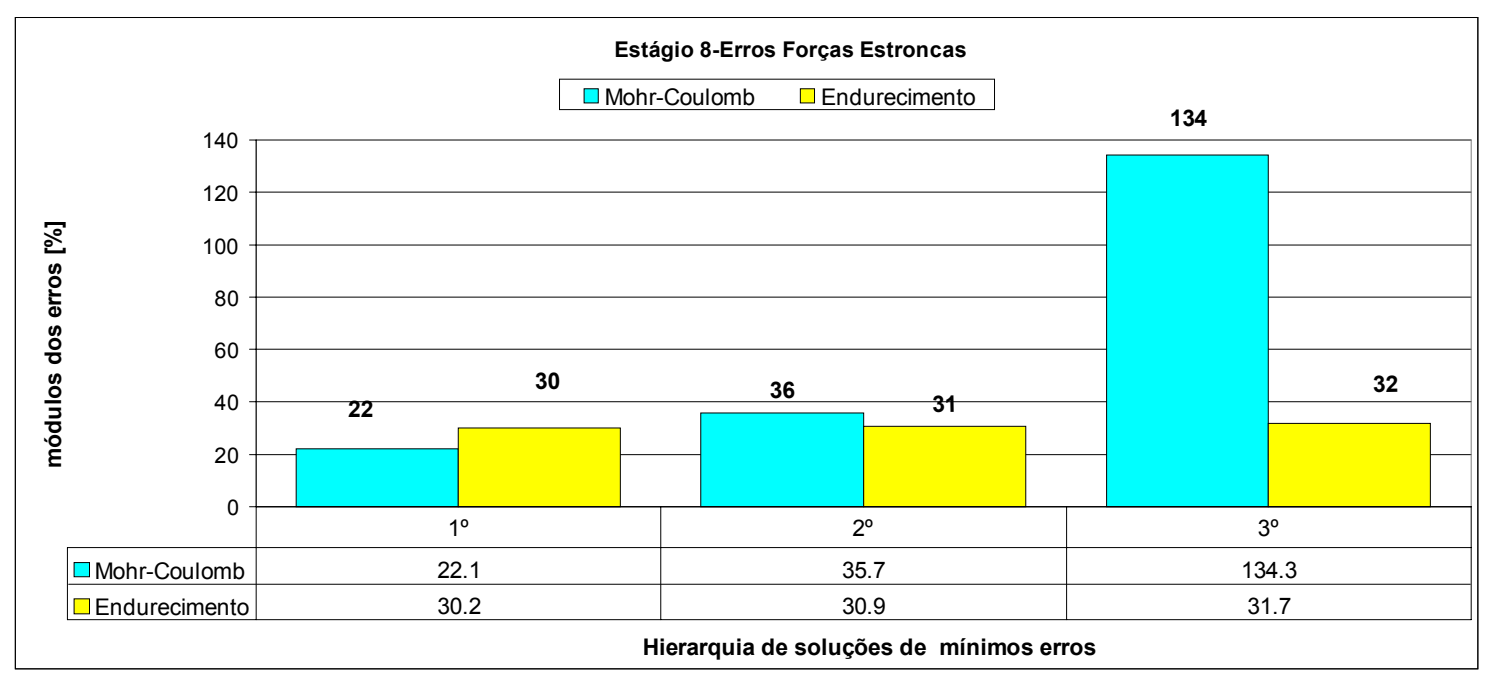

Figura 4-57- Estágio 8- Comparação entre os erros obtidos pelos modelos MohrCoulomb e Endurecimento - erros forças estroncas

$\mathrm{Da}$ análise da Figura 4-52 à Figura 4-57 percebe-se que o modelo de Endurecimento praticamente empatou nos estágio 3 e 5 (deslocamentos de paramento das fases inciais e média) com o modelo de Mohr-Coulomb nos erros de deslocamentos horizontais de paramentos, havendo vantagem para o modelo de Endurecimento na precisão da representação das forças nas estroncas. 
Finalmente no estágio 8 (profundidade máxima escavada) o modelo de Endurecimento obteve vantagem em relação aos deslocamentos de paramentos (melhor relação média e desvio padrão) e em relação às forças nas estroncas foram duas das três melhores soluções.

Em virtude do exposto considera-se que para as combinações de parâmetros estudadas o modelo de Endurecimento superou o modelo de Mohr-Coulomb principalmente na precisão das forças nas estroncas (estágios 5 e 8) e também na representação dos deslocamentos horizontais de paramentos para o estágio 8 de escavação.

Os mínimos erros de deslocamentos horizontais de paramentos obtidos, ou seja os melhores ajustes à deformada do paramento, para os dois modelos (Mohr-Coulomb e Endurecimento) foram obtidos para o estágio 5. 


\section{Capítulo 5 - Estimativa de danos causados edifícios pelas escavações da vala da seção experimental $n^{\circ} 1$}

O nível de danos em edifícios provocados pelo processo de escavação de valas de metrôs está relacionado a muitos fatores. De acordo com ISE (1989) estes fatores estão relacionados com:

- a forma como o processo de escavação é feito, ou seja, a geometria e velocidade da escavação

- o tempo para a instalação das estroncas e a pré-compressão

- o peso dos equipamentos e materiais de construção na borda da vala

- a variação de temperatura (quando houver estroncas metálicas)

- a ocorrência de chuvas e a permeabilidade do solo

- a possibilidade de ocorrência de trincas de tração no solo

- a velocidade de rebaixamento do lençol freático e a tensão de sucção

- o nível de tensões de pré-adensamento

- a rigidez do sistema de escoramento da vala

- o tipo de fundação dos edifícios e sua rigidez

- a posição da vala em relação à edificação considerada

- a forma da bacia de recalques e sua magnitude

- a interação solo-estrutura.

Ao tentar estimar-se o nível de danos em edificações percebe-se como é complexa a representação deste sistema. 
Além da grande variabilidade inerente aos processos de formação dos solos, há influência do processo construtivo que pode alterar o estado do solo dificultando ainda mais o conhecimento dos parâmetros do solo.

Devido a estes parâmetros, na fase de projeto simplificações são necessárias e quase obrigatórias. Nesta etapa pode-se fazer uso de sondagens e ensaios de laboratório para obtenção de parâmetros pontuais.

Para se estimar as relações do estado do solo, com os processos construtivos e dos danos que estes poderão vir a provocar nas estruturas, ISE (1989) recomenda que se considere nos aspectos da interação solo-estrutura, a influência das poropressões, as características de deformações do solo e o estado de tensões in situ. No ítem 5.1 faz-se um apanhado geral baseado em ISE (1989), sobre os apectos de influência na interação solo-estrutura .

\section{1 -Aspectos da interação solo-estrutura}

Consideração da interação solo-estrutura é muito importante para as estruturas que suportam o solo, devido ao fato do solo além de gerar carregamento para as estruturas, também prover resistência aos carregamentos.

A estrutura transfere o carregamento gerado para o solo que está sendo suportado pelas massas de solo "adjacentes". A forma como esta transferência se dá, depende entre outras coisas, do tipo de estrutura de suporte, da rigidez relativa e do método utilizado para a construção do sistema de contenção.

Em muitos casos, as tensões atuantes no solo e nos elementos estruturais da contenção dependem significativamente das rigidezes e dos deslocamentos relativos dos elementos estruturais.

A consideração da interação, englobando rigidez e deformações, é essencial para uma adequada avaliação das tensões, forças e momentos fletores na estrutura de contenção.

Além disto a consideração da interação pode envolver outros elementos importantes como :

- interações químicas especialmente em locais onde a agressividade química do solo pode atacar a estrutura vindo a alterar sua rigidez e também alterar a permeabilidade 
- transferência de calor que pode alterar os esforços das estruturas de contenção, principalmente as forças nas estroncas, se estas forem metálicas.

\subsubsection{Influência das Poropressões}

Freqüentemente o comportamento dos solos saturados é governado por princípios de tensões efetivas enunciados pela mecânica dos solos clássica. Geralmente, incrementos de poropressão induzem uma perda de rigidez e da resistência ao cisalhamento. Em solos saturados a lei que comanda a variação desta resistência está associada ao coeficiente de permeabilidade do solo. Em solos com baixa permeabilidade como siltes e argilas o período para a estabilização pode se estender a anos e até décadas.

\subsubsection{Influência das características de deformação do solo}

Alguns aspectos da interação solo-estrutura são sensíveis aos detalhes do comportamento do solo na deformação.

De acordo com Figura 5-1 o solo na trajetória OAB tem um modo de deformação que pode ser aproximado pela teoria da elasticidade linear.

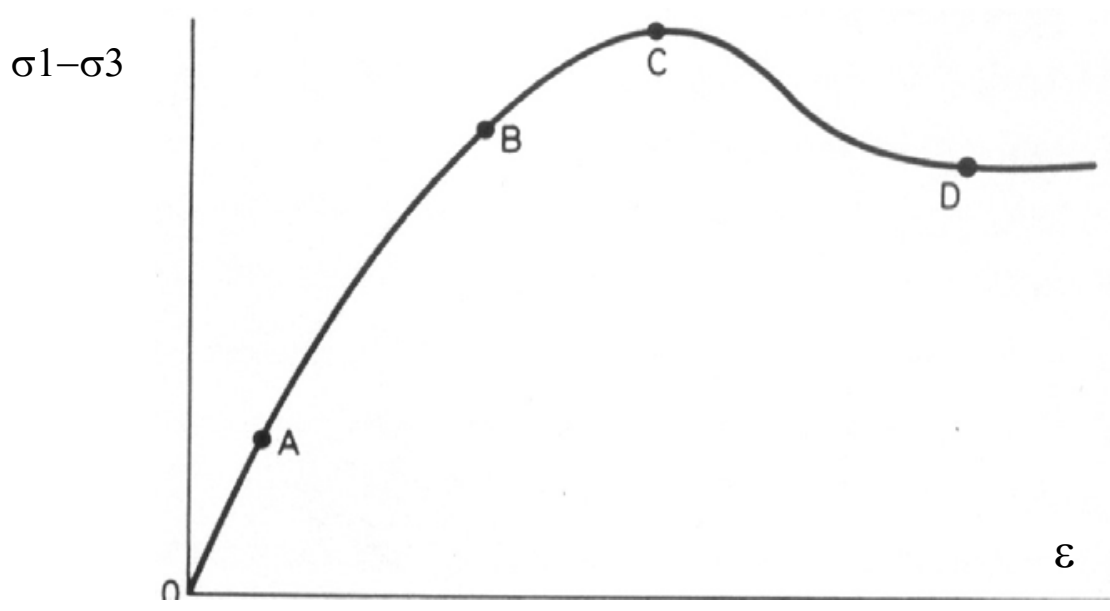

Figura 5-1-Exemplo de curva tensão $x$ deformação 
A partir do ponto $\mathrm{B}$, a deformação plástica torna-se significativa e o pico de tensão é atingido no ponto C. O aumento de deformação é acompanhado por uma redução da resistência como ilustra o ponto $\mathrm{D}$, a condição de estado crítico e grandes deformações podem se reduzir a valores residuais. A resistência residual é particularmente relevante em argilas.

Muitos solos apresentam rigidez muito alta para pequenas deformações, o que, por exemplo, ocorre no trecho OA, característica que é de grande importância para a interação solo-estrutura.

Em zonas de elevadas tensões o pico representado por $\mathrm{C}$ pode ser ultrapassado localmente em regiões restritas do maciço de solo (inidcadas por pontos de plastificação).

As deformações volumétricas influenciarão a interação, podendo em argilas ser retardadas devido às poropressões. De acordo com (ISE, 1989), para representar o comportamento volumétrico alguns modelos elásticos podem ser adequados, porém para argilas moles os modelos devem representar também as deformações plásticas volumétricas.

\subsection{3 -Influência do estado de tensões in situ}

As tensões que atuam nas estruturas de contenção, dependem das tensões iniciais horizontais que agem no solo, da rigidez da estrutura e do método de construção.

O estado de tensões horizontais in situ pode ser representado pelo coeficiente de empuxo em repouso Ko. Este parâmetro pode ser obtido por ensaios in situ ou em laboratório em amostras indeformadas. Este parâmetro sofre a influência da história de tensões do solo, através de processos de sedimentação, químicos, físicos (sucção) ou tectônicos.

A dificuldade de obtenção de valores de $K o$ in situ não deve impedir a busca de sua obtenção, uma vez que sua consideração é de extrema importância para a confiabilidade das estimativas de projeto e mesmo para as retroanálises baseadas em instrumentações. 


\section{2 -Tipos de danos causados à edificações}

De acordo com ISE (1989), o nível de danos causados em edifícios está associado a três questões envolvendo movimentações das estruturas. Estes movimentos afetam principalmente a aparência da edificação, as funções para as quais foram projetadas e a estabilidade estrutural.

\section{3 -Desvio dos elementos em relação à vertical e à horizontal}

Os desvios visíveis de elementos estruturais em relação à horizontal e à vertical podem, de acordo com ISE (1989), causar desconforto e atitudes alarmantes nas pessoas. Desvios que podem ser percebidos em relação à própria estrutura ou em relação a estruturas da vizinhança costumam ser percebidos quando excedem na vertical $1: 250$ e na horizontal 1:100

\section{4 -Definições dos movimentos das fundações}

Durante as etapas do processo construtivo de um edifício o solo sofre uma série de deslocamentos provocados pelo alívio e pelo acréscimo de tensões.

Estão representados de forma conceitual na Figura 5-2 os deslocamentos que ocorrem durante o processo construtivo de um edifício. 


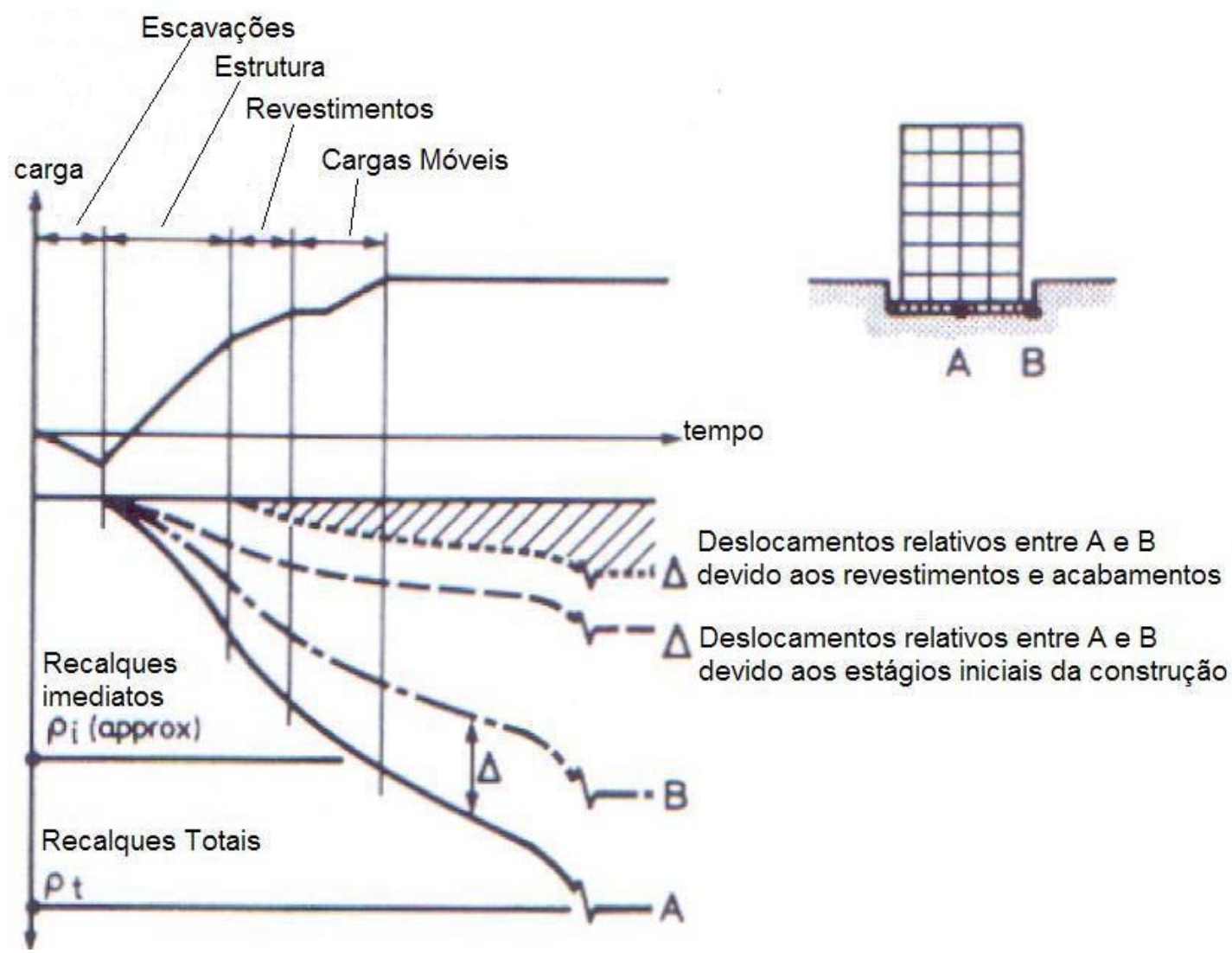

Figura 5-2- Deslocamentos conceituais que ocorrem no solo das fundações de um edifício (ISE, 1989)

Estes deslocamentos terão grande relação com os possíveis danos que a estrutura possa vir a sofrer.

A partir destes movimentos obtêm-se os parâmetros:

- recalque $\delta$

- recalque relativo $\delta_{p}$

- rotação $\phi$

- deformação angular $\alpha$

- deflexão Relativa $\Delta$

- razão de Deflexão $\Delta / L$

- desaprumo $\omega$

- distorção angular ou rotação relativa $\beta$

Esses parâmetros estão detalhados na Figura 5-3 a Figura 5-5 


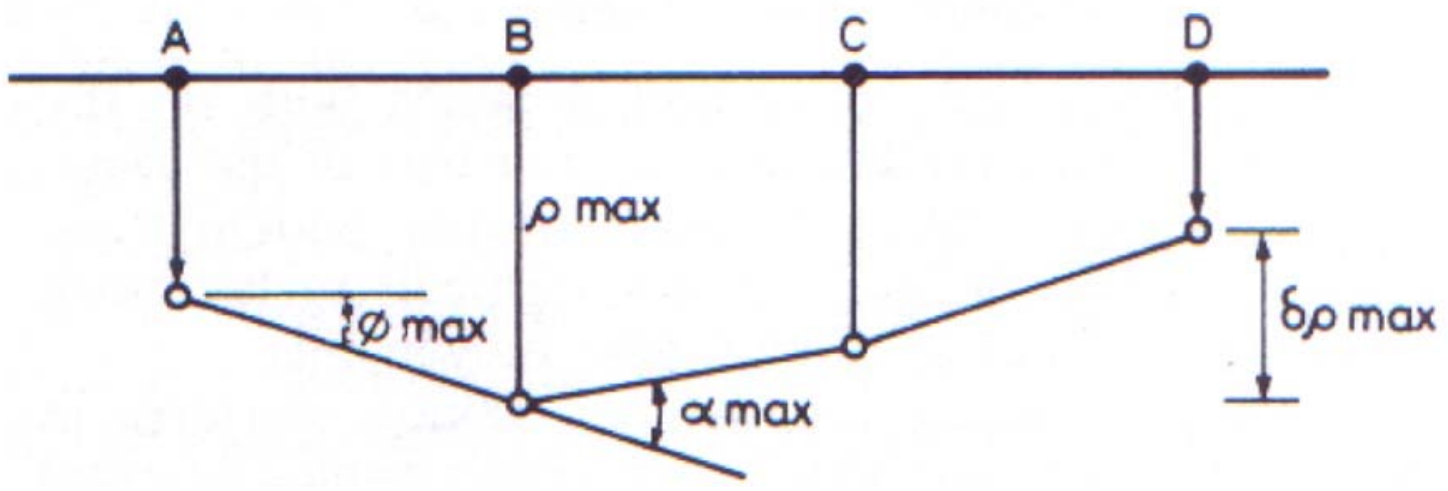

Figura 5-3-Definições de recalque $\delta$, recalque relativo $\delta$ p e rotação $\phi$ e deformação angular $\alpha$ (ISE, 1989)

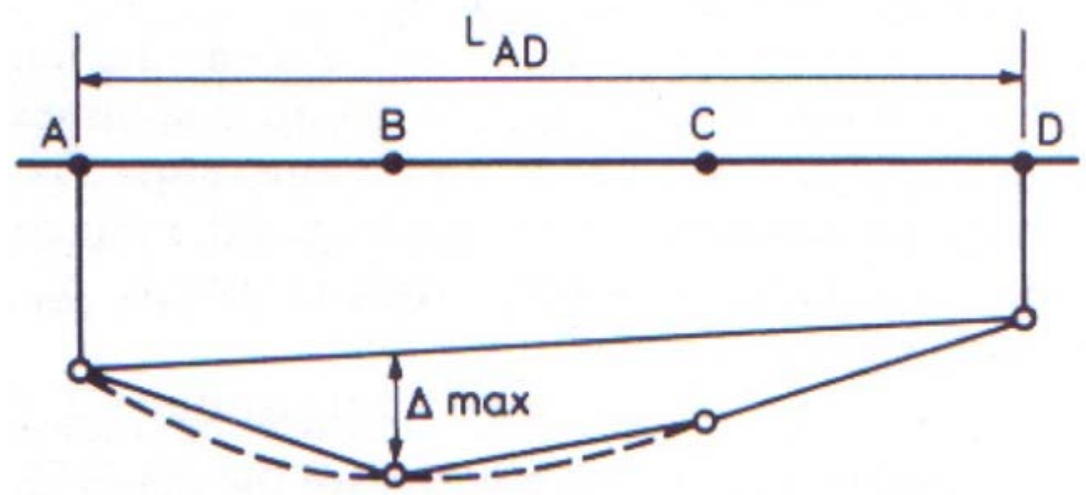

Figura 5-4-Definições de deflexão relativa $\Delta$, e razão de deflexão $\Delta L$ (ISE, 1989)

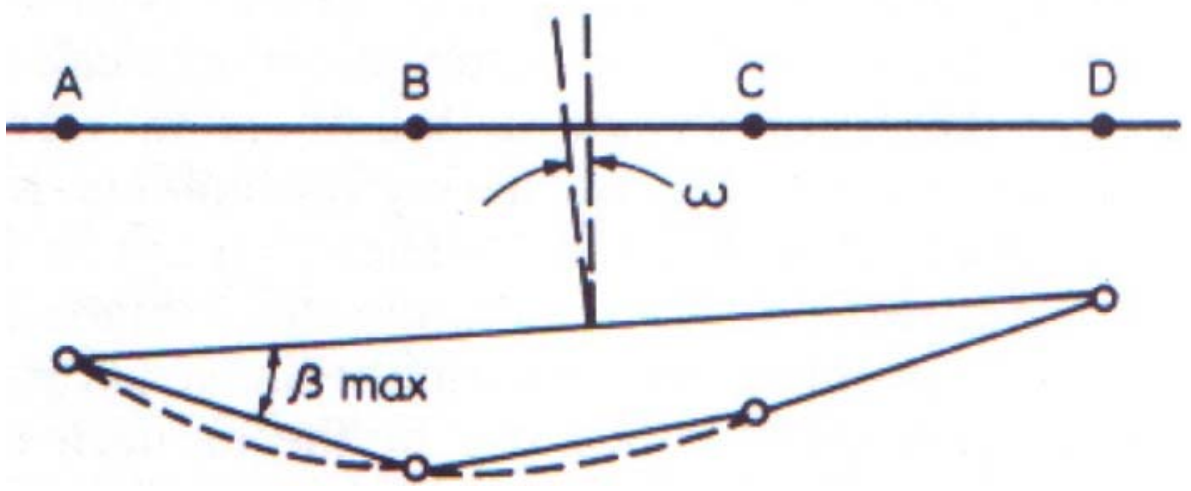

Figura 5-5-Definição de desaprumo $\omega$, rotação relativa (distorção angular) $\beta$ (ISE, 1989)

Há distinção entre os tipos de deslocamentos impostos pelo solo ao paramento se ele estiver em balanço ou travado por estroncas. 
A Figura 5-6 apresenta os principais tipos de deslocamentos sofridos pelo paramento nas escavações. A situação (A) representa a deformada do paramento em situação de balanço, onde somente a ficha (interface pe'do paramento e solo) é responsável pela estabilidade do conjunto.Na situação (B) além da ficha o paramento está bloqueado no topo por uma estronca
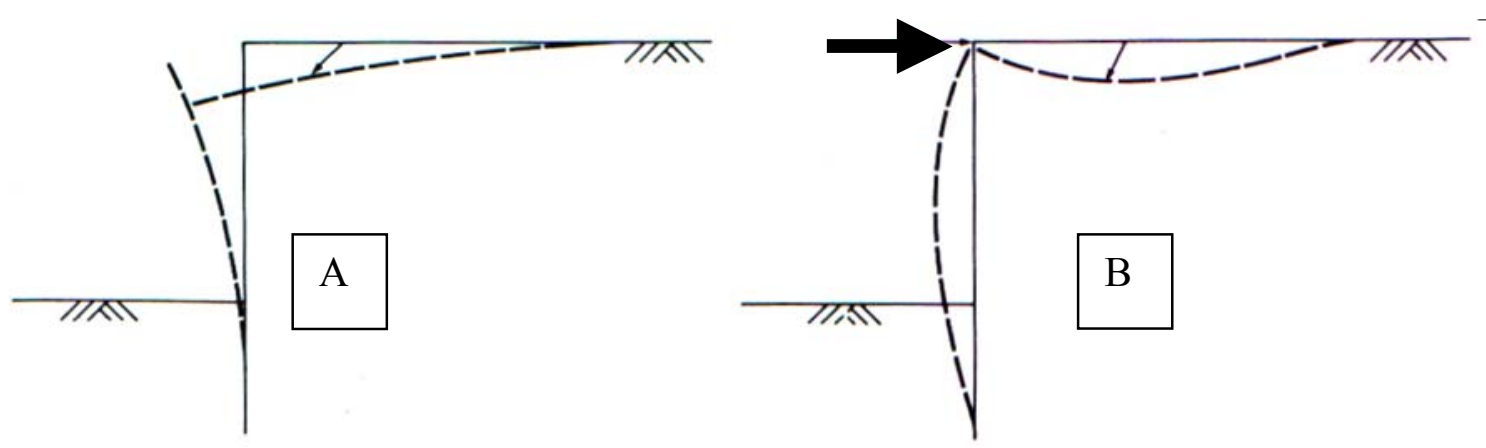

Figura 5-6- Tipos de deslocamentos de paramentos em balanço (A) e estroncados (B)(ISE, 1989)

\section{5 -Exemplo de estimativa de danos}

O exemplo que será utilizado para demonstrar a aplicação dos critérios de estimativa de danos é hipotético, uma vez que no local da execução das escavações da S.E.-1, não havia edificação instrumentada para podermos estabelecer uma comparação entre o nível de danos real e o estimado.

Deve-se ainda ressaltar que apesar de termos adotado um edifício hipotético com fundações rasas, isto na realidade não seria possível uma vez que neste local, os valores de resistência SPT (Figura 2-6), são muito baixos para adotar-se este tipo de fundação e certamente se houvesse algum edifício este teria que ter fundações profundas, uma vez que a argila porosa vermelha mole não é adequada para o uso de fundações diretas.

Fica portanto ressaltado que, a idéia utilizada é apenas a de ilustrar a aplicação dos métodos para estimar o nível de danos e a qualidade construtiva.

Supondo-se que o edifício hipotético estivesse: 
- apoiado ao solo através de sapatas corridas a $1 \mathrm{~m}$ de profundidade $(799,34)$

- com seus locais de apoio em qualquer abscissa medida na superfície distando entre $25 \mathrm{~m}$ e $0 \mathrm{~m}$ do paramento esquerdo da vala (estaca 1857) Figura 3-12.

A partir destas premissas calcularam-se:

- os valores de distorção angular máxima $\beta$ (recalque diferencial), a que estaria sujeito um edifício se estivesse apoiado na região acima citada.

- o nível de danos a que estaria sujeito segundo os critérios de BOSCARDIN e CORDING (1989).

- o nível de qualidade construtiva atribuído a esta vala em questão de acordo com O’ROURKE (1990) (RANZINI, 1996).

A seguir faz-se uma breve apresentação dos fatores de cada critério de estimativa de danos.

O critério de qualidade construtiva considera as relações do deslocamento horizontal máximo do paramento $\left(\delta_{\mathrm{h}}\right)$, e do recalque vertical máximo de superfície $\left(\delta_{\mathrm{v}}\right)$, com a profundidade da escavação. Em função destas relações, associa níveis de qualidade construtiva A, B e C.

Sendo os níveis definidos como:

$\mathrm{A}=$ construção cuidadosa

$\mathrm{B}=$ construção mediana

$\mathrm{C}=$ construção com dificuldades 

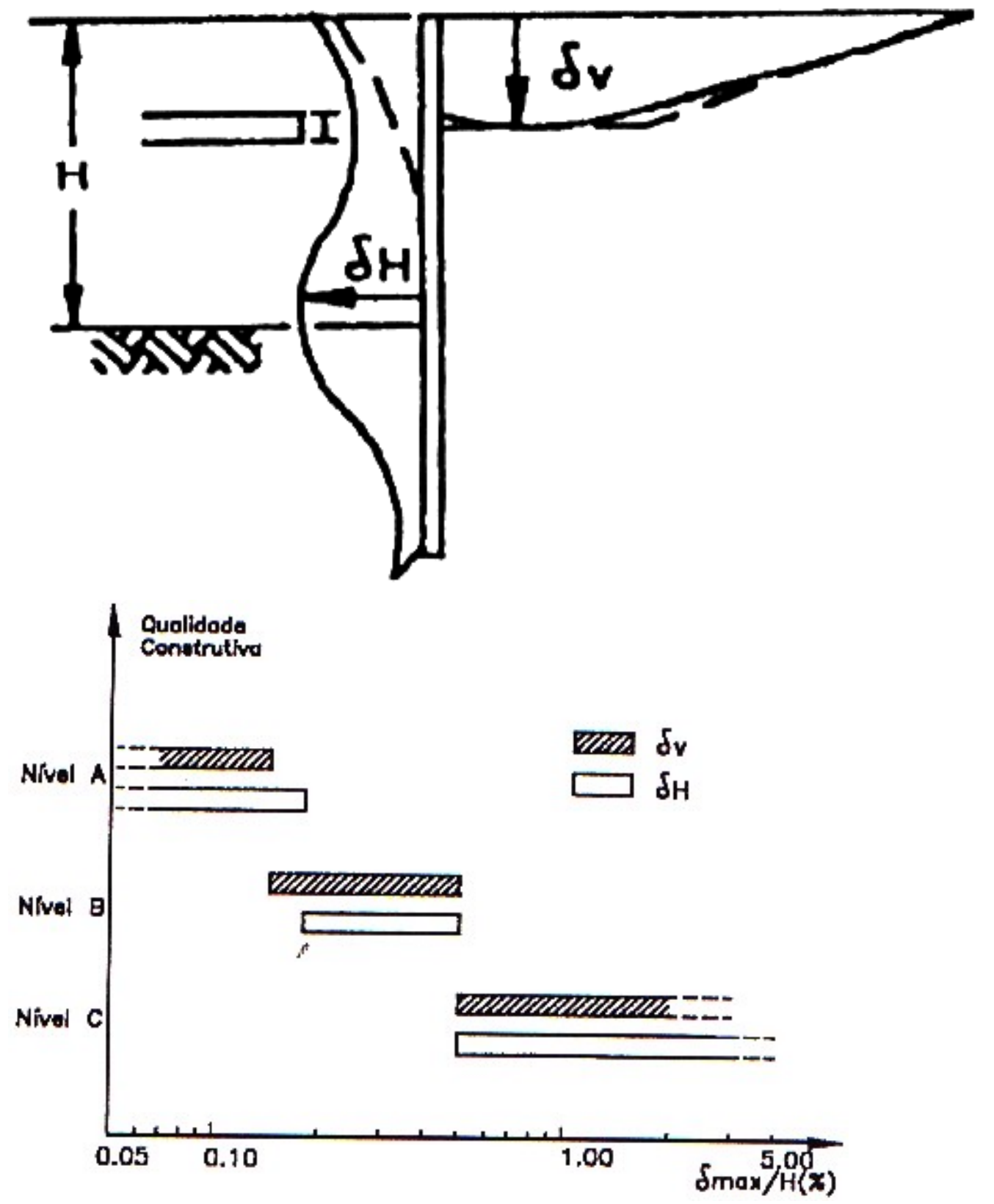

Figura 5-7- Nível de deslocamentos em função da qualidade construtiva apud O'ROURKE (1990) (RANZINI, 1996)

Em pesquisas realizadas por BOSCARDIN e CORDING (1989) foi desenvolvido um critério para estimativa de danos causados em edificações em função da deformação horizontal $\left(\varepsilon_{\mathrm{h}}\right)$ e da distorção angular ( $\beta$ que ocorreu no solo e que por conseqüência serão impostas às fundações dos edifícios. Este critério é apresentado na Figura 5-8. 


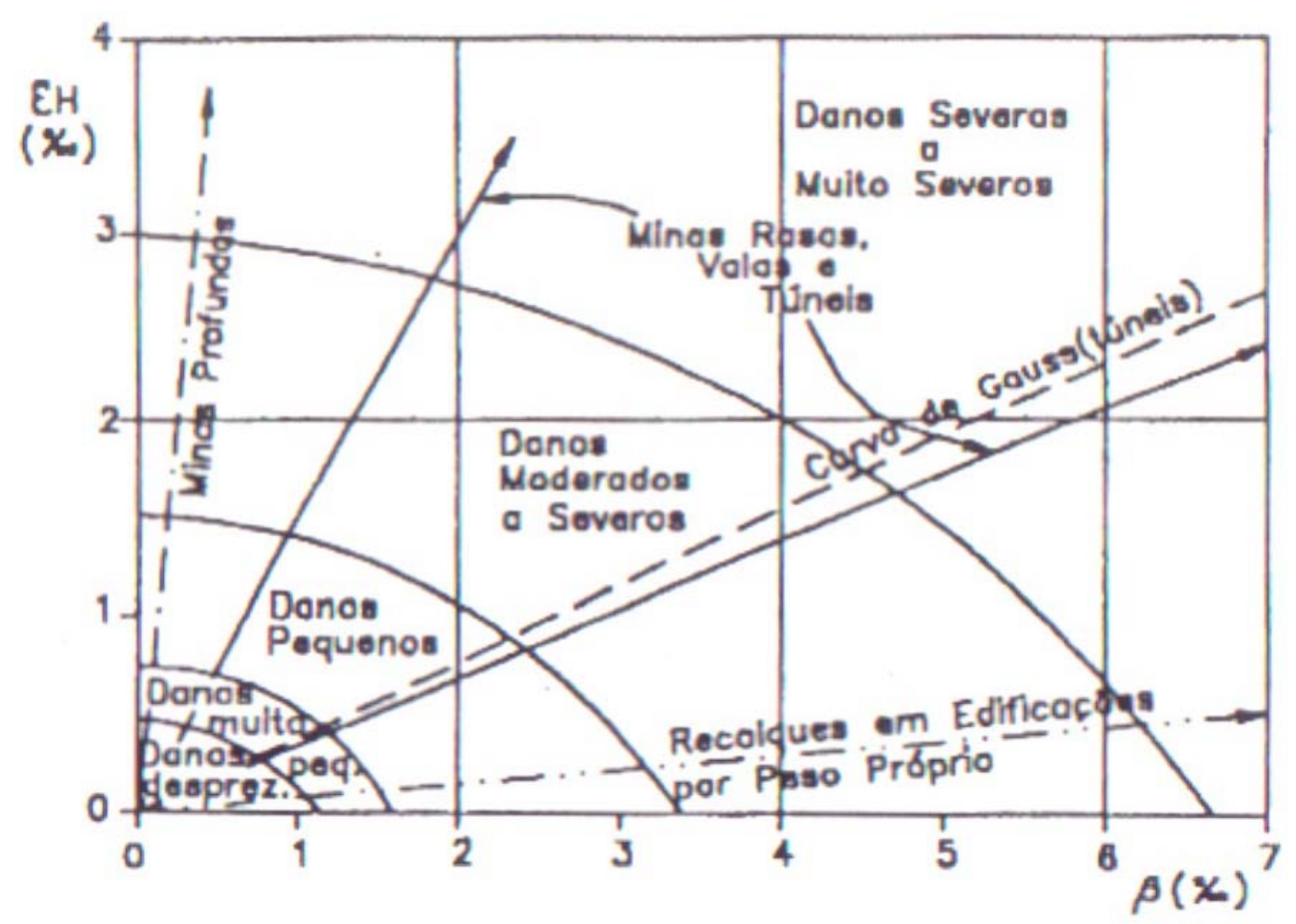

Figura 5-8- Nível de danos provocados a edifícios BORCARDIN e CORDING (1989) (RANZINI, 1996)

BURLAND et al. (1977) adotaram uma classificação de danos, que vai de desprezíveis a muito severos. Isto é feito em função da abertura das trincas, que é representada na Tabela 5-1 
Tabela 5-1-Classificação de danos em edificações BURLAND et al. (1977) (RANZINI, 1996)

\begin{tabular}{|c|c|c|}
\hline $\begin{array}{c}\text { Classes de } \\
\text { Danos }\end{array}$ & Descrição dos Danos & $\begin{array}{c}\text { Espessura } \\
\text { aproximada das } \\
\text { Trincas }(\mathbf{m m})\end{array}$ \\
\hline Desprezíveis & Trincas capilares & $<0,1$ \\
\hline $\begin{array}{c}\text { Muito } \\
\text { Pequenos }\end{array}$ & $\begin{array}{l}\text { Trincas estreitas de fácil reparo. Trincas na } \\
\text { alvenaria externa, visíveis sob inspeção } \\
\text { detalhada. }\end{array}$ & $<1$ \\
\hline Pequenos & $\begin{array}{l}\text { Trincas facilmente preenchidas. Várias fraturas } \\
\text { pequenas no interior da edificação. Trincas } \\
\text { externas e sujeitas à infiltração. Portas e janelas } \\
\text { emperrando um pouco nas esquadrias }\end{array}$ & $<5$ \\
\hline Moderados & $\begin{array}{l}\text { O fechamento das trincas requer significativo } \\
\text { preenchimento. Talvez seja necessária a } \\
\text { substituição de pequenas áreas de alvenaria } \\
\text { externa. Portas e janelas emperradas. Redes de } \\
\text { utilidade podem estar interrompidas }\end{array}$ & $\begin{array}{l}5 \text { a } 15 \text { ou várias } \\
\text { com mais de } 3 \mathrm{~mm}\end{array}$ \\
\hline Severos & $\begin{array}{l}\text { Necessidade de reparos envolvendo remoção de } \\
\text { pedaços de parede, especialmente sobre portas e } \\
\text { janelas. Esquadrias de portas e de janelas bastante } \\
\text { fora de esquadro. Paredes fora de prumo, com } \\
\text { eventual deslocamento de vigas de suporte. } \\
\text { Utilidades interrompidas. }\end{array}$ & $\begin{array}{l}15 \text { a } 25 \text { e também } \\
\text { em função do } \\
\text { número de trincas }\end{array}$ \\
\hline Muito Severos & $\begin{array}{l}\text { Reparos significativos envolvendo reconstrução } \\
\text { parcial ou total. Paredes requerem escoramento. } \\
\text { Janelas quebradas. Perigo de instabilidade. }\end{array}$ & $\begin{array}{l}\text { Usualmente }>25 \mathrm{e} \\
\text { também em função } \\
\text { do número de } \\
\text { trincas }\end{array}$ \\
\hline
\end{tabular}

A partir dos critérios de BOSCARDIN e CORDING (1989), BURLAND et al. (1977) e O'ROURKE (1990), foram estimados os danos causados ao edifício hipotético, 
já descrito nesta seção e calcularam-se os valores de recalques verticais máximos, máximos deslocamentos horizontais de paramento, máximas distorções (recalques diferenciais) e máximas deformações horizontais.

Isto foi feito para cada uma das duas situações consideradas na Tabela 4-17 para o estágio 5. Com isto obtiveram-se os níveis de danos e a qualidade construtiva a partir dos critérios citados. A Tabela 5-2 apresenta estas informações. 
Tabela 5-2- Resumo dos danos,da qualidade construtiva a partir deformações horizontais máximas, recalques verticais, distorções angulares da Tabela 4-17

\begin{tabular}{|c|c|c|c|c|c|c|}
\hline Situação & & $\begin{array}{r}\text { Deslocam } \\
\text { parame }\end{array}$ & $\begin{array}{l}\text { ntos de } \\
\text { tos }\end{array}$ & & [2]Força & roncas $A$ \\
\hline Estágio & 3 & 5 & 8 & 3 & 5 & 8 \\
\hline$\delta \mathbf{v}_{\text {máx }}[\mathbf{m}]$ & 0.0020 & 0.0049 & 0.0043 & 0.0021 & 0.0126 & 0.0105 \\
\hline$\delta H_{\text {máx . .[m] }}$ & 0.0033 & 0.0098 & 0.0160 & 0.0036 & 0.0134 & $\overline{0.0142}$ \\
\hline Ehmáx \%o & 0.098 & 2.33 & 0.641 & 0.110 & 2.370 & 1.015 \\
\hline$\beta_{\text {máx }} \% 0$ & 0.03 & 0.04 & 0.05 & 0.03 & 0.21 & 0.20 \\
\hline Hescav. [m] & 6.5 & 6.5 & 8.9 & 6.5 & 6.5 & 8.9 \\
\hline$\delta H_{\text {máx } / \text { Hescav. [\%] }}$ & 0.001 & 0.0015 & 0.0018 & 0.0006 & 0.0021 & 0.0016 \\
\hline Qualidade construtiva & A & A & A & A & A & A \\
\hline $\begin{array}{l}\text { nível de danos } \\
*\end{array}$ & D & $M$ a $S$ & $\mathbf{M} \mathbf{P}$ & D & $M$ a $S$ & $\mathbf{P}$ \\
\hline
\end{tabular}

* Nível de Danos : $\mathrm{D}=$ Desprezíveis, $\mathrm{M}=$ Moderados, $\mathrm{MP}=$ Muito pequenos, $\mathrm{P}=$ Pequenos, $\mathrm{M}$ a $\mathrm{S}=$ Moderados a Severos 
A partir da análise da Tabela 5-2 percebe-se que o critério de BOSCARDIN e CORDING (1989) apresenta variações nos níveis de danos previstos. Por este critério os tipos de danos que seriam esperados no estágio 5 das escavações, variariam de pequenos a moderados e severos. Se analisarmos a Tabela 5-1 veremos que poderiam ocorrer sérios danos à estrutura e às redes de serviço, fazendo com que a estrutura deixasse de atender ao critério de estado limite de utlização.

Estas variações não foram detectadas pelo critério de qualidade construtiva de O'ROURKE (1990), que apresentou para todas as situações o nível A de qualidade construtiva, significando construção cuidadosa, ou seja este critério demonstrou-se limitado em comparação ao critério de BOSCARDIN e CORDING (1989).

Portanto, de acordo com o defendido por BOSCARDIN e CORDING (1989), a consideração da deformação horizontal, é de extrema importância para a estimativa de danos a edificações. 


\section{6 - A forma das bacias de recalque}

Foi constatado que o melhor modelo de ajuste de deslocamentos globais foi obtido pelo modelo de Endurecimento. Além disto, o melhor ajuste de deslocamentos de paramento simulados em relação aos instrumentados foi o obtido para o estágio 5 . Fizeram-se ajustes entre vários tipos de modelos, um deles era o do tipo Yield Density aplicado por CELESTINO e RUIZ (1998) com bons resultados para ajustes a bacias de recalques instrumentadas causadas por escavações de túneis, mas que não se adequam à forma da curva de recalques de valas.

\subsubsection{Ajustes de funções polinomiais}

Dentre os tipos de equações utilizados para a averiguação da aderência às bacias de recalques simuladas, os modelos de melhor ajuste foram os de relações de polinômios. As relações polinomiais foram obtidas a partir do software de ajuste de curvas TableCurve 2D (2003).

A representação dos ajustes é feita a partir da Figura 5-9 até a Figura 5-10

As funções de ajuste podem ser visualizadas pelas curvas e os pontos foram obtidos das simulações para o estágio 5 .

Para a situação 1 (parâmetros escolhidos a partir do mínimo erro de deslocamentos do estágio 5), obteve-se a relação de polinômios de grau 3.

Obteve-se o coeficiente de correlação $r^{2}=0.99995$, sendo a equação do polinômio ajustada

$$
\mathrm{y}=\left(\mathrm{a}+\mathrm{cx}+\mathrm{ex}^{2}+\mathrm{gx} \mathrm{x}^{3}\right) /\left(1+\mathrm{bx}+\mathrm{dx} \mathrm{x}^{2}+\mathrm{fx}^{3}\right)
$$

Onde:

$\mathbf{y}$ - ordenada de um ponto de interesse da bacia de recalque. Esta ordenada tem nível de referência zero a $1 \mathrm{~m}(799,34)$ de profundidade da superfície (nível 800,34); x é abcissa de referência zero no paramento (estaca 1857) e cresce negativamente para a esquerda se afastando da vala.

$\mathbf{x}$ - abcissa do ponto considerado.

Foram obtidos os coeficientes :

$$
\begin{aligned}
& a=-0.00493795 \\
& b=-0.00078659 \\
& c=-0.00053317 \\
& d=0.00516774
\end{aligned}
$$


$e=-0.000061855$

$f=-0.00028684$

$g=-2.4256 E-07$

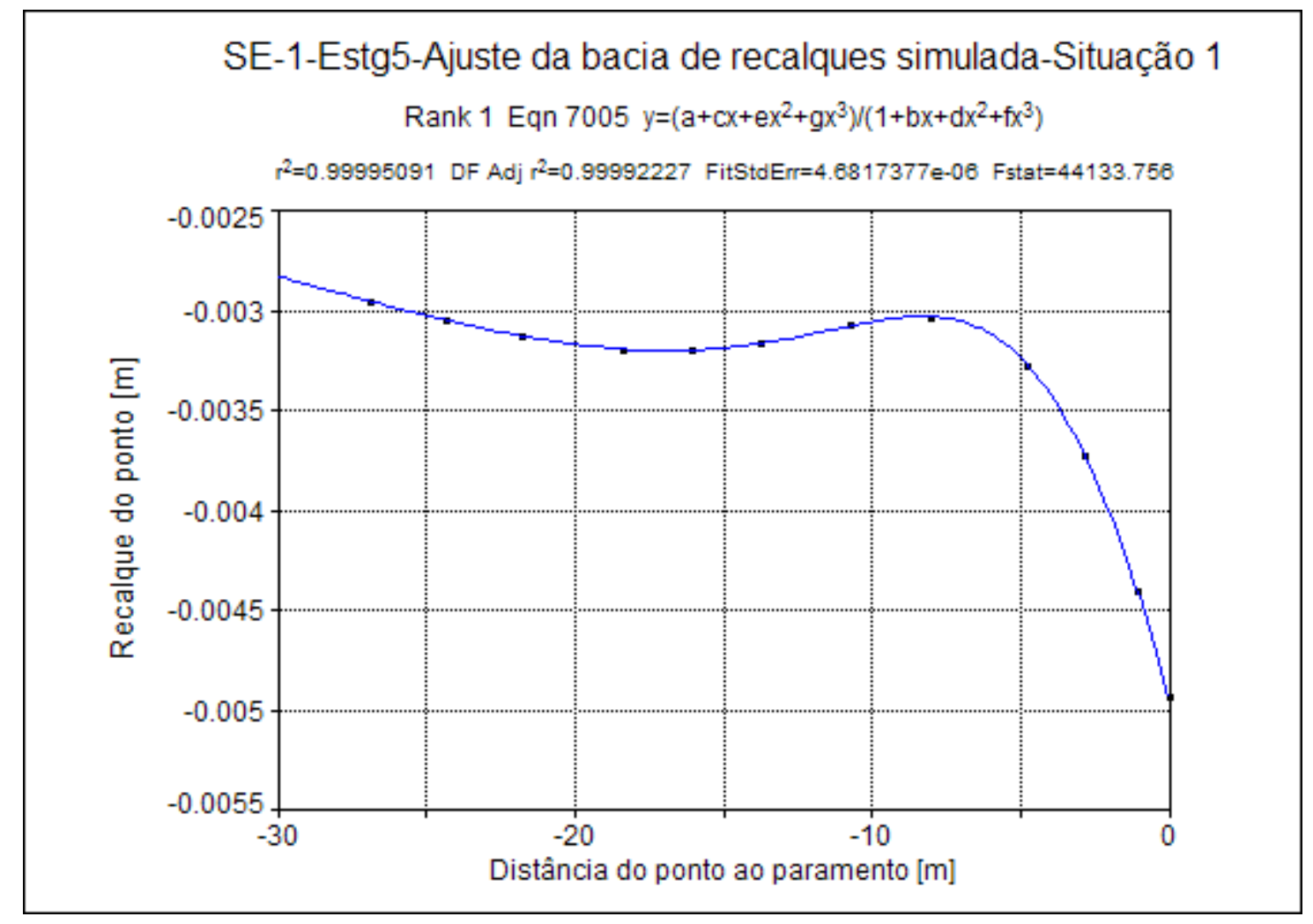

Figura 5-9-Ajuste da bacia de recalques ajustada por uma relação de polinômiossituação 1

Para a situação 2 (parâmetros escolhidos a partir do mínimo erro de forças nas estroncas) para o estágio 5 obteve-se a relação de polinômios de grau 4 $\mathrm{y}=\left(\mathrm{a}+\mathrm{cx}+\mathrm{ex}^{2}+\mathrm{gx}^{3}\right) /\left(1+\mathrm{bx}+\mathrm{dx}^{2}+\mathrm{fx}^{3}+\mathrm{hx}^{4}\right)$, com coeficiente de correlação $r=0.99272$, e coeficientes:

$a=-0.01107751$

$b=0.000617507$

$c=0.000878805$

$d=-0.00409213$

$e=0.000337385$ 
$f=-0.00409533$

$g=6.07544 E-05$

$h=5.74963 E-05$

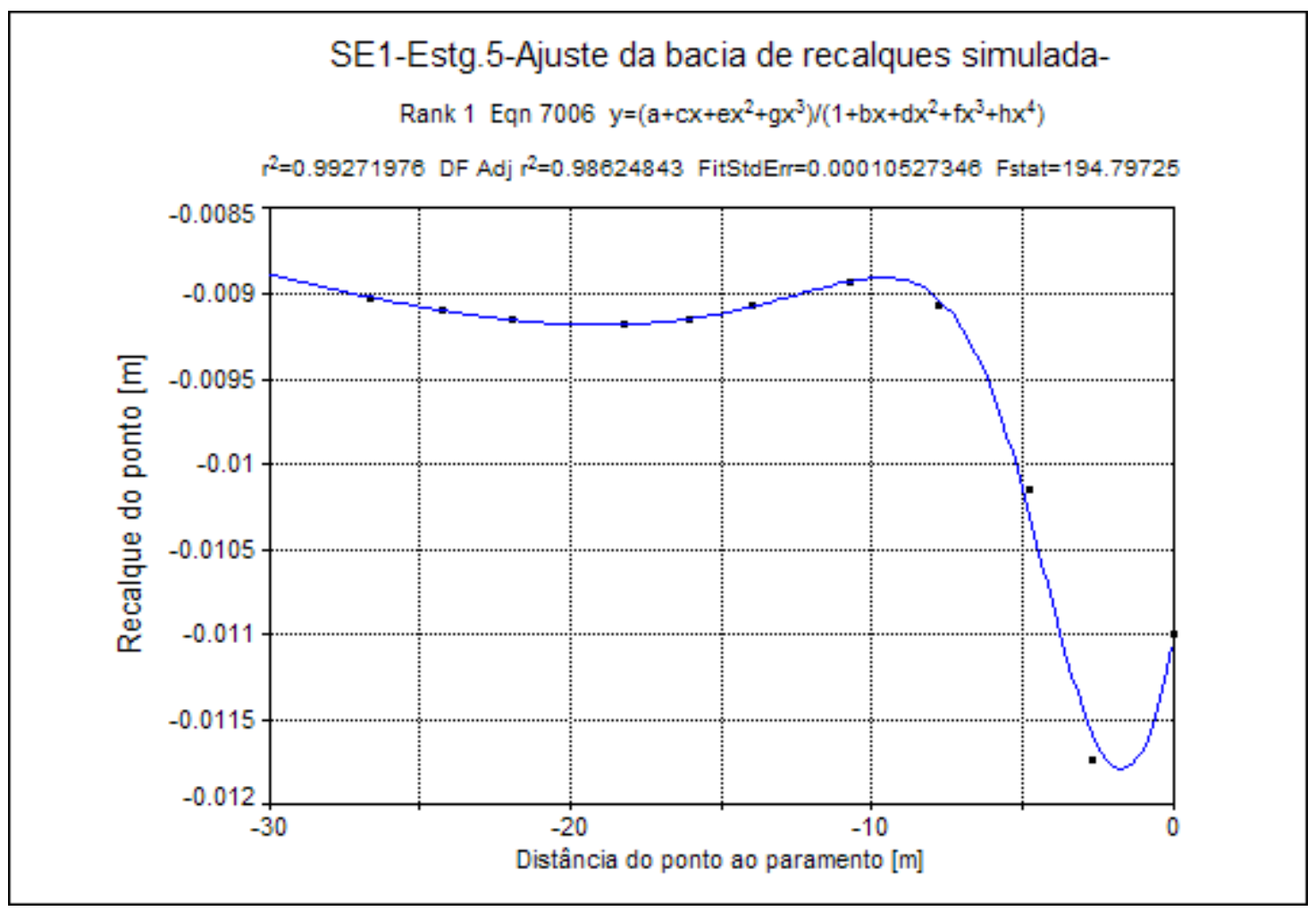

Figura 5-10 - Ajuste da bacia de recalques ajustada por uma relação de polinômios -situação 2

Da Figura 5-9 até Figura 5-10, percebe-se que as curvas que melhor descreveram as bacias de recalques simuladas para o estágio 5 , foram as de relações polinomiais de graus variando de 3 a 4 . Os ajustes tiveram $r^{2}$ superior a 0.98 , sendo muito satisfatórios. 


\section{7 -Relações entre deslocamentos horizontais máximos e profundidade da vala}

Foi desenvolvido por OU et al. (1993) um critério interessante, e de utilização muito expedita, a partir do estudo de 10 casos distintos de escavações de valas em Taiwan. As profundidades das escavações eram todas diferentes e variaram de $7.65 \mathrm{~m}$ a $21 \mathrm{~m}$ de profundidade. As larguras das escavações variaram de 31 a $140 \mathrm{~m}$ e os comprimentos de paramento de 16.75 a 33m. Os métodos construtivos foram bottomup, top-down, método das bermas e atirantamento.

O critério baseia-se nas variáveis descritas na Figura 5-11

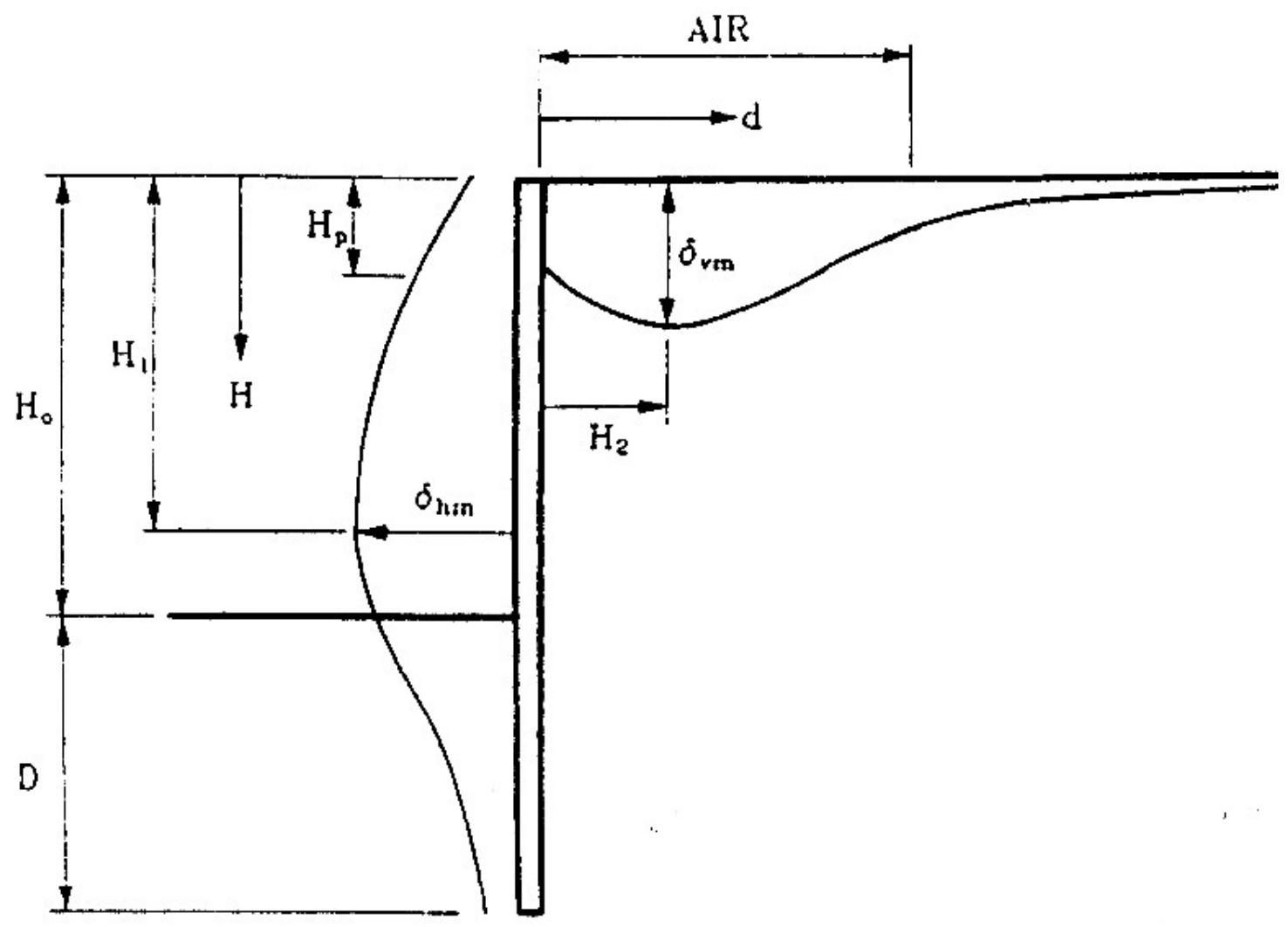

Figura 5-11-Definição das variáveis da escavação utilizadas no método, apud OU et al. (1993) 
Sendo

$H$ : a profundidade provisória da escavação no momento considerado

Ho: a profundidade final da escavação

$H p$ : o nível da estronca

$d$ : distância do ponto considerado ao paramento(na horizontal)

$D$ : comprimento da ficha do paramento

$H_{1}$ : locação da máxima deflexão horizontal.

$\mathrm{H}_{2}$ : distância na horizontal ao paramento do ponto de máximo recalque vertical

$\delta_{h m}$ : magnitude da máxima deflexão lateral do paramento

$\delta_{v m}$ : magnitude do máximo recalque de superfície

AIR: região aparente de influência

A partir dos estudos de casos de obra, os autores observaram que:

- a profundidade onde a máxima deflexão lateral do paramento ocorre aumenta com a profundidade das escavações.

- exceto para o $1^{\circ}$ estágio de escavação, a posição do ponto de máxima deflexão lateral ocorre com freqüência próximo à superfície.

Como comparação aos dez casos de Taiwan foram plotados no mesmo gráfico de OU et al. (1993) os pontos de deslocamentos horizontais máximos de paramentos instrumentados nos estágios de escavação da S.E.-1, Figura 5-12 


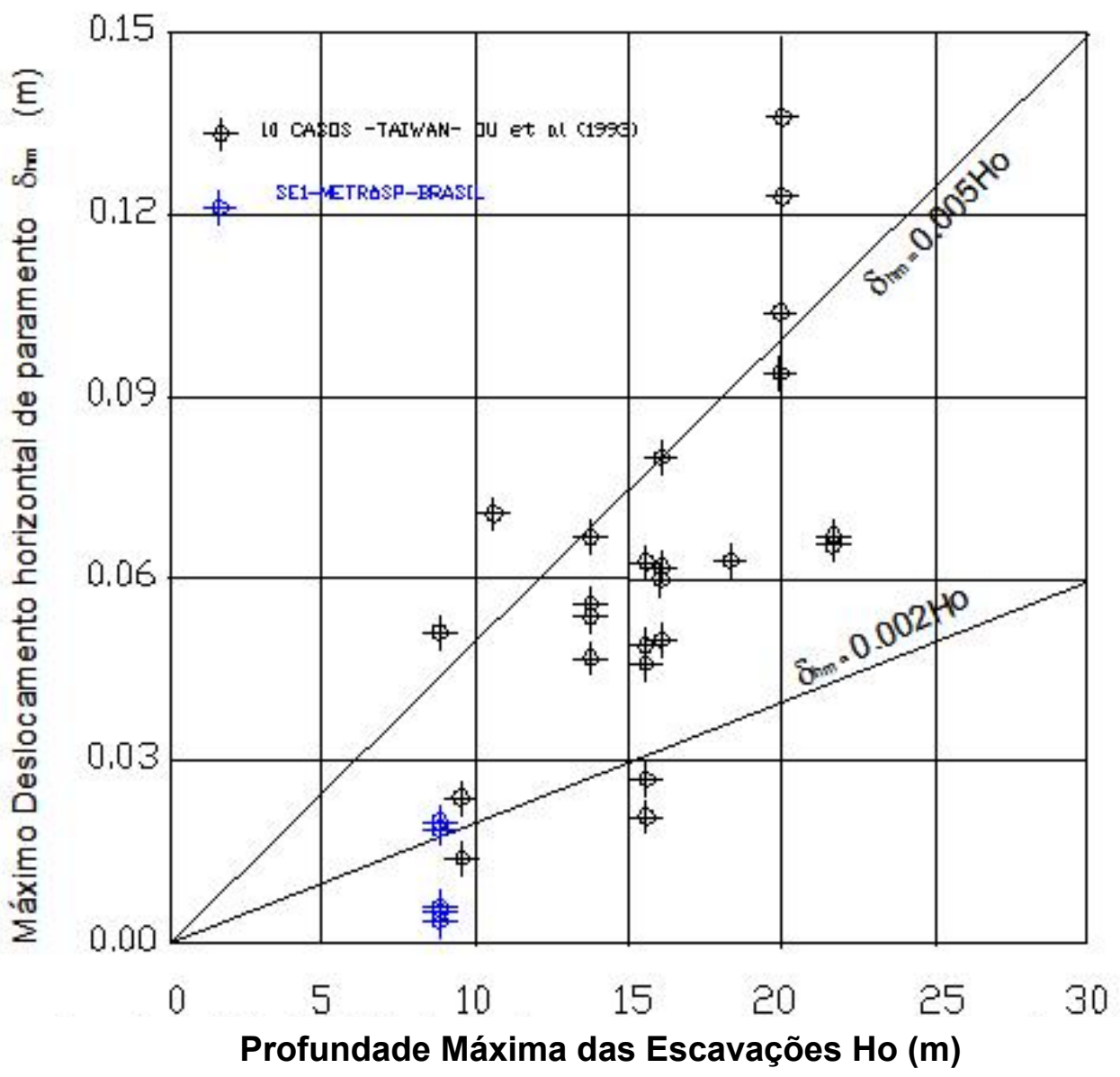

Figura 5-12- instrumentação observações de campo de OU et al. (1993) acrescidas das instrumentações da S.E.-1 Metrô S.P.

Da análise da Figura 5-12 percebe-se que aproximadamente 50\% dos pontos da S.E.-1 estiveram próximos ao limite $\delta_{\mathrm{hm}}=0.002 \mathrm{Ho}$ e os outros $50 \%$ abaixo deste limite.

Tabela 5-3-Valores da relação $\left(\delta_{\mathrm{hm}} / \mathrm{Ho}\right)$ para a S.E.-1 do Metrô S.P.

\begin{tabular}{|c|c|c|c|}
\hline Estágio & $\delta_{\mathbf{h m}} * \mathbf{1 0}^{-\mathbf{3}} \mathbf{( m )}$ & Ho $\mathbf{( ~ m})$ & $\delta_{\mathbf{h m}} / \mathbf{H o}$ \\
\hline 2 & 5.9 & 8.9 & 0,0007 \\
\hline 3 & 5.1 & 8.9 & 0,0006 \\
\hline 5 & 18.7 & 8.9 & 0,0021 \\
\hline 6 & 19.8 & 8.9 & 0,0022 \\
\hline 7 & 18.7 & 8.9 & 0,0021 \\
\hline 8 & 18.3 & 8.9 & 0,00206 \\
\hline
\end{tabular}


Outros autores desenvolveram trabalhos nesta linha podendo-se citar PECK (1969) e CLOUGH e O’ROURKE (1990).

Abaixo apresentam-se os intervalos encontrados por estes autores, em outras escavações e por este trabalho para a S.E.-1

$\delta_{\mathrm{hm}}=0.002$ Ho obtido por CLOUGH e O'ROURKE (1990)

$\delta_{\mathrm{hm}}=0.002 \mathrm{Ho} \mathrm{a} 0.005 \mathrm{Ho}$ obtidos por OU et al. (1993)

$\delta_{\mathrm{hm}}=0.01$ Ho obtido por PECK (1969)

$\delta_{\mathrm{hm}}=0.0006 \mathrm{Ho}$ a $0.022 \mathrm{Ho}$ obtidos por este trabalho para a S.E.-1

Portanto conclui-se que o limite superior dos deslocamentos máximos horizontais da S.E.-1 se aproximaram mais dos obtidos por PECK (1969) e o limite inferior aos propostos por CLOUGH e O'ROURKE (1990) e OU et al. (1993).

\section{8 -Região de influência dos recalques}

Para a previsão da região aparente de influência (AIR) onde haveria danos aos edifícios adjacentes às escavações, o método de OU et al. (1993) propõe uma relação para determinação da região aparente de influência (AIR).

Isto é feito a partir das associações do comprimento do paramento (Ho+D), associado com a tan(45- $\phi / 2)$, onde $\phi$ é o ângulo de atrito do solo. A Figura 5-13, exemplifica o exposto. 


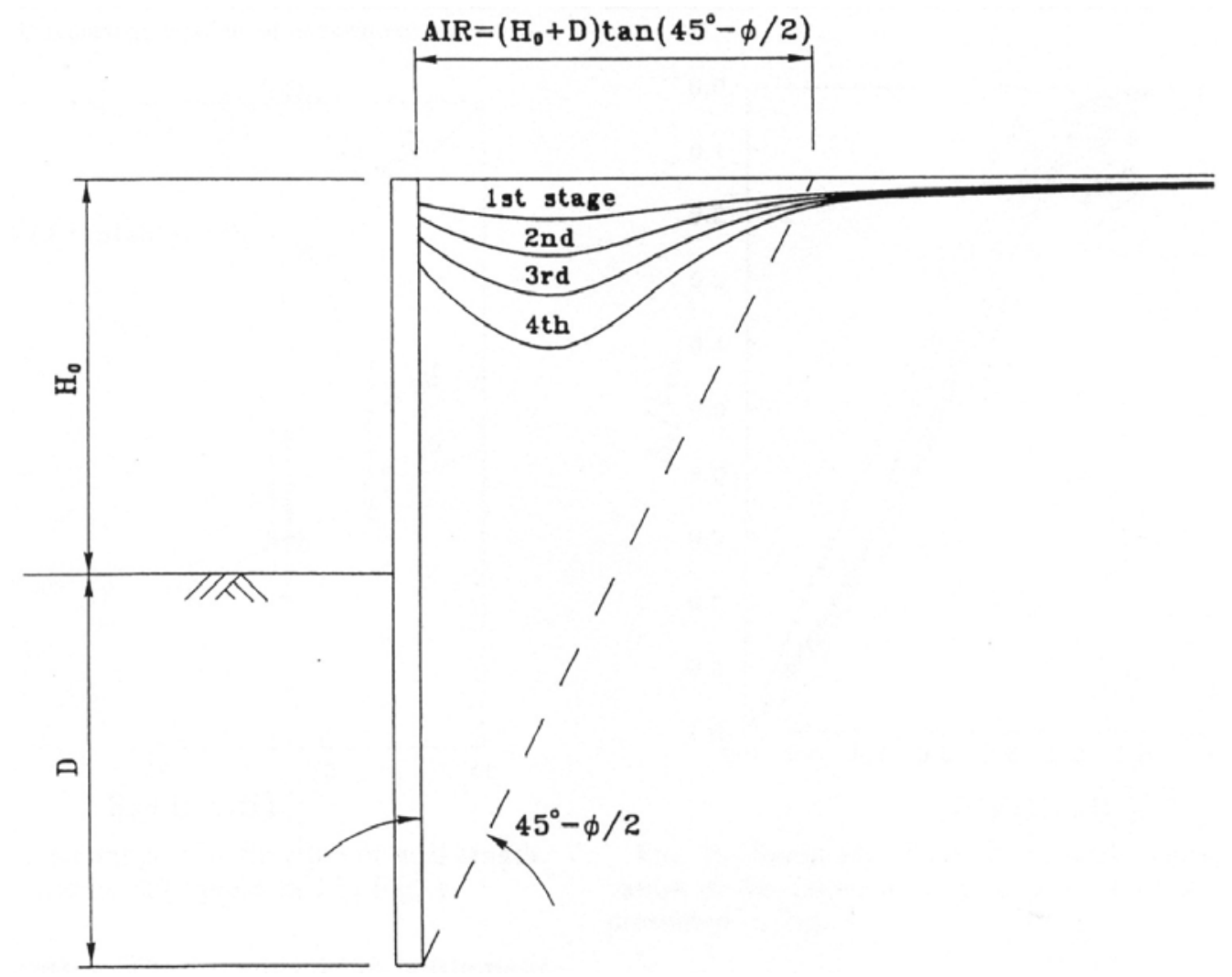

Figura 5-13-Relação entre o comprimento do paramento e a região de influência dos recalques (OU et al., 1993)

Para o caso da seção experimental 1, a região de influência da escavação, a partir do paramento seria:

$$
\begin{aligned}
& \mathrm{AIR}=(\mathrm{Ho}+\mathrm{D}) * \tan \left(45^{\circ}-\phi / 2\right) \\
& \mathrm{AIR}=6.73 \mathrm{~m}
\end{aligned}
$$

De acordo com a norma NC-03 (1980) do Metrô S.P., a curva de recalques de superfície tem a forma aproximada de uma parábola de $2^{\circ}$ grau, anulando-se a uma distância de $2^{*}$ Hescavação, ou seja, a $17.8 \mathrm{~m}$ de distância para o estágio 8 e a $13 \mathrm{~m}$ para o estágio 5.

Os resultados obtidos pelas simulações da S.E.-1 indicaram um recalque vertical máximo de 5,4mm. Sendo que para este caso a NC-03 (1980) sugere que para argilas porosas siltosas vermelhas:

$$
\delta_{\text {vertical }}=0.15 \% * \mathrm{H}_{\text {escavação }}
$$


Para o estágio $5, \mathrm{H}_{\text {escavação }}=6.5 \mathrm{~m}$, então, $\delta_{\text {vertical }}=9.75 \mathrm{~mm}$, portanto, sendo aproximadamente o dobro do valor obtido de acordo com a previsão obtida pelas simulações para o estágio 5. Estando portanto o critério do Metrô de São Paulo a favor da segurança com relação a este caso hipotético estudado.

Para averiguar a coerência das relações de recalques $\mathrm{x}$ profundidades máximas de escavação e de recalques $\mathrm{x}$ distância do paramento, obtidas via simulação, com a figura elaborada por PECK (1969), Figura 5-14, calcularam-se as relações:

Recalque / máx. profundidade da escavação $=\delta_{\mathrm{v}} / \mathrm{H}_{\text {máx }}$.

Distância à escavação / máx. profundidade da escavação $=\mathrm{D} / \mathrm{H}_{\text {máx }}$.

A partir dos resultados de recalques de 1 a $5 \mathrm{~mm}$, obtidos de 0 a $25 \mathrm{~m}$ do paramento pelas simulações do estágio 5 , e a profundidade máxima de escavação $(\mathrm{H}=8.9 \mathrm{~m})$, obtiveram-se os extremos superiores e inferiores do intervalo:

$0.001 / 8.9$ a $0.005 / 8.9=0.01 \%$ a $0.06 \%$ limites inferior e superior de $\delta_{\mathrm{v}} / \mathrm{H}_{\text {máx }}$, relativos ao estágio 5 .

$25 / 8.9=2.81$ valor de $\mathrm{D} / \mathrm{H}_{\text {máx }}$ para o ponto a $25 \mathrm{~m}$ do paramento

Analisando-se estes resultados e locando-os na Figura 5-14, que representa o critério proposto por PECK (1969), percebe-se que eles estão na região II , correspondente às argilas muito moles a moles, portanto, de forma coerente com o tipo de solo da S.E.-1 em estudo. 


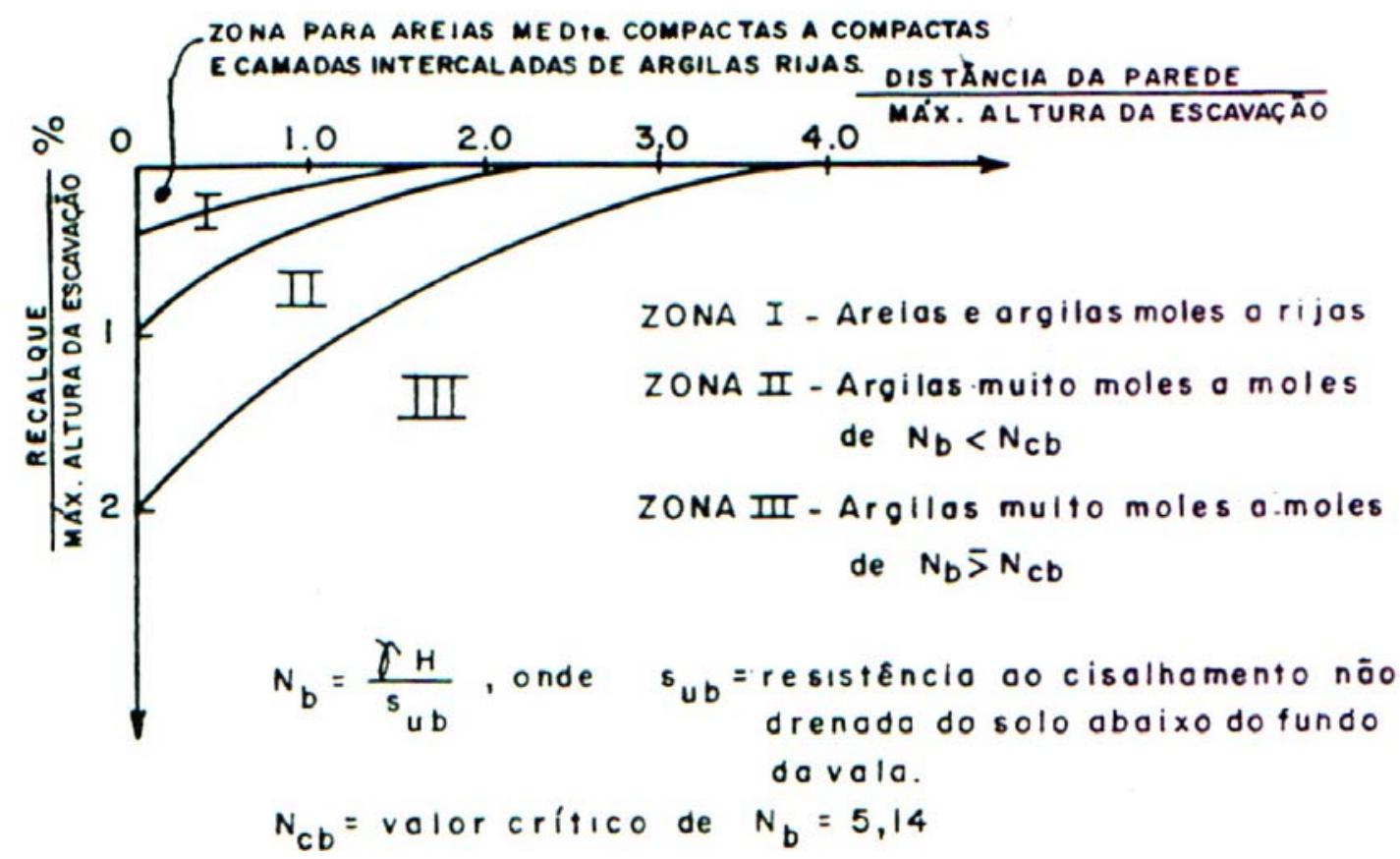

Figura 5-14- Proposição de PECK (1969) relacionando recalques e distâncias da escavação com profundidade da escavação, figura traduzida por NC-03 (1980). 


\section{Capítulo 6 - CONSIDERAÇÕES FINAIS E TRABALHOS FUTUROS}

Comparando-se os modelos de Mohr-Coulomb e de Endurecimento, percebe-se que a retroanálise com o modelo de Endurecimento apresentou erros menores que com o modelo de Mohr-Coulomb em todos os estágios para forças nas estroncas e com relação aos deslocamentos de paramentos no estágio 8 . Apenas no estágio 3 pode-se considerar que a qualidade dos resultados foi semelhante tanto para forças nas estroncas como para deslocamentos de paramentos. O melhor ajuste de deslocamentos de paramentos foi obtido para o estágio 5 .

Da análise dos resultados obtidos, para o modelo de Endurecimento considerase que:

- $\quad$ O conjunto de parâmetros que torna os resultados dos modelos simulados (para os estágios 3 e 5) mais próximos aos da instrumentação é:

$c=\mathrm{f}(\mathrm{SPT}) \mathrm{kPa}$ obtida do ensaio in situ SPT

$K o=[0,4$ a 0,53$]$ coerente com ensaios de laboratório

$\gamma_{\text {nat }}=13,5 \mathrm{kN} / \mathrm{m}^{3} \quad$ coerente com ensaios de laboratório

$E_{50=}[2800$ a 360000$] \mathrm{kPa}$.

Rinter $=[0,2$ a 0,5$]$

Os valores de $E_{50}$ obtidos por retroanálise para a camada 2 de argila porosa no estágio 3 (modelo de Endurecimento) superaram muito os valores obtidos em laboratório por MASSAD (1992). Porém os resultados de $E_{50}$ obtidos em laboratório não avaliam o comportamento do sistema solo-estrutura, mas apenas o material solo. Por outro lado, para solos estruturados como é o caso da argila porosa, é sabido que ensaios triaxiais e de placa produzem resultados de módulos inferiores aos reais, por 
efeitos de quebra de estrutura, muitas vezes ausentes nas solicitações do processo de escavação de valas.

- O modelo de Endurecimento foi superior ao de Mohr-Coulomb para representar as escavações desta seção experimental estudada. Porém isto, não significa que ele seja o mais apropriado para simular o comportamento da argila porosa. Além disto, se não houver correção da restrição ao valor mínimo de $E_{u r}=2 * E_{50}$, para valores menores que 2 , este modelo parece apresentar limitações para representar os avanços de escavação desta seção experimental.

- É necessário aferir o modelo de Endurecimento e o de Mohr-Coulomb com os resultados obtidos pelo já consagrado software do Metrô de São Paulo (ESCOR), que já foi aferido com dados de instrumentação de muitas escavações ao longo das construções das linhas do Metrô, desta forma será possível saber se os modelos em M.E.F. utilizados (software PLAXIS (2002)), são confiáveis e se podem ser utilizados em projetos. Principalmente pelo modelo de endurecimento ter sido concebido e testado para condições de solos europeus e americanos.

Da análise dos resultados obtidos para o modelo de Mohr-Coulomb considerase que:

- O conjunto de parâmetros que torna os resultados do modelo (para os estágios 3

e 5) mais próximos aos da instrumentação é:

$$
\begin{aligned}
& c=[10 \text { a } 30] \mathrm{kPa} \\
& K o=0,45 \\
& \gamma_{\text {nat }}=15 \mathrm{kN} / \mathrm{m}^{3} \\
& E_{50}=[3200 \text { a } 72000] \mathrm{kPa} \\
& \text { Rinter }=0,5
\end{aligned}
$$

Todos estes parâmetros estão coerentes com os valores obtidos em laboratório por MASSAD (1992) e MASSAD (1978).

- Para o estágio 8 nada se pode afirmar, pois a versão 7 do PLAXIS (1998) utilizada na primeira fase de estudos (modelo de Mohr-Coulomb), tem uma limitação quanto à representação de aplicação simultânea de forças concentradas (efeito de temperatura) no nível B e no nível A de estroncamento. 
- A técnica de retroanálise aliada ao software Plaxis através de MEF mostrou-se eficiente, servindo aos propósitos do trabalho.

- A retroanálise somente baseada em valores de deslocamentos de paramentos pode conduzir a resultados que mascaram a realidade, dando a falsa impressão de que se obteve um bom ajuste em relação ao protótipo instrumentado. Este fato só pode ser confirmado se houver também medições de forças nas estroncas e recalques de superfície.

- Dentre os fatores que podem ter prejudicado os ajustes da simulação aos resultados de instrumentação deve-se citar:

- A possibilidade de erros de instrumentação, de acordo com o observado nos estágios 1 e 4 . A ausência de informações relativas às sobrecargas acidentais durante o período de leitura dos instrumentos, como caminhões e equipamentos de escavação.

- $\quad$ elevado valor do módulo $E_{u r}=2 * E_{50}$ (limite inferior do software), que impediu que o processo de retroanálise fosse feito para valores menores dessa relação, principalmente sabendo-se que MASSAD (1992) obteve valores mínimos de $E_{u r}=1,2 * E_{50}$

- Simplificações feitas no cálculo quanto à consideração do papel efetivo dos pranchões em um modelo de deformações planas.

- Simplificações feitas na consideração da "continuidade" do paramento, não tendo sido possível considerar as variações dos deslocamentos relativos solo-perfil e solo-pranchões, sendo que o solo não obedece ao estado plano de deformações junto à contenção.

- Simplificações na consideração do encunhamento e no comportamento de sua interface com os perfis.

- Simplificações nas considerações dos efeitos de temperatura por limitações do software, pois não permite a aplicação de temperaturas diferentes na face superior e inferior do perfil (estroncas). Ausência de dados sobre a temperatura do paramento. 
- Da análise paramétrica realizada, há indícios que os parâmetros que mais influenciam nos deslocamentos horizontais e verticais de paramentos e nas forças das estroncas dependem da magnitude de todos os parâmetros, do estágio de escavação analisado, do ponto do paramento em estudo e do nível das estroncas.

- Quanto às previsões de danos à edificação hipotética feita para o estágio 5, o modelo de BOSCARDIN e CORDING (1989) mostrou-se conceitualmente mais consistente que o modelo de O'ROURKE (1990).

- Quanto à previsão dos recalques verticais hipotéticos, o modelo simulado se aproximou mais dos valores previstos por CLOUGH e O'ROURKE (1990) e OU et al. (1993).

- Quanto à forma das bacias de recalque os modelos de relações polinomiais de graus 3 a 4 resultam em ótimos ajustes.

- O critério empírico proposto pela NC-03 do Metrô S.P., estimou o máximo recalque vertical para o estágio 5 como sendo o dobro do encontrado nas simulações, sendo portanto a favor da segurança para este caso hipotético.

- O critério proposto por PECK (1969), para regiões de valores de recalques esperados em função dos tipos de solo, mostrou-se muito adequado e preciso.

\section{Trabalhos futuros}

- Fica a sugestão, nos casos de paredes atirantadas, tanto de comportamento rígido como flexível, de que sejam instrumentadas as forças nos tirantes, para que o critério de decisão da escolha do intervalo de parâmetros adequados não fique somente baseado em erros de deslocamentos horizontais de paramento.

- Outro parâmetro importante a ser instrumentado é o deslocamento vertical de paramentos, muito influenciado pelo fator de redução de adesão na interface $R_{\text {inter }}$, uma vez que o deslocamento relativo dos materiais na interface tem 
grande relevância sobre deslocamentos verticais de paramento e esforços nas estroncas.

- Com relação a análise paramétrica seria esclarecedor se fossem feitas variações individuais diferentes de $+30 \%$ e $-30 \%$ utilizadas para esta seção experimental estudada e para outras.

- Em virtude da grande variabilidade das cargas nas bordas e mesmo dentro das valas, seria muito útil colocarem-se células de carga enterradas para registros de tais cargas. Além disto, filmadoras e levantamento fotográfico diário, ajudariam a detectar a influência que a presença de veículos como caminhões basculantes e retroescavadeiras possam causar no deslocamento de paramento como nas forças das estroncas.

- É necessária também a medida de poropressões, que sabemos influenciar bastante o comportamento dos solos, pois a ocorrência de chuvas mesmo que rápidas, pode alterar estes valores, e trazer conseqüência sobre esforços nas estroncas e deslocamentos de paramentos.

- A medida de Ko em tempo real (durante as escavações) com dilatômetros permitirá a redução das combinações de parâmetros, reduzindo-se assim o tempo de retroanálise e o melhor conhecimento da taxa de variação de $K o$ com a variação da poropressão e das tensões normais e sobrecargas acidentais.

- É de fundamental importância que sejam feitas programações e ensaios de parâmetros e que todas as medidas venham acompanhadas das variabilidades para que seja possível aplicar o modelo de retroanálise probabilística.

- A medição da temperatura também nos paramentos e no solo deve ser feita concomitantemente com as leituras nas estroncas e devem ser lidas com freqüência elevada.

- Deve-se alterar no software PLAXIS o limite mínimo para redução do módulo de carregamento-descarregamento a um valor menor que 2, para que não haja restrição ao processo de retroanálise. 
- O desenvolvimento de um módulo de retroanálise para o software PLAXIS pouparia muito tempo na entrada e saída de dados, principalmente neste trabalho onde foram realizadas 810 simulações.

- O desenvolvimento no software PLAXIS de função de temperatura que permita aplicar diferenciais de temperatura (nas faces dos perfis) tanto no paramento como nas estroncas. 


\section{Capítulo 7 - BIBLIOGRAFIA}

AKAMINE, I. (1985). Análise dos Resultados da Instrumentação da Estação República do Metrô de São Paulo. Dissertação (Mestrado) - Escola Politécnica , Universidade de São Paulo, São Paulo. 1985

AKUTAGAWA,S. (1991). A Back Analysis Program System for Geomechanics Applications . 325p. PHD thesis - University of Queensland, Queensland. 1991.

AlOUCHE, L. A. (1983). 15 Anos da Companhia do Metropolitano de São Paulo. São Paulo : Companhia Lithográphica Ypiranga

ANJOS, A. P. V. (1996). Análise do Comportamento Tensão-Deformação de um Solo Adensado Anisotropicamente e Carregado Segundo Diferentes Trajetórias de Tensões. Dissertação (Mestrado) -Escola Politécnica, Universidade de São Paulo, São Paulo. 1996.

AOKI , N. e CINTRA, J. C. A. (1999). Carga Admissivel em Fundações Profundas . São Carlos : Universidade de São Paulo Projeto Reenge.

ASCE (1996). American Society of Civil Engineers. Technical Engineering and Design Guides as Adapted From The U.S.-Army Corps Of Engineers No 15 - Design Of Sheet Pile Walls . Virginia-USA

BERNARDES,H.M. (2000). Retroanálise do efeito estrutural das reações álcaliagregado em barragens de concreto. - Tese (Doutorado) - Escola Politécnica Universidade de São Paulo, São Paulo. 2000.

BRANCO, P. ; NEGRO, A. ; COTINHO P. T. (1990). Recalques de superfície, qualidade construtiva de túneis e danos em edificações. Simpósio sobre Instrumentação Geotécnica de Campo -ABGE, v.único , n., p.239-247 ,Rio de Janeiro CELESTINO, T.B. ; MITSUSE, C. T. ; FERRARI, O. A. ; LEMOS, L. B. (1987). Avanços técnicos obtidos na execução dos túneis singelos da extensão norte do metrô 
de São Paulo-Anais do $5^{\circ}$ Congresso Brasileiro de Geologia de Engenharia. ABGE, p.33-62, São Paulo.

CELESTINO, T.B. e RUIZ, A.P.T. (1998). Shape of settlement troughs due to tunnelling through different types of soft ground -Felsbau16:2, p.118-121

CHERUBINI C. (2000). Probabilistic Aproach to the design of anchored sheet pile walls. Computers and Geotechnics. , 26, 309-330.

CIVIDINI,A.; JURINA,L.; GIODA,G. (1981). Some aspects of 'characterization' problems in geomechanics. International Journal of Rock Mechanics and Mining Sciences. v.18 p.487-503.

CIVIDINI, A.; MAIER, G.; NAPPI, A. (1983). Parameter estimation of a static geotechnical model using a Bayes' approach. Fifth international Conference on Numerical Methods in Geomechanics .v.20, N.5 p.215-226.

CIVIDINI,A.; GIODA, G.; CARINI,A. (1991). A finite element analysis of the time dependent behaviour of underground openings . Computers and Geotechnics. p.14491454.

CLOUGH, G. W., and DUNCAN, e O'ROURKE, T.D. (1990). Construction- induced movements of in situ walls.Proceedings Designs and Performance of Earth Retaining Structure, ASCE Special Conference, Ithaca, New York, p. 439-470.

NC-03 (1980). Normas técnicas complementares. Companhia do Metropolitano de São Paulo. São Paulo,v. II .

BOSCARDIN, M.D.; CORDING, E. J. (1989). Building response to excavationinduced settlement . Journal of Geotechnical Engineering -ASCE , v.115 , n., p.1-21, COSTA, A. (2000). Aplicação das técnicas de retroanálise em obras civis. 96p. Dissertação (Mestrado)- Escola Politécnica, Universidade de São Paulo, São Paulo. 2000 .

COZZOLINO, V. M. N. (1972). Tipos de sedimentos que constituem a bacia de são paulo. 116p. Tese (Doutorado) - Escola Politécnica, Universidade de São Paulo, São Paulo. 1972.

DUNCAN, J. M. e CHANG, C.Y. (1970). Nonlinear analysis of stress and strain soils . Journal of the Soil Mechanics and Foudantions Division, ASCE, vol. 96, No SM5, 99. 1629-1653 
DESAI, C S e SIRIWARDANE, H J (1984). Constitutive Laws for Engineering Materials with Emphasis on Geologic Material. New Jersey : Prentice-Hall, Inc., Englewood Cliffs.

ESQUÍVEL, E.R. (1978). Análise de estruturas de contenção de valas: a importância dos modelos bidimensionais. $6^{\circ}$ Congresso Brasileiro de Mecânica dos Solos e Engenharia de Fundações , São Paulo 1978, v.II , p.93-111

FENG, Z. L. E LEWIS, R.W. . (1987). Optimal estimation of in situ ground stresses from displacement measuremeṇt . International Journal for Numerical and Analytical Methods in Engineering , v., n.11, p.391-408.

FUJII, J. (1976). Método dos Elementos finitos aplicado ao problema de escavação. 309p. Dissertação (Mestrado) - COPPE, Universidade Federal do Rio de Janeiro, Rio de Janeiro. 1976.

GENS, A. ; LEDESMA A. ; ALONSO, E. E. . (1988). Back analysis using prior information-aplication to the staged excavation of a cavern in rock. Proceedings of the Sixt International Conference on Numerical Methods in Geomechanics , v., n., p.20092016.

GIODA, G. (1980). Indirect identification of the average elastic characteristics of rock masses .Proceedings of the International Conference on Structural Foundations on Rock, Sydney, p.65-73.

GIODA, G.; JURINA,L. (1981). Numerical identification of soil-structure interaction pressures. International Journal for Numerical and Analytical Methods in Geomechanics , v.5, p.391-408.

GIODA, G.; MAIER, G. . (1980). Direct search solution of a inverse problem in elstoplasticity: identification of cohesion, friction angle and in situ stress by pressure tunnel tesț . International Journal for Numerical Methods in Engineering , v., n.15, p.1823-1848,

GUERRA, E. S. (1982). Cálculo Estático de Escoramentos de Valas: Proposta de Metodologia para Construção de Envoltória Aparente de Tensões. Dissertação (Mestrado) - Escola Politécnica, Universidade de São Paulo, São Paulo. 1996.

HACHICH,W. ; NEGRO JR.; A. (1990). Retroanálise probabilística: um modelo para interpretação de medidas de convergência em túneis. in: Simpósio sobre Instrumentação Geotécnica de Campo-SINGEO'90. Rio de Janeiro

HASUI, Y.; SADOWSKI, G. R. ; CARNEIRO, A. M. . (1975). The Ribeira Folded Beḷt . Revista Brasileira de Geociencias , v.5, n., p.257-266, 
IPT (1972). Observação do comportamento de numa escavação para construção do Metrô - secção experimental $\mathrm{n}^{\mathrm{o}}$ 1- Relatório $n^{o} 6294$ - Instituto de Pesquisas Tecnológicas ( $5^{\circ}$ via), abril, São Paulo

IPT2 (1972). Comportamento do escoramento numa escavação do Metrô de São Paulo Secção Experimental n ${ }^{\circ}$ 1- Publicação ${ }^{\circ} 963$ - Instituto de Pesquisas Técnológicas, sem data, São Paulo.

ISE (1989) The Institution of Structural Engineers, The Institution Of Civil Engineers, International Association for Bridge and Structural Engineering- Soil Structure Interaction-The real behaviour of structures. London : Institution of Structural Engineers.

KAVANAGH K. T. (1973). Experiment versus analysis : computational techniques for the description of static material response. International Journal for Numerical Methods in Engineering, v.5, p.503-515.

KIM,Y.T.; LEE,S.R. (1997). An equivalent model and back-analysis tecnique for modelling in situ consolidation behavior of drainage-installed soft deposits. Computers and Geotechnics .v. 20,n.2. p.125-142.

KIRSTEN, H. A. D. (1976) Determination of rock mass elastic moduli by back analysis of deformation measurements. Proceedings of the Symposium on Exploration for Rock Engineering, Johannersburg, p. 165-172.

LAMBE, T. W. (1973) -Predictions in Soil Engineering-Geotechnique v. 23, n.2, p. 149-202

LEE,I-M; KIM, D-H. (1999). Parameter estimation using extended Bayesian method in tunnelling . Computers and Geotechnics . v.24 p.109-124.

LEITE, R.L.L. (1992) Escavações Escoradas In: Mesa redonda solos da cidade de São Paulo, São Paulo., p. 279-328.

LEVADA, C. (1996). Aplicação do modelo elasto-plástico de Kim-Lade na representação do comportamento tensão-deformação de solos da cidade de São Paulo . 140p. Dissertação (Mestrado) - Escola de Engenharia de São Carlos, Universidade de São Paulo, São Carlos. 1996.

MAFFEI, C. E. M. ; ESQUIVEL, E R. ; SOZIO, L. E. ; MARZIONA, J. D. (1987)

Reduction of bracing system through monitoring . International Conference on Soil Structure Interaction, Paris -França, p. 641-648. 
MARZIONNA,J.D. (1979) Sobre o cálculo estático de valas. 81p. Dissertação (Mestrado) -Escola Politécnica, Universidade de São Paulo, São Paulo, 1981.

MASSAD, F. (1978). Efeito da temperatura nos empuxos de terra sobre escoramentos de vala. 200p. Tese (Doutorado) - Escola Politécnica, Universidade de São Paulo, São Paulo. 1978.

MASSAD,F.;PINTO,C.S.; NADER,J.J. (1992). Resistência e deformabilidade .

In:Arsenio Negro Jr. Argimiro A. Ferreira Urbano R. Alonso Paulo A. C. Cruz . Solos da Cidade de São Paulo .São Paulo ,Cap.5 ,p.141-180.

MITCHELL (1992).-Fundamentals of soil behavior-Berkeley-2a. ed.

NIMIR, W.A. (1979). Sobre o cálculo de paredes-diafragma em valas de metrôs .158p. Tese (Doutorado) - Escola de Engenharia de São Carlos, Universidade de São Paulo, São Carlos. 1979

NC-03 (1980). Normas Técnicas Complementares- Companhia do Metropolitano de São Paulo- Capítulo V, vol II -Cálculo das Obras do Método em Trincheira”- São Paulo OU, Y.C. e HSIEH, P.G. e CHIOU, D.C. (1993). Characteristics of ground surface settlement during excavation - Canadian Geotechnical Journal , n.30 p. 758-767. PARREIRA, A. B. (1991). Análise de Túneis Rasos em Solo - O Túnel Mineiro Paraíso da Linha Paulista do Metropolitano da Cidade de São Paulo. 296p. Tese (Doutorado) Pontifícia Universidade Católica, Rio de Janeiro. 1991.

PECK R. B. (1969). “Deep excavations and tunneling in soft ground: State-of-the- Artreport "Proceedings $7^{\text {th }}$ Int. Conf. On Soil Mech. and Found. Engineering, Sociedad Mexicana de Mecanica de Suelos, Mexico City, 225-290.

PENNA, A. S. D. P. D. (1982). Estudo das propriedades das argilas da cidade de São Paulo aplicado à engenharia de fundações . 266p. Dissertação (Mestrado) - Escola Politécnica, Universidade de São Paulo, São Paulo. 1982.

PINTO, C. S. (1996). Propriedades dos Solos. In: HACHICH, W. et al. (editores). Fundações Teoria e Prática. São Paulo : AMBS/ABEF/PINI-Cap. 2, p. 51-118. PINTO, C. S. (2000). Curso básico de mecânica dos solos. São Paulo :Ofitextos. PLAXIS (1998). Finite element code for soil and rock analyses-version 7. Netherlands: PLAXIS B.V.-Licença pertencente ao grupo de Geotêxtil da EESC-USP.

PLAXIS (2002). Finite element code for soil and rock analyses -version 8.1: Netherlands - PLAXIS B.V. -Licença pertencente a Terratek- Rio de Janeiro. 
RANZINI, S. M. T., NEGRO, ARSÊNIO JR. (1996). Obras de contenção: tipos, métodos construtivos, dificuldades executivas. In: HACHICH, W. et al. (editores). Fundações Teoria e Prática. São Paulo : AMBS/ABEF/PINI Fundações Teoria e Prática Capítulo 13-pp. 497-515 São Paulo, 1ª . Edição, editora Pini.

RICCOMINI, C. (1989). O Rift Continental do sudoeste do Brasịl. 256p. Tese (Doutorado)- Instituto de Geociências, Universidade de São Paulo, São Paulo. 1989.

SCHANZ, T. E VERMEER, P. A. E BONNIER, P.G. (1999). The Hardening soil model : formulation and verification . Beyond 2000 in Computational Geotechnics - 10 Years of Plaxis International, v., n., p.281-295.

SAKURAI, S; TAKEUCHI,K. (1983). Back analysis of measured displacements of tunnels. rock mechanics and rock engineering. v.16 p.173-180.

SAKURAI, S. (1988). Interpretation of the results of displacement measurements in cut slopes. . Proceedings of Second International Conference on Field Measurements in Geomechanics . Kobe. p.1155-1166.

SANCIO, R.T. (1981). The use of back-calculations to obtain the shear and tensile strength of weathered rocks. in: Proceedings of the International Symposium on Weak Rock. Tokyo. September. pp.6.

TableCurve 2D (2003). SYSTAT SOFTWARE INC.-Versão Demo 5.50 .4522.1800IC TEIXEIRA, A.H.; GODOY, N.S. (1996). Análise, projeto e execução de fundações rasas. In: HACHICH, W. et al. (editores). Fundações Teoria e Prática. São Paulo : AMBS/ABEF/PINI -Cap. 7, p. 227-264.

YANG, L. E STERLING, R. L. (1989). Back analysis of rock tunnel using boundary element method . Journal of Geotechnical Engineering-ASCE , v., n.115 (8) , p.11631169 , Agosto. 


\subsection{BIBLIOGRAFIA CONSULTADA}

AKUTAGAWA,S.; BROWN,E.T.; MEEK,J.L.; CHITOMBO,G. (1991). The direct modulus factoring method for the back analysis of young's moduli. p.931-936.

ALMEIDA, F. F. M. . (1967). Origem e evolução da plataforma brasileira . Boletim do Departamento Nacional de Produção Mineral -Div. Geologia e Mineralogia , v., n.241 , p.36.

ASSAN, A. E. (2003). Método dos Elementos Finitos -Primeiros Passos. Campinas : Editora Unicamp.

ATKINSON \& BRANSBY. (1978). The Mechanics of Soils. Londres

BORJA, R.I. (1990). Analysis of incremental excavation based on critical state theory . Journal of Geotechnical Engineering, ASCE. , 116, 964-986.

BOSE,S.K.; SOM,N.N. (1998). Parametric study of a braced cut by finite element method. Computers and Geotechnics .v. 22 (2) p.91-107.

BURLAND, J. B. ; SIMPSON, B. ; ST. JOHN, H. D. (1977). Movements Around Excavations in London Clay . Proceedings 7th European Conference Soil Mechanics and Foundation Engineering, v., n.1 , p.13.

FERNANDES M., CARDOSO A.J.S., TRIGO J.F.C., MARQUES J.M.M.C (1993).

Bearing capacity faiulure of tied back walls a complex case of soil wall interaction.

Computers and Geotechnics. , 15, p.87-103.

CELESTINO,T.B.;BURIN,S.M.;CLEMENTE,L.G.;FERNANDEZ,A.A. (1990).

Utilização de dados de instrumentação em túneis urbanos. in: Simpósio sobre

Instrumentação Geotécnica de Campo-SINGEO'90. Rio de Janeiro.

FINNO, R.J., AND NERBY, S.M. (1989). Saturated clay response during braced cut construction., 115, 1065-1084.

GONÇALVES,M.J.C.R. (1992). Análise do Comportamento das Escavações Pregadas na Rotura. Dissertação (Mestrado) - Faculdade de Engenharia, Universidade do Porto, Portugal. 1992.

JOHN W. BULL. (1994 ). Soil Structure interaction numerical analysis and modeling New York, 1a.

LAMBE, T. W. e WHITMAN, R. V. (1969). Soil Mechanics: John Wiley \& Sons, Inc. 
LINS,P.G.C. (1997). Perspectiva e aplicações das redes neurais em geotecnia: uma revisão bibliográfica. EESC - USP. p.72.

LINS,P.G.C.; CELESTINO,T.B. (1998). Determinação por elementos finitos do fator de segurança para um talude instável . XI Congresso Brasileiro de Mecânica dos Solos e Engenharia Geotécnica, v.1, p.349-354.

LONG, MICHAEL (2001) Database for retaining wall and ground movements due to deep escavations - Journal of Geotechnical Engineering and Geoenvironmental Engineering -ASCE , v. 127, n. 3, p.203-224, março.

MAFFEI, C e ESQUÍVEL, E. R. e OLIVEIRA,R. (1977). A model for calculating earth -retaining structures . International Symposium on Soil Structure Interaction , v., n., p., 03/01/1977.

NAYLOR, D J e PANDE, G N. (1981). Finite elements in geotechnical engineering . Swansea U.K. ,1a.

ORTIGÃO, J.A.R.(1993). Introdução à mecânica dos solos dos estados críticos-Rio de Janeiro -L.T.C.

SOHN,M.D.;SMALL,M,J;PAANTAZIDOU,M. (2000). Reducing uncertainty in site characterization using Bayes Monte Carlo methods . Journal of Envionmental Engineering , v.126, n.10, p.893-902, outubro.

PINTO, C.S. (2000). Curso básico de mecânica dos solos. São Paulo: Ofitextos.

POULOS, H G e DAVIS, E. H. (1974). Elastic solutions for soil and rock mechanics. New York, 1a.

ROWE. P.W. (1962). The Stress-dilatancy relation for static equilibrium of an assembly of particles in contact,Proc. of Royal Soc. A.269, p. 500-527.

SOHN,M.D.;SMALL,M,J.; PAANTAZIDOU,M. (2000). Reducing uncertainty in site characterization using bayes monte carlo methods . Journal of Environmental Engineering , v.126, n.10, p.893-902, outubro.

SONMEZ,H.;ULUSAY,R.;GOKCEOGLU,C. (1998). A Practical procedure for the back analysis of slope failures in closely jointed rock masses. International Journal of Rock Mechanics and Mining Sciences. v.35 p.219-233.

TERZAGHI, K. e PECK, R. B. (1967). Soil mechanics in engineering practice . Urbana Illinois ,2a. 
TRONDI, R. R. (1993). Cálculo evolutivo de paredes de contenção. Dissertação (Mestrado) -Escola de Engenharia de São Carlos, Universidade de São Paulo, São Carlos. 1993.

TSCHEBOTARIOFF, G. P. (1973). Fundações, estruturas de arrimo e obras de terra . São Paulo : Mc Graw Hill 2a.

UNIVERSIDADE DE SÃO PAULO. Escola de Engenharia de São Carlos. Serviço de Biblioteca (1996). Diretrizes para elaboração de teses e dissertações na EESC-USP. 2.ed. São Carlos. 
APÊNDICE A

Figuras com exemplos de resultados fornecidos pelo software PLAXIS (2002) 


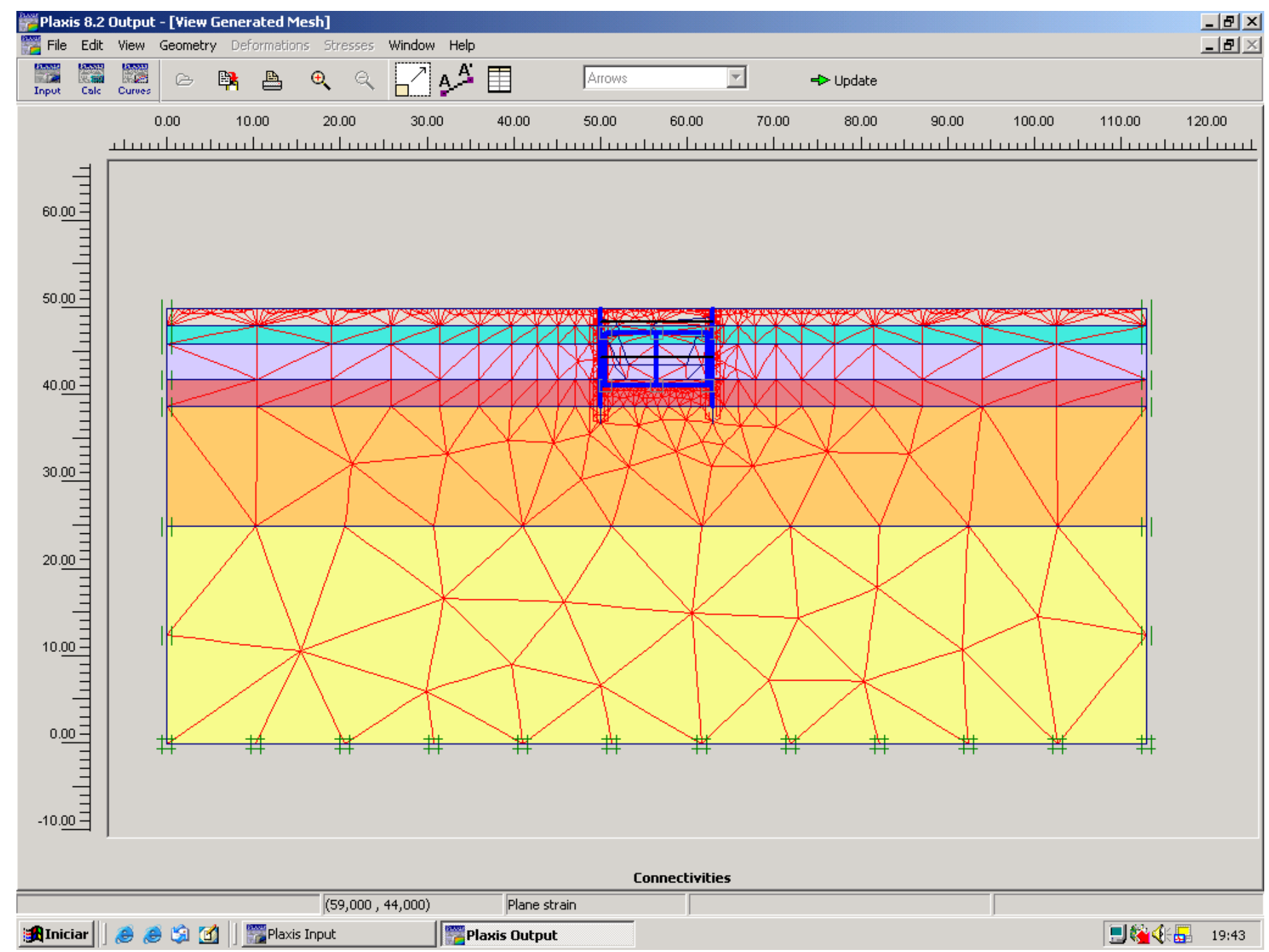

Exemplo da malha gerada e dos refinamentos de linha nas regiões da superfíci, fundo da vala e paramentos. 


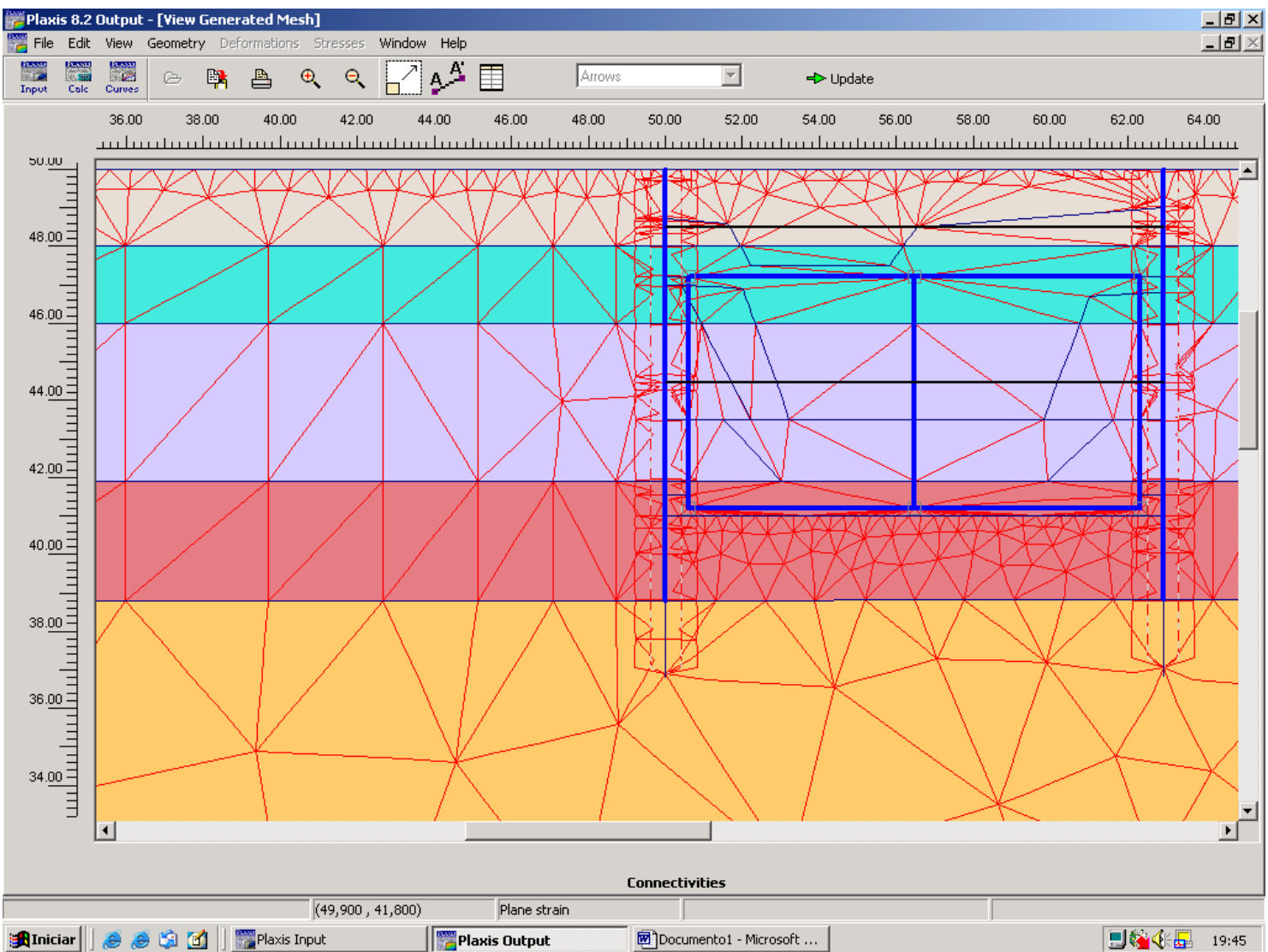

$1^{\circ}$. Zoom da região de refinamento de linha 


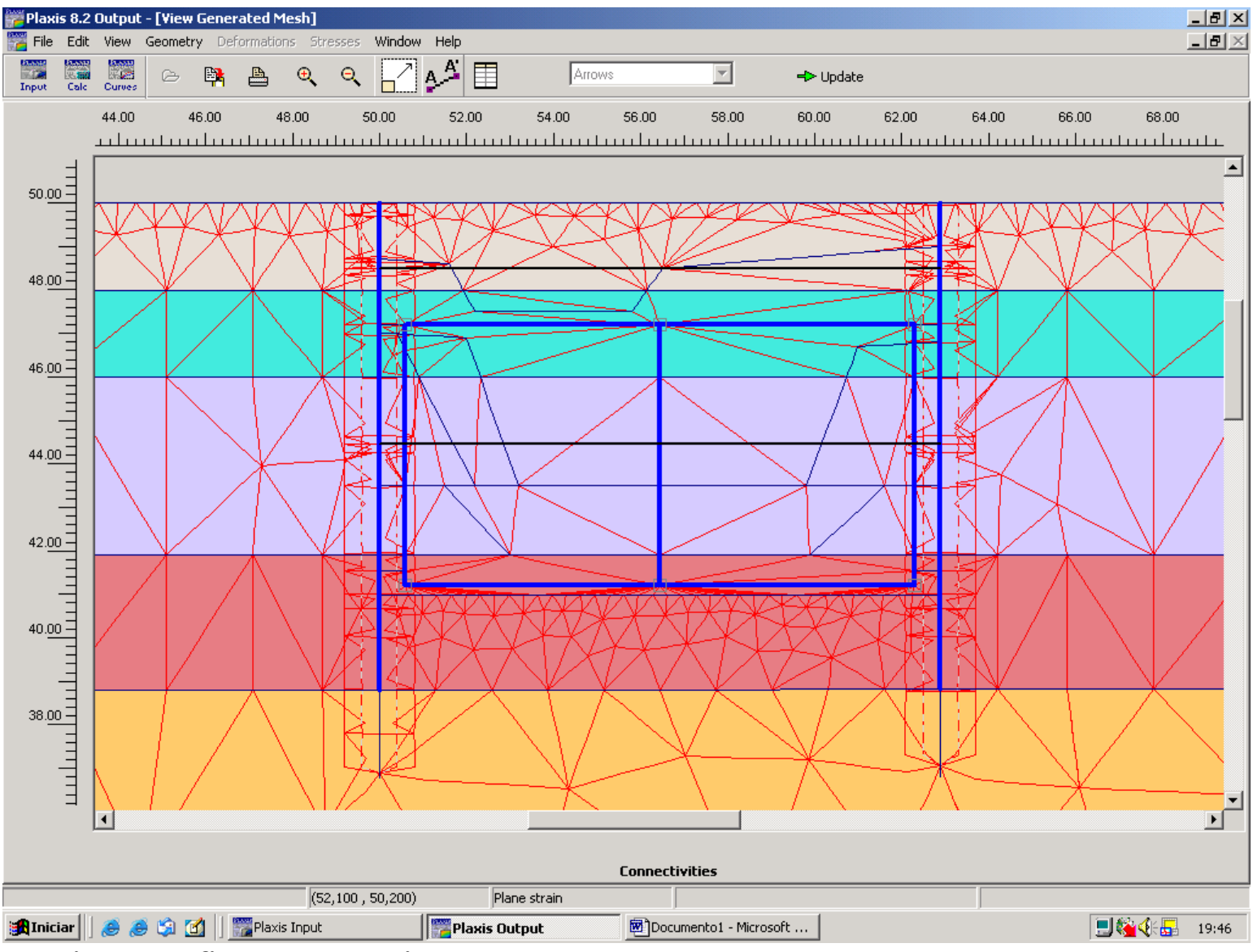

\section{$2^{\circ}$. Zoom da região de refinamento de linha}




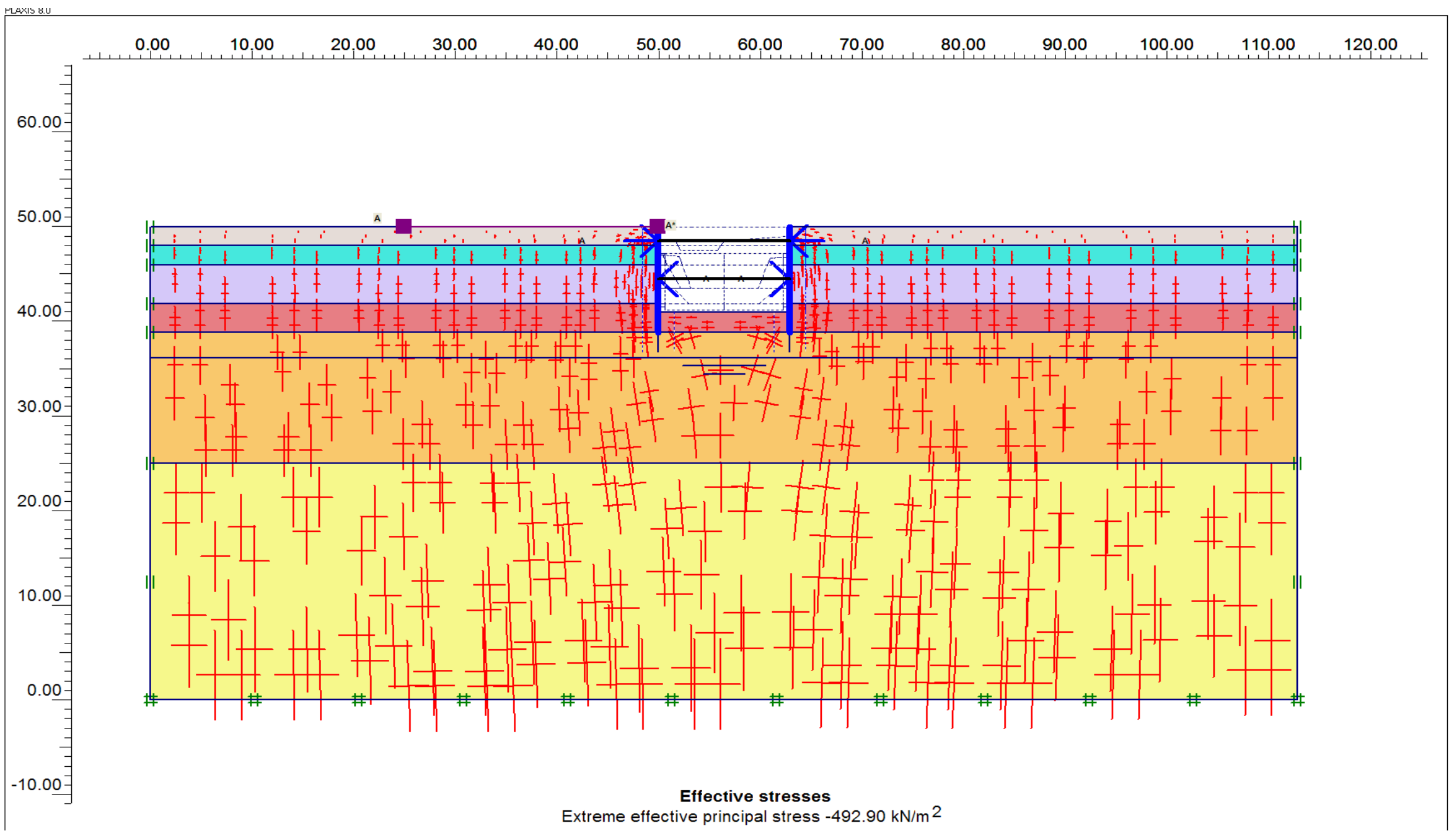

Tensões efetivas para o estágio 8 obtidas a partir dos parâmetros da retroanálise do estágio 3 


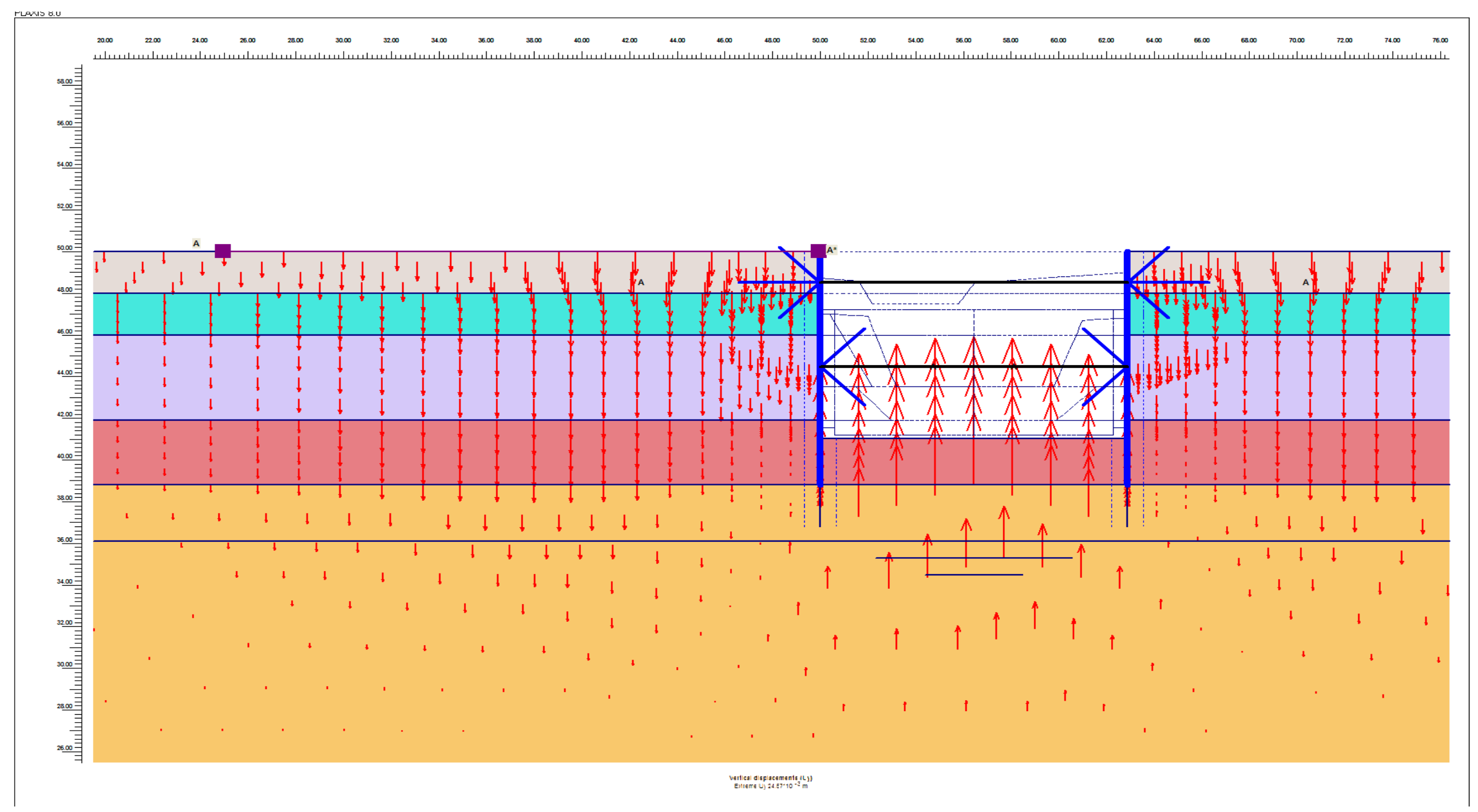

Deslocamentos Verticais totais no estágio 8 a partir dos parâmetros obtidos da retroanálise do estágio 3 


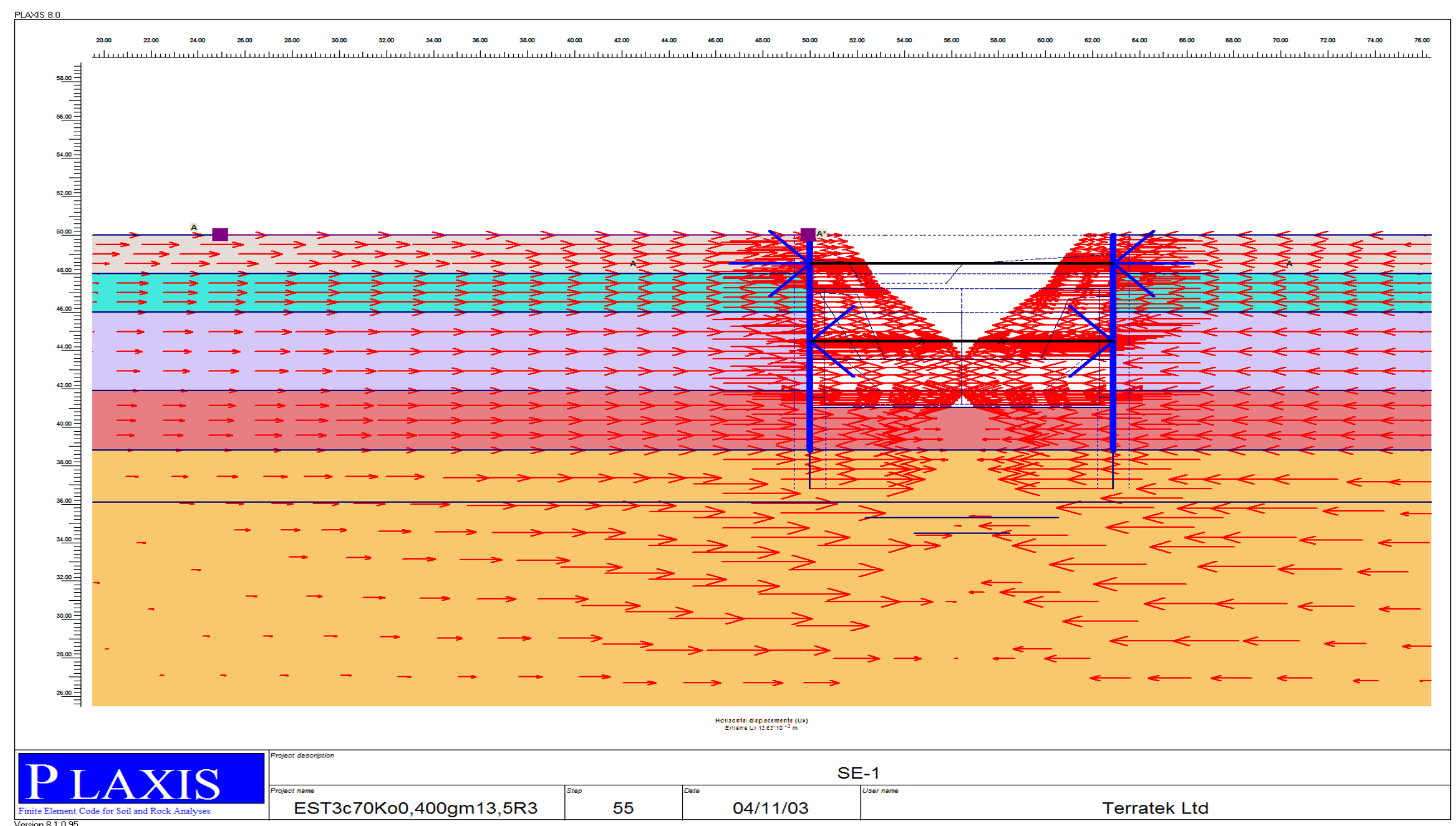

Deslocamentos horizontais totais do estágio 8 obtidos a partir da retroanálise do estágio 3 


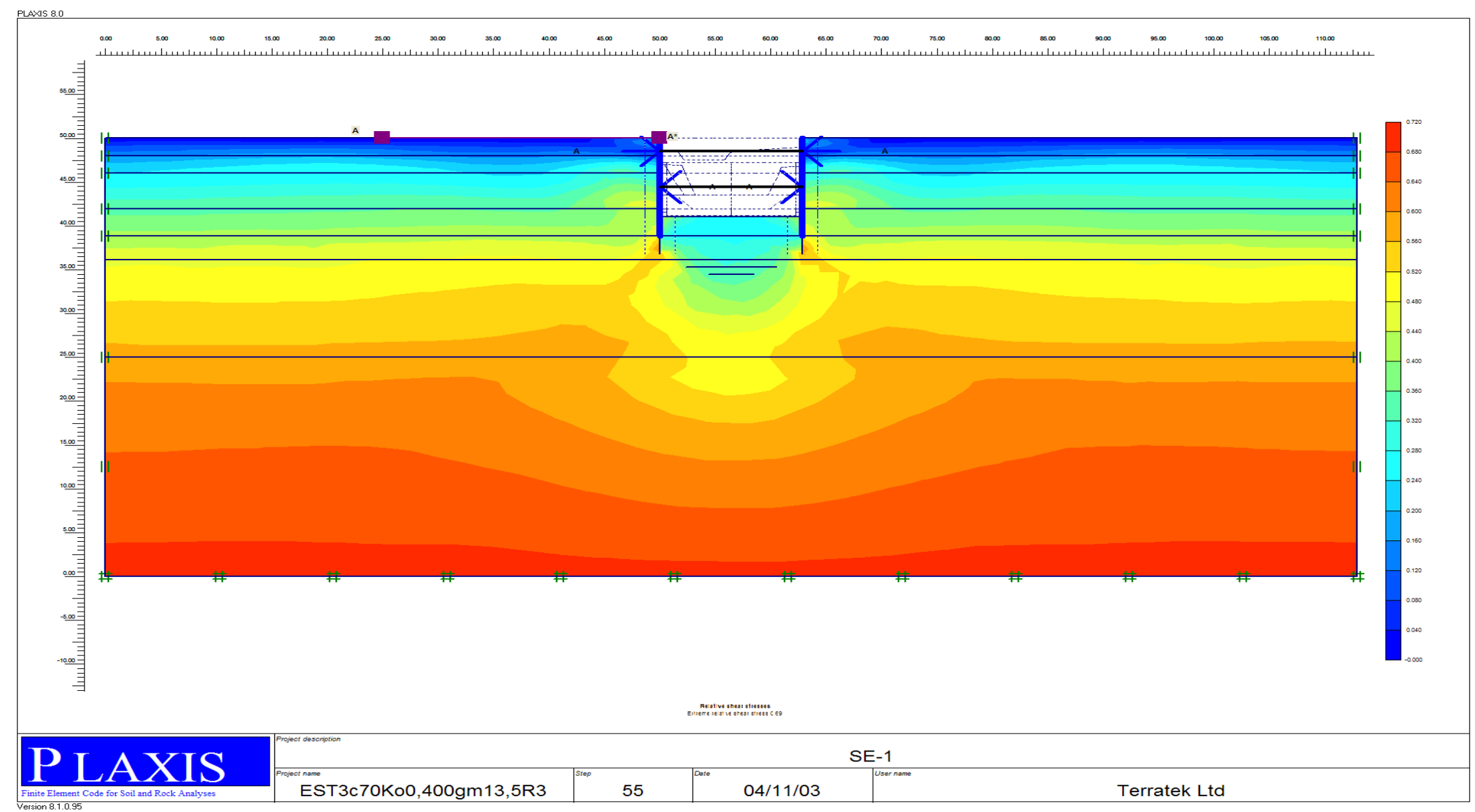

Tensões efetivas no estágio 8 obtidas a partir dos parâmetros da retroanálise do estágio 3 
Plaxis 8.1 Input - EST5c70Ko0531G13,5R10temp.plx

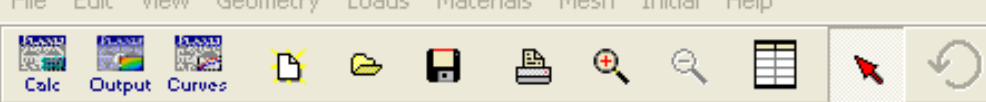

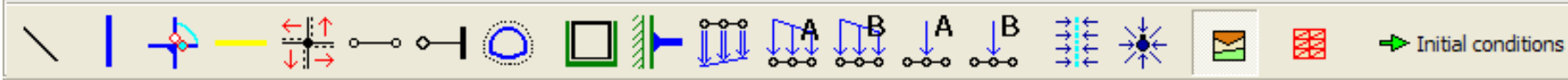

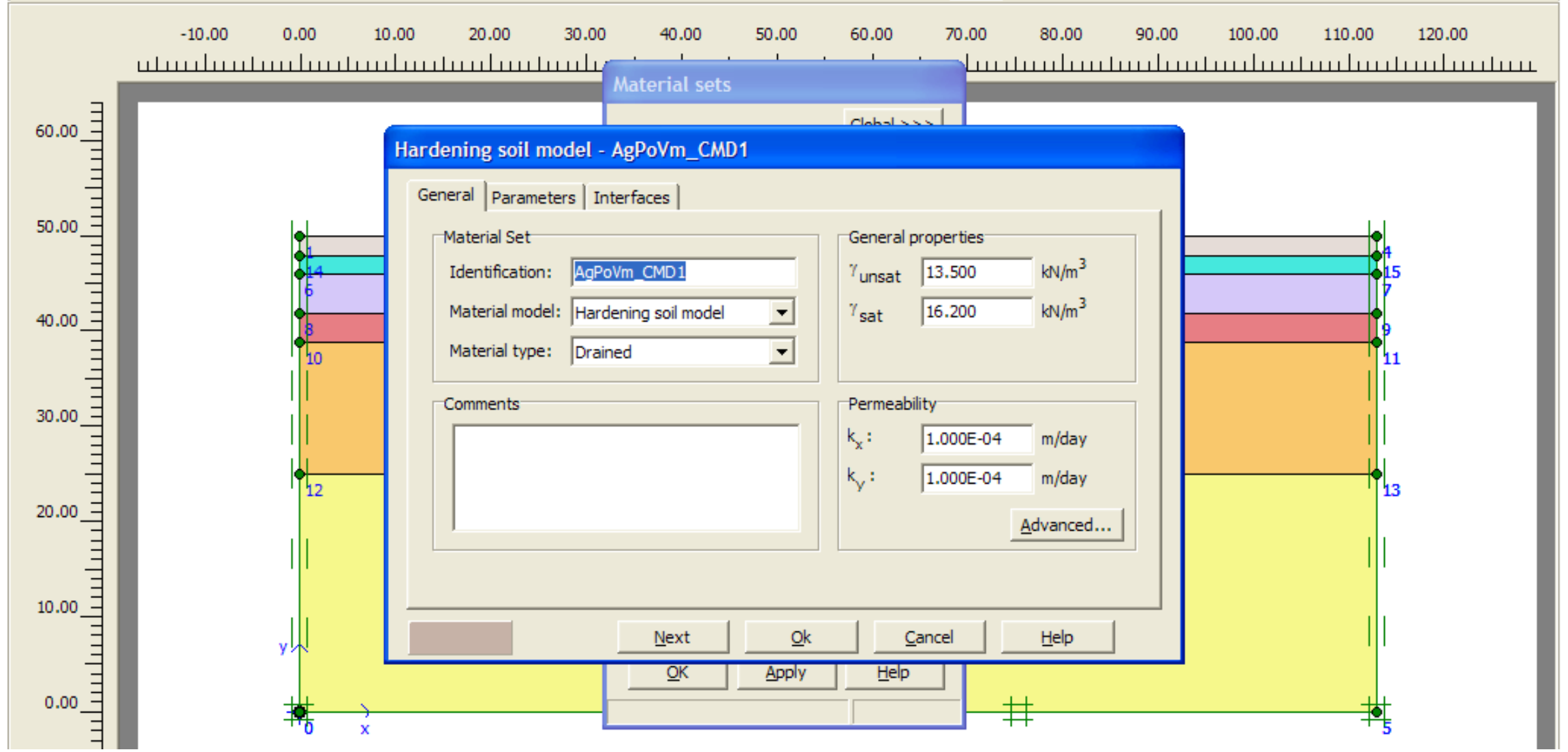

\section{Tela de Entrada do PLAXIS}


Plaxis 8.1 Input - EST 5c70Ko0531G13,5R10temp.plx

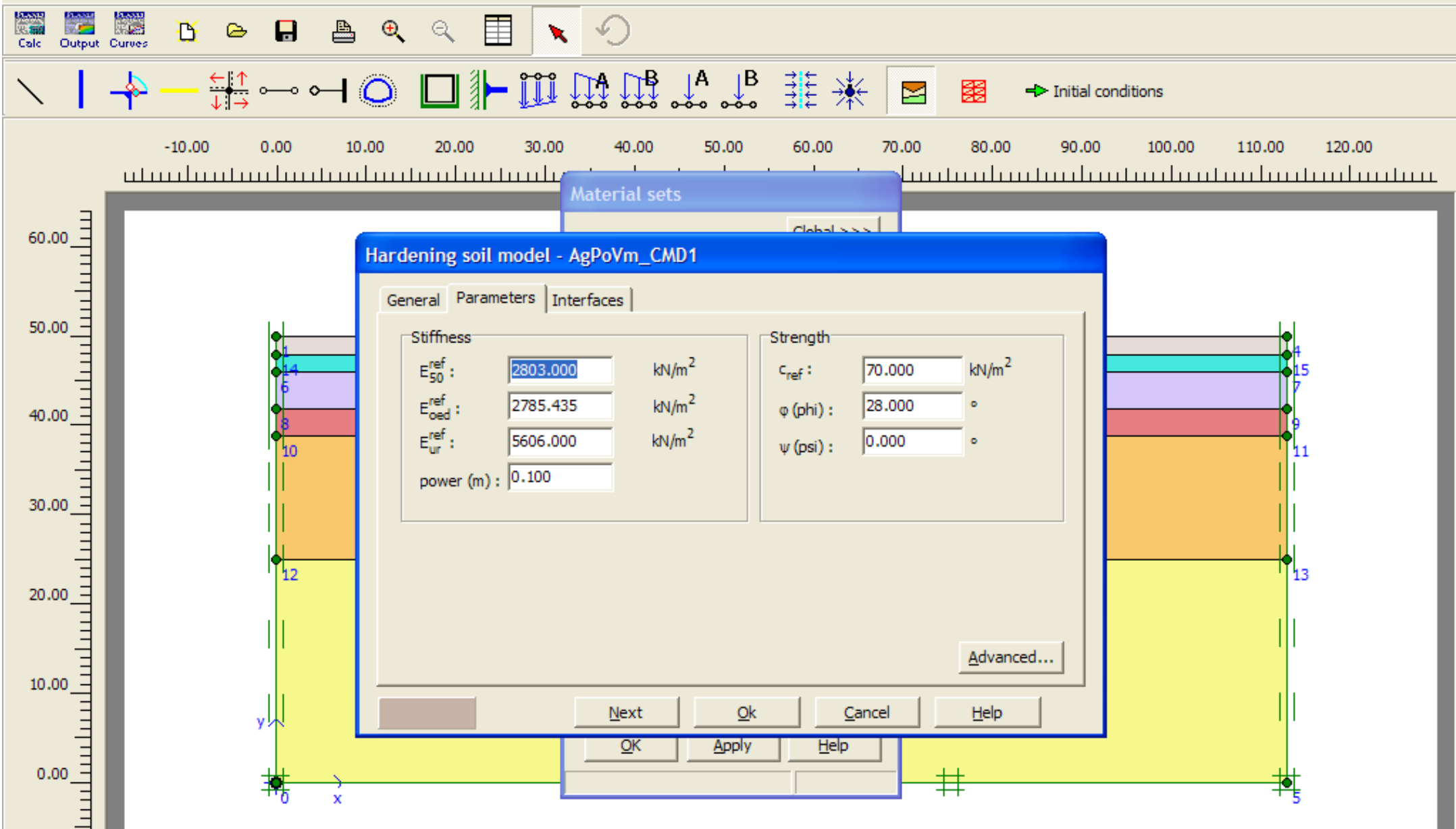

Tela de Entrada do PLAXIS para o modelo de Endurecimento. 


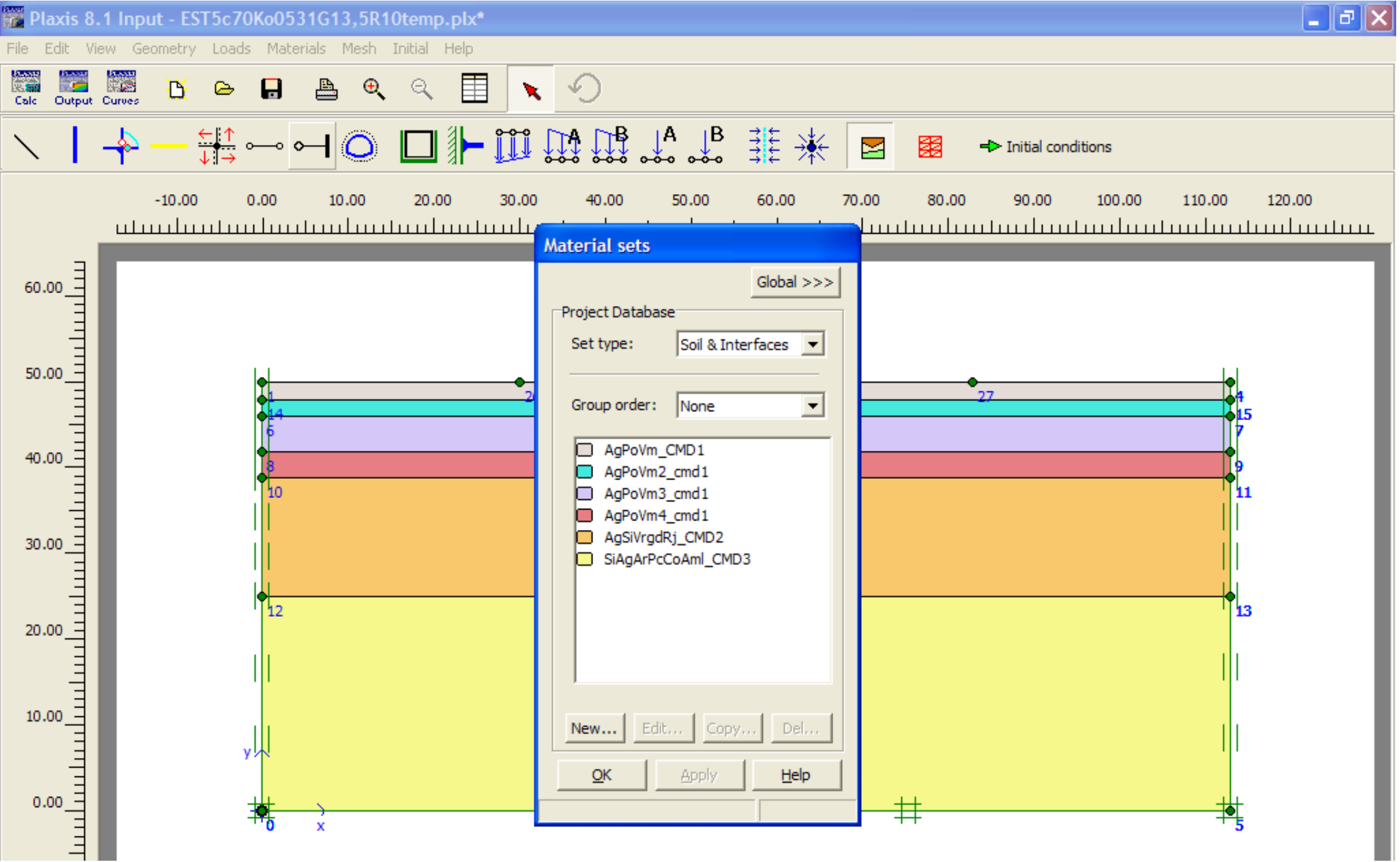

Tela de Entrada do PLAXIS, distribuição das camadas. 


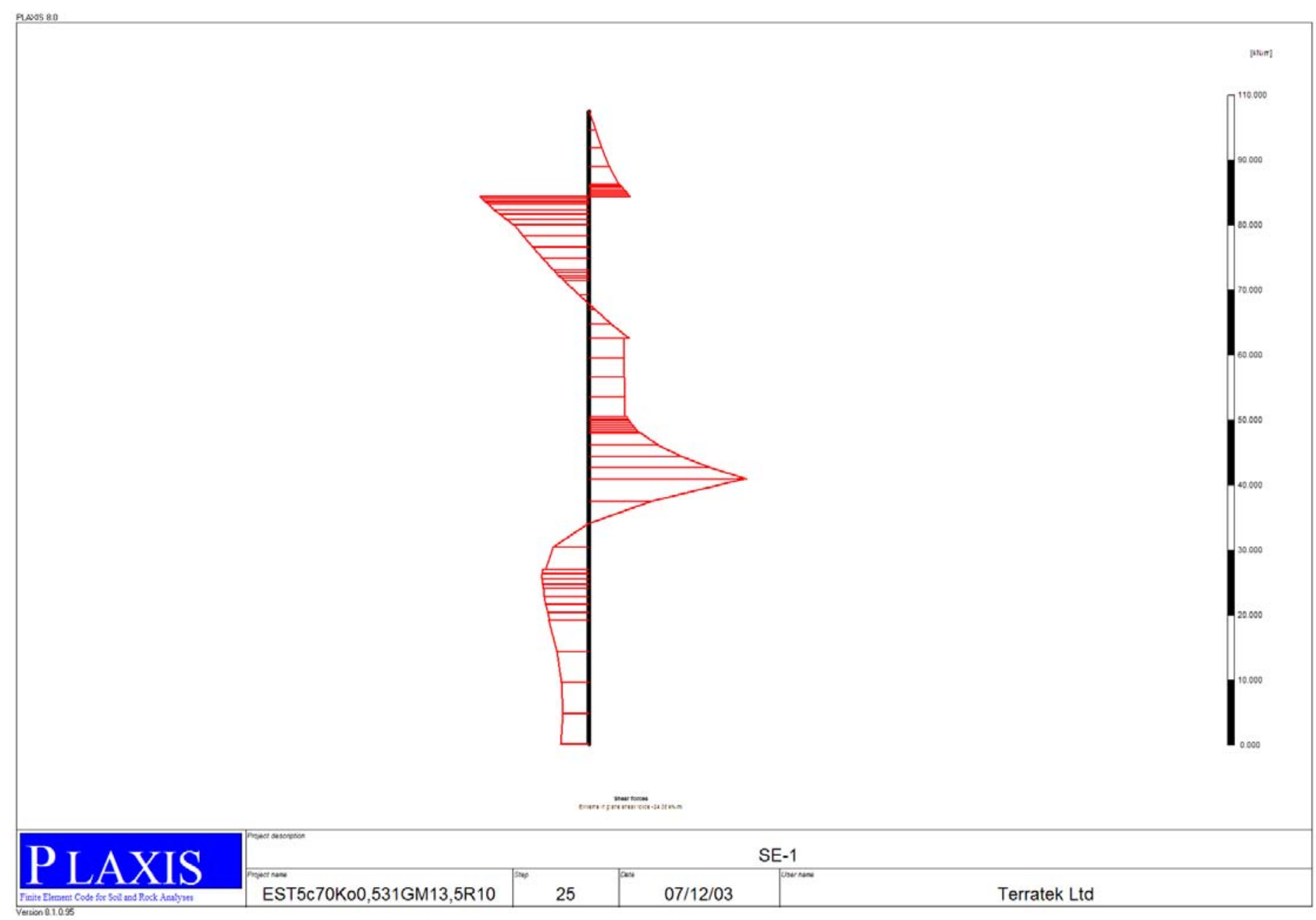

Tela de saída do PLAXIS: diagrama de força cortante do estágio 5 


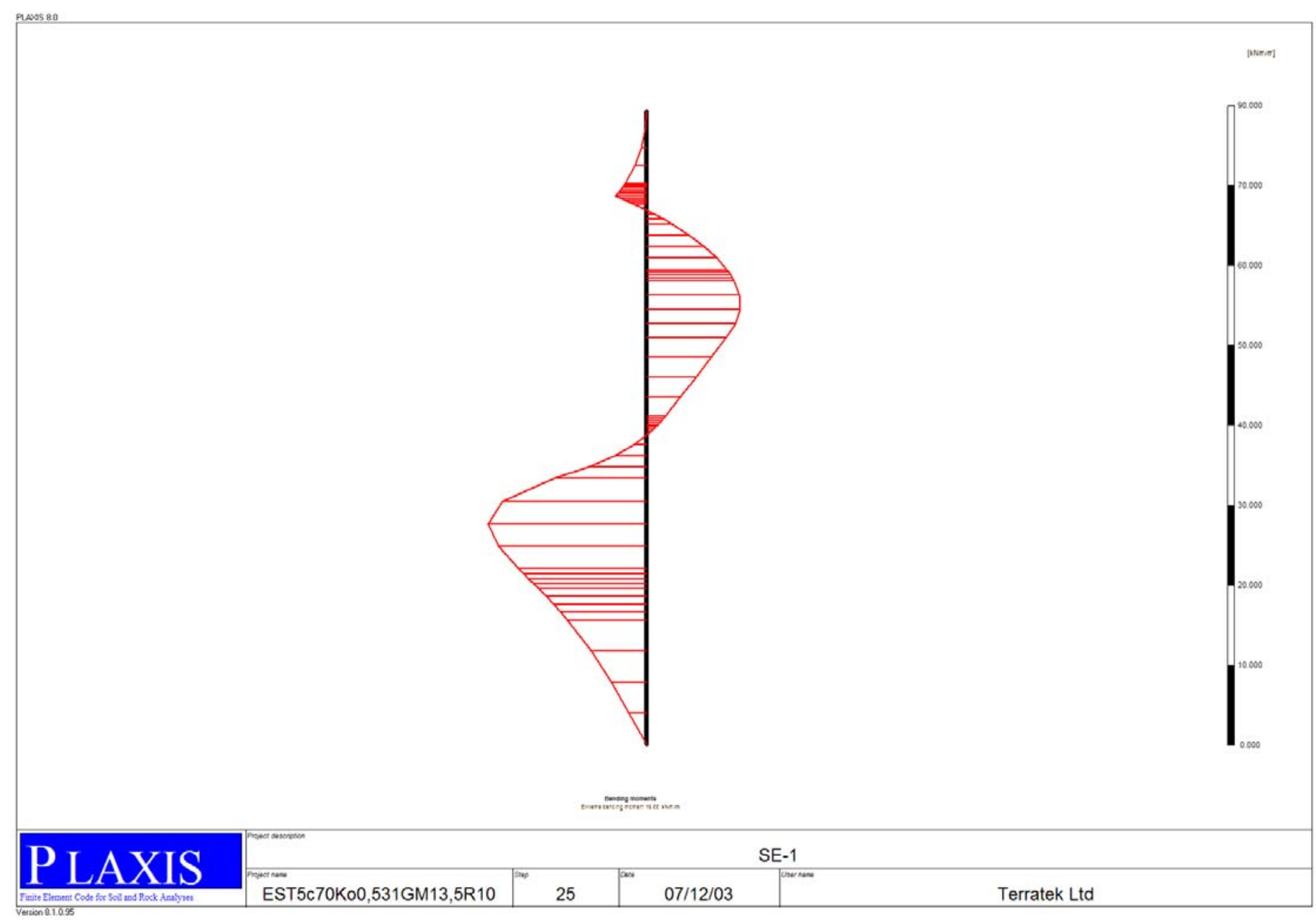

Tela de saída do PLAXIS: diagrama de momento fletor do estágio 5 


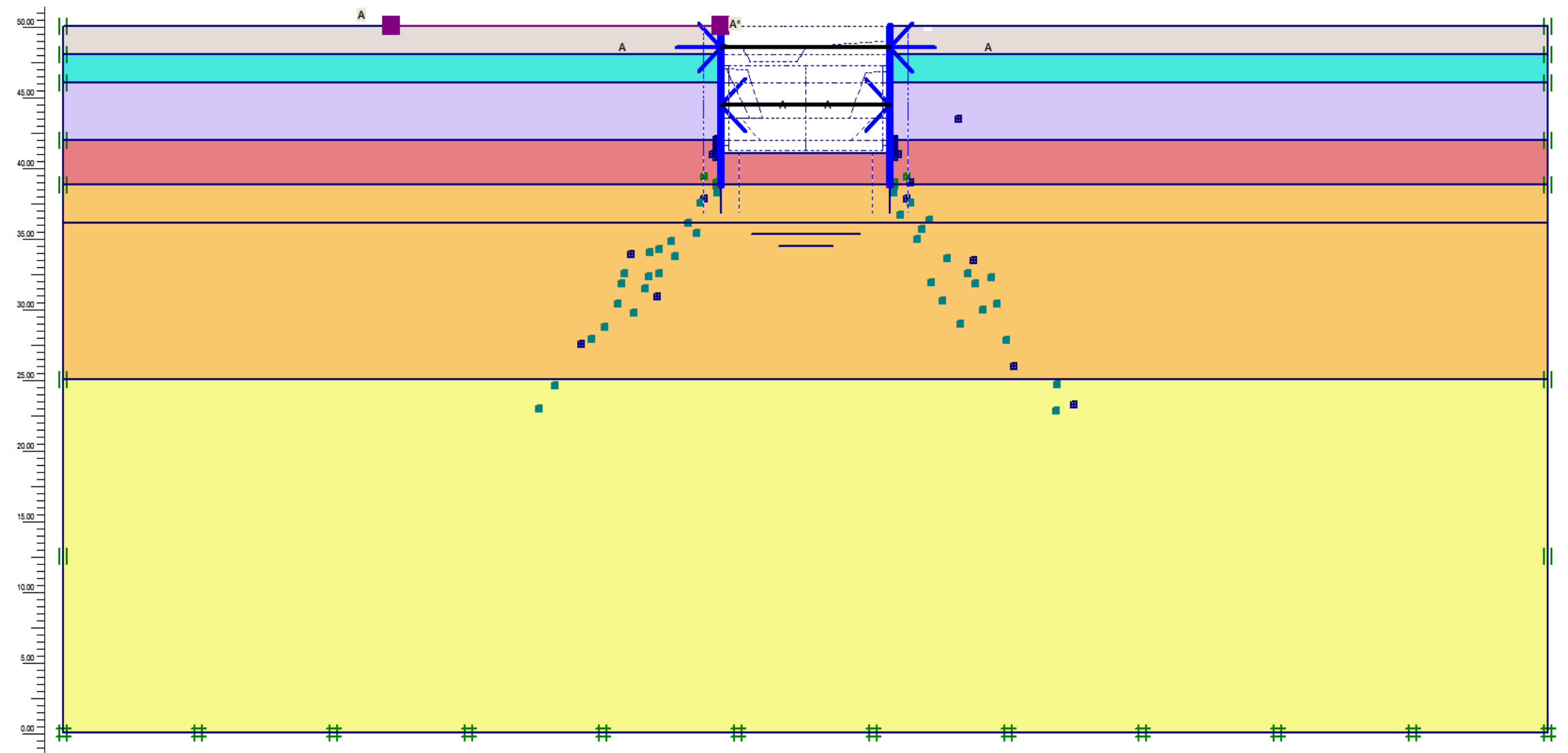

Pontos de plastificação no estágio 8 a partir dos parâmetros obtidos por retroanálise do estágio 3 - critério de Modelo de Endurecimento 